\title{
The role of the buyer in affecting buyer-seller relationships : empirical studies in a retail context
}

Citation for published version (APA):

Odekerken-Schroder, G. J. (1999). The role of the buyer in affecting buyer-seller relationships : empirical studies in a retail context. [Doctoral Thesis, Maastricht University]. Maastricht University. https://doi.org/10.26481/dis.19990701go

Document status and date:

Published: 01/01/1999

DOI:

10.26481/dis.19990701go

Document Version:

Publisher's PDF, also known as Version of record

\section{Please check the document version of this publication:}

- A submitted manuscript is the version of the article upon submission and before peer-review. There can be important differences between the submitted version and the official published version of record.

People interested in the research are advised to contact the author for the final version of the publication, or visit the DOI to the publisher's website.

- The final author version and the galley proof are versions of the publication after peer review.

- The final published version features the final layout of the paper including the volume, issue and page numbers.

Link to publication

\footnotetext{
General rights rights.

- You may freely distribute the URL identifying the publication in the public portal. please follow below link for the End User Agreement:

www.umlib.nl/taverne-license

Take down policy

If you believe that this document breaches copyright please contact us at:

repository@maastrichtuniversity.nl

providing details and we will investigate your claim.
}

Copyright and moral rights for the publications made accessible in the public portal are retained by the authors and/or other copyright owners and it is a condition of accessing publications that users recognise and abide by the legal requirements associated with these

- Users may download and print one copy of any publication from the public portal for the purpose of private study or research.

- You may not further distribute the material or use it for any profit-making activity or commercial gain

If the publication is distributed under the terms of Article $25 \mathrm{fa}$ of the Dutch Copyright Act, indicated by the "Taverne" license above, 


\title{
The Role of the Buyer in Affecting Buyer-Seller Relationships
}

\author{
Empirical Studies in a Retail Context
}


Odekerken-Schröder, Gaby

The Role of the Buyer in Affecting Buyer-Seller Relationships: Empirical Studies in a Reail Context / Gaby Odekerken-Schröder - Maastricht: Gaby Odekerken-Schröder - III. - Met ${ }^{\text {lit. }}$ opgave - Met samenvatting in het Nederlands.

ISBN 90-9012690-2

NUGI 686

Trefw.: relatiemarketing - consumentengedrag

(1) 1999, Gaby Odekerken-Schröder, Maastricht.

All rights reserved. No part of this publication may be reprinted or utilized in any form or by any electronic, mechanical, or other means, now known or hereafter invented, including photocopying and recording or in any information storage or retrieval system, without written permission from the copyright owner.

Cover designed by:

Printed by:

Financial support provided by:
De Visscher \& Van Nevel (B).

Econoom B.V.. Beek.

the Dutch Retail Association (HBD) and Albert Heijn. 


\title{
The Role of the Buyer in Affecting Buyer-Seller Relationships
}

\author{
Empirical Studies in a Retail Context
}

\section{PROEFSCHRIFT}

ter verkrijging van de graad van doctor aan de Universiteit Maastricht, op gezag van Rector Magnificus,

Prof. Dr. A.C. Nieuwenhuijzen Kruseman, volgens het besluit van het College van Decanen in het openbaar te verdedigen op donderdag 1 juli 1999 om 14.00 uur

door

Gaby Josephina Odekerken-Schröder 
Promotoren:

Prof. Dr. J.D.P. Kasper

Prof. Dr. J.C. Hoekstra (Erasmus Universiteit Rotterdam / Rijksuniversiteit Groningen

\section{Beoordelingscommissie:}

Prof. Dr. J.G.A.M. Lemmink (voorzitter)

Prof, Dr. H.R. Commandeur (Erasmus Universiteit Rotterdam / Universiteit Nyenrode Universiteit Gent)

Prof. Dr. F.Ch. Palm 




\section{Preface and Acknowledgements}

This dissertation could be accomplished thanks to the support of several individuals and institutions. deserving my sincere gratitude. In particular, I am extremely indebted to my advisors Hans Kasper and Janny Hoekstra for their ongoing support during the entire process and their ceaseless confidence in a successful completion of my study. Hans Kasper gave me the opportunity to start working at the department of Marketing and Marketing Research and gradually deepened my interest in the research field. In addition, he realized financial support for this dissertation by introducing me to the Dutch Retail Association. During the final stage, Hans provided me with detailed feedback on drafts of the chapters and was willing and able to comply with my tight time schedule. Despite the substantial geographical distance between Groningen and Maastricht, Janny Hoekstra also agreed to operate as my Ph.D. advisor. Her overwhelming expertise in the field of relationship marketing contributed heavily to the conceptual part of my study. In addition, her unfailing enthusiasm and vivid personality provided strong support during the hectic period of reviewing preliminary chapters. In spite of their busy schedules Hans and Janny were always willing to make efforts in order to plan a meeting. Thank you very much for enabling me to realize this ambition!

Besides the valuable contributions of both advisors I had the privilege of closely working together with my Belgian colleague Kristof De Wulf. We met at a Ph.D. course in Groningen and coincidentally discovered that we had similar research interests and that we shared our advisor Janny Hoekstra. These discoveries turned out to be the beginning of a unique joint research project that was based on mutual respect and trust. Kristof's incredible drive, his sound research skills, and his helicopter view can be regarded as a shining example of a successful Ph.D student. Looking back at the past two years, I especially remember our challenging discussions, race against the clock and our moments of silly laughter. Thanks Kristof!!! Furthermore, I would like to take the opportunity to express my feelings of gratitude to the members of my graduation committee Harry Commandeur. Jos Lemmink, and Franz Palm for providing me with constructive feedback related to their field of expertise. Their comments highly improved the quality of my manuscript. Moreover, I am extremely grateful to Dawn Iacobucci, Rudy Moenaert and Patrick Van Kenhove for reading the manuscript and providing me with valuable and constructive suggestions. I especially admire Dawn's tremendous research expertise and her sincere enthusiasm complemented with her willingness to share this knowledge and experience with Ph.D. students.

Next, I would like to thank my (former) colleagues of the department of Marketing and Marketing Research for their patience and support. Martin Wetzels is the first, who deserves to be praised. His thorough knowledge with respect to structural equation modeling and his willingness to reply to my questions time and again highly improved the quality of my empirical research. Besides, I appreciate the company, support, and patience of my (former) roommates Mirella Kleijnen, Annouk Lievens, Elsbeth van Marle, and Luc Wiertz who took care of the social aspects related to my job. Mirella Kleijnen holds a very special position as she took over the majority of my responsibilities related to education during the final stage of my research. Her capabilities and everlasting enthusiasm guaranteed a successful completion of all the tasks she fulfilled. Moreover, she did a 
great research job, as she recruited Dutch interviewers, coordinated the Dutch field study, and did the tedious data entry of the Dutch data. Thank you!

With respect to the field study, I would like to express my sincere gratitude to the Dutch Retail Association that provided financial support for conducting the empirical research. In particular 1 am grateful to Geert Posma, Willem van Teeseling, and Robert-Jan Verheij who enriched my study with valuable insights from practice. E5-Mode (Belgium) provided practical support during the qualitative research stage of this study, which was also very beneficial. Furthermore, 1 highly value the cooperation of Eindhoven Heuvelgalerie, Wijnegem Shopping Center (Belgium) and Oriando Shopping Mall (United States) concerning the quantitative research. In line with this, I am greatly indebted to Kristy Ellis (University of Florida) who took complete responsibility for the data collection in the United States. I highly appreciate the wonderful job she did in arranging this unique, transatlantic field study. Moreover, I would like to thank Charles Pahud de Mortanges and Eelko Dijkstra for their sound translation of my questionnaire. Finally, 1 highly acknowledge the financial support of Albert Heijn's Grant enabling the extensive data collection. Despite the indispensable financial and practical support, data collection would not have been possible without the dedication and expertise of a large team of Dutch, Belgian and American interviewers and without the response of many consumers. The cooperation of all these people has been invaluable for the success of my field study. Thanks!

A completely different aspect of writing a book concerns the design of the cover and the final printing. In this respect I am indebted to printing office Econoom B.V. and in particular to Jean Romans. His dedication and expertise were a great relief during the final stage of this project. Moreover, 1 would like to thank Georges Van Nevel associated to advertising agency De Visscher and Van Nevel for his creativity and professionalism in designing the cover of this book.

"A friend in need is a friend indeed!" First of all, I would like to thank Mariël and Roel for their friendship, hospitality, their weekly dinners, and their sincere interest in my study. Moreover, 1 appreciate the practical support and kind signs of interest by Joyce, Anton, Jolanda, and Léon. To conclude with, I want to thank Liesbeth, Fred, Anneke, and Loes for their unique friendship. Besides having these close personal friends, I am privileged to be raised by my loving parents. They created a solid basis for all my studies, stimulated me to explore the unknown, and supported the decisions I made. Thanks a lot, mom and dad! At the end of this preface, I want to thank my husband and best friend Armand who has been the driving force behind my achievements. He respected my irregular working hours, took care of our household, and provided assistance with practical aspects of my dissertation. Armand, you gave me the needed self-confidence, always relied on my capabilities, and went deeply into my research, resulting in valuable discussions with respect to content. And this is only the tip of the iceberg why I love you! Thank you so much! 


\section{Table of Contents}

\section{Chapter 1: Introduction to the Research Problem}

I.1 Introduction

1.2 Research Justification.

1.2.1 Importance

1.2.2 Shortcomings of Existing Research.

1.2.2.1 Conceptual Shortcomings

1.2.2.2 Empirical Shortcomings.

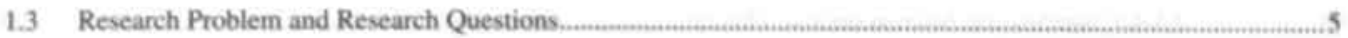

1.4 Research ScOpe.

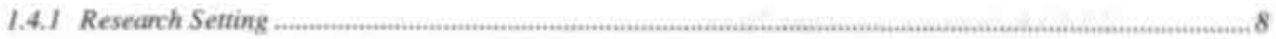

1.4.1.1 Two Product Categories.

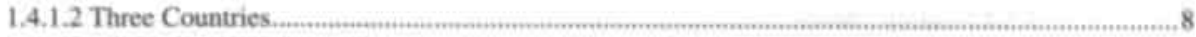

1.4 .2 Unit of A nalysis .......

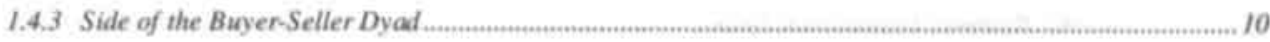

15 Intended Research Contributions ..............

1.5.1 Scientific Contribution................

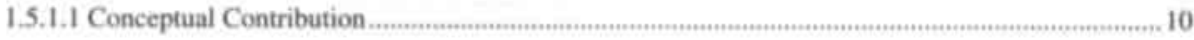

1.5.1.2 Methodological Contribution

1.5.1.3 Empirical Contribution .....

1.5.2 Managerial Contribution.....

1.6 Defining Important Terms........

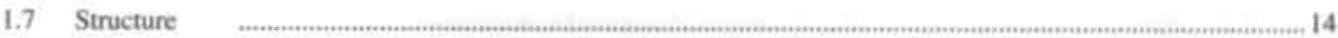

\section{PART I: THEORETICAL FRAMEWORK}

\section{Chapter 2: Relationship Marketing in a Consumer Context}

2.I Introduction

2.2 The Concept of Relational Exchange.

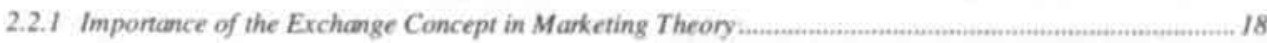

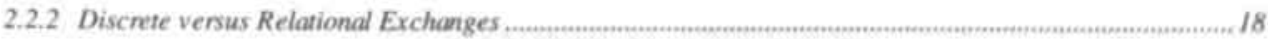

2.2.3 Definition of a Relationship.................... 19

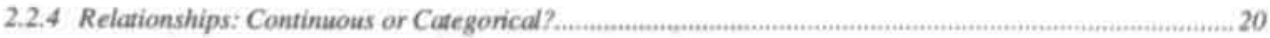

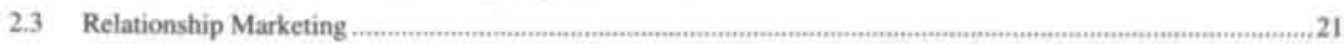

2.3.I Definition of Relationship Marketing ......... 21

2.3.2 Characteristics Influencing Relationship Marketing Effectiveness.....................................................23

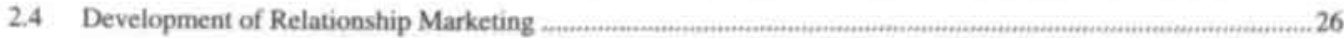

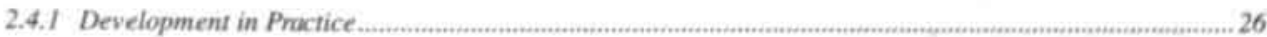


2.4.2 A Brief Oveniew of Scientific Development...................................................................................................... 26

2.5 Applicability of Relationship Marketing in a Consumer Context ......................................................................28

2.5.I Overview of Theories Underlying Relationship Marketing ......................................................................29

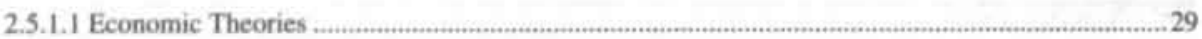

2.5.1.2 Behavioral Theories ....................................................................................................................29

2.5.1.3 Economic/Behavioral Theories. 30

2.5.2 General versus Context-Specific Relationship Manketing Theory ............................................................... 30

2.5.3 Chancteristics of Consumer versus Business-to-Business Marketing ....................................................... 33

2.5.4 A pplicability of Theories Undertying Relationship Marketing in a Consumer Context.............................. 33

2.5.4.1 Neoclassical Microeconomic Theory ................................................................................................ 34

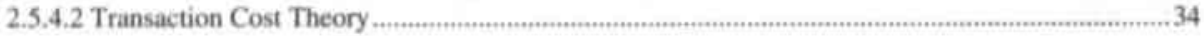

2.5.4.3 Relational Contracting Theory ..................................................................................................... 36

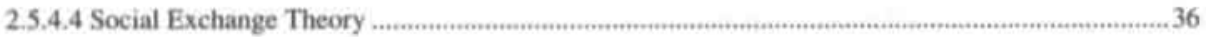

2.5.4.5 Equity Theory ……,

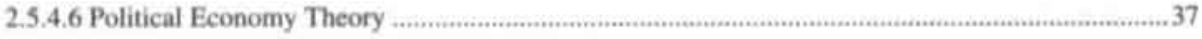

2.5.4.7 Resource Dependence Theory ….......................................................................................................37

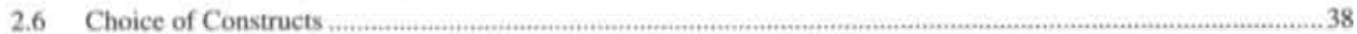

2.7 Summary and Conclusions ..................................................................................................................................... 39

\section{Chapter 3: The Role of Buyer Relationship Proneness}

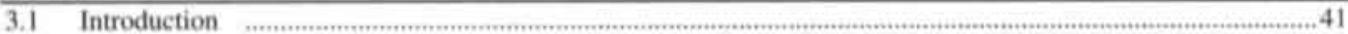

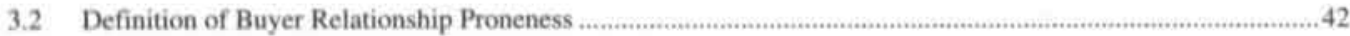

3.3 Importance of Buyer Relationship Proneness ............................................................................................44

3.3.1 Buyer Relationship Proneness as a Potential Basis for Segmentation .....................................................44

3.3.2 Shortcomings in Existing Reseanch....................................................................................................46

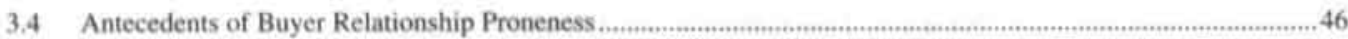

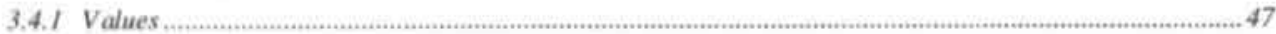

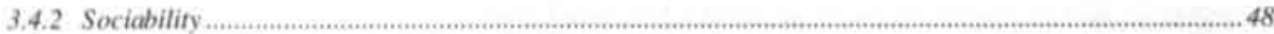

3.4 .3 Social Recognition.........,

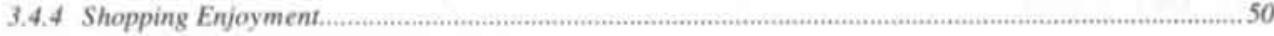

3.4.5 Enduring Product Categony Involvement .............................................................................................51

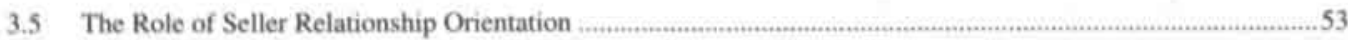

3.6 Summary and Conclusions .................................................................................................................................5

\section{Chapter 4: Relationship Outcomes}

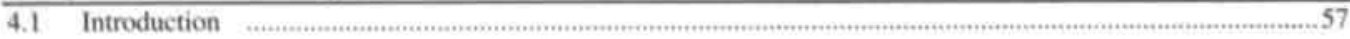

4.2 Attitudinal Relationship Outcomes ........................ 57

4.2.1 Relationship Sarisfaction. Tnust, and Relationship Commitment: Similar or Divergent Constnucts? ......... 58

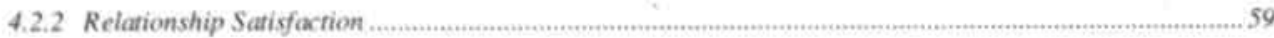


4.2.2.1 Definition of Relationship Satisfaction

4.2.2.2 Importance of Relationship Satisfaction _...

4.2.2.3 Relationship Satisfaction as a Relationship Outcome.............n.m.

4.2.3 Tnast.

4.2.3.1 Definition of Trust ............

4.2.3.2 Importance of Trust..............

4.2.3.3 Trust as a Relationship Outcome ...

4.2.4 Relationship Commitment ....

4.2.4.1 Definition of Relationship Commitment.

4.2.4.2 Importance of Relationship Commitment ............................................................................66

4.2.4.3 Relationship Commitment as a Relationship Outeome............................................................67

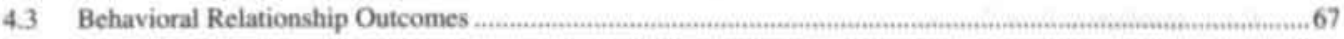

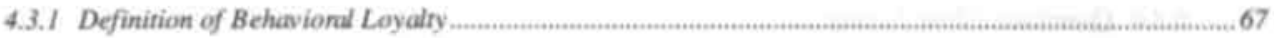

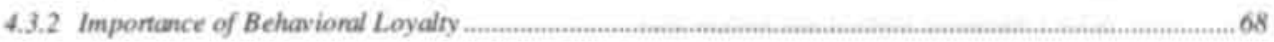

4.3.3 Behavional Loyalry as a Relationship Outcome.

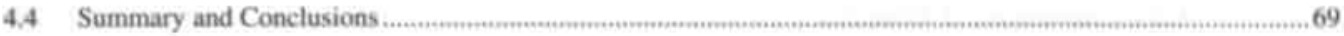

\section{Chapter 5: Research Model and Hypotheses}

5.1 Introduction ...

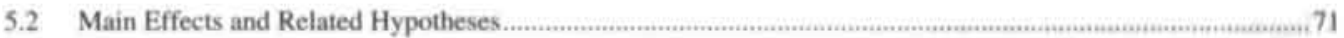

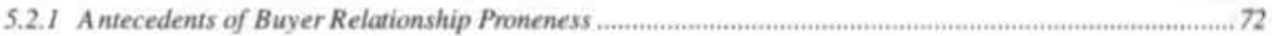

5.2.2 Buyer Relationship Proneness and Seller Relationship Onentation .........................................................73

5.2.3 Seller Relationship Orientation and Relationship Satisfaction .......................................................................74

5.2.4 Seller Relationship Orientation and Relationship Commitment .......................................................... 75

5.2 .5 Buyer Relationship Pronenexs and Relationship Satisfaction..................................................................... 75

5.2.6 Buyer Relationship Proneness and Relationship Commitment........................................................................ 76

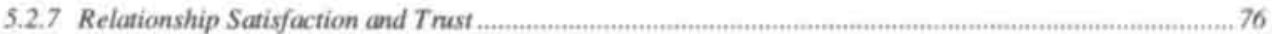

5.2.8 Trust and Relationship Commitment .................................................................

5.2.9 Relationship Commitment and Behavional Loyalty ...........................................................................

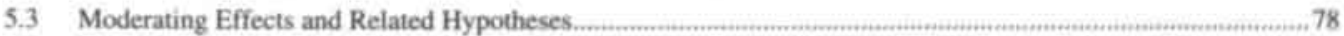

\section{PART II: EMPIRICAL RESEARCH}

\section{Chapter 6: Research Methodology and Item Construction}

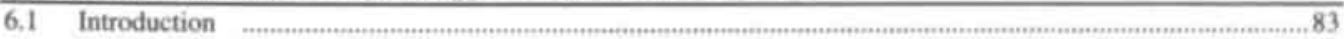

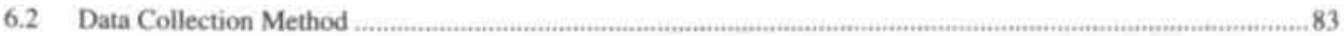

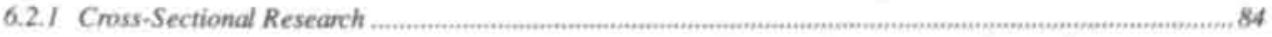

6.2 .2 Non-Experimental Research

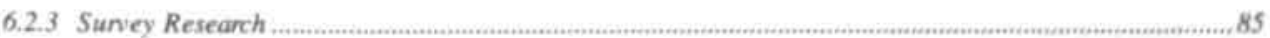




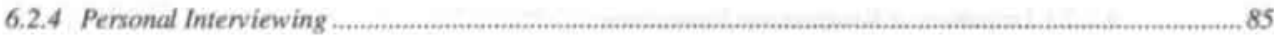

6.2.5 Mall-Intercept Interviewing ......... 86

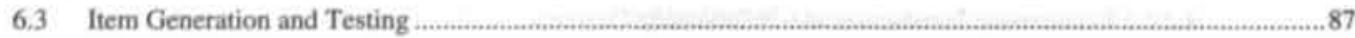

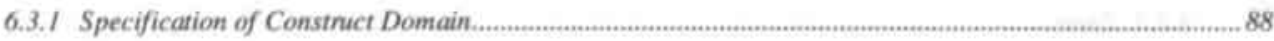

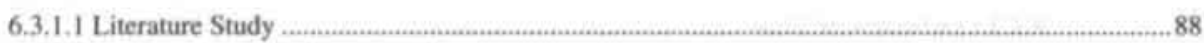

6.3.1.2 Discussions with Practitioners ….................................................................................................88

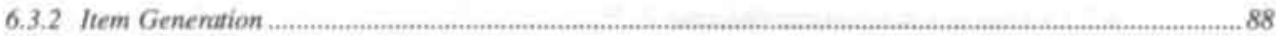

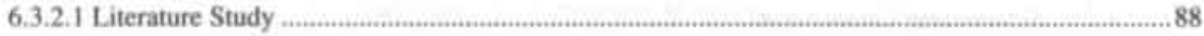

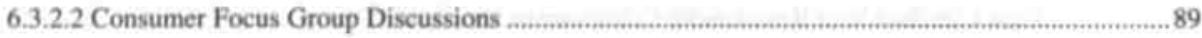

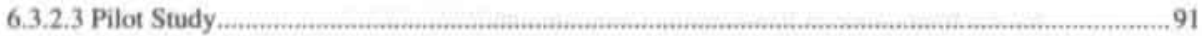

6.3.2.4 Measurement Format of 1tems ….................................................................................................92

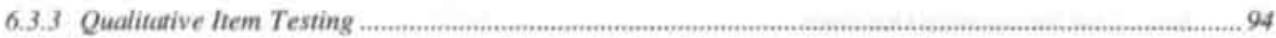

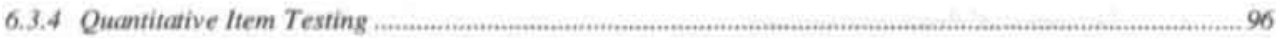

6.3.4.1 Sampling Method and Sample Size ...................................................................................................96

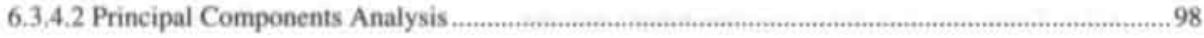

6.3.4.3 Assessment of Reliability _.................................................................................................

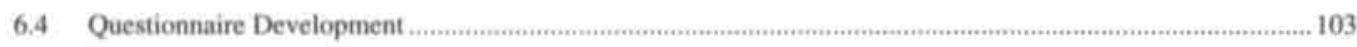

6.5. Summary and Conclusions

\section{Chapter 7: Empirical Results}

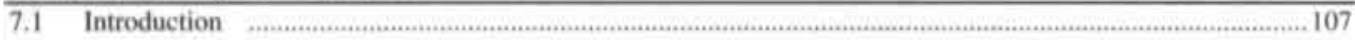

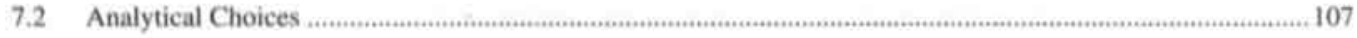

7.2.1 Why Structumal Equation Modeling? .........................................................................................

7.2.2 Procedural Decisions related to Using Structural Equation Modeling...................................................... 108

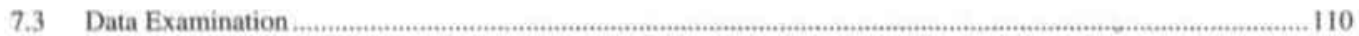

7.3.1 Data Verification....................................

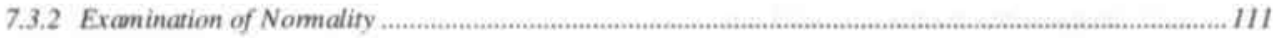

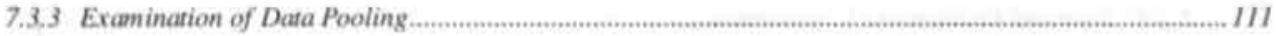

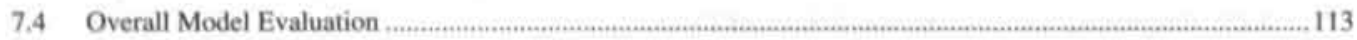

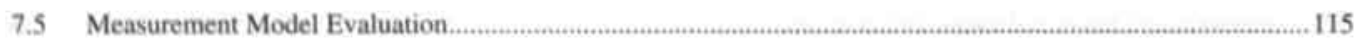

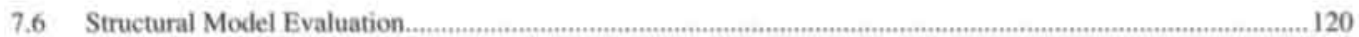

7.6.1 Evaluation of the Hypothesized Model.

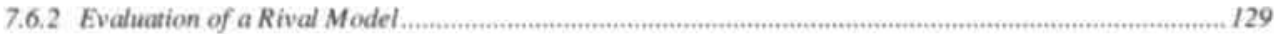

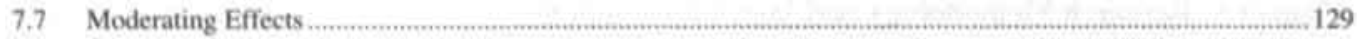

7.7.1 Modenating Effects of Seller Relationship Orientation ...........................................................................130

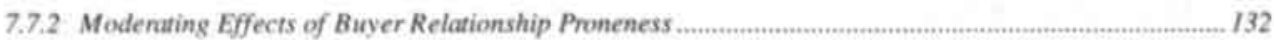

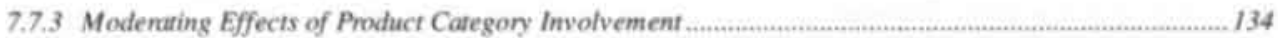

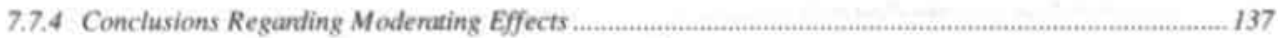

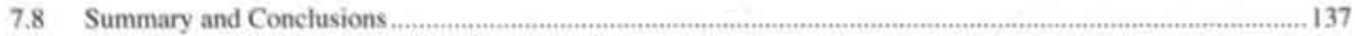




\section{Chapter 8: Conclusions, Limitations, and Implications}

\begin{tabular}{|c|c|}
\hline 8.1 & 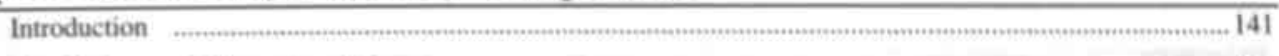 \\
\hline 8.2 & Conclusions and Discussion of Results .................................... \\
\hline 8.3 & Limitations \\
\hline 8.3 & Implications \\
\hline & 8.3.I Theoretical Implications ............ 151 \\
\hline & 8.3.2 Managerial Implications ............. 153 \\
\hline
\end{tabular}

8.4 Directions for Future Research........ 155 


\section{REFERENCES, APPENDICES, SAMENVATTING, CURRICULUM VTTAE}

References

Appendix 1

Theories Underlying Relationship Marketing

Appendix 2

Overview of Empirical Research on Attitudinal Relationship Outcomes.

Appendix 3

Questionnaire Pilot Study

Appendix 4

Quantitative ltem Testing

Appendix 5

Questionnaire

Appendix 6

Univariate Statistics.

Appendix 7

Measure Evaluation

Appendix 8

Covariance Matrices 


\section{List of Tables and Figures}

\section{Tables}

Table 1-1:

Table 1-2:

Table 2-1:

Table 2-2:

Table 2-3:

Table 6-1:

Table 6-2:

Table 6-3:

Table 6-4:

Table 7-1:

Table 7-2:

Table 7-3:

Table 7-4:

Table 7-5:

Table 7-6:

Table 7-7:

Table 7-8:

Table 7-9:

Table 7-10:

Table 7-11:

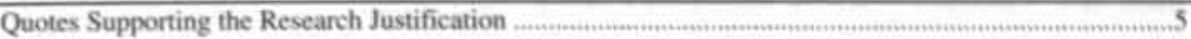

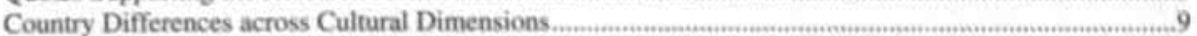

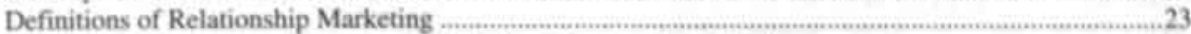

Comparative Summary of Theories Underlying Relationship Marketing ............................................31

Major Differences between Consumer and Business-to-Business Marketing …...........................................35

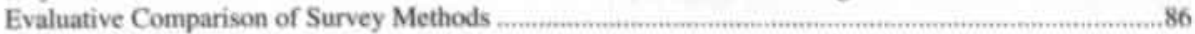

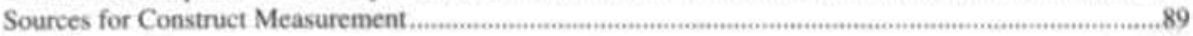

Item Formulations.

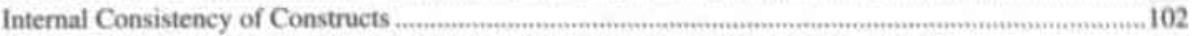

Profile of the Samples (after listwise deletion of cases incorporating missing values) ................................110

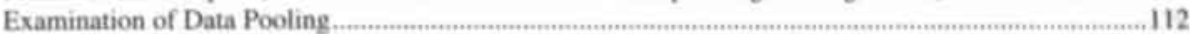

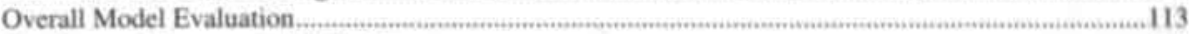

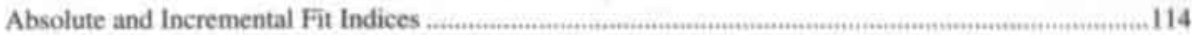

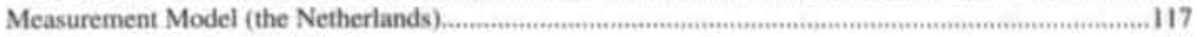

Measurement Model (Belgium) ..........................118

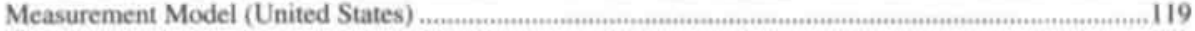

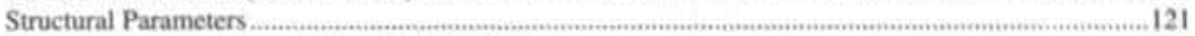

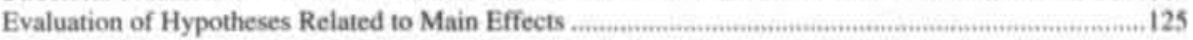

Decomposition of Structural Effects (the Netherlands) ....................................................................126

Decomposition of Structural Effects (Belgium) ………....

Table 7-13: Size and Distribution of Sub-Samples According to the Level of Seller Relationship Orientation...........131

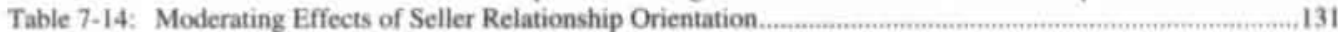

Table 7-15: Change in Path Coefficients Based on Level of Seller Relationship Orientation ..................................132

Table 7-16: Size and Distribution of Sub-Samples According to the Level of Buyer Relationship Proneness ...........133

Table 7-17: Moderating Effects of Buyer Relationship Proneness ........................................................................133

Table 7-18: Change in Path Coefficients Based on Level of Buyer Relationship Proneness......................................134

Table 7-19: Size and Distribution of Sub-Samples According to the Level of Product Category Involvement .......... 135

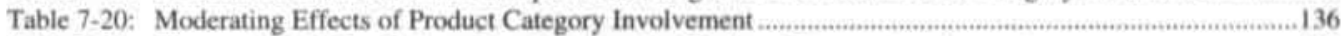

Table 7-21: Change in Path Coefficients Based on Level of Product Category Involvement .....................................136

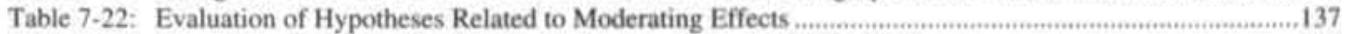

Table A2-1: Summary of Relationship Satisfaction Research (period 1985-1998) ….................................................194

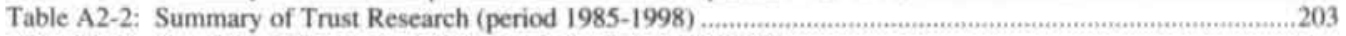

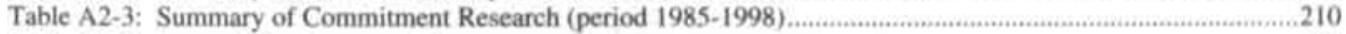

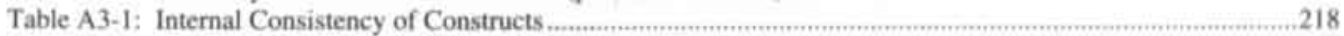

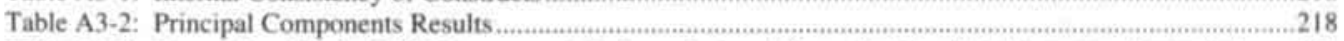

Table A3-3 Regression Results LOV-Components Independent and Buyer Relationship Proneness Dependent.......218

Table A4-1: Principal Components Analysis with Oblique Rotation (the Netherlands Clothing) ..................................220

Table A4-2: Principal Components Analysis with Oblique Rotation (the Netherlands Food) ......................................221

Table A4-3: Principal Components Analysis with Oblique Rotation (Belgium Clothing) ............................................222

Table A4-4: Principal Components Analysis with Oblique Rotation (Belgium Food) ..................................................2223

Table A4-5: Principal Components Analysis with Oblique Rotation (Aggregated Sample) …......................................224

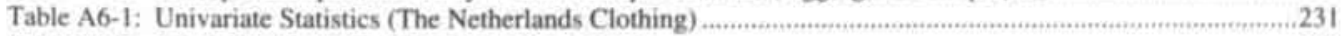

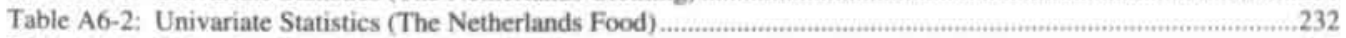

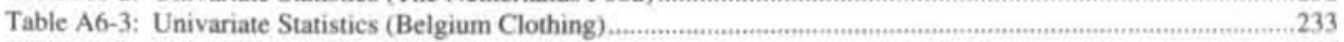

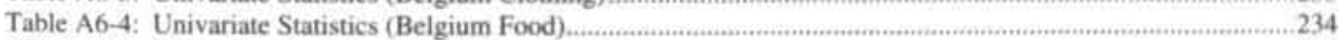

Table A6-5; Univariate Statistics (United States Clothing) …...............................................................................235

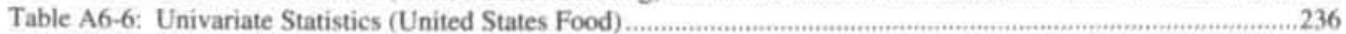

Table A7-1: Principal Components Analysis with Oblique Rotation (the Netherlands Clothing) ...............................238

Table A7-2: Principal Components Analysis with Oblique Rotation (the Netherlands Food) .....................................239

Table A7-3: Principal Components Analysis with Oblique Rotation (Belgium Clothing) …..........................................240

Table A7-4: Principal Components Analysis with Oblique Rotation (Belgium Food) ...........................................241

Table A7-5: Principal Components Analysis with Oblique Rotation (United States Clothing) ...................................242

6


Table A7-6: Principal Components Analysis with Oblique Rotation (United States Food) ….....................................243

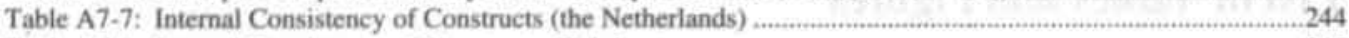

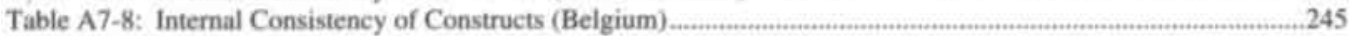

Table A7-9: Internal Consistency of Constructs (United States) ...............................................................................246

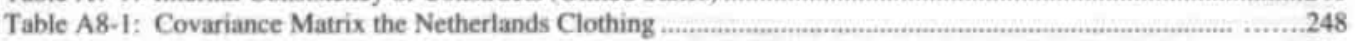

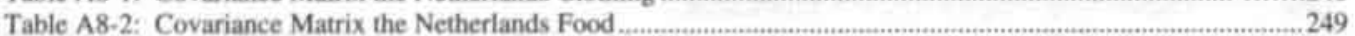

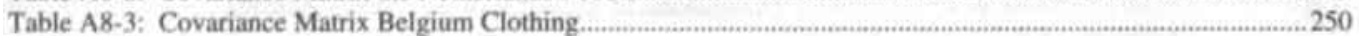

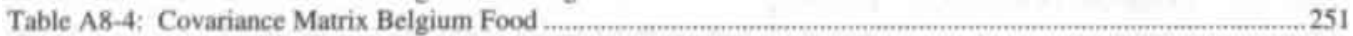

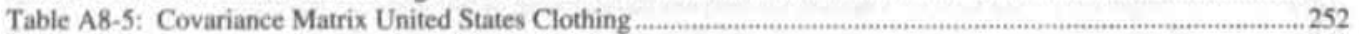

Table A8-6: Covariance Matrix United States Food

\section{Figures}

Figure 1-1: Main Elements of the Conceptual Model .................................................................................8

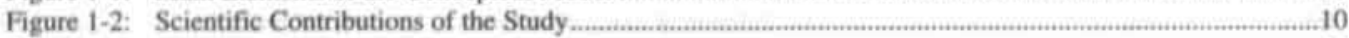

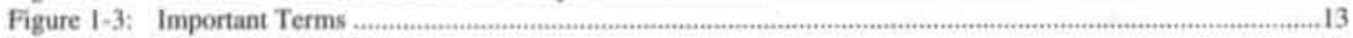

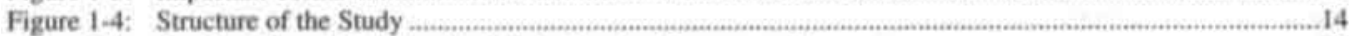

Figure 2-1: Applicability of Relationship Marketing in a Consumer Context.

Figure 2-2: General, Context-Specific, and Mixed Relationship Marketing Theory.......................................................32

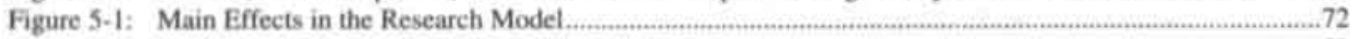

Figure 5-2: Moderating Effects in the Research Model.

Figure 6-1: Selection of Data Collection Method.

Figure 6-2: Overview of Item generation. Testing, and Questionnaire Development...................................................87

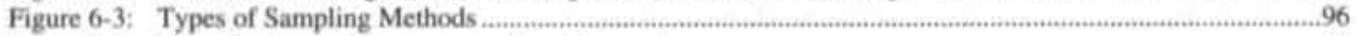

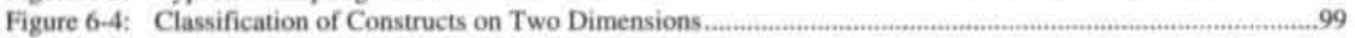

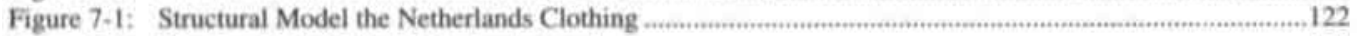

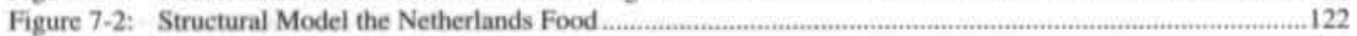

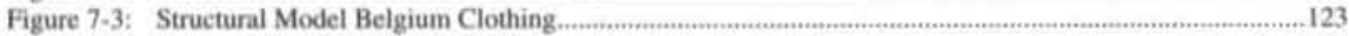

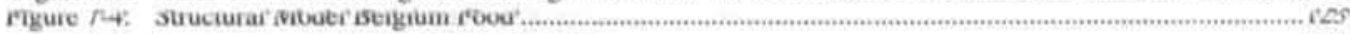

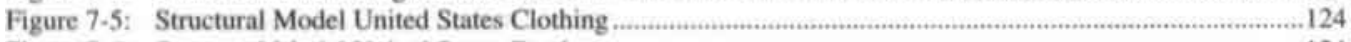

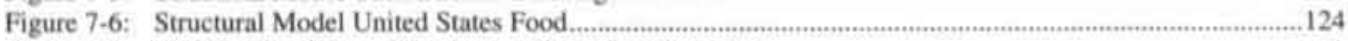

Figure 7-7: Moderating Effects of Seller Relationship Orientation............................................................................130

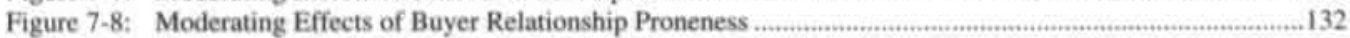

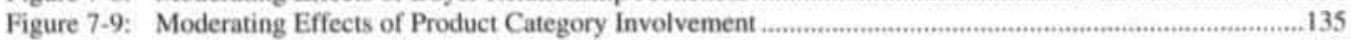

Figure 8-1: Moderating Effects of Seller Relationship Orientation ................................................................

Figure 8-2: Moderating Effects of Buyer Relationship Proneness …........................................................................148

Figure 8-3: Moderating Effects of Product Category Involvement ......................................................................149 


\title{
Executive Summary
}

According to some estimates (Reichheld 1996), US corporations now lose half of their customers in five years and disloyalty reduces corporate performance up to 50 percent. More than ever, it appears that transaction-oriented market approaches have large difficulties in finding an appropriate answer to contemporary market challenges. Under pressure of eroding repeat purchases and intensified competitive pressures in saturated markets, companies increasingly realize that such approaches are no longer sufficient. As a result, several authors underline the fact that - for reasons of efficiency and effectiveness - keeping existing customers deserves more attention than attracting new customers. Customer loyalty, the buzzword of the 1990s, has become a key business priority for most companies today.

Yet, extremely limited information is available on customer reasons for engaging in relationships with companies, on the nature of these relationships, or on their consequences. The basic questions of whether, why, and in which forms customers seek and value ongoing relationships with companies remain largely unanswered. Especially in a consumer retail environment, systematic research on relationship marketing is practically lacking. In their Harvard Business Review article. Fournier. Dobscha, and Mick (1998) recently stressed the crucial importance of undertaking research on buyer-seller relationships.

On the one hand, they indicate the increased opportunities that sellers have for enhancing buyerseller relationships.

\begin{abstract}
"Relationship marketing is in vogue. Managers talk it up. Companies profess to do it in new and better ways every day. Academics extol its merits. And why not? The new. increasingly efficient ways that companies have of understanding and responding to customers' needs and preferences seemingly allow them to build more meaningful connections with consumers than ever before. These connections promise to benefit the bottom line by reducing costs and increasing revenues ... Companies may delight in leaming more about their customers than ever before and in providing features and services to please every possible palate"
\end{abstract}

On the other hand, they warn companies for not listening to the true needs and wants of customers.

"Customers cope. They tolerate sales clerks who hound them with questions every time they buy a battery. They muddle through the plethora of products that line grocery store shelves. They deal with the glut of new features in their computers and cameras. They juggle the flood of invitations to participate in frequent buyer reward programs. Customer satisfaction nutes in the United States are at an all-time low, while complaints, boycotts, and other expressions of consumer discontent rise ... Caught up in our enthusiasm for our information-gathering capabilities and for the potential opponunities that long-term engagements with customers hold, is it possible that we have forgotten that relationships take two?" 
The objective of our study was to investigate whether the statements of Fournier, Dobscha, and Mick (1998) hold in a retail environment: are retailers actually capable of 'building connections' with consumers though increased efforts and which consumers are interested in these efforts? First, we wanted to find out to which extent the strength of buyer-seller relationships is influenced by characteristics of the buyer. More specifically, we investigated whether the proneness of a customer to engage in relationships (referred to as buyer relationship proneness) has an impact on the strength of the buyer-seller relationship. The study was intended to provide retailers with insights on the relative importance of four individual characteristics potentially influencing buyer relationship proneness: sociability, social recognition, shopping enjoyment, and product category involvement. Identifying those buyers who are most prone to engage in relationships is expected to be beneficial to retailers as the efficiency of their marketing investments increases as a result of it. Second, we measured the impact that retailers can have on enhancing their relationship with customers through increasing their efforts (referred to as seller relationship orientation). Knowing the effects of these efforts on the strength of buyer-seller relationships can provide retailers with powerful guidelines for fine-tuning their relationship marketing strategies. In order to accomplish these objectives, more than 1,700 face-to-face interviews were administered in three different countries (the Netherlands, Belgium, and United States) for two different product categories (casual clothing and food). The main results of the study are outlined below.

First, our results indicated that the effectiveness of relationship marketing strategies is not only determined by a retailer's approach to the market, but also for a very large part by the nature of this retailer's customers. Our resuits even show that a buyer's purchasing behavior is relatively more dependent on the proneness of this buyer to engage in relationships than on the efforts of the retailer. Consequently, retailers should not only focus at optimizing their efforts towards customers, but should equally pay attention to finding the right customers. In addition to the more traditional criteria of product-market segmentation such as market size, market growth, and expected market share, retailers need to be more sensitive to average levels of buyer relationship proneness in particular product-markets. Segmenting buyers according to levels of buyer relationship proneness is expected not only to affect share of market, but also expected share of customer as relationship prone customers have a higher tendency to remain loyal to one store. Segmentation and communication based on buyer relationship proneness assist retailers in reducing waste of resources. Second, our results stress the need for retailers to take buyers' product category involvement carefully into consideration. This appeared to be a characteristic inflating buyers' relationship proneness in all the countries and industries investigated. However, only partial support was found for the other individual characteristics investigated. Our conclusions did not hold for each country and for each product category examined. As today's retailers increasingly offer comparable merchandise, copy competitors' price promotions, share common distribution systems, and treat customers well in terms of services offered, they should direct the majority of their attention to highly involved, relationship prone buyers.

Third, in addition to the direct effects of buyer relationship proneness and seller relationship orientation on relationship strength, both constructs also fulfil a moderating role. Our results underline that the same efforts of a retailer towards customers can result in higher levels of relationship satisfaction and relationship commitment in case these customers are more prone to 
engage in relationships. Dependent upon the level of a buyer's relationship proneness, retailers' strategies are more or less effective. Retailers should keep this in mind when targeting customers. Therefore, it could be beneficial for retailers to adjust their efforts according to levels of buyer relationship proneness. For example, customers who are less relationship prone might have less appreciation for customer loyalty cards or other expressions of retailers' efforts. Moreover, the impact of a retailer's efforts was found to be dependent upon the level of a buyer's product category involvement. Consumers who were more involved with the product category also revealed higher levels of relationship satisfaction and relationship commitment. As product category involvement may differ across market segments, our results imply that the effectiveness of relationship marketing strategies equally differs across market segments.

Fourth, retailers should be aware of the fact that the behavioral loyalty of their customers is dependent upon more factors than relationship commitment only. Behavioral loyalty towards a store can result from seller-related, buyer-related, and situational factors. While our results show that seller- and buyer-related factors have important, indirect influences on behavioral loyalty, situational variables such as distance to the store, competition, existence of a monopoly, and familiarity with a store apparently also play a crucial role in affecting behavioral loyalty. However, the direct effects of relationship commitment on behavioral loyalty were relatively larger in the clothing samples as opposed to the food samples. This might be an indication of the fact that habit and inertia play a more important role in food markets selling convenience goods than in clothing markets selling shopping goods. This result is a first step in investigating whether and why it is easier to build brand loyalty in some product categories than in others. It appears that building loyalty in a clothing environment is relatively more easy than in a food environment.

Concluding, our results demonstrate that the statements of Fournier, Dobscha, and Mick (1998) are too bold to be true in a retail environment. Customers do want to be approached by sellers as is evidenced by the positive impact that seller relationship orientation has on important parameters of relationship marketing success such as relationship satisfaction and relationship commitment. However, their warning for not considering the role of the buyer in affecting the nature of buyerseller relationships is an important and a valid one. More than ever, it appears that retailers should take into consideration the characteristics of individual buyers in their relationship marketing strategies as is evidenced by the strong influence of buyer relationship proneness on the strength of buyer-seller relationships. 


\section{Chapter Structure}

1.1 Introduction.

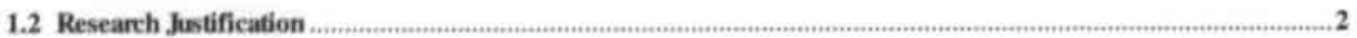

1.2 .1 Importance

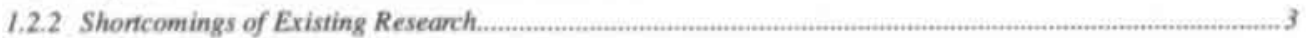

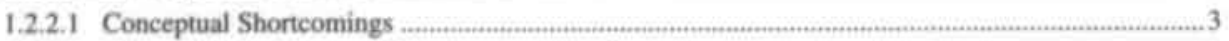

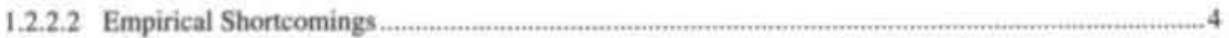

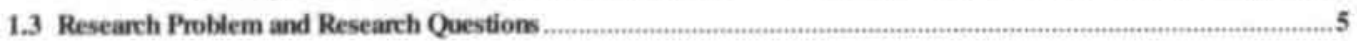

1.4 Research Seope

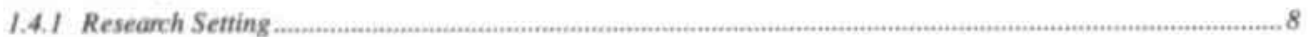

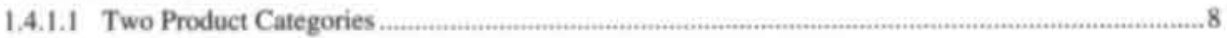

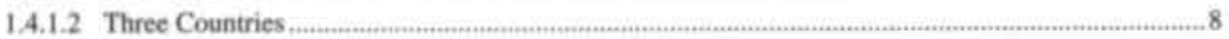

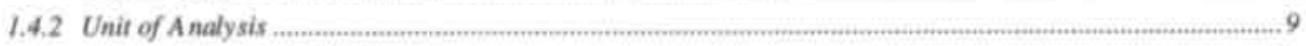

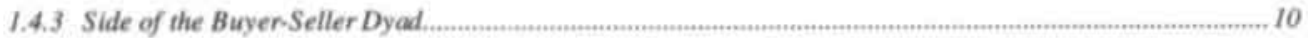

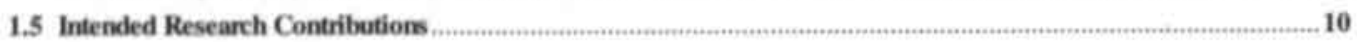

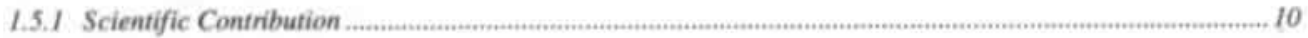

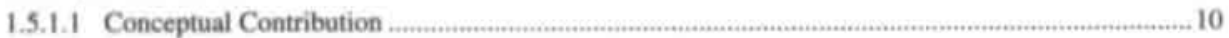

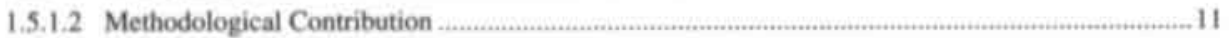

1.5.1.3 Empirical Contribution

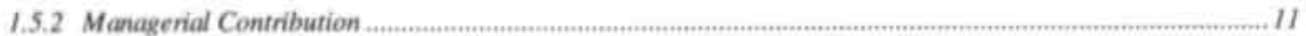

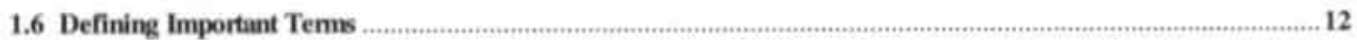

1.7 Structure 


\section{Chapter 1 Introduction to the Research Problem ${ }^{1}$}

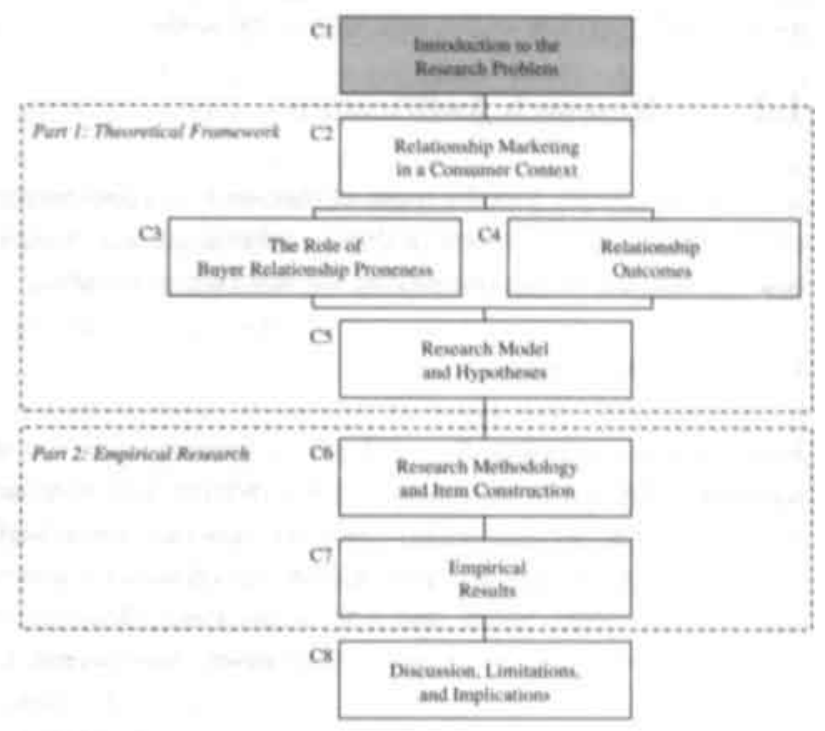

\subsection{Introduction}

In contemporary marketing literature, there exists a general agreement about the value of relationship marketing ${ }^{2}$ for both buyers and sellers ${ }^{3}$ (Berry 1983: Iacobucci and Ostrom 1996: Morgan and Hunt 1994; Sheth and Parvatiyar 1995a). Value from the perspective of a buyer is reflected by the specific buyer benefits that can result from close buyer-seller relationships ${ }^{4}$ (Barlow 1992; Berling 1993; Buttle 1996; Dwyer, Schurr, and Oh 1987; Evans and Laskin 1994; Ganesan 1994; Goff et al, 1997; Gummesson 1987; Jüttner and Wehrli 1994: Reichheld 1993: Turnbull and Wilson 1989; Webster 1994a). From a seller's perspective, relationship marketing is often suggested as a means for gaining competitive advantage in today's quickly evolving and highly competitive markets (Gwinner, Gremler, and Bitner 1998; Kahn 1998; Reichheld 1993; Sharma and Sheth 1997; Tumbull and Wilson 1989). Several scholars even consider the changing focus from successive, independent exchanges to relational exchanges as a true paradigm shift in marketing (Bendapudi and Berry 1997; Evans and Laskin 1994; Grönroos 1994a; Morgan and Hunt 1994; Webster 1992; Weitz and Jap 1995).

In section 1.2, we first provide justifications for our study. In section 1.3, we outline our research problem and its resulting research questions. Section 1.4 describes the scope of the study. In section

This study is largely based on a joint research project with De Wulf (1999). While De Wuif (1999) emphasizes the role of the seller in enhancing buyer-seller relationships, this study focuses at the role of the buyer in affecting buyer-seller relationships. Any potential weaknesses are the author's sole responsibility. For our definition of 'relationship marketing', see section 1.6.

In this study. 'a seller' refers to a company as opposed to a salesperson.

For our definition of a 'buyer-seller relationship', see section 1.6. 
1.5, we comment upon the major intended scientific and managerial contributions of this study. In section 1.6, we define the most important terms that are used in the study. Finally, in section 1.7, we give a brief overview of the structure of the study.

\subsection{Research Justification}

In 1.2.1, we clarify that the topic of this study is considerably important for marketing science to be investigated. In 1.2.2, we indicate several shortcomings of existing research in the area of relationship marketing reinforcing the need for our study.

\subsubsection{Importance}

Relationship marketing has undeniably been one of the major research topics examined in the marketing discipline during the 1990s (Möller and Halinen-Kaila 1998; Morgan and Hunt 1994: Sheth and Parvatiyar 1995a). Several scholars have highlighted the importance of enhancing customer relationships as a prerequisite for effective marketing (Kotler 1992; McCort 1994; Perrien and Ricard 1995; Shani and Chalasani 1992; Sharma and Sheth 1997; Zinkhan 1994). This importance is further evidenced by journals' special issues on relationship marketing and loyalty (European Journal of Marketing 1996; Industrial Marketing Management 1997; International Journal of Research in Marketing 1997; Journal of Marketing Management 1997; Journal of the Academy of Marketing Science 1995) and by high quality conferences targeted at this topic (American Marketing Association 1996-1997; Emory University Conferences 1993-1998). In addition. 'Understanding the customer experience' and 'Relationship Marketing' are respectively ranked as second and fourth research priorities in the Marketing Science Institute's list of research priorities for 1998-2000.

Several authors recognize the increasing importance of investigating (1) relationships in consumer environments, (2) the role of buyer relationship proneness ${ }^{5}$ in affecting buyer-seller relationships, and (3) the role of seller relationship orientation ${ }^{6}$ in enhancing buyer-seller relationships. These three research opportunities are discussed next.

First, considerable proof has already been accumulated that relationship marketing is useful in industrial and channel contexts (Anderson and Narus 1984; Berry 1983; Bitner 1990: Crosby and Stephens 1987; Frazier and Antia 1995; Geyskens et al. 1996; Morgan 1991; Reichheld 1993). Recently, the value of relationship marketing is increasingly recognized in consumer markets (Fournier 1998; Gwinner, Gremler, and Bitner 1998; lacobucci and Ostrom 1996; Schijns 1999). More and more, consumers want to be respected and approached as individuals (Beddoe 1995; Peppers and Rogers 1993; Petrison, Blattberg, and Wang 1993; Rapp and Collins 1990). Therefore, gathering and strategically using individual consumer information for purposes of enhancing relationships with them are considered to improve sellers' competitive positions in consumer

While the term 'buyer relationship proneness' is not used as such in literature, the ideas behind this construct are reflected in existing literature. For our definition of buyer relationship proneness, see section 1.6.

6 While the term 'seller relationship orientation' is not used 'as such in literature, the ideas behind this construct are reflected in existing literature. For our definition of seller relationship orientation, see section 1.6. 
markets (De Bonis and Nucifora 1994; Fletcher, Wright, and Desai 1996; Hoekstra 1994: McCutcheon and Wang 1995; Nash 1993). It seems particularly vital for retail ${ }^{7}$ businesses to focus on enhancing relationships with consumers (Beatty et al. 1996; Berry and Gresham 1986; Ellis 1995: Gengler and Popkowski Leszcyc 1997; Macintosh and Lockshin 1997). As a result of intensifying competition and nonstop price promotions, retailers increasingly complain about declining loyalty of consumers. From a seller's perspective, relationship marketing strategies in retail are particularly relevant in the contemporary environment because they have the potential to reduce customer defection (Macintosh and Lockshin 1997). Consumers increasingly look for retailers who provide not only value in terms of acceptable prices and attractive assortments, but also relationship value (Arnold, Handelman, and Tigert 1996).

Second, identifying those buyers who are most prone to engage in buyer-seller relationships is considered to yield important benefits to the seller given the considerable investments that are often needed for enhancing such relationships (Barnes 1995/1997; Bendapudi and Berry 1997; Christy, Oliver, and Penn 1996). Recently, several academics underline the importance of segmenting the market according to buyer relationship types. One of the criteria that can be used to classify buyers into relationship types is their level of relationship proneness (Bendapudi and Berry 1997; Evans and Laskin 1994; Gwinner, Gremler, and Bitner 1998; Sheth and Parvatiyar 1995b).

Third, several authors are starting to recognize that more research is needed in order to better understand the effects of a seller's efforts ${ }^{8}$ on buyers' attitudes towards and behaviors during their relationship with this seller (Barnes 1994; Dwyer, Schurr, and Oh 1987; Webster 1992). Despite sellers' apparent interests in these effects, there is little information available to them about how to design or implement profitable relationship strategies (Beatty et al. 1996).

Consequently, a consumer's proneness to engage in buyer-seller relationships and his perception of seller relationship orientation are the core topics investigated in this study.

\subsubsection{Shortcomings of Existing Research}

Given the widespread attention of academics as well as practitioners for relationship marketing (Dwyer, Schurr, and Oh 1987; Morgan and Hunt 1994; Nevin 1995), one would expect it to have a rich tradition of theory development, scale development, and empirical research. However, this is only partially true. In this section, we describe conceptual and empirical shortcomings of existing relationship marketing research.

\subsubsection{Conceptual Shortcomings}

There exists no general agreement between authors on a definition of relationship marketing (Blois 1995; Evans and Laskin 1994; Gummesson 1994: Perrien and Ricard 1995). Moreover, most definitions in relationship marketing research tend to be broad, generic, or all-encompassing, which makes them less valuable for directing marketing practice and theory development. Furthermore,

\footnotetext{
7. The terms 'retail' and 'consumer' are used interchangeably in this study.

For our definition of a 'relationship effort', see section 1.6 .
} 
few attempts have been made to critically examine the applicability of existing relationship marketing constructs in a consumer context (e.g. Gruen 1995). Consequently, there is a need for (1) determining which relational constructs are most relevant in a consumer setting and for (2) providing more precise and directive definitions of these constructs in order to support empirical validation (Bagozzi 1995: Peterson 1995).

\subsubsection{Empirical Shoncomings}

First, while there exists a large body of knowledge on channel and industrial relationships, systematic empirical research on relationship marketing in a retail environment is practically lacking (Beatty et al. 1996; Gummesson 1994; Gwinner, Gremler, and Bitner 1998; Macintosh and Lockshin 1997; Shani and Chalasani 1992; Zinkhan 1994).

Second, while the value of relationship marketing has mainly been viewed from a seller's perspective, the buyer's perspective has been largely neglected (Barnes 1995/1997; Bendapudi and Berry 1997: Sheth and Parvatiyar 1995b). Since most definitions of relationship marketing stress the existence of advantages for both parties in a relationship, this is somewhat surprising (Berry 1995; Dwyer, Schurr, and Oh 1987; Grönroos 1990a; Shani and Chalasani 1992). Despite the lack of empirical attention, several academics recognize the importance of taking a buyer perspective in investigating relationships (Barnes 1994: Beatty et al. 1996; Bendapudi and Berry 1997; Bitner 1995; Christy, Oliver, and Penn 1996; Fournier 1998; Gruen 1995; Gwinner, Gremler, and Bitner 1998; Reichheld 1993: Sheth and Parvatiyar 1995b). The importance of the buyer's role is stressed by Sheth and Parvatiyar (1995b, p. 256) who stated that "the marketer's motivation to engage in relationship marketing is tempered by the consumers' motivation to reduce their choice set to be in relationship with a firm or a brand". In line with this, Dwyer. Schurr, and Oh (1987) stressed the importance of both sellers' and buyers' motivational investments in a relationship as determinants of relationship outcomes ${ }^{9}$. Also Fournier, Dobscha, and Mick (1998) remarked that marketers, in their enthusiasm to gather information from consumers, might have forgotten that relationships take two.

Third. traditional thinking focused on the implicit assumption that the dominant forces in a relationship are of a destructive nature as opposed to more constructive relationship thinking (Achrol 1997; Kalwani and Narayandas 1995). While previous research on relationship marketing mainly focused at constraint-based relationships ${ }^{10}$ (Andaleeb 1996; Bendapudi and Berry 1997: Ganesan 1994; Geyskens et al. 1996; Johnson 1999; Morgan and Hunt 1994; Palmer 1995), there exists a lack of research on relationships resulting from more positive buyer motivations, referred to as dedication-based relationships.

Table 1-1 includes some quotes that support the justification of the current research.

9. For our definition of a 'buyer-seller relationship outcome', see section 1.6.

10 In chapter three and appendix one, we discuss the difference between constraint- and dedication-based motivations to enhance buyer-seller relationships. 


\begin{tabular}{|c|c|}
\hline Quotes & References \\
\hline $\begin{array}{l}\text { "Targeting profitable customers for relationship } \\
\text { marketing involves study and analysis of loyalty- and } \\
\text { defection-prone customers, searching for distinguishing } \\
\text { patterns in why they stay or leave, what creates value for } \\
\text { them and who they are" }\end{array}$ & - Berry 1995, p. 239 \\
\hline $\begin{array}{l}\text { - What are the costs and benefits from the customer's } \\
\text { perspective of staying in a service relationship?" }\end{array}$ & - Bitner 1995, p. 250 \\
\hline $\begin{array}{l}\text { "Further research should also examine the reasons that } \\
\text { people give for favouring high or low levels of store } \\
\text { loyalty" }\end{array}$ & - East et al. 1997, p. 412 \\
\hline $\begin{array}{l}\text { "Yet, no one has examined customer reasons for } \\
\text { engaging in relationships with sellers (i.e., sales } \\
\text { personnel), the nature of these relationships, or their } \\
\text { consequences" }\end{array}$ & - Ellis 1995, p. 4 \\
\hline $\begin{array}{l}\text { "Customers should be surveyed, by customer type, to } \\
\text { determine which aspects of relationship marketing should } \\
\text { be emphasized for them" }\end{array}$ & - Evans and Laskin 1994, p. 451 \\
\hline $\begin{array}{l}\text { forms consumers seek and value ongoing relationships .... } \\
\text { remain largely unanswered" }\end{array}$ & - Fournier 1998. p. 343 \\
\hline $\begin{array}{l}\text { no systematic, empirical investigation has been } \\
\text { published examining the benefits customers receive from } \\
\text { being in a relationship" }\end{array}$ & - Gwinner, Gremler, and Bitner 1998, p. 102 \\
\hline $\begin{array}{l}\text {-... taking the consumer perspective, and understanding } \\
\text { what motivates consumers to become loyal, is important" }\end{array}$ & - Sheth and Parvatiyar 1995b, p. 256 \\
\hline $\begin{array}{l}\text { - There is a need for research on why customers stay loyal } \\
\text { to a firm and what makes them leave the firm" } \\
\text { "In consumer goods marketing. research is needed to } \\
\text { understand the factors that lead consumers to seek out and } \\
\text { value ongoing relationships with brands, manufacturers, } \\
\text { and resellers of various kinds" }\end{array}$ & $\begin{array}{l}\text { - Strandvik and Liljander 1994, p. } 26 \\
\text { - Webster 1992, p. } 14\end{array}$ \\
\hline
\end{tabular}

\subsection{Research Problem and Research Questions}

From the previous section, it has become clear that, despite conceptual and empirical research efforts addressed at a wide variety of relationship marketing issues, several areas for improvement can still be recognized. The research problem that is investigated in this study is especially focused at these areas. We examine the following research problem:

What are the antecedents of buyer relationship proneness and what are the effects of buyer relationship proneness and seller relationship orientation on relationship outcomes in a retail context? 
This research problem is subdivided into the following research questions:

(1) What are the antecedents of buyer relationship proneness?

(2) What are the effects of buyer relationship proneness on relationship outcomes?

(3) What are the effects of seller relationship orientation on relationship outcomes?

(4) What are the effects of buyer relationship proneness on seller relationship orientation?

(5) What are the interrelationships between relationship outcomes?

(6) To what extent are the effects of

(a) buyer relationship proneness moderated by seller relationship orientation?

(b) seller relationship orientation moderated by buyer relationship proneness?

(c) seller relationship orientation moderated by product category involvement?

(1) What are the antecedents of buyer relationship proneness?

Academics as well as practitioners often assume that a relationship can be built with any buyer in any situation (Barnes 1995/1997). However, several scholars have recently recognized that buyers can differ in their proneness to engage in relationships (Bendapudi and Berry 1997; Ellis 1995). Despite conceptual research attempts examining relationship proneness, no systematic, empirical investigation has been published yet (Barnes 1995; Bendapudi and Berry 1997; Christy, Oliver, and Penn 1996; Gwinner, Gremler, and Bitner 1998). In this study, a precise definition of the concept of relationship proneness is formulated, followed by an operationalization of the concept enabling its measurement. Knowledge about the antecedents of relationship proneness will provide an answer to the question why buyers differ in their degree of relationship proneness (Beatty et al. 1996; Biong and Selnes 1995: Ellis 1995). This answer will assist sellers in making justifiable choices with respect to targeting and communicating with buyers (Bendapudi and Berry 1997; Sheth and Parvatiyar 1995b). Therefore, the present study empirically investigates the relationship between buyer relationship proneness and its antecedents.

(2) What are the effects of buyer relationship proneness on relationship outcomes?

Several recent publications suggest that the success of a relational strategy also depends on buyers' individual characteristics (Barnes 1997; Fournier 1998; Sheth and Parvatiyar 1995b). In this study, buyers' relationship proneness is regarded as an individual characteristic. In a conceptual paper, Beatty et al. (1996) argued that buyer relationship motivation is one of the factors related to relationship outcomes. In line with this, Bendapudi and Berry (1997) proposed that buyer proneness to engage in relationships influences the success of relationship enhancement strategies. Also Fournier, Dobscha, and Mick (1998) recently argued that the buyer is not necessarily a willing participant in relationship strategies set up by the seller. Therefore, we empirically test the relationship between buyer relationship proneness and relationship outcomes.

(3) What are the effects of seller relationship orientation on relationship outcomes?

It is commonly agreed upon that relationship-oriented sellers strive to enhance buyer-seller relationships (Christopher, Payne, and Ballantyne 1994: Copulsky and Wolf 1990; Dwyer, Schurr, and Oh 1987; Evans and Laskin 1994; Fischer and Bristor 1994: Ganesan 1994; Grant 
and Schlesinger 1995: Saxe and Weitz 1982; Shani and Chalasani 1992; Stum and Thiry 1991). Therefore, it can be expected that the level of seller relationship orientation affects relationship outcomes. This study empirically validates this relationship.

(4) What are the effects of buyer relationship proneness on seller relationship orientation?

We expect that buyers who are more relationship prone are more receptive to a seller's efforts directed at these buyers. In other words, relationship prone buyers could be more inclined to perceive such efforts than non-relationship prone buyers. In this study, we empirically investigate the relationship between buyer relationship proneness and seller relationship orientation.

(5) What are the intemelationships between relationship outcomes?

In industrial and channel contexts, there exists a general agreement about the interrelationships between relationship satisfaction. trust, relationship commitment, and behavioral loyalty (Baker, Simpson, and Siguaw 1999; Crosby, Evans, and Cowles 1990; Doney and Cannon 1997; Geyskens et al. 1996; Gruen 1995; Morgan and Hunt 1994; Selnes 1998). This study examines the interrelationships between these constructs in a retail environment.

\section{(6) To what extent are the effects of}

(a) buyer relationship proneness modented by seller relationship orientation?

(b) seller relationship orientation moderated by buyer relationship proneness?

(c) seller relationship orientation modenated by product category involvement?

Since a relationship has been described as an intermittent exchange " between two or more parties during a longer period of time (Hinde 1979: Hoekstra 1994), some scholars state that buyer relationship proneness alone is not sufficient for positive relationship outcomes to appear (Beatty et al. 1996; Bendapudi and Berry 1997; Sheth and Parvatiyar 1995b). Dwyer, Schurr, and Oh (1987) already recognized that buyer and seller motivational investments in a relationship jointly determine relationship outcomes. In addition to the direct effect of buyer relationship proneness and seller relationship orientation on relationship outcomes, this study empirically tests the existence of three moderator effects. First, seller relationship orientation is hypothesized to moderate the relationship between buyer relationship proneness and relationship outcomes. Second, buyer relationship proneness is hypothesized to moderate the relationship between seller relationship orientation and relationship outcomes. Moreover, several scholars assume that enhancing relationships is generally easier in high involvement contexts as opposed to low involvement contexts (Berry 1995; Christy, Oliver, and Penn 1996: Leuthesser 1997; Metcalf, Frear, and Krishnan 1992). Consequently, the moderating effect of a buyer's involvement with the product category is investigated on the relationship between seller relationship orientation and relationship outcomes.

The described research questions form the building blocks of the study. In line with these questions, the main elements of our conceptual model are portrayed in figure $1-1^{12}$.

For our definition of a 'buyer-seller exchange', see section 1.6.

In section 1.6, we provide a more detailed picture of this conceptual model including the definitions of its constructs. In chapter five, we provide the hypotheses related to the interrelationships between the constructs. 


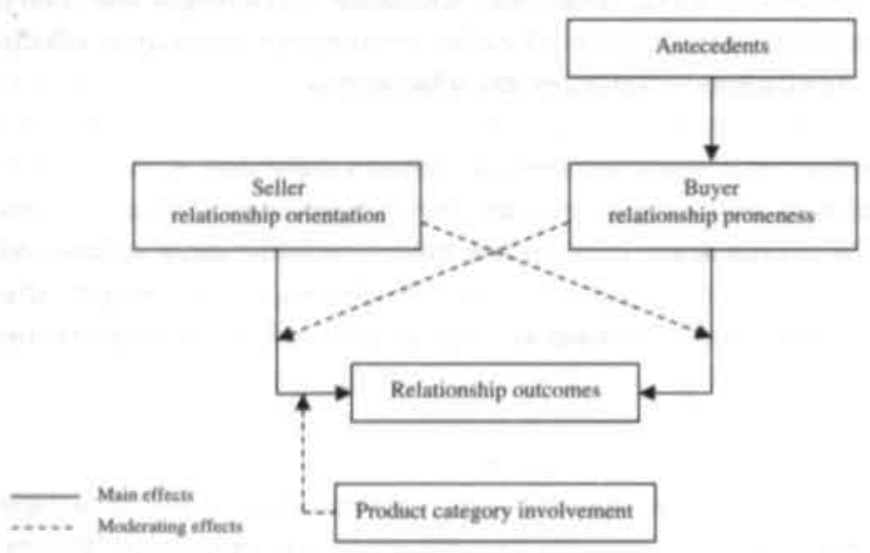

Figure 1-1: Main Elements of the Conceptual Model

\section{$1.4 \quad$ Research Scope}

\subsubsection{Research Setting}

\subsubsection{Two Product Categories}

We focus upon buyers' positive motivations to engage in buyer-seller relationships (dedicationbased relationships). We assume that such motivations mainly apply to highly competitive and transparent market environments as buyers are not constrained by limited choice or lack of information in such markets (Frazier and Rody 1991). Consequently, the empirical research in this study is conducted in two highly competitive and transparent markets, the retail markets of casual clothing ${ }^{13}$ and food. Both markets are generally acknowledged to have reached maturity, to be overstored, and to have difficulties differentiating themselves based on merchandise selection only (Berry and Gresham 1986; Ellis 1995; Ghosh 1994). As Anderson, Fornell, and Rust (1997) classify clothing stores and supermarkets in opposite quadrants based upon customer satisfaction and productivity, both markets are expected to be sufficiently heterogeneous. Moreover, the generalizability of our results is expected to benefit from the fact that our samples cover a wide variety of clothing and food retailers including discount stores, mass merchandisers, traditional department stores, as well as prestige stores.

\subsubsection{Three Countries}

Following recent suggestions to advance studies' external validity by examining data from different countries (Geyskens et al. 1996; Iacobucci and Ostrom 1996; Schwartz 1992) and given the fact that cultural differences can influence perceptions of relational phenomena (Iacobucci and Ostrom

13 As clothing is generally recognized as a product that does not fall neatly into one product category (Hong and Rucker 1995), we limited our scope to the market of casual clothing. 
1996), the current study is conducted in the Netherlands. Belgium, as well as the United States. Hofstede (1980) demonstrated that the Netherlands. Belgium and the United States differ significantly on four cultural dimensions: power distance, uncertainty avoidance, individualism, and masculinity. Table 1-2 reports the values for each country.

Table 1-2: Country Differences across Cultural Dimensions

\begin{tabular}{lcccc}
\hline Country & Individualism & Masculinity & Power distance & Uncertainty avoidance \\
\hline The Netherlands & 80 & 14 & 38 & 53 \\
Belgium & 75 & 54 & 65 & 94 \\
United States & 91 & 62 & 40 & 46 \\
\hline
\end{tabular}

Source: $\quad$ Hofstede, Geert (1980), "Culture's Consequences: International Differences in Work-Related Values," in Cross Cultural Research and Methodology Series, volume 5, Walter J. Lonner and John W. Berry. eds. Beverly Hills; Sage Publications.

Given the differences between the countries examined in this study, we expect our samples to be suitable for purposes of demonstrating whether our model holds up beyond the data on which it was based.

\subsubsection{Unit of Analysis}

In his conceptual exchange framework, Bagozzi (1975) classified exchanges according to exchange types. Exchange types refer to the number of parties involved in an exchange and the directions of this exchange. 'Restricted exchanges' refer to two-party reciprocal relationships, 'generalized exchanges' refer to reciprocal relationships between parties who give to one party but who receive from another party, and 'complex exchanges' refer to mutual relationships between at least three parties. The type of relationship we investigate is a two-party reciprocal relationship between a single consumer and a single store. Iacobucci and Ostrom (1996) referred to the consumer-store relationship as a mixed individual-to-firm dyad as opposed to individual-to-individual and firm-tofirm dyads.

First, our research questions are related to perceptions of one single consumer. The construct of seller relationship orientation is defined as a single consumer's perceptions of the extent to which a seller actively makes efforts to regular customers of this seller. Moreover, the construct of buyer relationship proneness is defined as an individual consumer characteristic. Finally, relationship outcomes are defined from an individual consumer's perspective. Yau (1988) stated that Western families only take other family members into account when buying decisions concern major purchases. As the product categories investigated in this study cannot be considered as such, the individual consumer is regarded as a suitable unit of analysis for our purposes.

Second, we investigate a consumer's relationship with one particular store. In a retail context, a buyer can have a relationship with a store chain, a particular store, a particular department within a store, or with an individual sales associate (Beatty et al. 1996; Macintosh and Lockshin 1997). We expect the validity and reliability of consumers' responses to be higher for questions related to one particular store than for questions related to a store chain. Buyers may not be able to reveal valid and reliable perceptions of a retail chain as they usually visit only a limited number of stores in the chain. Moreover, we did not focus on a buyer's relationship with a particular store department as a 
unit of analysis as we expect that the phenomenon of having relationships with specific store departments is relatively stronger related to American culture. Finally, we do not incorporate a buyer's relationship with a particular sales associate as a unit of analysis because considerably more research efforts have been directed at relationships with sales associates as opposed to relationships with one particular store (Beatty et al. 1996; Crosby, Evans, and Cowles 1990; Ellis 1995).

\subsubsection{Side of the Buyer-Seller Dyad}

For a dedication-based relationship to exist, both the buyer and the seller are supposed to benefit from this relationship (Barnes 1995/1997; Dwyer, Schurr, and Oh 1987; Gwinner, Gremler, and Bitner 1998). Consequentiy, most definitions of relationship marketing mention advantages for both parties (Dwyer, Schurr, and Oh 1987). While the majority of research efforts related to relationship marketing emphasized the seller perspective to the neglect of the buyer perspective (Barnes 1994: Sheth and Parvatiyar 1995b), this study collects data from the buyer side of the relationship. All constructs in this study are measured as buyer perceptions. As already mentioned, this also holds for the construct of seller relationship orientation that is measured as a buyer's perception of seller efforts directed towards regular customers of this seller.

\subsection{Intended Research Contributions}

\subsubsection{Scientific Contribution}

Successively, we discuss the study's intended conceptual, methodological, and empirical contributions. Figure 1-2 represents these three areas and their levels of contribution.

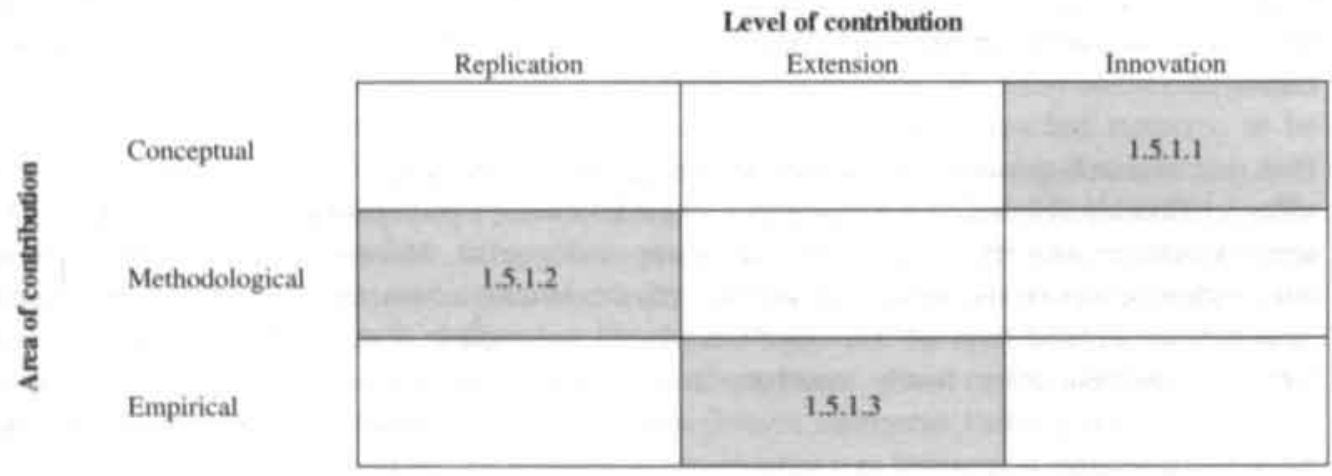

Figure 1-2: Scientific Contributions of the Study

\subsubsection{Conceptual Contribution}

This study contributes to relationship marketing theory in three ways. First, it critically examines existing theories underlying relationship marketing in light of their potential contribution to understanding consumer relationships. A review of these theories in chapter two serves as a guiding 
framework for selecting and developing relationship marketing constructs that are relevant in a consumer context and for formulating research hypotheses concerning the relationships between these constructs. Second, this study defines and operationalizes two new relationship marketing constructs: buyer relationship proneness and seller relationship orientation. This allows us to generate knowledge on the effects of buyers' individual characteristics and sellers' efforts on relationship outcomes. Finally, in order to assess why a buyer is prone to engage in relationships, we distinguish between, define, and operationalize different antecedents of buyer relationship proneness.

\subsubsection{Methodological Contribution}

Our methodological contribution concerns a replication of existing methods. The methodology used in this study is in line with generally accepted practices (e.g. Churchill 1979; Hair et al. 1998). Strong efforts were made to enhance the validity and reliability of the constructs included in the study. We used qualitative research methods to generate knowledge useful for construct development. Moreover, extensive qualitative as well as quantitative test stages were set up in order to purify construct items.

\section{5,1.3 Empirical Contribution}

This study makes an empirical contribution by investigating buyer-seller relationships in a retail context viewed from a buyer perspective. We assess the impact of two new constructs, buyer relationship proneness and seller relationship orientation, on relationship outcomes. Moreover, we assess the effect of various antecedents on the level of buyer relationship proneness. A multi-context approach is employed in order to enhance the external validity of our results. As already mentioned in 1.4.1, the empirical study conducted on basis of six samples spread across two product categories and three countries,

\subsubsection{Managerial Contribution}

According to some estimates (Reichheld 1996), US corporations now lose half of their customers in five years and disloyalty reduces corporate performance up to 50 percent. More than ever, it appears that transaction-oriented market approaches have large difficulties in finding an appropriate answer to contemporary market challenges (Evans and Laskin 1994; Perrien and Ricard 1995). Companies increasingly realize that such approaches are no longer sufficient within the current, turbulent marketing environment. As a result, several authors underline the fact that - for reasons of efficiency and effectiveness - keeping existing customers deserves more attention than attracting new customers (Achrol 1997; Barnes 1995; Kalwani and Narayandas 1995; Naumann and Shannon 1992; Perrien, Paradis, and Banting 1995; Reichheld and Sasser 1990).

Identifying those buyers who are most prone to engage in relationships is expected to be beneficial to retailers as the efficiency of their marketing investments increases as a result of it (Barnes 1995: Bendapudi and Berry 1997; Christy, Oliver, and Penn 1996). Moreover, knowing the effects of 
relationship marketing strategies on relationship outcomes can provide retailers with powerful guidelines for fine-tuning their efforts aimed at enhancing valuable relationships (Ganesan 1994). The current research thus contributes to more effective relationship marketing strategies in a retail environment by helping to improve the identification of consumers who are most prone to react positively to retailers' relationship strategies.

\subsection{Defining Important Terms}

In this section, the most important terms used in this study are defined. First, we present our definitions of buyer-seller exchange, buyer-seller relationship. buyer-seller relationship outcome, and relationship marketing. These concepts are further discussed in chapters two and three. Second, the constructs investigated in this study are visualized and described in figure 1-3. We will elaborate on these constructs in chapters three and four.

\section{(1) Buyer-seller exchange}

A product/service, financial, information, and/or social exchange between a buyer and a seller (based on: Crosby and Stephens 1987; MacNeil 1980; Pelton, Strutton, and Lumpkin 1997).

(2) Buyer-seller relationship

One or more exchanges between a buyer and a seller that are perceived by the buyer as being interrelated to potential past and future exchanges with the seller (based on: Barnes 1995; Hinde 1979; Webster 1992).

(3) Buyer-seller relationship outcome

A buyer's attitude towards or behavior during the buyer-seller relationship (definition developed for this study).

(4) Relationship marketing

A seller's efforts aimed at enhancing relationship outcomes of buyer-seller relationships (definition developed for this study). 
Selier relationship orientation

A bayer's werall perception of the extent to which a seller actively indars efforts wowards regular buyes that are inteaded to contribute in the custoner value of itese regular boyen

\section{Anterredents}

\section{Sariabilitiv}

A buyer's individual characteristic repersenting the vendency to affiliate with othen and to prefer being with others to remaining alone

\section{Secial meregeition}

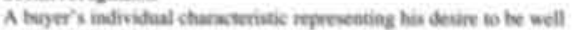
respenced by ethen

\section{Shepping enjeyment}

A buyer's individual characteristic representieg the sendescy bo fied shopping moe enjoy alde and to experience gester shopring plesiure thas chen

\section{Muduct eategang invalvemeat}

A boyer's perceived importance of the profuct categury hased an hir inhereat meeds, values, and interests

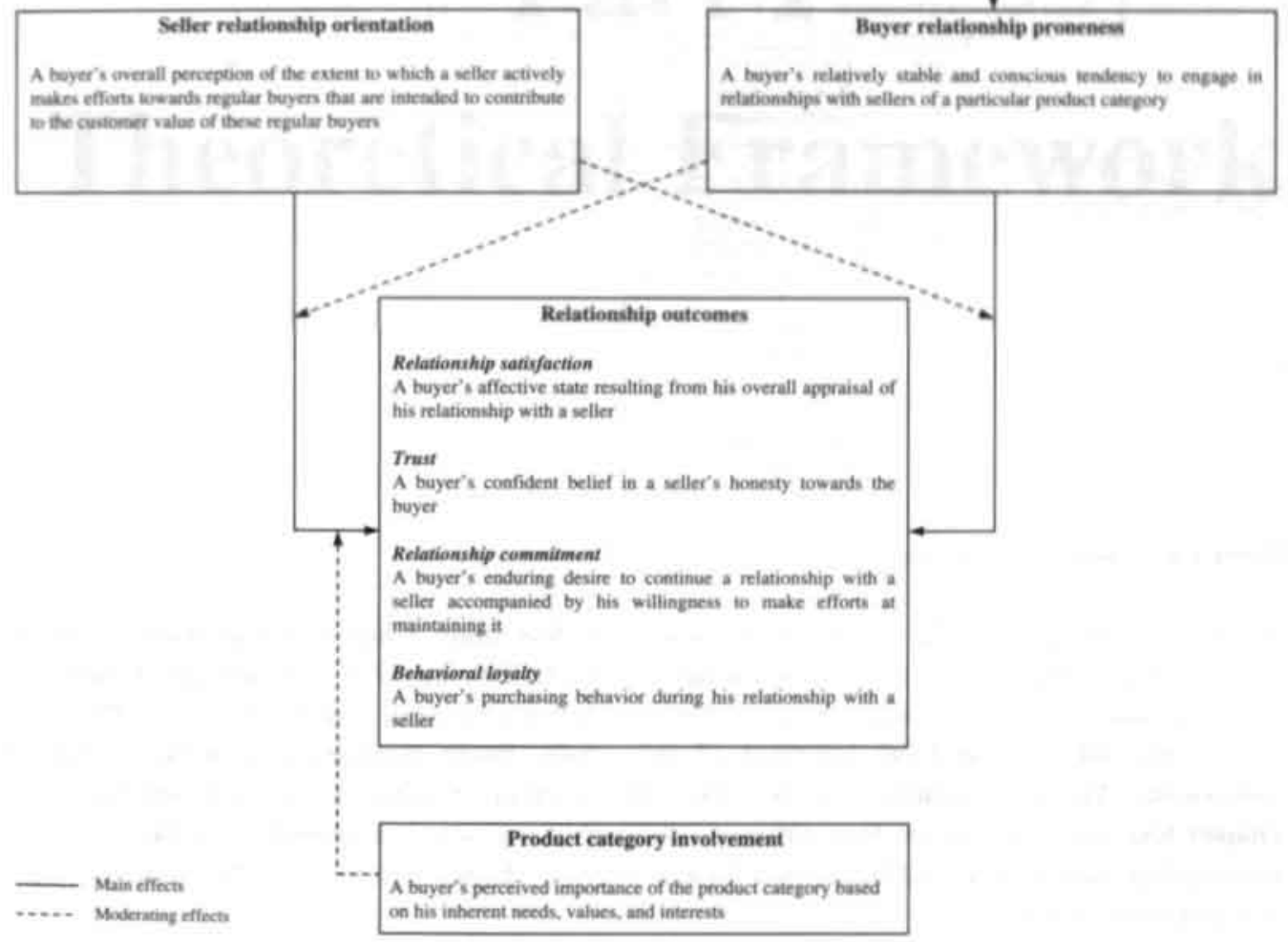

\section{Figure 1-3: Important Terms}




\subsection{Structure}

In this section, we briefly outline the structure of this study. Figure 1-4 visualizes the structure of this study.

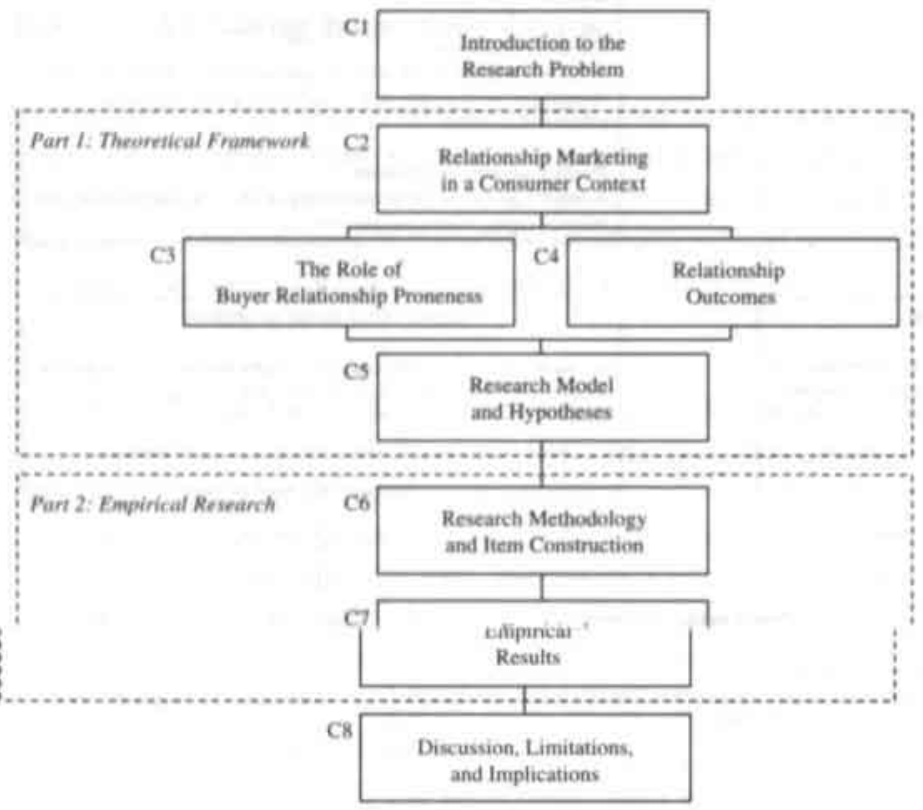

Figure 1-4: Structure of the Study

In part one, we discuss the theoretical framework of this study. Chapter two contains a critical review of relationship marketing in a consumer context. Its objective is to provide a basis for selecting relationship marketing constructs that are relevant in a retail context. In chapter three, we discuss the role of the focal construct of this study, buyer relationship proneness, and its antecedents. The same chapter also describes the construct of seller relationship orientation. In chapter four, we elaborate on four different relationship outcomes: relationship satisfaction, trust, relationship commitment, and behavioral loyalty. Finally, chapter five includes the research model and related hypotheses.

In part two, we present the empirical research of this study. Chapter six describes the research methodology and the process of item generation and testing. Chapter seven presents the empirical results related to testing the research hypotheses mentioned in chapter five.

Finally, chapter eight discusses the main results of the study, points out its limitations, suggests several possible research directions for the future, and discusses theoretical and managerial implications. 


\section{Part I}

\section{Theoretical Framework}




\section{Chapter Structure}

2.1 Introduction.

2.2 The Concept of Relational Exchange

2.2.1 Importance of the Exchange Concept in Marketing Theory

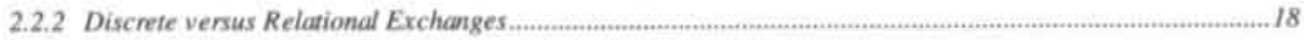

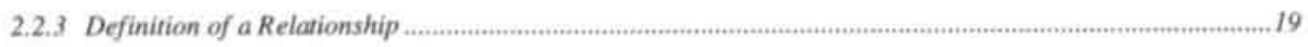

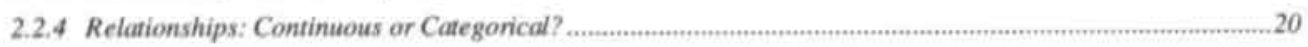

2.3 Relationship Marketing

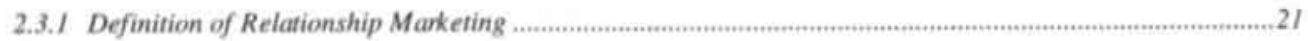

2.3.2 Characteristics Influencing Relationship Marketing Effectiveness.............................................23

2.4 Development of Relationship Marketing

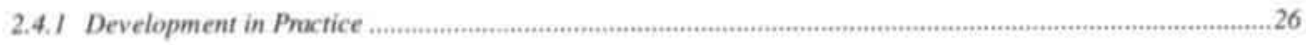

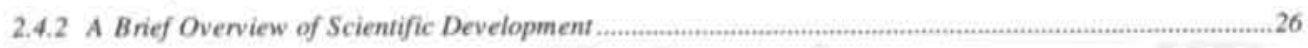

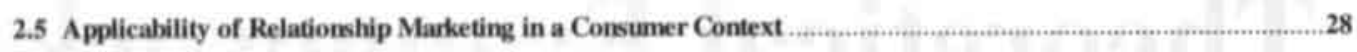

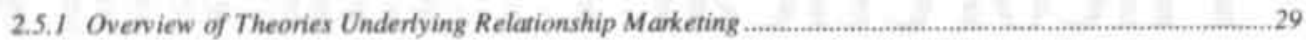

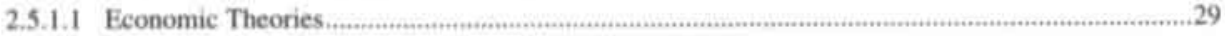

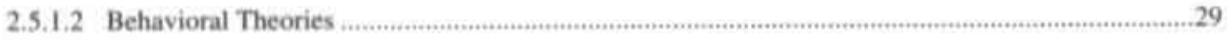

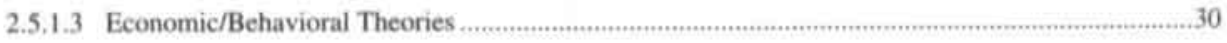

2.5.2 General versus Context-Specific Relationship Marketing Theory ..............................................................30

2.5.3 Characteristics of Consumer versus Business-to-Business Marketing .......................................................33

2.5.4 Applicability of Theories Underlying Relationship Marketing in a Consumer Context,..............................33

2.5.4.1 Neoclassical Microeconomic Theory ......................................................................................34

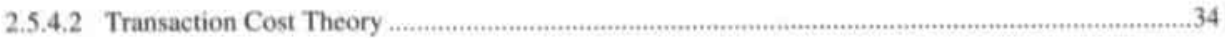

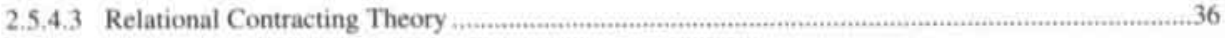

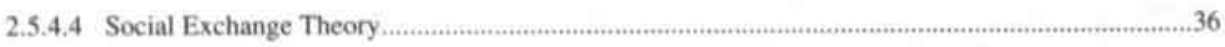

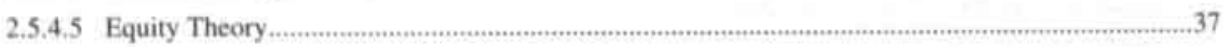

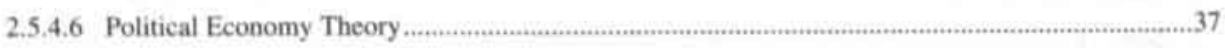

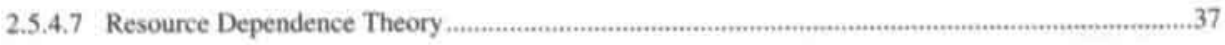

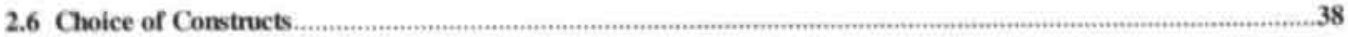

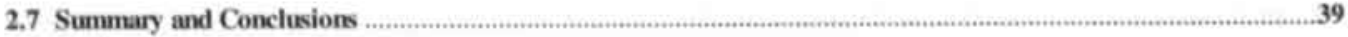




\section{Chapter 2 Relationship Marketing in a Consumer Context ${ }^{1}$}

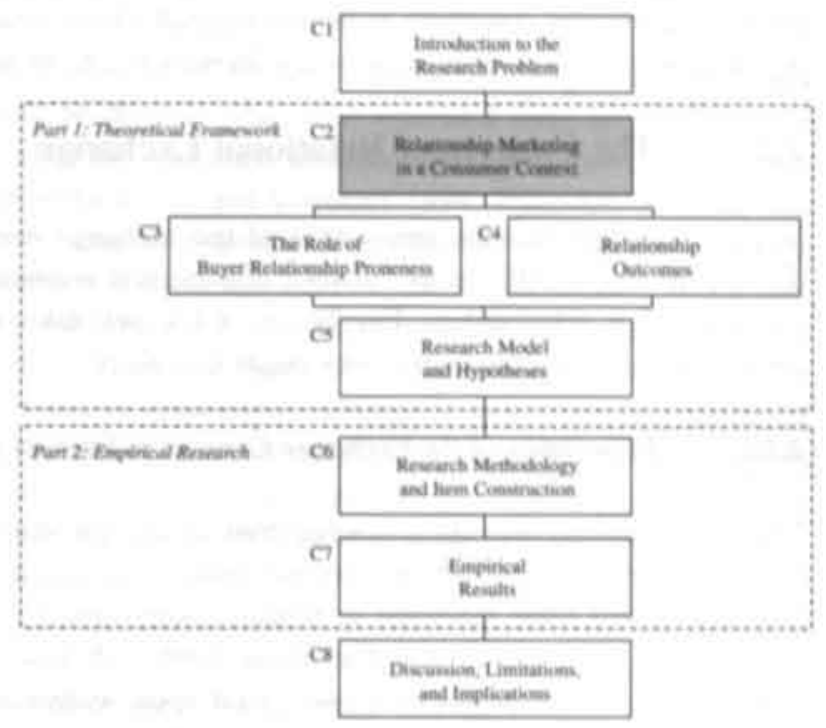

\section{$2.1 \quad$ Introduction}

Knowledge on relationship marketing is still in its early stages of development. It is characterized by a fragmented set of approaches and is surrounded by a lot of confusion and disagreement (Grönroos 1994a; Gummesson 1997; Wilson 1995). Relationship marketing approaches are partly independent and partly overlapping, draw on different underlying theories, and often focus on issues at different levels of aggregation and units of analysis (Moller and Halinen-Kaila 1998). Gundlach. Achrol, and Mentzer (1995) stressed that, given the focus of relationship marketing on social determinants of behavior, relationship marketing constructs tend to be complex, overlapping. amorphous, and often ambiguous.

Bennett (1996) argued that a debate on the roots of relationship marketing would benefit its further theoretical development and guide empirical research. Since relationship marketing has mainly evolved from business-to-business contexts ${ }^{2}$, a critical study of the theories underlying relationship marketing is especially relevant for the further development of conceptual and empirical efforts in the consumer relationship domain. The general objective of this chapter is to provide a guiding framework for determining which relational constructs are most relevant in consumer environments.

In section 2.2, we discuss the concept of relational exchange and delineate the meaning of a relationship. In section 2.3, we define relationship marketing and comment upon characteristics that can impact relationship marketing effectiveness. In section 2.4, we discuss the development of

This chapter is mainly based on Odekerken-Schröder and De Wulf (1999).

In this dissertation, a business-to-business context refers to industrial and/or channel contexts. 
relationship marketing. In section 2.5 , we evaluate the applicability of seven underlying theories of relationship marketing to consumer relationships ${ }^{3}$. Since the choice of a particular theory implies the choice of particular constructs to be investigated, this evaluation serves as the basis for determining which constructs to include in our study. In section 2.6, we motivate this choice of constructs.

\subsection{The Concept of Relational Exchange}

In 2.2.1, we underline the importance of the exchange concept in marketing theory. In 2.2.2, we discuss the major differences between discrete and relational exchanges. In 2.2.3, we discuss the meaning of a relationship. Finally, in 2.2.4, we take a position in the discussion whether relationships are of a continuous or categorical nature.

\subsubsection{Importance of the Exchange Concept in Marketing Theory}

Marketing thinking was initially organized around the institutional school of thought emphasizing functions performed by wholesalers and retailers as marketing institutions. Institutional marketing thinkers viewed these functions as fundamentally linked to exchanges (Grönroos 1994a; Lehtinen and Mittila 1995; Sheth and Parvatiyar 1995a; Webster 1992). This approach was gradually replaced by a more managerial one based upon analytical frameworks drawn from economics, behavioral science, and quantitative methods (Webster 1992). Since the neoclassical microeconomic paradigm with its focus on profit maximization and transaction efficiency was at the root of this more managerial approach, exchanges became even more central to marketing (Arndt 1983; Webster 1992). Concluding, marketing theory and research have always been focused at exchange as their core variable of interest (Bagozzi 1975; Callaghan, McPhail, and Yau 1995; Davis 1995; Dodge and Fullerton 1997; Dwyer, Schurr, and Oh 1987; Frazier, Spekman, and O'Neal 1988; Hallén, Johanson, and Seyed-Mohamed 1991; Houston and Gassenheimer 1987; Kalwani and Narayandas 1995; Kasper 1982; Macintosh and Gentry 1995; Rylander, Strutton, and Pelton 1997; Sheth and Parvatiyar 1995a; Solomon et al. 1985).

\subsubsection{Discrete versus Relational Exchanges}

Until the early 1980s, marketing literature generally regarded marketing exchanges as successions of discrete, independent transactions, thereby ignoring much of the heart of marketing (Davis 1995; Dwyer, Schurr, and Oh 1987; Houston and Gassenheimer 1987; Morgan and Hunt 1994; Rylander, Strutton, and Pelton 1997; Webster 1992). Exchanges with the market were supposed to lead to profit. Marketing objectives were generally reduced to speeding up the transaction and increasing the transaction value (Webster 1992). MacNeil (1980) was the first to criticize the study of exchange in marketing for merely looking at exchange as a discrete act and for failing to recognize the importance of ongoing buyer-seller relationships. He claimed that the neoclassical microeconomic assumption of profit maximization is only relevant in the context of discrete exchanges (Sheth and Parvatiyar 1995a). Moreover, he noticed that pure discrete transactions are

Each of these theories underlying relationship marketing is discussed on its content, strengths, and limitations in appendix one. 
extremely rare in modern marketing exchanges (Fontenot and Wilson 1997: Gruen 1995; Robicheaux and Coleman 1994; Weitz and Jap 1995).

MacNeil (1980) was the first to make a distinction between discrete exchanges and relational exchanges. An exchange is considered to be discrete when it is separated from all else between exchange partners before, during, and after the exchange (Frazier, Spekman, and O'Neal 1988; Lusch and Brown 1996; MacNeil 1980; Robicheaux and Coleman 1994; Rylander, Strutton, and Pelton 1997). In other words, a discrete exchange is evaluated independently without any reference to those transactions that have gone before and to those transactions that are yet to come. It is a onetime utility-driven exchange of value between two parties with no prior or subsequent exchange (Fontenot and Wilson 1997; Hinde 1979: Morgan and Hunt 1994; Webster 1992; Weitz and Jap 1995). On the contrary, the main characteristic of a relational exchange is its position in a history of previous exchanges and an anticipated future of expected exchanges. A relational exchange is assessed not in isolation, but as a continuation of past exchanges likely to continue in the future (Anderson 1995: Czepiel 1990; Dwyer, Schurr, and Oh 1987; Iacobucci and Ostrom 1996).

\subsubsection{Definition of a Relationship}

Bagozzi (1995) explicitly criticized relationship marketing literature for neglecting to conceptualize what a marketing relationship is. We agree with Bagozzi (1995) as we argue that adequate relationship marketing research is impossible without knowledge on the meaning of its core variable of interest, the buyer-seller relationship.

In this study, a buyer-seller relationship is defined as "one or more exchanges between a buyer and $a$ seller that are perceived by the buyer as being interrelated to potential past and future exchanges with the seller". We define a buyer-seller exchange as "a product/service, financial, information, and/or social exchange between a buyer and a seller". Four elements form the building blocks of both definitions. First, Hinde (1979, p. 15) noticed that "to discuss how long we must talk to a stranger in the street before we can properly say we have a relationship with him would not be very constructive". In other words, it is impossible to determine where a discrete exchange goes over in a relationship. In line with Webster (1992), we regard one exchange as a necessary and sufficient condition for a relationship to exist. One exchange marks the beginning of a continuum of relationships. Second, we agree with Bames (1995, p. 1395) who postulated that "no relationship will exist unless the customer feels that one exists". Whether or not a seller feels that a relationship with a buyer exists, is not the issue. As it is the aim of the seller to enhance buyer perceived relationship outcomes, it does not matter what the seller's perceptions are. Third, it is required for a relationship to exist that a buyer perceives his exchange(s) with the seller to be interrelated to potential past and future exchanges (Anderson 1995; Czepiel 1990; Dwyer, Schurr, and Oh 1987; lacobucci and Ostrom 1996). Finally, a relationship can be composed of multiple types of exchanges (Pelton, Strutton, and Lumpkin 1997). In our view, a buyer-seller relationship is not necessarily based on purchase exchanges, but can equally be composed of financial, information, and social exchanges. 


\subsubsection{Relationships: Continuous or Categorical?}

While discrete and relational exchanges are generally recognized as two extreme types of exchanges, there exists some discussion related to the nature of intermediate exchange types.

Most scholars think of a continuum ranging from pure discrete exchanges to relational exchanges (Bennett 1996; Ganesan 1994; Grönroos 1990b; Gundlach and Murphy 1993; Kalwani and Narayandas 1995: Metcalf, Frear, and Krishnan 1992; Noordewier, John, and Nevin 1990; Webster 1992). Webster (1992) stated that, although pure transactions are rare, they mark the beginning of a continuum for thinking about types of relationships and provide a useful starting point for theoretical analysis. While discrete exchanges are often characterized by self-serving and conflicting behavior, relational exchanges are considered to serve the interests of all parties in the exchange (Davis 1995; Dwyer, Schurr, and Oh 1987).

Other scholars think of more explicit stages in which buyer-seller relationships can be positioned (Dwyer, Schurr, and Oh 1987: Weitz and Jap 1995). According to them, relationships evolve from one stage to another in response to exchanges and fluctuations in the contextual environment (Dabholkar, Johnston, and Cathey 1994; Fournier 1998). Generally speaking, a relationship progresses from an initial exchange between two exchange parties, through increasing levels of awareness and exchange between the parties, to interdependence between parties (Bejou 1997: Bennett 1996; Grönroos 1990b: Nielson 1998: Stone, Woodcock, and Wilson 1996: Weitz and Jap 1995: Wilson 1995). This general sequence is commonly translated into the five-phased model of awareness, exploration, expansion, commitment, and dissolution suggested by Dwyer, Schurr, and Oh (1987). However, theoretical process-oriented frameworks of the relationship lifecycle differ in the number of stages that are posited, the nature of the processes believed to be critical for relationship development at each stage, and the mechanisms governing transitions between stages (Fournier 1998).

While some authors assume that a particular relationship can be attributed to one specific stage, we postulate that only outcomes of a relationship ${ }^{4}$ can be measured. We argue for a representation of exchanges on a continuum, as classifying exchanges into different stages of 'relationship extent' does not permit adequate empirical validation and testing. Delineating separate stages in empirical research is rather ambiguous because no objective criterion exists that allows an unequivocal distinction between relationship stages.

In chapter four, the following relationship outcomes are discussed: relationship satisfaction, trust, relationship commitment, and behavioral loyalty. 


\section{$2.3 \quad$ Relationship Marketing}

\subsubsection{Definition of Relationship Marketing}

The term 'relationship marketing' appeared for the first time' in a 1983 article by Berry (Barnes 1994; Berry 1995; Grönroos 1994a). Berry (1983, p. 25) defined relationship marketing as "attracting, maintaining, and ... enhancing customer relationships". Christopher, Payne, and Ballantyne (1994) referred to relationship marketing on a micro level when only the relationship between a company and its end customers is focused upon. This type of relationship corresponds to what Gummesson (1997) called 'the classic dyad' in his classification of 30 different types of relationships. Several authors recognize that this classic dyad is only one out of many possible relationship forms (Gummesson 1997; lacobucci and Ostrom 1996; Morgan and Hunt 1994). On a broader level, relationship marketing can refer to multiple dyads: internal company relationships (relationships between a company and its employees, functional departments, or business units), supplier relationships (relationships between a company and product or service providers), lateral relationships (relationships between a company and competitors, non-profit organizations, or government departments), or buyer relationships (relationships between a company and its intermediary' or end customers) (Christopher, Payne, and Ballantyne 1994: Dwyer. Schurr and Oh 1987; Gruen 1995; Kotler 1992; Morgan and Hunt 1994). In the same way. Sheth (1994) distinguished between horizontal, vertical, and stakeholder relationships. lacobucci and Ostrom (1996) classified relationships into individual-to-individual, individual-to-firm, and firm-to-firm relationships.

Mainly because of the multidimensional character and the relative newness of relationship marketing. literature has not yet agreed upon a common definition. This has resulted in a conceptualization of relationship marketing that is quite different between various scholars (Achrol 1997; Barnes 1995; Bejou 1997; Blois 1995; Evans and Laskin 1994: Gummesson 1994: Kalwani and Narayandas 1995; Parker and Funkhouser 1997; Perrien and Ricard 1995). This is evidenced by table 2-1. Despite large differences in definitions of relationship marketing, most definitions that have been suggested, share a certain degree of commonality (Robicheaux and Coleman 1994). Most authors agree that relationship marketing is characterized by the following elements.

\section{(1) Aim for common benefits}

While a buyer can increase his perceived level of customer value by engaging in a relationship with a seller, a seller's benefits of building relationships with buyers are continuity and profit generation (Barnes 1995/1997; Beatty et al. 1996; Berry 1995; Blois 1995; Buchanan 1992; Dwyer, Schurr, and Oh 1987; Hinde 1979; Shani and Chalasani 1992; Wilson 1995).

\section{(2) Asymmetrical steering}

Asymmetrical steering refers to the notion that the effectiveness of relationship marketing strategies is controlled by the seller (Blois 1995: Dwyer. Schurr, and Oh 1987; Ganesan 1994;

Berry (1983) was the first to mention the term 'relationship marketing'. However, others already recognized the importance of building relationships before 1983 without explicitly using the term (Bagozzi 1975; Hảkansson 1982; MacNeil 1980). 
Gundlach and Cadotte 1994; Levitt 1983; Perrien, Paradis, and Banting 1995; Perrien and Ricard 1995). The thought of asymmetrical steering is more or less similar to the outdated view on marriage in which the husband assumes leadership in the relationship (Perrien, Filiatrault. and Ricard 1993). Most relationship marketing definitions indeed stress a seller's efforts to enhance the buyer-seller relationship as expressed by the seller's commitment to the customer, his fulfillment of promises towards the customer, his use of knowledge about customers to help them satisfy their needs, and his continuous dialogue with customers (Bennett 1996). However, by distinguishing between a seller's motivational relationship investment and a buyer's motivational relationship investment, Dwyer, Schurr, and Oh (1987) criticized this asymmetrical view and claimed that seller-managed relationships only cover a limited set of possible types of relationships. Christy, Oliver, and Penn (1996) similarly stated that, while exchanges are often initiated and managed by the seller, there is no reason why a buyer should not make the first move and take responsibility for enhancing the buyer-seller relationship. Weitz and Jap (1995) equally distinguished between exchanges characterized by authoritative or unilateral (asymmetric) control and exchanges characterized by normative or bilateral (symmetric) control. Also Wish, Deutsch, and Kaplan (1976) indicated that interpersonal relationships can vary along a symmetry-asymmetry continuum.

\section{(3) Continuity}

Continuity between successive exchanges implies that exchanges are not separated from each other but form a whole within a framework of long-term perspectives. In this way, exchanges obtain a special status and cannot be regarded as occasional exchanges (Barnes 1995; Low 1996: Shani and Chalasani 1992). Continuity between exchanges supposes that buyers are and remain loyal to a seller.

As can be concluded from table 2-1, most definitions of relationship marketing are of a generic and all-encompassing nature, limiting empirical validation. In line with Bagozzi (1995) and Peterson (1995), we think it is more fruitful to formulate targeted definitions of relationship marketing in order to direct relationship marketing practice, empirical research, and theory development. For purposes of this study, we formulated a definition of relationship marketing that incorporates the three core elements of relationship marketing and that is suitable for operationalization purposes. We define relationship marketing as " $a$ seller's efforts aimed at enhancing relationship outcomes of buyer-seller relationships". This definition includes the core components of other relationship marketing definitions. First, the aim for common benefits is reflected by the fact that enhanced relationship outcomes (buyer benefits) also imply benefits for the seller (e.g. increased behavioral loyalty). Second, our definition refers to asymmetrical steering by the seller as it involves a seller's efforts to enhance the buyer-seller relationship. Finally, our definition contains the element of continuity as the enhancement of relationship outcomes is inextricably related to a continuation of exchanges. While the basic elements included in our definition are in line with other definitions, our definition better lends itself for operationalization. It explicitly addresses the questions of what the objectives of relationship marketing are and how these can be measured. This focus in the definition facilitates empirical investigation and guides our choice of constructs to be investigated. 


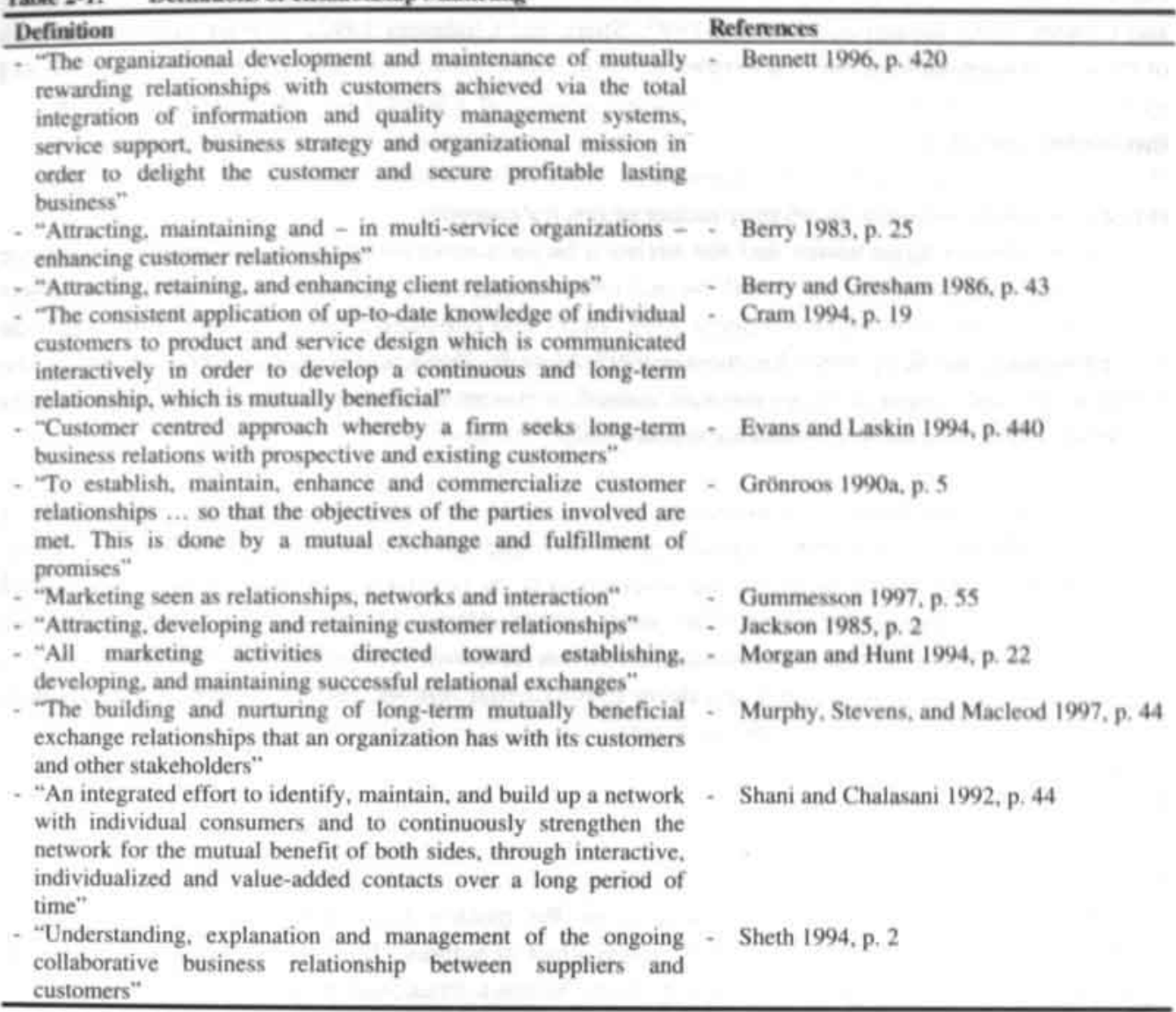

\subsubsection{Characteristics Influencing Relationship Marketing Effectiveness}

Relationship marketing practices are not considered to be effective in every situation or context (Heide and John 1990; Kalwani and Narayandas 1995; Matthyssens and Van den Bulte 1994; Pressey and Mathews 1997; Wray, Palmer, and Bejou 1994). Not every exchange has the potential to grow into a relationship and a thorough cost-benefit analysis is required before a decision to invest in relationship marketing is made (Houston and Gassenheimer 1987: Jüttner and Wehrli 1994: Low 1997; Wray, Palmer, and Bejou 1994). Low (1997) even indicated that, under certain conditions, parties should actively and consciously play the market, seek out opportunities, and develop an opportunistic mentality.

Several scholars mention characteristics that can influence the effectiveness of relationship marketing strategies. Such characteristics are commonly assumed to stimulate the inherent 'relationship-friendliness' (Christy, Oliver, and Penn 1996) of buyer-seller exchanges. We classify them into: (1) buyer characteristics, (2) product/service characteristics, (3) environmental 
characteristics, and (4) exchange situation characteristics (Berry and Gresham 1986: Crosby, Evans. and Cowles 1990; Javalgi and Moberg 1997; Shani and Chalasani 1992). A brief overview of each of these characteristics is provided below.

\section{Buyer characteristics $^{6}$}

\section{(1) Degree of involvement with the product or service category}

Some scholars hypothesize that the higher a buyer's involvement with the product or service category, the more this buyer will be inclined to engage in a long-term relationship with sellers of these products or services (Berry 1995; Berry and Gresham 1986; Christy, Oliver, and Penn 1996; King and Ring 1980; Leuthesser 1997; Metcalf, Frear, and Krishnan 1992). However, the role of involvement in buyer-seller relationships has received little attention until now (Beatty et al. 1996: Metcalf, Frear, and Krishnan 1992).

\section{(2) Proneness to engage in relationships}

Not all buyers are inherently equally prone to engage in relationships with sellers. Evidently, relationship marketing strategies are assumed to be more effective in case a buyer shows a high proneness to engage in buyer-seller relationships. However, the role of buyer relationship proneness in buyer-seller relationships has not received any empirical attention until now (Beatty et al. 1996; Bendapudi and Berry 1997; Christy, Oliver, and Penn 1996; Dwyer, Schurr, and Oh 1987; Pressey and Mathews 1997).

\section{Product/senvice characteristics}

\section{(1) Degree of complexity of the product or service}

The more complex a product or service is, the more a buyer feels the need to engage in relational behavior with the seller of this product or service (Berry 1995; Christy, Oliver, and Penn 1996; Crosby. Evans, and Cowles 1990; Metcalf, Frear, and Krishnan 1992).

\section{(2) A bility to customize or differentiate the product or senvice}

The more a product or service is suitable for customization or differentiation, the more opportunities are available to a seller for building a close relationship with a buyer (Christy, Oliver, and Penn 1996; Crosby, Evans, and Cowles 1990).

(3) Difficulty of evaluating exchange outcomes

Since the costs of negotiating. monitoring, and enforcing performance are greater when performance ambiguity is present, transaction cost analysis suggests that performance ambiguity is a key factor leading buyers to focus upon long-term relationships with sellers. Building long-term relationships reduces the perceived risk associated with ambiguous outcomes of exchanges (Bendapudi and Berry 1997: Berry 1995; Crosby, Evans, and Cowles 1990: Dwyer. Schurr, and Oh 1987; Williamson 1975).

\footnotetext{
6 Both buyer characteristics are included in our conceptual model presented in chapter five.
} 


\section{Environmental chanacteristics}

(1) Degree of dynamism and uncertainty related to the manket or product environment Relationship marketing is generally believed to be more effective in situations characterized by uncertainty and dynamism (Anderson and Weitz 1989; Buchanan 1992; Christy, Oliver, and Penn 1996; Crosby, Evans, and Cowles 1990; Leuthesser 1997). For example, Berry (1995) and Kasper (1999) stated that relationship marketing is especially suited in services because their intangibility and credence properties increase the need to reduce perceived risk.

\section{(2) Switching costs}

The costs and inconveniences related to switching to a different exchange partner tend to strengthen existing relationships between buyers and sellers (Anderson and Weitz 1992; Christy, Oliver, and Penn 1996; Ganesan 1994; Smith and Barclay 1997).

\section{Exchange situation chamacteristics}

(1) Exchange frequency

When each exchange would be handled as a discrete transaction, a greater frequency of exchanges typically involves higher transaction costs (Bendapudi and Berry 1997). As a result, repeated exchange between buyers and sellers is generally considered to facilitate relationship marketing (Bendapudi and Berry 1997; Berry 1995; Berry and Gresham 1986; Christy, Oliver, and Penn 1996; Crosby, Evans, and Cowles 1990; Metcalf, Frear, and Krishnan 1992; Wray, Palmer, and Bejou 1994).

(2) Degree of social exchange

Metcalf, Frear, and Krishnan (1992, p. 29) referred to social exchange as "the interpersonal relationships which exist between members of the buying and selling centers". In general, relationships are considered to have a larger growth potential in situations characterized by high degrees of social exchange (Berry 1995; Berry and Gresham 1986; lacobucci and Ostrom 1996; Metcalf, Frear, and Krishnan 1992; Nielson 1998).

\section{(3) Task definition}

Belk (1975) defined task definitions as "the reasons that occasion the need for consumers to buy or consume a product or service". A consumer can be loyal to a certain store for a specific task definition, but disloyal to the same store when experiencing another task definition. It could for example well be that loyalty levels could be more defensible or less vulnerable in some task definitions than in others, influencing relationship marketing effectiveness ( $\mathrm{V}$ an Kenhove, De Wulf, and Van Waterschoot 1999).

\section{(4) Age of the relationship}

Anderson and Weitz (1989) suggested that relationship marketing effectiveness is generally lower when relationships are relatively young (Heide and John 1990; Leuthesser 1997; Lusch and Brown 1996: Metcalf, Frear, and Krishnan 1992). 
To the author's knowledge, no empirical efforts have been made to measure the effects of the above mentioned characteristics on relationship effectiveness. In chapter three and chapter five, we discuss the roles of product category involvement and buyer relationship proneness in influencing relationship outcomes.

\subsection{Development of Relationship Marketing}

\subsubsection{Development in Practice}

Two hundred years ago, the uncontrived approach to the market was through building long-term relationships between buyers and sellers. During this pre-industrial era, direct exchanges between buyers and sellers developed in a natural way and necessitated friendship, co-operation, reliance, and trust among marketing actors (Peppers and Rogers 1995; Sheth and Parvatiyar 1995a; Wilson 1995). Sellers knew each of their buyers individually and suggested appropriate, customized product offerings (Berry 1995; Wray, Palmer, and Bejou 1994). This situation changed during the industrial era in which marketers shifted their concerns towards sales and promotion of goods instead of relationship enhancement. Increasing buyer choice through producing various assortments of goods became significant issues, thereby diverting marketers' attention from building individual customer relationships to mass marketing practices (Davis 1995). During that period, the prevailing microeconomic profit-maximization paradigm focused marketers' attention at optimizing independent transactions between buyers and sellers (Webster 1992).

From the post-industrial era on. marketers started realizing the limitations of their transactionoriented strategies under pressure of eroding repeat purchases and intensified competitive pressures in increasingly saturated markets (Sheth and Parvatiyar 1995a). Gummesson (1997) explicitly referred to the industrial era as just a brief interlude and stated that marketers have moved to a new era in which relationships are back. While researchers tend to view the processes of enhancing relationships in the pre- and post-industrial eras as essentially the same, both are of a different nature. While relationships evolved in a natural way during the pre-industrial era, more conscious seller strategies aimed at enhancing relationships with buyers are followed in the current, postindustrial era. Relationship marketing in the post-industrial era has mainly found its way into management practice mainly as a result of the growth of information technology and service economies (Achrol 1997; Bejou 1997; Bennett 1996; Berry 1995: Sheth and Parvatiyar 1995a). New practices have been developed for implementing relationship marketing resulting from technological advances enabling sellers to recognize and listen to individual buyers on a continuous basis, to interact with them, to quickly respond to their preferences, and to communicate directly in differentiated ways with a large number of them (Bennett 1996: Nielson 1998; Sheth and Parvatiyar 1995a; Spekman 1988; Wray, Palmer, and Bejou 1994).

\subsubsection{A Brief Overview of Scientific Development}

Given practitioners' important role in the development of relationship marketing, it is not surprising that relationship marketing was first implemented by practitioners before it became a focus for academics (Davis 1995; Grönroos 1994a; Perrien, Filiatrault, and Ricard 1993). Dodge and 
Fullerton (1997, p. 2) pointed at this dividing wall between theory and practice by stating that "nowhere is the disparity between practice and academic theory more apparent than it is on ... relationship marketing". Rylander, Strutton, and Pelton (1997) stated that relationship marketing 'enjoys' the unusual status of being an overused and underdeveloped designation at the same time.

Nevertheless, scholars refocused their traditional, transactional marketing thinking by placing a greater emphasis upon the creation of customer value and by drawing their attention to relationship marketing. Kotler's (1992, p. 1) phrase "companies must move from a short-term transactionoriented goal to a long-term relationship-building goal" underlines this interest in relationship marketing. While Webster (1992, p. 1) referred to relationship marketing as a 'fundamental reshaping of the field, others consider it to be a genuine paradigm shift altering the basic foundations of marketing theory (Bendapudi and Berry 1997; Dodge and Fullerton 1997; Fournier 1998; Grönroos 1990a/1994b; Gummesson 1997; Keep, Hollander, and Dickinson 1998; MeGahan and Ghemawat 1994; Morgan and Hunt 1994; Parker and Funkhouser 1997; Sheth and Parvatiyar 1995b: Webster 1992; Wray, Palmer, and Bejou 1994). In line with Webster (1992), we support the notion that relationship marketing should not be considered as a completely new research paradigm. While the time orientation of studying exchanges has shifted from short-term to long-term, both "traditional" marketing theory and relationship marketing theory focus on exchanges as their focal study subject. Moreover, the basic principles of traditional marketing theory are still deemed to be applicable in relationship marketing theory.

The early works on relationship marketing were written by Arndt (1983), Bagozzi (1975), Berry (1983), Day and Wensley (1983), Dwyer, Schurr, and Oh (1987), Håkansson (1982), Levitt (1983). and MacNeil (1980). Scientific attention for relationship marketing mainly emerged within the fields of industrial marketing and channel marketing (Bejou 1997; Dahlstrom, MeNeilly, and Speh 1996; Doney and Cannon 1997; Grönroos 1994a; Gummesson 1997; Peterson 1995; Ping 1993; Webster 1992). This is not surprising as, by their very nature, industrial and channel market exchanges are relationship based. Consistent with the strategic interest of industrial buyers for 'justin-time' techniques and their search for reliable suppliers, long-term buyer-seller relationships are often considered to be of strategic relevance in industrial contexts (Doney and Cannon 1997; Lewin and Johnston 1997; Perrien and Ricard 1995). In a channel context, buyer-seller exchanges are generally characterized by high interdependencies and direct exchanges between partners, stimulating the need to cooperate on a long-term basis (Doney and Cannon 1997).

Today, the practical and scientific importance of relationship marketing are still being recognized (Bendapudi and Berry 1997; Fournier 1998; Gwinner, Gremler, and Bitner 1998; Schijns 1999; Venetis 1997; Wetzels 1998). We expect this interest for relationship marketing to continue and even intensify in the future as a result of various market evolutions such as globalization, market fragmentation, increased competitive pressures, as well as technological developments such as the higher penetration of new information and communication technologies (Cram 1994: Davis 1997: Dowling and Uncles 1997; Grant and Schlesinger 1995; Hoekstra 1994; Pine, Peppers, and Rogers 1995). More specifically, the importance of relationship marketing in consumer markets will grow as resellers have gained increased power and as information technology has put individual consumers in more direct contact with resellers and manufacturers (Webster 1992). 


\subsection{Applicability of Relationship Marketing in a Consumer Context}

The theories most commonly referred to in relationship marketing literature are: (1) neoclassical microeconomic theory, (2) transaction cost theory, (3) relational contracting theory, (4) social exchange theory, (5) equity theory, (6) political economy theory, and (7) resource dependence theory. In this section, we want to determine which of these theories are most relevant for explaining relationships in a consumer context.

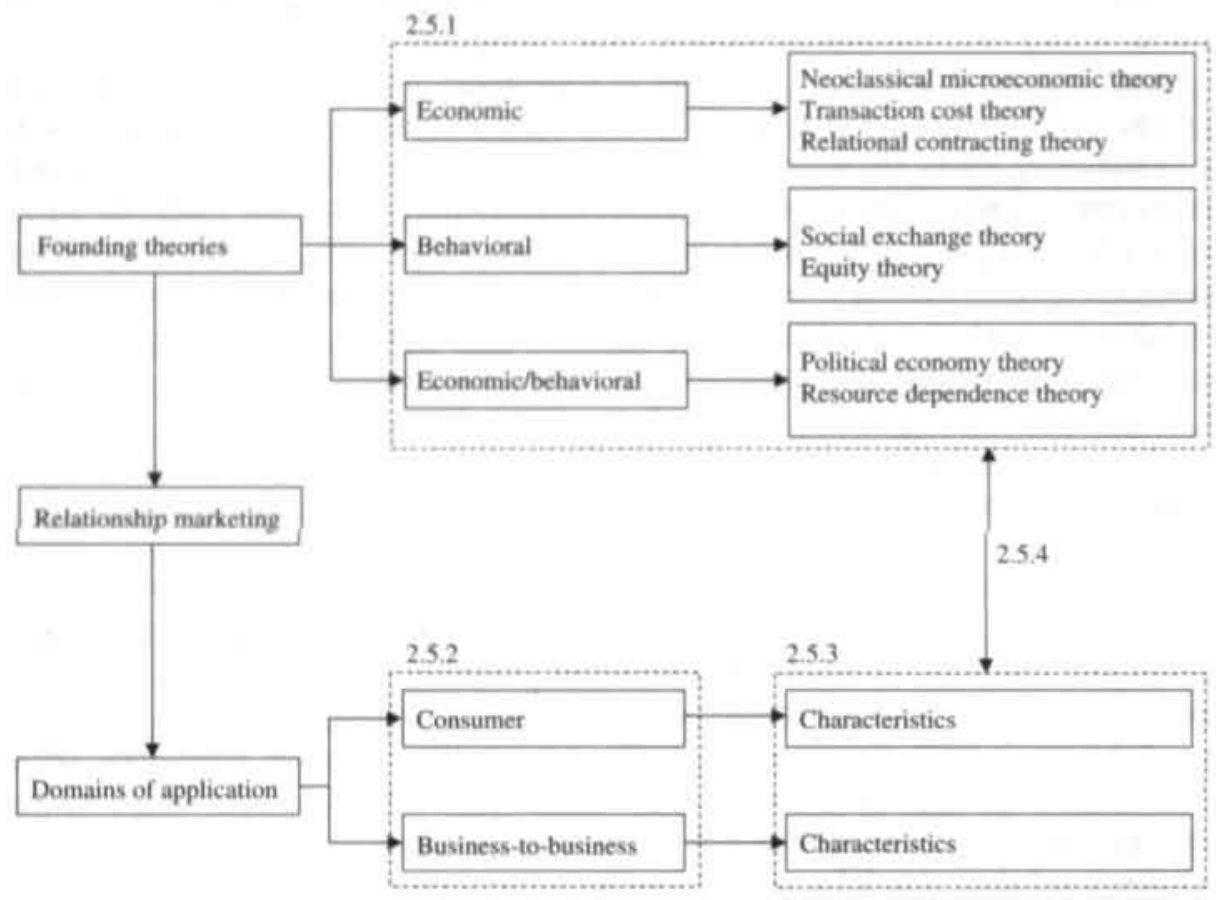

Figure 2-1: Applicability of Relationship Marketing in a Consumer Context

Figure 2-1 outlines the structure of this section. In 2.5.1, we group theories into economic, behavioral, and economic/behavioral theories and briefly describe each theory. In 2.5 .2 , we discuss whether separate relationship marketing theories are needed for consumer versus business-tobusiness situations. In 2.5.3, we describe the main discriminating characteristics of consumer versus business-to-business markets and outline their impact on differences between consumer and business-to-business relationships. Finally, in 2.5 .4 , we evaluate the applicability of each of the theories presented in 2.5 .1 in consumer situations. 


\subsubsection{Overview of Theories Underying Relationship Marketing?}

Underlying theories of relationship marketing tend to be fragmented into two seemingly disparate approaches: an economic approach that is efficiency oriented and a behavioral approach that is more socially oriented and borrowing from social psychology and organization theory (Stern and Reve 1980), Although we explicitly categorize theories into 'economic' and 'behavioral' approaches, we recognize that economic theories can contain behavioral elements and that behavioral theories can contain economic elements. This categorization is principally conducted in order to create a framework of thought for theory evaluation.

In table 2-2, theories underlying relationship marketing are compared on their key assumptions, their main unit of analysis, and their main constructs of interest. While we do not dare to claim that this table provides an exhaustive picture of all underlying theories of relationship marketing, it is intended to act as a framework for evaluating the relevance of theories most commonly referred to. Below, the main characteristics of each theory are briefly described.

\subsubsection{Economic Theories}

(1) Neoclassical microeconomic theony.

This theory departs from the assumptions of rational and utility seeking behavior. Its main unit of analysis consists of aggregated supply and demand markets striving for market equilibrium (Arndt 1983).

(2) Transaction cost analysis.

This theory departs from the assumptions of bounded rationality and opportunism. Its main unit of analysis consists of single transactions involving transaction costs. The main objective of transaction cost analysis is to prescribe an optimal relationship governance mode that minimizes transaction costs (Williamson 1975/1985).

(3) Relational contracting theory.

In line with transaction cost analysis, this theory departs from the assumptions of bounded rationality and opportunism. Its main unit of analysis consists of exchange episodes. The main objective of this theory is to describe the impact of social norms on these episodes in addition to the impact of explicit contracts (MacNeil 1980).

\subsubsection{Behavional Theories}

(1) Social exchange theory. This theory departs from the assumption of equality between exchange partners who are driven by self-interest and reciprocity. Its main unit of analysis consists of relational exchanges. The main objective of social exchange theory is to describe exchanges between partners and their effects on relationship outcomes (Thibaut and Kelley 1959). This

Each of the theories underlying relationship marketing is discussed on its content, strengths, and limitations in appendix one. 
theory primarily focuses upon dedication as a determinant of relationship formation and growth.

(2) Equity theory. This theory departs from the assumption that exchange partners are driven by economic productivity motives. Its main unit of analysis consists of relational exchanges. The main objective of equity theory is to describe the processes leading to and the consequences of fair and just distribution of inputs and outputs between exchange partners (Adams 1965).

\subsubsection{Economic/Behaviomal Theories}

(1) Political economy theory.

This theory assumes that economic as well as sociopolitical forces affect institutional behavior and performance. Its main unit of analysis consists of relational exchanges between institutions. Economic forces refer to the institutions that transform inputs into outputs and to the processes by which goods and services are allocated. Sociopolitical forces refer to the power and control systems that legitimize, facilitate, monitor, and regulate exchange transactions. The main objective of political economy theory is to describe authority and control patterns, conflict and conflict management procedures, and external and internal determinants of institutional exchange (Benson 1975; Stern and Reve 1980).

(2) Resource dependence theory.

This theory departs from the assumption that there exists inequality between self-interested exchange partners. Its main unit of analysis consists of relational exchanges. The main objective of resource dependence theory is to describe the processes of increasing control and decreasing dependence in a relationship (Emerson 1962; Salancik and Pfeffer 1978). This theory primarily focuses upon constraints that determine the formation and growth of relationships.

In the next section, we discuss whether relationship marketing theory is generally applicable to consumer as well as to business-to-business contexts or whether it is context-specific.

\subsubsection{General versus Context-Specific Relationship Marketing Theory}

As already indicated, theoretical knowledge on buyer-seller relationships mainly originated from conceptual and empirical work in industrial and channel contexts (Fischer and Bristor 1994: Gwinner, Gremler, and Bitner 1998; Peterson 1995; Pressey and Mathews 1997; Wilson 1995). Business-to-business marketers have consistently emphasized long-term relationship building and have studied many relational constructs (Iacobucci and Ostrom 1996; Webster 1992). Surprisingly little empirical and conceptual work has been conducted on relational phenomena in the consumer domain (Fournier 1998; Gruen 1995: Sheth and Parvatiyar 1995b). Recently, the applicability of relationship marketing has been extended from business-to-business to consumer environments (Gundlach, Achrol, and Mentzer 1995; Iacobucci and Ostrom 1996: Wray. Palmer, and Bejou 1994). Dwyer, Schurr, and Oh (1987) specifically underlined that both consumer and business-tobusiness markets can benefit from enhancing relationships between buyers and sellers. However, the 
broadened scope of relationship marketing to consumer environments has raised some questions with respect to the generalizability of industrial and channel relationship concepts to consumer relationships. Whereas some scholars are convinced of the existence of one overall relationship marketing theory, others argue that relationship marketing is context-specific.

Table 2-2: Companative Summary of Theories Underlying Relationship Marketing

\begin{tabular}{|c|c|c|c|}
\hline $\begin{array}{l}\text { Theories } \\
\text { Ecenomic thearies }\end{array}$ & Key assumptions & Main unit of analysis & Main coustructs of interest \\
\hline $\begin{array}{l}\text { Neoclassical } \\
\text { microeconomic } \\
\text { theory }\end{array}$ & $\begin{array}{l}\text { Competitive markets driven } \\
\text { by price mechanism } \\
\text { Profit and utility } \\
\text { maximization } \\
\text { Well-defined and stable } \\
\text { preference structures }\end{array}$ & $\begin{array}{l}\text { Aggregated supply } \\
\text { and demand }\end{array}$ & $\begin{array}{l}\text { Cost } \\
\text { Income distribution } \\
\text { Market equilibrium } \\
\text { Market structure } \\
\text { Profit } \\
\text { Relative price } \\
\text { Utility }\end{array}$ \\
\hline $\begin{array}{l}\text { Transaction cost } \\
\text { theory }\end{array}$ & $\begin{array}{l}\text { Bounded rationality } \\
\text { Environmental uncertainty } \\
\text { Existence of optimal } \\
\text { relationship govemance } \\
\text { mode which minimizes } \\
\text { transaction costs } \\
\text { Opportunism and self. } \\
\text { interest }\end{array}$ & $\begin{array}{l}\text { - Single excharge } \\
\text { transaction }\end{array}$ & $\begin{array}{l}\text { Conflict } \\
\text { Coal incongruence } \\
\text { Performance ambiguity } \\
\text { Transaction costs } \\
\text { Transaction specific investments }\end{array}$ \\
\hline $\begin{array}{l}\text { Relational } \\
\text { contracting theory }\end{array}$ & $\begin{array}{l}\text { Bounded rationality } \\
\text { - Environmental uncertainty } \\
\text { Opportunism and self. } \\
\text { interest }\end{array}$ & * Exchange episode & $\begin{array}{ll} & \text { Consistency } \\
-\quad \text { Fexibility } \\
-\quad \text { Information exchange } \\
-\quad \text { Motuality } \\
-\quad \text { Power } \\
-\quad \text { Solidarity }\end{array}$ \\
\hline $\begin{array}{l}\text { Social exchange } \\
\text { theory }\end{array}$ & $\begin{array}{l}\text { Equality between exchange } \\
\text { partners } \\
\text { Reciprocity } \\
\text { Self-interest }\end{array}$ & - Relational exchange & $\begin{array}{ll} & \text { Adaptation } \\
& \text { Comparison level (of alternatives) } \\
& \text { Cooperation } \\
- & \text { Relationship commitment } \\
- & \text { Relationship satisfaction } \\
& \text { Similarity } \\
\text { Social norms } & \text { Trust }\end{array}$ \\
\hline Equity theory & $\begin{array}{l}\text { Desire to have fair and just } \\
\text { distribution of profits } \\
\text { Economic productivity } \\
\text { motives }\end{array}$ & - Relational exchange & $\begin{array}{l}\text { Input } \\
\text { Output } \\
\text { Role expectations/stress } \\
\text { Relationship satisfaction } \\
\text { Social norms } \\
\text { Trust }\end{array}$ \\
\hline \multicolumn{4}{|l|}{$\begin{array}{l}\text { Economic/ } \\
\text { behavional theories }\end{array}$} \\
\hline $\begin{array}{l}\text { Potitical economy } \\
\text { theory }\end{array}$ & $\begin{array}{l}\text { Economic and } \\
\text { sociopolitical forces } \\
\text { affecting collective } \\
\text { behavior and performance }\end{array}$ & - Relational exchange & $\begin{array}{l}\text { Authority } \\
-\quad \text { Conflict } \\
\text { - Control } \\
\text { Power }\end{array}$ \\
\hline $\begin{array}{l}\text { Resource } \\
\text { dependence theory }\end{array}$ & $\begin{array}{l}\text { Inherent goal confliet } \\
\text { Inequality between } \\
\text { exchange partners } \\
\text { Self-interest } \\
\text { - Tendency to increase } \\
\text { control and decrease } \\
\text { dependence }\end{array}$ & - Relational exchange & $\begin{array}{l}\text { Authority } \\
-\quad \text { Conflict } \\
\text { - } \text { Dependence } \\
\text { - Pnterdependence } \\
\text { Power } \\
\text { Uncertainty }\end{array}$ \\
\hline
\end{tabular}

Several scholars call for efforts directed at synthesizing existing theories into a general relationship marketing theory (Gummesson 1997; Iacobucci and Ostrom 1996; Mudambi and Mudambi 1995; 
Robicheaux and Coleman 1994; Webster 1992). For example, Bagozzi (1995, p. 272) stated that "we lack a grand or all-encompassing theory at the moment, or even one with moderate generalizability". Proponents of a general relationship marketing theory claim that both consumers and businesses engage in relationships for the same motivations: to optimize expected equity (tradeoff between exchange costs and benefits) and to increase the predictability of exchange outcomes (Christy, Oliver, and Penn 1996; Parker and Funkhouser 1997; Peterson 1995). Taking such analogies between consumer and business-to-business relationships results in a view of consumers having potentially the same concerns as firms (Parker and Funkhouser 1997).

Despite potential theoretical advances that can result from applying industrial and channel relationship constructs in consumer contexts, scholars in favor of context-specific relationship marketing theories state that too much emphasis has been placed on borrowing existing constructs from other disciplines and marketing areas to fit relationship marketing research (Bejou 1997; Möller and Halinen-Kaila 1998; Mudambi and Mudambi 1995). According to them, scholars should avoid the confusion that is caused by mixing different types of theory and focus their efforts at developing more rigorous 'partial' relationship marketing theories (Möller and Halinen-Kaila 1998). They stress that consumer and business-to-business relationships are based on different underlying assumptions (Fischer and Bristor 1994; Wilson 1995). For example, Moller and Halinen-Kaila (1998) explicitly stated that it is misleading to talk about relationship marketing without any reference to the distinction between consumer and inter-organizational relationship marketing. According to them, both modes of relationship marketing pose very different challenges for customer relationship management.

General

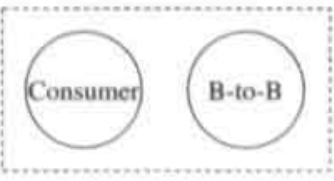

Context-specific

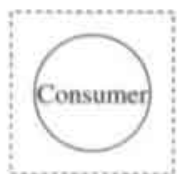

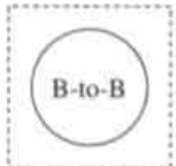

Mixed

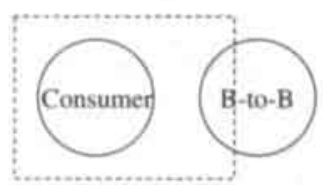

\section{Figure 2-2: Genenl, Context-Specific, and Mixed Relationship Marketing Theory}

In our opinion, both lines of thought can potentially contribute to our understanding of consumer relationships. Researchers can benefit from using the same constructs in different contexts, which does not imply that all of these constructs are applicable in the context under investigation. In line with Gruen (1995), we support the notion that the study of consumer relationships can benefit from incorporating relational constructs that are unique to consumer markets as well as those that are shared with business-to-business markets. This implies that we prefer a mixed theory of investigating consumer relationships as opposed to a general or context-specific theory (see figure 2-2). This mixed approach corresponds to Iacobucci and Ostrom's (1996) view that the study of many relational constructs in business-to-business environments provides a rich source of knowledge that can, at least partially, be applied successfully to consumer situations. 


\subsubsection{Characteristics of Consumer versus Business-to-Business Marketing}

In order to assess which of the theories described in 2.5 .1 are applicable to consumer markets, this section discusses the differences between consumer and business-to-business markets. With respect to buyer characteristics, consumer markets are generally characterized by a large number of smallsized buyers who exhibit lower levels of involvement, product knowledge, and loyalty as opposed to buyers in business-to-business markets. Also the number of sellers is typically higher in consumer environments. With respect to product characteristics, consumer products tend to involve lower levels of purchase risk, technical complexity, and service requirement. In table 2-3, we emphasize the major differences that exist between consumer and business-to-business marketing ${ }^{8}$.

Differences between consumer and business-to-business markets have consequences for the types of buyer-seller relationships that exist in both markets. In general, buyers and sellers are less dependent upon each other in consumer contexts as opposed to business-to-business contexts. While consumers can easily switch sellers given their low idiosyncratic investments, they can hardly exert power on these sellers given their relatively low purchase size. Business-to-business relationships are often characterized by struggles for power, domination. and control. In contrast, consumers generally have difficulties exerting power over marketers because they only represent a fraction of a seller's business (Fischer and Bristor 1994; Pressey and Mathews 1997). Concluding, we may state that consumer relationships are more difficult to build than business-to-business relationships. Consumers are generally more polygamous than businesses as a result of lower purchase risks and a wider choice between a large number of sellers (Keng and Ehrenberg 1984; Pressey and Mathews 1997). Consequently, constraint-based relationship motivations are deemed to be less important in consumer markets.

In section 2.5.4, we take a critical look at the extent to which each of the theories described (see table 2-2) can be applied usefully in a consumer context taking into account the specific characteristics of consumer environments (see table 2-3).

\subsubsection{Applicability of Theories Underying Relationship Marketing in a Consumer Context}

Since no single conceptual model is able to capture all elements that might have a potential relevance for relationship marketing (Fontenot and Wilson 1997), well-founded choices have to be made concerning the inclusion of relationship marketing constructs into our research model. In order to be able to make these choices, this section discusses the implications of the before mentioned characteristics of consumer markets/exchanges for the applicability of each theory underlying relationship in a consumer context. The criterion we use for evaluating the applicability of a theory to consumer relationships examined in our study is the level of correspondence between this theory's characteristics (table 2-2) and characteristics of the consumer market (table 2-3).

\footnotetext{
Traditionally, marketing scholars separated the areas of consumer and business-to-business marketing and argued that there exists a clear dichotomy between both fields (Fern and Brown 1985: Gross et al. 1993: Mowen 1990). While the differences mentioned in table 2-3 are in many situations genuine, this is not always the case. In a study investigating consumer and business-to-business marketing differences, Fern and Brown (1985) concluded that more differences existed within consumer and business-to-business marketing environments than between them.
} 


\subsubsection{Neoclassical Microeconomic Theory}

Neoclassical microeconomic theory departs from a wide range of assumptions that are often not relevant in modern consumer environments (Dabholkar, Johnston, and Cathey 1994). It states that exchange parties engage in exchanges in order to maximize their profits and utilities, that they have well-defined and stable preference structures, and that markets are purely driven by the price mechanism (Arndt 1983; Dabholkar, Johnston, and Cathey 1994; Pandya and Dholakia 1992; Sheth and Parvatiyar 1995a). Consequently, neoclassical microeconomic theory has often been criticized for its limited applicability to different exchange situations (Pandya and Dholakia 1992).

In reality, consumer relationships are driven by a variety of different forces exceeding pure utility maximization and price optimization (Bendapudi and Berry 1997). Moreover, today's consumers are more and more difficult to describe in terms of preference structures. A consumer's behavior and motivations are increasingly difficult to grasp. Shim and Eastlick (1998, p. 139) stated that "technological developments and market conditions, combined with relatively affluent, highly mobile, and increasingly time-scarce consumers, have all played important roles in affecting retail changes". Current retail markets are characterized by increased competition and new types of retail formats (Amold, Oum, and Tigert 1983; Kline and Wagner 1994). Such markets cannot be expected to be purely driven by the price mechanism. As a result, neoclassical microeconomic theory does not seem to provide a relevant framework for explaining consumer relationships in a retail context.

\subsubsection{Transaction Cost Theon}

Transaction cost theory has most often been applied to organizational issues such as sales organization, distribution, and market entry decisions (Heide and John 1992). Given the criticism that has been directed at transaction cost theory following its sole focus on costs, neglect of the role of people, and unrealistic assumption of opportunistically inclined parties, transaction cost theory does not seem to provide a useful framework for explaining relationship enhancement in a consumer context either (Dabholkar, Johnston, and Cathey 1994; Heide and John 1992; Houston and Gassenheimer 1987: Morgan and Hunt 1994: Weitz and Jap 1995).

Transaction cost theory describes transactions according to three criteria: asset specificity, uncertainty, and frequency (Mudambi and Mudambi 1995; Robicheaux and Coleman 1994: Sharma and Sheth 1997; Varadarajan and Cunningham 1995). According to transaction cost theory, higher levels of asset specificity, uncertainty, and transaction frequency lead to higher transaction costs, and, consequently, to a higher relevance of transaction cost theory (Bowen and Jones 1986; Heide and John 1992: Mudambi and Mudambi 1995; Robicheaux and Coleman 1994). In our opinion, asset specificity as well as uncertainty are generally lower in consumer markets as opposed to business-to-business markets. First, asset specificity is assumed to be lower in consumer markets because a consumer's costs of having a relationship with a seller are generally lower, given the ease 
Table 2-3: Major Differences between Consumer and Business-to-Business Marketing

\section{MARKET CHARACTERISTCS}

\section{Buyer chanacteristics}

Buyer geographic concentration

Buyer knowledge level

Buyer loyalty

Buyer purchase involvement

Buyer purchase motives and skills

Buyer size

Buying center complexity

Buying center size

Number of buyers.

\section{Seller chanacteristics}

Key account management

Number of sellers

Seller knowledge level

\section{Product chanacteristies}

Product specification

Purchase process

Purchase risk

Service requirement

Systems selling

Technical complexity

\section{EXCHANGE CHARACTERISTICS}

\section{Average sales size}

Buyer dependence on the seller

Buyer power

Buyer size in relation to seller size

Buyer/seller exchange

Buyer/seller reciprocity

Ease of buyer switching from seller

Idiosyncratic investments

Level of contractual agreements

Negotiation level

Party steering buyer-seller relationship

Purchase frequency

Seller dependence on the buyer

\section{Consumer marketing}

Business-to-business narketing

$\begin{array}{ll}\text { Low } & \text { High } \\ \text { Low } & \text { High } \\ \text { Low } & \text { High } \\ \text { Low } & \text { High } \\ \text { Emotional/self-gratifying } & \text { Rational/professional } \\ \text { Small } & \text { Large } \\ \text { Low } & \text { High } \\ \text { Individual } & \text { Group } \\ \text { High } & \text { Low }\end{array}$

$\begin{array}{ll}\text { Not important } & \text { Important } \\ \text { High } & \text { Low } \\ \text { Low } & \text { High }\end{array}$

$\begin{array}{ll}\text { Standardized } & \text { Customized } \\ \text { Simple } & \text { Complex } \\ \text { Low } & \text { High } \\ \text { Low } & \text { High } \\ \text { Less frequent } & \text { More frequent } \\ \text { Low } & \text { High }\end{array}$

Source: Based upon (1) Bingham, Frank G. Jr. and Barney T. Raffield III (1990), Business to Business Markering, Homewood: Irwin, (2) Eckles, Robert W, (1990), Business Markering Management - Marketing of Business Products and Senvices, Englewood Cliffs: Prentice-Hall, (3) Fern, Edward and James Brown (1985), "The Industrial/Consumer Marketing Dichotomy: A Case of Insufficient Evidence," Joumal of Marketing. 48 (Spring), 68-77, (4) Gruen, Thomas W. (1995), "The Outcome Set of Relationship Marketing in Consumer Markets," Intemational Business Review, 4 (4), 447-69, (5) Gross, Andrew C., Peter M. Banting, Lindsay N. Meredith, and L. David Ford (1993), Business Marketing, Boston: Houghton Mifflin Company. (6) Hutt, Michael D. and Thomas W. Speh (1992), Business Marketing Management - A Strutegic View of Industrial and Organizational Markets, fourth ed., Forth Worth: The Dryden Press, (7) Möller, Kristian and Aino Halinen-Kaila (1998). "Relationship Marketing: Its Disciplinary Roots and Future Directions," in Proceedings of the 27th EMAC Conference, Per Andersson, Ed. Stockholm: European Marketing Academy, 289.310. 
with which consumers can 'take or leave' these relationships (Beatty et al. 1996; Dwyer, Schurr, and Oh 1987). Second, uncertainty is generally expected to be lower in consumer contexts as opposed to business-to-business contexts. In most consumer markets, performance ambiguity is considered to be low given the low need for post-purchase evaluation, the low risk associated to consuming a product, and equal information disposal between consumers and sellers (Berry 1995; Bitner 1995). Concluding, we postulate that transaction cost analysis is less suitable for explaining consumer relationships.

\subsubsection{Relational Contracting Theory}

Dwyer, Schurr, and Oh (1987) noticed that, while modern contract law only seems applicable to business-to-business situations, their relationship process model has its roots in interpersonal literature making it equally useful for analyzing consumer buying situations in which the stakes are high. However, the stakes in consumer-retailer relationships are generally low. The casual clothing and food retail markets investigated in this study are highly competitive and transparent markets. Both markets are generally acknowledged to have reached maturity, to be overstored, and to have difficulties differentiating themselves based on merchandise selection only (Berry and Gresham 1986: Ellis 1995; Ghosh 1994). Consequently, consumers have ample choice in these retail markets and can easily switch between alternative retailers. Viewed from this perspective, relational contracting theory seems to be less applicable to explain relationships in a consumer context.

\subsubsection{Social Exchange Theony}

As the term suggests, social exchange theory views social exchanges at the core of relationships. These exchanges between partners are driven by self-interest, are characterized by cooperation and reciprocity, and are intended to lead to mutually beneficial economic and/or non-economic outcomes (Dwyer, Schurr, and Oh 1987; Frazier and Rody 1991; Levitt 1983; Metcalf, Frear, and Krishnan 1992; Perrien and Ricard 1995). The outcomes of both parties in an exchange relationship are affected through communication and transformation processes (Duncan and Moriarty 1998; Hallén, Johanson, and Seyed-Mohamed 1991; Oliver and Swan 1989). This view of social exchange theory on relationships corresponds closely to the kind of relationships we encounter in consumer situations. Sellers undertake efforts (communication and transformation processes) towards consumers through socially interacting with these consumers. These efforts are intended to lead to positive relationship outcomes (Bloemer and De Ruyter 1998), Our definition of a relationship, "one or more exchanges between a buyer and a seller that are perceived by the buyer as being interrelated to potential past and future exchanges with the seller", is related to the social exchange paradigm as it emphasizes the key role of exchanges. To sum up, social exchange theory seems to be very relevant for explaining relationships between consumers and retailers. 


\subsubsection{Equity Theory}

Equity theory focuses upon the evaluation and fair distribution of relationship inputs and outputs". Each party in an exchange is assumed to compare his ratio of relationship inputs and outputs to a particular standard of comparison. In case inputs are balanced against outputs in a relationship (relationship equity), partners are believed to be satisfied with their relationship (Geyskens 1998: Houston and Gassenheimer 1987; Huppertz. Arenson, and Evans 1978; Oliver and Swan 1989). Equity theory can easily be applied to consumer exchanges. Efforts undertaken by a seller can be viewed as this seller's relationship inputs (and a consumer's relationship outputs), while relationship outcomes can be regarded as this seller's relationship outputs. As a result, equity theory seems to provide an appropriate framework for analyzing consumer relationships.

\subsubsection{Political Economy Theory}

Political economy theory is concerned with the allocation of economic resources, authority, and power (Stern and Reve 1980). It has mainly been developed for explaining collective, organizational, and institutional behavior (Amdt 1983; Pandya and Dholakia 1992). Consequently. the unit of analysis of political economy theory consists of relational exchanges between collective entities. Amdt (1983, p. 51) underlined this collective unit of analysis by stating that "the household may be viewed as a special case of small organizations leading to emphasis on goals, power bases, conflict management, and allocation rules". Political economy theory examines both the internal structures of a group as well as its external environment. Since our unit of analysis is the individual consumer, the study of group behavior and internal group structure is not relevant for our purposes. Political economy theory is more useful to analyze relationships with industrial customers. suppliers, joint venture partners, resellers, and other stakeholders (Webster 1992). While political economy theory is generally praised for its general and integrative nature, it seems to provide little added value for explaining the dyadic consumer-seller relationship.

\subsubsection{Resource Dependence Theory}

Resource dependence theory states that exchange partners become more dependent upon each other as (1) outputs from an exchange become more important (referred to as criticality), (2) the magnitude or proportion of trade with one partner increases (referred to as quantity). (3) the business is concentrated with fewer partners (referred to as replaceability), and (4) it becomes more difficult to locate potential alternative exchange partners (referred to as slack) (Andaleeb 1995; Krapfel, Salmond, and Spekman 1991). Table 2-3 showed that buyers and sellers are generally much less dependent upon each other in consumer markets as opposed to business-to-business markets.

In consumer markets, exchange outputs are generally less important, exchange quantities are lower, business concentration is lower, and the location of alternative exchange partners is easier compared

Relationship outputs and relationship outcomes are defined differently in this dissertation. While relationship outcomes refer to a buyer's attitude towards or behavior during the buyer-seller relationship, relationship outputs are considered as a seller's efforts that are perceived by the buyer. 
to business-to-business markets (see table 2-3). Given the competitive and open nature of the retail markets investigated in this study, the existence of constraints such as authority, control, conflict, and resource dependence within these markets is likely to be small. According to Weitz and Jap (1995), the use of power as a coordinating mechanism is limited to asymmetric relationships relationships in which one party is more powerful than another party. In most consumer-retailer exchange settings, a power balance exists in the sense that the retailer cannot exert a lot of power over the consumer and the consumer cannot exert a lot of power over the retailer either. Consumers are generally less dependent upon retailers because they can choose from a wide range of alternative retailers. Retailers are generally less dependent upon consumers because their business with one consumer only represents a small fraction of their total business. As a result, it seems that constructs that are related to cooperation, coordination, and collaboration hold more promises for explaining relationship enhancement in consumer contexts than constructs that are related to dependence, power, and conflict. In other words, resource dependence theory is less suitable as an explanatory theory for consumer relationships.

\subsection{Choice of Constructs}

Summarizing the previous sections, we argue that especially social exchange theory and equity theory hold most promises for explaining consumer-retailer relationships. Most ideas and constructs mentioned in other theories are less likely to aid in explaining consumer relationships given the fact that their assumptions are not in line with retail situations. Examples of such constructs are dependence, power, non-retrievable investments, and switching costs (Anderson and Weitz 1989: Doney and Cannon 1997; Heide and Weiss 1995; Wilson 1995). Such relational constructs are not considered irrelevant in a consumer context, but are rather thought to play a less substantial role in explaining consumer relationships.

This study wants to explore the effects of buyer relationship proneness and seller relationship orientation on relationship outcomes. The construct of buyer relationship proneness is rooted in social exchange theory given its emphasis on social tendencies of the buyer. The construct of seller relationship orientation is inspired by equity theory as outputs (seller efforts) play a central role in describing the construct. Moreover, buyer relationship proneness and product category involvement are included in the study as they are recognized to influence relationship effectiveness (see section 2.3.2). The constructs of buyer relationship proneness, seller relationship orientation, and product category involvement are discussed in chapter three.

Moreover, relationship outcomes are the prime constructs of interest in social exchange and equity theory. We study the following attitudinal relationship outcomes: relationship satisfaction, trust, and relationship commitment. These constructs are recognized as being indispensable building blocks of relationship marketing (Geyskens 1998). For more than three decades, the construct of relationship satisfaction has been researched, underlining its importance in marketing research (Crosby, Evans, and Cowles 1980: Dwyer and Oh 1987; Geyskens 1998; Hunt and Nevin 1974; Rosenberg and Stern 1971: Selnes 1998; Stern and Reve 1980; Tax. Brown, and Chandrashekaran 1998). Moreover, trust is considered as one of the most critical constructs in relationship marketing theory (Anderson, Lodish, and Weitz 1987: Anderson and Narus 1990; Anderson and Weitz 1992: Crosby. 
Evans, and Cowles 1990; Doney and Cannon 1997; Dwyer and Oh 1987; Dwyer, Schurr, and Oh 1987; Gundlach and Murphy 1993: Hallén, Johanson, and Seyed-Mohamed 1991; Moorman. Desphandé, and Zaltman 1993: Morgan and Hunt 1994: Schurr and Ozanne 1985; Smith and Barclay 1997). Finally, several scholars consider relationship commitment to be an essential ingredient of successful long-term relationships (Andaleeb 1996; Dwyer. Schurr, and Oh 1987; Geyskens et al. 1996; Lund 1985; Macintosh and Lockshin 1997; Morgan and Hunt 1994; Scheer and Stern 1992). While these constructs have mainly been examined in business-to-business contexts, it is recently acknowledged that they may be relevant in a consumer context too (lacobucci and Ostrom 1996: Macintosh and Lockshin 1997). It is generally recognized that relationship outcomes can be of an attitudinal as well as a behavioral nature (Dick and Basu 1994; Gruen 1995). We add behavioral loyalty as an additional relationship outcome in order to assess the behavioral impact of seller relationship orientation and buyer relationship proneness. Relationship outcomes are described in chapter four.

\subsection{Summary and Conclusions}

The objective of this chapter was to provide a basis for the selection of constructs to be included in our study. Successively, we discussed the concept of relational exchange, the concept of relationship marketing. the development of relationship marketing, the applicability of theories underlying relationship marketing in a consumer context, and the choice of constructs to be investigated in this study. The renewed attention for relationship marketing is mainly driven by practitioners' experiences of eroding repeat purchases and intensified competitive pressures and by the development of new communication and information technologies allowing the principles of relationship marketing to be applied to a large group of consumers. Academic literature increasingly devotes conceptual and empirical research efforts to relationship marketing as a topic of interest. Some scholars even consider relationship marketing thinking to be the basis for a completely new marketing paradigm. Practitioners as well as academics are shifting their focus from mainly discrete transactional thinking to more relational thinking.

Despite the current interest for the relationship marketing paradigm, no single definition of relationship marketing is agreed upon. We define relationship marketing as "a seller's product, service, and relationship efforts aimed at enhancing relationship outcomes of buyer-seller relationships". Moreover, several scholars indicate that relationship marketing is not always an effective strategy. If particular characteristics are present, relationships are easier to build. We made a distinction between buyer, product/service, environmental, and exchange situation characteristics potentially influencing relationship effectiveness. In order to decide which theories are most relevant for explaining relationships in a consumer context, we first compared seven theories that can be categorized as either economic, behavioral, or economic/behavioral. Second, we described the main differences between consumer and business-to-business markets and exchanges. It appeared that certain theories obtained a better match between their own characteristics and consumer market characteristics. More specifically, social exchange theory and equity theory especially lend themselves for describing relationships in consumer markets. As a result, the constructs, which are included as variables of interest in this study, and the hypotheses, which are formulated with respect to their interrelationships, are based upon these two theories. 


\section{Chapter Structure}

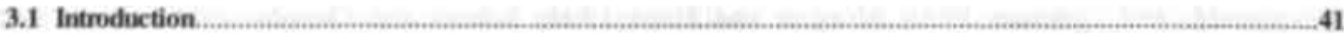

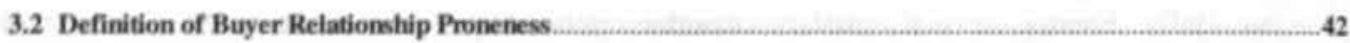

3.3 Importance of Buyer Relationship Proneness .......44

3.3.1 Buyer Relationship Pnoneness as a Potential Bavis for Segmentation.

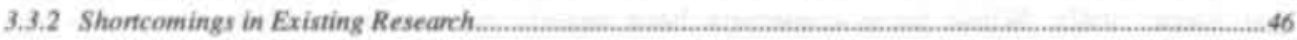

3.4 Antecedents of Buyer Relationship Proneness .............46

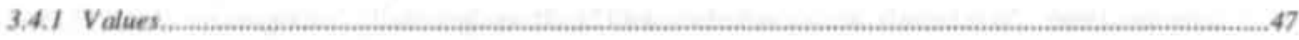

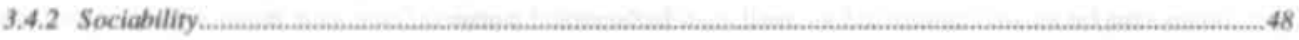

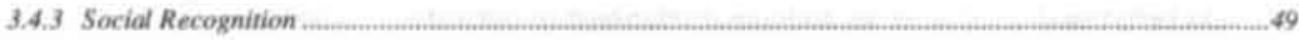

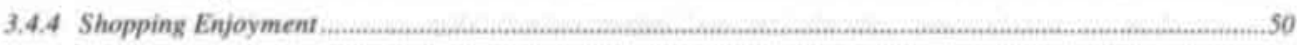

3.4.5 Enduring Product Category Involvement.

3.5 The Role of Seller Relationship Orientation. 53

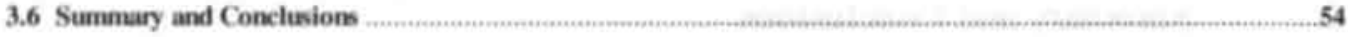




\section{Chapter 3 The Role of Buyer Relationship Proneness}

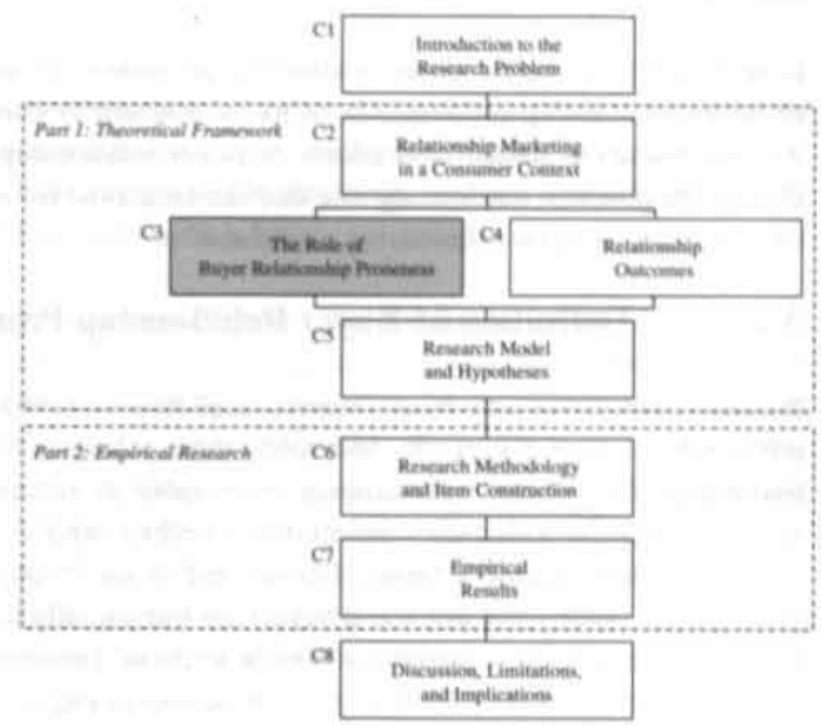

\subsection{Introduction}

In the previous chapter, we stated that social exchange theory and equity theory hold most promises for explaining consumer-retailer relationships because their assumptions and main constructs are in line with retail situations. This theoretical choice is consistent with our focus on the voluntary nature of buyer-seller relationships in a retail context (Smith and Barclay 1997).

Bagozzi (1975, p. 33) already stated that "retailers, for example, know that they will not obtain repeat purchases if the consumer is taken advantage of and deceived". While the majority of relationship marketing studies dealt with relationships based on dependence and locking in buyers (constraint-based relationships), this study focuses on positive motivations of buyers driven by a stable and conscious tendency to engage in relationships with sellers (dedication-based relationships) (Barnes 1995/1997; Davis 1995; Ganesan 1994; Houston 1986; Oliver and Swan 1989: Palmer 1995; Smith and Barclay 1997). Bendapudi and Berry (1997) suggested that individuals are motivated to engage in relationships either because they genuinely want to or because they believe they have no other option. According to them, constraints will only determine the stability of the relationship, whereas dedication determines the quality of the relationship'. As we emphasize dedication-based relationships, we focus on buyers who want to engage in relationships, despite the fact that the contemporary competitive environment offers sufficient alternatives. Consequently, a buyer's relatively stable and conscious tendency to engage in

While the stability of a relationship refers merely to the occurrence of repeat exchanges, the quality of a relationship additionally refers to an attitudinal dimension of commitment to the relationship. The stability of a relationship might be unrelated to psychological commitment and, consequently, can only be regarded as a weak indicator of the true quality of a relationship (Jacoby and Chestnut 1978: Oliva, Oliver, and MacMillan 1992). 
relationships with sellers - in this study referred to as 'buyer relationship proneness' - is the focus of this chapter.

In section 3.2, we define buyer relationship proneness. In section 3.3 , we explain why the construct of buyer relationship proneness is of major concern in contemporary marketing. Third, in section 3.4 , we discuss potential antecedents of buyer relationship proneness. Finally, in section 3.5 , we discuss the potential moderating role that can be played by seller relationship orientation in affecting the outcomes of buyer relationship proneness.

\subsection{Definition of Buyer Relationship Proneness}

Barnes (1995/1997) and Pine, Peppers, and Rogers (1995) emphasized that not all buyers want relationships with sellers. In line with them, Dwyer, Schurr, and Oh (1987) recognized the importance of 'buyers' motivational investment in relationships'. Bendapudi and Berry (1997) similarly mention 'customers' receptivity to relationships' implying that not all buyers will desire long-term relationships. Christy, Oliver, and Penn (1996) referred to the term 'psychologically predisposed', to express that some buyers are intrinsically inclined to engage in relationships, where the relationship itself represents a benefit to them. Despite its recognized importance, no research has yet investigated the role of buyers' proneness to engage in relationships with sellers in affecting relationship outcomes (Barnes 1995/1997; Bendapudi and Berry 1997; Christy, Oliver, and Penn 1996; Sheth and Parvatiyar 19956).

In this study, we introduce the concept of 'buyer relationship proneness' and define it as "a buyer's relatively stable and conscious tendency to engage in relationships with sellers of a particular product category". We position the concept of buyer relationship proneness as an individual characteristic. Early work on store loyalty suggests that buyers' store loyalty behavior is not consistent across products and, as a result, cannot be regarded as an individual characteristic of buyers (Goldman 1977-1978). In a recent study, East et al. (1997) claimed the other extreme by arguing that store loyalty is a characteristic of the individual buyer. Morris and Holman (1988) suggested that the factors influencing loyalty, rather than loyalty itself, can be regarded as buyers' individual characteristics. In line with them, we postulate that a buyer's relationship proneness, which may influence a buyer's relationship with a seller, can be regarded as an individual characteristic. Our definition of buyer relationship proneness is based on related concepts mentioned in existing literature. Below, we briefly comment upon our definition.

\section{(1) Relatively stable}

We assume that buyer relationship proneness is relatively stable, as it is only contingent upon a particular product category but not upon the situation or the seller. Therefore, the concept can be regarded as a domain-specific attitude that can be defined as an individual characteristic of the buyer (Shim and Eastlick 1998). An attitude is defined as a person's overall evaluation of a concept. Consumers can have attitudes towards various physical, social, and imaginary objects. and towards their own behaviors or actions (Kardes 1999; Kokkinaki and Lunt 1997; Peter and Olson 1996). Buyer relationship proneness is a buyer's attitude toward the idea of engaging in relationships with sellers of a particular product category. It is generally acknowledged that an 
attitude represents a relatively stable predisposition to respond to an object (Homer and Kahle 1988: Yoo, Park, and Macinnis 1998).

\section{(2) Conscious tendency}

Before, we positioned buyer relationship proneness as a domain-specific attitude. As an attitude does not reflect the actual behavior towards the object, buyer relationship proneness can be described as a tendency (Churchill 1995; Homer and Kahle 1988; Howard 1989; Kardes 1999; Korgaonkar, Lund, and Price 1985; Shim and Eastlick 1998).

Inspired by Jacoby and Chestnut (1978), recently Bloemer and De Ruyter (1998) defined store loyalty as a non-random response that is a function of psychological processes. Many authors in loyalty literature similarly stress that true loyalty is based on more than mere inertia or convenience (Bloemer 1993; Bloemer and Kasper 1995 Day 1969; Dick and Basu 1994; Fournier and Yao 1997; Hennig-Thurau and Klee 1997; Jacoby and Chestnut 1978; Jacoby and Kyner 1973: Oliver 1997; Rust and Zahorik 1993; Schiffman and Kanuk 1987; Schijns 1999; Uncles and Laurent 1997). For example, Dick and Basu (1994) argued that true loyalty may not reflect situational constraints but is rather guided by a strong internal disposition. In line with this, we emphasize a conscious tendency as opposed to a habitual tendency to engage in relationships with sellers.

\section{(3) Engage in relationships}

As we mentioned, the concept of buyer relationship proneness is defined with respect to sellers of a particular product category rather than with respect to one single seller. Consequently, we focus on the tendency to engage in relationships as opposed to the tendency to maintain or enhance relationships. According to us, a buyer's tendency to maintain or enhance relationships would not be generic as it would be contingent upon a particular seller and this would bear close resemblance to the construct of relationship commitment (Anderson and Weitz 1989; Dwyer. Schurr, and Oh 1987; Geyskens et al. 1996: Kumar, Scheer, and Steenkamp 1995a; Mohr, Fisher, and Nevin 1996; Moorman. Zaltman, and Desphandé 1992; Morgan and Hunt 1994; Scheer and Stern 1992; Young and Denize 1995).

In relationship marketing it is currently common practice to refer to a longer period of time when describing relationships (Christopher, Payne, and Ballantyne 1994; Evans and Laskin 1994: Gummeson 1996; Hoekstra 1998). In chapter two, we defined a relationship as "one or more exchanges between a buyer and a seller that are perceived by the buyer as being interrelated to potential past and future exchanges". This implies that exchanges are not separated from each other but form a whole within a framework of long-term perspectives (Barnes 1995/1997; Low 1996: Shani and Chalasani 1992). Therefore, buyer relationship proneness is related to a relationship as opposed to a single, independent exchange.

\section{(4) Sellers of a particular product category}

Since several authors stress that a buyer's proneness to engage in relationships might vary across groups of sellers (Barnes 1997; Bendapudi and Berry 1997; Christy, Oliver, and Penn 1996), we postulate that buyer relationship proneness has to be defined within a particular product 
category. Recently, Page and Sharp (1997) proposed that consumers are likely to be willing to engage in relationships with retailers when their involvement is high for a certain product category. The underlying thought is that these consumers are already interested in the product category and that, consequently, the relationship can add value. In loyalty literature it is generally acknowledged that the higher the involvement in a product category, the greater the likelihood of loyalty towards specific offerings within that category (Christy, Oliver, and Penn 1996; Dick and Basu 1994; Goldman 1977/1978; Leuthesser 1997; Solomon et al. 1985). As buyers are more involved with some product categories than with others (Laurent and Kapferer 1985; Zaichkowsky 1985), we define buyer relationship proneness as an attitude towands relationships with sellers of a particular product category as opposed to an attitude towards relationships with sellers in general.

\subsection{Importance of Buyer Relationship Proneness}

In order to demonstrate the importance of buyer relationship proneness, we first describe the importance of segmenting the market on the basis of buyer relationship proneness (3.3.1). Second, we describe the shortcomings in existing research (3.3.2).

\subsubsection{Buyer Relationship Proneness as a Potential Basis for Segmentation}

Company protits are commoniy related to the reaizzation of intee kèy suategiès: ( 1 ) acquaring new buyers, (2) enhancing the profitability of existing buyers, and (3) extending the duration of buyer relationships (Grant and Schlesinger 1995). Transaction marketing approaches are mainly directed at accomplishing and optimizing the first two strategies. However, driven by numerous developments in the marketplace, these marketing approaches are increasingly less effective and efficient and often result in decreasing company performance (Evans and Laskin 1994; Perrien and Ricard 1995). Reichheld (1996) claimed that US corporations now lose half of their customers in five years and warns that disloyalty decreases corporate performance up to 50 percent. In literature. several possible reasons for this are enumerated such as more demanding customers, increased customer resistance to traditional mass media advertising. crowded retail environments with undifferentiated product and pricing offerings, a wider variety of messages and media directed at customers, global competition, increased fragmentation of markets, and slow-growth economies and industries (Davis 1997; Pine, Peppers, and Rogers 1995; Woodruff 1997). As a result of these changes in the marketing environment, today, sellers have developed both the willingness and ability to enhance relationships with their buyers. Their willingness results from the fact that sellers increasingly believe in the power of customer relationships as it is generally agreed upon that these relationships provide them with better financial results, increased market knowledge, more stable market conditions, increased sales opportunities, and more flexible approaches of the market (Anderson, Fornell, and Rust 1997; Beatty et al. 1996; Bendapudi and Berry 1997; Bennett 1996; Christy, Oliver, and Penn 1996; Copulsky and Wolf 1990; Crosby and Stephens 1987; De Wulf 1998; Dowling and Uncles 1997; Dwyer, Schurr, and Oh 1987; Evans and Laskin 1994; Grant and Schlesinger 1995: Jüttner and Wehrli 1994; Kalwani and Narayandas 1995: Leuthesser 1997; McCort 1994; Perrien. Filiatrault, and Ricard 1993; Perrien, Paradis, and Banting 1995; Pine, Peppers, and Rogers 1995; Reichheld 1993; Reichheld and Sasser 1990; Stone, Woodcock, and 
Wilson 1996). Sellers' ability to engage in relational exchanges is primarily a result of technological advances (Berry 1995; Dwyer, Schurr, and Oh 1987; Jüttner and Wehrli 1994; Pine, Peppers, and Rogers 1995; Sheth and Parvatiyar 1995b; Stone, Woodcock, and Wilson 1996).

Due to these changes in the marketing environment relationship marketing is generally praised as a valuable strategy. However, recently, several authors are claiming that the success of relationship marketing is not only dependent upon the strategy or its implementation. but just as much upon the preferences of the individual buyer (Fournier 1998; Gwinner, Gremler, and Bitner 1998). Different authors emphasized the awkward situation potentially resulting from an automatic application of a relationship marketing strategy to every buyer (Barnes 1995/1997; Bendapudi and Berry 1997; Christy. Oliver, and Penn 1996; Ellis 1995). The assumption that a relationship can be formed with any buyer in any situation often leads to seller efforts to form relationships in situations where a relationship cannot be formed, simply because the buyer does not want a relationship. The result is that resources are wasted, buyers are disappointed or even might perceive these efforts as intrusive (Barnes 1995/1997; Ganesan 1994; Krapfel, Salmond, and Spekman 1991; Shani and Chalasani 1992).

In chapter two, we already mentioned that the effectiveness of relationship marketing is recognized to be contingent upon several characteristics (Berry 1995; Crosby, Evans, and Cowles 1990: Pine, Peppers, and Rogers 1995: Shani and Chalasani 1992). According to Bendapudi and Berry (1997, p. 31) "a contingency approach to relationship marketing involves understanding when and why customers are most receptive to relationship maintenance". In line with the suggested contingency approach, interpersonal literature, literature on employee-firm relationships and relationship marketing literature acknowledged that different buyers have different needs and motivations to engage in a relationship. As a result of differing underlying needs and motivations, buyers might be prone to different types of relationships (Andaleeb 1996; Anderson 1995; Bagozzi 1995; Beatty et al. 1996; Bendapudi and Berry 1997; Duck 1988; Ellis 1995; Fournier 1998: Ganesan 1994; Geyskens et al. 1996; Gwinner, Gremler and Bitner 1998; Haslam and Fiske 1992; Hinde 1979; Morgan and Hunt 1994; Williamson 1975). Concordant to these ideas, Lovelock (1983) proposed to segment markets on the basis of the type of relationship a buyer desires.

Although the previous discussion served as a breeding ground for our ideas, those insights seem to be directed at a buyer's relationship with one single seller as opposed to sellers of a particular product category. For example two of Bendapudi and Berry's (1997) customer variables potentially influencing buyer relationship proneness are relationship specific investments and social bonding with the seller that are clearly related to one particular relationship. As opposed to these situational variables, that may be triggered by life situations (Carver and Scheier 1992; Forman and Sriram 1991), Christy, Oliver, and Penn (1996) suggested that some buyers are psychologically predisposed to belong to relationships. This predisposition is comparable to buyer relationship proneness, which is rather an individual characteristic than a situational variable. Bendapudi and Berry (1997) recognized that enhancing relationships with buyers involves both investments and opportunity costs for the seller and consequently, sellers could benefit from identifying those buyers who are most prone to engage in relationships. From these ideas, we deduce the notion that it would be 
rather important and beneficial to gain knowledge about buyer relationship proneness in order to use this concept as a segmentation basis.

\subsubsection{Shortcomings in Existing Research}

It can be anticipated that research on relationship marketing may benefit from literature on close personal relationships (Bagozzi 1995: Dabholkar, Johnston, and Cathey 1994; Fournier and Yao 1997; Verhallen and De Nooij 1982). Studies investigating relationship quality have already drawn heavily on existing literature on interpersonal relationships (Crosby, Evans, and Cowles 1990; Glenn 1990; Gotlieb, Grewal, and Brown 1994; Hennig-Thurau and Klee 1997: Lagace, Dahlstrom. and Gassenheimer 1991: Wray, Palmer, and Bejou 1994). While there exists a rich source of research investigating the relationship between individual buyer characteristics and buying behavior (Bearden 1977; Dash, Schiffman, and Berenson 1976; East et al. 1997; Finn and Louviere 1996; Keng and Ehrenberg 1984; Korgaonkar, Lund, and Price 1985; Mattson 1982; Pierce et al. 1997; Samli 1975; Tauber 1972), several authors recognize that the existing literature on interpersonal relationships and individual buyer characteristics has only been scarcely used in relationship marketing literature (Christy, Oliver, and Penn 1997; Fournier 1998; Howard 1989; lacobucci and Hibbard forthcoming: Kline and Wagner 1994).

Researchers gradually start to recognize the value of individual characteristics in establishing effective relationships. Recently, several authors described different concepts that may be comparable to buyers' proneness to engage in relationships with sellers (Barnes 1995/1997; Beatty et al. 1996; Bendapudi and Berry 1997; Christy, Oliver, and Penn 1996: Ellis 1995; Sheth and Parvatiyar 1995b). However, their contribution mainly consists of emphasizing the need to incorporate buyers' tendency to engage in relationships without investigating the way in which individual characteristics influence relationship outcomes. Some of them provide a broad description of their idea, others only mention their idea without any further explanation. Consequently, empirical research in this area is completely lacking (Bendapudi and Berry 1997; Gwinner, Gremler, and Bitner 1998).

In this section we demonstrated that buyer relationship proneness could be applied as a valuable segmentation variable. Moreover, relationship marketing research investigating individual characteristics like buyer relationship proneness is largely lacking. As a result there is a need for research related to this construct. In the following section we present potential factors determining buyer relationship proneness.

\subsection{Antecedents of Buyer Relationship Proneness}

Recently, several authors recognized that it is important to understand what rypes of buyers are relationship prone (Barnes 1995; Bendapudi and Berry 1997; Berry 1995; Biong and Selnes 1995; Macintosh and Lockshin 1997; Sheth and Parvatiyar 1995b). While a wider range of factors such as culture or peer groups (Sheth and Parvatiyar 1995b) might influence buyer relationship proneness, we limit ourselves to studying buyers' individual characteristics that potentially influence their relationship proneness. Contrary to more general factors, these individual characteristics can easily 
be applied for targeting and communicating with buyers (Bendapudi and Berry 1997; Sheth and Parvatiyar 1995b).

As we want to apply a value instrument in order to determine which individual characteristics to include, we need an instrument that is simple to administer. Therefore, we first give an overview of instruments to assess a buyer's underlying values (3.4.1). Next we introduce four individual characteristics potentially influencing buyer relationship proneness: sociability $(3,4.2)$, social recognition (3.4.3), shopping enjoyment $(3,4,4)$, and finally enduring product category involvement (3.4.5).

\subsubsection{Values}

It is generally acknowledged that a buyer's individual characteristics are largely based on his underlying values (Beatty, Kahle, and Homer 1991; Kamakura and Novak 1992; Kokkinaki and Lunt 1997; Mason, Durand, and Taylor 1983; Rokeach 1973; Shim and Eastlick 1998). It goes beyond the scope of this study to describe all the existing instruments for measuring values. Therefore. we focus on the most frequently used instruments: Rokeach's (1973) Value Survey (RVS), Motivational Domains of Schwartz and Bilsky (1987/1990), and Kahle's (1983) List of Values (LOV).

The most frequently used instrument for measuring human values is the Rokeach Value Survey (RVS). Rokeach (1973) defined a value as "an enduring belief that a specific mode of conduct or end-state of existence is personally or socially preferable to an opposite or converse mode of conduct or end-state of existence". His instrument consists of 18 instrumental values and 18 terminal values (Braithwaite and Law 1985; Clare and Sanford 1979; Homer and Kahle 1988; Kamakura and Mazzon 1991; Miethe 1985: Pitts and Woodside 1983). Terminal values refer to long-range life goals whereas instrumental values represent the behavioral means for achieving them. Rokeach (1973) was one of the first authors who emphasized that values are part of a value system in which each value is ordered in priority relative to other values. As most situations in life activate more than one value and often involve a conflict between different values, several authors recognize that such a systems approach is more appropriate than relying on a single value, (Kamakura and Mazzon 1991: Kamakura and Novak 1992: Schwartz 1992; Schwartz and Bilsky 1987/1990). RVS has been successfully used in a number of contexts and its strengths lie in its versatility and its well-defined conceptualization of values (Braithwaite and Law 1985). However, several authors stress the limitations of the instrument, mainly consisting of a questionable comprehensiveness and representativeness of the items and the suitability of the hierarchical model (Braithwaite and Law 1985; Homer and Kahle 1988). Another critical point of the RVS is that it does not regard values as general frames of reference or evaluative dispositions, but rather as belonging to a person (Clare and Sanford 1979). Moreover. several scholars (Braithwaite and Law 1985; Homer and Kahle 1988; Kamakura and Mazzon 1991; Miethe 1985) mention that RVS only results in rank ordering of values, which is more appropriate for intra-individual comparisons than for comparisons on an aggregate level. Approximately 15 years later. Schwartz and Bilsky (1987/1990/1992) introduced motivational domains and argued that values are cognitive representations of three types of universal human requirements and that they can be derived from 
requirements of the organism itself, from social requirements related to exchange, or from social institutional requirements. They claim that all the values incorporated in RVS refer to one of the motivational domains they suggest. In their view, values are regarded as criteria rather than as qualities inherent in objects, which is in line with Clare and Sanford's (1979) suggestion. Another instrument to assess a person's values is List of Values (LOV). LOV modifies Rokeach's terminal values into a smaller set of nine primarily person-oriented values more directly related to a person's daily-life roles and situations (Kahle 1983; Kahle, Beatty, and Homer 1986; Kamakura and Mazzon 1991: Kamakura and Novak 1992). The values from the LOV also correspond to the Schwartz and Bilsky (1987/1990) framework. The LOV instrument has frequently been applied in consumer marketing to find relationships with criterion variables and is simple to administer. The majority of these studies provide evidence for the validity of LOV (Beatty, Kahle, and Homer 1991; Kahle, Beatty, and Homer 1986). Applications of LOV in value segmentation have dealt with the scale at a relatively concrete level (Kamakura and Novak 1992).

Whereas RVS significantly contributed to the development of a fruitful theory on values, its limitations and extensiveness (Braithwaite and Law 1985; Homer and Kahle 1988) limit its applicability for our purpose. As Schwartz and Bilsky's (1987/1990/1992) motivational domains are comparable to RVS and even more extended, this instrument is not a viable option either. LOV provides a manageable instrument and has already been successfully applied to consumer marketing (Beatty, Homer, and Kahle 1988; Beatty, Kahle, and Homer 1991; Kamakura and Novak 1992). In order to make an appropriate choice of individual characteristics potentially influencing buyer relationship proneness, we first select an instrument for measuring buyers' values. Based on the mentioned strengths of LOV and limitations of potential other instruments, we select LOV. This instrument is applied in a pilot study that is described in chapter six. The pilot study enabled us to distinguish three individual characteristics ${ }^{2}$ : sociability, social recognition, and shopping enjoyment, which are introduced below.

\subsubsection{Sociability}

An individual's inclination to enter relationships might be determined by the extent to which he is comfortable with being close to others. Consequently, a construct potentially related to buyer relationship proneness is sociability. Park and Waters (1988) argued that sociability is a main construct in personality theory. Although definitions of personality are not unequivocal they share components referring to stable tendencies based on enduring, inner psychological characteristics that make one individual unique and different from all others (Duck 1988; Engel, Blackwell, and Miniard 1995; Eysenck and Eysenck 1985; Maddi 1989; Park and Waters 1988). Currently, several authors agree on the usefulness of the five-factor model for personality (Barrick and Mount 1991; Carver and Scheier 1992; Costa and McCrae 1988; Deniston and Ramanaiah 1993; Fleenor and Eastman 1997; Goldberg 1990/1993; Hofstee, de Raad, and Goldberg 1992; McCrae and Costa 1987/1989: Peabody and Goldberg 1989: Sadowski and Cogburn 1997). However, considerable questioning and criticism have been directed at the use of personality instruments such as the five-

2. The author thanks Patrick Schumacher (student at Maastricht University) for his helpful insights related to these constructs. 
factor model in the study of consumer behavior given the fact that they were designed for other purposes (Cobb and Hoyer 1986: Villani and Wind 1975).

In interpersonal relationships, research on attachment styles proved that some people are comfortable with relationships whereas others avoid social contacts (Bartholomew and Horowitz. 1991). While attachment theory is concerned with an individual's propensity to establish strong affective bonds to others (Bartholomew and Horowitz 1991), research on sociability investigates the propensity of individuals to be with other people rather than being alone (Carver and Scheier 1992). Sociability is characterized by traits such as sociable, exhibitionist, and expressive. The highly sociable person has many friends and knows many people (Barrick and Mount 1991; Sadowski and Cogburn 1997). Sociability can be regarded as a preference for affiliation or a need to be with people (Cheek and Buss 1981). Buss and Plomin (1984) stated that the highly sociable person, by definition, seeks relationships. Sociable persons tend to be enjoying social exchanges, tend to be responsive to others and are likely to have many friends. A sociable person is inclined to interact with others, because he derives pleasure from the social interaction itself. It is not a matter of desiring social rewards, but rather intrinsically valuing the process of exchange with other people (Carver and Scheier 1992). Engaging in buyer-seller relationships might be one of the ways to satisfy the need for exchanges with other people. In chapter two, we defined a buyer-seller relationship as "one or more exchanges between a buyer and a seller that are perceived by the buyer as being interrelated to potential past and future exchanges" and noticed that an exchange can be related to social aspects. Moreover, Ellis (1995) found empirical evidence for the hypothesis that highly sociable buyers tend to have buyer-salesperson relationships that are social in nature and she argued that sociability is positively correlated to willingness to maintain relationships. Based on the existing knowledge on interpersonal relationships and a successful application to buyer-salesperson relationships, we postulate that sociability could also play a role in buyer-seller relationships by being a potential antecedent of buyer relationship proneness.

Cheek and Buss (1981, p. 330) defined sociability as "a tendency to affiliate with others and to prefer being with others to remaining alone" and argue that this is a standard definition accepted by most psychologists. In line with this, we define sociability as "a buyer's individual characteristic representing the tendency to affiliate with others and to prefer being with others to remaining alone".

\subsubsection{Social Recognition}

Individuals tend to have a need for social recognition. Various researchers have analyzed the motivational power of recognition. Maslow's (1970) 'Hierarchy of Needs' theory postulates that five categories of needs motivating an individual can be distinguished. One category, self-esteem needs, contains recognition, as a subsidiary esteem need. The Socially Acquired Dominant Motive Theory distinguished three types of needs. According to this theory, individuals have typically one overbearing need, which is driving their behavior. People who are characterized by a high need for affiliation have a strong desire for obtaining approval and reassurance from others (Wilson 1994). Herzberg's Two-Factor Theory acknowledges that recognition by others has the potential to motivate an individual in a work setting (Herzberg 1968). Cross and Smith (1995) regarded 
recognition of a customer's achievements, status, or information needs as being critical success factors in the establishment of long-term relationships with customers. Therefore, we postulate that another construct potentially related to buyer relationship proneness is social recognition. In literature on interpersonal relationships, Brock et al. (1998) defined social recognition as a person's relatively stable cognitive appraisal that others care for and value him. The construct of social recognition demonstrates affinity to the construct of acceptance (Collins and Read 1990). Social recognition is recognized to guide relationship development and to define the resulting type of relationship (Kirkpatrick and Davis 1994). Another related construct is the construct of 'selfconfidence', which is a person's evaluation of his own abilities and his impression of how others feel about him. Dash, Schiffman, and Berenson (1976) suggested that a person's self-confidence influences his store choice. Carver and Scheier (1992) used another related construct the so-called 'need for positive regard' that is described as having a strong built-in motivation to be accepted and to have love, friendship, and affection of others.

In buyer-seller relationships social recognition is related to the construct of personalization. Mittal and Lassar (1996, p. 96) used the term personalization to describe the social exchange between buyer and seller. As sellers relate to buyers, in either a cold and impersonal or warm and personal way, personalization can be regarded as a means of showing social recognition for the other party (Mittal and Lassar 1996). Forman and Sriram (1991) similarly claimed that some people engage in buyer-seller relationships in a search for human contact and social recognition. Indicators of personalization are attempts to get to know the customer as a person and to exhibit personal warmth (Crosby, Evans, and Cowles 1990; O'Brien and Jones 1995; Stone, Woodcock, and Wilson 1996). This corresponds largely to what Ramsey and Sohi (1997) called the feeling of 'being included in the communication process' and of 'being liked and treated with respect'.

Literature on interpersonal relationships hence demonstrated that people engage in relationships, as they want to be valued. Moreover, literature on buyer-seller relationships showed that the seller could provide the buyer with social recognition. Consequently, we postulate that a buyer who desires social recognition is prone to engage in relationships, because he expects that a relationship may satisfy his desire for social recognition. In line with Brock et al. (1998), we define social recognition as "a buyer's individual characteristic representing the desire of being well-respected by others".

\subsection{4}

\section{Shopping Enjoyment}

A third construct potentially related to buyer relationship proneness is shopping enjoyment. Several efforts have been made to develop different shopper typologies (Bellenger and Korgaonkar 1980; Goldman 1977-1978: Westbrook and Black 1985). Westbrook and Black (1985) for example, distinguished a rough dichotomy in shopping orientations by defining recreational versus economic shoppers. In line with them, Bellenger and Korgaonkar (1980) defined recreational shoppers as "those who enjoy shopping as a leisure-time activity", hence exhibiting shopping enjoyment. Convenience or economic shoppers "dislike shopping or are neutral toward it, and thus approach retail store selection from a time- or money-saving point of view" (p. 78). This group of shoppers will therefore lack shopping enjoyment. Another group of authors distinguishes between hedonic 
and utilitarian shoppers (Babin, Darden, and Griffin 1994; Hirschman and Holbrook 1982; Holbrook and Hirschman 1982). They argue that utilitarian shoppers aim at accomplishing the consumption task, whereas hedonic shoppers strive for fun and entertainment related to shopping. Engel, Blackwell, and Miniard (1995) used the term 'shopping addiction' to express a buyer finding release in shopping. O'Guinn, and Faber (1989) simply expressed shopping enjoyment as the enjoyment that buyers receive from the shopping experience. Gutman and Mills (1982) argued that people who enjoy shopping, like to shop in many different stores. Forsythe, Butler, and Schaefer (1990) and Solomon (1987) investigated the association between shopping enjoyment and the consultation of salespeople aiding in the buying process. Their studies showed that people who lack shopping enjoyment value relationships with salespeople.

These insights suggest that people who lack shopping enjoyment are interested in buyer-seller relationships as these relationships might mitigate the unpleasant shopping task. Moreover, the mentioned studies imply that people, who do enjoy shopping, like to shop in many different stores as opposed to one store with which they build a relationship. As a result we expect that a buyer's shopping enjoyment is negatively related to his relationship proneness. In line with Bellenger and Korgaonkar (1980), we define shopping enjoyment as "a buyer's individual chamacteristic representing the tendency to find shopping more enjoyable and to experience greater shopping pleasure than others".

\subsection{5}

\section{Enduring Product Category Involvement}

In addition to the three individual characteristics derived from the List of Values, we investigate the role of enduring product category involvement. Page and Sharp (1997) recently proposed that consumers are more likely to engage in relationships with retailers when their product category involvement is high. The underlying thought is that the relationship can add value if consumers are already interested in the product. Consequently, we expect that product category involvement is related to buyer relationship proneness. The concept of involvement received considerable attention from consumer researchers (Arora 1982; Celsi and Olson 1988: Day, Royne Stafford, and Camacho 1995; Goodman et al. 1995; Greenwald and Leavitt 1984; Laurent and Kapferer 1985; Mittal and Lee 1989; Morgan and Dev 1994; Park and Mittal 1985; Rodgers and Schneider 1993; Slama and Tashchian 1985: Swinyard 1993; Zaichkowsky 1985). Bloch (1981/1982) and Dick and Basu (1994) suggested that highly involved individuals are more brand loyal. King and Ring (1980) argued that the level of fashion involvement is a valid dimension for fashion market segmentation. In their opinion, a strong relationship exists between fashion involvement and clothing spending. Consequently, the level of fashion involvement is hypothesized to influence consumers' store choice (King and Ring 1980).

Several efforts have been made to develop measurement scales of product category involvement (Bloch, Sherrell, and Ridgeway 1986; Jain and Srinivasan 1990; Lastovicka and Gardner 1979; Laurent and Kapferer 1985; Ratchford 1987; Tigert, Ring, and King 1976; Zaichkowsky 1985). Two frequently cited scales are Zaichkowsky's (1985) 'Personal Involvement Inventory' (PII) and Laurent and Kapferer's (1985) 'Consumer Involvement Profiles' (CIP). However, several problems concerning the operationalization of product category involvement can be distinguished (Mittal 
1995: Mittal and Lee 1989): (1) the distinction between types of involvement, (2) the definition of involvement, (3) the construct validity of involvement, and (4) the difference between involvement and its antecedents.

\section{(1) The distinction between types of involvement}

The most common distinction between types of involvement is the distinction between situational and enduring involvement (Arora 1982; Bloch 1982; Celsi and Olson 1988: Day. Royne Stafford, and Camacho 1995). Situational involvement reflects concern with a specific situation such as a purchase occasion (Laurent and Kapferer 1985). Therefore, purchase involvement can be regarded as one type of situational involvement (Beatty and Smith 1987; Beatty, Homer, and Kahle 1988; Slama and Tashchian 1985). Enduring involvement reflects a general and permanent concern with the product class, also referred to as product involvement or ego involvement (Beatty. Homer, and Kahle 1988; Laurent and Kapferer 1985: Park and Mittal 1985). However, this distinction is not explicitly reflected in the involvement measures. For example, Zaichkowsky (1985) states that, while PII was developed to measure enduring product involvement, it can also be applied to measure purchase involvement. Moreover, Mittal (1995) and Mittal and Lee (1989) argue that Laurent and Kapferer (1985) do not explicitly distinguish between product involvement and purchase involvement.

\section{(2) Definition of involvement}

A large number of authors define involvement as 'perceived importance' or 'interest in' (Beatty, Homer, and Kahle 1988: Laurent and Kapferer 1985; Mittal and Lee 1989; Mittal 1995). whereas some define the construct as 'perceived relevance' (Day, Royne Stafford, and Camacho 1995; Zaichkowsky 1985). The latter meaning of involvement suggests that a product's relevance automatically implies its importance (Mittal 1995). This is not necessarily true. For instance, toilet paper is relevant, but not necessarily involving.

\section{(3) Constnuct validity of involvement}

Construct validity exists when a measure corresponds to its intended meaning (Hair et al. 1998: Kerlinger 1986). As the PII intends to measure perceived relevance, several of its items measure aspects other than relevance (Day, Royne Stafford, and Camacho 1995; Mittal 1995). The same remark holds for the CIP, which intends to measure importance, but includes also aspects not representing importance (Jain and Srinivasan 1990; Mittal 1995).

\section{(4) The difference between involvement and its antecedents}

Several authors mingle the antecedents of involvement and the involvement construct itself. For example, Laurent and Kapferer (1985) distinguish between four involvement facets: risk importance, sign value, pleasure value, and risk probability. According to Mittal (1995) and Mittal and Lee (1989), an object can be important either because it has sign value, pleasure value, and/or risk. They state that any one but not all of these facets need to be present for an object to be involving. Rodgers and Schneider (1993) also argue that involvement in the CIP scale is not adequately distinguished from its potential antecedents. The same holds for the PII of Zaichkowsky (1985) who sums the items of antecedents of involvement as well as involvement itself into one single involvement index. Consequently, she incorrectly assumes 
that all potential antecedents of involvement influence the level of involvement. Mittal (1995) criticizes this assumption as high levels of one antecedent can be sufficient for involvement to exist. For instance, a product can be involving because it is exciting, but it needs not be exciting to be involving. Therefore, it is not justified to sum the scores of the various antecedents (Day. Royne Stafford, and Camacho 1995: Mittal 1995: Mittal and Lee 1989).

In line with other authors (Beatty, Homer, and Kahle 1988; Day, Royne Stafford, and Camacho 1995: Mittal 1995), we define product category involvement as "a buyer's penceived importance of the product category based on the buyer's inherent needs, values, and interests". Since we are interested in the influence of product category involvement on buyer relationship proneness, we do not pay attention to the antecedents of product category involvement and only focus on the perceived importance of a product category. Moreover, we operationalize this definition based on importance items only (see chapter six).

\subsection{The Role of Seller Relationship Orientation ${ }^{3}$}

The discussion in the previous sections of this chapter could have created the impression that buyer relationship proneness is a necessary and sufficient condition for successful relationships. Buyer relationship proneness can be regarded as only one factor contributing to the success of relationships, but a seller's efforts that a buyer perceives might be another important factor. Consequently, we assume that relationship outcomes are determined by buyer relationship proneness as well as by seller relationship orientation (Dwyer, Schurr, and Oh 1987; Sheth and Parvatiyar 1995b). Seller relationship orientation, consisting of a seller's efforts, aims at building long-term customer relationships of mutual advantage by achieving future goals and by evaluating both current and future outcomes (Christopher, Payne, and Ballantyne 1994; Fischer and Bristor 1994; Ganesan 1994; Saxe and Weitz 1982).

While the term 'seller relationship orientation' is new to the field of relationship marketing, several related terms have already been used to describe sellers' efforts directed at buyers. A concept that has much in common with relationship orientation is the concept of 'relational selling behavior' often referred to in a customer-salesperson context (Beatty et al. 1996: Biong and Selnes 1995: Crosby, Evans, and Cowles 1990). Also the concept of relationship quality (Bejou, Wray, and Ingram 1996; Crosby, Evans, and Cowles 1990; Fournier 1998; Hennig-Thurau and Klee 1997; Leuthesser 1997; Moorman, Zaltman, and Desphandé 1992; Perrien, Filiatrault, and Ricard 1993; Wray, Palmer, and Bejou 1994) is related to the notion of seller relationship orientation. While some authors refer to relationship quality as a relationship outcome composed of the dimensions relationship satisfaction and trust, others consider it an input variable affecting relationship outcomes. Only the latter interpretation of relationship quality corresponds to our meaning of seller relationship orientation. Finally, the concepts of market orientation and customer orientation show resemblance to our construct of seller relationship orientation. Both Narver and Slater (1990) and Kohli and Jaworski (1993) consider market orientation as a set of explicit behaviors and activities directed at delivering superior value to the customer. According to Narver and Slater (1990), three behavioral characteristics determine whether or not a company is market oriented: customer

For a more complete discussion of seller relationship orientation, we refer to De Wulf (1999). 
orientation, competitor orientation, and inter-functional co-ordination. The customer orientation component of market orientation is most closely related to our definition of seller relationship orientation.

We define seller relationship orientation "a buyer's overall perception of the extent to which a seller actively makes efforts towards regular buyers that are intended to contribute to the customer value of these regular buyers". Below, we comment upon the major components of this definition.

\section{(1) A buyer's overall perception.}

We do not directly measure a seller's efforts by collecting information from the seller. Instead, seller relationship orientation is defined as a buyer's perception of the extent to which this seller actively makes efforts towards regular customers of this seller. Buyer expectations, generally integrated in quality and satisfaction measurement, are not included in our definition.

(2) Actively makes efforts.

Seller relationship orientation differs from relationship longevity. While relationship longevity is regarded as the mere existence of a continuous exchange between a buyer and a seller (Ganesan 1994; Lusch and Brown 1996), seller relationship orientation refers to the perceived efforts undertaken by a seller to add value to these exchanges. Bitner (1995) stated that relationship longevity can reduce consumer stress because it may teach the consumer what to expect. However, this type of 'convenience benefit' - for example resulting from the fact that a consumer gradually learns where products are located in a supermarket - is not regarded as an actively provided effort because the supermarket has no active role in its development. Measuring the effects of efforts that can be manipulated by the seller results in a higher managerial relevance.

(3) Intended to contribute to the customer value of these regular buyers.

The efforts that a seller directs at regular buyers are intended to increase the customer value of these regular buyers. In our study, the extent to which a seller's relationship orientation increases customer value is evaluated by measuring the strength of the relationship between seller relationship orientation and relationship outcomes. A consumer's costs of engaging in a relationship with a retailer are not included in our definition. These costs or 'negative contribution to customer value' are generally considered to be extremely low given the ease with which consumers can 'take or leave' relationships (Beatty et al. 1996; Dwyer, Schurr, and Oh 1987).

Summarizing, we can state that the buyer's proneness to engage in relationships as well as the efforts a seller makes will affect relationship outcomes.

\subsection{Summary and Conclusions}

The objective of this chapter was to provide a sound definition of the concept of buyer relationship proneness and to discuss its potential antecedents. We defined buyer relationship proneness as "a buyer's relatively stable and conscious tendency to engage in relationships with sellers of a 
particular product category" and positioned it as a buyer's individual characteristic. Recent literature recognizes that it would be beneficial to segment the market on the basis of buyer relationship proneness, as a misapplication of relationship marketing implies disappointed buyers and a waste of resources. Despite its recognized importance, research on buyers individual characteristics based on research investigating interpersonal relationships is largely lacking. Recently, several authors acknowledged the need to investigate what types of buyers will be relationship prone, Consequently, we want to investigate potential antecedents of buyer relationship proneness. We applied the List of Values to distinguish three individual characteristics potentially influencing buyer relationship proneness. First, sociability is related to a person's preference to be with other people. Second, social recognition refers to a buyer's need to be valued by others. Finally, shopping enjoyment implies a buyer's individual characteristic representing a tendency to find shopping more enjoyable than others. These three individual characteristics are expected to be related to a buyer's relationship proneness. In addition, we suggested that the concept of enduring product category involvement might be related to buyer relationship proneness, as involved people are already interested in the product category and hence a relationship can add value. Finally, we argue that relationship outcomes will be influenced by buyer relationship proneness as well as by seller relationship orientation. Seller relationship orientation is defined as "a buyer's overall perception of the extent to which a seller actively makes efforts towards regular buyers that are intended to contribute to customer value of these regular buyers".

The relationship outcomes potentially resulting from buyer relationship proneness and seller relationship orientation are discussed in chapter four. 


\section{Chapter Structure}

4.1 Introduction.

4.2 Attitudinal Relationship Outcomes. 57

4.2.I Relationship Satisfaction, Trust, and Relationship Commitment: Similar or Divergent Constructs?

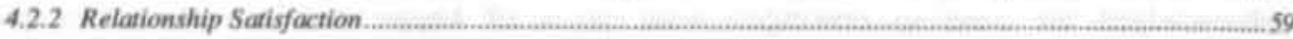

4.2.2.1 Definition of Relationship Satisfaction .

4.2.2.2 Importance of Relationship Satisfaction ...n......

4.2.2.3 Relationship Satisfaction as a Relationship Outcome ........................................................61

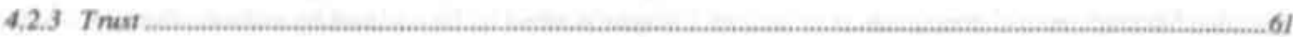

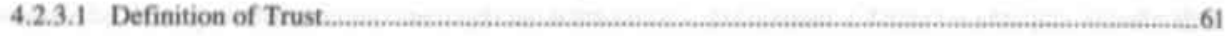

4.2.3.2 Importance of Trust.

4.2.3.3 Trust as a Relationship Outcome..num.....

4.2.4 Relationship Commitment.

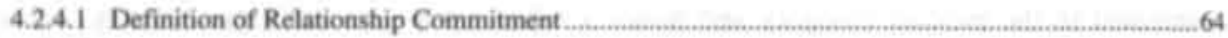

4.2.4.2 Importance of Relationship Commitment ......................................................................................66

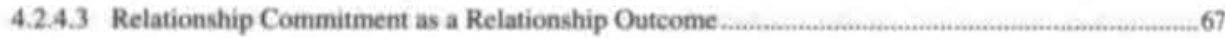

4.3 Behaviond Relationship Odtcomes...

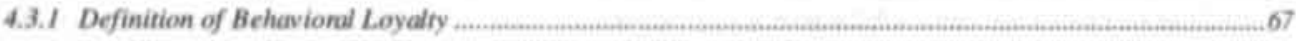

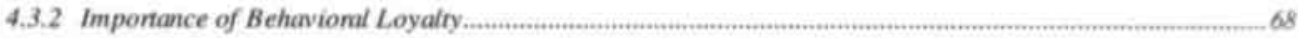

4.3.3 Behavional Loyalty as a Relationship Outcome ........................................................................................ 69

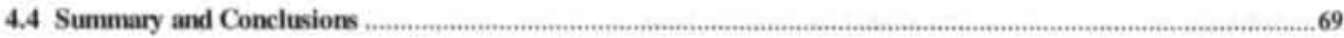




\section{Chapter 4 Relationship Outcomes}

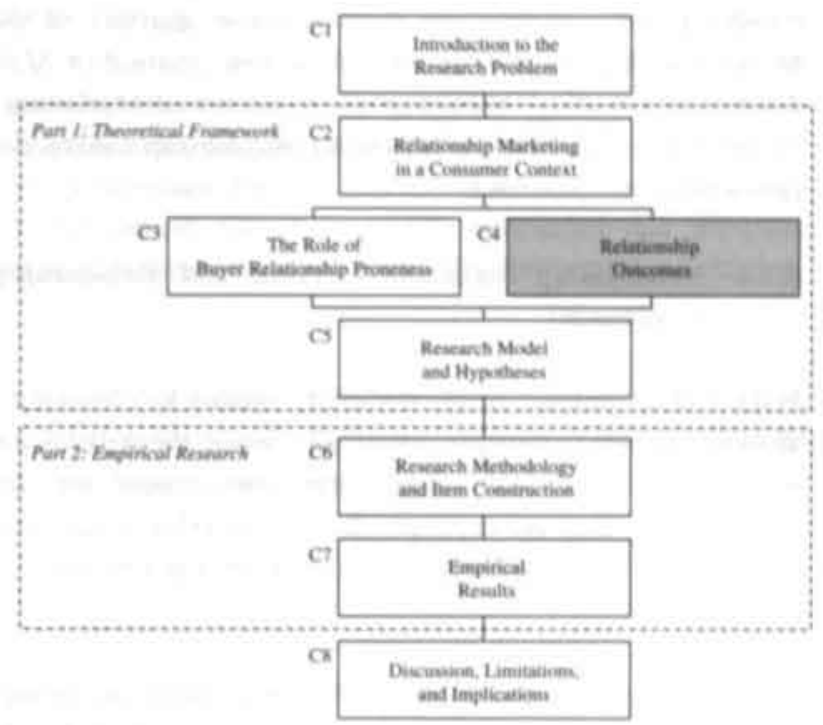

\subsection{Introduction}

As previously indicated in chapter two, social exchange theory and equity theory are primarily focused at relationship outcomes (Smith and Barclay 1997). Conceptual models that theorize both attitudinal and behavioral relationship outcomes have strong precedence in relationship marketing studies (Bloemer 1993; Bloemer and Kasper 1995; Crosby, Evans, and Cowles 1990; Day 1969; Dick and Basu 1994; Fournier and Yao 1997; Gruen 1995: Jacoby and Chestnut 1978; Jacoby and Kyner 1973; Hennig-Thurau and Klee 1997; Moorman, Desphandé, and Zaltman 1993; Moorman, Zaltman, and Desphandé 1992; Morgan and Hunt 1994; Oliver 1997; Rust and Zahorik 1993; Schiffman and Kanuk 1987; Uncles and Laurent 1997). As already indicated in section 2.6. frequently reported relationship outcomes are relationship satisfaction, trust, relationship commitment, and behavioral loyalty (Baker, Simpson, and Siguaw 1999; Crosby, Evans, and Cowles 1990; Doney and Cannon 1997; Geyskens et al. 1996; Gruen 1995; Morgan and Hunt 1994; Odekerken-Schröder et al. 2000; Selnes 1998). This chapter discusses these four types of relationship outcomes.

\subsection{Attitudinal Relationship Outcomes}

In 4.2.1, we summarize the discussion related to the degree of similarity of relationship satisfaction, trust, and relationship commitment and support the view that these constructs can be considered as truly distinct. In 4.2 .2 to 4.2 .4 , we successively discuss each of these attitudinal relationship outcomes. First, we support our choice of a definition for each construct. Second, we indicate the importance that is attributed to each of these outcomes in relationship marketing literature. Third, we provide support for considering them as outcomes of relationships. In appendix two, we provide 
an overview of the major empirical marketing studies related to relationship satisfaction, trust, and relationship commitment'. Articles covering the 1985-1998 period were collected on basis of computer bibliographic and issue-by-issue searches of the Intemational Joumal of Research in Marketing, Joumal of Consumer Research, Joumal of Marketing. Joumal of Marketing Research, Joumal of Retailing, Joumal of the Academy of Marketing Science, and Marketing Science. In all, 34 empirical papers were related to relationship satisfaction, 24 papers to trust, and 19 papers to relationship commitment.

\subsubsection{Relationship Satisfaction, Trust, and Relationship Commitment: Similar or Divergent Constructs?}

Fiske (1982) pointed at the difficulty related to obtaining sufficient discrimination between more abstract, general concepts, especially when these have attributes in common. Since relationship satisfaction, trust, and relationship commitment are all attitudinal outcomes of buyer-seller relationships, they are conceptually closely related and, consequently, it is conceivable that they all measure the same underlying idea (Dwyer and Oh 1987; Geyskens 1998; Rylander, Strutton, and Pelton 1997).

It is not surprising that there exists some discussion related to the similarity or divergence of the three constructs. Inaccurate conceptualizations have contributed to the confusion related to their distinction. For example, Sullivan and Peterson's (1982) conceptualization of trust also includes efforts in establishing a relationship, which is considered as a fundamental building block of relationship commitment. Moorman, Desphandé, and Zaltman (1993) noticed that trust has not been systematically distinguished from related factors. Difficulties in distinguishing between attitudinal types of relationship outcomes have been even further aggravated due to the conceptualization of relationship quality. Several authors consider relationship satisfaction and trust as dimensions or indicators of the higher order concept of relationship quality (Bejou, Wray, and Ingram 1996; Crosby, Evans, and Cowles 1990; Dwyer and Oh 1987; Hennig-Thurau and Klee 1997; Kumar, Scheer, and Steenkamp 1995a; Lagace, Dahlstrom, and Gassenheimer 1991; Leuthesser 1997; Scheer and Stern 1992; Wray, Palmer, and Bejou 1994). Hennig-Thurau and Klee (1997) and Leuthesser (1997) further argued to add relationship commitment as an additional dimension of relationship quality. Considering relationship satisfaction, trust, and relationship commitment as components of a higher order construct would imply that they basically measure the same concept. providing indications of their similarity.

However, there are various reasons to assume that relationship satisfaction, trust, and relationship commitment are distinct constructs. Scholl (1981) proposed that relationship commitment can act independently of relationship satisfaction and trust. Rusbult's (1980/1983) investment model based on social exchange theory distinguishes between relationship satisfaction, which is the level of affect experienced in the relationship, and relationship commitment, which is the intent to maintain

This overview is a further extension and adaptation of Geyskens' (1998) meta-analysis of channel relationships. While Geyskens (1998) provided an overview of relationship satisfaction and trust articles in a channel context. we include an overview of articles focusing on relationship satisfaction, trust, and relationship commitment in different contexts. 
and feel attached to a relationship (Sprecher 1988). In line with this, Porter et al. (1974) suggested that relationship satisfaction and commitment are related but distinguishable attitudes. Williams and Hazer (1986, p. 230) even stated that studies "failing to include both satisfaction and commitment should be viewed cautiously", suggesting it is important to incorporate both constructs and to understand the difference between relationship satisfaction and commitment. In his conceptual model. Gruen (1995) distinguished between relationship satisfaction, trust, and relationship commitment as psychological outcomes of relationships. Finally, in a recent meta-analysis including 97 empirical papers covering the 1970-1996 period, Geyskens (1998) concluded that adequate levels of discriminant validity were obtained between the constructs of relationship satisfaction. trust, and relationship commitment.

Consequently, there exists ample support for the distinction between relationship satisfaction, trust, and relationship commitment. In the following sections, each of these constructs is discussed on its definition, its importance, and its status as a relationship outcome.

\subsubsection{Relationship Satisfaction}

\subsubsection{Definition of Relationship Satisfaction}

Appendix two shows that there exists no consensus on the conceptualization and measurement of relationship satisfaction (Geyskens 1998). Most authors use Anderson and Narus' (1984, p. 66) definition of relationship satisfaction formulated as an "affective state resulting from the appraisal of all aspects of a firm's working relationship with another firm" (Anderson and Narus 1990; Gassenheimer and Ramsey 1994; Skinner, Gassenheimer, and Kelley 1992; Smith and Barclay 1997). However, several other definitions of relationship satisfaction are in circulation. In a channel context, Mohr, Fisher, and Nevin (1996, p. 105) defined relationship satisfaction as "the dealer's evaluation of the characteristics of the channel relationship". In a services context, Crosby, Evans, and Cowles (1990, p. 70) referred to "an emotional state that occurs in response to an evaluation of interaction experiences". Macintosh and Lockshin (1997, p. 489) defined relationship satisfaction in a retail environment as a "customer's overall evaluation of the store experience".

Based on Anderson and Narus (1984), we define relationship satisfaction as "a buyer's affective state resulting from his overall appraisal of his relationship with a seller". Below, the rationale behind this definition is briefly discussed.

\section{(1) Affective state}

Relationship satisfaction is generally conceptualized as an overall affective or emotional state (Andaleeb 1996; Anderson and Narus 1984/1990; Crosby, Evans, and Cowles 1990; Ganesan 1993/1994; Gassenheimer, Davis, and Dahlstrom 1998; Gassenheimer and Ramsey 1994; Price 1991; Scheer and Stern 1992; Schul, Little, and Pride 1985; Smith and Barclay 1997). Anderson and Narus (1990) underlined that relationship satisfaction is affective and that it can be contrasted with more objective or 'rational' relationship outcomes. Consequently, we explicitly integrate the affective nature of relationship satisfaction into our definition. 


\section{(2) Overall appraisal of his relationship}

Relationship satisfaction is viewed as 'cumulative satisfaction' as opposed to 'transactionspecific satisfaction'. While transaction-specific satisfaction is an individual evaluation of a particular experience, cumulative satisfaction refers to a more abstract construct that describes a buyer's overall evaluation of his experience to date (Anderson, Fornell, and Rust 1997: Bolton 1998; Dwyer and Oh 1987: Frazier, Gill, and Kale 1989: Gaski 1986; Gaski and Nevin 1985; Johnson, Anderson, and Fornell 1995; Johnson et al. 1993; Kale 1986; Kumar, Stern and Achrol 1992; Macintosh and Lockshin 1997; Oliver 1997: Ping 1993/1994: Scheer and Stern 1992: Skinner, Gassenheimer, and Kelley 1992). Ping (1993, p. 346) stressed the cumulative nature of satisfaction in buyer-seller relationships by stating that a buyer "may be dissatisfied with an individual event, yet still satisfied with the supplier relationship overall". According to several authors (Gwinner, Gremler, and Bitner 1998; Storbacka, Strandvik, and Grönroos 1994; Young and Denize 1995) overall satisfaction is a function of satisfaction with the contact person(s), core service, and organization. In this study, we focus on an overall appraisal of relationships because consumers are expected to accept incidental lower levels of transaction-specific satisfaction without breaking the relationship with this seller.

\section{(3) No measurement of expectations}

It is a commonly accepted practice to collect both perceptions and expectations data in order to measure the concept of satisfaction. Researchers generally agree that expectations serve as reference points in customers' assessment of performance (Bolton and Drew 1991; Cronin and Taylor 1992/1994; Parasuraman, Zeithaml, and Berry 1988/1991/1994a; Park and Choi 1998: Spreng and Mackoy 1996). However, several measurement concerns have been raised about collecting information on expectations ${ }^{2}$ (Brown, Churchill, and Peter 1993: Carman 1990; Cronin and Taylor 1992/1994; Parasuraman, Zeithaml, and Berry 1993/1994a/1994b; Peter. Churchill, and Brown 1993). Moreover, we assume that it is more difficult for buyers to express their expectations related to more abstract concepts such as a relationship. For example, while it is relatively easy to declare expectations related to the service level in a restaurant, it is generally more difficult to formulate expectations about the relationship with this restaurant. Following the above mentioned concerns, our definition of relationship satisfaction is not based upon the perceptions-expectations disconfirmation paradigm and only measures buyer perceptions related to their relationship with a seller.

\subsubsection{Imponance of Relationship Satisfaction}

For more than three decades, the construct of relationship satisfaction has been researched. underlining its importance in marketing research (Crosby. Evans, and Cowles 1990; Dwyer and Oh 1987; Frazier 1983; Geyskens 1998; Hunt and Nevin 1974; Rosenberg and Stern 1971: Selnes 1998:

Peter. Churchill and Brown (1993) listed three psychometric problems that are related to using difference scores of perceptions and expectations: (1) difference scores are characterized by lower reliabilities, (2) they typically do not demonstrate discriminant validity, and (3) they often lead to unequality of variances between respondents. Using direct measures of perceptions-expectations disconfirmation has been proposed as an alternative to calculating difference scores (Brown. Churchill and Peter 1993; Parasuraman. Zeithaml and Berry 1993/1994a; Spreng and Mackoy 1996). However, these measures are more difficult to interpret by respondents and, as a result. may decrease the validity of the information collected. 
Stern and Reve 1980; Tax, Brown, and Chandrashekaran 1998). Geyskens' (1998) meta-analysis of relationship satisfaction indicated that relationship satisfaction is the most popular construct in empirical studies on channel relationships. Recently, the importance of relationship satisfaction is increasingly recognized in consumer relationship studies (Bolton 1998; Crosby, Evans, and Cowles 1990; Crosby and Stephens 1987; Macintosh and Lockshin 1997; Tax, Brown, and Chandrashekaran 1998).

\subsubsection{Relationship Satisfaction as a Relationship Outcome}

Satisfaction with the relationship is generally regarded as an outcome of buyer-seller relationships (Anderson and Narus 1984/1990; Dwyer and Oh 1987; Gaski 1986; Gaski and Nevin 1985; Johnson et al. 1993; Keith, Jackson, and Crosby 1990; Lewis and Lambert 1991; Mohr, Fisher, and Nevin 1996; Smith and Barclay 1997; Stern and Reve 1980). Anderson and Narus (1990) considered relationship satisfaction as a close proxy for concepts such as perceived relationship effectiveness. Relationship satisfaction is considered to be an important relationship outcome because it has been found to be correlated with more tangible outcome measures such as cooperation. conflict. relationship continuity, exit from the relationship, and company profits (Anderson and Narus 1984/1990; Bolton 1998; Dwyer and Oh 1987; Ganesan 1993/1994; Gassenheimer and Ramsey 1994; Lewis and Lambert 1991; Ping 1993; Scheer and Stern 1992; Selnes 1998; Skinner. Gassenheimer, and Kelley 1992; Smith and Barclay 1997; Stern and Reve 1980). Consequently, relationship satisfaction is regarded as a relationship outcome in this study.

\subsubsection{Trust}

\subsubsection{Definition of Trust}

In line with other authors (Macintosh and Lockshin 1997; Morgan and Hunt 1994: Tax, Brown, and Chandrashekaran 1998), we define trust as "a buyer's confident belief in a seller's honesty towards the buyer" Below, we elaborate upon the motivations behind this definition.

\section{(1) A buyer's confident belief}

Several scholars consider perceived trustworthiness and trusting behaviors as two distinct, but related aspects of trust (Andaleeb 1996; Smith and Barclay 1997). While trustworthiness refers to a belief (Andaleeb 1995; Anderson and Narus 1990; Anderson and Weitz 1989; Geyskens et al. 1996; Kumar, Scheer, and Steenkamp 1995a/1995b; Scheer and Stern 1992; Schurr and Ozanne 1985; Siguaw, Simpson, and Baker 1998) or confidence (Crosby, Evans, and Cowles 1990; Macintosh and Lockshin 1997: Morgan and Hunt 1994; Tax, Brown, and Chandrashekaran 1998), trusting behaviors are related to the (willingness of) engagement in risk-taking behavior reflecting a reliance on a partner (Andaleeb 1996; Dahlstrom and Nygaard 1995: Ganesan 1994; Giffin 1967; Moorman, Desphandé, and Zaltman 1993; Moorman, Zaltman, and Desphandé 1992; Schlenker, Helm, and Tedeschi 1973). Both the belief and behavioral reliance aspects of trust indicate the critical roles of uncertainty and vulnerability to trust in buyer-seller relationships (Achrol 1997: Andaleeb 1995: Crosby, Evans, and Cowles 
1990; Doney and Cannon 1997: Moorman, Desphandé, and Zaltman 1993; Moorman, Zaltman, and Desphandé 1992; Rempel. Holmes, and Zanna 1985).

Some scholars merge both aspects into one definition of trust (Anderson, Lodish, and Weitz 1987: Ganesan 1994; Moorman, Desphandé, and Zaltman 1993; Moorman. Zaltman, and Desphandé 1992). For example, Moorman, Zaltman, and Desphandé (1992, p. 82) defined trust as "a willingness to rely on an exchange partner in whom one has confidence". They claim that both trustworthiness and trusting behavior must be present for trust to exist. According to them, buyers who believe that their seller is trustworthy, but do not rely on this seller, show only limited trust (Moorman, Desphandé, and Zaltman 1993).

Other scholars claim that trustworthiness is a necessary and sufficient condition for trust to exist (Andaleeb 1995: Anderson and Narus 1990; Anderson and Weitz 1989; Geyskens et al. 1996; Morgan and Hunt 1994). For example, Morgan and Hunt (1994) defined trust as trustworthiness only, as they suggest that trusting behaviors automatically result from trustworthiness. This group of authors suggests not to include trustworthiness and trusting behavior into one unidimensional construct of trust. In line with this, we argue that incorporating trustworthiness and trusting behavior into one definition leads to unnecessary conceptual confusion and empirical validation difficulties. According to us, such a conceptualization of trust troubles the distinction between trust as an attitude and the potential behavioral outcomes of trust. The above mentioned discussion suggests that, by limiting the conceptualization of trust to trustworthiness, a more clear view on the notion of trust will result. Consequently, we define trust as a belief in a seller (trustworthiness) and not as a willingness to rely on this seller.

(2) Seller's honesty towards the buyer

Trust is considered to exist if one party believes the other party to be honest or benevolent (Andaleeb 1995: Doney and Cannon 1997; Ganesan 1994: Kumar, Scheer, and Steenkamp 1995b: Larzelere and Huston 1980: Wetzels 1998). Trust in a partner's honesty is the belief that the partner stands by its word, fulfills promised role obligations, and is sincere (Anderson and Narus 1990; Doney and Cannon 1997; Dwyer and Oh 1987; Gundlach and Murphy 1993; Kumar, Scheer, and Steenkamp 1995a/1995b; Larzelere and Huston 1980; Scheer and Stern 1992). Trust in a partner's benevolence is the belief that the partner is interested in the other partner's welfare, is willing to accept short-term mistakes, and will not undertake unexpected actions that can negatively affect the other partner (Anderson, Lodish, and Weitz 1987: Anderson and Narus 1990; Crosby, Evans, and Cowles 1990; Doney and Cannon 1997; Kumar. Scheer, and Steenkamp 1995a/1995b; Larzelere and Huston 1980).

While several scholars recognize the conceptual difference between honesty and benevolence. discriminant validity between both constructs often seems difficult to achieve (Ganesan 1994: Kumar, Scheer, and Steenkamp 1995b). As stated by Larzelere and Huston (1980, p. 596), "while benevolence and honesty are conceptually distinct, they may turn out to be so intertwined ... that they are operationally inseparable". Except for some notable exceptions distinguishing between separate honesty and benevolence constructs (Ganesan 1994; Schurr and Ozanne 1985). the majority of studies tends to include only one (Anderson, Lodish, and Weitz 1987; Morgan 
and Hunt 1994; Scheer and Stern 1992) or a mixture of both aspects of trust (Kumar. Scheer, and Steenkamp 1995a/1995b; Siguaw, Simpson, and Baker 1998) in a single, unidimensional trust measure. In our opinion, while minor conceptual differences between honesty and benevolence might exist, a distinction between both does not add to our understanding of the outcomes of trust. Previous studies have demonstrated the difficulties arising when trying to achieve discriminant validity. Moreover, the notion of benevolence is primarily relevant in contexts that are characterized by moderate to high levels of uncertainty. In the consumer markets we investigate, uncertainty is generally low given the low need for post-purchase evaluation, the low risk associated to consuming a product, and the equal information disposal between consumers and sellers (Berry 1995; Bitner 1995). As a result, we measure honesty instead of benevolence in order to measure trust.

\subsubsection{Importance of Trust}

Trust has received a lot of attention in anthropology, economics, organizational theory, social psychology, sociology, and marketing (Dahlstrom and Nygaard 1995; Doney and Cannon 1997). Since the publication of Dwyer. Schurr. and Oh's article (1987), stressing the need for more attention to the trust concept, researchers in marketing have increasingly incorporated trust in empirical models of marketing relationships. Several scholars consider trust as one of the most critical constructs in relationship marketing theory (Anderson, Lodish, and Weitz 1987; Anderson and Narus 1990; Anderson and Weitz 1989; Crosby, Evans, and Cowles 1990; Doney and Cannon 1997: Dwyer and Oh 1987; Dwyer, Schurr, and Oh 1987; Gundlach and Murphy 1993: Moorman, Desphandé, and Zaltman 1993; Morgan and Hunt 1994; Schurr and Ozanne 1985; Smith and Barclay 1997). Its recognized importance is partly rooted in the belief that trust leads to the desirable attitude of commitment (Andaleeb 1996; Anderson and Weitz 1989; Ganesan 1994; Geyskens et al. 1996; Macintosh and Lockshin 1997; Moorman, Zaltman, and Deshpandé 1992; Morgan and Hunt 1994; Siguaw, Simpson, and Baker 1998).

Previous empirical research on trust was primarily conducted in channels of distribution (Andaleeb 1995/1996: Anderson, Lodish, and Weitz 1987: Anderson and Narus 1990; Anderson and Weitz 1989; Dahlstrom and Nygaard 1995; Dwyer and Oh 1987; Ganesan 1994; Geyskens et al. 1996; Kumar, Scheer, and Steenkamp 1995a/1995b; Morgan and Hunt 1994; Scheer and Stern 1992; Schurr and Ozanne 1985; Siguaw, Simpson, and Baker 1998) and industrial relationships (Doney and Cannon 1997; Moorman, Desphandé, and Zaltman 1993; Moorman, Zaltman, and Desphandé 1992; Smith and Barclay 1997). Apart from some notable exceptions (Crosby, Evans, and Cowles 1990; Macintosh and Lockshin 1997; Tax, Brown, and Chandrashekaran 1998), the role of trust has not been investigated in consumer relationships yet. The nearly exclusive attention for trust in business-to-business environments can be explained by the predominantly uncertain and vulnerable situations in which business-to-business parties often find themselves. In such situations, trust is especially deemed to be relevant. As indicated by Moorman, Desphandé, and Zaltman (1993, p.92). "if a trustor has complete knowledge about an exchange partner's actions, is able to control the exchange partner, or has not transferred critical sources to an exchange partner, trust is not necessary in the relationship". While certain consumer situations may involve less risk, trust is still deemed to be important in such situations as consumers will only be committed to a relationship 
with a seller when they have trust in this seller. While it is generally recognized that relationship commitment can exist without trust in constraint-based relationships (Bendapudi and Berry 1997), trust is considered as a necessary condition for relationship commitment to occur in dedicationbased relationships. This is also indicated by Beatty et al. (1996) who emphasized the importance of trust in retail situations and Macintosh and Lockshin (1997) who recently found empirical evidence for the importance of trust in such contexts.

\subsubsection{Tnust as a Relationship Outcome}

Several authors consider trust as a relationship outcome. In interpersonal relationships, trust is considered to be one of the most desirable outcomes of any close relationship (Afifi and Metts 1998; Rempel, Holmes, and Zanna 1985). Many scholars claim that the development of trust is also an important outcome measure of dyadic buyer-seller relationships (Dahlstrom and Nygaard 1995; Dwyer, Schurr, and Oh 1987; Gundlach. Achrol, and Mentzer 1995; Mohr and Nevin 1990; Morgan and Hunt 1994; Odekerken-Schröder et al. 2000; Rylander. Strutton, and Pelton 1997; Wray. Palmer, and Bejou 1994).

The reason why scholars regard trust as an outcome of relationships is underlined by Moorman, Desphandé, and Zaltman (1993, p. 93). They indicate that trust is "more a function of interpersonal factors than of individual factors". As a result, trust is considered to be a product of the relationship between two parties as opposed to an individual characteristic of either party (Moorman, Desphandé, and Zaltman 1993). It evolves out of past experience related to prior exchanges, and, consequently, develops as the relationship matures (Rempel, Holmes, and Zanna 1985). Consequently, we consider trust as an outcome of relationships.

\subsubsection{Relationship Commitment}

\subsubsection{Definition of Relationship Commitment}

Relationship commitment is generally referred to as an enduring desire to maintain a relationship (Anderson and Weitz 1989; Dwyer, Schurr, and Oh 1987; Geyskens et al. 1996: Kumar, Scheer, and Steenkamp 1995a; Mohr, Fisher, and Nevin 1996; Moorman, Zaltman, and Desphandé 1992; Morgan and Hunt 1994; Scheer and Stern 1992; Young and Denize 1995). The concept of relationship commitment is similar to the concept of long-term orientation that comprises the desire and utility of a buyer to have a long-term relationship with a seller (Anderson and Weitz 1992; Dwyer, Schurr, and Oh 1987; Ganesan 1993/1994; Gruen 1995; Hennig-Thurau and Klee 1997).

Commitment is a complex phenomenon and elusive construct that is poorly understood and subject to a variety of forces (Kumar. Scheer, and Steenkamp 1995b; Rylander. Strutton, and Pelton 1997). While the essence of commitment is stability, solidarity, cohesion, and sacrifice (Anderson and Weitz 1992; Dwyer, Schurr, and Oh 1987; Geyskens 1998; Gundlach and Murphy 1993). significantly varying conceptualizations of relationship commitment are found in literature (Anderson and Weitz 1992; Hennig-Thurau and Klee 1997). In line with Morgan and Hunt (1994), we define relationship commitment as "a buyer's enduring desire to continue a relationship with a 
seller accompanied by his willingness to make efforts at maintaining it". Below, we elaborate on the motivations underlying this choice.

\section{(1) Enduring}

Relationship commitment is believed to make sense only over the long term. This implies that the desire to continue a relationship and the willingness to make efforts directed at sustaining this relationship must reveal consistency over time (Gundlach. Achrol, and Mentzer 1995; Macintosh and Lockshin 1997; Moorman, Zaltman, and Desphandé 1992; Tax, Brown. and Chandrashekaran 1998).

(2) Desire to continue a relationship with a seller accompanied by his willingness to make efforts at maintaining it

Most scholars consider relationship commitment as comprising one or more of the following dimensions: (1) expectation of continuity (Anderson, Håkansson, and Johanson 1994: Crosby, Evans, and Cowles 1990; Doney and Cannon 1997), (2) desire of continuity (Andaleeb 1996: Anderson and Weitz 1989; Geyskens et al. 1996; Gundlach. Achrol, and Mentzer 1995; Kumar, Scheer, and Steenkamp 1995a/1995b; Macintosh and Lockshin 1997; Mohr, Fisher, and Nevin 1996; Moorman, Zaltman, and Desphandé 1992; Siguaw, Simpson, and Baker 1998; Tax. Brown, and Chandrashekaran 1998), and (3) willingness to invest (Anderson and Weitz 1989: Gundlach, Achrol, and Mentzer 1995; Morgan and Hunt 1994; Olsen and Granzin 1992; Siguaw, Simpson, and Baker 1998: Van Lange et al. 1997a/1997b). Anderson and Weitz (1992. p. 19) merged these three dimensions into their definition of relationship commitment formulated as "a desire to develop a stable relationship, a willingness to make short-term sacrifices to maintain the relationship, and a confidence in the stability of the relationship".

First, we support the notion that relationship commitment defined as 'expectation of continuity' does not capture the true meaning of commitment. In contrast to commitment, expectation of continuity can also be affected by a buyer's perception of a seller's intentions to continue the relationship (Anderson and Weitz 1989; Doney and Cannon 1997: Dwyer, Schurr, and Oh 1987: Kumar, Scheer, and Steenkamp 1995a/1995b; Lund 1985). Low expectations of future exchange would point to current relationship problems, whereas high expectations of future exchange represent a favorable evaluation of the current relationship (Crosby, Evans, and Cowles 1990). As we are only interested in measuring relationship attitudes of the buyer, we do not include expectations of continuity into our definition of relationship commitment. Second, we point to the currently unresolved question whether relationship commitment is best captured as a unidimensional construct or as some combination of 'desire for continuity' and 'willingness to invest' (Rylander, Strutton, and Pelton 1997). In our opinion, the desire for continuity is a necessary, but not sufficient condition for relationship commitment as it might be based on habitual cues only. Willingness to invest refers to a buyer's desire to do more than just remain in the relationship by making capital and/or effort investments (Dwyer, Schurr, and Oh 1987; Kumar, Scheer, and Steenkamp 1995b). We postulate that the desire to continue a relationship should be accompanied by a willingness to make efforts at maintaining the relationship. Therefore, in line with other authors, our definition of relationship commitment implies that both components have to be present as a condition for commitment to occur (Anderson and 
Weitz 1992; Gundlach, Achrol, and Mentzer 1995; Morgan and Hunt 1994; Siguaw, Simpson, and Baker 1998).

\section{(3) The construct of relationship commitment versus its underlying drivers}

Some scholars have noted that different motivations can underlie the notion of relationship commitment as it can result from either dedication (affective commitment) or constraints (calculative commitment) to the relationship (Geyskens 1998; Geyskens et al. 1996: Mathieu and Zajac 1990: Strandvik and Liljander 1994: Wetzels 1998: Young and Denize 1995). Kumar, Scheer, and Steenkamp (1995b, p. 351) referred to affective commitment as "the desire to continue a relationship because of positive affect toward the partner". A second, more instrumental type of commitment is referred to as calculative commitment. While calculative commitment refers to buyers' commitment to a seller because they need to, buyers who are affectively committed are motivated to continue their relationship with the seller because they want to (Geyskens 1998: Geyskens et al. 1996: Lund 1985: Mohr. Fisher, and Nevin 1996; Stanley and Markman 1992; Venetis 1997). In literature, the difference between affective and calculative commitment is described by various terms such as dedication-based versus constraint-based relationship maintenance (Bendapudi and Berry 1997), social versus economic commitment (Young and Denize 1995), personal dedication versus constraint commitment (Stanley and Markman 1992), and attitudinal and instrumental commitment (Achrol 1997; Gundlach, Achrol, and Mentzer 1995).

Geyskens (1998, p. 50) stated that "the use of global commitment measures - which measure intention to continue a relationship without consideration of the underlying motivation - could confound or mask different, and possibly even opposite effects on affective commitment versus calculative commitment". While we fully agree with the relevance of distinguishing between affective and calculative drivers of commitment, we argue that creating two separate commitment constructs tangles up the difference between the commitment construct itself and the underlying reasons for the emergence of commitment. In our opinion, there exists only one commitment construct that can be driven by affective and/or calculative drivers. Any of these two drivers, but not necessarily both, need to be present in order for a buyer to be committed. Therefore, our definition of relationship commitment does not explicitly refer to its underlying motivations. This view is in line with $\mathrm{O}^{\prime}$ Reilly and Chatman (1986), who made a distinction between the motives or bases of commitment, but not between different types of commitment.

\subsubsection{Importance of Relationship Commitment}

Since the $1960 \mathrm{~s}$, commitment has been a frequently studied variable in organizational contexts (Becker and Billings 1993; Hunt, Wood, and Chonko 1989; Kelley and Davis 1994; Mathieu and Zajac 1990; Porter et al. 1974; Rylander, Strutton, and Pelton 1997). Today, commitment is often integrated as a key variable of interest in relationship marketing studies (Doney and Cannon 1997; Geyskens 1998; Macintosh and Lockshin 1997; Mohr, Fisher, and Nevin 1996; Ping 1997; Siguaw, Simpson, and Baker 1998; Tax, Brown, and Chandrashekaran 1998). 
Several scholars consider commitment as an essential ingredient of successful relationships (Andaleeb 1996; Dwyer, Schurr, and Oh 1987; Geyskens et al. 1996; Lund 1985: Macintosh and Lockshin 1997; Morgan and Hunt 1994; Scheer and Stern 1992). Gundlach. Achrol, and Mentzer (1995, p. 78) claimed that commitment "may well become a focal point of explanation in marketing, as the discipline moves further away from the transactional view of exchange and embraces the relational view". Relationship commitment is considered important because it is hypothesized to lead to cooperation, to reduce the temptation of attractive short-term alternatives, and to enhance profitability (Andaleeb 1996; Anderson and Weitz 1992; Morgan and Hunt 1994).

\subsubsection{Relationship Commitment as a Relationship Outcome}

Commitment to a buyer-seller relationship is generally regarded as an important relationship outcome (Andaleeb 1996; Anderson and Weitz 1989; Crosby, Evans, and Cowles 1990; Ganesan 1993/1994; Geyskens et al. 1996; Macintosh and Lockshin 1997: Mohr. Fisher, and Nevin 1996; Moorman, Zaltman, and Desphandé 1992; Morgan and Hunt 1994; Smith and Barclay 1997; Young and Denize 1995). According to Dwyer, Schurr, and Oh (1987), relationship commitment represents the highest stage in relationship bonding. In line with this, Mohr and Nevin (1990) stated that commitment is a highly desirable 'qualitative outcome'. Morgan and Hunt (1994, p. 22) stressed that the level of relationship commitment "distinguishes productive, effective relational exchanges from those that are unproductive and ineffective - that is whatever produces relationship marketing successes instead of failures". Consequently, relationship commitment is regarded as a relationship outcome in this study.

\subsection{Behavioral Relationship Outcomes}

In addition to the described attitudinal relationship outcomes, 4.3.1 defines behavioral loyalty and distinguishes between various indicators of behavioral loyalty, 4.3 .2 discusses the importance of behavioral loyalty, and 4.3.3 supports the status of behavioral loyalty as a relationship outcome.

\subsubsection{Definition of Behavioral Loyalty}

Regarding the measurement of behavioral loyalty, two main approaches can be distinguished: an aggregate level approach focusing on stochastic modeling of purchase behavior (Agrawal 1996; Bayus 1992; Ehrenberg. Goodhardt, and Barwise 1990; Fader and Lattin 1993; Fader and Schmittlein 1993: Fournier and Yao 1997; Kahn, Kalwani, and Morrison 1986; Krishnamurthi and Raj 1991; Yim and Kannan 1999) and an individual level approach focusing on buyer-specific indices of behavioral loyalty (Dunn and Wrigley 1984; Kahn, Kalwani, and Morrison 1986; Raj 1982). Since this study focuses at individual buyers, we use the second approach.

Behavioral loyalty patterns of an individual have been measured on basis of numerous and varied empirical indices (Jacoby and Kyner 1973; Reynolds, Darden, and Martin 1974-1975). Jacoby and Chestnut (1978) reported on 33 behavioral loyalty measures used in previous studies. Due to this wide variety of measurement attempts, some state that loyalty research has lead to more controversy than to a body of accepted findings and generalizations (Jacoby and Chestnut 1978; Kumar, Ghosh. 
and Tellis 1992). In most studies, behavioral loyalty has been measured in one of four ways (Denison and Knox 1993; Enis and Paul 1970): (1) patronage ratios based upon the number of purchases made (Kelley 1967; Raj 1982; Tate 1961), (2) switching ratios based upon the number of successive purchases made (Farley 1968; Fournier and Yao 1997; Kahn, Kalwani, and Morrison 1986; Popkowski Leszczyc and Gönül 1996; Rao 1969), (3) budget ratios based upon the proportion of total expenditure within a product class (Cunningham 1961/1966; Dunn and Wrigley 1984; Fournier and Yao 1997: Goldman 1977/1978; Gruen 1995; Krishnamurthi and Raj 1991), and (4) multidimensional, composite measures based upon a combination of the previously mentioned ratios (Carman 1970; Enis and Paul 1970: Goldman 1977/1978: Jacoby and Chestnut 1978: Popkowski Leszczyc and Timmermans 1997). The first three ratios are generally referred to as simple, unidimensional measures of behavioral loyalty. Intentions to repurchase are not listed here, as we do not consider them to represent actual behavior. Various authors considered them to be only tentative measures of behavioral loyalty (Dick and Basu 1994; Oliva, Oliver, and MacMillan 1992: Sirohi, McLaughlin, and Wittink 1998).

In this study, behavioral loyalty is defined as "a buyer's purchasing behavior during his relationship with a seller". We operationalize behavioral loyalty as a unidimensional composite, budget ratio. First, we use a composite measure in order to be able to assess its reliability. This is in line with Sirohi. McLaughlin, and Wittink (1998) who measured store loyalty as a unidimensional construct consisting of underlying indicators. Second, we define behavioral loyalty as a unidimensional ratio because it has the advantage of relating to common experience and gives a better feel for behavior as opposed to pursuing the more mathematical approach reflected in multidimensional composite measures (Charlton 1973). Moreover, Denison and Knox (1993) indicated that most analysts consider budget ratios as the most appealing single measure of behavioral loyalty. However, they claim that budget ratios may only be evaluated in the context of clearly delineated product categories. They give the example that "were a consumer to shop regularly for everyday clothes in store A but, occasionally, buy expensive designer ware elsewhere, an analysis by expenditure alone would not clearly establish underlying loyalty to store A". Consequently, the behavioral loyalty indicators we use, are supposed to measure budget ratios within clearly defined product categories. In this study, these indicators are: (1) a buyer's proportion of expenditures made in one store within his total expenditures in a product class, (2) the relative number of times a buyer selects a store to buy from, and (3) a buyer's purchase frequency at one store compared to his purchase frequency at other stores where he is a regular customer.

\subsubsection{Importance of Behavional Loyalty}

Early studies on loyalty primarily focused at behavioral aspects of loyalty (Bellenger, Robertson, and Greenberg 1977; Carman 1970; Dunn and Wrigley 1984; Goldman 1977-1978; Miller and Granzin 1979: Newman and Werbel 1973). Since the 1960s, numerous academic and business models have examined the relationship between behavioral loyalty and market performance (Cunningham 1961/1966; Farley 1968; Kelley 1967; Tate 1961). While empirical evidence on this relationship is still scarce, the relationship between behavioral loyalty and bottom-line profits is considered to be much straighter than the relationship between for example satisfaction and bottomline profits (Babin and Darden 1996; Grant and Schlesinger 1995; Pearson 1994: Reichheld 1993; 
Reichheld and Sasser 1990; Storbacka, Strandvik, and Grönroos 1994; Stum and Thiry 1991). As generating profits is one of the most important objectives of a company, behavioral loyalty is considered to be an important outcome of relationships.

\subsubsection{Behavional Loyalty as a Relationship Outcome}

It is generally accepted that behavior acts as an end variable in consumer behavior models (Engel, Blackwell, and Miniard 1995; Kardes 1999; Mowen 1993; Peter and Olsen 1996). Sharp and Sharp (1997) explicitly stated that the effectiveness of relationship marketing efforts should be evaluated in terms of the behavioral changes they bring about. As a result, it is not surprising that behavioral loyalty is generally accepted as the ultimate relationship outcome (Hennig-Thurau and Klee 1997: Pine, Peppers, and Rogers 1995; Reichheld 1993; Reichheld and Sasser 1990).

\subsection{Summary and Conclusions}

The objective of this chapter was to discuss four frequently reported relationship outcomes: relationship satisfaction, trust, relationship commitment, and behavioral loyalty. The first three constructs can be regarded as attitudinal relationship outcomes, whereas the latter construct of behavioral loyalty can be viewed as a behavioral outcome of relationships.

Since relationship satisfaction, trust, and relationship commitment are apparently conceptually related, it is not surprising that there exists some discussion as to the similarity or divergence of the three constructs. A recent meta-analysis related to these three attitudinal outcomes provides sufficient support for making an explicit distinction between them. Existing definitions of each relationship outcome were used as a knowledge base and, if necessary, adapted to our understanding of the constructs and to the specificity of consumer environments. Moreover, the importance and the status as a relationship outcome of each of the constructs were emphasized.

In addition to attitudinal outcomes, we discussed the importance of behavioral loyalty. Two main approaches can be distinguished regarding the measurement of behavioral loyalty: an aggregate level approach focusing on stochastic modeling of purchase behavior and an individual level approach focusing on single indices of behavioral outcomes. Since the focus of this study is at the level of individual buyers, we opt for the latter approach and define behavioral loyalty at a unidimensional, composite level based on the budget ratio. 


\section{Chapter Structure}

5.1 Introduction

5.2 Main Effects and Related Hypotheses

5.2.I Antecedents of Buyer Relationship Proneness......... 72

5.2.2 Buyer Relationship Proneness and Seller Relationship Orientation..................................................... 73

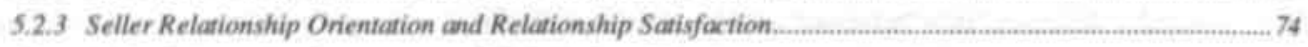

5.2.4 Seller Relationship Orientation and Relationship Commitment.

5.2.5 Buyer Relationship Proneness and Relationship Satisfaction .......................................................... 75

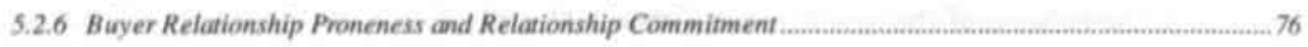

5.2.7 Relationship Satisfaction and Trust............. 76

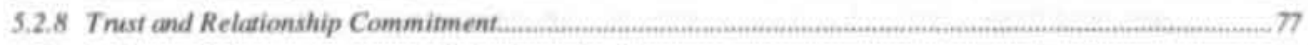

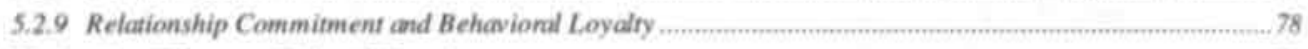

5.3 Moderating Effects and Related Hypotheses 


\section{Chapter 5 Research Model and Hypotheses ${ }^{1}$}

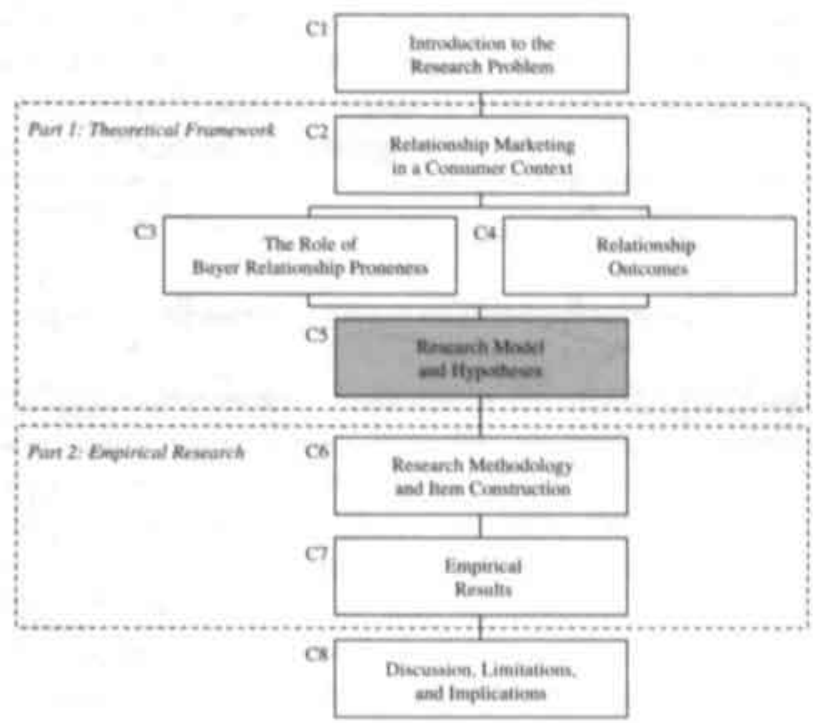

\section{$5.1 \quad$ Introduction}

This chapter discusses the research model and related hypotheses based on the research questions formulated in chapter one. In section 5.2, we present the main effects and support the hypotheses related to these main effects. Section 5.3 introduces the moderating effects in our research model and discusses the hypotheses related to these moderating effects.

\subsection{Main Effects and Related Hypotheses}

In figure 5-1, the research model visualizes the role of buyer relationship proneness and seller relationship orientation in affecting relationship outcomes. Relationship outcomes are operationalized by the four constructs discussed in chapter four: relationship satisfaction, trust, relationship commitment, and behavioral loyalty. Moreover, in order to gain insights into the factors influencing buyer relationship proneness, we distinguish between four different antecedents: sociability, social recognition, shopping enjoyment, and product category involvement. Finally, we expect seller relationship orientation to affect relationship outcomes.

Chapters five and six are inspired by the ideas reflected in previous studies of De Wulf and Odekerken-Schröder (1998/1999). 


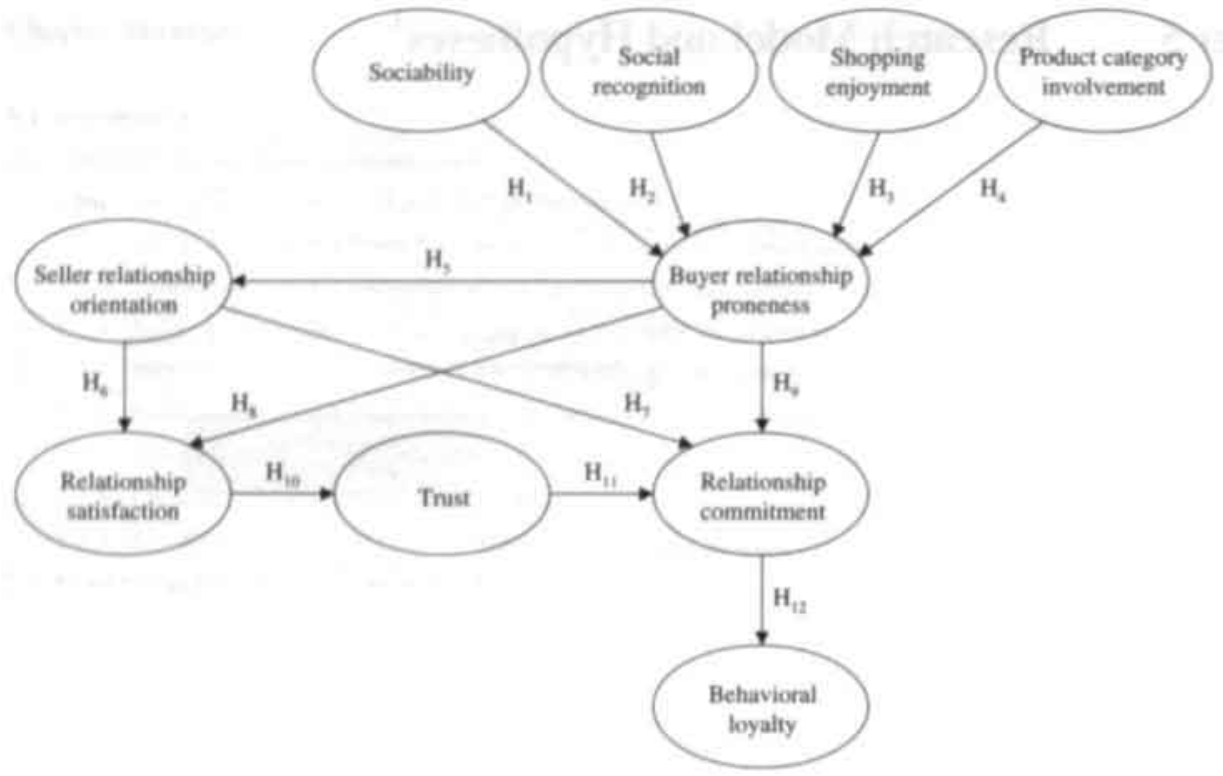

Figure 5-1: Main Effects in the Research Model

\subsubsection{Antecedents of Buyer Relationship Proneness}

We defined the construct of buyer relationship proneness as "a buyer's relatively stable and conscious tendency to engage in relationships with sellers of a particular product category" (see section 3.2). Based upon an extensive literature study (chapter three) and a pilot study (see chapter six), we distinguished four potential antecedents of buyer relationship proneness: sociability, social recognition, shopping enjoyment, and product category involvement.

In literature on interpersonal relationships, sociability is regarded as a preference to be with other people and to engage in relationships (Barrick and Mount 1991; Buss and Plomin 1984; Cheek and Buss 1981; Sadowski and Cogburn 1997). Sociable people do not look for social rewards, but are rather intrinsically valuing the relationships with other people (Carver and Scheier 1992). Although hardly any empirical research is available on sociability in buyer-seller relationships (Ellis 1995) we expect that sociability plays a role in strengthening a buyer's relationship proneness.

Consequently, we formulate the following hypothesis:

\section{$H_{1}$ A higher level of sociability leads to a higher level of buyer relationship proneness}

Literature on interpersonal relationships demonstrated that people engage in relationships, as they want to be valued. Kirkpatrick and Davis (1994) for example, suggested that social recognition guides personal relationship development. A related construct is need for positive regard, which Carver and Scheier (1992) described as a desire to be accepted and valued by others. In buyer-seller 
relationships social recognition is comparable to personalization. Mittal and Lassar (1996, p. 96) argued that personalization can be regarded as a means of showing social recognition for the other party. Forman and Sriram (1991) similarly claimed that some people engage in buyer-seller relationships in search for human contact and social recognition. Based on these insights, we postulate that a buyer who desires social recognition is prone to engage in relationships, because he expects that a relationship may satisfy his desire for social recognition.

Hence, we formulate the second hypothesis:

\section{$H_{3}$ : A higher level of social recognition leads to a higher level of buyer relationship proneness}

A third potential antecedent of buyer relationship proneness is shopping enjoyment. Shopping enjoyment is regarded as the enjoyment that buyers receive from the shopping experience (Bellenger and Korgaonkar 1980; O'Guinn and Faber 1989; Westbrook and Black 1985). As people who enjoy shopping. like to shop in many different stores (Gutman and Mills 1982) it can be expected that they do not like to engage in buyer-seller relationships. Buyer-seller relationships could be experienced as a reduction of the number of stores to shop in. Forsythe, Butler, and Schaefer (1990) and Solomon (1987) proved that people who lack shopping enjoyment value relationships with salespeople as these relationships might mitigate the unpleasant shopping task.

Consequently we hypothesize a negative relationship between shopping enjoyment and buyer relationship proneness:

\section{$H_{3}: \quad$ A higher level of shopping enjoyment leads to a lower level of buyer relationship proneness}

In loyalty literature it is generally recognized that involvement leads to loyalty (Bloch 1981; Dick and Basu 1994). Moreover, product category involvement has been proposed as a useful segmentation variable (King and Ring 1980). Recently, Page and Sharp (1997) proposed that consumers are more likely to engage in relationships with retailers when their product category involvement is high, because the relationship can add value if consumers are already interested in the product. Therefore, we expect that the level of product category involvement makes a positive contribution to buyer relationship proneness.

As a result, we propose the following hypothesis:

\section{H4: A higher level of product category involvement leads to a higher level of buyer relationship proneness}

\subsubsection{Buyer Relationship Proneness and Seller Relationship Orientation}

It can be argued that a buyer's perception of a seller's efforts is most probably influenced by this buyer's proneness to engage in relationships with sellers, leading to selective perception of this seller's efforts. A buyer characterized by a high level of relationship proneness may express a more 
positive perception of a seller's efforts compared to a buyer showing a low level of relationship proneness.

Few direct evidence exists in current marketing literature to support this hypothesis. This is mainly a result of the fact that we relate two relatively new constructs to each other. However, some suppon for the relationship between buyer relationship proneness and seller relationship orientation can be found in literature on interpersonal relationships. Research analyzing interpersonal attraction is considered to provide a suitable framework for describing buyer-seller relationships (Dwyer, Schurr, and Oh 1987). Simpson, Gangestad and Lerma (1990) demonstrated that people in search of a romantic relationship find potential partners to be more attractive than do people already involved in romantic relationships. According to congruence theory, parties seek relationships with alternative partners whose attitudes and behaviors are the same (Gassenheimer, Davis, and Dahlstrom 1998). Analogously, we hypothesize that buyers who are relationship prone perceive sellers to be more relationship oriented than do buyers who are less relationship prone. Also Berry (1995) stated that buyers who are loyalty-prone hope to find a seller that will effectively meet their needs.

Consequently, we formulate the following hypothesis.

H: A higher level of buyer relationship proneness leads to a higher level of seller relationship orientation

\subsubsection{Seller Relationship Orientation and Relationship Satisfaction}

Conceptually, satisfaction and performance are closely related (Anderson and Narus 1984; Ganesan 1993; Gotlieb, Grewal, and Brown 1994; Lewis and Lambert 1991; Ruekert and Churchill 1984). Satisfaction is basically an affective response to an evaluation of perceived performance. Previous research has indicated that performance judgments play an important role in influencing satisfaction (Churchill and Surprenant 1982; Flint, Woodruff, and Gardial 1997; Wray, Palmer, and Bejou 1994).

Performance can be assessed at a product level (Oliver 1997; Peter and Olson 1996), a service level (Parasuraman, Zeithaml, and Berry 1985; Spreng and Mackoy 1996; Storbacka, Strandvik, and Grönroos 1994), and a relationship level (Anderson and Narus 1990; Crosby, Evans, and Cowles 1990; Dwyer and Oh 1987; Fournier 1998; Lagace, Dahlstrom, and Gassenheimer 1991; Smith and Barclay 1997). At a relationship level, relationship performance has been shown to predict important relationship outcomes such as relationship satisfaction (Anderson and Narus 1990; Bejou, Wray, and Ingram 1996; Fournier 1998; Frazier 1983; Ganesan 1993; Gwinner, Gremler, and Bitner 1998; Kelley and Thibaut 1978: Smith and Barclay 1997). Buyers tend to be more satisfied with sellers who make deliberate efforts towards these buyers (Leuthesser 1997; Mohr. Fisher, and Nevin 1996). Baker, Simpson, and Siguaw (1999) recently found empirical support for their hypothesis that the level of perceived seller market orientation, a construct that resembles seller relationship orientation, is positively associated with relationship satisfaction. 
Consequently, as seller relationship orientation can be viewed as performance at the relationship level, we formulate the following hypothesis:

\section{H: A higher level of seller relationship orientation leads to a higher level of relationship satisfaction}

\subsubsection{Seller Relationship Orientation and Relationship Commitment}

The previous hypothesis proposed a relationship between seller relationship orientation and relationship satisfaction. In addition to this, several authors support an association between seller relationship orientation and relationship commitment. Dwyer, Schurr, and Oh (1987) suggested that high relational performance is necessary for commitment to occur. They stated that commitment is "... fueled by the ongoing benefits accruing to each partner" (p. 19). In line with this, Bennett (1996) argued that the strength of a buyer's commitment depends on his perceptions of efforts made by the seller.

Several authors empirically investigated the relationship between relational performance, a construct that shows similarities to the construct of seller relationship orientation, and relationship commitment. Morgan and Hunt (1994) hypothesized that relationship benefits directly influence commitment. They assumed that if sellers deliver superior benefits, buyers will highly value these sellers, leading to commitment. However, they did not find support for this relationship. In a channel context, Anderson and Weitz (1992) found empirical support for the path from relationshipspecific investments to commitment. Siguaw, Simpson, and Baker (1997) showed that distributors' perceptions of market-oriented efforts by suppliers result in a greater commitment to maintain the relationship. Gwinner, Gremler, and Bitner (1998) found that relationship benefits strengthen buyerseller ties and result in relationship continuity. Biong and Selnes (1995) demonstrated that various salesperson behaviors affect buyers' motivations to continue the relationship. Finally, Baker, Simpson, and Siguaw (1999) recently found empirical support for their hypothesis that the level of perceived seller market orientation, a construct that resembles seller relationship orientation, is positively associated with buyer commitment.

Given the conceptual and empirical support mentioned above, we formulate the following hypothesis.

\section{H: A higher level of seller relationship orientation leads to a higher level of relationship commitment}

\subsubsection{Buyer Relationship Proneness and Relationship Satisfaction}

In 5.2.3, we posited that a buyer's satisfaction with a relationship is dependent upon the efforts made by the seller (seller relationship orientation). However, there are reasons to assume that satisfaction is not merely dependent upon a seller's actions. Shani and Chalasani (1992, p. 44) defined relationship marketing as an "effort to identify, build, and sustain a network of individual consumers, and the continuous strengthening of this network in the advantage of both parties by means of interactive, personal, and value-adding contacts during a long period" (italics added). 
Given the need of both parties to be satisfied with the relationship, support can be found that the relationship proneness of a buyer affects relationship satisfaction as well.

No attempts have been made yet to investigate the impact of buyer relationship proneness on relationship outcomes (Beatty et al. 1996; Ellis 1995). Despite the fact that buyer relationship proneness has never been operationalized and measured in empirical research, there are some indications that it plays an important role in affecting relationship satisfaction. Storbacka, Strandvik, and Grönroos (1994) stated that buyers who are interested in relationships perceive satisfaction with a relationship to be important. In our view, this statement could be interpreted in one of two ways. First, relationship prone buyers could be more difficult to satisfy as a result of a more critical attitude towards relationships with sellers. This view corresponds with Kalwani and Narayandas (1995) who stated that customers who are willing to engage in relationships are the most difficult to satisfy. Second, relationship prone buyers could be easier to satisfy as a result of a higher receptivity towards a seller's efforts aimed at enhancing the relationship. In line with the second explanation, our assumption is that people who find satisfaction more important are easier to satisfy.

As a result, we posit the following hypothesis:

$H_{\mathrm{s}:}$

A higher level of buyer relationship pmoneness leads to a higher level of relationship satisfaction

\section{2 .6} Buyer Relationship Proneness and Relationship Commitment

In 5.2.4, we hypothesized that a buyer's commitment to a relationship is dependent upon seller relationship orientation. However, there are reasons to assume that commitment is not merely dependent upon the seller's actions. Support can be found that the relationship proneness of a buyer influences relationship commitment as well. However, relatively little theoretical work exists that aims at explaining why individual characteristics such as buyer relationship proneness should be related to commitment (Mathieu and Zajac 1990).

Individual characteristics have generally been considered as antecedents of commitment (Mathieu and Zajac 1990; Rylander, Strutton, and Pelton 1997). Individuals are generally committed to sellers that fulfill underlying needs of these individuals (Korgaonkar, Lund, and Price 1985; Mathieu and Zajac 1990). Storbacka, Strandvik, and Grönroos (1994) further indicated that a buyer's interest in relationships influences the level of commitment to a relationship in which the buyer is engaged.

Consequently, we posit that buyer relationship proneness and relationship commitment are positively related.

\section{Ho: A higher level of buyer relationship pnoneness leads to a higher level of relationship commitment}

\subsubsection{Relationship Satisfaction and Trust}

Several authors hypothesize a positive flow from relationship satisfaction to trust (Bendapudi and Berry 1997; Bennett 1996; Crosby, Evans, and Cowles 1990; Gruen 1995; Siguaw, Simpson, and 
Baker 1997; Tax, Brown, and Chandrashekaran 1998). Ganesan (1994) and Selnes (1998) found strong empirical support for the path from relationship satisfaction to trust. Moreover, Geyskens' (1998) meta-analysis revealed that relationship satisfaction significantly influences trust. However, other authors suggested a different causal ordering from trust to relationship satisfaction (Andaleeb 1996: Dahlstrom and Nygaard 1995; Doney and Cannon 1997; Ramsey and Sohi 1997; Smith and Barclay 1997).

Our research model posits a one-way causal flow from relationship satisfaction to trust. Our rationale for this is of a conceptual nature. Dwyer, Schurr, and Oh (1987) argued that satisfaction and trust are built during subsequent phases of relationship development, supporting a sequential satisfaction-trust relationship. Similarly, Selnes (1998) stated that trust refers to an aggregate evaluation that can be regarded as a result of relationship satisfaction.

Consequently, we hypothesize that satisfaction, developing in the shorter run and resulting from past exchanges, positively influences trust, developing in the longer run.

\section{H, A higher level of relationship satisfaction leads to a higher level of tnast}

\subsubsection{Trust and Relationship Commitment}

As relationships characterized by trust are so highly valued that parties will desire to commit themselves to such relationships, several authors indicate that trust positively affects commitment (Beatty et al. 1996; Bendapudi and Berry 1997; Dwyer, Schurr, and Oh 1987; Fontenot and Wilson 1997; Gruen 1995; Gundlach and Murphy 1993; Hennig-Thurau and Klee 1997; Moorman, Desphandé, and Zaltman 1993; Ramsey and Sohi 1997; Schurr and Ozanne 1985). In addition to conceptual support for a trust-commitment relationship, strong empirical evidence exists for a positive path from trust to relationship commitment (Andaleeb 1996; Anderson and Weitz 1989; Crosby, Evans, and Cowles 1990; Doney and Cannon 1997; Ganesan 1994; Geyskens et al. 1996; Macintosh and Lockshin 1997; Moorman, Zaltman, and Deshpandé 1992 ; Morgan and Hunt 1994).

Trust is hypothesized to affect relationship commitment as it is expected to generate the following benefits: (1) it reduces the perception of risk, (2) it increases the confidence of the buyer that shortterm inequities will be resolved over a long period, and (3) it reduces the transaction costs in an exchange relationship (Andaleeb 1996 ; Ganesan 1994). These benefits should build attachment and create a desire to continue the relationship (Andaleeb 1996).

In her meta-analysis, Geyskens (1998) arrived at the conclusion that the trust-commitment relationship has been over-researched and that the findings related to it are almost unanimous. She stated that "if these relationships are empirically pursued in the future, it should be only to demonstrate that there may be some conditions under which these relationships do not hold" (Geyskens 1998, p. 99). Our main research objective is to measure the influence of buyer relationship proneness on relationship outcomes. Since trust and relationship commitment are considered to be core relationship outcomes, their interrelationship is an essential component in any study on relationships. Moreover, this study is one of few studies investigating the relationship 
between trust and relationship commitment in a retail context. As in retail situations the trustcommitment relationship may not hold as a result of its typically lower level of uncertainty, we investigate the following hypothesis.

\section{$H_{i t} \quad$ A higher level of trust leads to a higher level of relationship commitment}

\subsubsection{Relationship Commitment and Behavioral Loyalty}

As indicated by the value-attitude-behavior hierarchy, it is commonly accepted that attitudes influence behavior (Engel, Blackwell, and Miniard 1995; Homer and Kahle 1988; Korgaonkar, Lund, and Price 1985; Peter and Olson 1996). Considerable conceptual and empirical evidence supports the notion that relationship commitment is the ultimate attitudinal outcome in relationships with causal precedence of relationship satisfaction and trust. While relationship satisfaction and trust develop in the relatively short term, relationship commitment develops in the longer run and is future oriented (Geyskens 1998). Relationship commitment refers to "a buyer's enduring desire to continue a relationship with a seller accompanied by his willingness to make efforts at maintaining it" (see 4.2.4.1). As a desire and willingness to act imply higher chances of actual behavior, we assume that there exists a positive relationship between relationship commitment and behavioral loyalty.

Some support can be found in literature regarding this assumption. Several authors support the notion that relationship commitment motivates buyers to act (Gruen 1995: Hennig-Thurau and Klee 1997; Mathieu and Zajac 1990). Liljander and Strandvik (1993) concluded that commitment and behavioral loyalty are related concepts. Morgan and Hunt (1994) found significant relationships between the level of a buyer's relationship commitment and his acquiescence, propensity to leave. and cooperation, all of which can be regarded as behavioral outcomes of relationships. Several organizational commitment studies focused on intent to leave and turnover as primary behavioral outcomes (Rylander, Strutton, and Pelton 1997). Moorman, Zaltman, and Desphandé (1992) suggested that buyers who are committed to a relationship may have a greater propensity to act because of their need to remain consistent with their commitment. Finally. Dick and Basu (1994) stated that the stronger relationship commitment, the more likely the buyer is to overcome potential obstacles in the buyer-seller relationship, resulting in repeat patronage.

Based on these insights, we formulate the following hypothesis:

\section{$H_{12} \quad A$ higher level of relationship commitment leads to a higher level of behavional loyalty}

\subsection{Moderating Effects and Related Hypotheses}

In figure 5-2, we visualize the moderating effects of seller relationship orientation. buyer relationship proneness, and product category involvement on the relationships from buyer relationship proneness and seller relationship orientation to attitudinal relationship outcomes. 


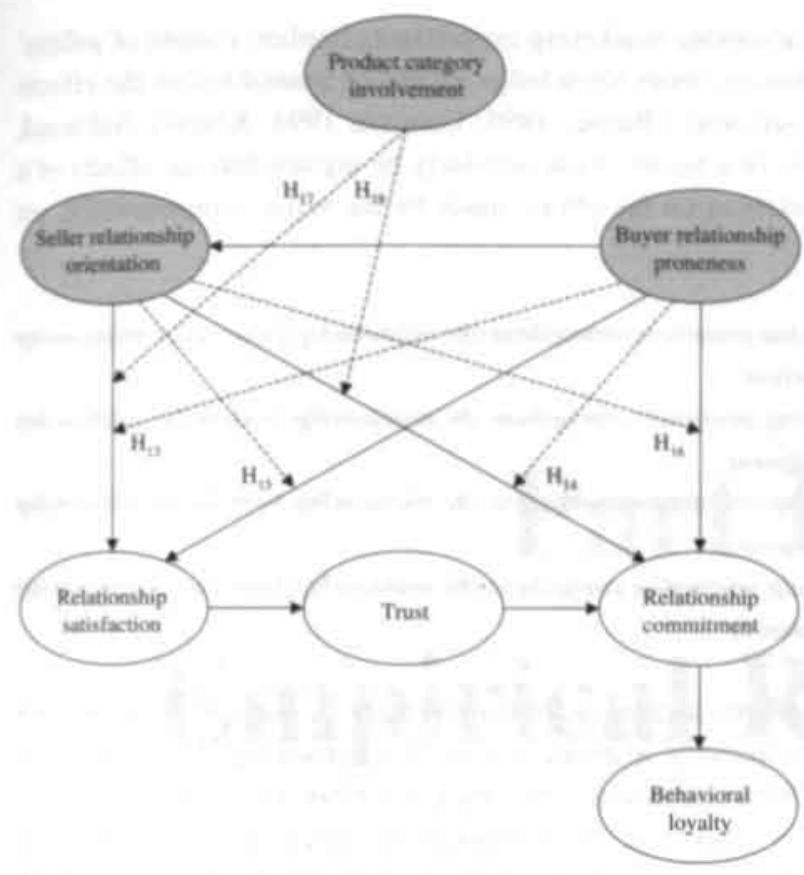

Figure 5-2: Modenating Effects in the Research Model

Geyskens (1998) recommended that future research should explore interactive patterns related to relationship satisfaction and commitment. Christy, Oliver, and Penn (1996) presented the conceptual idea that relationships are more likely to develop in some product markets than in others. In this section, we discuss the influence of three moderator variables on the paths originating from buyer relationship proneness and seller relationship orientation to relationship satisfaction and relationship commitment. Hypothesized moderator variables are buyer relationship proneness $\left(\mathrm{H}_{13}\right.$ and $\mathrm{H}_{14}$ in figure 5-2), seller relationship orientation $\left(\mathrm{H}_{15}\right.$ and $\mathrm{H}_{16}$ in figure 5-2), and product category involvement $\left(\mathrm{H}_{17}\right.$ and $\mathrm{H}_{48}$ in figure 5-2).

First, we motivate why buyer relationship proneness and seller relationship orientation can act as a moderator in our research model. From the perspective of a seller, directing efforts at buyers is not always considered to be a preferable strategy because not all types of buyers are prone to engage in relationships with sellers (Barnes 1995; Berry 1995; Christy, Oliver, and Penn 1996; Crosby, Evans, and Cowles 1990; Ellis 1995; Fournier 1998; Gwinner, Gremler, and Bitner 1998; Shani and Chalasani 1992). Consequently, the effects of seller relationship orientation on relationship outcomes can be moderated by buyers' proneness to engage in relationships with sellers (Sheth and

No moderating effects of product category involvement on the paths from buyer relationship proneness to relationship satisfaction and relationship commitment were estimated. The underlying reason for this is that both product category involvement and buyer relationship proneness refer to the same unit of analysis. In other words. one buyer exhibiting a certain level of buyer relationship proneness can only be characterized by one level of product category involvement. 
Parvatiyar 1995b). Since misdirecting relationship marketing investments implies a waste of sellers' resources and may lead to disappointed buyers, more knowledge should be assembled on the effects of buyer characteristics on relationship outcomes (Barnes 1995; Ganesan 1994; Krapfel, Salmond, and Spekman 1991). From the perspective of a buyer, it can similarly be argued that the effects of a buyer's relationship proneness are dependent upon the efforts made by the seller. Consequently, we suggest the following hypotheses:
$H_{15:} \quad$ A higher level of buyer relationship proneness strengthens the relationship from seller relationship orientation to relationship satisfaction
His: A higher level of buyer relationship proneness strengthens the relationship from seller relationship orientation to relationship commitment
His: A higher level of seller relationship orientation strengthens the relationship from buyer relationship proneness to relationship satisfaction
$H_{16}$ A higher level of seller relationship orientation strengthens the relationship from buyer relationship proneness to relationship commitment

Second, we discuss the moderating role of product category involvement. A high product category involvement of the buyer is expected to provide a stronger basis for enhancing the buyer-seller relationship (Christy, Oliver, and Penn 1996: Leuthesser 1997: Park and Choi 1998). Solomon et al. (1985) claimed that, in low involvement situations, the treatment of buyers as individuals will probably not pay, whereas in high involvement situations, they assume that buyers desire more personal treatment. Consequently, approaches by the seller, however well-intentioned, could be regarded by the buyer as undesirable in case the buyer's involvement level is low (Christy, Oliver, and Penn 1996). Consequently, we hypothesize that the effects of seller relationship orientation are moderated by product category involvement. The following hypotheses are suggested:
$H_{l}: \quad$ A higher level of product category involvement strengthens the relationship from seller relationship orientation to relationship satisfaction
$H_{1 s}$ A higher level of product category involvement strengthens the relationship from seller relationship orientation to relationship commitment

In the next chapter, we discuss the methodology used for investigating the formulated hypotheses. In chapter seven, we test each of these hypotheses by presenting the empirical results of our study. 


\section{Part II}

\section{Empirical Research}




\section{Chapter Structure}

6.1 Introduction.

6.2 Data Collection Method .

6.2 .1 Cross-Sectional Reseanch _.

6.2.2 Non-Experimental Rescarch................. 84

6.2 .3 Survey Research .......

6.2.4 Penonal Interviewing ............

6.2 .5 Mall-Intercept Inteviewing ....

6.3 Item Genention and Testing ....

6.3.I Specification of Constnact Domain _...

6.3.1.1 Literature Study . .

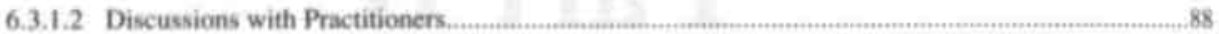

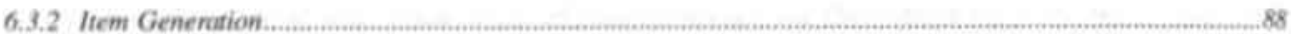

6.3.2.1 Literature Study ...

6.3.2.2 Consumer Focus Group Discussions .....

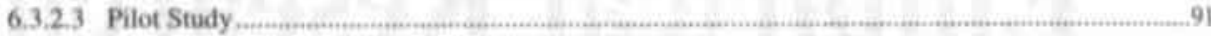

6.3.2.4 Measurement Format of Items ...

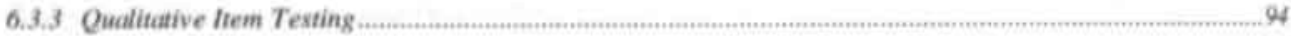

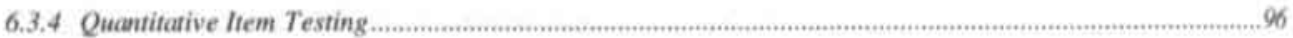

6.3.4.1 Sampling Method and Sample Size ........................................................................................96

6.3.4.2 Principal Components Analysis .......................................................................................................98

6.3.4.3 Assessment of Reliability . . . . .

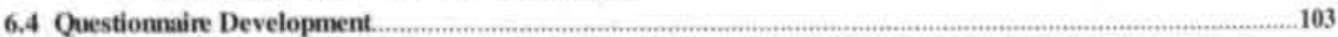

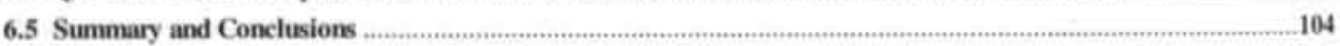




\section{Chapter 6 Research Methodology and Item Construction}

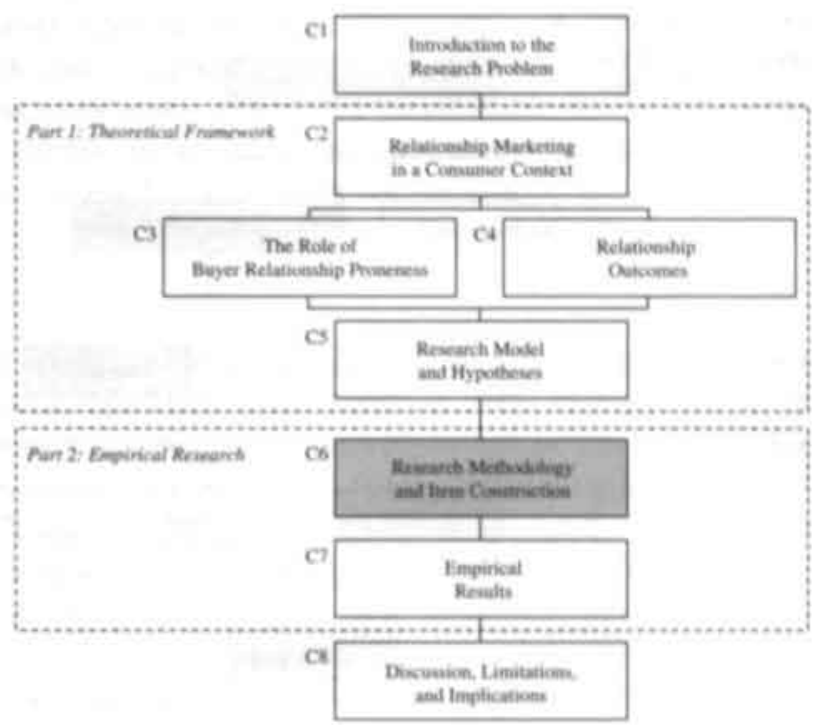

\subsection{Introduction}

This chapter is the link between the research model and related hypotheses described in the previous chapter and the empirical results outlined in the next chapter. Its purpose is to clarify and motivate the methodology used for evaluating the research hypotheses and to describe the process and results of item generation and testing. This chapter discusses the 'what', 'why', and 'how' questions related to methodological choices and their consequences in terms of the reliability and validity of the study. It does not yet discuss the performance of the measurement and structural models. These will be reported in the next chapter dealing with the study's empirical results.

In section 6.2, we provide justifications for collecting our data on basis of the mall-intercept personal interviewing method. Section 6.3 describes the process used to establish and initially test the items intended to measure each construct. Finally, in section 6.4, we discuss the development of our questionnaire.

\subsection{Data Collection Method}

The choice of an adequate data collection method should mainly be based on the type of research problem investigated (Kerlinger 1986). As a result, each of the choices made in this section will be evaluated in light of the specific problem investigated in this study. Figure 6-1 indicates which choices we made at various decision levels related to the data collection method. At each level, the option we selected, is shaded. 


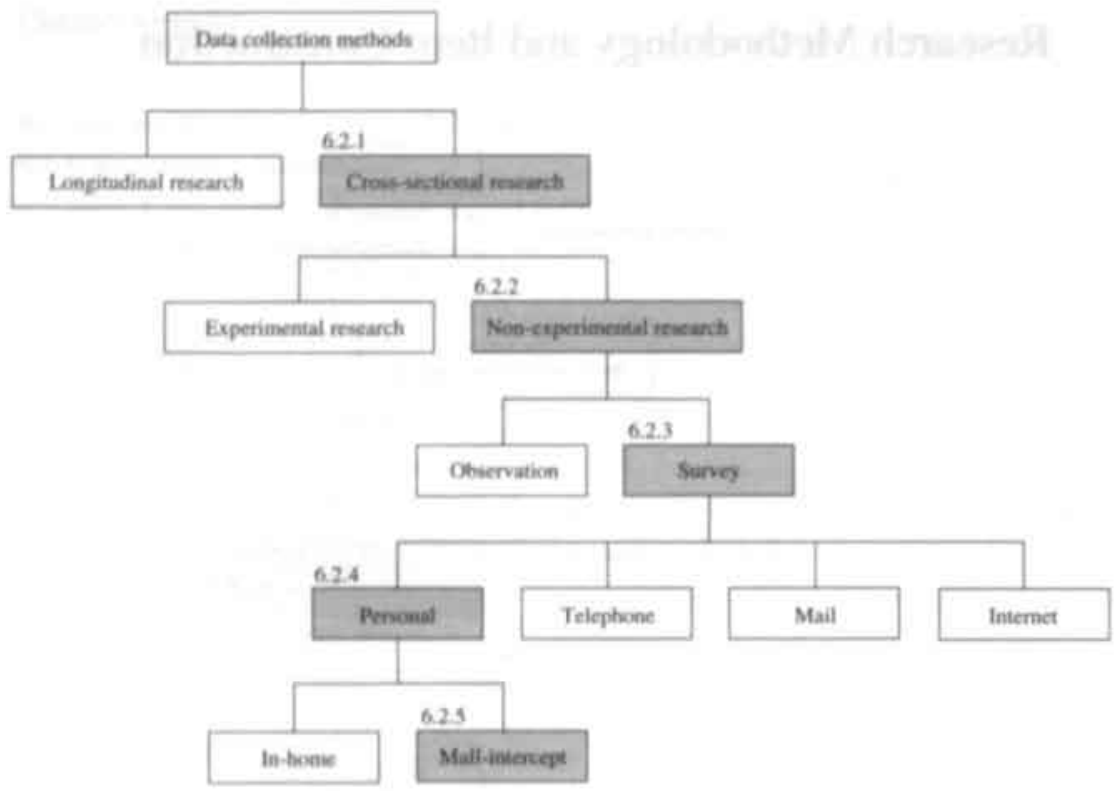

Figure 6-1: Selection of Data Collection Method

\subsubsection{Cross-Sectional Research}

Research can either be cross-sectional or longitudinal. In this study, we apply a cross-sectional design. Cross-sectional research involves "the collection of information from any given sample of population elements only once" (Malhotra 1996, p. 92). Longitudinal research on the other hand provides an in-depth view of the situation and the changes that take place over time (Dillon, Madden, and Firtle 1990/1993; Green, Tull, and Albaum 1988; Malhotra 1996). Scholars recognize that representative sampling and response biases are serious problems of longitudinal research (Churchill 1995; Malhotra 1996; Parasuraman 1991). In longitudinal research, the cooperation of panels is required. Respondents' refusal to cooperate, panel mortality, and payment of panel members increase the lack of representative sampling. Furthermore, response bias is increased as a result of the fact that panel members more consciously perform the investigated behaviors and that new panel members even tend to increase the investigated behavior (Churchill 1995; Malhotra 1996: Parasuraman 1991). Finally, longitudinal research implicitly requires long data collection periods. Based on these arguments and the objective of our study, a cross-sectional research is considered to be adequate in order to provide the required information in a valid and representative way.

\subsubsection{Non-Experimental Research}

In this study, we use a non-experimental as opposed to an experimental research method. Kerlinger (1986, p. 348) defined non-experimental research as "systematic, empirical inquiry in which the scientist does not have direct control of independent variables because their manifestations have 
already occurred or because they are inherently not manipulable". While experimental research generally allows obtaining high levels of internal validity as a result of the possibility to control, randomly assign, and manipulate, its lower external validity and artificiality are considered to be weaker elements (Churchill 1995; Cook and Campbell 1979; Dillon, Madden, and Firtle 1990; Kerlinger 1986; Malhotra 1996). As this study wants to generate generalizable results for a wide variety of retail situations, external validity is an important additional evaluation criterion. Consequently, the use of non-experimental research is suitable for our purpose.

\subsubsection{Survey Research}

Non-experimental research designs can consist of observation as well as survey methods of data collection (Churchill 1995: Dillon, Madden, and Firtle 1990: Kerlinger 1986; Malhotra 1996). In this study. we opt for survey research. Malhotra (1996, p. 130) defined surveys as "interviews with a large number of respondents using a pre-designed questionnaire". While behavior can adequately be assessed by means of observation, the reasons underlying these behaviors can hardly be uncovered through observational methods (Dillon, Madden, and Firtle 1990; Parasuraman 1991: Weiers 1988). Given this study's focus on attitudes and other perceptual data, observational research methods are not useful in the context of this study. Moreover, observational methods can lead to biases resulting from researchers' subjectivity related to interpreting observed behavior (Churchill 1995; Malhotra 1996; Parasuraman 1991; Weiers 1988). This is an additional argument for selecting survey research methods. Concluding, we consider the survey method as the most suitable method to collect our data.

\subsubsection{Personal Interviewing}

Survey methods are generally classified into mail, internet, telephone, and personal surveys. In this study, we apply personal surveys to gather the required data. A personal interview is generally defined as "a questionnaire administration method in which the interviewer and respondent have face-to-face contact" (Parasuraman 1991, p. 229). Table 6-1 gives an overview of the main advantages and disadvantages of the major survey methods. Positive and negative signs indicate the extent to which a specific method generates advantages respectively disadvantages from a methodological point of view.

According to Kerlinger (1986, p. 379), the personal interview "far overshadows the others as perhaps the most powerful and useful tool of social scientific survey research". This is similarly reflected in table 6-1 that indicates the relative superiority of personal interviews. Personal interviews outperform mail, internet, and telephone surveys on nearly all criteria, except for interviewer control and bias, cost, and social desirability bias. We made several efforts in order to overcome these potential weaknesses. First, interviewer control was enhanced by carefully selecting interviewers and regularly checking up on them during their interviewing task. Second, intensive interviewer briefing and training prior to the data collection were aimed at reducing potential interviewer bias (Parasuraman 1991). Moreover, the use of structured questionnaires that included detailed respondent instructions automatically diminished the risk of interviewer bias (De 
Table 6-1: Evaluative Comparison of Survey Methods

\begin{tabular}{|c|c|c|c|c|c|}
\hline \multirow[t]{2}{*}{ Criteria } & \multicolumn{2}{|c|}{ Mail / Intemet } & \multirow[t]{2}{*}{ Telephone } & \multicolumn{2}{|c|}{ Personal } \\
\hline & Direct & Panels & & In-home & Mall-intercept \\
\hline Sample chamacteristics & & & & & \\
\hline Sample representativeness & - & - & + & + & + \\
\hline Control chanacteristies & & & & & \\
\hline Control of environment & - & - & + & + & + \\
\hline Interviewer control & + & ++ & + & - & - \\
\hline Data characteristics & & & & & \\
\hline Data quantity & + & + & ? & + & + \\
\hline Data diversity & - & - & - & ++ & $\rightarrow$ \\
\hline Data completeness & $=$ & - & + & + & ++ \\
\hline Opportunity for clarification & - & - & + & ++ & + \\
\hline Interviewer bias & + & ++ & + & - & - \\
\hline Non-response bias & - & + & + & + & + \\
\hline Social desirability bias & + & ++ & + & - & - \\
\hline Order effect bias & - & - & + & + & + \\
\hline Process chanacteristics & & & & & \\
\hline Fexibility & - & - & + & + & ++ \\
\hline Speed & $-1+$ & $-1+$ & ++ & + & + \\
\hline Cost & ++ & + & $\therefore$ & $\cdots$ & 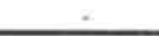 \\
\hline
\end{tabular}

Source: $\quad$ Adapted from (1) Churchill, Gilbert A. (1995), Marketing Research Methodological Foundations, sixth edition, Fort Worth: The Dryden Press, (2) De Pelsmacker, Patrick and Patrick Van Kenhove (1994). Marktonderzoek. Methoden en Toepassingen, Leuven/Apeldoom: Garant, (3) Dillon, William R., Thomas J. Madden, and Neil H. Firtle (1990), Marketing Research in a Marketing Environment, second edition, Homewood/Boston: Irwin, (4) Dillon, William R., Thomas J. Madden, and Neil H. Firtle (1993), Essentials of Marketing Research, Homewood/Boston: Irwin, (5) Green, Paul E., Donald S. Tull and Gerald Albaum (1988), Research for Marketing Decisions, fifth edition, Englewood Cliffs. NJ: Prentice Hall, (6) Malhotra, Naresh K. (1996), Marketing Research an Applied Orientation, second edition. Upper Saddle River. New Jersey: Prentice Hall, (7) Parasuraman, A. (1991), Marketing Research, second edition, Reading, Massachusets et al.: Addison-Wesley Publishing Company, (8) Peelen, Ed, Ham Commandeur, Erik Jan Hultink, and Richard van Pelt (1996), Multimedia in de Marketingstnategie. Bunnik: F\&G Publishing, and (9) Yu. Julie and Harris Cooper (1983), "A Quantitative Review of Research Design Effects on Response Rates to Questionnaires," Joumal of Marketing Research. 20 (February), 36-44.

Pelsmacker and Van Kenhove 1994). Further, interviewers were not aware of the underlying hypotheses of the study and could therefore not consciously bias the responses. Finally, we tried to avoid social desirability bias by training interviewers to keep the difficult balance between offering sufficient personal assistance to respondents and reading over respondents' shoulders (Dillon. Madden, and Firtle 1993).

\subsubsection{Mall-Intercept Interviewing}

Personal surveys can be classified into personal interviewing at home and mall-intercept personal interviewing (De Pelsmacker and Van Kenhove 1994; Dillon, Madden, and Firtle 1990/1993; Kerlinger 1973; Parasuraman 1991). In this study, we regard mall-intercept interviewing as the most suitable method for collecting our data. A mall-intercept personal interview involves "a centrallocation test facility at a shopping mall where respondents are intercepted while they are shopping" 
(Dillen, Madden, and Firtle 1990, p. 198). Table 6-1 compares mall-intercept personal interviewing with in-home personal interviewing. Mall-intercept interviewing is generally considered to lead to lower levels of sample representativeness and lower possibilities of collecting large amounts of data as opposed to in-home personal interviewing. Nevertheless, it outperforms in-home interviewing with respect to control over the environment, interviewer bias, cost, and speed (Dillon. Madden, and Firtle 1990/1993; Malhotra 1996). We made efforts to increase sample representativeness by imposing strict quota with respect to age, gender, time-of-the-day, and day-of-the-week (Dillon, Madden, and Firtle 1993). In addition, as the study's objectives are store-related, a shopping mall consisting of a large number of stores can be considered as a suitable environment for collecting data, stimulating sample representativeness. Moreover, our study does not require large amounts of questions. A typical interview only takes about ten minutes, which is considered to be within acceptable margins of mall-intercept interviewing length (Dillon, Madden, and Firtle 1990/1993).

Concluding, our data collection involves the use of non-experimental, mall-intercept personal surveys on a cross-sectional basis.

\subsection{Item Generation and Testing}

In this section, we discuss the methods used for generating and testing scale items. Our procedure is

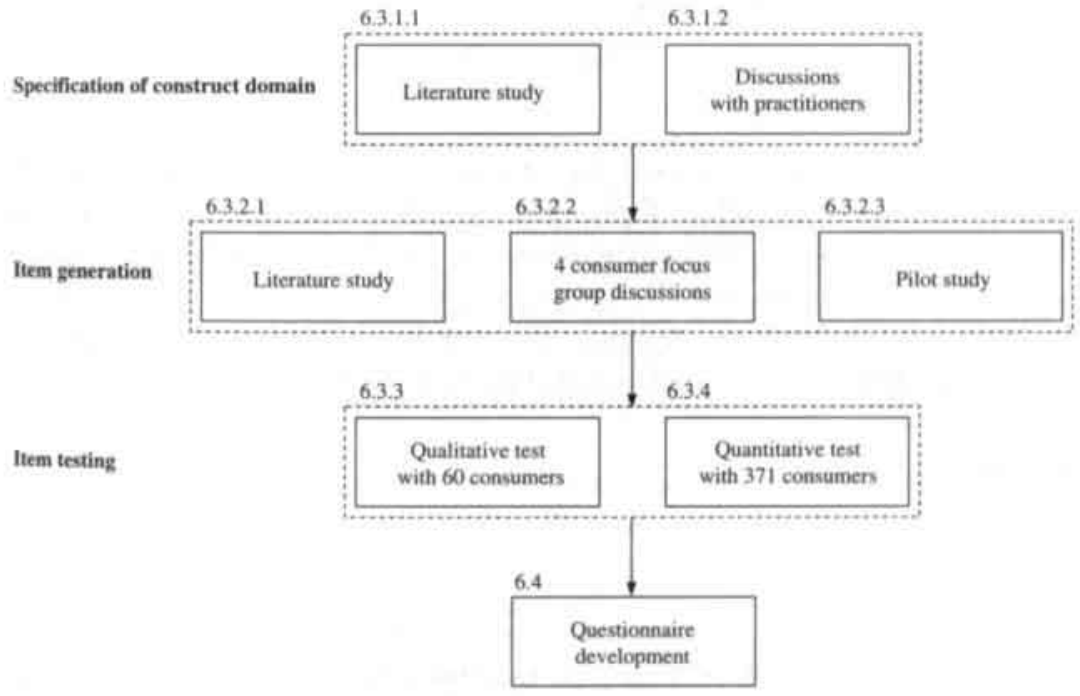

Figure 6-2: Overview of Item generation, Testing, and Questionnaire Development

based upon accepted methods of scale development in consumer research (Churchill 1979; DeVellis 1991). Figure 6-2 visually describes the various steps that were taken. 


\subsubsection{Specification of Construct Domain}

\subsubsection{Literature Study}

An electronic database was set up consisting of detailed bibliographic information on books, articles published in scientific journals, and articles published in conference proceedings. As the nature of our study required a cross-disciplinary approach, this literature review was related to various research fields such as channel marketing (e.g. Anderson and Weitz 1992; Geyskens et al. 1996). consumer marketing (e.g. Babin, Darden, and Griffin 1994: Fournier 1998), organization theory (e.g. Mathieu and Zajac 1990; Mowday 1991), relationship marketing (e.g. Dwyer, Schurr, and Oh 1987; Morgan and Hunt 1994), retail marketing (e.g. Beatty et al. 1996; Shim and Easlick 1998), services marketing (e.g. Cronin and Taylor 1992; Parasuraman, Zeithaml, and Berry 1985), and social psychology (e.g. Fehr 1988; Wish, Deutsch, and Kaplan 1976).

First, we scanned these information sources for the presence of constructs that are of interest to our study. Second, sources containing these constructs were examined on construct conceptualization and delineation. This examination of literature resulted in valuable insights related to definitions of and interrelationships between constructs. The results of this literature study were discussed in chapters three and four dealing with the constructs of buyer relationship proneness, seller relationship orientation, and relationship outcomes.

\subsubsection{Discussions with Practitioners}

The literature study was further complemented by several, detailed discussions with three representatives of the Dutch Retail Federation. Topics that were discussed centered on the factors that potentially influence buyer loyalty in retail environments. We applied brainstorming techniques in order to generate as much ideas as possible (De Pelsmacker and Van Kenhove 1994; De Ruyter and Scholl 1995). This was helpful in defining the construct domain, led to practical recommendations concerning data collection, and provided the basis for item generation.

\subsubsection{Item Generation}

\subsubsection{Literature Study}

The literature study mentioned in 6.3.1.1 also served as a basis for drawing a comprehensive picture of existing measurement scales for each of the constructs examined. Handbooks of marketing scales (e.g. Bearden, Netemeyer, and Mobley 1993; Bruner and Hensel 1992) were consulted for the same purpose. This led to the conclusion that measurement scales for some constructs were not available and, consequently, had to be developed for the purpose of our study. Measurement scales for other constructs were available, but had to be adapted in order to suit a retail environment. In table 6-2. we indicate the main sources that were used as input in order to generate items for measuring the constructs in this study. 


\begin{tabular}{|c|c|c|}
\hline Constnuct & Number of items & Source \\
\hline Sociability & 6 & Cheek and Buss 1981: Villani and Wind 1975 \\
\hline Social recognition & 6 & Developed for this study \\
\hline Shopping enjoyment & 6 & $\begin{array}{l}\text { Bellenger and Korgaonkar 1980; Gutman and Mills 1982; } \\
\text { Mittal and Lee } 1989\end{array}$ \\
\hline Product category involvement & 3 & Laurent and Kapferer 1985: Zaichkowsky 1985 \\
\hline Buyer relationship proneness & 6 & Developed for this study \\
\hline Seller relationship orientation & 6 & Developed for this study \\
\hline Relationship satisfaction & 6 & $\begin{array}{l}\text { Anderson and Narus 1984; Frazier, Gill, and Kale 1989; } \\
\text { Gottlieb, Grewal, and Brown 1994; Kumar, Stern, and } \\
\text { Achrol 1992; Ping 1993/1997; Scheer and Stern 1992; } \\
\text { Smith and Barclay 1997; Wray. Palmer, and Bejou 1994 }\end{array}$ \\
\hline Trust & 4 & $\begin{array}{l}\text { Dahlstrom and Nygaard 1995; Doney and Cannon 1997; } \\
\text { Geyskens et al. 1996; Kumar, Scheer. and Steenkamp } \\
\text { 1995a; Moorman, Zaltman, and Desphande 1992; Morgan } \\
\text { and Hunt 1994; Scheer and Stern 1992; Wray, Palmer. } \\
\text { and Bejou 1994 }\end{array}$ \\
\hline Relationship commitment & 4 & $\begin{array}{l}\text { Ganesan 1993: Mohr. Fisher, and Nevin 1996: Morgan } \\
\text { and Hunt 1994: Siguaw, Simpson, and Baker } 1998\end{array}$ \\
\hline Behavioral loyalty & 3 & Sirohi, MacLaughlin, and Wittink 1998 \\
\hline Total & 50 & \\
\hline
\end{tabular}

\subsubsection{Consumer Focus Group Discussions}

Focus group discussions were held as an additional source of inspiration for generating items. A focus group discussion involves "an objective discussion leader or moderator who introduces a topic to a group of respondents and directs their discussion of it in a nonstructured and natural fashion" (Parasuraman 1991, p. 256). Focus group discussions are typically the first step in a research process and have proved to be productive for generating information helpful in structuring questionnaires (Churchill 1995; De Pelsmacker and Van Kenhove 1994; Dillon, Madden, and Firtle 1990). The objective of the focus group discussions was to learn more about the wording consumers use to describe the constructs of buyer relationship proneness and seller relationship orientation and to generate insights into the antecedents of buyer relationship proneness.

Four consumer focus group discussions were organized dealing with customer loyalty to apparel stores as the main topic of discussion. The research sample for the focus groups consisted of customers of a medium-sized Belgian retail clothing chain. This clothing chain provided us with a database containing detailed information on the purchasing history of its customers. Customers were split into high- versus low-loyalty ${ }^{\prime}$ groups on basis of their purchasing pattern during the last five seasons (a season comprised six months). High-loyalty customers did a purchase during each of the last five seasons. Low-loyalty customers only did a purchase during the first two seasons. While there is no scientific basis for determining optimal focus group size, typical sizes vary between six to twelve people (De Pelsmacker and Van Kenhove 1994; De Ruyter and Scholl 1995; Dillon, Madden, and Firtle 1990/1993). 30 participants equally spread across age, gender, and level of loyalty towards the clothing chain were recruited by telephone. As focus groups must be as

Loyalty refers to behavioral loyalty. However, it differs from the way in which behavioral loyalty is operationalized in chapter four $(4.3 .1)$ as only database information on purchase behavior was available. 
homogeneous as possible with respect to demographic and socioeconomic characteristics (Churchill 1995: Dillon, Madden, and Firtle 1993: Parasuraman 1991), we split these participants into four homogeneous groups. Eventually, a total number of 23 participants showed up in four focus group discussions: seven women disloyal to the clothing chain, seven women loyal to the clothing chain, five men disloyal to the clothing chain, and four men loyal to the clothing chain. Care was taken to ensure that participants did not cooperate in focus groups before, avoiding the problem of so-called 'professional respondents' (Parasuraman 1991). Each participant received a monetary incentive in return for his cooperation. Relatively more women were recruited $(60 \%)$ than men $(40 \%)$ based upon the commonly accepted assumption that shopping for clothing is primarily a women's activity (Kline and Wagner 1994).

A typical focus group discussion lasts between one and a half and two hours (Churchill 1995; Parasuraman 1991). This corresponds with the duration of our focus group discussions. Moderators were completely familiar with the study's objectives and background, which was supposed to stimulate successful group discussions (Churchill 1995; De Ruyter and Scholl 1995; Parasuraman 1991). Moreover, it is generally recognized that creating a positive and friendly atmosphere helps to build effective group discussions (Parasuraman 1991). In our focus groups, we ensured that participants felt comfortable with one another during the discussion procedure and served some light refreshments before and during the session for this purpose. Participants were first asked to talk about their own behavior with respect to shopping for casual clothing. Second, we applied a direct questioning technique in order to acquire knowledge on participants' own relationship proneness and their feelings towards seller relationship orientation. Finally, as participants might not be willing to reveal their true perceptions and attitudes, we used two projective techniques during the remainder of the discussion. Participants' first exercise consisted of providing a detailed description (e.g. housing, environmental conditions, infrastructure, cars, and characteristics of inhabitants) of two hypothetical countries each differing with respect to the presence of relationshiporiented sellers. These descriptions were used as input for understanding the concept of seller relationship orientation. The second exercise involved a photo-sort. We asked participants to select two photos from a set of photos: one photo of which participants assumed the person on the photo to be relationship prone and one photo of which participants assumed the person on the photo not to be relationship prone. Male focus groups evaluated male photos, female focus groups evaluated female photos. We asked participants to describe the behavior and feelings of both persons selected. We probed participants with respect to their thoughts and feelings about buyer relationship proneness and seller relationship orientation. We recorded all focus group discussions for subsequent replay, transcription, and analysis.

Two experts independently analyzed the transcribed discussions by classifying related ideas and terms into distinct categories. Discrepancies in interpretation between both experts were solved on basis of in-depth bilateral discussions. These focus groups demonstrated that buyer relationship proneness could be strongly influenced by a buyer's shopping enjoyment and product category involvement. This was already outlined in chapter three. In addition, the participants agreed that seller relationship orientation refers to efforts a seller is generally making to enhance relationships with buyers. Moreover. we were able to get an overview of the vocabulary that consumers use to 
describe their relationship proneness and to talk about a seller's relationship orientation. This knowledge was helpful in directing item generation.

\subsubsection{Pilot Study}

Based on the literature study on values described in chapter three, we expected that the values included in the List of Values (LOV) might assist us in determining which individual characteristics to include as potential antecedents of buyer relationship proneness. We included buyer relationship proneness items generated from the literature study and focus groups, and values of the LOV in a one-page survey (see appendix three) and asked 187 international students - attending doctoral courses in Business Economics at Maastricht University - to complete this survey. Since the surveys were administered during class, the response rate amounted up to $100 \%$. Although the student population is different from our target population in the final data collection stage, we expected that data based on students' responses could provide us with the required preliminary insights.

First, we conducted a principal components analysis, which revealed three distinct components that we labeled 'sociability'. 'social recognition' and 'enjoyment'. Sociability consisted of the items 'sense of belonging'. 'warm relationships with others' and 'security'. Social recognition was composed of the items 'self-fulfillment', 'being well respected', 'self-respect' and 'sense of accomplishment'. Finally, enjoyment consisted of 'excitement' and 'fun and enjoyment of life' (tables A3-1 and A3-2, appendix three). Second, we investigated the components' internal consistencies resulting in Cronbach's alphas of respectively .67 (sociability), .74 (social recognition), and .55 (enjoyment) (table A3-1, appendix three). General threshold values should vary between .30 and .60 (Green, Tull, and Albaum 1988; Heide and John 1988: Steenkamp and Van Trijp 1991). In this pilot study, item-to-total correlations varied between .39 and .61. Finally, we conducted a linear regression analysis in order to investigate whether these three components were related to the dependent variable buyer relationship proneness. Table A3-3 (appendix three) shows that each of the components significantly contributes to buyer relationship proneness, whereas the total explained variance is rather low $\left(R^{2}=.12\right)$. This implies that more components might be needed to get a complete view of buyer relationship proneness. As we already mentioned in chapter three, we included enduring product category involvement as an additional, potential antecedent of buyer relationship proneness.

As the LOV is mainly used to classify respondents into groups on the basis of their top-ranked value only, which would not be suitable for our research goal, (Beatty, Kahle, and Homer 1991; Kamakura and Mazzon 1991; Novak and MacEvoy 1990), we decided to operationalize the resulting components by means of multi-item constructs. Sociability and social recognition are two individual characteristics that are frequently related to interpersonal relationships. We used existing and new items to construct a multi-item scale for both constructs. The resulting component enjoyment inspired us to include the construct of shopping enjoyment, regularly included in consumer behavior studies (Babin, Darden, and Griffin 1994; Hirschman and Holbrook 1982; Holbrook and Hirschman 1982). Summarizing, we included the constructs 'sociability', 'social recognition', and 'shopping enjoyment' rather than the values from the LOV. 


\subsubsection{Measurement Fomat of Items}

The previous steps provided us with an initial pool of items to be included in the questionnaire. The next step was to decide on the format of individual items. While self-report techniques for attitude assessment are most widely used in marketing research, researchers use different types of response scales (Churchill 1995). In this study, we selected the Likert scale ${ }^{2}$ for measuring items. We first explain our choice for the Likert scale, followed by the reasons underlying the specific format of the scale.

The use of a Likert scale implies asking respondents to indicate e.g. a degree of agreement or disagreement with a (series of) statement(s). This scale is regarded as an itemized rating scale because each category of the scale is numbered and/or briefly described (Churchill 1995: Malhotra 1996). The Likert scale is one of the most widely used attitude scaling techniques (Malhotra 1996). Its main strength is that it allows respondents to express the intensity of their feelings (Churchill 1995: DeVellis 1991). Moreover, its ease of construction and the simplicity of respondent directions are regarded as true advantages of the scale (Malhotra 1996). While the output from a pure technical standpoint is no stronger than an ordinal seale, the Likert scale is routinely treated at an interval level (De Pelsmacker and Van Kenhove 1994; Kerlinger 1986; Malhotra 1996: Weiers 1988).

We made seven decisions related to the specific format of our Likert scale: (1) odd or even number of response options, (2) number of response options, (3) balanced or unbalanced response options, (4) forced or non-forced choice of response options, (5) labels of response options, (6) choice indicators, and (7) positive or negative formulation.

\section{(1) Odd or even number of response options}

According to Malhotra (1996), the Likert scale consists by definition of an odd number of response options. If at least some of the respondents can reveal neutral responses, these respondents should be given the opportunity to express their neutrality (DeVellis 1991; Dillon. Madden, and Firtle 1993; Malhotra 1996; Weiers 1988). Since we expect that respondents can feel neutral about the statements included in our study, we opted for an odd number of response options including a neutral position.

\section{(2) Number of response options}

Traditional guidelines suggest using seven plus or minus two categories of response options (Dillon, Madden, and Firtle 1990; Parasuraman 1991; Weiers 1988). We selected a seven-point scale in our study. First, Churchill and Peter (1984) found empirical evidence for their hypothesis that there exists a positive relationship between the number of scale points and scale reliability. The larger the number of response options, the finer respondents can be discriminated from each other (Churchill and Peter 1984; Dillon, Madden, and Firtle 1990; Malhotra 1996; Martin 1978; Parasuraman 1991; Weiers 1988). The underlying reason for this is that a larger number of scale points leads to larger variances, resulting in increased reliability (DeVellis 1991: Nunnally 1978: Nunnally and Bernstein 1994). Second, the level of sophistication of

As the behavioral loyalty construct could not be measured on basis of a Likert scale, it was measured as a multiitem construct consisting of comparative as well as non-comparative scale items. 
intended data analysis techniques similarly influences the optimal number of categories. It is generally acknowledged that if sophisticated statistical techniques will be used, seven or more categories are required (Malhotra 1996). As advanced statistical analyses will be carried out in this study, we could not accept a five-point scale. Finally, as it is generally recognized that respondents have difficulties answering nine-point scales due to cognitive limitations (Churchill and Peter 1984: Malhotra 1996; Weiers 1988), we opted for a seven-point scale in our study.

\section{(5) Balanced or unbalanced response options}

This choice is related to the balance between the number of favorable and unfavorable response options (De Pelsmacker and Van Kenhove 1994; Green, Tull, and Albaum 1988; Weiers 1988). It is generally agreed upon that a Likert scale should be balanced in order to reduce response bias (Malhotra 1996; Parasuraman 1991). As a result, the Likert scale we use is of a balanced nature.

\section{(4) Forced or non-forced choice of nesponse options}

A forced scale is defined as a scale "that forces respondents to express an opinion because a 'no opinion' or 'no knowledge' option is not provided" (Malhotra 1996, p. 299). In situations where respondents can be expected to have an opinion about the topic under investigation, a forced scale discloses the largest amount of information (Dillon, Madden, and Firtle 1993; Malhotra 1996; Weiers 1988). We included two 'filter questions' (Malhotra 1996) in order to ensure that respondents possessed the necessary information for having an opinion about all statements. First, we only selected respondents who indicated that they buy clothing (or food) themselves. Second, in order to make sure that respondents could provide store-specific information, we only included those respondents who perceived themselves as being a regular customer of that store. As a result, we opted for forced response options.

\section{(5) Labels of response options}

A fifth decision was related to labels accompanying scale categories. First, it is generally agreed upon that the more response options are accompanied by labels, the less ambiguous the resulting scale will be. As a result, we provided category labels for every single response option. Second, verbal category descriptions are recognized to ensure that each respondent is operating from the same base (Dillon, Madden, and Firtle 1993). Consequently, verbal descriptions are used in this study. Third, verbal descriptions were accompanied by numerical designations, which enhances the soundness of treating the results as interval-scaled data (Weiers 1988). Finally, in order to be effective, category descriptions should be located as close to the categories as possible (Malhotra 1996). Therefore, we located labels immediately above the scale categories.

\section{(6) Choice indicators}

This decision concerns the way in which respondents can indicate their choices on the scale. Either circling numbers or ticking blank boxes can be used as choice indicators. As we expected that respondents might perceive higher numbers as representing more favorable answers (Malhotra 1996), we decided to use blank boxes. 


\section{(7) Positive versus negative formulations}

It is generally recognized that alternating between positively and negatively worded items is a good practice in order to reduce potential halo-effects. However, there may be a price to pay for including both positively and negatively worded items (Babakus and Boller 1991: Carman 1990; DeVellis 1991). In their refinement and reassessment of the SERVQUAL scale, Parasuraman, Zeithaml, and Berry (1991) discovered that using negatively worded items may be troublesome for several reasons. First, the standard deviation of negatively worded items was consistently higher than of positively worded items. According to them, this implies that respondents may have been confused by negatively worded items. Second, negatively worded items are perceived to be more awkward and less meaningful than positively worded items. Finally, the Cronbach's alpha coefficients of constructs in which negatively worded items were included, were consistently lower. Consequently, these authors decided to use only positively worded items in their final questionnaire. In line with them, we included only positively worded items in our survey.

\subsubsection{Qualitative Item Testing}

It is generally recognized that data collection should never begin without an adequate pre-test of the content and physical ąppearance of items (Churchill 1995: De Pelsmacker and Van Kenhove 1994: Dillon, Madden, and Firtle 1993; Malhotra 1996). Item pre-testing is considered as testing items on a small sample for the purpose of improving these items by identifying and eliminating potential problems (Malhotra 1996). This section illustrates in which way our items were tested in a qualitative way,

Consumers pre-tested items with respect to layout, item sequence, item wording, and item difficulty. Care was taken that tested consumers were similar to those included in the final data collection in terms of age, gender, and familiarity with the topic (Dillon, Madden, and Firtle 1990/1993; Green. Tull, and Albaum 1988; Malhotra 1996; Parasuraman 1991). Twelve interviewers were carefully briefed and instructed to pre-test the items by conducting personal in-home interviews with a group of consumers equally spread across age, gender, and country (the Netherlands and Belgium). This resulted in a pre-test sample of 60 consumers. Respondents were asked to complete the questionnaire after which they were asked to describe the meaning of each question, to explain their answer, and to state any problems they encountered while answering questions. This technique is referred to as the 'debriefing' procedure (Dillon, Madden, and Firtle 1993; Malhotra 1996). Moreover, respondents were asked to comment upon item sequence and layout. Interviewers prepared written reports in which they described the major problems encountered. On basis of these reports, interviewers and researchers jointly discussed potential improvements of the items.

These consumer pre-tests lead to considerable adaptations of item wording. sequence, and layout. Based upon the literature study, the focus group discussions with consumers, the pilot study, and the qualitative pre-test, the items presented in table 6-3 were formulated. 
Tble 6-3: Item Fomulations

\begin{tabular}{|c|c|c|}
\hline Sonstruct & Item & Statement/Question \\
\hline \multirow[t]{6}{*}{ iociability } & 1 & Generally, I am someone who likes to seek contact with others \\
\hline & 2 & Generally, I am someone who enjoys being among people \\
\hline & 3 & Generally, I am someone who has no difficulty "mingling" in a group \\
\hline & 4 & Generally, I am someone who, given the chance, seeks contact with others \\
\hline & 5 & Generally, $I$ am someone who is rather with someone instead of alone \\
\hline & 6 & $\begin{array}{l}\text { Generally, I am someone who prefers to spend his or her time in the company of } \\
\text { others }\end{array}$ \\
\hline \multirow[t]{6}{*}{ iocial recognition } & 1 & Generally, I am someone who likes to be well-liked \\
\hline & 2 & Generally. I am someone who likes to be appreciated by others \\
\hline & 3 & Generally, I am someone who is concerned about what friends think of him or her \\
\hline & 4 & Generally, I am someone who likes to be respected by others \\
\hline & 5 & Generally, I am someone who is concerned about what others think of him or her \\
\hline & 6 & Generally, 1 am someone who likes to be appreciated by acquaintances \\
\hline \multirow[t]{6}{*}{ Thopping enjoyment } & 1 & Generally, I am someone who enjoys shopping \\
\hline & 2 & Generally, I am someone who enjoys shopping to get ideas \\
\hline & 3 & $\begin{array}{l}\text { Generally, I am someone who enjoys shopping to see whether there is anything } \\
\text { new }\end{array}$ \\
\hline & 4 & Generally, I am someone who enjoys visiting several different stores \\
\hline & 5 & Generally, I am someone who enjoys shopping more than most people \\
\hline & 6 & $\begin{array}{l}\text { Generally, I am someone who considers shopping as a pleasant way to spend his } \\
\text { or her spare time }\end{array}$ \\
\hline \multirow{3}{*}{$\begin{array}{l}\text { Toduct category } \\
\text { involvement }\end{array}$} & 1 & Generally, I am someone who finds it important what clothes he or she buys \\
\hline & 2 & Generally, I am someone who is interested in the kind of clothing he or she buys \\
\hline & 3 & Generally, 1 am someone for whom it means a lot what clothes he or she buys \\
\hline \multirow{6}{*}{$\begin{array}{l}\text { Buyer relationship } \\
\text { proneness }\end{array}$} & 1 & Generally, I am someone who likes to have a special tie with an apparel store \\
\hline & 2 & Generally. I am someone who likes to be a regular customer of an apparel store \\
\hline & 3 & $\begin{array}{l}\text { Generally, } 1 \text { am someone who wants to be a steady customer of the same apparel } \\
\text { store }\end{array}$ \\
\hline & 4 & Generally, I am someone who enjoys having a close tie with an apparel store \\
\hline & 5 & $\begin{array}{l}\text { Generally, I am someone who is willing to "go the extra mile" to purchase at the } \\
\text { same apparel store }\end{array}$ \\
\hline & 6 & Generally, I am someone who tends to buy in the same apparel store \\
\hline \multirow{6}{*}{$\begin{array}{l}\text { Seller relationship } \\
\text { orientation }\end{array}$} & 1 & This store makes efforts to keep regular customers \\
\hline & 2 & This store makes an effort to increase regular customers' loyalty \\
\hline & 3 & This store makes an effort to maintain a long-term tie with regular customers \\
\hline & 4 & This store undertakes various actions to keep holding on to regular customers \\
\hline & 5 & This store makes various efforts to improve its tie with regular customers \\
\hline & 6 & This store really cares about keeping regular customers \\
\hline \multirow[t]{6}{*}{$\begin{array}{l}\text { Relationship } \\
\text { satisfaction }\end{array}$} & 1 & $\begin{array}{l}\text { This store provides me with the kind of relation I am looking for with an apparel } \\
\text { store }\end{array}$ \\
\hline & 2 & I am satisfied with the way this store treats me as a regular customer \\
\hline & 3 & My experiences as a regular customer of this store are positive \\
\hline & 4 & As a regular customer. I have a high quality relationship with this store \\
\hline & 5 & $\begin{array}{l}\text { I am happy with the efforts this store is making towards a regular customer like } \\
\text { me }\end{array}$ \\
\hline & 6 & I am satisfied with the relationship I have with this store \\
\hline
\end{tabular}


Table 6-3: Item Fommulations (continued)

\begin{tabular}{|c|c|c|}
\hline Construct & Item & Statement/Question \\
\hline \multirow[t]{4}{*}{ Trust } & 1 & This store gives me a feeling of trust \\
\hline & 2 & I have trust in this store \\
\hline & 3 & This store gives me a trustworthy impression \\
\hline & 4 & I can count on this store \\
\hline \multirow{4}{*}{$\begin{array}{l}\text { Relationship } \\
\text { commitment }\end{array}$} & I & I consider myself a regular customer of this store \\
\hline & 2 & I am willing to "go the extra mile" to remain a customer of this store \\
\hline & 3 & I feel loyal towards this store \\
\hline & 4 & Even if this store would be more difficuls to reach, I would still keep buying there \\
\hline \multirow[t]{3}{*}{ Behavioral loyalty } & 1 & What percentage of your total expenditures for clothing do you spend in this store? \\
\hline & 2 & $\begin{array}{l}\text { Of the } 10 \text { times that you select a store to buy clothes at, how many times do you } \\
\text { select this store? }\end{array}$ \\
\hline & 3 & $\begin{array}{l}\text { How often do you buy clothes in this store compared to other stores where you } \\
\text { buy elothes? }\end{array}$ \\
\hline
\end{tabular}

\subsubsection{Quantitative Item Testing}

This section discusses how the items presented in table 6-3 were tested on a quantitative basis.

\subsubsection{Sampling Method and Sample Size}

Sampling methods can be classified into probability and nonprobability sampling (Churchill 1995; Green. Tull, and Albaum 1988; Malhotra 1996; Parasuraman 1991). Figure 6-3 displays the major sampling methods available. In this study, a quota sampling method was used in order to generate the samples necessary for quantitatively testing the scale items. Below, we motivate our choice for the quota sampling method and further comment upon three decisions related to its use.

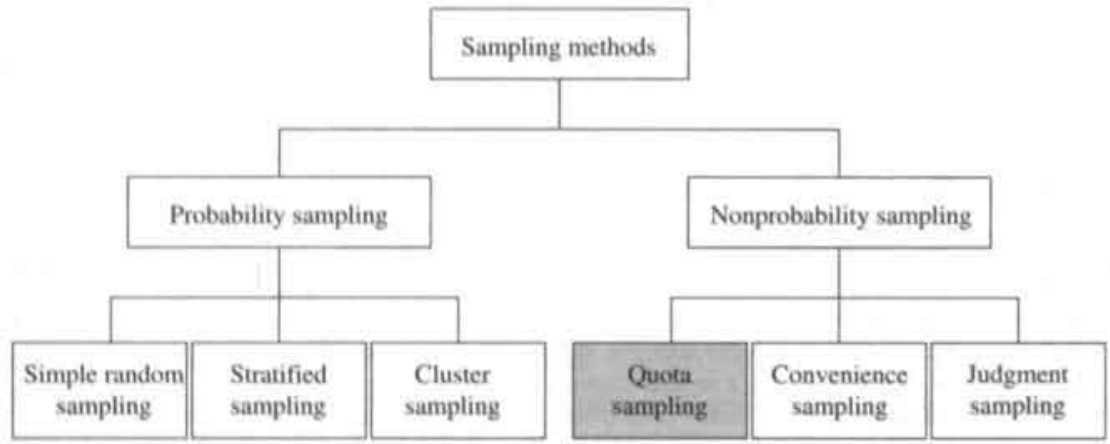

\section{Figure 6-3: Types of Sampling Methods}

While it is generally recognized that nonprobability sampling is inferior to probability sampling with respect to statistical precision and generalizability (Dillon, Madden, and Firtle 1990; Parasuraman 1991), probability sampling was not deemed to be a feasible option in this study. As already stated, our population consists of shopping mall visitors who buy clothing (food) themselves. Moreover, respondents were only allowed to report on stores of which they are regular 
customers. As a result, no prior knowledge on population units was available, preventing the use of probability sampling methods (Parasuraman 1991).

Nonprobability sampling methods are generally divided into convenience, judgment, and quota sampling techniques. In our opinion, quota sampling is the most suitable sampling procedure from the perspective of our study's research objectives. Quota sampling is defined as "a nonprobabilitysampling procedure in which (1) the population is divided into cells on the basis of relevant control characteristics, (2) a quota of sample units is established for each cell, and (3) interviewers are asked to fill the quotas assigned to the various cells" (Parasuraman 1991, p. 548). Given its characteristic of controlling the composition of the sample, quota sampling is considered to be the most refined form of nonprobability sampling (Parasuraman 1991). Several authors even argue that, under certain conditions, quota sampling obtains results that are close to those of the probabilistic stratifiedrandom-sampling procedure (De Pelsmacker and Van Kenhove 1994; Malhotra 1996; Parasuraman 1991). However, sample representativeness can decrease as a result of the omission of important quota criteria and the biases that may occur as a result of interviewers' subjective selection of respondents (Churchill 1995). Below, we describe the way in which we composed our quota samples, resulting from maximal efforts to avoid potential biases.

\section{(1) Division of research population in cells based upon control characteristics}

A recognized benefit of quota samples is that their representativeness can be enhanced by controlling for several relevant population characteristies at once (Parasuraman 1991). In this study, visitors were divided into cells based upon five quota characteristics: age ( 18 to 25 years. 26 to 40 years, 41 to 55 years, and older than 55 years), gender (female and male), time-of-theday (morning, early afternoon, and late afternoon), day-of-the-week (Wednesday, Friday, and Saturday), and allocated share-of-wallet for the store $(0-20 \%, 21-40 \%, 41-60 \%, 61-80 \%$, and $81-100 \%)$. As these quota are generally considered to influence attitudes and behavior towards shopping (Bellenger and Korgaonkar 1980; Carman 1970; Gutman and Mills 1982), they were relevant for the objectives of our study.

The procedure used for filling the required quota was as follows. Within time-of-the-day, dayof-the-week, and gender quota, interviewers judged mall visitors' ages. If a visitor was expected to fit the required age criterion, interviewers approached this visitor. Across our samples, an average of $37 \%$ of the persons who were approached participated. In case a visitor was willing to participate, a filter question related to buying in the product category was asked first. If respondents passed the filter, they were asked to indicate in which five stores they usually buy casual clothing (or food). Next, respondents indicated (1) their share-of-wallet for each store they listed (measured as a continuous scale from $0 \%$ to $100 \%$ ) and (2) the extent to which they felt being a regular customer of each store (measured on a noncomparative rating scale from 1 to 7). Respondents were split into groups according to the store they needed to provide information about ${ }^{3}$. Respondents were divided between five share-of-wallet levels $(0-20 \%, 21-40 \%, 41-60 \%$, $61-80 \%$, and $81-100 \%$ ) with the objective of approximating a normal distribution for the shareof-wallet variable. In line with Gwinner, Gremler, and Bitner (1998), only those stores were

This was done in order to achieve maximal spread in the values of behavioral loyalty, thereby enhancing detection of significant relationships between variables. 
included for which respondents indicated 'more or less', 'probably yes', 'certainly yes', and 'most definitely yes' to the question 'to what extent do you consider yourself a regular customer of this store?' in order to make sure that respondents were able to provide valid and reliable information on attitudes towards stores. Respondents were then asked to respond to the remaining questions focusing on that particular store.

\section{(2) Number of sample units in each cell}

Sample units were spread across countries and product categories (the Netherlands clothing $N=92$, the Netherlands food $N=104$, Belgium clothing $N=90$, Belgium food $N=85$ ). With respect to gender, two thirds of the visitors included in the sample were female. While statisties on the proportion of women in retail buying are not available, it is generally recognized that buying has traditionally been female-dominated (Kline and Wagner 1994). However, despite their lack of propensity for engaging in shopping activities, males are doing more of the shopping than was the case in previous generations and in categories that traditionally were not part of their shopping domain, such as grocery and clothing (Evans, Christiansen, and Gill 1996). Therefore, the emphasis in our sample was on female consumers, without neglecting male consumers. With respect to share-of-wallet, its frequencies were intended to approximate a normal distribution and, consequently, were not equally spread.

\section{(3) Representativeness of the sample}

Various steps were taken in order to maximize the representativeness of the quota sample. First. interviewers' judgments can affect the allocation of respondents to the defined quota. We made efforts to reduce potential interviewer selection bias by pointing out to the interviewers that all potential respondents falling within the quota should be approached, irrespective of their perceived friendliness or other characteristics that might influence interviewers' selections (Green. Tull and Albaum 1988: Parasuraman 1991). Second, biases potentially occurring as a result of traffic and parking flows were minimized by stratifying interviewers across mallentrance locations. Third, we reduced possible shopping pattern biases by stratifying interviews across time-of-the-day and day-of-the-week segments (Dillon, Madden, and Firtle 1990; Sudman 1980).

\subsubsection{Principal Components A nalysis}

The previously generated items were intended to measure multi-item constructs. It is generally acknowledged that multi-item measures should be preferred to single-item measures in order to measure constructs (Churchill 1979). A first advantage of a multi-item scale is its ability to soundly measure multifaceted and complex constructs. Second, multi-item scales allow an assessment of reliability and validity (Dillon, Madden, and Firtle 1993). In this section, we discuss the exploratory factor analyses applied to the items described in table 6-3.

One way to conduct an exploratory factor analysis is a principal components analysis. This is a data reduction technique aimed at constructing linear combinations of the original items that account for as much of the (original) total variation as possible. The successive linear combinations are extracted in such a way that they account for successively smaller amounts of the total variation 
(Dillon and Goldstein 1984), Our objective of the principal components analyses was to investigate whether items correctly measured the following intended constructs: sociability, social recognition, shopping enjoyment, product category involvement, buyer relationship proneness, "seller relationship cientation, relationship satisfaction, trust, relationship commitment, and behavioral loyalty. In oder to determine which constructs to group in the principal components analyses, we developed figure 6-4 on basis of the construct definitions presented in chapters three and four. Figure 6-4 indicates that constructs differ on two dimensions: what is the construct about (one store versus the respondent or stores in general) and who does the construct concern (the respondent versus regular castomers). Since we do not have any theoretical argument to assume that constructs in different qaadrants measure the same concept as they relate to a different unit of analysis, we conducted separate principal components analyses including the constructs of each quadrant.

What is it about?

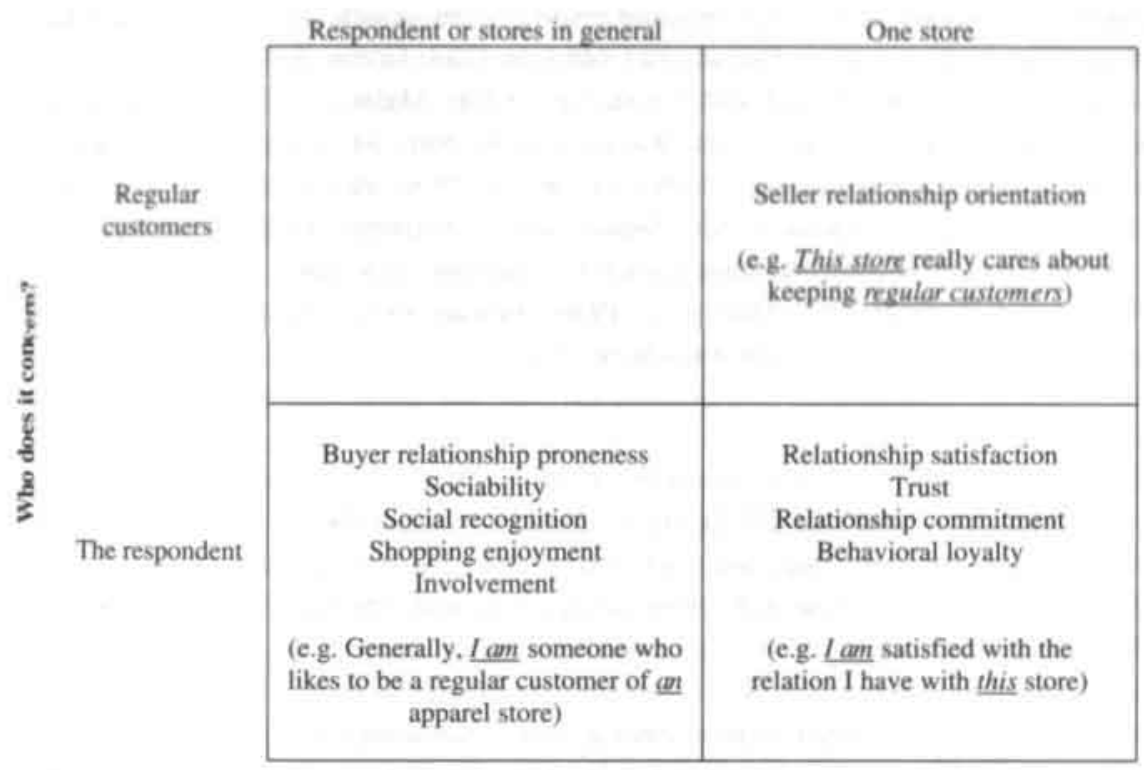

Figure 6-4: Classification of Constructs on Two Dimensions

Factor analysis is defined as "a multivariate statistical technique that is concerned with the identification of structure within a set of observed variables" (Stewart 1981, p. 51). Two types of factor analysis can be distinguished. When the underlying dimensions of a data set are unknown. exploratory factor analysis is appropriate. When the objective is theory building, relationships can be tested by use of confirmatory factor analysis (Dillon and Goldstein 1984; Stewart 1981). While some prior theoretical information on the common structure underlying the data was available (De Wulf and Odekerken-Schröder 1999), we applied exploratory factor analysis in order to select the most appropriate items for each construct from a broader list of items. While several techniques of exploratory factor analysis can be distinguished, empirical evidence has shown that the choice of one particular technique is not crucial to the final results (Stewart 1981). Since principal 
components analysis leads to unique reproducible results and since it is most commonly applied, we selected this technique (Churchill 1995; Green, Tull, and Albaum 1988; Kerlinger 1986; Weiers 1988). The procedure of reducing a total set of items in order to provide preliminary scales that can subsequently be tested and refined in a confirmatory factor analysis is commonly accepted (Gerbing and Anderson 1988; Steenkamp and van Trijp 1991).

Three technical decisions need to be taken in carrying out a principal components analysis: (1) the rotation method used, (2) the number of components derived, and (3) the minimal level of loadings and maximal level of item cross-loadings. Below, we motivate our choices related to these three aspects.

\section{(1) Rotation method used}

There are two methods to rotate component axes: orthogonal rotation and oblique rotation. As opposed to oblique rotations, orthogonal rotations result in components that are uncorrelated (De Pelsmacker and Van Kenhove 1994; Dillon and Goldstein 1984; Green. Tull, and Albaum 1988; Gundlach and Cadotte 1994; Howell 1987; Kerlinger 1986; Malhotra 1996). As there is no theoretical or intuitive reason to believe that the latent constructs we selected are uncorrelated, an oblique rotation procedure is considered to be the most appropriate. Five generally recognized oblique rotation methods are biquartimin. covarimin, oblimax, oblimin, and quartimin. While these five methods have different characteristics, their results are basically similar (Dillon and Goldstein 1984; Hair et al. 1998; Stewart 1981). As the default option in SPSS is oblimin, we applied this oblique rotation method.

(2) Number of components derived

As the underlying structure of the data sets was known in advance based upon previous studies (De Wulf and Odekerken-Schröder 1999), the number of components to be derived was not based on the criterion of eigenvalues nor on the scree-test, but was predetermined (Churchill 1995; De Pelsmacker and Van Kenhove 1994; Green, Tull, and Albaum 1988; Malhotra 1996: Stewart 1981).

\section{(3) Minimal level of item loadings and maximal level of item cross-loadings}

It is generally recognized that loadings should at least be .60 (Hair et al. 1995: Steenkamp and van Trijp 1991; Stewart 1981). Moreover, cross-loadings of .40 or less are considered to be too low to be of significant importance (Kerlinger 1986). We only accepted items that minimally loaded .65 on the hypothesized component and maximally loaded . 30 on the other components. Items were removed or adjusted in order to improve loadings.

The results of the principal components analyses are included in tables A4-1 to A4-4 (see appendix four). An aggregated evaluation of item performance in the four sub-samples together is outlined in table A4-5 (see appendix four). Summarizing, we can state that practically all items of intended constructs loaded on separate components, supporting their theoretical distinctiveness. However,

As structural equation modeling, the data analysis technique that will be used in chapter seven, is more rigid in its evaluation of construct unidimensionality than principal components analysis, we used more strict cut-off levels in the exploratory principal components analysis. 
principal components results differed between the four sub-samples with respect to the percentage of items that matched our criteria. While the Dutch sample showed $78 \%$ satisfactory items for dothing and $72 \%$ for food, the Belgian sample resulted in $76 \%$ satisfactory items for clothing and $74 \%$ for food 5 . This indicates that the performance of items differed across the four sub-samples. As could somewhat be expected (see 4.2.1), it appeared that the attitudinal relationship outcomes (relationship satisfaction, trust, and relationship commitment) were most difficult to distinguish. In al samples, trust and relationship satisfaction partially loaded on the same component. Decisions to select final items were based upon the decision rules outlined in the next section.

\subsubsection{Assessmemt of Reliability}

I this section, we report the results of a reliability analysis regarding each of the components included in table 6-4. Reliability is "the degree to which measures are free from error and therefore yield consistent results" (Peter 1979, p. 6). There are three basic methods for assessing reliability: (1) test-retest, (2) internal consistency, and (3) alternative forms (Peter 1979). Several scholars indicate that internal consistency measures are most useful for assessing the reliability of measures in marketing research (Churchill 1979; DeVellis 1991; Dillon, Madden, and Firtle 1990; Green, Tull. and Albaum 1988: Peter 1979; Peterson 1994). Internal consistency can be defined as "the reliability within single testing occasions" (Green, Tull, and Albaum 1988, p. 254). There exist two generally accepted methods to determine internal consistency reliability: item-to-total correlations and Cronbach's alpha (Cronbach 1951; Dillon, Madden, and Firtle 1990). First, we discuss the decision rules that we applied for selecting items from table A4-5 (see appendix four) to be included in the final stage of data collection. Second in table 6-4, item-to-total correlations and Cronbach's alpha coefficients are reported for the constructs measured by these selected items.

We applied the following decision rules for selecting items. First, we decided upon the number of items to select. We included three items for each construct in order to guarantee comparability between constructs' reliabilities. Various authors indicate that Cronbach's alpha values can artificially increase as a result of an increasing number of items (Churchill 1979; Churchill and Peter 1984; Malhotra 1996; Peter 1979; Peterson 1994). Churchill and Peter (1984, p. 363) stated that "other things being equal, measures can be made more reliable by increasing the number of items in the scale". Moreover, limiting construct measurement to three items avoided potential problems occurring as a result of respondents' boredom, irritation, and fatigue (Peter 1979). The second decision rule was related to the question which three items to select from the available set of items per construct. For each construct, we selected three items that loaded equal to or higher than .65 on their intended component and lower than .30 on other components.

The four sub-samples were merged into an overall sample of 371 respondents. The internal consistency of the constructs was explored through calculating Cronbach's alpha values for each construct and item-total correlations for each item. Both of them are reported in table 6-4. First, all constructs revealed Cronbach's alpha values of .80 or more, except sociability (.69), social

These percentages were calculated by dividing the number of shaded areas in table A4-5 by the total number of items (50). 
Tahle 6-4: Intemal Consistency of Constructs

\begin{tabular}{|c|c|c|c|}
\hline Construct & Items and comesponding item-to-total correlations ( $\left.{ }^{*}\right)$ & & $\alpha$ \\
\hline Sociability & $\begin{array}{l}\text { 1. Generally, I am someone who likes to seek contact with others } \\
\text { 3. Generally, I am someone who has no difficulty "mingling" in a group } \\
\text { 4. Generally, I am someone who, given the chance, seeks contact with others. }\end{array}$ & $\begin{array}{l}57 \\
.43 \\
.55 \\
\end{array}$ & .69 \\
\hline Social recognition & $\begin{array}{l}\text { 2. Generally, I am someone who likes to be appreciated by others } \\
\text { 4. Generally, I am someone who likes to be respected by others } \\
\text { 6. Generally, I am someone who likes to be appreciated by acquaintances }\end{array}$ & $\begin{array}{r}59 \\
.62 \\
43 \\
\end{array}$ & .71 \\
\hline $\begin{array}{l}\text { Shopping } \\
\text { enjoyment }\end{array}$ & $\begin{array}{l}\text { 1. Generally, I am someone who enjoys shopping } \\
\text { 3. Generally, I am someone who enjoys shopping to see whether there is } \\
\text { anything new } \\
\text { 6. Generally. I am someone who considers shopping as a pleasant way to spend } \\
\text { his or her spare time. }\end{array}$ & .80 & .90 \\
\hline $\begin{array}{l}\text { Product category } \\
\text { involvement }\end{array}$ & $\begin{array}{l}\text { 1. Generally, I am someone who finds it important what clothes he or she buys } \\
\text { 2. Generally, } 1 \text { am someone who is interested in the kind of clothing he or she } \\
\text { buys } \\
\text { 3. Generally, I am someone for whom it means a lot what clothes he or she buys }\end{array}$ & 74 & .88 \\
\hline $\begin{array}{l}\text { Buyer relationship } \\
\text { proneness }\end{array}$ & $\begin{array}{l}\text { 2. Generally, I am someone who likes to be a regular customer of an apparel } \\
\text { store } \\
\text { 3. Generally, I am someone who wants to be a steady customer of the same } \\
\text { apparel store } \\
\text { 5. Generally, I am someone who is willing to "go the extra mile" to purchase at } \\
\text { the same apparel store }\end{array}$ & .73 & .87 \\
\hline $\begin{array}{l}\text { Seller relationship } \\
\text { orientation }\end{array}$ & $\begin{array}{l}\text { 2. This store makes an effort to increase regular customers' loyalty } \\
\text { 5. This store makes various efforts to improve its tie with regular customers } \\
\text { 6. This store really cares about keeping regular customers }\end{array}$ & $\begin{array}{l}.69 \\
.69 \\
.70 \\
\end{array}$ & 83 \\
\hline $\begin{array}{l}\text { Relationship } \\
\text { satisfaction }\end{array}$ & $\begin{array}{l}\text { 4. As a regular customer, I have a high quality relationship with this store } \\
\text { 5. I am happy with the efforts this store is making towards a regular customer } \\
\text { like me } \\
\text { 6. I am satisfied with the relationship I have with this store }\end{array}$ & .61 & .80 \\
\hline Trust & $\begin{array}{l}\text { 1. This store gives me a feeling of trust } \\
\text { 2. I have trust in this store } \\
\text { 3. This store gives me a trustworthy impression }\end{array}$ & $\begin{array}{l}.73 \\
.77 \\
.70 \\
\end{array}$ & .86 \\
\hline $\begin{array}{l}\text { Relationship } \\
\text { commitment }\end{array}$ & $\begin{array}{l}\text { 2. I am willing to "go the extra mile" to remain a customer of this store } \\
\text { 3. I feel loyal towards this store } \\
\text { 4. Even if this store would be more difficult to reach, I would still keep buying } \\
\text { there }\end{array}$ & $\begin{array}{l}.60 \\
.62 \\
52\end{array}$ & .75 \\
\hline Behavioral loyalty & $\begin{array}{l}\text { 1. What percentage of your total expenditures for clothing do you spend in this } \\
\text { store? } \\
\text { 2. Of the } 10 \text { times that you select a store to buy clothes at, how many times do } \\
\text { you select this store? } \\
\text { 3. How often do you buy clothes in this store compared to other stores where } \\
\text { you buy clothes? }\end{array}$ & .79 & .85 \\
\hline
\end{tabular}

(*) Item numbers refer to the numbers included in table 6-3. 
recognition (.71), and relationship commitment $(.75)$. While there exists no commonly accepted standard as to which alpha level can be regarded as low or high, most scholars agree that alpha values within the range of .75 to .95 are desirable (Davis 1964: Kaplan and Saccuzzo 1982; Murphy and Davidshofer 1988; Nunnally 1967/1978; Peterson 1994).

Second, item-to-total correlations surpassed .60 , except the items of sociability $(.57, .43, .55)$, two items of social recognition (.59, .43), one relationship commitment item (.52), and one behavioral loyalty item (.59). General threshold values for item-to-total correlations range from .30 and .60 (Green. Tull, and Albaum 1988; Steenkamp and Van Trijp 1991).

As the internal consistency measures of the included constructs were appropriate, we could proceed to the development of the final questionnaire.

\subsection{Questionnaire Development ${ }^{6}$}

Several decisions were made related to the design of the questionnaire ${ }^{7}$ used in the final data collection: question sequence, questionnaire layout, questionnaire instructions, and questionnaire translation.

\section{(1) Question sequence}

First, it is generally recommended to use simple, interesting, and non-threatening questions at the start of a questionnaire (Churchill 1995; Malhotra 1996; Parasuraman 1991). Our questionnaire started with a simple question related to the individual shopping behavior of the respondent. Second, classification information should be asked at the end of the questionnaire, as the basic information should come first in case respondents stop answering questions (Churchill 1995: Parasuraman 1991). The only classification question related to age of the respondent was asked as the final question in our survey. Third, scholars agree that difficult or sensitive questions should be positioned late in questionnaire (Churchill 1995; Malhotra 1996). Questions related to the personality of the respondent (buyer relationship proneness), which are generally regarded as more threatening, were asked in the second part of our questionnaire. Finally, it is considered useful to divide a questionnaire into several logical parts. Skipping from topic to topic in a random fashion may confuse respondents, break their train of thought, and cause errors in the data (Malhotra 1996; Parasuraman 1991). In our questionnaire, questions were bundled according to the quadrants depicted in figure 6-4. Items within each quadrant were mixed in order to reduce potential halo-effects (Churchill 1995; De Pelsmacker and Van Kenhove 1994; Kerlinger 1986).

\section{(2) Questionnaire layout}

Physical characteristics of a questionnaire can affect the accuracy of the information obtained. First, if a questionnaire looks sloppy, respondents might think that the study is unimportant and might refuse to participate as a result of it (Churchill 1995; Malhotra 1996; Parasuraman 1991).

\footnotetext{
In appendix five, the questionnaire is included.

The questionnaires for clothing and food were identical except for the use of the terms 'apparel store' in the clothing questionnaire and 'supermarket' in the food questionnaire.
} 
The results of the pre-test with consumers assisted us in finetuning the layout of the questionnaire. Second, a crowded questionnaire can lead to errors because respondents become confused. Questions that are adequately separated from each other and that properly locate answer spaces will significantly lower error chances (Churchill 1995; Malhotra 1996; Mayer and Piper 1982). In our survey, questions were separated from each other by means of alternately using shaded and white lines, enhancing the readability of the statements.

\section{(3) Questionnaire instructions}

It is very important to provide clear instructions to respondents. First, the cover letter should convince the respondent to cooperate and clarify the purpose of the study (Churchill 1995; Parasuraman 1991). A brief cover letter was included at the beginning of our questionnaire. Second, instructions for individual questions should be placed as close to the questions as possible. It is a common practice to distinguish instructions from questions by using distinctive appearance (Malhotra 1996). In our questionnaire, instructions were located immediately above the corresponding questions in a separate, shaded box.

\section{(4) Questionnaire translation}

As the questionnaire was administered in both Dutch and English speaking countries, the original Dutch questionnaire had to be translated into English. Three main translation procedures can be distinguished: direct translation, back translation, and parallel translation. The main objective of a translation procedure is to enhance translation equivalence (Douglas and Craig 1983). Translation equivalence is defined as "the demonstration that two individuals from different countries with the same value on some variable will score at the same level on the same test; also called metric equivalence" (Malhotra 1996, p. 813). As back translation is the most commonly used translation technique (Malhotra 1996), we applied this procedure. Two qualified translators carried out the back translation procedure (Brislin 1980; Dillon, Madden. and Firtle 1990/1993; Malhotra 1996).

One translator first translated the original Dutch version of the questionnaire into English and a second translator then retranslated the questionnaire into Dutch. The first translator was a native speaker of American English and fluent in Dutch, whereas the second translator was a native speaker of Dutch and fluent in American English. Back translation allowed us to identify and correct possible discrepancies that arose in the meaning between the original and retranslated questionnaires. In consultation with the translators, we reconciled any differences that emerged. In a final step, the quality of the translation was evaluated by a mono-linguistic, native American on clarity and comprehensiveness of the translated questionnaire.

\subsection{Summary and Conclusions}

First, we motivated our choices for non-experimental research, cross-sectional research, survey research, personal interviewing and mall-intercept interviewing. Second, we discussed the methods used for generating and testing scale items together with their results. Successively, we discussed the specification of the construct domain, the procedures used for generating items, qualitative testing of these items, and quantitative testing of items accompanied by principal components 
analyses and internal consistency measures of the multi-item constructs. Finally, we commented upon the design and translation of the questionnaire used for the final data collection. 


\section{Chapter Structure}

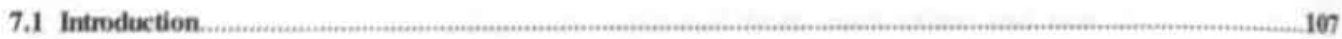

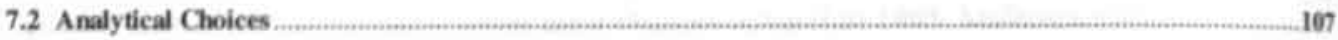

7.2.1 Why Sirnucturul Equation Modeling?

7.2.2 Procedunal Decisions related to Using Structural Equation Modeling _.......................................... 105

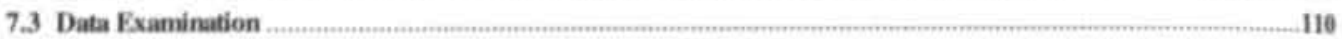

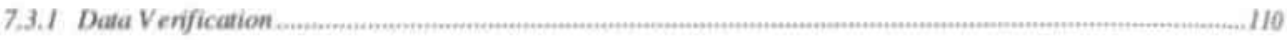

7.3.2 Examination of Nomality ...................

7.3.3 Examination of Data Pooling ...........

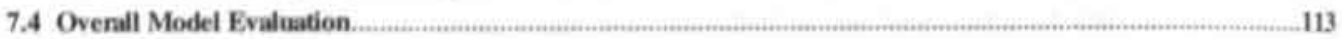

7.5 Measurement Model Evaluation. 115

7.6 Structural Model Evaluation. 120

7.6.1 Evaluation of the Hypothesized Medel ........... 120

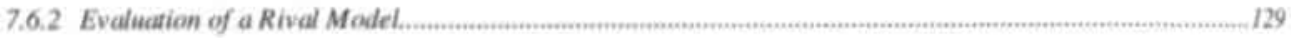

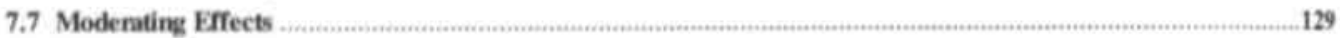

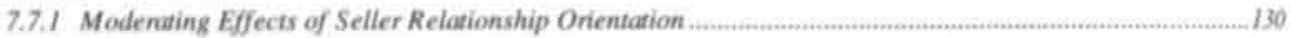

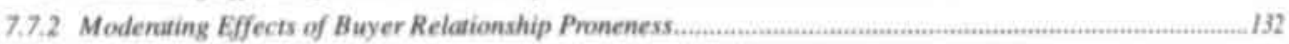

7.7 .3 Moderuting Effects of Product Category Involvement.

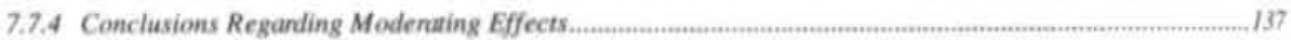

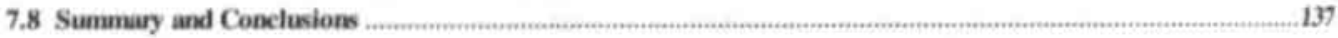




\section{Chapter 7 Empirical Results}

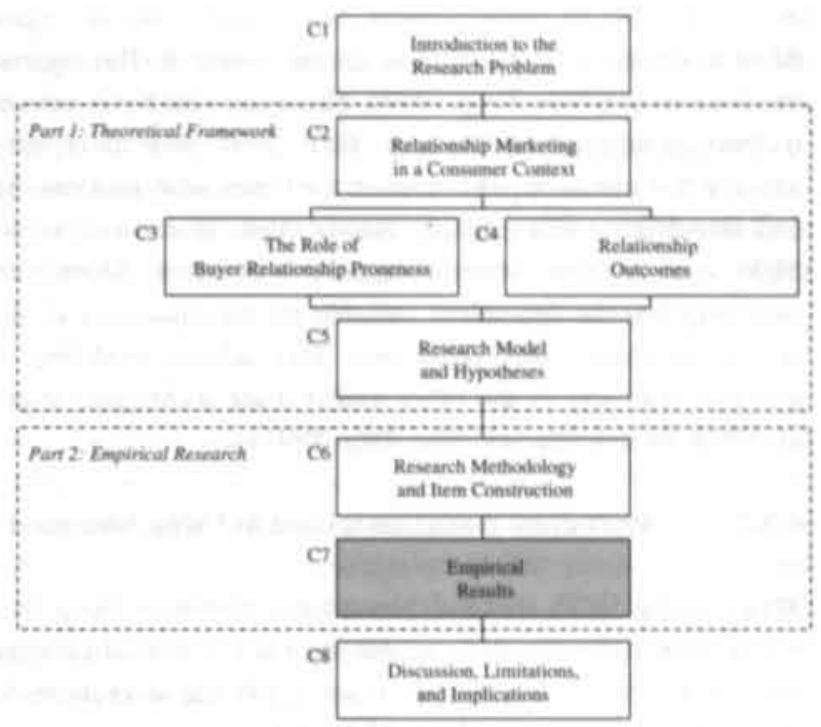

\subsection{Introduction}

The research model outlined in chapter five was empirically validated on basis of six different samples spread across countries (the Netherlands, Belgium, and United States) and product categories (casual clothing and food). This chapter presents the empirical results.

Section 7.2 describes choices and underlying motivations related to the use of structural equation modeling (SEM). Section 7.3 clarifies the steps that were taken for examining the properties of the raw data sets. In sections 7.4 to 7.6 , we evaluate the performance of the overall models, measurement models, and structural models related to each sample. Finally, section 7.7 reports the results of several two-group LISREL analyses related to each of the samples aimed at detecting moderating effects.

\subsection{Analytical Choices}

In this section, we motivate why SEM is the most suitable data analysis technique for testing the research hypotheses formulated in chapter five. Moreover, we explain several procedural decisions we made related to the implementation of SEM.

\subsubsection{Why Structural Equation Modeling?}

In this study, each construct represents a latent variable composed of three indicators, Moreover, testing the research hypotheses mentioned in chapter five implies investigating the relationships 
between latent constructs that can both act as dependent and independent variables. As a result, SEM is the most appropriate technique for investigating the proposed research model.

SEM is a widely used tool in academic research (Baumgartner and Homburg 1996; Hair et al. 1998; Steenkamp and Van Trijp 1991). There are two basic advantages of using SEM as opposed to more traditional analysis techniques. First, it is able to represent interrelated, latent concepts and to account for measurement error in the estimation process. Second, SEM allows to estimate multiple and interrelated dependence relationships. In contrast to for instance multiple regression analysis, SEM can estimate several equations at once. Moreover, these equations can be interrelated, implying that the dependent variable in one equation can simultaneously be an independent variable in one or more other equations. This allows modeling of complex relationships, which is not possible with any of the other multivariate techniques available (Fornell and Larcker 1981; Hair et al. 1998; Steenkamp and Van Trijp 1991).

\subsubsection{Procedurnl Decisions related to Using Structural Equation Modeling}

When using SEM, several procedural decisions need to be taken before estimation can occur. Successively, we discuss our choice for (1) a total disaggregation model, (2) three indicators per construct, (3) the covariance matrix, (4) the maximum likelihood estimation technique, (5) the single-step analysis, and for (6) LISREL.

\section{(1) Total disaggregation model}

There exist three levels of abstraction in modeling constructs: total aggregation, partial (dis)aggregation, and total disaggregation. In a total aggregation model, single, composite measures of constructs are used as input for SEM by combining all indicators of a construct. In a partial (dis)aggregation model, subsets of items are combined into various composites that are treated as multiple indicators of a particular construct. In a total disaggregation model, the true single items are used as multiple measures of a latent construct. As the latter approach allows the most explicit test of construct quality (Baumgartner and Homburg 1996), a completely disaggregated model is estimated in this study.

\section{(2) Number of indicators per construct}

The question of how many items should be used to measure a construct is not solved in literature (Baumgartner and Homburg 1996). While a construct can be represented with two indicators, three indicators is regarded as the preferred minimum number. As a general rule, three indicators per construct are needed for a model to be identified (Baumgartner and Homburg 1996; Bollen 1989; Hair et al. 1998). The use of only two indicators increases chances of creating an infeasible solution (Baumgartner and Homburg 1996; Bentler and Chou 1987; Hair et al. 1998). However, while it is generally recognized that it is advantageous to have many indicators per construct, too many indicators can result in a non-parsimonious measurement model (Anderson and Gerbing 1984; Baumgartner and Homburg 1996; Bentler and Chou 1987). In our study, all constructs were measured on basis of three items. 


\section{(3) Type of input matrix}

Basically, two types of input matrices can be used: correlation or covariance matrices. The covariance matrix has the advantage of providing valid comparisons of unstandardized coefficients across different populations or samples. This is not possible when models are estimated on basis of a correlation matrix. Overall, covariance matrices should be used in case a true 'test of theory' is being aimed for (Hair et al. 1998). Baumgartner and Homburg (1996, p. 148) recommended that "in future research all analyses be conducted on covariance matrices". In this study, several samples are compared to each other. Moreover, the purpose of the study is to test a proposed theoretical model. Consequently, the covariance matrix is used as an input matrix (see appendix eight).

\section{(4) Estimation technique}

Estimation techniques transform the covariance matrix of observed variables into structural parameters. There exist several estimation techniques such as generalized least squares maximum likelihood, ordinary least squares, two-stage least squares and unweighted least squares (Bollen 1989). Currently, maximum likelihood estimation is the most widely used approach in SEM (Anderson and Gerbing 1988; Baumgartner and Homburg 1996; Bollen 1989). It is recognized that maximum likelihood estimates are rather robust against moderate violations of the normality assumption provided that sample sizes are larger than 100 (Anderson and Gerbing 1988; Steenkamp and Van Trijp 1991). While asymptotically distribution-free (ADF) estimation procedures for non-normally distributed data exist, these generally require very large sample sizes, limiting their practical usefulness (Baumgartner and Homburg 1996: Jöreskog and Sörbom 1989; Steenkamp and Van Trijp 1991). Steenkamp and Van Trijp (1991) suggested that. for being able to use weighted least squares, an example of an ADF estimation technique, the sample size should be at least $1.5^{*}$ (number of items)*(number of items +1 ). In the context of this study, this would imply a sample size of minimally 3,825. As our samples were not large enough for that purpose, maximum likelihood is used to estimate the structural parameters in this study. Moreover, Baumgartner and Homburg (1996) argued that simulations by Sharma, Durvasula, and Dillon (1989) have shown that ADF techniques do not necessarily outperform maximum likelihood estimation methods, even though they might be expected to be more appropriate theoretically.

\section{(5) Single-step analysis}

A single-step analysis involves the simultaneous estimation of both measurement and structural models. A two-step analysis refers to a separate estimation of the measurement model prior to the simultaneous estimation of measurement and structural models (Anderson and Gerbing 1988). The first approach is considered to be preferable when the model possesses both strong theoretical rationale and highly reliable measures (Hair et al. 1998). This is also underlined by Kumar and Dillon (1987, p. 98) who stated that "though measurement and structure can be evaluated independently of each other, in general they should not be". Since principal components analyses revealed highly reliable measures of the constructs included in our research model (see table 6-4) and sufficient theoretical support exists for the structural model paths (see chapter five), a single-step analysis is considered to be most appropriate. 


\section{(6) Statistical program}

The most widely used program is LISREL, considered as a truly flexible statistical program for a number of research situations (Hair et al. 1998). In their review of the use of SEM in marketing research, Baumgartner and Homburg (1996) showed that 85 percent of authors used LISREL to perform their SEM analysis. In this study, LISREL version 8.14 using the SIMPLIS command language is used (Jöreskog and Sörbom 1993).

\subsection{Data Examination}

In 7.3.1, we discuss the way in which the raw data sets were examined, 7.3.2 describes the results of univariate and multivariate tests of normality for each of these data sets. Finally, in 7.3.3, we check whether it is allowed to pool our data sets across either countries or product categories.

\subsubsection{Data Verification}

Data were collected in three different countries (the Netherlands, Belgium, and United States) for two different product categories (casual clothing and food). In chapter six, the procedure used for collecting data in the quantitative test was explained, which is similar to the final data collection underlying the results presented in this chapter. Mall intercept personal interviews were administered at Eindhoven Heuvelgalerie (the Netherlands), Wijnegem Shopping Center (Belgium), and Orlando Shopping Mall (United States). This resulted in six different samples presented in table $7-1$.

Table 7-1: Profile of the Samples ${ }^{(*)}$

\begin{tabular}{|c|c|c|c|c|c|c|c|}
\hline \multicolumn{2}{|l|}{ Samples } & \multicolumn{2}{|c|}{ Gender (\%) } & \multicolumn{4}{|c|}{ Age (\%) } \\
\hline & $\mathbf{N}$ & Male & Female & $18-25$ & $26-40$ & $41-55$ & $\geq 55$ \\
\hline The Netherlands clothing & 338 & 30.5 & 69.5 & 29.0 & 25.4 & 20.1 & 25.4 \\
\hline The Netherlands food & 337 & 27.0 & 73.0 & 29.8 & 29.2 & 19.6 & 21.4 \\
\hline Belgium clothing & 302 & 30.2 & 69.8 & 24.8 & 25.2 & 23.8 & 26.1 \\
\hline Belgium food & 289 & 29.4 & 70.6 & 25.3 & 22.5 & 26.0 & 26.3 \\
\hline United States clothing & 230 & 32.6 & 67.4 & 36.5 & 31.3 & 23.5 & 8.7 \\
\hline United States food & 231 & 40.8 & 59.2 & 55.4 & 25.1 & 16.5 & 3.0 \\
\hline
\end{tabular}

${ }^{(*)}$ after listwise deletion of cases incorporating missing values

First, we checked whether coding errors appeared in the raw data sets. For those cases in which we observed coding errors, the original questionnaire was consulted in order to correct these errors (Baumgartner and Homburg 1996; Churchill 1995; Green, Tull, and Albaum 1988; Weiers 1988). Second, original values of the items of the construct 'behavioral loyalty' were recoded into their corresponding standardized values as they were initially measured on basis of different types of scales. Finally, we deleted cases incorporating missing values prior to data analysis. The practice of listwise case deletion is suitable as long as the proportion of missing values is not too large (Hair et al. 1998). While the percentage of deleted cases in the European samples was limited to less than one percent, respectively 9.8 and 19.5 percent of cases were deleted in the US samples. Nevertheless, no significant differences in sample composition (with regard to age and gender) before and after case deletion could be detected. Consequently, listwise deletion of cases in the US samples was not considered to be troublesome. 
Oae drawback of listwise deletion is that it may seriously reduce sample size, a key concern in SEM. Little theoretical guidance exists related to adequate sample sizes (Baumgartner and Homburg 1996). It is generally accepted that the minimal sample size needed to ensure appropriate use of maximum likelihood estimation is 100 to 150 (Anderson and Gerbing 1988). However, in case sample sizes become too large, maximum likelihood estimation becomes too sensitive and almost any difference is significant, making all goodness-of-fit measures indicate poor fit. As a result, a sample size of 200 is generally proposed as the critical sample size. However, larger sample sizes are required in case of model misspecification, model complexity, non-normality of data, or the use of alternative estimation procedures (Hair et al. 1998). In this study, we used somewhat larger sample sizes given the risk of moderate normality violations (see next section) and the complexity of the model. The univariate statistics for each of the items related to our constructs are reported in appendix six.

\subsection{Examination of Nomality}

SEM is quite sensitive to the distributional characteristics of the data, particularly the departure from multivariate normality. A lack of multivariate normality is troublesome because it inflates the chi-square statistic, creates upward bias in critical values for determining coefficient significance, and affects standard errors (Baumgartner and Homburg 1996; Bentler 1990; Hair et al. 1998; Jaccard and Wan 1996; Jöreskog and Sörbom 1989; Steenkamp and Van Trijp 1991). The necessary analyses for univariate and multivariate normality assessment can be conducted fairly easy with specialized programs such as PRELIS (Baumgartner and Homburg 1996; Jöreskog and Sörbom 1993). We used PRELIS2 in order to perform tests of normality based on the skewness and kurtosis of the observed variables (Bollen 1989).

In an effort aimed at generating normally distributed variables, one of the indicators of the endogenous construct behavioral loyalty was predetermined to follow a normal distribution (see 6.3.4.1). As several other constructs are directly or indirectly theoretically related to the construct of behavioral loyalty, this effort was expected to have a positive influence on the distributional characteristics of these other constructs. While this behavioral loyalty item followed a normal distribution, all samples revealed significant kurtosis and skewness p-values for most other observed variables. However, sample sizes were considered to be large enough to partially compensate for the existing kurtosis, reducing biases in parameter estimates (Hair et al. 1998) ${ }^{1}$. We did not transform non-normally distributed variables as this would introduce additional problems by altering the meaning of actual responses (Anderson, Lodish, and Weitz 1987; Gassenheimer, Davis, and Dahlstrom 1998).

\subsubsection{Examination of Data Pooling}

In order to decide whether we needed to estimate the structural model separately, we investigated the possibility of pooling data across countries and/or product categories. By means of several two-

However, we should take into consideration that larger sample sizes do not compensate for potential biases in standard errors caused by skewness of the data (Bollen 1989). 
group LISREL analyses, we assessed whether the country and/or product category affected the specifications of the structural model.

First, each of the country samples was split according to the type of product category, resulting in a separate clothing and food sample within each country. For each country, two nested models were evaluated in order to assess the impact of the product category ${ }^{2}$ : (1) a model in which all structural paths were set equal across the two product category samples (equal model in table 7-2) and (2) a model in which all structural paths were set free across the two product category samples (free model in table 7-2). Second, the same procedure was followed in order to assess the potential influence of the country on the structural model.

The results of the two-group analyses are presented in table 7-2. While the upper part of table 7-2 shows the fits across product categories within each country, the lower part describes the fits across countries within each product category. We evaluated the significance of the differences in $\chi^{2}$ values between nested models in order to determine if one model specification obtained a significantly better fit than another model specification. With respect to pooling across product categories, the free models in the Belgian and US samples obtained a significantly better fit than the equal models. This indicates that not all of the paths are equal across clothing and food. Since two of the three samples indicate a difference between clothing and food, we decided not to pool the data across product categories. With respect to pooling across countries, the differences between the equal and free models were statistically significant four out of six times. Therefore, we decided not to pool the data across countries either.

Table 7-2: Examination of Data Pooling

\begin{tabular}{|c|c|c|c|c|c|c|}
\hline \multirow[b]{2}{*}{ Pooling of product category samples } & \multicolumn{2}{|c|}{ Equal model } & \multicolumn{2}{|c|}{ Free model } & \multicolumn{2}{|c|}{ Differences } \\
\hline & df & $x^{2}$ & df & $x^{2}$ & df & $x^{2}$ \\
\hline Clothing versus food in the Netherlands & 846 & 1,811 & 834 & 1.796 & 12 & 15 \\
\hline Clothing versus food in Belgium & 846 & 1,926 & 834 & 1.889 & 12 & $37^{* *}$ \\
\hline Clothing versus food in US & 846 & 1,986 & 834 & 1,962 & 12 & $24^{* *}$ \\
\hline \multicolumn{7}{|l|}{ Pooling of country samples } \\
\hline The Netherlands versus Belgium for clothing & 846 & 1,823 & 834 & 1.763 & 12 & $60^{* *}$ \\
\hline The Netherlands versus Belgium for food & 846 & 1.795 & 834 & 1.779 & 12 & 16 \\
\hline The Netherlands versus US for clothing & 846 & 2,157 & 834 & 2,087 & 12 & $70^{* *}$ \\
\hline The Netherlands versus US for food & 846 & 2,258 & 834 & 2,241 & 12 & 17 \\
\hline Belgium versus US for clothing & 846 & 2,107 & 834 & 2,070 & 12 & $37 * *$ \\
\hline Belgium versus US for food & 846 & 2,378 & 834 & 2,348 & 12 & $30^{* 4}$ \\
\hline
\end{tabular}

(*) $p<.05,(* *) p<0.01$

Concluding, we can state that the data do not allow pooling across either product categories or countries. As a result, we separately report the evaluation of the overall model, the measurement model, and the structural model for the six samples in the next sections. Following this sequence of evaluating models estimated by SEM is a commonly accepted practice (Baumgartner and Homburg 1996: Hair et al. 1998).

2. It is a generally accepted practice to compare the overall fit of the equal and the free model in order to decide whether differences between samples exist (Bollen 1989: Jaccard and Wan 1996). 


\subsection{Overall Model Evaluation}

A first step in evaluating the overall model is an inspection of 'offending estimates'. Offending etimates are estimated coefficients in either the structural or measurement models that exceed acceptable limits. Examples are negative error variances, standardized coefficients exceeding or very close to 1.0, or very large standard errors associated with any estimated coefficients (Bollen 1989: Hair et al, 1998). None of the models estimated in each of the six samples revealed offending estimates.

A second step relates to assessing the overall goodness-of-fit for the structural equation models. This is not as clear-cut as with other multivariate dependence techniques. Although many guidelines have been suggested, no absolute test is available (Hair et al. 1998). As stated by Bollen (1989, p. 275 ), "selecting a rigid cutoff for the incremental fit indices is like selecting a minimum $\mathbf{R}^{2}$ for a regression equation. Any value will be controversial". The evaluation of goodness-of-fit measures in SEM has gained widespread interest in recent years, resulting in the continual development of new goodness-of-fit measures. Goodness-of-fit measures can be classified into absolute fit (stand-alone) measures and incremental fit measures (Baumgartner and Homburg 1996: Bentler and Bonnett 1980; Hair et al. 1998; Jaccard and Wan 1996; Marcoulides and Schumacker 1996). Absolute fit measures assess the overall model fit for both structural and measurement models collectively (Bollen 1989; Hair et al. 1998). Often used absolute fit measures are the chi-square test $\left(\chi^{2}\right)$, the ratio of chi-square to degrees of freedom $\left(\chi^{2} / \mathrm{df}\right)$, the goodness-of-fit index (GFI), the adjusted goodness-of-fit index (AGFI), the standardized root mean square residual (SRMR), and the root mean square error of approximation (RMSEA). Incremental fit measures compare the proposed model to another model, most often defined as a baseline model in which all latent variables are assumed to be uncorrelated (Baumgartner and Homburg 1996). Frequently reported incremental fit indices are the comparative fit index (CFI), Bentler and Bonnett's (1980) normed fit index (NFI), Tucker and Lewis' (1973) non-normed fit index (NNFI/TLI), and Bollen's (1989) incremental fit index (IFI) (Baumgartner and Homburg 1996; Bollen 1989; Hair et al. 1998; Jaccard and Wan 1996). Table 7-4 describes the characteristics and acceptable levels of fit for each of these fit measures. Table 7-3 shows the values of the various fit indices for each of the six samples.

Table 7-3: Overall Model Evaluation

\begin{tabular}{lcccccc}
\hline $\begin{array}{l}\text { Model fit } \\
\text { Absolute fit statistics }\end{array}$ & \multicolumn{2}{c}{ The Netherlands } & \multicolumn{2}{c}{ Belgium } & \multicolumn{2}{c}{ United States } \\
Clothing & Food & Clothing & Food & Clothing & Food \\
\hline$\chi^{2}$ (s87 & $792^{* *}$ & $788^{* *}$ & $715^{* *}$ & $792^{* *}$ & $827^{* * *}$ & $976^{* *}$ \\
$\chi^{2} / \mathrm{df}$ & 2.05 & 2.04 & 1.85 & 2.05 & 2.14 & 2.52 \\
GFI & .86 & .86 & .86 & .85 & .81 & .76 \\
SRMR & .060 & .077 & .067 & .077 & .067 & .069 \\
RMSEA & .056 & .055 & .053 & .060 & .070 & .081 \\
Incremental fit statistics & & & & & & \\
\hline AGFI & .84 & .84 & .84 & .81 & .77 & .71 \\
CFI & .93 & .93 & .93 & .92 & .92 & .89 \\
NFI & .88 & .88 & .85 & .86 & .86 & .83 \\
NNFITLI & .93 & .93 & .92 & .91 & .91 & .88 \\
IFI & .93 & .93 & .93 & .92 & .92 & .89 \\
\hline
\end{tabular}


Table 7-4: Absolute and Incremental Fit Indices

Fit index Description Acceptable fit Sersitive to

\begin{tabular}{ll} 
Absolute & Test of the null hypothesis that the estimated \\
\hline$\chi^{2}$ & variance-covariance matrix deviates from the \\
sample variance-covariance matrix only \\
because of sampling error \\
As the chi-square statistie is only meaningful \\
taking into account the degrees of freedom, \\
the chi-square value is divided by the \\
$\chi^{2}$ /df \\
number of degrees of freedom \\
Non-statistical measure representing a \\
comparison of the squared residuals from \\
prediction with the actual data not adjusted \\
for the degrees of freedom \\
Non-statistical measure representing the \\
square root of the mean of the squared \\
standardized residuals \\
Non-statistical measure representing how \\
well the fined model approximates the \\
population variance-covariance matrix per \\
degree of freedom
\end{tabular}

Incremental

\begin{tabular}{|c|c|c|c|}
\hline AGFI & $\begin{array}{l}\text { Non-statistical measure representing a } \\
\text { comparison of the sguared residuals from } \\
\text { prediction with the actual data adjusted for } \\
\text { the degrees of freedom }\end{array}$ & $\geq .90$ & $\begin{array}{l}\text { - Sample size } \\
\text { - Model complexiy }\end{array}$ \\
\hline CFI & $\begin{array}{l}\text { Non-statistical measure representing a } \\
\text { comparative index between the proposed and } \\
\text { null models adjusted for the degrees of } \\
\text { freedom }\end{array}$ & $\geq .90$ & - Model complexity \\
\hline NFI & $\begin{array}{l}\text { Non-statistical measure representing a } \\
\text { comparative index between the proposed and } \\
\text { null models not adjusted for the degrees of } \\
\text { freedom }\end{array}$ & $\geq .90$ & $\begin{array}{l}\text { - Sample size } \\
\text { - Model complexity }\end{array}$ \\
\hline $\mathrm{NNFI} / \mathrm{TLI}$ & $\begin{array}{l}\text { Non-statistical measure representing a } \\
\text { comparative index between the proposed and } \\
\text { null models adjusted for the degrees of } \\
\text { freedom }\end{array}$ & 2.90 & \\
\hline IFI & $\begin{array}{l}\text { Non-statistical measure representing a } \\
\text { comparative index between the proposed and } \\
\text { null models adjusted for the degrees of } \\
\text { freedom }\end{array}$ & 2.90 & - Model complexity \\
\hline
\end{tabular}

Source: Based on (1) Baumgartner. Hans and Christian Homburg (1996), "Applications of Structural Equation Modeling in Marketing and Consumer Research: A Review," Intemational Joumal of Research in Marketing, 13 (2), 139-61, (2) Bearden. William O. (1982), "Sample Size Effects on Chi Square and Other Statistics Used in Evaluating Causal Models," Joumal of Markering Research, 19 (4), 425-30. (3) Bentler, P.M. (1990), "Comparative Fit Indexes in Structural Models," Psychological Bulletin, 107 (2). 238-46, (4) Bollen, Kenneth A. (1989). Stnuctural Equations with Latent Variables. New York: Wiley, (5) Hair, Joseph F., Rolph E. Anderson, Ronald L. Tatham, and William C. Black (1998), Multivariate Data Analysis.Upper Saddle River, NJ: Prentice Hall, (6) Jaccard, James and Choi K. Wan (1996), LISREL Approaches to Interaction Effects in Multiple Regression. Thousand Oaks: Sage Publications.

Although the chi-square statistic of all models is statistically significant ( $<<.001)$, this is not unusual with large sample sizes (Boyle et al. 1992; Doney and Cannon 1997; Steenkamp and Van 
Trijp 1991). The ratios of chi-square to degrees of freedom are all within the acceptable range. While the values of GFI, AGFI, and NFI are somewhat lower than those of CFI, NNFI, and IFI, this is mainly a result of the fact that the former measures are easily affected by sample size. The latter fi measures all indicate close model fit (except in the US food model). This similarly holds for SRMR and RMSEA that fall below .08 (except RMSEA in the US food model).

A final measure to determine overall model fit is the relative number of standardized residuals representing the differences between observed and estimated covariance matrices (Baumgartner and Homburg 1996). Standardized residuals should not exceed $|2.58|$ (Steenkamp and Van Trijp 1991). In our samples the percentage of standardized residuals exceeding $|2.58|$ ranges from 8.9 percent to 22.5 percent $^{3}$. While this is relatively high, standardized residuals should be interpreted with caution as they are calculated under the assumption of multivariate normality (Baumgartner and Homburg 1996).

Given the adequacy of overall goodness-of-fit indices, no respecifications of the model were made and it can be concluded that all models obtained adequate degrees of fit (Bagozi and Yi 1988). As a result, it is allowed to proceed to the evaluation of both the measurement and the structural models.

\subsection{Measurement Model Evaluation}

We conducted confirmatory factor analyses of the indicators measuring the ten constructs incorporated in the hypothesized model (see figure 5-1) in order to examine the scales' psychometric properties more closely.

Tables 7-5 to 7-7 report the results of the measurement models related to the Dutch, Belgian, and US samples in terms of the composite reliabilities of all constructs, the percentage of variance explained of all constructs by their items, the loadings of all construct items, the standard errors of all construct items, and the correlations of all construct items with the construct they are intended to measure. We assessed the quality of each measurement model on unidimensionality, convergent validity, reliability, and discriminant validity across the six samples.

\section{(1) Unidimensionality}

Unidimensionality is an assumption underlying the calculation of reliability. The use of reliability measures, such as Cronbach alpha, does not ensure unidimensionality but instead assumes it exists. Unidimensionality should be assessed for all multiple-indicator constructs before assessing their reliability (Hair et al. 1998). As can be derived from the principal component analyses performed on all items (see tables A7-1 to A7-6 in appendix seven), items loaded on unique components, underlining the unidimensionality of all constructs. As a result, we can conclude that unidimensionality for each of the constructs was obtained.

Residuals exceeding $|2.58|$ might indicate that the errors between two items are correlated. However, since no theoretical grounds support error correlations between any pair of items in our study, we did not let errors correlate. 


\section{(2) Convergent validity}

Convergent validity is supported as a result of the fact that the overall fit of the models was good, that all loadings were highly statistically significant $(p<.01)$, and that the factor regression coefficients $\left(R^{2}\right)$ are larger than .50 (Hildebrandt 1987: Steenkamp and Van Trijp 1991). Only for some items, regression coefficients were lower than .50 .

\section{(3) Reliability}

Since a measurement instrument can have an unacceptable within-method convergent validity and still be reliable, reliability was assessed after having examined the convergent validity of the constructs (Steenkamp and Van Trijp 1991). First, as can be read from tables A7-7 to A7-9 in appendix seven, all Cronbach alpha values exceed .70 , indicating acceptable reliability levels. Second, as can be derived from tables 7.5 to 7-7, based on confirmatory factor analyses all of the composite reliability measures are also above .70, exceeding Bagozzi and Yi's (1988) minimum values of, 60 . As a result, we can conclude that all constructs yield high reliabilities.

(4) Discriminant validity

First, a series of nested confirmatory factor model comparisons in each of the samples assessed whether differences existed between models in case correlations between latent constructs were constrained to 1. Each of the 45 off-diagonal elements of the correlation matrix between constructs was fixed to 1 and the model was re-estimated each time. This resulted in 270 separate model estimations for the six samples taken together. $\chi^{2}$ differences were statistically significant for all 45 model comparisons $(p<.01)$ in all samples, indicating discriminant validity. Second, as a stronger test of discriminant validity, Fornell and Larcker (1981) suggested that the average percentage of variance extracted for each construct should be equal to or higher than .50 , which implies that the variance accounted for by each construct is greater than the variance accounted for by measurement error (Hair et al. 1998). All constructs met this criterion, except for the construct of relationship commitment in the Dutch (.49) and Belgian (.47) clothing samples. Overall, we can conclude that there exists sufficient evidence of discriminant validity between each pair of constructs. Especially in light of the potential difficulties of distinguishing between relationship satisfaction, trust, and relationship commitment (see chapter four), this is an important conclusion. Our measurement model supports a sufficient level of discriminant validity between these constructs.

Concluding, the measures in our study provide strong evidence of unidimensionality, convergent validity, reliability. and discriminant validity. Consequently, it is allowed to proceed to the structural model evaluation. 


\begin{tabular}{|c|c|c|c|c|c|c|c|c|c|c|c|}
\hline \multirow{3}{*}{ hems (see table 6-3) } & & \multicolumn{10}{|c|}{ The Netheriands } \\
\hline & & & & Clothing & & & & & Food & & \\
\hline & & 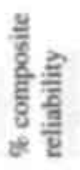 & $\frac{\mathrm{g}}{\frac{\mathrm{g}}{\mathrm{E}}} \frac{\mathrm{g}}{\mathrm{E}}$ & 耪 & $\frac{w}{n}$ & $" x$ & 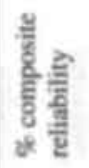 & 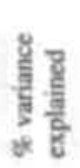 & $\frac{\text { है }}{\text { है }}$ & జ & 2 \\
\hline Sociability & & .74 & 51 & & & & .78 & 56 & & & \\
\hline & 1 & & & $41 * 0$ & .83 & .17 & & & $46 * 0$ & .79 & .21 \\
\hline & 3 & & & $.77 * *$ & .40 & .60 & & & $.84 * 6$ & .30 & .70 \\
\hline & 4 & & & $.87^{* *}$ & .24 & .76 & & & $.87^{\circ} \cdot$ & .25 & .75 \\
\hline Social recognition & & .87 & .69 & & & & .90 & .74 & & & \\
\hline & 2 & & & $.81^{* *}$ & 35 & .65 & & & $81 * 0$ & 34 & .66 \\
\hline & 4 & & & $.86 * 0$ & .26 & .74 & & & $.88 * 6$ & 23 &, 77 \\
\hline & 5 & & & $.82^{* *}$ & .33 & .67 & & & $.89 * 4$ & .20 & .80 \\
\hline Shopping enjoyment & & 94 & .83 & & & & 91 & .78 & & & \\
\hline & 1 & & & $93 * 0$ & .13 & 87 & & & $.87 * 4$ & .25 & .75 \\
\hline & 3 & & & $.88 * *$ & .22 & .78 & & & $.87 \%$ & .24 & .76 \\
\hline & 6 & & & $92 *$ & 16 & 84 & & & $91 * *$ & 17 & .83 \\
\hline $\begin{array}{l}\text { Product category } \\
\text { involvement }\end{array}$ & & .85 & .65 & & & & 91 & .77 & & & \\
\hline & 1 & & & $.79 * *$ & .38 & .62 & & & $.84^{* *}$ & .30 & .70 \\
\hline & 2 & & & $.84^{\circ 6}$ & .29 & .71 & & & $92 * *$ & 16 & .84 \\
\hline & 3 & & & $79 * a$ & .38 & .62 & & & $87^{* 0}$ & .24 & .76 \\
\hline $\begin{array}{l}\text { Buycr relationship } \\
\text { proneness }\end{array}$ & & 90 & .74 & & & & .88 & .70 & & & \\
\hline & 2 & & & $.84^{* * *}$ & 30 & .70 & & & $.84^{* 0}$ & .29 & .71 \\
\hline & 3 & & & $90^{* 0}$ & .19 & .81 & & & $.84 * 6$ & .29 & .71 \\
\hline & 5 & & & $.85 *$ & .28 & .72 & & & $.83^{* 6}$ & .31 & .69 \\
\hline $\begin{array}{l}\text { Seller relationship } \\
\text { orientation }\end{array}$ & & 90 & .75 & & & & .86 & 67 & & & \\
\hline & 2 & & & $.80^{*+*}$ & .36 & .64 & & & $.78^{* *}$ & 40 & .60 \\
\hline & 5 & & & $.87^{* 0}$ & .24 & .76 & & & $84^{* 0}$ & .29 & .71 \\
\hline & 6 & & & $92^{* * *}$ & 16 & .84 & & & $.84 * 0$ & .30 & .70 \\
\hline $\begin{array}{l}\text { Relationship } \\
\text { satisfaction }\end{array}$ & & .84 & .64 & & & & .75 & .50 & & & \\
\hline & 4 & & & $.83^{* *}$ & .30 & .70 & & & $.75^{+\infty}$ & .44 & .56 \\
\hline & 5 & & & $.84^{* *}$ & .30 & .70 & & & $.69 *$ & .52 & .48 \\
\hline & 6 & & & $.73^{* *}$ & .47 & .53 & & & $.69 *$ & .53 & .47 \\
\hline Trust & & .88 & .70 & & & & .84 & .63 & & & \\
\hline & 1 & & & $.74^{*-6}$ & .45 & .55 & & & $.74^{* 6}$ & .45 & .55 \\
\hline & 2 & & & $.87^{\circ}$ & .25 & .75 & & & $.82^{\circ \bullet}$ & .33 & .67 \\
\hline & 3 & & & $90^{\circ *}$ & 19 & .81 & & & $.82^{* 0}$ & .33 & .67 \\
\hline $\begin{array}{l}\text { Relationship } \\
\text { commitment }\end{array}$ & & .74 & .49 & & & & .75 & .51 & & & \\
\hline & 2 & & & $.70^{*-*}$ & .52 & .48 & & & $.75 * 0$ & .43 & 57 \\
\hline & 3 & & & $.76 *-$ & .42 & 58 & & & $.78 * 0$ & .39 & .61 \\
\hline & 4 & & & $.63^{* *}$ & .60 & .40 & & & $.59 * 0$ & .65 & .35 \\
\hline Behavional loyalty & & .77 & .53 & & & & .90 & .75 & & & \\
\hline & 1 & & & $.70^{* *}$ & .50 & 50 & & & $.77 * 0$ & .41 & .59 \\
\hline & 2 & & & $.78 * \bullet$ & .40 & .60 & & & $.94^{* *}$ & .12 & .88 \\
\hline & 3 & & & $.70^{* *}$ & 50 & .50 & & & $.89 * *$ & .21 & .79 \\
\hline
\end{tabular}

(") $\mathrm{p}<.05,(*) \mathrm{p}<.01$ 


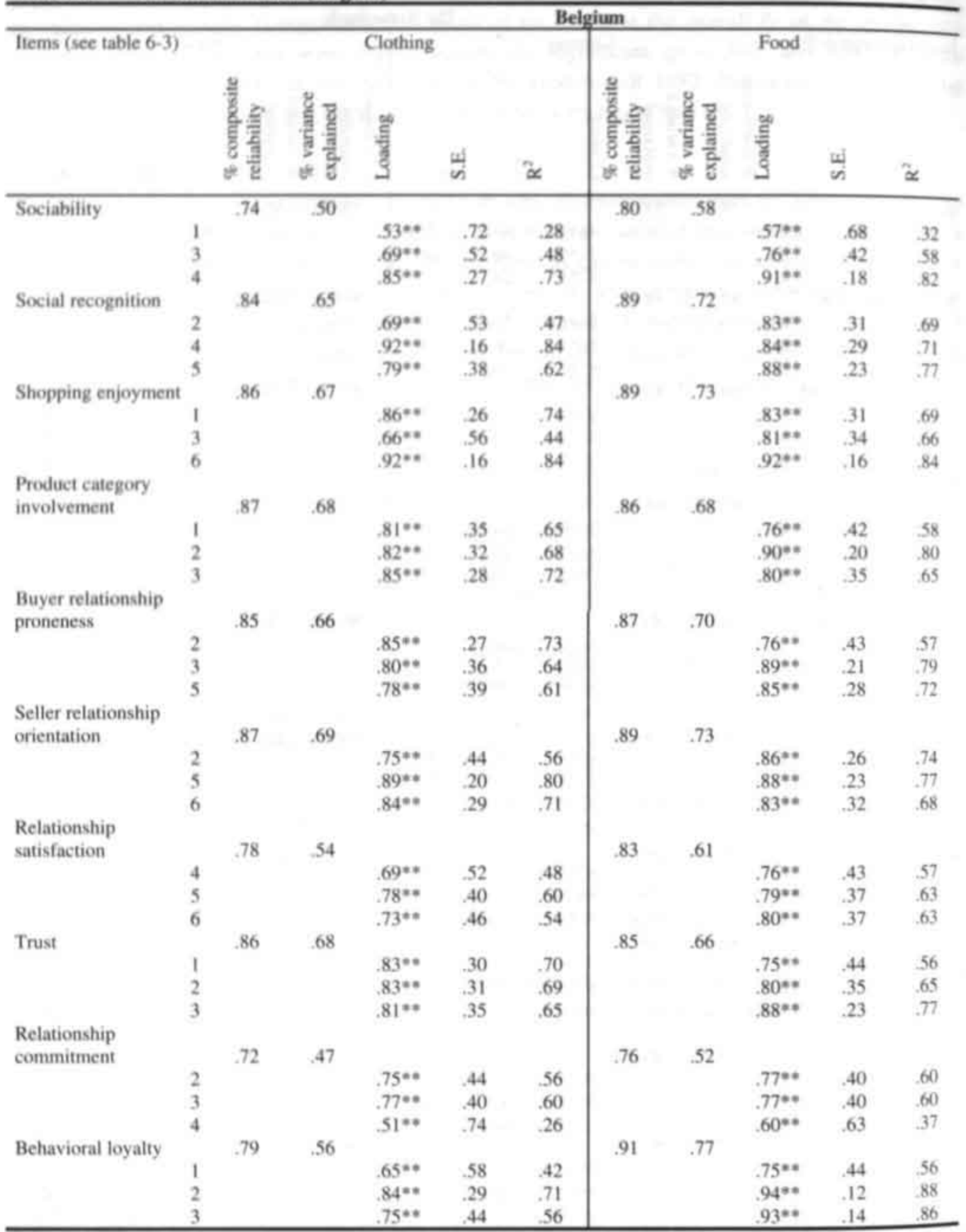

(*) $\mathrm{p}<.05,\left({ }^{* *}\right) \mathrm{p}<.01$ 


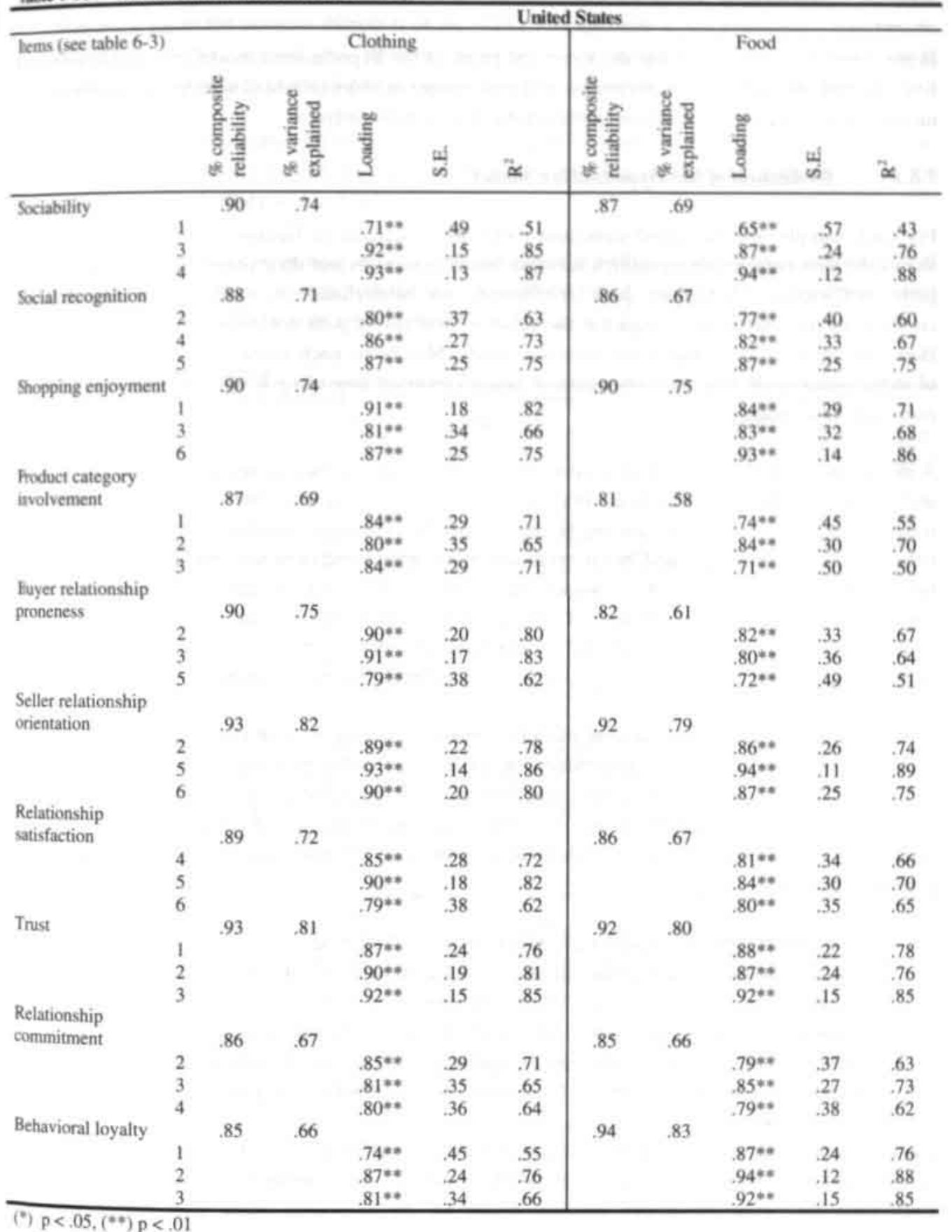




\subsection{Structural Model Evaluation}

In this section, we first evaluate the structural paths of the hypothesized model presented in chapter five. Second, we judge the performance of a rival model in order to assess whether the hypothesized model is robust against alternative formulations of structural paths.

\subsubsection{Evaluation of the Hypothesized Model}

For each sample, the estimated structural paths are visualized in figures 7-1 to 7-6. Each model shows the hypothesized relationships between latent constructs and their corresponding standardized path coefficients. Significant path coefficients are underlined in each figure. Standardized coefficients are useful for comparing the relative strength of path coefficients within one sample. However, they are not comparable across samples. Moreover, each model indicates the coefficient of determination $\left(\mathrm{R}^{2}\right)$ of each endogenous latent construct providing a relative measure of fit for each structural equation.

A first evaluation of the structural model involves checking whether all significant path coefficients are in the hypothesized direction. For each of the six samples in our study, most significant relationships between latent constructs are in the hypothesized direction, except for the paths between social recognition and buyer relationship proneness and between shopping enjoyment and buyer relationship proneness. This provides strong evidence for our conceptual model and its related hypotheses. Moreover, as nomological validity is assessed by testing the relationships with other constructs in a nomological net (Ruekert and Churchill 1984; Steenkamp and van Trijp 1991), this supports the nomological validity of the constructs integrated in the hypothesized model.

A second evaluation of the structural model is related to testing each of the hypotheses formulated in chapter five. Regarding the antecedents of buyer relationship proneness, we can conclude that product category involvement significantly affects buyer relationship proneness in all six samples $\left(\mathrm{H}_{4}\right.$ supported). Results are mixed across samples for sociability, social recognition, and shopping enjoyment as antecedents of buyer relationship proneness $\left(\mathrm{H}_{1}\right.$ partially supported and $\mathrm{H}_{2}$ and $\mathrm{H}_{3}$ partially rejected) ${ }^{4}$.

(1) In the Dutch samples, social recognition was not significantly related to buyer relationship proneness in the food sample. In the clothing sample, an inverse significant relationship between social recognition and buyer relationship proneness existed. Both sociability and shopping enjoyment were not significantly related to buyer relationship proneness in the Dutch clothing sample. In the food sample, a positive, significant relationship was found between shopping enjoyment and buyer relationship proneness, in contrast to the hypothesized negative relationship.

(2) In the Belgian samples, none of the antecedents sociability, social recognition, and shopping enjoyment were significantly related to buyer relationship proneness.

4 While the hypothesized effects of sociability. social recognition, and shopping enjoyment on buyer relationship proneness were not supported in each sample, the simple correlations between each of these constructs and buyer relationship proneness were significant at a $p<.05$ level in all samples. 
3) In the US samples, shopping enjoyment was significant in both the clothing and food samples. However, again the positive direction of the effect was opposite to the hypothesized direction. Moreover, social recognition showed a negative, significant relationship with buyer relationship proneness in the clothing sample, whereas a positive effect was hypothesized.

Vith respect to the other paths, all relationships were significant and in the hypothesized direction. Only seller relationship orientation was not significantly related to relationship commitment in the Eelgian food, in US clothing and in US food samples.

As high path coefficients can be indicative of multicollinearity problems, we checked the strength of the path coefficients between latent constructs as a final means of examining the structural model rsults. Detailed results can be read from table 7-8.

Thle 7-8: Structural Panameters

\begin{tabular}{|c|c|c|c|c|c|c|c|c|c|c|c|c|c|}
\hline \multirow{3}{*}{ Panumeter } & & \multicolumn{4}{|c|}{ The Netherlands } & \multicolumn{4}{|c|}{ Belgium } & \multicolumn{4}{|c|}{ United States } \\
\hline & & \multicolumn{2}{|c|}{ Clothing } & \multicolumn{2}{|c|}{ Food } & \multicolumn{2}{|c|}{ Clothing } & \multicolumn{2}{|c|}{ Food } & \multicolumn{2}{|c|}{ Clothing } & \multicolumn{2}{|c|}{ Food } \\
\hline & & Estimate & SE & Estimate & SE & Estimate & SE & Estimate & SE & Estimate & SE & Estimate & SE \\
\hline LEC-RP & $\gamma_{21}$ & $-15^{\circ}$ & .07 & -.04 & .08 & .08 & .08 & -.10 & .08 & $-.14^{*}$ & .07 & -.08 & .09 \\
\hline SOC-RP & $x_{2}$ & .11 & .07 & $.14^{*}$ & .08 & -.07 & .08 & -.01 & .08 & .01 & .07 & .04 & .09 \\
\hline ENJ-RP & $\gamma_{3}$ & -.05 & .06 & $.18^{20}$ & .07 & -.01 & .07 & .12 & .08 & $.17^{*}$ & .07 & $.17^{*}$ & .08 \\
\hline NV-RP & $x_{4}$ & $48^{2+*}$ & .08 & $33^{* *}$ & .06 & $.40^{* *}$ & .08 & $38 * 0$ & .07 & $.79 * \bullet$ & .11 & $.59 * *$ & 09 \\
\hline IP.RO & $\beta_{i 2}$ & $5 I^{+0}$ & .06 & $31 * 0$ & .06 & $.18^{\circ 0}$ & .07 & $.26 * *$ & .07 & $.45^{* 6}$ & .08 & $.44^{* 6}$ & 08 \\
\hline 2O-RS & $\beta_{n}$ & $.67^{* 0 *}$ & .07 & $.60^{\circ *}$ & .07 & $36 * 0$ & .07 & $.47^{* 0}$ & .07 & $.67^{* *}$ & .08 & $50^{* *}$ & .07 \\
\hline RP-RS & $\beta_{n z}$ & $.27^{* *}$ & .05 & $.27^{* *}$ & .06 & $.43^{*-4}$ & .07 & $39 *$ & .06 & $.26^{* * *}$ & .06 & $.41 *$ & .07 \\
\hline RS.TR & $\beta_{e}$ & $.73^{* *}$ & .08 & $.84^{* *}$ & .11 & $.73^{* *}$ & .09 & $.80^{* *}$ & .10 & $.75^{\circ \bullet}$ & .09 & $.82 * 0$ & .10 \\
\hline RO-MIT & $\beta_{3 I}$ & $16^{\circ}$ & .06 & $.16^{\circ}$ & .06 & $.21 * *$ & .06 & .10 & .06 & .11 & .06 & .06 & .05 \\
\hline RP-MIT & $\beta_{2}$ & $.60^{*-*}$ & .09 & $.46^{* *}$ & .07 & $34 * *$ & .07 & $36^{*-*}$ & .07 & $37^{* *}$ & .07 & $.36 * *$ & .08 \\
\hline TR-MIT & $\beta_{54}$ & $.30^{* *}$ & .07 & $.43^{+*}$ & .08 & $53^{* *}$ & .08 & $.58^{* 0}$ & .10 & $.57^{* 0}$ & .08 & $.66^{+*}$ & .11 \\
\hline MIT-BL. & $\beta_{5 s}$ & $.46^{* *+}$ & .08 & $.25^{* 4}$ & .06 & $.44^{* *}$ &, 08 & $.37 * *$ & .07 & $59 * 4$ & .09 & $.43^{* 6}$ & .09 \\
\hline SOC-REC & $\phi_{21}$ & $.45^{*-1}$ & .05 & $57^{* *}$ & .05 & $.49^{* 1}$ & .06 & $.42^{* * *}$ & .06 & $63^{* *}$ & .05 & $.61^{* 0}$ & .05 \\
\hline ENJ-REC & $\phi_{y}$ & $.25^{* * *}$ & .06 & $.40^{* * *}$ & .05 & $39 * *$ & .06 & $.48^{* *}$ & .05 & $50^{* 0}$ & .06 & $.44^{* *}$ & .06 \\
\hline ENJ-SOC & $\phi_{n}$ & $.19^{* \bullet}$ & .06 & $.44^{* *}$ & .05 & $.16^{\circ}$ & .07 & $46^{* 0}$ & .05 & $.59 * \bullet$ & .05 & $.42^{* *}$ & .06 \\
\hline INV-REC & $\phi_{u t}$ & $.47^{* * *}$ & .05 & .2900 & .06 & $.45^{\circ} \cdot$ & .05 & $37 * 0$ & .06 & $.44 * *$ & .06 & $.29^{* *}$ & .07 \\
\hline INV-SOC & $\phi w$ & $30^{* *}$ & .06 & $.18^{* *}$ & .06 & $.35^{* *}$ & .06 & $.13^{*}$ & .07 & $39^{* *}$ & .06 & $.20^{60}$ & .07 \\
\hline [NV-EN] & $\phi u$ & $38 * 0$ & .05 & $.18^{* *}$ & .06 & $25^{-1 *}$ & .06 & $.20^{* * *}$ & .06 & $.60^{* * *}$ & .05 & $.35 * *$ & .07 \\
\hline
\end{tabular}

(*) $\mathrm{p}<.05,(* *) \mathrm{p}<.01$

The following abbreviations are used: $\mathrm{SOC}=$ sociability, $\mathrm{REC}=$ social recognition, ENJ = shopping enjoyment, INV $=$ product category involvement, $R P=$ buyer relationship proneness, $R O=$ seller relationship orientation. $\mathrm{RS}=$ relationship satisfaction. $\mathrm{TR}=$ trust, $\mathrm{MIT}$ = relationship commitment, $\mathrm{BL}=$ behavioral loyalty.

First, we examined the strength of the path coefficients between exogenous and endogenous constructs $\left(\gamma_{11}\right)$. Although no limit has been set that determines when a path coefficient can be considered as high, values exceeding .90 are considered to be indicative of multicollinearity problems (Hair et al. 1998). All path coefficients between exogenous and endogenous constructs are below .80 in each of the samples. Second, we checked whether path coefficients between endogenous constructs $\left(\beta_{i j}\right)$ exceeded the level of .90 . While path coefficients between relationship satisfaction and trust range from .73 to .84 could indicate multicollinearity, we previously 


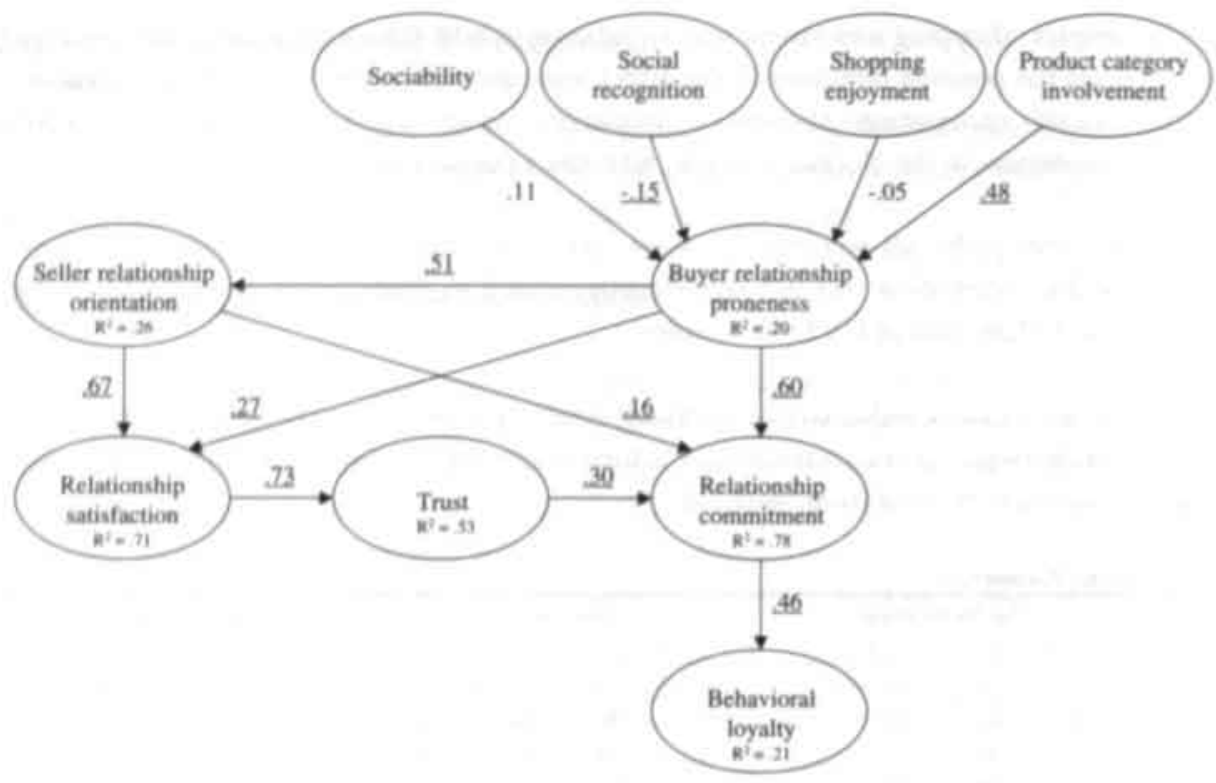

Figure 7-1: Structural Model the Netherfands Clothing

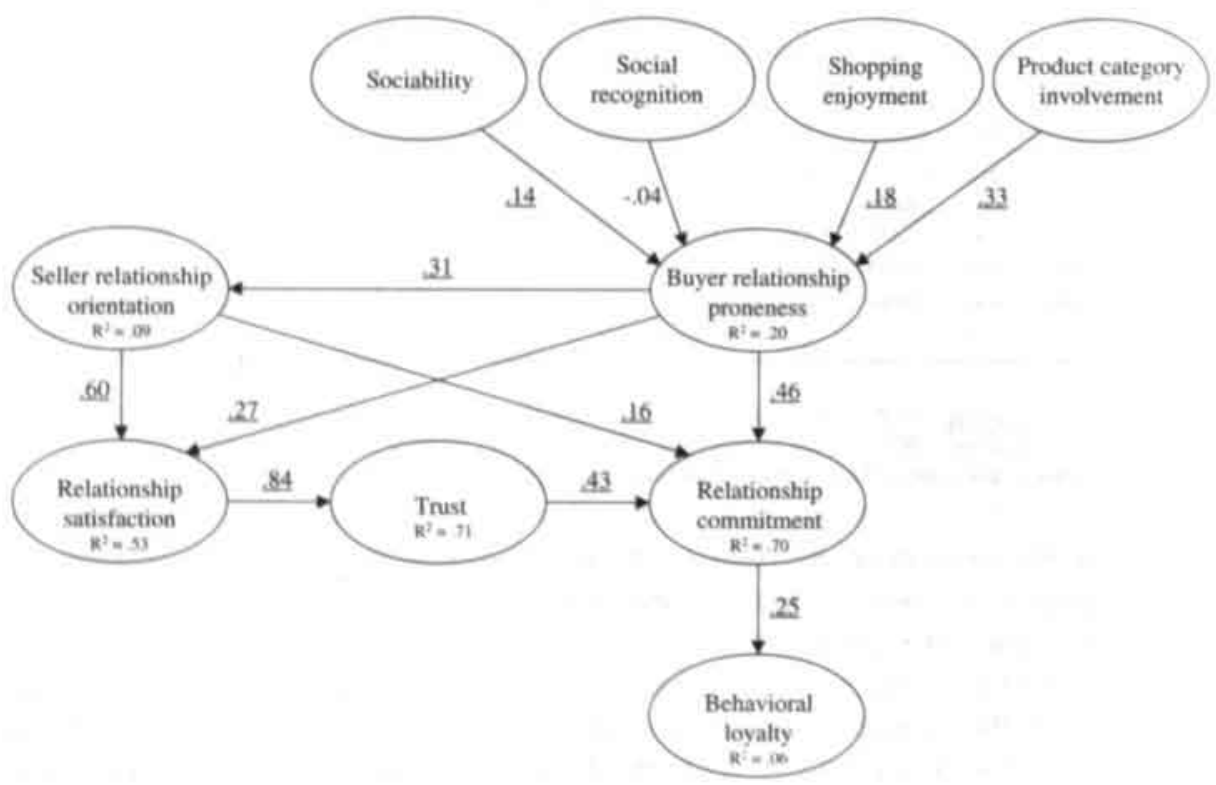

Figure 7-2: Structural Model the Netherdands Food 


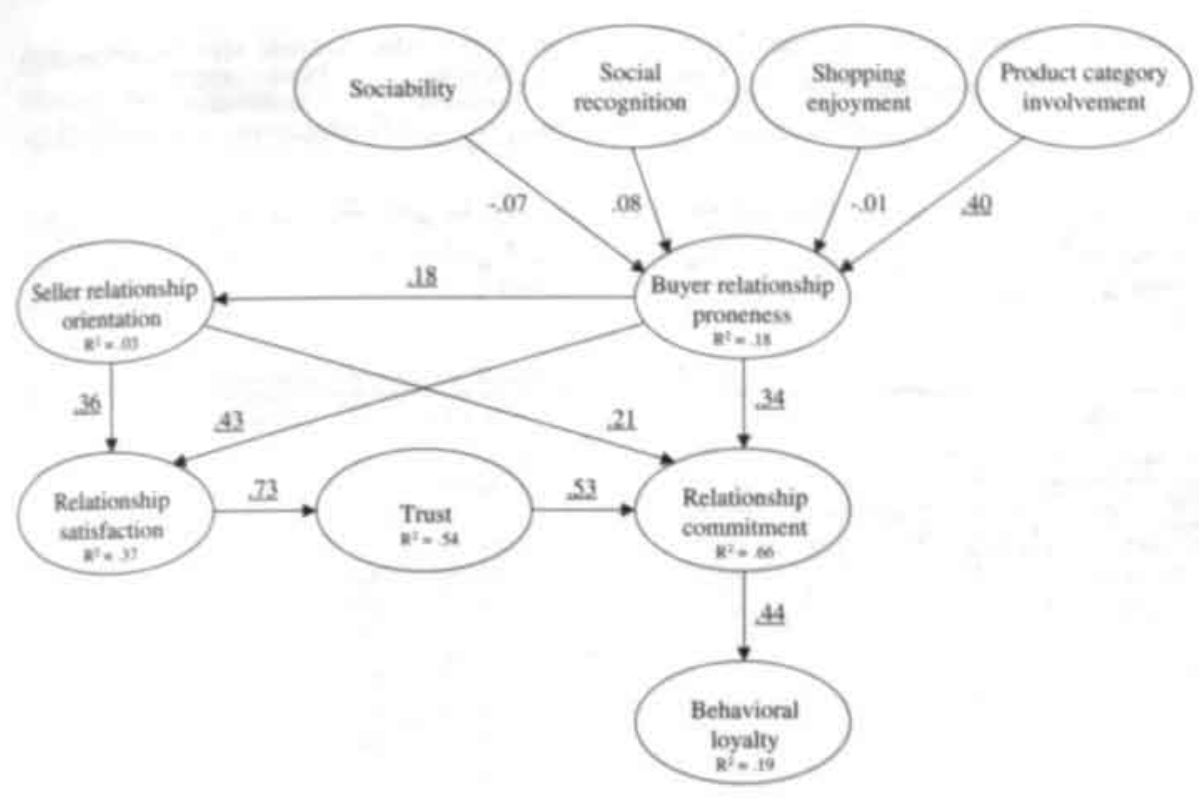

Figure 7-3: Structural Model Belgium Clothing

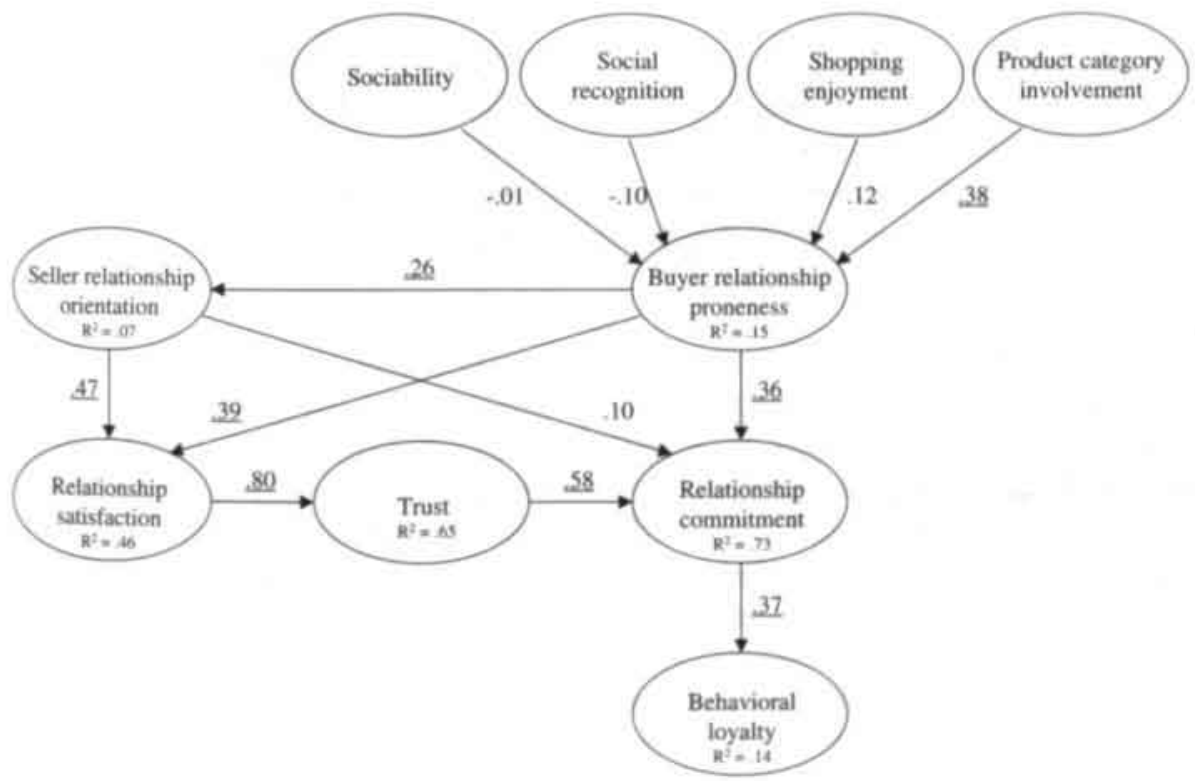

Figure 7-4: Structural Model Belgium Food 


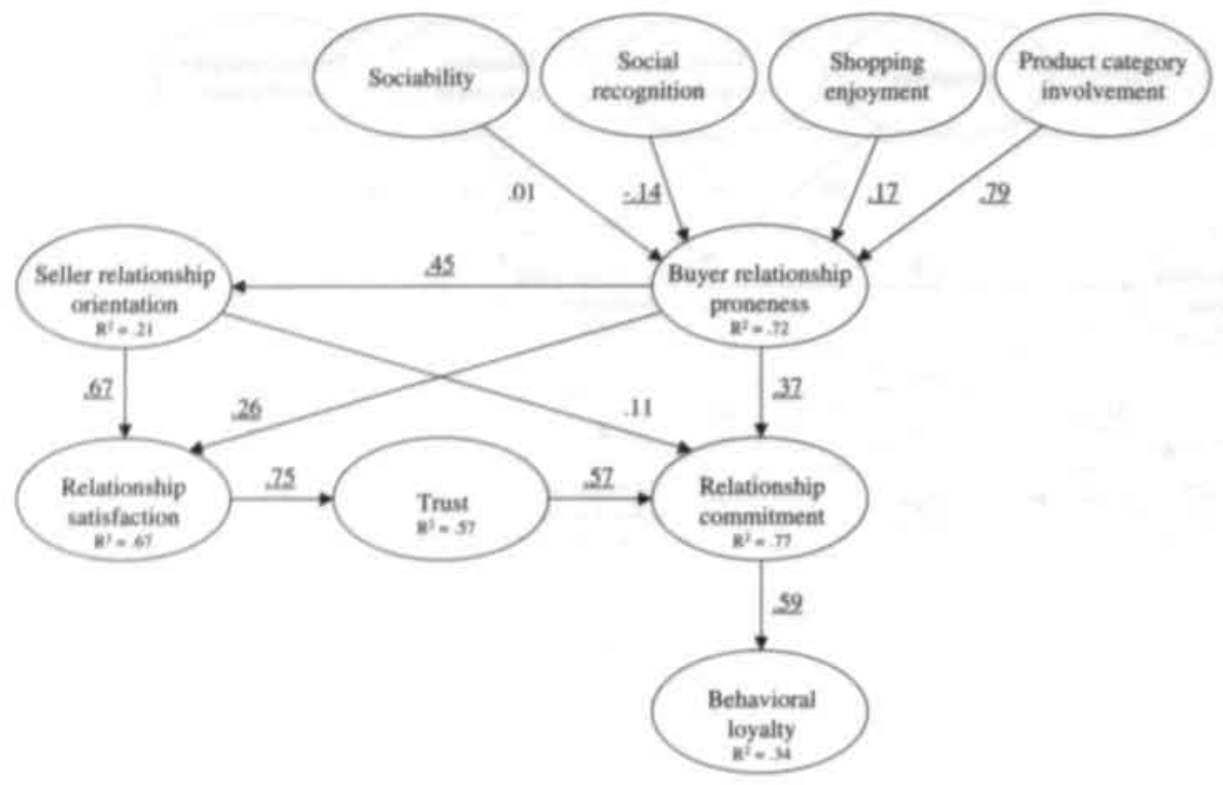

Figure 7-5: Structumal Model United States Clothing

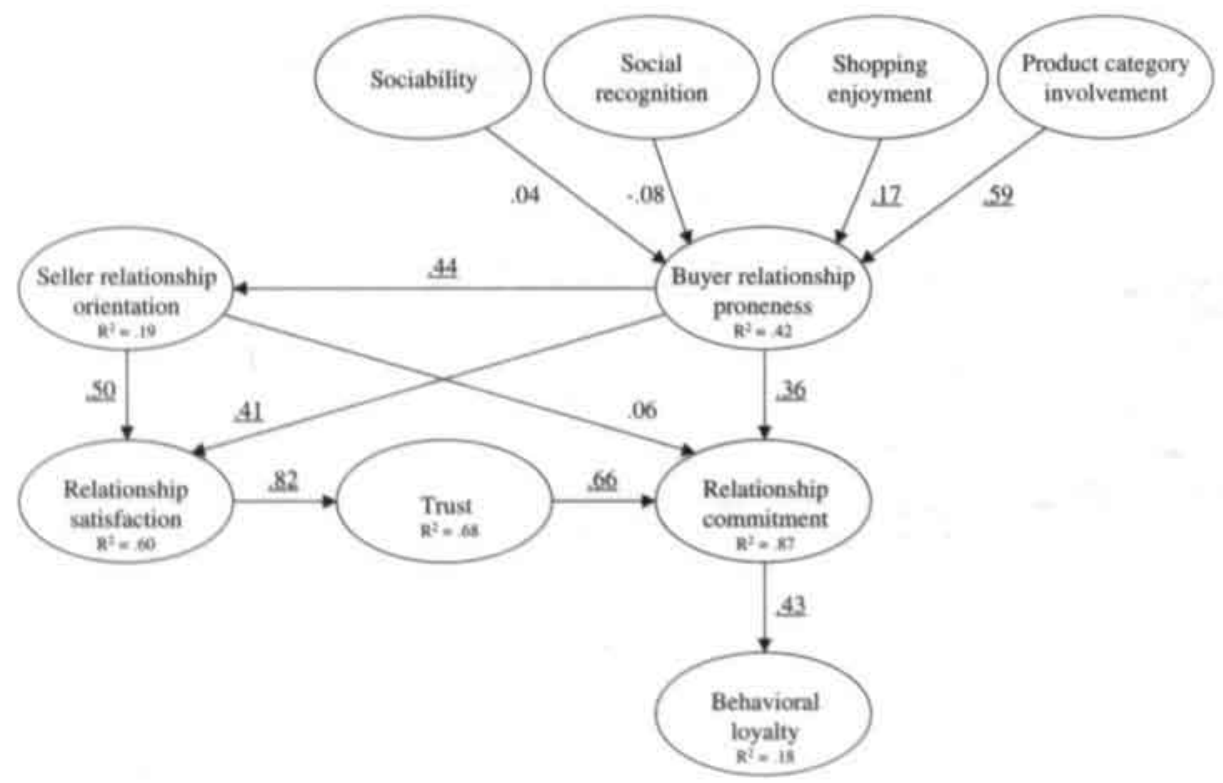

Figure 7-6: Structumal Model United States Food 
demonstrated that there exists sufficient discriminant validity between both constructs (see 7.5). Finally, we assessed the strength of the path coefficients between exogenous constructs $\left(\phi_{i}\right)$. The highest was .63, providing additional support for discriminant validity.

Table 7-9 provides an overview of the support found for each of the hypotheses in the six samples. The shaded cells in the table refer to path coefficients that are significant and in the hypothesized direction.

Tahle 7-9: Evaluation of Hypotheses Related to Main Effects

\begin{tabular}{|c|c|c|c|c|c|c|c|c|}
\hline \multirow{2}{*}{ Path } & \multirow{2}{*}{ Hypothesis } & \multicolumn{2}{|c|}{ The Netherlands } & \multicolumn{2}{|c|}{ Belgium } & \multicolumn{2}{|c|}{ United States } & \multirow[t]{2}{*}{ Result } \\
\hline & & C & $\mathbf{F}$ & c & $\mathrm{F}$ & C & $\mathrm{F}$ & \\
\hline SOC-RP & $\mathrm{H}_{\mathrm{t}}$ & .11 & 14 & -.07 & .01 & -.01 & .04 & Partially supported \\
\hline REC-RP & $\mathrm{H}_{2}$ & .15 & -.04 & .08 & -.10 &, 14 & -.08 & Partially rejected \\
\hline ENJ-RP & $\mathrm{H}_{3}$ & .05 & .18 & .01 & .12 & .17 & .17 & Partially rejected \\
\hline INV-RP & $\mathrm{H}_{4}$ & .48 & 33 & .40 & 38 & .79 & .59 & Supporied \\
\hline RP-RO & $\mathrm{H}$, & 51 & 31 & .18 & .26 & 45 & 44 & Supported \\
\hline RO-RS & $\mathrm{H}_{6}$ & .67 & .60 & .36 & 47 & .67 & 50 & Supported \\
\hline RO-MIT & $\mathrm{H}_{7}$ & .16 & .16 & .21 & .10 & .11 & -.06 & Partially supported \\
\hline RP-RS & $\mathrm{H}_{3}$ & .27 & 27 & .43 & 39 & 26 & 41 & Supported \\
\hline RP-MIT & $\mathrm{H}_{9}$ & .60 & 46 & 34 & 36 & 37 & .36 & Supported \\
\hline RS-TR & $\mathbf{H}_{10}$ & .73 & .84 & .73 & 80 & .75 & .82 & Supported \\
\hline TR-MIT & $\mathrm{H}_{11}$ & .30 & .43 & .53 & .58 & 57 & .66 & Supported \\
\hline MIT-BL & $\mathrm{H}_{12}$ & 46 & .25 & 44 & 37 & 59 & .43 & Supported \\
\hline
\end{tabular}

Shaded cells are at least significant at a $p<.05$ level. The following abbreviations are used: SOC $=$ sociability. REC $=$ social recognition, ENJ = shopping enjoyment, INV = product category involvement, $R P=$ buyer relationship proneness, $\mathrm{RO}=$ seller relationship orientation, $\mathrm{RS}=$ relationship satisfaction, $\mathrm{TR}=$ trust, $\mathrm{MIT}=$ relationship commitment, $\mathrm{BL}=$ behavioral loyalty, $\mathrm{C}=$ clothing. $\mathrm{F}=$ food.

Concluding, we obtained strong evidence for most of the hypothesized main effects. The majority of structural paths was stable across countries as well as product categories. In order to gain a better insight into the decomposition of the structural effects, tables 7-10 to 7-12 report the direct, indirect, and total effects among the constructs for all samples included in the study. The tables show that, in general, in addition to the previously reported direct effects, important significant indirect effects exist.

While LISREL provides modification indices suggesting potential improvements to the fit of the model, modifications should be implemented only after obtaining sound theoretical justification. Theory provides the rationale for almost all aspects of SEM (Hair et al. 1998). First, we checked whether any sound theoretical ground existed for each suggested modification. No sound evidence was found to change the basic structure of the model. Second, an examination of the proposed modifications to the model revealed that different modifications were suggested in each of the six samples. Since no theoretical basis existed for changing the model structure and since the proposed modifications were not consistent across samples, we did not modify the original structure of the model. However, in order to assess the robustness of the hypothesized model, we estimated an alternative model in each sample in which non-significant paths were no estimated. This did not strongly influence the significance and values of the path coefficients presented in figures 7-1 to 7 . 6. Moreover, an additional means for assessing the robustness of the hypothesized model is to compare this model to a rival model. In 7.6.2, we present the results of comparing our hypothesized model to a rival model. 
Table 7-10: Decomposition of Structumal Effects (the Netherlands)

\begin{tabular}{|c|c|c|c|c|c|c|}
\hline Effeet on buyer nelationship proneness & Direct & $\begin{array}{l}\text { Clothing } \\
\text { Indirect }\end{array}$ & Total & Direct & $\begin{array}{c}\text { Food } \\
\text { Indirect }\end{array}$ & Total \\
\hline $\begin{array}{l}\text { Sociability } \\
\text { Social recognition } \\
\text { Shopping enjoyment } \\
\text { Product category involvement } \\
\text { Fffect on seller nationship orientation }\end{array}$ & $\begin{array}{l}.11 \\
-15 * \\
-.05 \\
48+*\end{array}$ & $\begin{array}{l}+ \\
+ \\
= \\
=\end{array}$ & $\begin{array}{c}.11 \\
-.15^{\circ} \\
-.05 \\
48 * 4\end{array}$ & $\begin{array}{c}.14^{\circ} \\
-.04 \\
.18^{*} \\
33^{*}\end{array}$ & $\begin{array}{l}- \\
- \\
- \\
-\end{array}$ & $\begin{array}{l}.14 * \\
-.04 \\
.18 * 0 \\
33 *\end{array}$ \\
\hline $\begin{array}{l}\text { Sociability } \\
\text { Social recognition } \\
\text { Shopping enjoyment } \\
\text { Product category involvement } \\
\text { Buyer relationship proneness } \\
\text { Effect on relationhip satisfaction }\end{array}$ & $\begin{array}{c}- \\
- \\
51+0\end{array}$ & $\begin{array}{l}.05 \\
-.08 * \\
-.03 \\
25 * * \\
=\end{array}$ & $\begin{array}{c}.05 \\
-, 08 * \\
-.03 \\
25 * * \\
51 * *\end{array}$ & $\begin{array}{c}\cdot \\
\cdot \\
+ \\
31+\infty\end{array}$ & $\begin{array}{c}.04 * \\
-.01 \\
.06^{* *} \\
10^{* *}\end{array}$ & $\begin{array}{l}.04 * \\
-.01 \\
.06 * * \\
.10^{* 4} \\
31=0\end{array}$ \\
\hline $\begin{array}{l}\text { Sociability } \\
\text { Social recognition } \\
\text { Shopping enjoyment } \\
\text { Product category involvement } \\
\text { Buyer relationship proneness } \\
\text { Seller relationship orientation } \\
\text { Effect on trust }\end{array}$ & $\begin{array}{c}* \\
. \\
27 * * \\
67 * *\end{array}$ & $\begin{array}{c}.06 \\
-.09^{*} \\
-.03 \\
.30^{\circ *} \\
.34^{* 6} \\
-\end{array}$ & $\begin{array}{c}.06 \\
-.09^{*} \\
-.03 \\
30^{\circ *} \\
.61^{\bullet \bullet} \\
.67^{\circ \bullet}\end{array}$ & $\begin{array}{c}\cdot \\
. \\
27^{* 0} \\
60^{\circ *}\end{array}$ & $\begin{array}{c}.06 * \\
-.02 \\
.08 * * \\
.15 * \\
18^{*} \\
-\end{array}$ & $\begin{array}{l}.06^{*} \\
-.02 \\
.08^{* *} \\
15^{* *} \\
.45^{* *} \\
.60^{* *}\end{array}$ \\
\hline $\begin{array}{l}\text { Sociability } \\
\text { Social recognition } \\
\text { Shopping enjoyment } \\
\text { Product category involvement } \\
\text { Buyer relationship proneness } \\
\text { Seller relationship orientation } \\
\text { Relationship satisfaction } \\
\text { Effect on relationship commitment }\end{array}$ & 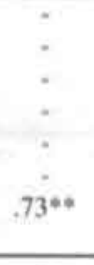 & $\begin{array}{c}.05 \\
-.07 * \\
-.02 \\
.22 * * \\
45^{* *} \\
49^{*} \\
-\end{array}$ & $\begin{array}{l}.05 \\
-.07 * \\
-.02 \\
.22 * * \\
.45^{* *} \\
.49^{* *} \\
.73^{* *}\end{array}$ & $\begin{array}{c}\cdot \\
- \\
- \\
- \\
- \\
-\end{array}$ & $\begin{array}{l}.05 * \\
-.02 \\
.07 * \bullet \\
.13 * * \\
38^{* *} \\
50^{* *} \\
-\end{array}$ & $\begin{array}{l}.05^{*} \\
-.02 \\
.07 * * \\
.13 * * \\
38^{* *} \\
50^{* *} \\
.84^{* *}\end{array}$ \\
\hline $\begin{array}{l}\text { Sociability } \\
\text { Social recognition } \\
\text { Shopping enjoyment } \\
\text { Product category involvement } \\
\text { Buyer relationship proneness } \\
\text { Seller relationship orientation } \\
\text { Relationship satisfaction } \\
\text { Trust } \\
\text { Effect on behavioral loyalty }\end{array}$ & $\begin{array}{c}- \\
60^{*+*} \\
16^{* *} \\
30^{* *}\end{array}$ & $\begin{array}{l}.09 \\
-.12^{*} \\
-.04 \\
39 * * \\
.21 * * \\
14^{* *} \\
22 * * \\
.\end{array}$ & $\begin{array}{l}.09 \\
-.12^{*} \\
-.04 \\
39^{* * *} \\
81^{* *} \\
30^{* *} \\
.22^{* *} \\
30^{* *}\end{array}$ & $\begin{array}{c}- \\
- \\
46^{* *} \\
16^{* *} \\
- \\
43^{* *}\end{array}$ & $\begin{array}{l}.09 * \\
-.03 \\
.12 * * \\
.22 * * \\
.22 * * \\
.22 * * \\
.36 * * \\
-\end{array}$ & $\begin{array}{l}.09^{*} \\
-.03 \\
.12^{* *} \\
.22^{* *} \\
.68^{* *} \\
.38^{* *} \\
.36 * * \\
.43^{* *}\end{array}$ \\
\hline $\begin{array}{l}\text { Sociability } \\
\text { Social recognition } \\
\text { Shopping enjoyment } \\
\text { Product category involvement } \\
\text { Buyer relationship proneness } \\
\text { Seller relationship orientation } \\
\text { Relationship satisfaction } \\
\text { Trust } \\
\text { Relationship commitment }\end{array}$ & $\begin{array}{c}\cdot \\
\cdot \\
\cdot \\
- \\
- \\
46^{* *} \\
\end{array}$ & $\begin{array}{l}.04 \\
-.06^{*} \\
.02 \\
.18^{* *} \\
37^{* *} \\
.14^{* *} \\
.10^{* *} \\
.14^{* *} \\
. \\
\end{array}$ & $\begin{array}{l}.04 \\
-.06^{*} \\
-.02 \\
.18^{* *} \\
37^{* *} \\
14^{* *} \\
.10^{* *} \\
.14^{* *} \\
.46^{* *} \\
\end{array}$ & $\begin{array}{c}- \\
- \\
- \\
- \\
- \\
- \\
25^{* *} \\
\end{array}$ & $\begin{array}{c}.02 \\
-.01 \\
.03^{*} \\
.06^{* *} \\
.17^{* *} \\
.09^{* *} \\
.09^{* *} \\
.11^{* *} \\
- \\
\end{array}$ & $\begin{array}{c}.02 \\
-.01 \\
.03^{*} \\
.06^{* *} \\
.17^{* *} \\
.09^{* *} \\
.09^{* *} \\
.11^{* *} \\
.25^{* *} \\
\end{array}$ \\
\hline
\end{tabular}

(*) $\mathrm{p}<.05,\left({ }^{* *}\right) \mathrm{p}<.01$ 
Tuhle 7.11: Decomposition of Structurnal EIfects (Belgium)

\begin{tabular}{|c|c|c|c|c|c|c|}
\hline Eflect on buyer relationship proneness & Direct & $\begin{array}{l}\text { Cothing } \\
\text { Indirect }\end{array}$ & Total & Direct & $\begin{array}{c}\text { Food } \\
\text { Indirect }\end{array}$ & Total \\
\hline Sociability & .07 & - & -.07 &,- 01 & $\cdot$ & 01 \\
\hline Social recognition & .08 & - & 08 & -.10 & - & -10 \\
\hline Shopping enjoyment & .01 & - & .01 & .12 & . & 12 \\
\hline Product category involvement & $40^{\circ-*}$ & $*$ & $.40^{\circ-4}$ & $38 * *$ & - & $.38 * *$ \\
\hline \multicolumn{7}{|l|}{ Effect on seller relationship orientation } \\
\hline Sociability & - & -.01 &. .01 & - & .00 & .00 \\
\hline Social recognition & - & 01 & .01 & - & -.03 & .03 \\
\hline Shopping enjoyment & - & .00 & .00 & - & .03 & .03 \\
\hline Product category involvement & $\therefore$ & $.07 * 0$ & $.07 * 0$ & $\cdot$ & $.10^{* *}$ & $.10^{* *}$ \\
\hline $\begin{array}{l}\text { Buyer relationship proneness } \\
\text { Effect on relationship satisfaction }\end{array}$ & & $.26 * 0$ & $\cdot$ & $26 * 4$ \\
\hline Sociability & . & -.03 &., 03 & - & .00 & .00 \\
\hline Social recognition & - & .04 & .04 & - & .05 & -.05 \\
\hline Shopping enjoyment & - & .00 & .00 & - & .06 & .06 \\
\hline Product category involvement & $=$ & $20^{* *}$ & $20 * 0$ & . & $19 * *$ & $.19 * *$ \\
\hline Buyer relationship proneness & $.43^{2 *}$ & $06=0$ & $.49 * *$ & $39 * 4$ & $.12^{* *}$ & $.51^{* *}$ \\
\hline Seller relationship orientation & $36 * *$ & - & $36^{* *}$ & $47^{* *}$ & 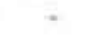 & $47^{* *}$ \\
\hline \multicolumn{7}{|l|}{ Effect on trust } \\
\hline Sociability & * & -.02 & -.02 & $\cdot$ & .00 & .00 \\
\hline Social recognition & - & .03 & .03 & $=$ & .04 &. .04 \\
\hline Shopping enjoyment & - & .00 &, 00 & - & 05 & .05 \\
\hline Product category involvement & - & $.14 * 6$ & $14 * 0$ & * & $16 * \bullet$ & $.16^{* *}$ \\
\hline Buyer relationship proneness & - & $36 * 0$ & $36 * 0$ & - & $41 * *$ & $.41^{* *}$ \\
\hline Seller relationship orientation & $\therefore$ & $.27 * *$ & $.27 * 0$ & - & $.37^{* *}$ & $.37 * 0$ \\
\hline Relationship satisfaction & $.73^{* 0}$ & $\cdot$ & $.73 * 0$ & $.80^{* *}$ & - & $.80^{\circ \bullet}$ \\
\hline \multicolumn{7}{|l|}{ Effect on relationship commitment } \\
\hline Sociability & - & -.04 &,- 04 & - & .00 & .00 \\
\hline Social recognition & - & .04 & .04 & - & .06 & -.06 \\
\hline Shopping enjoyment & - & .00 & .00 & - & .08 & .08 \\
\hline Product category involvement & - & $.23 * 0$ & $.23^{* *}$ & - & $.24 * *$ & $.24 * *$ \\
\hline Buyer relationship proneness & $.34^{* *}$ & $.22^{* 4}$ & $.56 * 0$ & $.36^{* *}$ & $.27 * 6$ & $.63^{* *}$ \\
\hline Seller relationship orientation & $.21^{* *}$ & $14 * *$ & $.35 * 0$ & .10 & $.22 *$ & $.32 * *$ \\
\hline Relationship satisfaction & + & $39 * *$ & $.39 * *$ & - & $.47 * \bullet$ & $.47^{* 4}$ \\
\hline Trust & $.53 * *$ & $\cdot$ & $.53^{* *}$ & $58 * *$ & - & $.58 * 0$ \\
\hline \multicolumn{7}{|l|}{ Effect on behavioral loyalty } \\
\hline Sociability & - & -.02 & -.02 & - & .00 & .00 \\
\hline Social recognition & - & .02 & .02 & - &,- 02 & -.02 \\
\hline Shopping enjoyment & . & .00 &, 00 & - & .03 & .03 \\
\hline Product category involvement & - & $10^{* *}$ & $10^{\circ *}$ & - & $.09 * *$ & $.09 * *$ \\
\hline Buyer relationship proneness & - & $.25^{\infty+\infty}$ & $.25^{\bullet *}$ & - & $.24^{* *}$ & $.24 * *$ \\
\hline Seller relationship orientation & - & $.15^{* 0}$ & $.15^{* *}$ & - & $.12^{* *}$ & $.12 * *$ \\
\hline Relationship satisfaction & - & $.17^{* *}$ & $.17^{* *}$ & - & $.18^{*+}$ & $.18 * *$ \\
\hline Trust & - & $.23 * *$ & $.23 * 0$ & $\therefore$ & $.22 *$ & $.22 *$ \\
\hline Relationship commitment & $44^{* *}$ & - & $.44^{* *}$ & $37 * 0$ & - & $.37 *=$ \\
\hline
\end{tabular}

(") $p<.05,(*) p<.01$ 
Table 7-12: Decomposition of Structural Effects (United States)

\begin{tabular}{|c|c|c|c|c|c|c|}
\hline Effeet on buyer relationship proneness & Direct. & $\begin{array}{l}\text { Cothing } \\
\text { Indirect }\end{array}$ & Total & Direct & $\begin{array}{c}\text { Food } \\
\text { Indirect }\end{array}$ & Total \\
\hline Sociability & .01 & $\cdot$ & .01 & .04 & - & .04 \\
\hline Social recognition & $-.14^{*}$ & - & $-.14^{*}$ & .08 & - & -.08 \\
\hline Shopping enjoyment & $.17^{*}$ & - & $.17^{\circ}$ & $17^{\circ}$ & - & $.17^{*}$ \\
\hline $\begin{array}{l}\text { Product category involvement } \\
\text { Effect on seller relationship orientation }\end{array}$ & $.79 * \bullet$ & $\cdot$ & $.79 * \bullet$ & $.59 * 0$ & - & $.59 * 0$ \\
\hline Sociability & - & .00 & .00 & - & .02 & .02 \\
\hline Social recognition & - & $.06 *$ & $.06^{*}$ & - & .04 & -.04 \\
\hline Shopping enjoyment & - & $08^{*}$ & $.08^{*}$ & $\cdot$ & $.08^{*}$ & $.08^{*}$ \\
\hline Product category involvement & $\dot{x}$ & $.36 * 0$ & $.36^{* *}$ & $\therefore$ & $.28 * *$ & $28 *$ \\
\hline Effect on relationship satisfaction & $45 *$ & - & $.45^{* *}$ & $44^{* *}$ & - & $44 * *$ \\
\hline Sociability & - & .00 & .00 & - & .03 & .03 \\
\hline Social recognition & - & -.08 & $-.08^{*}$ & - & .05 & .05 \\
\hline Shopping enjoyment & - & $.09^{\circ}$ & $.09^{*}$ & - & $.10^{\circ}$ & $.10^{*}$ \\
\hline Product category involvement & $=$ & $.44 * \bullet$ & $.44^{\circ *}$ & $\cdot$ & $.37 * *$ & $37 * *$ \\
\hline Buyer relationship proneness & $.26 * 4$ & $.30^{* *}$ & $.56 * 0$ & $.41^{* \bullet}$ & $.22 * \bullet$ & $.63 * v$ \\
\hline $\begin{array}{l}\text { Seller relationship orientation } \\
\text { Effect an trust }\end{array}$ & $.67 * 0$ & $\cdot$ & $.67 * *$ & \multicolumn{2}{|c|}{ Effect an trust } & $50 * 4$ \\
\hline Sociability & 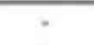 & .00 & .00 & - & .02 & .02 \\
\hline Social recognition & - & $-.06^{*}$ & $-.06^{*}$ & - & .04 & -.04 \\
\hline Shopping enjoyment & * & $.07 \bullet$ & $.07 *$ & - & $.09 *$ & $.09^{*}$ \\
\hline Product category involvement & . & $33^{* *}$ & $33 * *$ & - & $.30^{* *}$ & $.30^{* *}$ \\
\hline Buyer relationship proneness & - & $.42 * *$ & $.42 * *$ & - & $52 * *$ & $.52 * 0$ \\
\hline Seller relationship orientation & - & $.50^{* *}$ & $50^{* *}$ & - & $.38 * *$ & $.38 * *$ \\
\hline \multicolumn{7}{|l|}{ Effect on relationship commitment } \\
\hline Sociability & - & .01 & .01 & 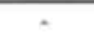 & .03 & .03 \\
\hline Social recognition & - & $-.09 *$ & $-.09^{*}$ & $\cdot$ & -.06 &,- 06 \\
\hline Shopping enjoyment & - & $.11^{*}$ & $.11^{\circ}$ & - & $12^{*}$ & $.12^{*}$ \\
\hline Product category involvement & 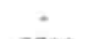 & $53^{* *}$ & $53^{* *}$ & $\cdot$ & $.43^{* *}$ & $.43^{* *}$ \\
\hline Buyer relationship proneness & $37^{* * *}$ & $.29 * *$ & $.66^{* *}$ & $36^{* * *}$ & $.36 * 4$ & $.72 *$ \\
\hline Seller relationship orientation & .11 & $.29 * *$ & $40^{* *}$ & .06 & $.24^{* *}$ & $30 *$ \\
\hline Relationship satisfaction & - & $.43 * 6$ & $43^{* *}$ & $\cdot$ & $.54^{* *}$ & $.54^{* *}$ \\
\hline Trust & $.57 * 0$ & - & $.57^{* *}$ & $.66^{* *}$ & $\cdot$ & $.66^{* *}$ \\
\hline \multicolumn{7}{|l|}{ Effect on behavional loyulty } \\
\hline Sociability & $\cdot$ & .00 & .00 & $\cdot$ & .01 & .01 \\
\hline Social recognition & $\cdot$ & -.05 & $-.05 *$ & $\cdot$ & -.02 & -.02 \\
\hline Shopping enjoyment & - & $.07 *$ & $.07^{*}$ & - & $.05 *$ & $.05^{*}$ \\
\hline Product category involvement & - & $31 *$ & $31=0$ & $\cdot$ & $.18^{2 * *}$ & $.18 * *$ \\
\hline Buyer relationship proneness & $\cdot$ & $.39 * \bullet$ & $39 * *$ & - & $31^{* *}$ & $.31 *$ \\
\hline Seller relationship orientation & - & $.23 * *$ & $.23 * *$ & $\cdot$ & $.13^{* *}$ & $.13^{* *}$ \\
\hline Relationship satisfaction & - & $.25^{* *}$ & $25 * *$ & - & $.23 * *$ & $.23^{* *}$ \\
\hline Trust & - & $.34^{* 0}$ & $.34^{* *}$ & - & $.28 * 0$ & $28^{* *}$ \\
\hline Relationship commitment & $.59 * 0$ & - & $.59 * *$ & $.43^{\text {** }}$ & - & $43^{* *}$ \\
\hline
\end{tabular}

(*) $p<.05,(* *) p<.01$ 


\subsubsection{Evaluation of a Rival Model}

In SEM, it is generally agreed upon that researchers should compare rival models and not just test the performance of a proposed model (Bollen and Long 1992; Hair et al. 1998; Morgan and Hunt 1994). The model we hypothesized in chapter five is parsimonious as it permits no direct paths from any antecedent of buyer relationship proneness to any relationship outcome (relationship satisfaction, trust, relationship commitment, and behavioral loyalty). In order to assess the robustness of our hypothesized model, we formulated a rival, less parsimonious model positing direct relationships from sociability, social recognition, shopping enjoyment, and product category involvement not only to buyer relationship proneness, but also to seller relationship orientation and all relationship outcomes. Moreover, in the rival model, we estimated direct paths from buyer relationship proneness and seller relationship orientation to all relationship outcomes. Although this rival model has never been suggested in literature, there is some support for additional paths estimated in the rival model (Cheek and Buss 1981; Forsythe, Butler, and Schaefer 1990; Geyskens 1998; Gutman and Mills 1982; Kirkpatrick and Davis 1994; Page and Sharp 1997; Sadowski and Cogburn 1997).

In line with Morgan and Hunt (1994), we compared the hypothesized model with the rival model on the following criteria: (1) overall fit of both models as measured by CFI, (2) parsimony of both models, (3) percentage of both models' hypothesized parameters that are statistically significant, and (4) squared multiple correlations for each of the endogenous constructs in both models. With respect to the overall fit of both models, the average CFl for the rival model is slightly higher than the average CFI for the hypothesized model across samples (.93 versus .94). In contrast, in order to achieve this slight increase in CFI, an additional 24 paths needed to be estimated in the rival model, reducing this model's parsimony. Stated alternatively, we accomplished a great increase in parsimony from 36 paths in the rival model to 12 paths in the hypothesized model by sacrificing only $1 \%$ in CFI. Moreover, only $50 \%$ of the paths in the rival model were significant as opposed to $69 \%$ in the hypothesized model. Furthermore, the robustness of the hypothesized model is supported as a result of the fact that all significant effects in the rival model are equally significant in the hypothesized model. Finally, little additional explanatory power is gained resulting from the rival model as the mean increment in squared multiple correlations for the endogenous constructs is only .048. Given the low sacrifice in CFI and the decisive gain in parsimony, we find support for the robustness of the hypothesized model.

In the next section, we continue the analysis by investigating the moderating effects of seller relationship orientation, buyer relationship proneness, and product category involvement on the paths originating from buyer relationship proneness and seller relationship orientation.

\subsection{Moderating Effects}

In 7.7.1, we investigate whether seller relationship orientation moderates the relationship from buyer relationship proneness to relationship satisfaction/relationship commitment. In 7.7.2, we assess the moderating influence of buyer relationship proneness on the relationship from seller relationship orientation to relationship satisfaction/relationship commitment. Finally, 7.7.3 discusses 
the moderating effect of product category involvement on the relationship from seller relationship orientation to relationship satisfaction/relationship commitment.

It is a commonly accepted practice to assess the existence of moderating effects by means of multigroup analysis (Jaccard and Wan 1996; Ping 1995). Total samples were split in two sub-samples according to the values of the moderating variable. One sub-sample contained about one third of the lowest values for the moderating variable (e.g. relationship proneness low), while the other subsample contained about one third of the highest values for the moderating variable (e.g. relationship proneness high). As a result, cases of which the moderating variables' values lie around the median level were excluded. This ensured a high level of within-group homogeneity and a high level of between-group heterogeneity. The sizes of the various sub-samples are described in tables 7-13, 7. 16 , and 7-19.

\subsubsection{Modenating Effects of Seller Relationship Orientation}

Figure 7-7 visually depicts the moderating effect of seller relationship orientation on the relationship from buyer relationship proneness to relationship satisfaction/relationship commitment.

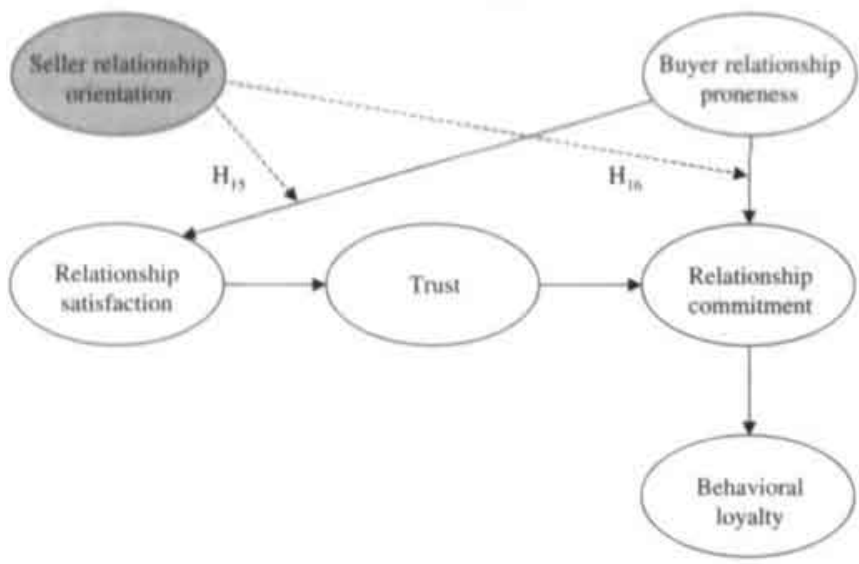

Figure 7-7: Modenating Effects of Seller Relationship Orientation

In table 7-13, the characteristics of the sub-samples generated on basis of the level of seller relationship orientation are shown.

Table 7.14 displays the results of 18 separate structural model estimations in terms of degrees of freedom and $\chi^{2}$ generated. In the equal models, all paths of the structural model visualized in figure 7.7 are set equal across high- and low-relationship orientation sub-samples. In the 'RP-RS free' models, all paths are constrained to be equal across high- and low-relationship orientation subsamples, except for the relationship from buyer relationship proneness to relationship satisfaction. In the 'RP-MIT free' models, all paths are constrained to be equal across sub-samples, except for the relationship from buyer relationship proneness to relationship commitment. 
Iable 7-13: Size and Distribution of Sub-Samples According to the Level of Seller Relationship Orientation

\begin{tabular}{|c|c|c|c|c|c|c|c|}
\hline \multirow[t]{2}{*}{ Sub-Samples } & \multirow[b]{2}{*}{$\mathbf{N}$} & \multicolumn{2}{|c|}{ Gender (G) } & \multicolumn{4}{|c|}{ Age (\%) } \\
\hline & & Male & Female & $18-25$ & $26-40$ & $41-55$ & $>55$ \\
\hline The Netherfands clothing & 338 & 30.5 & 69.5 & 29.0 & 25.4 & 20.1 & 25.4 \\
\hline Seller relationship orientation low & 127 & 29.1 & 70.9 & 39.4 & 33.1 & 15.7 & 11.8 \\
\hline Seller relationship orientation high & 124 & 31.5 & 68.5 & 14.5 & 21.8 & 25.8 & 37.9 \\
\hline The Nethertands food & 337 & 27.0 & 73.0 & 29.8 & 29.2 & 19.6 & 21.4 \\
\hline Seller relationship orientation low & 122 & 31.1 & 68.9 & 29.5 & 28.7 & 22.1 & 19.7 \\
\hline Seller relationship orientation high & 125 & 20.8 & 79.2 & 24.8 & 28.0 & 17.6 & 29.6 \\
\hline Belgium clothing & 302 & 30.2 & 69.8 & 24.8 & 25.2 & 23.8 & 26.1 \\
\hline Seller relationship orientation low & 117 & 29.3 & 70.7 & 28.2 & 35.9 & 17.1 & 18.8 \\
\hline Seller relationship orientation high & 97 & 28.9 & 71.1 & 18.6 & 14.4 & 25.8 & 41.2 \\
\hline Belgium food & 289 & 29.4 & 70.6 & 25.3 & 22.5 & 26.0 & 26.3 \\
\hline Selier relationship orientation low & 103 & 29.1 & 70.9 & 31.1 & 23.3 & 23.3 & 22.3 \\
\hline Seller relationship orientation high & 98 & 34.7 & 65.3 & 13.3 & 17.3 & 33.7 & 35.7 \\
\hline United States clothing & 230 & 32.6 & 67.4 & 36.5 & 31.3 & 23.5 & 8.7 \\
\hline Seller relationship orientation low & 75 & 37.3 & 62.7 & 53.3 & 18.7 & 18.7 & 9.3 \\
\hline Seller relationship orientation high & 90 & 26.7 & 73.3 & 24.4 & 40.0 & 26.7 & 8.9 \\
\hline United States food & 231 & 40.8 & 59.2 & 55.4 & 25.1 & 16.5 & 3.0 \\
\hline Seller relationship orientation low & 83 & 36.7 & 63.3 & 56.6 & 26.5 & 14.5 & 2.4 \\
\hline Seller relationship orientation high & 78 & 40.8 & 59.2 & 46.2 & 30.8 & 20.5 & 2.6 \\
\hline
\end{tabular}

As can be derived from table 7-14, differences in chi-square values between models served as a hasis for deciding whether or not seller relationship orientation acts as a moderating variable. A significant decrease in chi-square from the equal model to a model in which one relationship is set free implies that the moderator variable has a significant influence on that relationship. Table 7-14 reveals that the construct of seller relationship orientation significantly moderates the relationship between buyer relationship proneness and relationship satisfaction in two samples (Belgium food and United States food). The relationship between buyer relationship proneness and relationship commitment is similarly significantly affected by seller relationship orientation in two samples (the Netherlands food and Belgium food).

Table 7-14: Moderating Effects of Seller Relationship Orientation

\begin{tabular}{|c|c|c|c|c|c|c|c|}
\hline \multirow[b]{2}{*}{ Model } & & \multicolumn{2}{|c|}{ The Netherdands } & \multicolumn{2}{|c|}{ Belgium } & \multicolumn{2}{|c|}{ United States } \\
\hline & & Clothing & Food & Clothing & Food & Clothing & Food \\
\hline \multirow[t]{2}{*}{ Equal model } & df & 201 & 201 & 201 & 201 & 201 & 201 \\
\hline & $\chi^{2}$ & 624.85 & 529.76 & 434.15 & 512.69 & 520.32 & 656.90 \\
\hline \multirow[t]{2}{*}{ RP-RS free } & $\hat{\mathrm{df}}$ & 200 & 200 & 200 & 200 & 200 & 200 \\
\hline & $x^{2}$ & 624.78 & 527.25 & 433.06 & 505.08 & 517.07 & 652.14 \\
\hline \multirow{2}{*}{ RP.MIT free } & df & 200 & 200 & 200 & 200 & 200 & 200 \\
\hline & \multicolumn{6}{|c|}{ Model differences } & 656.19 \\
\hline \multirow[t]{2}{*}{ Equal versus RP-RS free } & df & 1 & 1 & 1 & 1 & 1 & 1 \\
\hline & $x^{2}$ & .07 & 2.51 & 1.09 & $7.61^{*-\infty}$ & 3.25 & $4.76^{*}$ \\
\hline \multirow[t]{2}{*}{ Equal versus RP-MIT free } & df & 1 & 1 & 1 & 1 & I & 1 \\
\hline & $x^{2}$ & .01 & $8.31^{* 0}$ & .94 & $4.92^{\circ}$ & .15 & .71 \\
\hline
\end{tabular}

(*) $\mathrm{p}<.05,(* *) \mathrm{p}<.01$

The following abbreviations are used: RP = buyer relationship proneness, RS = relationship satisfaction.

MrT = relationship commitment

Table 7-15 reports the differences in within-group path coefficients between the sub-samples. As hypothesized, in case of significant differences between path coefficients, these were consistently 
lower in the low-relationship orientation sub-sample than in the high-relationship orientation subsample. This implies that the effects of buyer relationship proneness on relationship satisfaction and relationship commitment are stronger in case buyers perceive sellers to be making larger efforts towards them.

Table 7-15: Change in Puth Coefficients Based on Level of Seller Relationship Orientation

\begin{tabular}{lccc}
\hline Path from RP-RS & $\begin{array}{c}\text { Within-group path coefficient } \\
\text { RO low }\end{array}$ & $\begin{array}{c}\text { Change in coefficient } \\
\text { RO high }\end{array}$ \\
\hline The Netherlands clothing & .51 & .48 & -.03 \\
The Netherlands food & .25 & .46 & +.21 \\
Belgium clothing & .35 & .48 & +.13 \\
Belgium food & .22 & .58 & $+.36^{* *}$ \\
United States clothing & .34 & .57 & +.23 \\
United States food & .42 & .68 & $+.26^{*}$ \\
Path frum RP-MrT & & & -.01 \\
\hline The Netherlands clothing & .72 & .71 & $+.28^{* *}$ \\
The Netherlands food & .33 & .61 & +.12 \\
Belgium clothing & .29 & .41 & $+.23 *$ \\
Belgium food & .20 & .43 & +.04 \\
United States clothing & .39 & .43 & -.04 \\
United States food & .71 & .67 & \\
\hline
\end{tabular}

(") $\mathrm{p}<.05,(* *) \mathrm{p}<.01$

The following abbreviations are used: RP = buyer relationship proneness, RS = relationship satisfaction, MIT = relationship commitment.

Concluding, we can state that the construct of seller relationship orientation acts as a moderator in some of the samples examined, providing partial support for $\mathrm{H}_{15}$ and $\mathrm{H}_{16}$. Moreover, in case seller relationship orientation moderates a specific relationship, it consistently does so in the hypothesized direction.

\subsubsection{Modenating Effects of Buyer Relationship Proneness}

Figure 7-8 visually depicts the moderating effect of buyer relationship proneness on the relationship from seller relationship orientation to relationship satisfaction/relationship commitment.

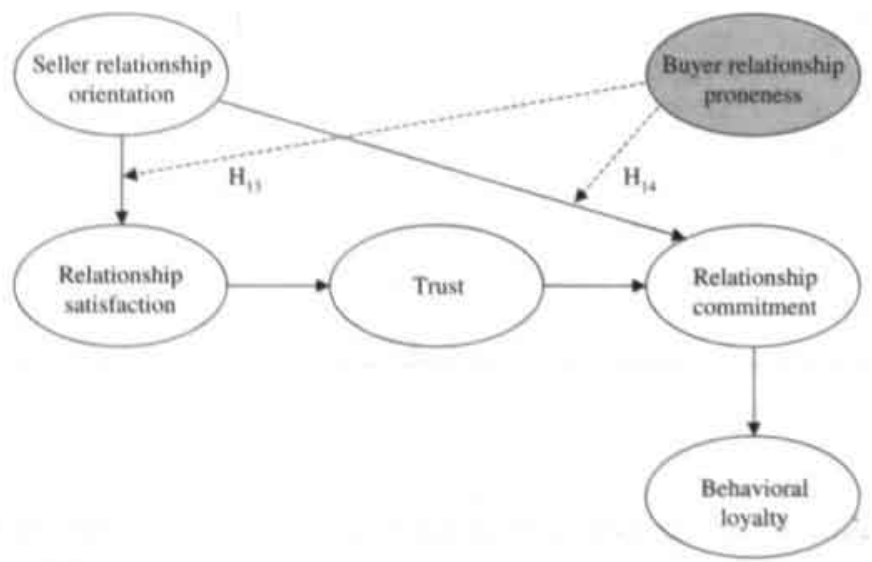

Figure 7-8: Modenating Effects of Buyer Relationship Proneness 
In table 7-16, the characteristics of the sub-samples generated on basis of the level of buyer relationship proneness are shown.

Talke 7-16: Size and Distribution of Sub-Samples According to the Level of Buyer Relationship Proneness

\begin{tabular}{|c|c|c|c|c|c|c|c|}
\hline \multirow{2}{*}{ Sub-samples } & \multirow[b]{2}{*}{$\mathbf{N}$} & \multicolumn{2}{|c|}{ Gender (\$) } & \multicolumn{4}{|c|}{ Age (\$) } \\
\hline & & Male & Female & 18.25 & $26-40$ & $41-55$ & $>55$ \\
\hline The Nethertands clothing & 338 & 30.5 & 69.5 & 29.0 & 25.4 & 20.1 & 25.4 \\
\hline Buyer relationship proneness low & 110 & 30.9 & 69.1 & 30.9 & 35.5 & 15.5 & 18.2 \\
\hline Buyer relationship proneness high & 128 & 31.3 & 68.8 & 16.4 & 18.8 & 23.4 & 41.4 \\
\hline The Netheriands food & 337 & 27.0 & 73.0 & 29.8 & 29.2 & 19.6 & 21.4 \\
\hline Buyer relationship proneness low & 106 & 34.9 & 65.1 & 33.1 & 35.2 & 17.1 & 14.3 \\
\hline Buyer relationship proneness high & 116 & 20.7 & 79.3 & 19.8 & 19.8 & 21.6 & 38.8 \\
\hline Belgium clothing & 302 & 30.2 & 69.8 & 24.8 & 25.2 & 23.8 & 26.1 \\
\hline Buyer relationship proneness low & 102 & 26.5 & 73.5 & 36.3 & 24.5 & 21.6 & 17.6 \\
\hline Bayet relationship proneness high & 110 & 30.9 & 69.1 & 13.6 & 23.6 & 25.5 & 37.3 \\
\hline Belgium food & 289 & 29.4 & 70.6 & 25.3 & 22.5 & 26.0 & 26.3 \\
\hline Buyer relationship proneness low & 107 & 23.4 & 76.6 & 32.7 & 30.8 & 25.2 & 11.2 \\
\hline Buyer relationship proneness high & 100 & 30.0 & 70.0 & 18.0 & 17.0 & 23.0 & 42.0 \\
\hline United States clothing & 230 & 32.6 & 67.4 & 36.5 & 31.3 & 23.5 & 8.7 \\
\hline Buyer relationship proneness low & 75 & 40.0 & 60.0 & 48.0 & 21.3 & 20.0 & 10.7 \\
\hline Buyer relationship proneness high & 78 & 24.4 & 75.6 & 25.6 & 38.5 & 26.9 & 9.0 \\
\hline United States food & 231 & 40.8 & 59.2 & 55.4 & 25.1 & 16.5 & 3.0 \\
\hline Buyer relationship proneness low & 88 & 52.4 & 47.6 & 59.1 & 23.9 & 15.9 & 1.1 \\
\hline Buyer relationship proneness high & 91 & 38.6 & 61.4 & 51.6 & 30.8 & 14.3 & 3.3 \\
\hline
\end{tabular}

Table 7-17 displays the results of 18 separate structural model estimations in terms of degrees of freedom and $\chi^{2}$ generated. In the equal models, all paths of the structural model visualized in figure 7-8 are set equal across high- and low-relationship proneness sub-samples. In the 'RO-RS free' models, all paths are constrained to be equal across high- and low-relationship proneness subsamples, except for the relationship from seller relationship orientation to relationship satisfaction. In the 'RO-MIT free' models, all paths are constrained to be equal across sub-samples, except for the relationship from seller relationship orientation to relationship commitment.

Table 7-17: Moderating Effects of Buyer Relationship Proneness

\begin{tabular}{|c|c|c|c|c|c|c|c|}
\hline \multirow[b]{2}{*}{ Model } & & \multicolumn{2}{|c|}{ The Netherfands } & \multicolumn{2}{|c|}{ Belgium } & \multicolumn{2}{|c|}{ United States } \\
\hline & & Clothing & Food & Clothing & Food & Clothing & Food \\
\hline \multirow[t]{2}{*}{ Equal model } & df & 201 & 201 & 201 & 201 & 201 & 201 \\
\hline & $\chi^{2}$ & 582.17 & 385.09 & 518.41 & 398.56 & 514.74 & 530.74 \\
\hline \multirow[t]{2}{*}{ RO-RS free } & $\mathrm{df}$ & 200 & 200 & 200 & 200 & 200 & 200 \\
\hline & $\chi^{2}$ & 581.56 & 385.00 & 517.78 & 392.12 & 509.41 & 517.23 \\
\hline \multirow[t]{2}{*}{ RO-MIT free } & $\hat{\mathrm{df}}$ & 200 & 200 & 200 & 200 & 200 & 200 \\
\hline & \multicolumn{6}{|c|}{ Model differences } & 528.01 \\
\hline \multirow[t]{2}{*}{ Equal versus RO-RS free } & df & 1 & 1 & 1 & 1 & 1 & 1 \\
\hline & $x^{2}$ & .61 & .09 & .63 & $6.44^{*}$ & $5.33^{\circ}$ & $13.51 * 0$ \\
\hline \multirow{2}{*}{ Equal versus RO-MTT free } & df & 1 & 1 & 1 & 1 & 1 & 1 \\
\hline & $x^{2}$ & .02 & .49 & .01 & $10.04 * *$ & .17 & 2.73 \\
\hline
\end{tabular}

(") $\mathrm{p}<.05,(*) \mathrm{p}<.01$

The following abbreviations are used: $R O=$ seller relationship orientation, $\mathrm{RS}=$ relationship satisfaction.

MIT = relationship commitment. 
The results show that the construct of buyer relationship proneness significantly moderates the relationship from seller relationship orientation to relationship satisfaction in three samples (Belgium food, United States clothing, and United States food). The relationship between seller relationship orientation and relationship commitment is significantly affected by buyer relationship proneness in only one sample (Belgium food).

Table 7-18 reports the differences in within-group path coefficients between the sub-samples. As hypothesized, the path coefficients were consistently lower in the low-relationship proneness subsample than in the high-relationship proneness sub-sample in case significant differences were found. This implies that the effects of seller relationship orientation on relationship satisfaction and relationship commitment are stronger in case buyers are more prone to engage in relationships with sellers.

Tahle 7-18: Change in Path Coefficients Based on Level of Buyer Relationship Proneness

\begin{tabular}{lccc}
\hline Puth from RO-RS & $\begin{array}{c}\text { Within-group path coeficient } \\
\text { RP low }\end{array}$ & $\begin{array}{c}\text { Change in coefficient } \\
\text { RP high }\end{array}$ & -.05 \\
\hline The Netherlands clothing & .76 & .71 & +.02 \\
The Netherlands food & .64 & .66 & -10 \\
Belgium clothing & .46 & .36 & $+.29 *$ \\
Belgium food & 31 & .60 & $+.14 *$ \\
United States clothing & .67 & .81 & $+.32 * *$ \\
United States food & .44 & .76 & -.02 \\
Puth from RO-MrT & & & +.11 \\
\hline The Netherlands clothing & .35 & .33 & -.01 \\
The Netherlands food & .15 & .26 & $+.42 * *$ \\
Belgium clothing & .27 & .26 & +.07 \\
Belgium food & -.09 & .33 & +.19 \\
United States clothing & .15 & .22 & .18 \\
United States food & -.01 & & \\
\hline
\end{tabular}

$(*) \mathrm{p}<.05,(* *) \mathrm{p}<.01$

The following abbreviations are used: $\mathrm{RO}=$ seller relationship orientation,

$\mathrm{RS}=$ relationship satisfaction. $\mathrm{MTT}=$ relationship commitment.

Concluding, we can state that the construct of buyer relationship proneness acts as a moderator in some of the samples examined, providing partial support for $\mathrm{H}_{13}$ and $\mathrm{H}_{14}$. Moreover, in case buyer relationship proneness moderates a specific relationship, it consistently does so in the hypothesized direction.

\subsubsection{Moderating Effects of Product Category Involvement}

Figure 7-9 visually depicts the moderating effect of product category involvement on the relationships from seller relationship orientation to relationship satisfaction/relationship commitment".

3. As already mentioned in chapter five, no moderating effects of product category involvement on the paths from buyer relationship proneness to relationship satisfaction and relationship commitment were estimated. The underlying reason for this is that both product category involvement and buyer relationship proneness refer to the same unit of analysis. In other words, one buyer exhibiting a certain level of buyer relationship proneness can only be characterized by one level of product category involvement. 


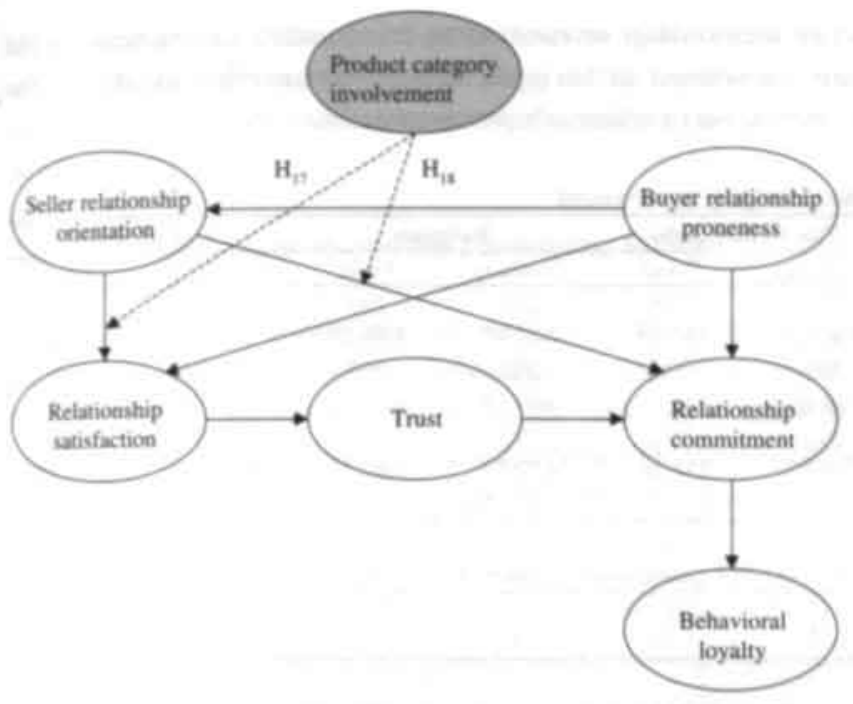

Figure 7.9: Moderating Effects of Product Category Imvolvement

In table 7-19, the characteristics of the sub-samples generated on basis of the level of product category involvement are shown.

Table 7-19: Size and Distribution of Sub-Samples According to the Level of Product Category Involvement

\begin{tabular}{lc|cc|cccc}
\hline \multirow{2}{*}{ Sub-Samples } & \multirow{2}{*}{$\mathrm{N}$} & \multicolumn{3}{|c|}{ Gender(\%) } & \multicolumn{4}{c}{ Age (\%) } \\
\cline { 3 - 8 } & 338 & Male & Female & $18-25$ & $26-40$ & $41-55$ & $>55$ \\
\hline The Netherfands clothing & 30.5 & 69.5 & 29.0 & 25.4 & 20.1 & 25.4 \\
Product category involvement low & 116 & 37.1 & 62.9 & 31.9 & 27.6 & 19.8 & 20.7 \\
Product category involvement high & 104 & 29.8 & 70.2 & 25.0 & 17.3 & 22.1 & 35.6 \\
\hline The Netherlands food & 337 & 27.0 & 73.0 & 29.8 & 29.2 & 19.6 & 21.4 \\
Product category involvement low & 96 & 34.4 & 65.6 & 51.0 & 25.0 & 14.6 & 9.4 \\
Product category involvement high & 104 & 25.0 & 75.0 & 16.3 & 28.8 & 25.0 & 29.8 \\
\hline Belgium clothing & 302 & 30.2 & 69.8 & 24.8 & 25.2 & 23.8 & 26.1 \\
Product category involvement low & 108 & 31.8 & 68.2 & 23.1 & 25.9 & 25.9 & 25.0 \\
Product category involvement high & 92 & 25.0 & 75.0 & 17.4 & 21.7 & 23.9 & 37.0 \\
\hline Belgium food & 289 & 29.4 & 70.6 & 25.3 & 22.5 & 26.0 & 26.3 \\
Product category involvement low & 97 & 34.0 & 66.0 & 39.2 & 23.7 & 29.9 & 7.2 \\
Product category involvement high & 107 & 27.1 & 72.9 & 9.3 & 17.8 & 25.2 & 47.7 \\
\hline United States clothing & 230 & 32.6 & 67.4 & 36.5 & 31.3 & 23.5 & 8.7 \\
Product category involvement low & 75 & 40.0 & 60.0 & 38.7 & 21.3 & 25.3 & 14.7 \\
Product category involvement high & 76 & 23.7 & 76.3 & 39.3 & 34.2 & 18.4 & 7.9 \\
\hline United States food & 231 & 40.8 & 59.2 & 55.4 & 25.1 & 16.5 & 3.0 \\
Product category involvement low & 89 & 44.8 & 55.2 & 58.4 & 21.3 & 18.0 & 2.2 \\
Product category involvement high & 112 & 40.2 & 59.8 & 52.7 & 26.8 & 17.0 & 3.6 \\
\hline
\end{tabular}

Table 7-20 displays the results of 18 separate structural model estimations in terms of degrees of freedom and $\chi^{2}$ generated. In the equal models, all paths of the structural model visualized in figure $7-9$ are set equal across high- and low-product category involvement sub-samples. In the 'RO-RS free' models, all paths are constrained to be equal across high- and low-involvement sub-samples, 
except for the relationship from seller relationship orientation to relationship satisfaction. In the 'RO-MIT free' models, all paths are constrained to be equal across sub-samples, except for the relationship from seller relationship orientation to relationship commitment.

Table 7-20: Modenating Effects of Product Categony Involvement

\begin{tabular}{|c|c|c|c|c|c|c|c|}
\hline \multirow[b]{2}{*}{ Model } & & \multicolumn{2}{|c|}{ The Nethertands } & \multicolumn{2}{|c|}{ Belgium } & \multicolumn{2}{|c|}{ United States } \\
\hline & & Clothing & Food & Clothing & Food & Clothing & Food \\
\hline \multirow[t]{2}{*}{ Equal model } & df & 293 & 293 & 293 & 293 & 293 & 293 \\
\hline & $x^{2}$ & 530.72 & 557.29 & 449.47 & 684.28 & 603.96 & 1.410 .09 \\
\hline \multirow[t]{2}{*}{ RO-RS free } & df & 292 & 292 & 292 & 292 & 292 & 292 \\
\hline & $x^{2}$ & 528.60 & 556.17 & 449.28 & 684.09 & 597.76 & $1,384.24$ \\
\hline \multirow[t]{2}{*}{ RO-MIT free } & df & 292 & 292 & 292 & 292 & 292 & 292 \\
\hline & \multicolumn{6}{|c|}{ Model differences } & $2,597.00$ \\
\hline \multirow[t]{2}{*}{ Equal versus RO-RS free } & df & 1 & 1 & 1 & 1 & 1 & 1 \\
\hline & $\chi^{2}$ & 2.12 & 1.12 & .19 & 19 & $6.20^{*}$ & $25.85 *$ \\
\hline \multirow[t]{2}{*}{ Equal versus RO-MIT free } & df & I & 1 & I & 1 & 1 & 1 \\
\hline & $x^{2}$ & 1.10 & 1.49 & $9.74^{* *}$ & $4.03^{*}$ & .42 & $<0$ \\
\hline
\end{tabular}

$(\bullet) \mathrm{p}<.05 .(*) \mathrm{p}<.01$

The following abbreviations are used: $\mathrm{RO}=$ seller relationship orientation, $\mathrm{RS}=$ relationship satisfaction,

MIT = relationship commitment.

Table 7-20 reveals that the construct of product category involvement significantly moderates the relationship from seller relationship orientation to relationship satisfaction in two samples (United States clothing and United States food) and the relationship from seller relationship orientation to relationship commitment in two other samples (Belgium clothing and Belgium food).

Table 7-21 reports the differences in within-group path coefficients between the sub-samples. All of the path coefficients were consistently lower in the low-involvement sub-sample than in the highinvolvement sub-sample in case significant differences were found. This implies that the effects of seller relationship orientation on relationship satisfaction and relationship commitment are stronger in case buyers are more involved with the product category.

Table 7-21: Change in Path Coefficients Based on Level of Product Category Involvement

\begin{tabular}{lccc}
\hline Path from RO-RS & $\begin{array}{c}\text { Within-group path coefficient } \\
\text { INV low }\end{array}$ & $\begin{array}{c}\text { Change in coefficient } \\
\text { INV high }\end{array}$ & \\
\hline The Netherlands clothing & .63 & .71 & +.08 \\
The Netherlands food & .51 & .60 & +.09 \\
Belgium clothing & .38 & .33 & -.05 \\
Belgium food & .46 & .41 & -.05 \\
United States clothing & .62 & .75 & $+.13^{*}$ \\
United States food & .34 & .53 & $+.19^{* *}$ \\
Puth from RO-MIr & & & +.11 \\
\hline The Netherlands clothing & .08 & .19 & -14 \\
The Netherlands food & .26 & .12 & $+.35^{* *}$ \\
Belgium clothing & .02 & .37 & $+.24^{*}$ \\
Belgium food & -.04 & .20 & +.07 \\
United States clothing & .07 & .14 & + \\
United States food &.- &.- & \\
\hline
\end{tabular}

(*) $\mathrm{p}<.05,(* *) \mathrm{p}<.01$

The following abbreviations are used: $\mathrm{RO}=$ seller relationship orientation.

RS $=$ relationship satisfaction. MIT $=$ relationship commitment. 
Concluding, we can state that the construct of product category involvement acts as a moderator in some of the samples examined, providing partial support for $\mathrm{H}_{17}$ and $\mathrm{H}_{18}$. Moreover, in case product category involvement moderates a specific relationship, it consistently does so in the hypothesized direction.

\subsubsection{Conclusions Regarding Moderating Effects}

Table 7-22 provides a comparative overview of the paths that were found to be moderated by seller relationship orientation, buyer relationship proneness, and product category involvement for each of the six samples. As can be read from the table, no consistent pattern can be detected across the samples. As a result, none of the hypotheses $\mathrm{H}_{13}$ to $\mathrm{H}_{20}$ was fully supported. Only partial and inconsistent support was found for the theoretically hypothesized moderating effects.

Table 7-22: Evaluation of Hypotheses Related to Moderating Effects

\begin{tabular}{|c|c|c|c|c|c|c|c|c|}
\hline Path & Hypothesis & \multicolumn{2}{|c|}{ The Netherlands } & \multicolumn{2}{|c|}{ Belgium } & \multicolumn{2}{|c|}{ United States } & \multirow[t]{2}{*}{ Result } \\
\hline \multicolumn{2}{|c|}{ RP moderates } & C & $\mathrm{F}$ & C & F & C & $\mathbf{F}$ & \\
\hline RO-RS & $\mathrm{H}_{13}$ & -.05 & .02 & -.10 & 29 & .14 & 32 & Partially supported \\
\hline RO-MIT & $\mathrm{H}_{14}$ & -.02 & .11 & -.01 & 42 & .07 & 19 & Partially supported \\
\hline \multicolumn{9}{|c|}{ RO moderates } \\
\hline RP-RS & $\mathrm{H}_{15}$ & -.03 & .21 & .13 & .36 & .23 & 26 & Partially supported \\
\hline RP.MIT & $\mathrm{H}_{16}$ & -.01 & 28 & .12 & 23 & .04 & -.04 & Partially supported \\
\hline \multicolumn{9}{|c|}{ INV moderates } \\
\hline RO-RS & $\mathbf{H}_{17}$ & .08 & .09 & -.05 & -.05 & 13 & 19 & Partially supported \\
\hline RO-MIT & $\mathrm{H}_{\mathrm{ir}}$ & .11 & -.14 & .35 & .24 & .07 & - & Partially supported \\
\hline
\end{tabular}

Shaded cells are at least significant at a $p<.05$ level.

The following abbreviations are used: $\mathrm{RO}=$ seller relationship orientation, $\mathrm{RP}=$ buyer relationship proneness, $\mathrm{RS}=$ relationship satisfaction, $\mathrm{MIT}=$ relationship commitment, $\mathrm{INV}=$ product category involvement, $\mathrm{C}=$ clothing. $\mathrm{F}=$ food.

\subsection{Summary and Conclusions}

In this chapter, we supported our choice for SEM as a data analysis technique. The procedure we used, was based upon a total disaggregation model, three indicators per construct, the use of a variance-covariance matrix, maximum likelihood estimation, and a single-step analysis. LISREL was used to conduct the analyses.

The raw data were first examined for coding errors, recoded if necessary, and cases incorporating missing values were listwise deleted before data analysis. While the data appeared to be nonnormally distributed, the sample sizes were considered large enough to partially compensate for this problem. No data sets were pooled across product categories or countries. As a result, separate models were estimated for each sample.

The goodness-of-fit measures of overall models and the performance of measurement models were satisfactory. Moreover, the structural models did not reveal any offending estimates and most significant relationships were in the hypothesized direction. 
Full support was obtained for the positive relationships from product category involvement to buyer relationship proneness, from buyer relationship proneness to seller relationship orientation, from buyer relationship proneness to relationship satisfaction, from buyer relationship proneness to relationship commitment, from seller relationship orientation to relationship satisfaction, from relationship satisfaction to trust, from trust to relationship commitment, and from relationship commitment to behavioral loyalty. Partial support was found for the relationship from sociability to buyer relationship proneness. The relationships from social recognition and shopping enjoyment to buyer relationship proneness were partially rejected. Moreover, the relationship between seller relationship orientation and relationship commitment was partially supported.

The structural model was not respecified as modification indices suggested different modifications across samples and as no sound theoretical reasons could support model respecifications. However. a rival model was estimated in order to assess the robustness of the hypothesized model. The hypothesized model proved to be robust.

Finally, we found partial support for the moderating effects of seller relationship orientation, buyet relationship proneness, and product category involvement. 


\section{Notes}




\section{Chapter Structure}

8.1 Introduction

8.2 Discussion of Results 150

8.3 Limitation

$\mathbf{8 . 4}$ Implication

8.5.1 Theoretical Implications 153

8.5.2 Managerial Implications

8.5 Directions for Future Research 


\section{Chapter 8 Discussion, Limitations, and Implications}

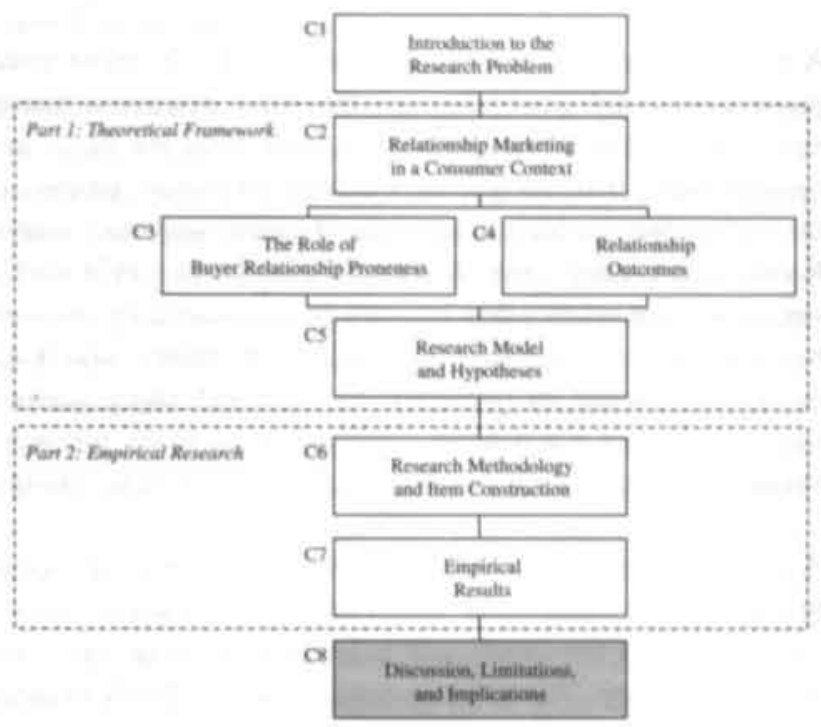

\subsection{Introduction}

In section 8.2, we outline the main conclusions of our study and discuss its results. In section 8.3 , we discuss the study's major limitations. In section 8.4 , we describe the theoretical and managerial implications of our study's results. Finally, section 8.5 indicates some important directions for future research.

\subsection{Discussion of Results}

In this section, we discuss the results related to the main and moderating effects in the hypothesized model'. This provides an answer to each of the research questions formulated in chapter one.

(1) What are the antecedents of buyer relationship proneness?

In this study, four antecedents of buyer relationship proneness were examined: sociability, social recognition, shopping enjoyment, and product category involvement. In chapter five, we hypothesized positive paths from sociability $\left(\mathrm{H}_{1}\right)$, social recognition $\left(\mathrm{H}_{2}\right)$, and product category

\footnotetext{
This study involves an empirical validation of our conceptual model in three different countries (The Netherlands, Belgium, and United States) and two different product categories (casual clothing and food). As stated in chapter one, cultural differences exist between the countries we incorporated. Moreover, Anderson, Fornell, and Rust (1997) consider clothing stores and supermarkets as sufficiently heterogeneous. Although our empirical results demonstrated differences between countries and product categories, it was no explicit objective of this study to explain the underlying reasons for these differences. Consequently, no separate discussion is devoted to disentangling such differences. Instead, our motivation behind collecting data from six samples was based upon the improvement of external validity.
} 
involvement $\left(\mathrm{H}_{4}\right)$ to buyer relationship proneness and a negative path from shopping enjoyment $\left(\mathrm{H}_{3}\right)$ to buyer relationship proneness.

A first observation is that product category involvement reveals a consistent, significant and strong. positive relationship with buyer relationship proneness across the six samples. This confirms Page and Sharp's (1997) assumption that consumers are likely to be willing to enter relationships with retailers when their involvement is high for certain product categories. It also provides support for the notion that product category involvement underlies individual characteristics of buyers (Beatty. Kahle, and Homer 1988; Kokkinaki and Lund 1997) such as buyer relationship proneness. The strong positive relationship between product category involvement and buyer relationship proneness has important implications for retailers. Retailers who want to enhance their relationships with consumers should be sensitive to cues indicating consumers' involvement with the product category. In case a consumer exhibits interest in the product category, this consumer's tendency to engage in a relationship with the retailer is likely to be stronger.

A second observation is that sociability showed a weak, significant, positive relationship with buyer relationship proneness in the Dutch food sample only. Someone who seeks interpersonal relationships is apparently not necessarily looking for a relationship with a store of a particular product category. This is in contrast to Ellis's (1995) findings showing that highly sociable people are looking for social relationships with sales associates. Social recognition showed a significant but weak, negative relationship with buyer relationship proneness in only two samples (the Dutch and US clothing samples). The direction of the relationship found is in contrast to our hypothesis, implying that the more an individual looks for appreciation and respect by others, the less inclined he is to engage in relationships with stores. It is remarkable that the two significant relationships appeared in a clothing context. While these results are somewhat equivocal, they are partially in line with Ellis (1995), Mittal and Lassar (1996), and Fournier (1998) who stated that research on interpersonal relationships can be valuable as input for research on buyer-seller relationships. Finally, shopping enjoyment revealed a weak, significant, positive relationship with buyer relationship proneness in the Dutch food sample and in the US clothing and food sample. This result is in contrast to the assumption that people who lack shopping enjoyment will be more prone to engage in relationships (Ellis 1995; Forsythe, Butler, and Schaefer 1990; Solomon 1986). A potential explanation for the large number of non-significant paths from shopping enjoyment to buyer relationship proneness is in line with Beatty et al. (1996) who stated that shopping motivations are different from relationship motivations. Consequently, the reasons that consumers have for shopping are not necessarily related to the reasons that consumers have for engaging in relationships with stores.

\section{(2) What are the effects of buyer relationship proneness on relationship outcomes?}

In reply to the need for more research on the impact of buyer relationship proneness on relationship outcomes (Beatty et al. 1996; Ellis 1995), we investigated the relationships from buyer relationship proneness to relationship satisfaction $\left(\mathrm{H}_{8}\right)$ and relationship commitment $\left(\mathrm{H}_{9}\right)$. Our study found strong empirical support for positive paths between both pairs of constructs. In all six samples, buyers characterized by higher levels of relationship proneness were more satisfied with and 
cmmitted to their relationship with a seller. Despite cultural differences between the countries (Hofstede 1980) examined, both relationships were consistently significant and positive in all country samples. Moreover, the effects were found to be stable across product category samples.

Cur results strongly contradict Kalwani and Narayandas' (1995) conceptual idea that buyers who $x$ relationship prone are relatively more difficult to serve satisfactorily. Moreover, our results sapport the belief that personal characteristics are at the basis of relationship commitment (Sorgaonkar, Lund, and Price 1985; Mathieu and Zajac 1990; Rylander, Strutton, and Pelton 1997; Sorbacka, Strandvik, and Grönroos 1994). Although it is generally acknowledged that relationship stisfaction and relationship commitment are key constructs in relationship marketing research Anderson and Narus 1990: Doney and Cannon 1997; Dwyer, Schurr, and Oh 1987; Geyskens 1998: Macintosh and Lockshin 1997; Morgan and Hunt 1994; Smith and Barclay 1997), it is sirprising to notice that no previous study has ever empirically investigated the effect of buyer rlationship proneness on both constructs. In this study, we found that buyer relationship proneness and trust have comparable total effects on relationship commitment. This is an extraordinary finding gven the abundance of attention directed at the role of trust in affecting relationship commitment Andaleeb 1996: Anderson and Weitz 1989: Crosby, Evans, and Cowles 1990; Doney and Cannon 197; Ganesan 1994; Geyskens et al. 1996; Moorman, Zaltman, and Deshpandé 1992; Morgan and Funt 1994). According to us, previous studies on relationship marketing suffer from the omission of buyer relationship proneness as an important construct. Our results imply that the effectiveness of nlationship marketing strategies is largely affected by the proneness of buyers to engage in relationships. Failing to include buyer relationship proneness in future studies on relationship marketing could result in flawed conclusions related to the antecedents and consequences of satisfaction with and commitment to buyer-seller relationships.

A general observation across all samples is that relationship commitment is relatively stronger influenced by buyer-related factors (buyer relationship proneness), whereas relationship satisfaction is relatively stronger affected by seller-related factors (seller relationship orientation). This seems a plausible outcome as relationship commitment refers to "an enduring desire to continue a relationship" and relationship satisfaction refers to "the overall appraisal of a relationship with a seller". Consequently, from a nomological point of view, one would expect buyer relationship proneness to be related stronger to relationship commitment, while seller relationship orientation is expected to have more in common with relationship satisfaction. This might lead to the tentative conclusion that it will be very hard to establish relationship commitment without a buyer being prone to engage in relationships with sellers, making seller relationship orientation of secondary importance. On the other hand, it will be very hard to establish relationship satisfaction without a seller's efforts aimed at enhancing this relationship, making buyer relationship proneness of secondary importance.

\section{(3) What are the effects of seller relationship orientation on relationship outcomes?}

In chapter five, we hypothesized positive paths from seller relationship orientation to relationship satisfaction $\left(\mathrm{H}_{6}\right)$ and relationship commitment $\left(\mathrm{H}_{7}\right)$. Our study found strong empirical support for both hypotheses. First, higher levels of seller relationship orientation consistently lead to higher 
levels of relationship satisfaction across country and product category samples. This is in line with researchers who previously indicated that performance judgments such as seller relationship orientation play an important role in influencing relationship satisfaction (Anderson and Nans 1990; Churchill and Surprenant 1982; Flint, Woodruff, and Gardial 1997; Fournier 1998; Smith and Barclay 1997: Wray, Palmer, and Bejou 1994). As satisfaction and performance are closely related (Anderson and Narus 1984; Ganesan 1993; Gotlieb, Grewal, and Brown 1994; Lewis and Lambert 1991: Ruekert and Churchill 1984), the construct of seller relationship orientation can be regarded as a performance variable and, therefore, is closely related to relationship satisfaction. While the positive effects of constructs similar to seller relationship orientation on relationship satisfaction were previously found in industrial and channel contexts (Anderson and Narus 1990; Kumar, Stern. and Achrol 1992; Lewis and Lambert 1991: Smith and Barclay 1997), this study indicates the importance of seller relationship orientation in influencing relationship satisfaction in a consumer context. Consumers tend to be more satisfied with retailers who are perceived to make deliberate efforts aimed at enhancing the consumer-retailer relationship.

Second, the path from seller relationship orientation to relationship commitment was significant and positive in three samples. This finding is in accordance with previous empirical findings concerning the effects of related constructs on relationship commitment in channel and industrial contexts (Anderson and Weitz 1992; Morgan and Hunt 1994; Siguaw, Simpson, and Baker 1997). Our significant results imply that the more consumers perceive a retailer to be making efforts towards them, the more these consumers are committed to their relationship with this retailer. However, the path from seller relationship orientation to relationship commitment is weaker than the path from seller relationship orientation to relationship satisfaction. Contrary to Dwyer, Schurr, and Oh (1987) and Bennett (1996), our results indicate that a buyer's relationship commitment does not always depend on his perceptions of efforts made by the seller.

A general observation across all samples is that relationship satisfaction is relatively stronger influenced by seller-related factors (seller relationship orientation), whereas relationship commitment is relatively stronger influenced by buyer-related factors (buyer relationship proneness). This seems a plausible outcome as relationship satisfaction refers to "the overall appraisal of a relationship with a seller" and relationship commitment refers to "an enduring desire to continue a relationship". This might lead to the tentative conclusion that it will be very hard to establish relationship satisfaction without a seller's efforts aimed at enhancing this relationship. making buyer relationship proneness of secondary importance. On the other hand, it will be very hard to establish relationship commitment without a buyer being prone to engage in relationships with sellers, making seller relationship orientation of secondary importance.

\section{(4) What are the effects of buyer relationship proneness on seller relationship orientation?}

Berry (1995) stated that relationship prone buyers are more keen to find a seller that will actively meet their needs. Kalwani and Narayandas (1995) stated that customers who are willing to engage in relationships are also the most difficult to serve satisfactorily because they are sensitive to or intolerant of any mistakes. In response to this, we empirically investigated the relationship from buyer relationship proneness to seller relationship orientation. Our study revealed a significant 
positive relationship between both constructs in all six samples. This confirms previous results found in interpersonal literature indicating that people in search of relationships perceive potential partners to be more attractive than people not in search of relationships (Simpson, Gangestad, and Lerma 1990). Our finding implies that perceptions of a seller's efforts to enhance the relationship are strongly inflated by the inherent proneness of buyers to engage in relationships with sellers. It appears that relationship prone buyers see a seller's efforts through rose-colored glasses. Our results contrast the viewpoints of Kalwani and Narayandas (1995). According to them, sellers need to make relatively stronger efforts towards relationship prone buyers as opposed to non-relationship prone buyers in order to generate the same level of perceived efforts. Our results indicate that this is not the case.

\section{(5) What are the interrelationships between relationship outcomes?}

Several authors doubt whether relationship satisfaction, trust, and relationship commitment can be regarded as three distinct constructs (Bejou, Wray, and Ingram 1996: Crosby, Evans, and Cowles 1990: Dwyer and Oh 1987; Hennig-Thurau and Klee 1997; Kumar, Scheer, and Steenkamp 1995a; Lagace, Dahlstrom. and Gassenheimer 1991: Leuthesser 1997; Scheer and Stern 1992; Wray, Palmer, and Bejou 1994). Contrary to their belief, we found strong empirical support for their distinctiveness as evidenced by the results of the measurement models reported in chapter seven (see 7.5). This supports Geyskens' (1998) empirical evidence on basis of an extensive meta-analysis incorporating the three constructs.

In chapter five, we hypothesized that relationship satisfaction positively influences trust $\left(\mathrm{H}_{10}\right)$, which in turn positively affects relationship commitment $\left(\mathrm{H}_{11}\right)$. ultimately leading to behavioral loyalty $\left(\mathrm{H}_{12}\right)$. These interrelationships are confirmed in all six samples, providing strong empirical evidence across countries and product categories. While these relationships have been explored to a large extent in previous research (e.g. Anderson and Weitz 1989; Ganesan 1994; Geyskens 1998; Morgan and Hunt 1994: Selnes 1998), we provide strong support for their existence in consumer environments. Our results indicated that relationship satisfaction positively influences trust in a consumer context, which is in line with previous conceptual ideas of Bendapudi and Berry (1997). Gruen (1995), and Tax, Brown, and Chandrashekaran (1998). With respect to the trust-commitment relationship, Moorman, Deshpandé, and Zaltman (1993) expected that the influence of trust on relationship commitment wold be less strong in a consumer environment as opposed to a businessto-business environment as consumer contexts typically involve less uncertainty and vulnerability. Our results prove the contrary and support the view of Beatty et al. (1996) and Macintosh and Lockshin (1997) who stated that trust is also important in retail situations. Finally, we found strong evidence for a positive relationship between relationship commitment and behavioral loyalty. This confirms previous results found by Morgan and Hunt (1994) and Moorman, Zaltman, and Deshpandé (1992).

The percentage of variance explained of all attitudinal relationship outcomes is considerably high with values ranging from .37 to .87 . This is not the case for the behavioral loyalty construct of which the variance explained ranges from .06 to .34 . This should not be surprising as a consumer's purchasing behavior is clearly determined by additional influencing factors. For example, the 
distance to the store, its assortment, and other elements of the retail mix have their effect on behavioral loyalty of consumers (Ghosh 1994).

(6a) To what extent are the effects of buyer retationship proneness moderated by seller relationship orientation?

In chapter five, we hypothesized that the effects of buyer relationship proneness on relationship satisfaction/relationship commitment would be moderated by seller relationship orientation. Our results indeed show that seller relationship orientation acts as a moderator in some of our samples examined, providing partial support for hypotheses $\mathrm{H}_{15}$ and $\mathrm{H}_{16}$. Figure 8-1 visualizes the effects of seller relationship orientation on the strength of the relationship between buyer relationship proneness and relationship satisfaction/relationship commitment.
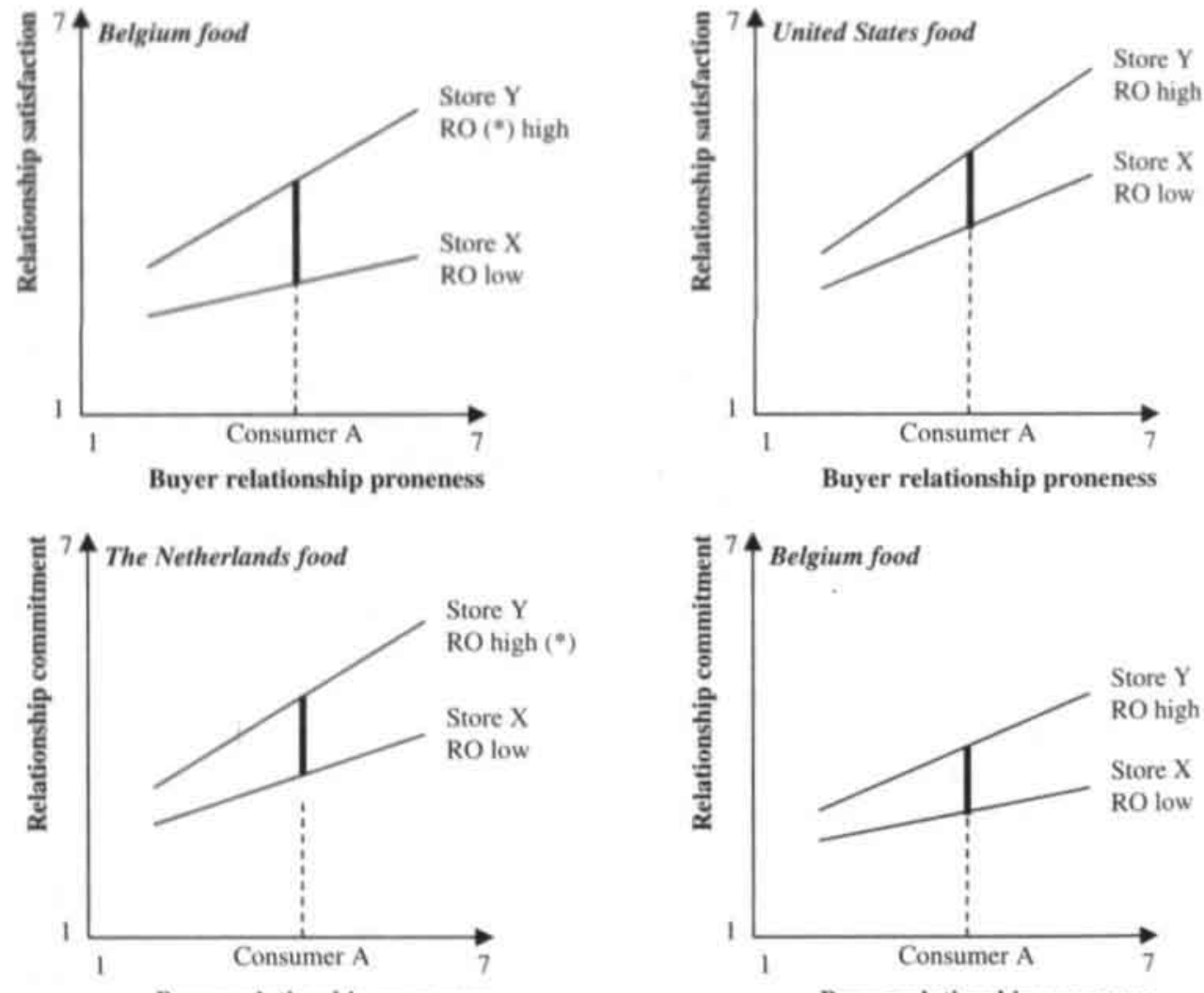

Buyer relationship proneness

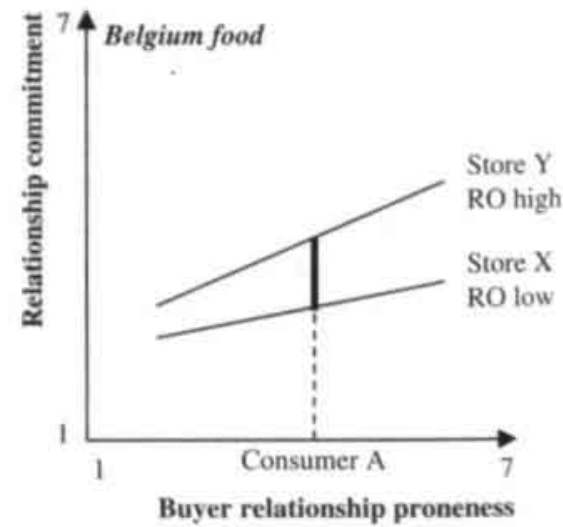

(*) $\mathrm{RO}=$ seller relationship orientation

\section{Figure 8-1: Moderating Effects of Seller Relationship Orientation}

Only the significant changes in path coefficients are visualized in figure 8-1, based upon table 7-15. The figure shows that one level of relationship proneness can lead to different levels of relationship 
satisfaction/relationship commitment as a result of different levels of seller relationship orientation. Consumer A's relationship proneness leads to a higher level of relationship satisfaction/relationship commitment with store $\mathrm{Y}$ as this store is more relationship oriented than store $\mathrm{X}$. Stores making larger efforts to enhance relationships with consumers relatively reap more benefits from these consumers' relationship proneness. A potential explanation for this is that consumers exhibiting relationship proneness have a higher appreciation for sellers that are relationship oriented.

It is interesting to notice that the above mentioned moderator effects occur in a food context. If a customer perceives one apparel store to be making stronger efforts than another apparel store, the effect of this customer's relationship proneness on his relationship satisfaction/relationship commitment is more or less the same for both apparel stores. However, if the same customer perceives one supermarket to be making stronger efforts than another supermarket, the effect of this customer's relationship proneness on his relationship satisfaction/relationship commitment is stronger for the supermarket that makes greater efforts.

\section{(6b) To what extent are the effects of seller relationship orientation moderated by buyer relationship proneness?}

Our results show that buyer relationship proneness acts as a moderator in some of our samples examined, providing partial support for hypotheses $\mathrm{H}_{13}$ and $\mathrm{H}_{14}$. Figure 8-2 visualizes the effects of buyer relationship proneness on the strength of the relationship between seller relationship orientation and relationship satisfaction/relationship commitment. Only the significant changes in path coefficients are visualized in figure 8-2, based upon table 7-18. As shown in the figure, the same store X characterized by a particular level of seller relationship orientation generates different levels of relationship satisfaction/relationship commitment as a result of different levels of buyer relationship proneness. Consumer B demonstrates a higher level of relationship satisfaction/relationship commitment because his inherent relationship proneness is higher than consumer A. This result confirms earlier assumptions that buyer characteristics can influence the effectiveness of relationship marketing investments (Barnes 1995/1997: Ganesan 1994: Krapfel. Salmond, and Spekman 1991). As suggested by other authors (Barnes 1995; Bendapudi and Berry 1997: Dwyer. Schurr, and Oh 1987), a potential explanation for this is that buyers who are less relationship prone are less sensitive to a seller's efforts directed at them.

In line with the moderating effect of seller relationship orientation, it appears that the moderating effect of buyer relationship proneness is mainly present in a food context. Out of four significant moderator effects, only one is significant in a clothing context. Moreover, the moderating effect of buyer relationship proneness in a clothing context is the smallest of the four significant moderator effects. An intuitive explanation for this is that, in an apparel store, it is more common practice to receive for example personal service, extra attention, and customized advice. This may imply that each type of customer, whether relationship prone or not, expects apparel stores to make particular efforts. This might explain why the level of buyer relationship proneness does not seriously strengthen the effect of seller relationship orientation on relationship satisfaction/relationship commitment. This is in contrast to the more anonymous, standard self-service that is provided in a typical supermarket (Page and Sharp 1997). Supermarkets generally make fewer efforts to their 
customers as opposed to apparel stores. Consequently, in case a certain supermarket does make particular efforts towards its customers, it seems that these efforts are especially perceived and welcomed by relationship prone customers. This is in line with our earlier conclusion that relationship prone buyers seem to have a more positive selective perception of a seller's efforts.
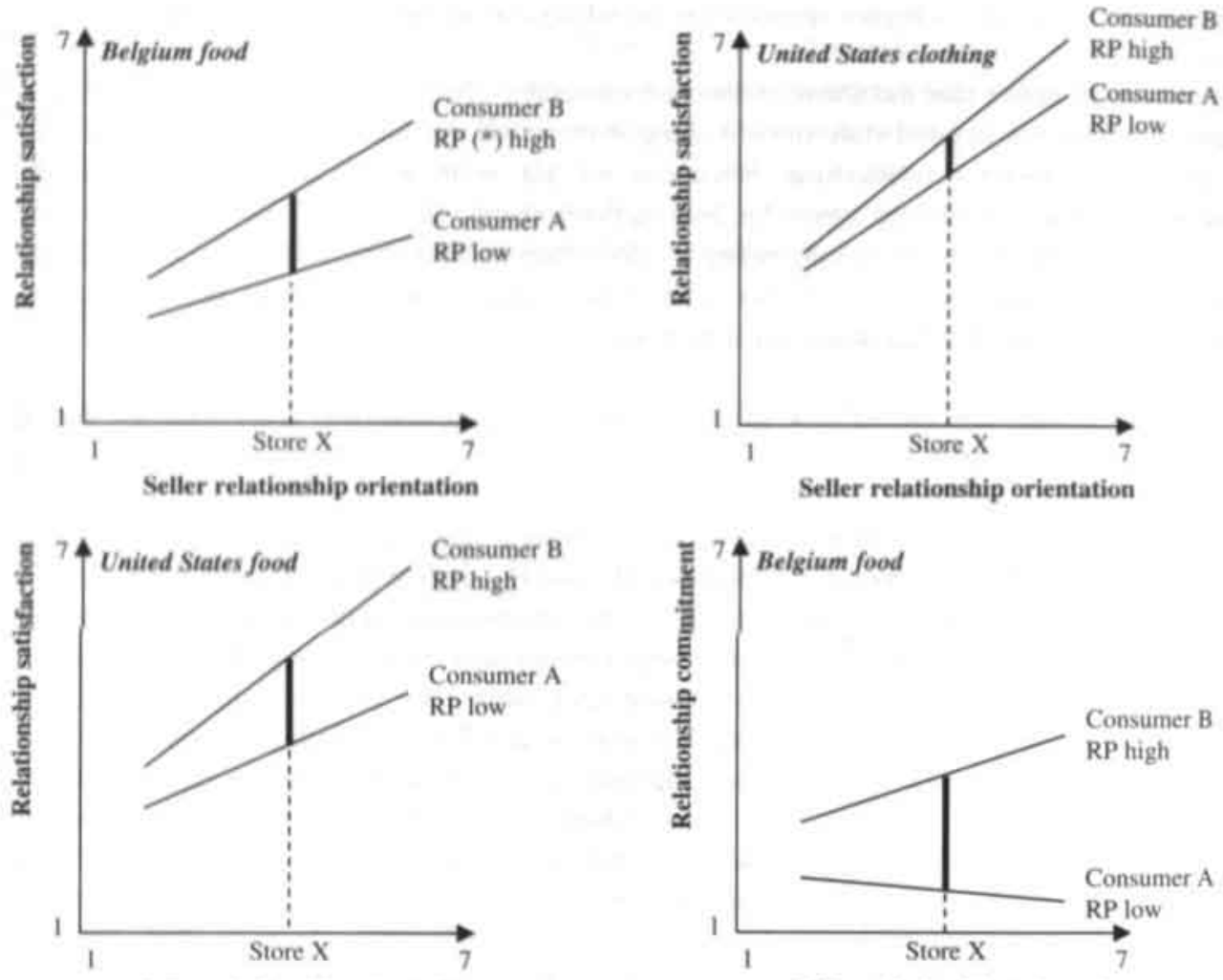

Seller relationship orientation

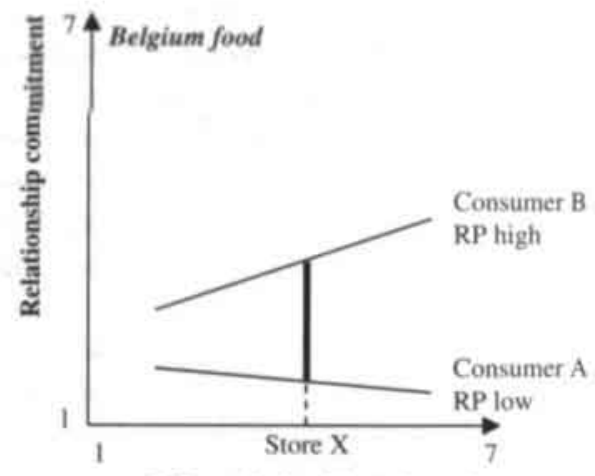

Seller relationship orientation

(*) $\mathrm{RP}=$ buyer relationship proneness

Figure 8-2: Modenating Effects of Buyer Relationship Proneness

(6c) To what extent are the effects of seller relationship orientation moderated by product category involvement?

Our results show that product category involvement acts as a moderator in some of our samples examined. providing partial support for hypotheses $\mathrm{H}_{1}$, and $\mathrm{H}_{48}$. Figure 8-3 visualizes the effects of product category involvement on the strength of the relationship between seller relationship orientation and relationship satisfaction/relationship commitment. Only the significant changes in path coefficients are visualized in figure 8-3, based upon table 7-21. As shown in the figure, the same store $\mathrm{X}$ characterized by a particular level of seller relationship orientation generates different 
levels of relationship satisfaction/relationship commitment as a result of different levels of product category involvement. Consumer B demonstrates a higher level of relationship satisfaction/relationship commitment because his involvement with the product category is higher than consumer A's product category involvement. Our results do not provide direct support for Christy. Oliver, and Penn's (1996) notion that sellers' efforts, however well-intended, could be regarded by the buyer as undesirable in case this buyer's involvement level is low. The term undesirable' would imply a negative relationship between seller relationship orientation and relationship satisfaction/relationship commitment as a result of low product category involvement. Our results merely suggest that consumers with a lower degree of product category involvement are kss influenced by a seller's efforts, which is in line with Solomon et al.'s (1985) point of view. In the Belgian clothing and food samples, it even seems that relationship commitment of low involved buyers is not affected at all by increased relationship efforts. Also Leuthesser (1997) noticed that a buyer's stake in his relationship with a seller tends to be higher in case of high involvement with the product category. It can be reasonably expected that higher stakes in a relationship cause buyers to ippreciate a seller's efforts more strongly.

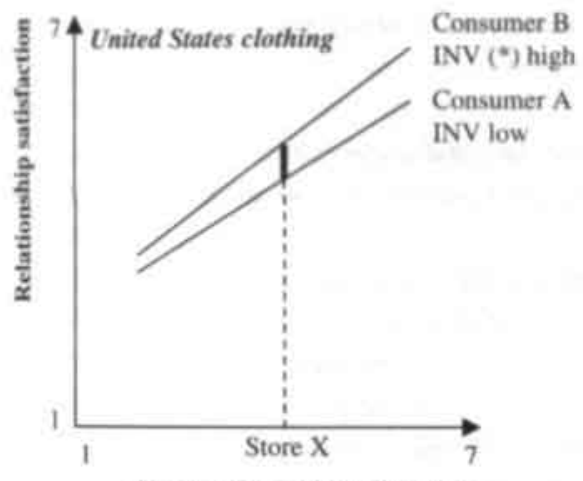

Seller relationship orientation

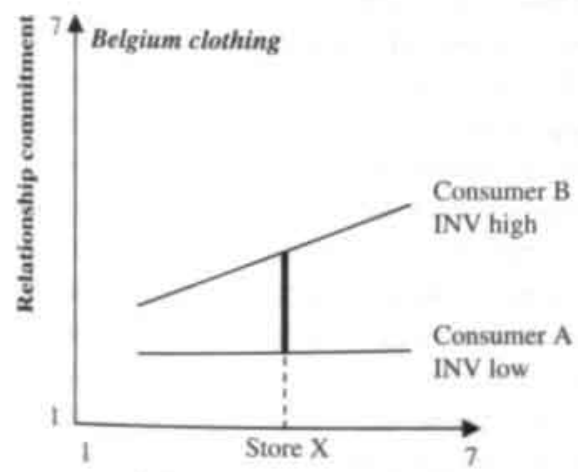

Seller relationship orientation
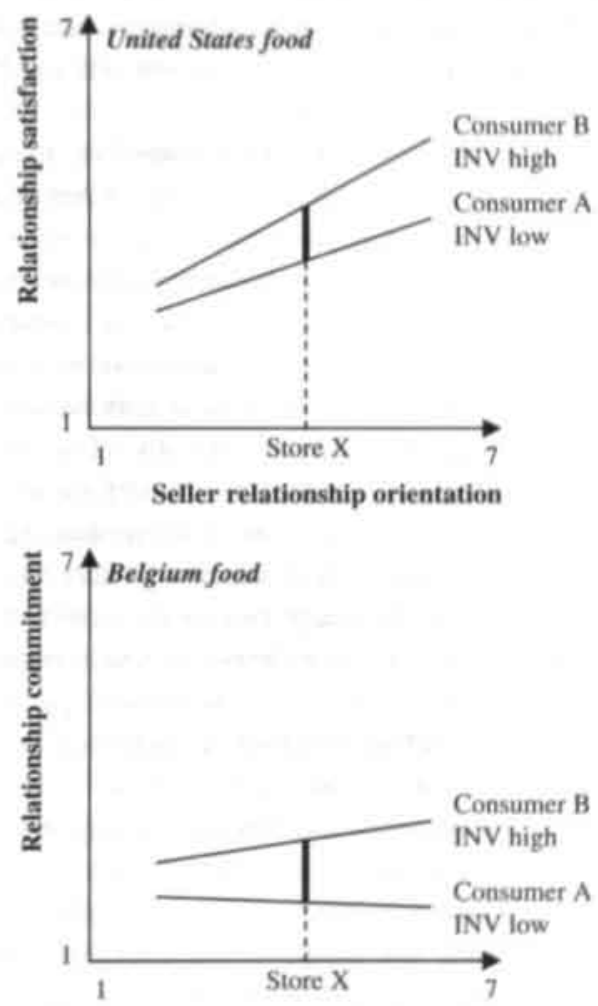

Seller relationship orientation

(*) INV = product category involvement

Figure 8-3: Modenating Effects of Product Category Involvement 
This discussion of moderator effects emphasizes that sellers should never lose out of sight the importance of buyer-related factors in determining relationship satisfaction and relationship commitment. No matter how much trouble the seller goes through in order to increase his relationship orientation. these efforts can be seriously tempered or strengthened by buyer relationship proneness and product category involvement of the buyer.

\subsection{Limitations}

First, since our study is of a cross-sectional nature and since no experimental research was conducted, no definite conclusions can be drawn concerning the causality of the relationships in our conceptual model. Structural modeling techniques do not allow to determine the direction of causality, nor do they even allow to conclude that a causal relationship exists (Dillon and Goldstein 1984). While Geyskens (1998) remarked that no research has yet investigated buyer-seller relationships on a longitudinal basis, it is generally recognized that longitudinal studies and experiments provide stronger inferences for causality. Moreover. longitudinal research can improve our understanding of the process dynamics and cumulative effects of buyer-seller relationships that are not apparent in 'snapshots' of current relationships.

Second, some biases might have occurred in collecting our data and interpreting our results. A first bias might have been introduced by the omission of important variables. For example, although the variance explained of buyer relationship proneness is significant with values ranging from . 15 to .72 , this suggests that additional antecedents of buyer relationship proneness are needed in order to more extensively explain this construct. A second threat to validity may be common method bias. As we used one single questionnaire to measure all constructs included, the strength of the relationships between these constructs may be somewhat inflated. A third potential bias is related to the measurement of behavioral loyalty. The true meaning of behavioral loyalty may only be partially captured as the behavioral loyalty measure was self-declared by respondents. No database information could be used as input for measuring actual purchasing behavior. This study could be improved with access to more substantial data on customer purchase histories that are not subject to potential recall loss. It would then be possible to look at longer strings of purchases and to perhaps incorporate contextual information. A fourth potential bias is related to non-nomality of the data. As our data were not normally distributed, this may create an upward bias in critical values for determining coefficient significance. However, sample sizes were considered to be large enough to partially compensate for this problem (Hair et al. 1998). A fifth bias might result from interviewer bias. However, intensive interviewer briefing and training prior to the data collection were aimed at overcoming this potential weakness. Moreover, the use of a structured questionnaire including detailed respondent instructions automatically diminished the risk of interviewer bias. Finally. interviewers were not aware of the hypotheses investigated. Sixth, our study might suffer from social desirability biases as a result of face-to-face interactions between interviewers and respondents. We tried to reduce this bias by stating to respondents that there were no right or wrong answers. Furthermore, we attempted to avoid social desirability bias by training interviewers to maintain the difficult balance between offering sufficient personal assistance to respondents and reading over respondents' shoulders. Finally, a potential bias could be related to the existence of 
halo effects. For example, respondents who indicated being loyal to a particular store might provide positively biased answers to questions related to this store. Respondents might be worried to provide inconsistent answers.

\subsection{Implications}

\subsubsection{Theoretical Implications}

Until now, relationship marketing literature has mainly been characterized by the use of rather general and ambiguous definitions of the concepts 'relationship' and 'relationship marketing'. This has resulted in a lack of consistency in the interpretation and measurement of different relationship constructs (Achrol 1997: Barnes 1995: Bejou 1997: Blois 1995; Evans and Laskin 1994; Gummesson 1994; Kalwani and Narayandas 1995; Parker and Funkhouser 1997; Perrien and Ricard 1995). We reformulated the meaning of a relationship and relationship marketing by explicitly introducing a clear starting point of a relationship, by formulating a relationship from the perspective of a buyer. In our view, this could be a first step in the direction of improved consistency among relationship marketing researchers. Moreover, our study was based on a thorough investigation of the applicability of underlying theories to relationship marketing in consumer context. It is the first attempt to translate the usefulness of a broad range of theories originating from various disciplines to the study of consumer relationships. This assured the theoretical soundness and coherence of the conceptual model.

Macintosh and Lockshin (1997) suggested that future research in retail should expand the range of relationship variables studied at all levels of the relationship. Retail managers would benefit from a greater understanding of which specific behaviors lead to greater trust and relationship commitment. In response to this, our study made a significant contribution to relationship marketing theory by introducing, defining, and operationalizing two new constructs 'buyer relationship proneness' and 'seller relationship orientation'. Following Churchill's (1979) procedure of scale development, considerable efforts were made to generate valid and reliable measurement scales for both constructs. We formulated theoretically sound and practically applicable definitions of both constructs, generated highly reliable and valid measurement scales, and investigated their role in six different consumer samples spread across three countries and two product categories. The level of external validity was further increased as consumers reported on one store out of a broad range of stores including discount stores, mass merchandisers, traditional department stores, as well as prestige stores. The scales we developed demonstrated their applicability to a broad range of contexts. Moreover, buyer relationship proneness and seller relationship orientation proved to be of crucial importance in determining relationship outcomes. Despite the fact that these constructs have never been operationalized in previous empirical research, their contribution to explaining relationship satisfaction and relationship commitment turned out to be decisively important. This underlines that not only seller-related variables should be investigated when trying to explain relationship outcomes. It appears that buyer-related factors are of comparable importance. The importance of seeing through the eyes of the consumer is especially emphasized by the fact that a consumer's behavioral loyalty is much stronger influenced by this consumer's proneness to engage in relationships than by a retailer's efforts. As buyer relationship proneness proved to be an 
important variable across all six samples, some previous studies' results may have been affected by its omission. Consequently, we postulate that future research on consumer relationships could benefit from consistently incorporating this construct in research models.

In line with Morgan and Hunt (1994) who stated that trust and relationship commitment are central to understanding relationships, we argue that buyer relationship proneness is an additional key variable in consumer markets characterized by dedication-based relationships. In addition to the crucial role of trust in establishing relationship commitment, various other constructs in our hypothesized model proved to play a comparable or even stronger role in affecting relationship commitment. Our results provide strong support for the fact that there is more to relationship commitment than trust alone. Especially buyer relationship proneness enters the field as a true competitor of trust. In all samples, the total effect of buyer relationship proneness on relationship commitment was larger than the total effect of trust. This result indicates the crucial role of contingency factors in determining the effectiveness of relationship marketing. Consumers are not necessarily willing participants in relationship marketing strategies of retailers.

The importance of buyer relationship proneness and seller relationship orientation is equally underlined by the existence of reciprocal moderator effects of both constructs on each other's effects on relationship outcomes. We demonstrated the existence of three moderating constructs. The extent to which a consumer's proneness to engage in relationships is translated into relationship satisfaction/relationship commitment is higher in case retailers make stronger efforts towards this consumer. Moreover, the effect of a retailer's efforts on a consumer's relationship satisfaction/relationship commitment is much stronger for consumers who are relationship prone and/or highly involved with the product category. These results are in line with Dwyer, Schurr, and Oh (1987) and Sheth and Parvatiyar (1995b) who stated that the buyer as well as the seller determine relationship outcomes. In addition, we detected industry effects as stronger moderating effects were found in a food context as opposed to a clothing context.

Baumgartner and Steenkamp (1996) postulated that research has shown that the consistency between rather general traits/attitudes and specific behaviors is often low. One proposed solution is to turn instead to individual characteristics that are more closely linked to the particular behavior in question. We attempted to relate personality characteristics to buyer relationship proneness instead of linking them directly to behavioral loyalty. Four antecedents of buyer relationship proneness were defined, operationalized, and measured. Strong support for their discriminant validity was found in each of the samples. We were able to prove that especially product category involvement as an antecedent explains a major part of the variance in buyer relationship proneness.

Our results add to the widespread knowledge that relationship satisfaction, trust, and relationship commitment are key relationship outcomes. However, as far as we know, this is the first study that investigated all three constructs together in a consumer environment. As there still exists a lot of ambiguity with respect to defining the relationship outcomes of relationship satisfaction, trust. relationship commitment, we contributed to the theoretical delineation of these constructs. Across the samples, the three attitudinal relationship outcomes revealed,strong and stable relationships with the other constructs investigated. Moreover, we concluded that they reveal sufficient discriminant 
validity, supporting recent cries to make a clear distinction between them in relationship marketing research (Geyskens 1998; Gruen 1995). While the path coefficients from relationship satisfaction to trust were very high across samples ranging from .73 to .84 , this was not alarming as the percentage of variance extracted by both constructs was consistently above .50 across samples. Moreover, discriminant validity was checked by fixing each of the 45 off-diagonal elements of the correlation matrix between constructs to 1 and re-estimating the model each time. $\chi^{2}$ differences were statistically significant for all 45 model comparisons $(p<.01)$ in all samples, providing strong support for discriminant validity. As relationship satisfaction, trust, and relationship commitment all play different roles in our research model, it seems warranted to plead for incorporating all three constructs in future studies focusing on the effects of relationship marketing.

Finally, our results show that relationship commitment and behavioral loyalty are only weakly, yet significantly related. Consequently, researchers should be aware of the fact that, while relationship commitment is often regarded as the ultimate relationship outcome, it is only able to explain a relatively small share of the variance of behavioral loyalty. It appears that a much wider range of variables than relationship commitment alone influences behavioral loyalty. First, our results revealed several strong significant indirect effects of buyer relationship proneness, seller relationship orientation, relationship satisfaction, and trust on behavioral loyalty. Second, several variables we omitted in this study could have an important impact on the level of behavioral loyalty. Examples of such variables are situational cues such as familiarity with a particular store, the distance to a store and competing stores, or the existence of a monopoly. As a result, high levels of behavioral loyalty can accompany low levels of relationship commitment and low levels of behavioral loyalty can accompany high levels of relationship commitment. This raises some questions with respect to the applicability of Oliver's (1997) four consecutive phases of loyalty. Oliver (1997) stated that loyalty generally evolves from cognitive loyalty to affective loyalty. conative loyalty, and action loyalty. Since Oliver (1997) hypothesized that consumers move from positive attitudinal loyalty to positive behavioral loyalty, there is an implicit assumption that there exists a strong positive relationship between both. Our data seem to provide support for Dick and Basu's (1994) framework of loyalty who distinguish between four loyalty types based upon different combinations of high and low levels of behavioral and attitudinal loyalty. This idea underlies the concept of 'true customer loyalty'. True customer loyalty is generally assumed to exist if both behavioral loyalty and relationship commitment are strong (Dick and Basu 1994; Jacoby and Chestnut 1978; Oliver 1997; Schiffman and Kanuk 1987; Uncles and Laurent 1997). Many authors define these attitudinal aspects as commitment to the relationship (Bloemer and Kasper 1995; Jacoby and Kyner 1973; Schiffman and Kanuk 1987; Schijns and Schröder 1996). Jacoby and Kyner (1973, p. 3) stated that "the notion of commitment provides an essential basis for distinguishing between brand loyalty and other forms of repeat purchasing behavior and holds most promise for assessing the relative degrees of brand loyalty". Our results support the relevance of making such a distinction.

\subsubsection{Managerial Implications}

A first observation relevant for management practice is that the effectiveness of relationship marketing is not only determined by actions of the retailer. but also for a very large part by the 
nature of this retailer's customers. Our results even show that a buyer's behavior is relatively mote dependent on buyer relationship proneness than on seller relationship orientation. Consequently. retailers should not only focus at optimizing their efforts towards customers, but should equally pay attention to finding the right customers (Reichheld 1996). In addition to the more traditional criteria of product-market segmentation such as market size, market growth, and expected market share, retailers need to be more sensitive to average levels of buyer relationship proneness in particular product-markets (Van der Walt et al. 1994). Segmenting buyers according to levels of buyer relationship proneness is expected not only to affect share of market, but also expected share of customer as relationship prone customers have a higher tendency to remain loyal to one store. Segmentation and communication based on buyer relationship proneness will assist retailers in reducing waste of resources. Moreover, by collecting information on buyer relationship proneness, retailers can make a better assessment of which efforts they should direct at which customers. This has important implications for retailers as it might help them in defining market segments. Retailers focusing at relationship prone markets may improve these markets' perceptions of their efforts.

Second, the moderating effects of buyer relationship proneness show that a retailer's level of relationship orientation results in higher levels of relationship satisfaction and relationship commitment for relationship prone buyers. Dependent upon the level of a buyer's relationship proneness, retailers' strategies are more or less effective. Retailers should keep this in mind when targeting customers. Therefore, it could be beneficial for a retailer to adjust his efforts according to levels of buyer relationship proneness. For example, customers who are less relationship prone might have less appreciation for customer loyalty cards or other expressions of retailers' efforts. Moreover, the moderating effect of product category involvement shows that the impact of a retailer's efforts is dependent upon the level of a buyer's product category involvement. As product category involvement may differ across market segments, our results imply that the effectiveness of relationship marketing strategies equally differs across market segments.

Third, retailers should be aware of the fact that the behavioral loyalty of their customers is dependent upon more factors than relationship commitment only. Behavioral loyalty towards a store can result from seller-related, buyer-related, and situational factors. While our results show that seller- and buyer-related factors have important indirect influences on behavioral loyalty, situational variables such as distance to the store, competition, existence of a monopoly, and familiarity with a store apparently also play a crucial role in affecting behavioral loyalty. However, in addition to the effects of situational variables on behavioral loyalty, our study demonstrates that the roles of seller relationship orientation and buyer relationship proneness cannot be neglected.

Finally, our empirical studies show that the unstandardized direct effects of relationship commitment on behavioral loyalty are relatively larger in the clothing market as opposed to the food market. This might be an indication of the fact that habit and inertia play a more important role in food markets selling convenience goods than in clothing markets selling shopping goods. In response to Dekimpe et al.'s (1997) directions for future research, our result is a first step in investigating whether and why it is easier to build brand loyalty in some product categories than in others. It appears that building loyalty in a clothing environment is relatively more easy than in a food environment. 


\subsection{Directions for Future Research}

In our study, we empirically validated the hypothesized model in three countries differing according to the four cultural dimensions distinguished by Hofstede (1980). As culture is supposed to influence consumer behavior (Usunier 1993), we could expect to detect and actually detected (see 73.3) cross-country differences in the structural model. According to Usunier (1993), the Netherlands and Belgium can be categorized into different affinity zones, implying that a similar marketing strategy for the same product applied in both countries will not produce similar results. However, the role of seller efforts in affecting relationship outcomes was found to be comparable across Belgium and the Netherlands. Moreover, we could hypothesize that buyer relationship proneness is inversely related to Hofstede's (1980) dimension of individualism: the more a culture is individualized with respect to interpersonal relationships, the more individuals could be expected to seek 'substitute' relationships with for instance stores. As average levels of buyer relationship proneness were found to be somewhat higher in the United States as opposed to the Netherlands and Belgium (see appendix six), this might be attributed to the fact that individualism is highest in the United States (see table 1-2 in chapter one). Despite these differences in the level of buyer relationship proneness between countries, all paths originating from buyer relationship proneness are significant and positive in each of the three countries in both product categories. Although it was no explicit objective of our study, an interesting direction for future research could be to explicitly integrate cultural variables in cross-country research on consumer relationships.

Second, as it can be expected that the strength of the paths in our research model is dependent upon the type of retailer investigated, it would be interesting to conduct a research focusing at the differences between large store chains and small, independent neighborhood stores. We hypothesize that small neighborhood stores demonstrate more relationship-friendly characteristics than large store chains, as the degree of social exchange and the possibilities for customization are generally larger. While larger store chains generally operate on basis of anonymous self-service, the survival of small, independent stores is often dependent upon personal service and knowledge of customers' preferences.

Third, as the variance explained of buyer relationship proneness could still be increased, future research should explore additional antecedents. Morgan and Hunt (1994) for instance, discovered a positive relationship between shared values and both, relationship commitment and trust in businessto-business environment. Voss and Voss (1997) argue that in a retail setting, shared values might manifest themselves in form of goal congruence between consumes and retailer, referring to an example of a discount supermarket providing every day low prices. Another potential, additional variable might be a buyer's risk aversion (Dowling and Staelin 1994). It might be hypothesized that a higher level of a buyer's risk aversion will lead to a higher level of buyer relationship proneness, as relationships with retailers might be perceived as risk reducing. Additional variables would not only increase the percentage of explained variance of buyer relationship orientation, but would similarly allow measuring the relative impact of these antecedents. In this way, retailers get insights into those factors that can be used as input for communication and segmentation purposes. 
Fourth, in response to limitations previously mentioned, an experimental research design would create stronger inferences for causality and reduce for example common method bias and interviewer bias. By controlling for different levels of seller relationship orientation, we would be able to assess the 'pure' impact of seller relationship orientation on relationship outcomes, eliminating disturbing influences. Evidently, the external validity of such an approach is lower as a result of the more restricted research setting. An e-commerce environment could be a perfect setting for conducting such an experiment. Alternative versions of an e-commerce web site on basis of the level of seller relationship orientation could be created, representing the treatments in the experiment. Subsequently, homogenous groups of internet users could be composed and confronted with one specific treatment. Their buying behavior during an extended period of time could be tracked, complemented with survey data collected at the end of the experiment. On basis of ANOVA or multi-group SEM analyses, conclusions could be drawn with respect to the impact of seller relationship orientation on attitudes towards and behavior during the relationship.

Fifth, as it is hypothesized that loyal buyers are willing to accept incidental lower levels of product or service efforts without breaking the relationship, it is a fascinating research direction to investigate the influence of critical incidents on the level of relationship outcomes. Critical incidents are top-of-mind, even in the long run. From this perspective, it is useful to incoorporate them in relationship marketing research (Odekerken-Schroder 2000). This would require the use of a longitudinal research design that measures the level of relationship outcomes at multiple points in time and that collects information on critical incidents that occurred in the meantime. Critical incidents can be studied by applying the Critical Incident Technique (CIT), a method that was developed by Flanagan (1954) in psychology for collecting and classifying stories or critical incidents by employing content analysis. According to Flanagan (1954, p. 327) an incident is "any observable human activity that is sufficiently complete in itself to permit inferences and predictions to be made about the person performing the act". A critical incident "makes a 'significant' contribution, either positively or negatively, to the general aim of the activity" (Flanagan 1954, p. 338). The CIT has proven to be useful in a variety of research contexts (Bitner, Booms, and Tetreault 1990; Duffy 1983). In the context of services, Bitner, Booms, and Tetreault (1990, p. 73) defined critical incidents as "specific interactions between customers and service firm employees that are especially satisfying or especially dissatisfying".

Finally, as stressed in chapter two, the effectiveness of relationship marketing strategies is hypothesized to be dependent upon various contingency variables. In this study, we investigated and demonstrated the role of buyer relationship proneness and product category involvement as contingency variables. This indicates the crucial importance of further assessing the role of other variables potentially affecting the success of relationship marketing strategies. Future research should especially devote attention to the effects of product/service characteristics, environmental characteristics, and/or exchange situation characteristics. 


\section{References}

A

Acturol, Ravi S. (1997), "Changes in the Theory of Interorganizational Relations in Marketing: Toward a Network Paradigm," Joumal of the A cademy of Marketing Science, 25 (1), 56-71.

- Adams, J.S. (1965), "Inequity in Social Exchange," Advances in Experimental Social Psychology, 2, 267-99.

- Afifi, Walid, A. and Sandra Metts (1998), "Characteristics and Consequences of Expectation Violations in Close Relationships," Joumal of Social and Personal Relationships, 15 (3), 365-92.

- Agrawal, Deepak (1996), "Effect of Brand Loyalty on Advertising and Trade Promotions: A Game Theoretic Analysis with Empirical Evidence," Marketing Science, 15 (1), 86-108.

- Andaleeb. Syed Saad (1992), "The Trust Concept: Research Issues for Channels of Distribution," in Research in Marketing. 11, Sheth, Jagdish N., ed. Greenwich, Conn. and London: JAI Press, 1-34.

- - (1995). "Dependence Relations and the Moderating Role of Trust: Implications for Behavioral Intentions in Marketing Channels," Intemational Joumal of Reseanch in Marketing, 12 (2), 157-72.

- - (1996), "An Experimental Investigation of Satisfaction and Commitment in Marketing Channels: The Role of Trust and Dependence," Joumal of Retailing. 72 (1), 77-93.

- Anderson, James C. (1995), "Relationships in Business Markets: Exchange Episodes, Value Creation, and Their Empirical Assessment," Joumal of the A cademy of Marketing Science, 23 (4), 346-50.

- -- and David W. Gerbing (1988), "Structural Equation Modeling in Practice: A Review and Recommended TwoStep Approach," Psychological Bulletin. 103 (3), 411-23.

- Hảkan Hâkansson, and Jan Johanson (1994), "Dyadic Business Relationships Within a Business Network Context," Joumal of Marketing, 58 (October), 1-15.

- Anderson, Erin, Leonard M. Lodish, and Barton A. Weitz (1987), "Resource Allocation Behavior in Conventional Channels," Joumal of Marketing Research. 24 (1), 85-97.

-- and -- (1992), "The Use of Pledges to Build and Sustain Commitment in Distribution Channels," Joumal of Marketing Research, 29 (1), 18-34.

- Anderson, Eugene W., Claes Fornell, and Roland T. Rust (1997), "Customer Satisfaction. Productivity, and Profitability: Differences Between Goods and Services," Marketing Science, 16 (2), 129-45.

- Anderson, James C. and James A. Narus (1984), "A Model of the Distributor's Perspective of DistributorManufacturer Working Relationships," Joumal of Marketing, 48 (4), 62-74.

- - and -.. (1990), "A Model of Distributor Firm and Manufacturer Firm Working Relationships," Joumal of Marketing, 54 (1), 42-58.

- Amdt, Johan (1983). "The Political Economy Paradigm: Foundation for Theory Building in Marketing," Joumal of Marketing, 47 (4), $44-54$.

- Arnold, Stephen J., Jay Handelman and Douglas J. Tigert (1996), "Organizational Legitimacy and Retail Store Patronage," Joumal of Business Research, 35 (3), 229-39.

- -... Tae H. Oum, and Douglas J. Tigert (1983), "Determinant Attributes in Retail Patronage: Seasonal, Temporal, Regional, and International Comparisons," Joumal of Marketing Research, 20 (2), 149-57.

- Arora. Raj (1982), "Validation of an S-O-R Model for Situation, Enduring, and Response Components of Involvement," Joumal of Marketing Research, 19 (4), 505-16.

B

Babakus, Emin and Gregory W. Boller (1992), "An Empirical Assessment of the SERVQUAL Scale," Joumal of Business Research, 24 (3), 253-68.

- Babin, Barry J. and William R. Darden (1996), "Good and Bad Shopping Vibes: Spending and Patronage Satisfaction," Joumal of Business Research, 35, 201-6.

- _., -.., and Mitch Griffin (1994), "Work and/or Fun: Measuring Hedonic and Utilitarian Shopping Value," Joumal of Consumer Research, 20 (4), 644-56.

- Bagozzi, Richard P. (1975), "Marketing as Exchange," Joumal of Marketing, 39 (October), 32-9.

- (1986), Principles of Marketing Management. Chicago: Science Research Associates.

- (1995), "Reflections on Relationship Marketing in Consumer Markets," Joumal of the Academy of Marketing Science, 23 (4), $272-7$.

- and Youjac Yi (1988), "On the Evaluation of Structural Equation Models," Joumal of the Academy of Marketing Science, 16 (Spring), 7-94. 
- Baker. Thomas L.. Penny M. Simpson, and Judy A. Siguaw (1999), “The Impact of Suppliers' Perceptions of Reseller Market Orientation on Key Relationship Constructs," Joumal of the Academy of Marketing Science, 27 (1). 50-7.

- Barlow, Richard G. (1992), "Relationship Marketing - The Ultimate in Customer Services," Retail Control, 60 (3), 29.37.

- Barnes, James G. (1994), "Close to the Customer: but is it Really a Relationship?," Joumal of Marketing Management, 10, 561-70.

- .... (1995). "The Quality and Depth of Customer Relationships," in Proceedings of the 24th EMAC Conference, Michelle Bergadaà, ed. Cergy Pontoise: European Marketing Academy, 1393-402.

- .... (1997), "Closeness, Strength, and Satisfaction: Examining the Nature of Relationships between Providers and Financial Services and Their Retail Customers," Psychology and Marketing, 14 (8), 765-90.

- Barrick, Murry R. and Michael K. Mount (1991), "The Big Five Personality Dimensions and Job Performance: A Meta-Analysis," Personnel Psychology, 44, 1-26.

- Bartholomew, Kim and Leonard M. Horowitz (1991), "Attachment Styles Among Young Adults: A Test of a Four-Category Model," Joumal of Personality and Social Psychology, 61 (2), 226-44.

- Batra, Rajeev and Olli T. Athola (1990), "Measuring the Hedonic and Utilitarian Sources of Consumer Attitudes," Marketing Letters, 2 (2), 159-70.

- Baumgartner, Hans and Christian Homburg (1996), "Applications of Structural Equation Modeling in Marketing and Consumer Research: A Review," Intemational Joumal of Research in Marketing. 13 (2), 139-61.

- Bayus, Barry L. (1992), "Brand Loyalty and Marketing Strategy: An Application to Home Appliances," Marketing Science, II (1), 21-38.

- Bearden, William O. (1977), "Determinant Attributes of Store Patronage: Downtown versus Outlying Shopping Centers," Joumal of Retailing, 53 (2), $15-22$.

- ..., R.G. Netemeyer, and M.F. Mobley (1993). Handbook of Marketing Scales" Multi-ltem Measures for Marketing and Consumer Behavior Reseanch. London: Sage Pulications.

- ...., Subhash Sharma, and Jesse E. Teel (1982), "Sample Size Effects on Chi Square and Other Statistics Used in Evaluating Causal Models," Joumal of Marketing Research, 19 (4), 425-30.

- Beatty, Sharon E. and Scott M. Smith (1987), "External Search Effort: An Investigation Across Several Product Categories," Joumal of Consumer Research, 14 (1), 83-95.

- .... Pamela Homer, and Lynn R. Kahle (1988), "The Involvement-Commitment Model: Theory and Implications," Joumal of Business Research, 16 (2), 149-67.

- ...., Lynn R. Kahle, and Pamela Homer (1991), "Personal Values and Gift-Giving Behaviors: A Study Across Cultures," Journal of Business Research, 22, 149-57.

- ...., Morris Mayer, James E. Coleman, Kristy Ellis Reynolds, and Jungki Lee (1996), "Customer-Sales Associate Retail Relationships," Joumal of Retailing, 72 (3), 223-47.

- Becker, Thomas E. and Robert S. Billings (1993), "Profiles of Commitment: An Empirical Test," Joumal of Organizational Behavior, 14 (2), 177-90.

- Beddoe, Toby (1995), "Moving from an Account-Based to a Customer-Focused Marketing Database System: A Case Study," Joumal of Database Marketing, 2 (3), 238-45.

- Bejou, David. Barry Wray ,and Thomas N. Ingram (1996), “Determinants of Relationship Quality: An Artificial Neural Network Analysis," Joumal of Business Research. 36 (2), 137-43.

- .... (1997). "Relationship Marketing: Evolution. Present State, and Future," Psychology and Marketing, 14 (8). 727-36,

- Belk, R.W. (1975), "Situational Variables in Consumer Behavior," Joumal of Consumer Research, 2 (December), 157-64.

- Bell. David R., Teck-Hua Ho, and Christopher Tang (1998), "Determining Where to Shop: Fixed and Variable Costs of Shopping," Joumal of Marketing Research, 35 (August), 352-69.

- Bellenger. Danny N. and Pradeep K. Korgaonkar (1980), "Profiling the Recreational Shopper," Joumal of Retailing. 56 (3), 77-92.

- .... Dan H. Robertson. and Barnett A. Greenberg (1977), "Shopping Center Patronage Motives," Joumal of Retailing. 53 (2), 29-38.

- Bendapudi. Neeli and Leonard L. Berry (1997), "Customers" Motivations for Maintaining Relationships With Service Providers," Joumal of Retailing, 73 (1), 15-37.

- Bennett. Peter. D. (1989), Dictionary of Marketing Tems, Chicago: American Marketing Association.

- Bennett, Roger (1996), "Relationship Formation and Governance in Consumer Markets: Transactional Versus the Bchaviourist Approach." Joumal of Marketing Management, 12, 417-36. 
Benson. 1. Kenneth (1975), "The Interorganizational Network as a Political Economy," Administrative Science Quanerty, 20 (June), 376-96.

- Bentler, P.M. (1990), "Comparative Fit Indexes in Structural Models," Prychological Bulletin, 107 (2), 238-46.

- - and D.G. Bonnett (1980), "Significance Tests and Goodness of Fit in the Analysis of Covariance Structures," Prychological Bulletin. 88 (3), 588-606.

- - and C. Chou (1987). "Practical Issues in Structural Modeling," Sociological Methods and Research, 16 (August), 78-117.

- Berting. Robert J. (1993), The Emerging Approach to Business Strategy: Building a Relationship Advantage," Business Horizons, 36 (4), 16-27.

- Berry, Leonard L. (1983), "Relationship Marketing," in Emerging Perspectives on Services Marketing, Leonard L. Berry, G. Lynn Shostack, and Gregory Upah, eds. Chicago, IL: American Marketing Association, 25-8.

- - and Larry G. Gresham (1986), "Relationship Retailing: Transforming Customers into Clients," Business Horizons, (November-December), 43-7.

- - (1995), "Relationship Marketing of Services - Growing Interest, Emerging Perspectives," Joumal of the Academy of Marketing Science, 23 (4), 236-45.

- Bettman, James R. (1979). An Information Processing Theory of Consumer Choice. Reading: Addison Wesley.

- Bingham, Frank G. Ir. and Barney T. Raffield III (1990), Business to Bussiness Marketing. Homewood: Irwin.

- Biong. Harald and Fred Selnes (1995), "Relational Selling Behavior and Skills in Long-term Industrial BuyerSeller Relationships," Intemational Business Review, 4 (4), 483-98.

- Bitner, Mary Jo (1990), "Evaluating Service Encounters: The Effects of Physical Surroundings and Employee Responses," Joumal of Marketing, 54 (2), 69-82.

- -.- (1995), "Building Service Relationships: It's All About Promises," Joumal of the Academy of Marketing Science, $23(4), 246-51$.

- Bernard H. Booms, and Lois A. Mohr (1994), "Critical Service Encounters: The Employee's Viewpoint," loumal of Markering, 58 (4), 95-106.

- ..-., and M.S. Tetreault (1990), "The Service Encounter: Diagnosing Favorable and Unfavorable Incidents," Joumal of Marketing. 54, 71-84.

- Blattherg, Robert C. and John Deighton (1991). "Interactive Marketing: Exploiting the Age of Addressability," Sloan Management Review, 33 (Autumn). 5-14.

- Rashi Glazer, and John D.C. Little (1994), The Marketing Information Revolution. Boston: Harvard Business School Press.

- Bloch. Peter H. (1981). "An Exploration into the Scaling of Consumers' Involvement in a Product Class," in Adrances in Consumer Research, 8, Monroe, ed. Ann Arbor, MI: Association for Consumer Research, 61-5.

- -.. (1982), "Involvement Beyond the Purchase Process: Conceptual Issues and Empirical Investigation," in Advances in Consumer Research, 9. A.A. Mitchell, ed. Ann Arbor, M1: Association for Consumer Research, 413. 17.

- -.. Daniel L. Sherrell, and Nancy M. Ridgeway (1986), "Consumer Search: An Extended Framework," Joumal of Consumer Research," 13 (1), 119-26.

- Bloemer. Josée (1993), "Loyaliteit en Tevredenheid, een Studie naar de Relatie tussen Merktrouw en Consumententevredenheid," doctoral dissertation, Maastricht University.

- - and Ko de Ruyter (1998), "On the Relationship between Store Image, Store Satisfaction, and Store Loyalry," Eumpean Joumal of Marketing, 32 (5/6), 499-513.

- _- and Hans Kasper (1995). "The Complex Relationship between Consumer Satisfaction and Brand Loyalty," Joumal of Economic Psychology, 16 (2), 311-29.

- Blois, Keith (1995), "Relationship Marketing in Organizational Markets: What is the Customer's View?" in Proceedings of the 24th EMAC Confenence. Michelle Bergadaà, ed. Cergy Pontoise: European Marketing Academy, 131-48.

- Bollen, Kenneth A. (1989). Stnuchumal Equations with Latent Variables. New York: John Wiley and Sons.

- - and J. Scott Long (1992), "Tests for Structural Equation Models: Introduction," Sociological Methods and Research. 21 (November), 123-31.

- Bolton, Ruth N. (1998), "A Dynamic Model of the Duration of the Customer's Relationship with a Continuous Service Provider: The Role of Satisfaction," Marketing Science, 17 (1), 45-65.

- - and James H. Drew (1991). "A Multistage Model of Customers' Assessments of Service Quality and Value," Joumal of Consumer Research. 17 (4). 375-84. 
- Boorom, Michael L., Jerry R. Goolsby, and Rosemary P. Ramsey (1998), "Relational Communication Traits and Their Effect on Adaptiveness and Sales Performance," Joumal of the Academy of Marketing Seience, 26 (1), 16. 30.

- Bowen, David E. and Gareth R. Jones (1986), "Transaction Cost Analysis of Service Organization-Customer Exchange," Academy of Management Review, 11 (2), 428-41,

- Boyle, Brett. F. Robent Dwyer, Robert A. Robicheaux, and James T. Simpson (1992), "Influence Strategies in Marketing Channels: Measures and Use in Different Relationship Structures," Joumal of Marketing Research, 29 (November), 462-73.

- Braithwaite, V.A. and H.G. Law (1985), "Structure of Human Values: Testing the Adequacy of the Rokeach Value Survey," Joumal of Penonality and Social Psychology, 49 (1), 250-63.

- Brislin, R.W. (1980), "Translation and Content Analysis of Oral and Written Materials," in Handbook of CrossCultural Psychology: Methodology, H.C. Triandis and J.W. Berry, eds. Boston. MA: Allyn and Bacon.

- Brock. Douglas M., Irwin G. Sarason, Hari Sanghvi, and Regan A.R. Gurung (1998), "The Perceived Acceptance Seale: Development and Validation," Joumal of Social and Personal Relationships, 15 (1), 5-21.

- Brown, Tom J., Gilben A. Churchill, and J. Paul Peter (1993), "Improving the Measurement of Service Quality." Joumal of Retailing, 69 (1), 127-39.

- Brown, James R., Jean L. Johnson, and Harold F. Koenig (1995), "Measuring the Sources of Marketing Channel Power: A Comparison of Altemative Approaches," Intemational Joumal of Research in Marketing. 12 (4), 333-54.

- Bruner, Gordon C. and Paul J. Hensel (1992), Marketing Scales Handbook, A Compilation of Multi-liem Measures, Chicago, III.: American Marketing Association.

- Buchanan, Lauranne (1992), "Vertical Trade Relationships: The Role of Dependence and Symmetry in Attaining Organizational Goals," Joumal of Marketing Research, 29 (February), 65-75.

- Buss, Amold H. and Robert Plomin (1984), Tempenment: Early Developing Personality Traits. Hillsdale, New York: Eribaum.

- Buttle, Francis (1996), Relationship marketing. Theory and practice. London: Paul Chapman Publishing.

- Callaghan, Michael B., Janelle McPhail, and Oliver H.M. Yau (1995), "Dimensions of a Relationship Marketing Orientation: An Empirical Exposition," in Proceedings of the Seventh Bi-A nmual Word Marketing Congress. Ken Grant and Ian Walker, eds, Melbourne: Monash University, 10/59-10/65.

- Campbell, N.C.G. and M.T. Cunningham (1983), "Customer Analysis for Strategy Development in Industrial Markets," Strutegic Management Joumal, 4, 124-36.

- Carman, James M. (1970), "Correlates of Brand Loyalty: Some Positive Results," Joumal of Marketing Research. $7(1), 67-76$.

- $\quad$ - (1990), "Consumer Perceptions of Service Quality: An Assessment of the SERVQUAL Dimensions," Joumal of Retailing, 66 (1), 33-55,

- Carver. Charles S. and Michael F. Scheier (1992), Perspectives on Personality. Boston: Allyn and Bacon.

- Celsi. Richard L. and Jerry C. Olson (1988). "The Role of Involvement in Attention and Comprehension Processes," Joumal of Consumer Reseanch, 15 (2), 210-24.

- Chartton. P. (1973), "A Review of Shop Loyalty," Joumal of the Market Research Society, 15 (1). 35-51.

- Cheek. Jonathan M. and Amold H. Buss (1981), "Shyness and Sociability," Joumal of Personality and Social Psychology, 41 (2), 330-9.

- Child, Peter, Robert J, Dennis. Timothy C. Gokey. Tim I. McGuire, Mike Sherman, and Mare Singer (1995), "Can Marketing Regain the Personal Touch?," The McKinsey Quarterly, 3, 112-25.

- Christopher, Martin, Adrian Payne, and David Ballantyne (1994), Relationship Marketing. Bringing Quality. Customer Service and Marketing Together. Oxford: Butterworth Heinemann.

- Christy, Richard, Gordon Oliver, and Joe Penn (1996), "Relationship Marketing in Consumer Markets," Joumal of Marketing Management, 12, 175-87.

- Churchill, Gilbert A. (1979), "A Paradigm for Developing Better Measures of Marketing Constructs," Joumal of Marketing Research, 16 (1), 64-73.

- ... (1995), Marketing Research: Methodological Foundations. Forth Worth: The Dryden Press.

- ... and J. Paul Peter (1984), "Research Design Effects on the Reliability of Rating Scales: A Meta-Analysis". Joumal of Marketing Research, 21 (4), 360-75,

- ... and Carol Surprenant (1982). "An Investigation into the Determinants of Customer Satisfaction." Joumal of Marketing Research, 19 (4), 491-504. 
Clare, Donald A. and Donald G. Sanford (1979), "Mapping Pensonal Value Space: A Study of Managers in Four Organizations," Human Relations, 32 (8), 659-66.

- Coase, Ronald H. (1937), "The Nature of the Firm," Economica, 4, 386-405.

- Cobb, Cathy J. and Wayne D. Hoyer (1986), "Planned Versus Impulse Purchase Behavior," Joumal of Retailing, 62 (4), 384-409.

- Collins, N.L. and S.J. Read (1990), "Adult Attachment, Working Models, and Relationship Quality in Dating Couples," Joumal of Personaliry and Social Psychology, 58, 644-63.

- Cook. Thomas D. and Donald T. Campbell (1979). Quasi-Experimentation: Design and A nalysis Issues for Field Seftings, Chicago: Rand McNally.

- Copulsky, Jonathan R. and Michael J. Wolf (1990), "Relationship Marketing: Positioning for the Future," Joumal of Business Strategy, (July/August), 16-20.

- Costa, Paul T. Jr. and Robert R. MeCrae (1988), "From Catalog to Classification: Murray's Needs and the FiveFactor Model," Joumal of Personaliry and Social Psychology, 55 (2), 258-65.

- Cram. Tony (1994), The Power of Relationship Makketing. Keeping Customers for Life. London: Pitman Publishing.

- Cronbach, Lee J. (1951), "Coefficient Alpha and the Internal Structure of Tests," Psychometrika, 16 (3), $297-334$.

- Cronin, J. Joseph and Stephen A. Taylor (1992), "Measuring Service Quality: A Reexamination and Extension," Joumal of Marketing. 56 (3), 55-68.

- - and - (1994), "SERVPERF Versus SERVQUAL: Reconciling Performance-Based and Perceptions-MinusExpectations Measurement of Service Quality," Joumal of Marketing, 58 (I), 125-31.

- Crosby, Lawrence A., Kenneth R. Evans, and Deborah Cowles (1990), "Relationship Quality in Services Selling: An Interpersonal Influence Perspective," Joumal of Marketing. 54 (3), 68-8I.

- - and Nancy Stephens (1987). "Effects of Relationship Marketing on Satisfaction, Retention, and Prices in the Life Insurance Industry," Joumal of Marketing Research, 24 (November), 404-11.

- - and James R. Taylor (1983). "Psychological Commitment and its Effects on Post-Decision Evaluation and Preference Stability Among Voters," Joumal of Consumer Reseanch, 9 (March), 413-3I.

- Cross, Richard and Janct Smith (1995), Customer Bonding. Illinois: USA NTC Business Books.

- Cunningham. R.M. (1961), "Customer Loyalty to Store and Brand," Harvand Business Review, 40 (November/December), 127-37.

- Cunningham, Scott M. (1966), "Brand Loyalty - What, Where, How Much?," Hanard Business Review, 34 (January/February), 116-28.

- Czepiel, John A. (1990), Managing Relationships with Customers: A Differentiating Philosophy of Marketing. San Francisco: Jossey-Bass.

\section{D}

- Dabholkar, Pratibha, Wesley J. Johnston and Amy S. Cathey (1994), "The Dynamics of Long-Term Business-10Business Exchange Relationships," Joumal of the A cademy of Marketing Science, 22 (2), 130-45.

- Dahlstrom, Robert, Kevin M. McNeilly, and Thomas W. Speh (1996), "Buyer-Seller Relationships in the Procurement of Logistical Services," Joumal of the Academy of Marketing Science, 24 (2), 110-24.

- ... and Arne Nygaard (1995), "An Exploratory Investigation of Interpersonal Trust in New and Mature Markets," Joumal of Retailing, 71 (4), 339-61.

- Dash, Joseph F., Leon G. Schiffman, and Conrad Berenson (1976), "Risk and Personality-Related Dimensions of Store Choice," Joumal of Marketing. 40 (January), 32-9.

- Davis, Frederick B. (1964), Educational Measurements and Their Interpretation, Belmont. CA: Wadsworth.

- Davis, J. Charlene (1995), "Dependency, Self-interest, and Relationship Marketing." Joumal of Marketing Theory and Practice, 3 (4), 17-23.

- Davis, Judy Foster (1997), "Maintaining Customer Relationships Through Effective Database Marketing: A Perspective for Small Retailers," Joumal of Marketing Theory and Practice, 5 (2), 31-42.

- Dawson. Scott, Peter H. Bloch, and Nancy M. Ridgway (1990), "Shopping Motives, Emotional States, and Retail Outcomes," Joumal of Retailing, 66 (4), 408-27.

- Day. Ellen, Marla Royne Stafford, and Alejandro Camacho (1995), "Opportunities for Involvement Research: A Scale-Development Approach," Joumal of Advertising, 24 (3), 69-75.

- Day. George S. (1969). "A Two-Dimensional Concept of Brand Loyalty," Joumal of Advertising Research, 9 (3). 29.35.

- (1990), Market Driven Strutegy: Processes for Creating Value. New York: Free Press. 
- _.- and Robin Wensley (1983), "Marketing Theory with a Strategic Orientation," Joumal of Marketing, 47 (Fall). 79-89.

- De Bonis. Nicholas and Alf Nucifona (1994), "Progressive Databases: The Underpinning for Relationship Micromarketing." Joumal of Database Marketing, 2 (2), $134-40$.

- Dekimpe, Marnik G., Jan-Benedict E.M. Steenkamp, Martin Mellens, and Piet Vanden Abeele (1997), "Decline and Variability in Brand Loyalty." Intemational Joumal of Research in Marketing, 14 (5), 405-20.

- Denison, Tim and Simon Knox (1993), Cashing In On Loyal Customers. The Divi and Indemnity for Retailen, Institute for Advanced Research in Marketing/Cranfield School of Management: Cranfield.

- Deniston, William M. and Nerella V. Ramanaiah (1993), "California Psychological Inventory and the Five-Factor Model of Personality." Psychological Repons, 73, 491-6.

- De Pelsmacker. Patrick and Patrick Van Kenhove (1994), Marktonderzoek. Leuven/Antwerpen: Garant.

- De Ruyter, Ko and Norbert Scholl (1995), Kwalitatief Marktonderzoek: Theorie en Praktijkcases. Utrecht: Lemma BV.

- DeVellis, Robent F. (1991) Scale development, Theory and Applications. Applied Social Research Methods Series, 26.

- De Wulf, Kristof (1998), "Relationship Marketing," in Services Management. An Integnzted A ppruoch. Bart Van Looy, Roland Van Dierdonck, and Paul Gemmel, eds. London: Financial Times/Pitman Publishing.

- ... (1999), "The Role of the Seller in Enhancing Buyer-Seller Relationships. Empirical Studies in a Retail Context." doctoral dissertation, University of Ghent.

- ..., Janny C. Hoekstra, and Harry R. Commandeur (1999), "The Opening and Reading Behavior of Business-teBusiness Diroct Mail," Industrial Marketing Management, forthcoming.

- ... and Gaby Odekerken-Schroder (1998), "Operationalizing and Modeling the Relationship between Retailer Relationship Orientation. Consumer Relationship Proneness, and Consumer Loyalty," in 1998 Research Confenence Proceedings, Contemponay Knowledge of Relationship Marketing, Jagdish N. Sheth and Anil Menon. eds. Atlanta/Georgia: Emory University, 96.

- .... and .... (1999), "The Influence of Seller Relationship Orientation and Buyer Relationship Proneness on Trust, Commitment, and Behavioral Loyalty in a Consumer Environment," working paper. University of Ghent.

- Dick, Alan S. and Kunal Basu (1994), "Customer Loyalty: Toward an Integrated Conceptual Framework," Joumal of the A cademy of Marketing Science, 22 (2), 99-113.

- Dillon, William R. and Matthew Goldstein (1984), Multivariate Analysis. Methods and A pplications, New York: John Wiley and Sons.

- ...., Thomas J. Madden, and Neil H. Firtle (1990), Manketing Research in a Marketing Environment, second edition. Homewood/Boston: Irwin.

- ..., ...., and -... (1993), Essentials of Marketing Research, Homewood/Boston: Irwin.

- Dodge, H. Robert and Sam Fullerton (1997). "From Exchanges to Relationships: A Reconceptualization of the Marketing Paradigm," Joumal of Marketing Theory and Practice, 5 (2), 1-7.

- Doney. Patricia M. and Joseph P. Cannon (1997), "An Examination of the Nature of Trust in Buyer-Seller Relationships," Joumal of Marketing, 61 (2), 35-51.

- Douglas, Susan P. and C. Samuel Craig (1983), Intemational Marketing Research, Englewood Cliffs, NJ: Prentice Hall.

- Dowling. Grahame R. and Richard Staelin (1994). "A Model of Perceived Risk and Intended Risk-Handling Activity," Joumal of Consumer Research, 21 (June), 119-34.

- _- and Mark Uncles (1997), "Do Customer Loyalty Programs Really Work?," Sloan Management Review, 38 (4), 71-82.

- Duck, Steve W. (1988) Handbook of Personal Relationships. New York: John Wiley \& Sons Lid.

- - (1992) Human Relationships. Trowbridge: Sage Publications.

- Duffy, D.J. (1983), "The Critical Incident Method, An Overlooked Way of Human Relations Training for Small Business," American Joumal of Small Business, 8, 11-3.

- Duncan. Tom and Sandra E. Moriarty (1998), "A Communication-Based Marketing Model for Managing Relationships," Joumal of Marketing, 62 (2), 1-13.

- Dunn, Richard and Neil Wrigley (1984), "Store Loyalty for Grocery Products: An Empirical Study," A rea, 16. $307-14$.

- ... and Sejo Oh (1987), "Output Sector Munificence Effects on the Internal Political Economy of Marketing Channels," Joumal of Marketing Research, 24 (November), 347-58.

- ..., Paul H. Schurr, and Sejo Oh (1987), "Developing Buyer-Seller Relationships," Joumal of Marketing, 51 (2). $11-27$. 
East, Robert, Patricia Harris, Wendy Lomax, and Gill Wilson (1997), First-Store Loyalty to US and British Supermarkets," in Proceedings of the 27th EMAC Conference, Per Andersson, ed. Stockholm: European Marketing Academy, 401-15.

- Edkles. Robert W. (1990), Business Marketing Management - Marketing of Business Products and Services. Englewood Cliffs: Prentice-Hall.

- Ehrenberg, A.S.C., G.J. Goodhardt, and Barwise T.P. (1990), "Double Jeopardy Revisited," Joumal of Marketing. 54 (July), 82-91.

- Ellis, Kristy (1995), "The Determinants of the Nature and Types of Customer-Salesperson Relationships in a Retail Setting: An Empirical Study," doctoral dissertation, University of Alabama.

- Emerson, Richard M. (1962), "Power-Dependence Relations," American Sociological Review, 27 (February), 31. 41.

- Engel, James F., Roger D. Blackwell, and Paul W. Miniard (1995), Consumer Behavior. Forth Worth: The Dryden Press.

- Enis, Ben M. and Gordon W. Paul (1970), "Store Loyalty as a Basis for Market Segmentation," Joumal of Retuiling, 46 (Fall), 42-56.

- Evans, Joel R. and Richard L. Laskin (1994). "The Relationship Marketing Process: A Conceptualization and Application," Industrial Marketing Management, 23 (5), 439-52.

- Evans, Kenneth R. Tim Christiansen, and James D. Gill (1996), "The Impact of Social Influence and Role Expectations on Shopping Center Patronage Intentions," Joumal of the Academy of Marketing Science, 24 (3), 208-18

- Eysenck. Hans J. and Michael W. Eysenck (1985), Personality and Individual Differences, A Natund Science Approach. New York: Plenum Press.

Fader, Peter S. and James M. Lartin (1993), "Accounting for Heterogeneity and Nonstationarity in a CrossSectional Model of Consumer Purchase Behavior." Marketing Science, 12 (3), 304-17.

- _- and David C. Schmittlein (1993), "Excess Behavioral Loyalty for High-Share Brands: Deviations from the Dirichlet Model for Repeat Purchasing." Joumal of Marketing Research, 30 (4). 478-93.

- Farley, J.V. (1968), "Dimensions of Supermarket Choice Patterns," Joumal of Marketing Research, 5, 206-8.

- Fehr. Beverley (1988), "Prototype Analysis of the Concepts of Love and Commitment," Joumal of Personality and Social Psychology, 55 (4), 557-79.

- Fern, Edward F and James R. Brown (1985), "The Industrial/Consumer Marketing Dichotomy: A Case of Insufficient Evidence," Joumal of Marketing, 48 (2), 68-77.

- Finn, Adam and Jordan J. Louviere (1996), "Shopping Center Image, Consideration, and Choice, Anchor Store Contribution," Joumal of Business Reseanch, 35, 241-51.

- Fischer, Eileen and Julia Bristor (1994), "A Feminist Poststructuralist Analysis of the Rhetoric of Marketing Relationships," Intemational Joumal of Research in Marketing. II (4). 317-31.

- Fiske, Donald W. (1982), "Convergent-Discriminant Validation in Measurements and Research Strategies," in Forms of Validity in Research, D. Brinberg and L.H. Kidder, eds. San Francisco: Jossey-Bass Inc., 77-92.

- Flanagan, J.C. (1954), "The Critical Incident Technique", Psychological Bulletin, 51 (July). 327-58.

- Fleenor, John, W, and Lorrina Eastman (1997), "The Relationship Between the Five Factor Model of Personality and the California Psychological Inventory," Educational and Psychological Measurement, 57 (4), 698-703.

- Fetcher, Keith, George Wright, and Caroline Desai (1996), "The Role of Organizational Factors in the Adoption and Sophistication of Database Marketing in the UK Financial Services Industry." Joumal of Direct Marketing, 10 (1). 10-21.

- Fiat, Daniel J., Robert B. Woodruff, and Sarah Fisher Gardial (1997), "Customer Value Change in Industrial Marketing Relationships. A Call for New Strategies and Research," Industrial Marketing Management, 26 (2) 163 . 75.

- Fontenot, Renée J. and Elizabeth J. Wilson (1997), "Relational Exchange: A Review of Selected Models for a Prediction Matrix of Relationship Activities," Joumal of Business Reseanch, 39 (1), 5-12.

- Ford, D. (1980), "The Development of Buyer-Seller Relationships in Industrial Markets," European Joumal of Manketing, $14(5 / 6), 339-53$ 
- Forman, Andrew M. and Ven Sriram (1991), "The Depersonalization of Retailing: Its Impact on The 'Lonely' Consumer," Joumal of Retaling. 67 (2), 226-43.

- Fornell, Claes and David F. Larcker (1981), "Evaluating Structural Equation Models with Unobservable Variables and Measurement Error," Joumal of Marketing Research, 18 (3), 39-50.

- Forsythe, Sandra, Sara Butler, and Rober Schaefer (1990), "Surrogate Usage in the Acquisition of Women', Business Apparel," Joumal of Retailing. 66 (Winter). 446-69.

- Fournier, Susan (1998), "Consumen and Their Brands: Developing Relationship Theory in Consumer Research." Joumal of Consumer Research, 24 (2), 343-73.

- -..., Susan Dobscha, and David Glen Mick (1998), "Preventing the Premature Death of Relationship Marketing." Hanard Business Review, (January-February), 42-4.

- ... and Julie L. Yao (1997), "Reviving Brand Loyalty: A Reconceptualization within the Framework of Consumer-Brand Relationships", International Joumal of Research in Marketing. 14 (5), $451-72$.

- Frazier, Gary L. (1983) op te zoeken

- .... and Kersi D. Antia (1995), "Exchange Relationships and Interfirm Power in Channels of Distribution," Joumal of the A cademy of Marketing Science, 23 (4), 321-6.

- ...., James D. Gill, and Sudhir H. Kale (1989), "Dealer Dependence Levels and Reciprocal Actions in a Channel of Distribution in a Developing Country," Joumal of Marketing, 53 (January), 50-69.

- ... and Raymond C. Rody (1991), "The Use of Influence Strategies in Interfirm Relationships in Industrial Product Channels," Joumal of Marketing, 55 (January), 52-69.

- ...., Robert E. Spekman, and Charles R. O'Neal (1988), "Just-In-Time Exchange Relationships in Industrial Markets," Joumal of Marketing, 52 (October), 52-67.

- ... and John O. Summers (1986), "Perceptions of Interfirm Power and Its Use within a Franchise Channel of Distribution," Joumal of Marketing Research, 23 (2), 169-76.

- Frenzen, Jonathan K. and Harry L. Davis (1990), "Purchasing Behavior in Embedded Markets," Joumal of Consumer Reseanch, 17 (1), 1-12.

\section{G}

- Gansesan, Shankar (1993), "Negotiation Strategies and the Nature of Channel Relationships," Joumal of Marketing Reseanch. 30 (2), 183-203.

- .... (1994), "Determinants of Long-Term Orientation in Buyer-Seller Relationships," Joumal of Marketing. 58 (2). $1-19$.

- Gaski. John F. (1986). "Interrelations among a Channel Entity's Power Sources: Impact of the Exercise of Reward and Coercion on Expert, Referent, and Legitimate Power Sources," Joumal of Marketing Research, 23 (1), $62-77$.

- .... and John R. Nevin (1985), "The Differential Effects of Exercised and Unexercised Power Sources in a Marketing Channel," Joumal of Marketing Research, 22 (May), 130-42.

- Gassenheimer. Jule B., Charlene Davis, and Robert Dahlstrom (1998), "Is Dependent What We Want to Be? Effects of Incongruency." Joumal of Retailing, 74 (2), 247-71.

- ..... Franklin S. Houston, and J. Charlene Davis (1998), "The Role of Economic Value, Social Value, and Perceptions of Faimess in Interorganizational Relationship Retention Decisions," Joumal of the Academy of Marketing Science, 26 (4), 322-37.

- ..- and Rosemary Ramsey (1994). "The Impact of Dependence on Dealer Satisfaction: A Comparison of ResellerSupplier Relationships," Joumal of Retailing. 70 (3), 253-66.

- Gengler, Charles E. and Peter T.L. Popkowski Leszcye (1997), "Using Customer Satisfaction Research for Relationship Marketing: A Direct Marketing Approach," Joumal of Direct Marketing. 11 (1), 23-9.

- Gerbing David W. and James C. Anderson (1988), "An Updated Paradigm for Scale Development Incorporating Unidimensionality and Its Assessment," Joumal of Marketing Research, 20 (January), 63-70.

- Geyskens, Inge (1998), "Trust. Satisfaction, and Equity in Marketing Channel Relationships," doctoral dissertation, Catholic University of Louvain.

- .... Jan-Benedict E.M. Steenkamp, Lisa K. Scheer, and Nirmalaya Kumar (1996), "The Effects of Trust and Interdependence on Relationship Commitment: A Trans-Atlantic Study." Intemational Joumal of Research in Marketing, 13 (4), 303-17.

_ _....... and Nirmalaya Kumar (1998). "Generalizations about Trust in Marketing Channel Relationships Using Meta-Analysis," Intemational Joumal of Reseanch in Marketing, 15 (3), 223-48.

- Ghosh, Avijit (1994), Retail Management. Forth Worth: The Dryden Press. 
Giffin, Kim (1967), The Contribution of Studies of Source Credibility to a Theory of Interpersonal Trust in the Communication Process," Pyychological Bulletin, 68 (2), 104-20.

- Glenn, Norval (1990), "Quantitative Research on Marital Quality in the 1980s: A Critical Review," Joumal of Mariage and the Family. 52, 818-31.

- Goff. Brent G. James S. Boles, Danny N. Bellenger, and Carrie Stojack (1997), "The Influence of Salesperson Selling Behaviors on Customer Satisfaction with Products," Joumal of Retailing, 73 (2), 171-83.

- Goldterg. Lewis R. (1990), "An Alternative 'Description of Personality": The Big-Five Factor Structure," Joumal of Personality and Social Psychology. 59 (6). 1216-29.

- - (1993), "The Structure of Phenotypic Personality Traits," A merican Pyychologist, 48 (1), 26-34.

- Goldman, Arieh (1977-1978), "The Shopping Style Explanation for Store Loyalty," Joumal of Retailing, 53 (4). 33-46.

- Goodman, Paul S., Mark Fichman, F. Javier Lerch, and Pamela R. Snyder (1995), "Customer-Firm Relationships, Involvement, and Customer Satisfaction." A cademy of Management Joumal, 38 (5), 1310-24.

- Gotheb, Jerry B., Dhruv Grewal, and Stepen W. Brown (1994), "Consumer Satisfaction and Perceived Quality: Complementary or Divergent Constructs?." Joumal of A pplied Psychology, 79 (6), 875-85.

- Grant. Alan W.H. and Leonard A. Schlesinger (1995), "Realize Your Customers' Full Potential," Havand Business Review, 73 (5), 59-72.

- Grayson, Kent and Tim Ambler (1999), " The Dark Side of Long-Term Relationships in Marketing Services," Joumal of Marketing Research, 36 (February), 132-41.

- Green, Paul, E., Donald S. Tull, and Gerarld Albaum (1988), Research for Marketing Decisions. Englewood Cliffs: Prentice Hall.

- Greenwald, Anthony G. and Clark Leavitt (1984). "Audience Involvement in Advertising: Four Levels." Joumal of Consumer Research, 11 (1), 581-92.

- Grewal, Dhruv, R. Krishnan. Julie Baker, and Norm Borin (1998), "The Effect of Store Name. Brand Name and Price Discounts on Consumers' Evaluations and Purchase Intentions," Joumal of Retailing, 74 (3), 331-52.

- Grönnoos, Christian (1990a). "Relationship Approach to Marketing in Service Contexts: The Marketing and Organizational Behavior Interface," Joumal of Business Research. 20 (1), 3-11.

- - (1990b), "Marketing Management or Market-Oriented Management," in Senvice Management and Marketing: Managing the Moments of Tnuth in Service Competition, Lexington MA: Lexington books. 125-53.

- -.. (1994a). "From Marketing Mix to Relationship Marketing: Towards a Paradigm Shift in Marketing." Management Decision, 32 (2), 4-20.

- -.. (1994b), "Quo Vadis, Marketing? Toward a Relationship Marketing Paradigm," Joumal of Marketing Management, 10.347-60.

- - (1995), "Relationship Marketing: The Strategy Continuum," Joumal of the Academy of Marketing Science, 23 (4). $252-4$.

- Gross, Andrew C., Peter M. Banting, Lindsay N. Meredith, and I. David Ford (1993), Business Marketing, Boston: Houghton Mifflin Company.

- Gruen, Thomas (1995), "The Outcome Set of Relationship Marketing in Consumer Markets," Intemational Business Review, 4 (4), 447-69.

- Gummesson, Evert (1987), "The New Marketing-Developing Long-term Interactive Relationships," Long Range Planning. 20 (4), 10-20.

- (1994), "Making Relationship Marketing Operational," The Intemational Joumal of Service Industry Management. 5 (5), 5-20.

- (1997), "Relationship Marketing - The Emperor's New Clothes or a Paradigm Shift?," Marketing and Research Todary, 25 (1), 53-60.

- Gundlach, Gregory T. and Patrick E. Murphy (1993). "Ethical and Legal Foundations of Relational Marketing Exchanges," Joumal of Marketing, 57 (4), 35-46.

- ..., Ravi S. Achrol, and John T. Mentzer (1995), "The Structure of Commitment in Exchange," Joumal of Marketing. 59 (1). 78-92.

- and Emest R. Cadotte (1994), "Exchange Interdependence and Interfirm Interaction: Research in a Simulated Channel Setting." Joumal of Marketing Research, 31 (November), 516-32.

- Gupta. Sunil, Michael R. Hagerty, and John G. Meyers (1983), "New Directions in Family Decision Making Research" in Advances in Consumer Research, 10, Bagozzi. Richard P. and Alice M. Tybout, eds. Ann Arbor. Mich: Association for Consumer Research.

- Gutman, Jonathan and Michael K. Mills (1982), "Fashion Life Style, Self-Concept, Shopping Orientation and Store Patronage: An Integrative Analysis," Joumal of Retailing, 58 (2), 64-86. 
- Gwinner, Kevin P. Dwayne D. Gremler, and Mary Jo Bitner (1998), "Relational Benefits in Services Indestries: The Customer's Perspective," Joumal of the A cademy of Marketing Seience, 26 (2), 101-14.

\section{H}

- Hair, Joseph F. Rolph E. Anderson, Ronald L. Tatham, and William C. Black (1998), Multivariate Daza A nalysis. Upper Saddle River, NJ: Prentice Hall.

- Hakkanson H. (1982) Intemational Marketing and Punchasing of Industrial Goods: An Intenactive Approach. Chichester: John Wiley and Sons.

- Hallberg, Garth (1995), All Consumers Are Not Created Equal: The Differemtial Marketing Strutegy for Brand Loyalry and Profits. New York: John Wiley and Sons.

- Hallén, Lars, Jan Johanson, and Nazeem Seyed-Mohamed (1991), "Interfirm Adaptation in Business Relationships," Joumal of Marketing. 55 (A pril), 29-37.

- Haslam, Nick and Alan Page Fiske (1992), "Implicit Relationship Prototypes: Investigating Five Theories of the Cognitive Organization of Social Relationships," Joumal of Experimental Social Psychology, 28 (5), 441-74

- Heide, Jan B. (1994), "Interorganizational Governance in Marketing Channels," Joumal of Marketing. 58 (1), 7185.

- - and George John (1990), "Alliances in Industrial Purchasing: The Determinants of Joint Action in BuyerSupplier Relationships," Joumal of Marketing Research, 27 (February), 24-36.

- _- and George John (1992), "Do Norms Matter in Marketing Relationships?," Joumal of Marketing. 56 (2), 32. 44.

- _.- and Allen M. Weiss (1995), "Vendor Consideration and Switching Behavior for Buyers in High-Technology Markets," Joumal of Marketing, 59 (3), 30-43.

- Hennig-Thurau, Thorsten and Alexander Klee (1997), "The Impact of Customer Satisfaction and Relationship Quality on Customer Retention: A Critical Reassessment and Model Development," Psychology \& Marketing. 14 (8), 737-64.

- Hensel, Paul J. and Gordon C. Bruner (1992), "Scaling and Measurement: Multi-ltem Scaled Measures in Sales Related Research," Joumal of Personal Selling and Sales Management, 12 (3), 77-82.

- Herzberg. Frederick (1968), "One More Time: How Do You Motivate Employees," Hanvand Business Review. (1). 53-62.

- Hildebrandt, Lutz (1987). "Consumer Retail Satisfaction in Rural Areas: A Reanalysis of Survey Data," Joumal of Economic Psychology, 8 (1), 19-42.

- Hinde, Robert A. (1979), Towands Understanding Relationships. London: Academic Press.

- Hirschman, Elizabeth C. and Morris B. Holbrook (1982), "Hedonic Consumption: Emerging Concepts, Methods and Propositions," Joumal of Marketing, 46 (3), 92-101.

- Hoekstra, Janny C. (1994), "Direct marketing: van respons tot relatie," inaugural speech. University of Groningen.

- -...-(1998), Direct Marketing: CE modulen. Groningen: Wolters-Noordhoff.

- Hofstede, Geert (1980), "Culture's Consequences: International Differences in Work-Related Values," in Cross Cultural Research and Methodology Series, volume 5, Walter J. Lonner and John W. Berry, eds. Beverly Hills: Sage Publications.

- Hofstee. Willem K.B., Boele de Raad, and Lewis R. Goldberg (1992), "Integration of the Big Five and Circumplex Approaches to Trait Structure," Joumal of Personality and Social Psychology, 63 (1). 146-63.

- Holbrook, Morris B. and Elizabeth C. Hirschman (1982). "The experiential Aspects of Consumption: Consumet Fantasies, Feelings, and Fun," Joumal of Consumer Research, 9, (September), 132-40.

- Homer, Pamela M. and Lynn R. Kahle (1988), "A Structural Equation Test of the Value-Attitude-Behaviot Hierarchy," Joumal of Personality and Social Psychology, 54 (4), 638-46.

- Hong. Keum-Hee and Margaret Rucker (1995). "The Role of Product Type and Consumer Fashion Involvement in Clothing Satisfaction," Joumal of Consumer Satisfaction, Dissatisfaction and Complaining Behavior, 8, 198-207.

- Houston. Franklin S. (1986). "The Marketing Concept: What it is and What It is Not," Joumal of Marketing, 50 (2), 81-87.

- -... and Jule B. Gassenheimer (1987), "Marketing and Exchange," Joumal of Marketing, 51 (4), 3-18.

- Howard, John A. (1989), Consumer Behavior in Marketing Strutegy. Englewood Cliffs, NJ: Prentice Hall.

- ... and Jagdish N. Sheth (1969), The Theory of Buyer Behavior. New York: John Wiley and Sons.

- Howard, Daniel J., Charles Gengler, and Ambuj Jain (1995), "What's in a Name? A Complimentary Means of Persuasion," Joumal of Consumer Research, 22 (2), 200-11. 
Howell, Roy D. (1987), "Covariance Structure Modeling and Measurement Issues: A Note on 'Interrelations Among a Channel Entity's Power Sources'," Joumal of Manketing Research, 24 (February), 119-26.

- Hughes, Arthur M. (1991). The Complete Database Manketer. Tapping Your Customer Base to Maximize Sales and Increase Profits. Chicago/llinois: Probus Publishing Company.

- Hunt, Shelby D. and John R. Nevin (1974), "Power in a Channel of Distribution: Sources and Consequences," Jowmal of Marketing Reseanch, 11 (2), 186-93.

- _- Van R. Wood, and Lawrence B. Chonko (1989). "Corporate Ethical Values and Organizational Commitment in Marketing." Joumal of Marketing, 53 (3), 79-90.

- Hupperz. John W.. Sidney J. Arenson, and Richard H. Evans (1978), "An Application of Equity Theory to BuyerSeller Exchange Situations," Joumal of Marketing, 15 (2), 250-60.

- Hutt. Michael D. and Thomas W. Speh (1992), Business Marketing Management - A Strategic View of Industrial and Ongarizational Markets. Forth Worth: The Dryden Press.

- lacobucci, Dawn, Kent A. Grayson, and Amy L. Ostrom (1994). "The Calculus of Service Quality and Customer Satisfaction: Theoretical and Empirical Differentiation," in Advances in Senvices Marketing and Management: Research and Practice, 3. Teresa A. Swartz, David E. Bowen, and Stephen W. Brown, eds. Greenwich/London: JAl Press, 1-67.

- - and Amy L. Ostrom (1996), "Commercial and Interpersonal Relationships; Using the Structure of Interpersonal Relationships to Understand Individual-to-Individual, Individual-to-Firm, and Firm-to-Firm Relationships in Commerce," Intemational Joumal of Research in Marketing. 13 (1), 53-72.

- lacobucci, Dawn and Jonathan D. Hibbard (forthcoming), "Toward an Encompassing Theory of Business Marketing Relationships (BMRs) and Interpersonal Commercial Relationships (ICRs): An Empirical Generalization," Joumal of Interactive Marketing.

- Jaccard, James and Choi K. Wan (1996), LISREL Approaches to Interaction Effects in Multiple Regression. Thousand Oaks: Sage Publications.

- Jackson, Barbara Bund (1985), "Build Customer Relationships that Last," Harvard Business Review, 63 (6), 120 8.

- Jacoby, Jacob and Robert W. Chestnut (1978), Brand Loyalty: Measurement and Management. New York: John Wiley and Sons, Inc.

- - and David B. Kyner (1973), "Brand loyalty Vs. Repeat Purchasing Behavior," Joumal of Marketing Research. $10(1), 1-9$.

- Jain. Kapil and Narasimhan Srinivasan (1990), "An Empirical Assessment of Multiple Operationalizations of Involvement," in Advances in Consumer Research, 17. Marvin Goldberg. Gerald Gorn and Richard Pollay, eds. Provo, UT: The Association for Consumer Research, 594-602.

- James, E. Lincoln and Hairong Li (1993), "Why Do Consumers Open Direct Mail? Contrasting Perspectives," Joumal of Direct Marketing. 7 (2), 34-40.

- Javalgi, Raajshekhar and Christopher R. Moberg (1997), "Service Loyalty: Implications for Service Providers," The Joumal of Services Marketing, 11 (3), 165-79.

- Jaworski. Bernard J. and Ajay K. Kohli (1993), "Market Orientation: Antecedents and Consequences," Joumal of Marketing, 57 (3), 53-70.

- Jenkinson, Angus (1995), Valuing Your Customers. From Quality Information to Quality Relationships Through Database Marketing, London: McGraw-Hill.

- Johnson, Jean L. (1999), "Strategic Integration in Industrial Distribution Channels: Managing the Interfirm Relationship as a Strategic Asset," Joumal of the A cademy of Marketing Science, 27 (1), 4-18.

- Tomoscki Sakano, Joseph A. Cote, and Naoto Onzo (1993). "The Exercise of Interfirm Power and Its Repercussions in U.S.-Japanese Channel Relationships," Joumal of Marketing, 57 (2), 1-10.

- Johnson, Michael D. Eugene W. Anderson, and Claes Fornell (1995), "Rational and Adaptive Performance Expectations in a Customer Satisfaction Framework," Joumal of Consumer Research, 21 (4), 695-707.

- Joreskog. Karl G. and Dag Sorrbom (1989), LISREL 7: A Guide to the Program and Applications. Chicago: Jöreskog and Sörbom/SPSS Inc.

- and - (1993), LISREL 8: Stnactural Equation Modeling with the SIMPLIS Command Language. Chicago. IL: Scientific Software International. 
- Jittner. Uta and Hans Peter Wehrli (1994), "Relationship Marketing from a Value System Perspective," Intemational Joumal of Service Industry Management, 5 (5), 54-73.

\section{K}

- Kahle, Lynn R. (1983), Social Values and Social Change: A daptation of Life in America. New York: Pracger.

- - Sharon E, Beatty, and Pamela Homer (1986), "Alternative Measurement Approaches to Consumer Values The List of Values (LOV) and Values and Life Style (VALS)," Joumal of Consumer Research. 13 (December). 405-9.

- -... Manohar U. Kalwani, and Donald G. Morrison (1986), "Measuring Varicty Seeking and Reinforcement Behaviors Using Panel Data," Joumal of Marketing Research, 23 (2), 89-100.

- Kahn, Barbara E. (1998), "Dynamic Relationships With Customers: High Variety Strategies," Joumal of the Academy of Markting Science, 26 (1), 45-53.

- Kale. Sudhir H. (1986), "Dealer Perceptions of Manufacturer Power and Influence Strategies in a Developing Country," Joumal of Marketing Research, 23 (November), 387-93.

- Kalwani, Manohar U. and Narakesari Narayandas (1995), "Long-Term Manufacturer-Supplier Relationships: Do They Pay Off for Supplier Firms?," Joumal of Marketing, 59 (January), 1-16.

- Kamakura, Wagner A. and José Afonso Maznon (1991), "Value Segmentation: A Model for the Measurement of Values and Value Systems," Joumal of Consumer Research. 18 (September), 208-18.

- - and Thomas P. Novak (1992), "Value-System Segmentation: Exploring the Meaning of LOV," Joumal of Consumer Research, 19 (June), 119-32.

- Kaplan, Robert W. and Dennis P. Saccuzro (1982), Psychological Testing: Principles, Applications, and lsaes, Monterey, CA: Brooks/Cole.

- Kardes, Frank R. (1999), Consumer Behavior \& Managerial Decision Making. Reading/Massachusetts: Addison Wesley.

- Kasper; Hans (1982), "Marketing en Consumentensoevereiniteit. Een Onderzoek naar de Invloed van Consumentenklachten op de Strategie van de Onderneming," doctoral dissertation, Free University of Amsterdam.

- - (1999), Services Marketing Management, An Intemational Perspective. New York: John Wiley and Sons.

- Keep, William W., Stanley C. Hollander, and Roger Dickinson (1998), "Forces Impinging on Long-Term Business-to-Business Relationships in the United-States: A Historical Perspective," Joumal of Marketing. 62 (2), $31-45$.

- Keith, Janet E., Donald W. Jackson, and Lawrence A. Crosby (1990), "Effects of Alternative Types of Influence Strategies under Different Channel Dependence Structures," Joumal of Marketing. 54 (3), 30-41.

- Kelley, R.F. (1967), "Estimating Ultimate Performance Levels of New Retail Outlets," Joumal of Marketing Research, 4 (February), 13-9.

- Kelley, Scott W, and Mark A. Davis (1994), "Antecedents to Customer Expectations for Service Recovery." Joumal of the A cademy of Marketing Science, 22 (1), 52-61.

- Kelley. Harold H. and John W. Thibaut (1978), Interpersonal Relations, New York: John Wiley and Sons.

- Keng. Kau Ah and Andrew S.C. Ehrenberg (1984), "Patterns of Store Choice," Joumal of Marketing Research, 21 (4). 399-409.

- Kerlinger, Fred N. (1986), Foundations of Behavioral Research. Fort Worth: Harcourt Brace Jovanovich College Publishers.

- King. Charles W. and Lawrence J. Ring (1980), "Market Positioning Across Retail Fashion Institutions: A Comparative Analysis of Store Types," Joumal of Retalling, 56 (1), 37-55.

- Kirkpatrick, L.A. and K.E. Davis (1994), "Attachment Style, Gender, and Relationship Stability: A Longitudinal Analysis," Joumal of Personality and Social Psychology, 66, 502-12.

- Kline, Barbara and Janet Wagner (1994), "Information Sources and Retail Buyer Decision-Making: The Effect of Product-Specific Buying Experience," Joumal of Retailing, 70 (1), 75-88.

- Kokkinaki, Flora and Peter Lunt (1997). The Relationship Between Involvement, Attitude Accessibility and Attitude Behaviour Consistency." British Joumal of Psychology, 36, 497-509.

- Korgaonkar, Pradeep K., Daulat Lund, and Barbara Price (1985), "A Structural Equations Approach Toward Examination of Store Attitude and Store Patronage Behavior," Joumal of Retailing, 61 (2), 39-60.

- Kotler, Philip (1992), "It's Time for Total Marketing," Business Week Advance, Executive brief 2.

- (1997), Marketing Management: Analysis, Planning, Implementation, and Control. New Jersey: Prentice Hall International.

- _. and Sidney J. Levy (1969), "Broadening the Concept of Marketing." Joumal of Marketing. 33 (January). 10-5. 
Krapfel, Robert E., Deborah Salmond, and Robert Spekman (1991), "A Strategic Approach to Managing BuyerSeller Relationships," European Joumal of Marketing. 25 (9), 22-37.

- Krishnamurthi, Lakshman and S.P. Raj (1991). "An Empirical Analysis of the Relationship Between Brand Loyalty and Consumer Price Elasticity," Marketing Science, 10 (2), $172-83$.

- Kumar, Ajith and William R. Dillon (1987), "The Interaction of Measurement and Structure in Simultaneous Equation Models with Unobserved Variables," Joumal of Marketing Research, 24 (1), 98-105.

- Kumar, V.. Amit Ghosh, and Gerard J. Tellis (1992), "A Decomposition of Repeat Buying," Marketing Letters, 3 (4), 407-17.

- Kumar, Nirmalya, Lisa Scheer, and Jan-Benedict EM. Steenkamp (1995a), "The Effects of Supplier Faimess on Vulnerable Resellers," Joumal of Marketing Research, 32 (1), 54-65.

- - - and - (1995b), "The Effects of Perceived Interdependence on Dealer Attitudes," Joumal of Marketing Research, 32 (3), 348-56.

- Louis W. Stern, and Ravi S. Achrol (1992), "Assessing Reseller Performance From the Perspective of the Supplier," Joumal of Marketing Research, 29 (2), 238-53.

L

- Lagace, Rosemary R., Robert Dahlstrom, and Jule B. Gassenheimer (1991), "The Relevance of Ethical Salesperson Behavior on Relationship Quality: The Pharmaceutical Industry." Joumal of Personal Selling \& Sales Management, 11 (4), 39-47.

- Lam, Simon S.K. and Ka Shing Woo (1997), "Measuring Service Quality: A Test-Retest Reliability Investigation of SERVQUAL," Joumal of the Market Research Sociery, 39 (2), 381-96.

- Larzeiere, Robert E. and Ted L. Huston (1980). "The Dyadic Trust Scale: Toward Understanding Interpersonal Trust in Close Relationships," Joumal of Mamiage and the Family, X (August), 595-604.

- Lastovicka, John L. and David M. Gardner (1979), "Components of Involvement," in A tritude Research Plays for High Stakes, J.C. Maloney and B. Silverman, eds. Chicago: American Marketing Association, 53-73.

- Laurent. Gilles and Jean-Noel Kapferer (1985), "Measuring Consumer Involvement Profiles," Joumal of Marketing Research, 22 (1), 41-53.

- Lehtinen, Uolevi and Tuula Mittila (1995), "One More Time: A Conceptual Framework for Relationship Marketing." in Proceedings of the Seventh Bi-Annual World Marketing Congress, Ken Grant and Ian Walker, eds. Melbourne: Monash University, 1/35-1/42.

- Leuthesser, Lance (1997), "Supplier Relational Behavior: An Empirical Assessment," Industrial Marketing Management, 26 (3), 245-54.

- Levitt, Theodore (1983), "After the Sale is Over," Harvard Business Review, 61 (September/October), 87-93.

- Lewin, Jeffrey E. and Wesley J. Johnston (1997), "Relationship Marketing Theory in Practice: A Case Study." Joumal of Business Research, 39 (1), 23-31.

- Lewis, M. Christine and Douglas M. Lambert (1991). "A Model of Channel Member Performance, Dependence, and Satisfaction," Joumal of Retailing, 67 (2), 205-25.

- Liljander, Veronica and Tore Strandvik (1993), "Estimating Zones of Tolerance in Perceived Service Quality and Perceived Service Value," Intemational Joumal of Senvice Industry Management, 4 (2), 6-28.

- Lovelock, Christopher H. (1983) "Classifying Services to Gain Strategic Marketing Insights," Joumal of Marketing. 47 (Summer) 9-20.

- Low, Brian Koon Huat (1996), "Long-Term Relationship in Industrial Marketing - Reality or Rhetoric?," Industrial Marketing Management, 25 (1) 23-35.

- (1997), "Managing Business Relationships and Positions in Industrial Networks," Industrial Marketing Management, 26, 189-202.

- Lund, Mary (1985), The Development of Investment and Commitment Scales for Predicting Continuity of Personal Relationships," Joumal of Social and Personal Relationships, 2, 3-23.

- Lusch, Rober F. and James R. Brown (1996), "Interdependency, Contracting, and Reiational Behavior in Marketing Channels," Joumal of Marketing, 60 (October), 19-38.

\section{M}

Macintosh, Gerrard and James W. Gentry (1995), "Cognitive Process Differences between Discrete and Relational Exchange," Intemational Business Review, 4 (4), $435-46$.

- and Lawrence S. Lockshin (1997), "Retail Relationships and Store Loyalty: A Multi-Level Perspective," Intemational Joumal of Research in Marketing, 14 (5), 487-97. 
- MacNeil, lan R. (1978), "Contracts: Adjustment of Long-Term Economic Relations under Classical, Neoclassical and Relational Contract Law," Nonthwestem Univensiry Law Review, 72 (6), 854-905.

- ... (1980). The New Social Contract. New Haven/London: Yale University Press.

- Maddi, Salvatore R. (1989), Personaliry Theories, A Comparutive Approach. Pacific Grove, California: Brooks/Cole Publishing Company.

- Malhotra, Naresh K. (1996), Marketing Research, An A pplied Orientation. Second edition, Upper Saddle River, New Jeney: Prentice Hall.

- Marcoulides George A. and Randall E. Schumacker (1996), Advanced Structumal Equation Modeling, Issues and Techniques. Mahwah: Lawrence Erlbaum Associates Publishers.

- Martin, Warren S. (1978), "Effects of Scaling on the Correlation Coefficient: Additional Considerations," Joumd of Marketing Research, 15 (2), 304-8.

- Maslow, Abraham H. (1970), Motivation and Personality. New York : Harper \& Row Publishers.

- Mason, Joseph Barry, Richard M. Durand, and James L. Taylor (1983), "Retail Patronage: A Causal Analysis of Antecedent Factors", in Patronage Behavior and Retail Management, William R. Darden and Rober F. Lusch. eds.. North-Holland, New York.

- Mathieu, John E. and Dennis M. Zajac (1990), "A Review and Meta-Analysis of the Antecedents, Correlates, and Consequences of Organizational Commitment," Psychological Bulletin, 108 (2), $171-94$.

- Matthyssens, Paul and Christophe Van den Bulte (1994), "Getting Closer and Nicer: Partnerships in the Supply Chain." Long Range Planning, 27 (1), 72-83.

- Mattson, Bruce E. (1982), "Situational Influences on Store Choice," Joumal of Retailing, 58 (3), 46-58.

- Mayer, Charles S. and Cindy Piper (1982), "A Note on the Importance of Layout in Self-Administered Questionnaires," Joumal of Marketing Research, 19 (3), 390-1.

- McCort, J. Daniel (1994), "A Framework for Evaluating the Relational Extent of a Relationship Marketing Strategy: The Case of Non-Profit Organizations," Joumal of Dinect Marketing, 8 (2), 53-65.

- MeCrae, Robert R. and Paul T. Costa, Jr. (1987), "Validation of the Five-Factor Model of Personality Across Instruments and Observers," Joumal of Personality and Social Psychology, 52 (1), 81-90.

- - and .... (1989), "The Structure of Interpersonal Traits: Wiggin's Circumplex and the Five-Factor Model," Joumal of Personality and Social Psychology, 56 (4), 586-95.

- MeCutcheon, Shannon and Paul Wang (1995), "Leveraging Database Marketing to Create a More CustomerFocused Organization," Joumal of Database Marketing, 3 (1), 68-76.

- McGahan, Anita M. and Pankaj Ghemawat (1994), "Competition to Retain Customers," Marketing Science, 13 (2), 165-76.

- McKenna, Regis (1995), "Real-Time Marketing," Havand Business Review. 73 (4), 87-95.

- Metcalf, Lynn E., Carl R. Frear, and R. Krishnan (1992), "Buyer-Seller Relationships: An Application of the IMP Interaction Model," European Joumal of Marketing, 26 (2), $27-46$.

- Miethe, Terance D. (1985), "The Validity and Reliability of Value Measurements," The Joumal of Psychology. 119 (5), 441-53.

- Miller, Kenneth E. and Kent L. Granzin (1979), "Simultaneous Loyalty and Benefit Segmentation of Retail Store Customers," Joumal of Retailing, 55 (1), 47-60.

- Mittal, Banwari (1995), "A Comparative Analysis of Four Scales of Consumer Involvement," Psychology and Marketing, 12 (7), 663-82.

- _.. and Walfried M. Lassar (1996), "The Role of Personalization in Service Encounters," Joumal of Retailing. 72 (1). 95-109.

- _.. and Myung-Soo Lee (1989), "A Causal Model of Consumer Involvement," Joumal of Economic Psychology. $10(3), 363-89$.

- Mohr, Jakki J., Robert J. Fisher and John R. Nevin (1996), "Collaborative Communication in Interfirm Relationships: Moderating Effects of Integration and Control," Joumal of Marketing, 60 (3), 103-15.

- - -.- and John R. Nevin (1990), "Communication Strategies in Marketing Channels: A Theoretical Perspective," Joumal of Marketing. 54 (4), 36-51.

- Möller, Kristian and Aino Halinen-Kaila (1998), "Relationship Marketing: Its Disciplinary Roots and Future Directions," in Proceedings of the 27th EMAC Conference, Per Andersson, ed. Stockholm: European Marketing Academy, 289-310.

- Moorman. Christine, Rohit Desphande, and Gerald Zaltman (1993), "Factors Affecting Trust in Market Research Relationships," Joumal of Marketing, 57 (1), 81-101. 
- Gerald Zaltman, and Rohit Deshpandé (1992), "Relationships Between Providers and Users of Market Research: The Dynamics of Trust Within and Between Organizations," Joumal of Marketing Reseanch, 58 (August). 20-38.

- Morgan, N.A. (1991), "Corporate Legal Advice and Client Quality Perceptions," Marketing Inteilligence and Planning, $8(6), 33-9$.

- Morgan, Robert M. and Shelby D. Hunt (1994), "The Commitment-Trust Theory of Relationship Marketing," Joumal of Marketing, 58 (3), 20-38.

- Morgan, Michael S. and Chekitan S. Dev (1994), "An Empirical Study of Brand Switching for a Retail Service," Joumal of Retailing. 70 (3), 267-82.

- Morris, Michael H. and Jeanne L. Holman (1988), "Source Loyalty in Organizational Markets: A Dyadic Perspective," Joumal of Business Research, 16 (2), 117-31.

- Mowday, R.T. (1991), "Equity Theory Predictions of Behavior in Organizations," in Motivation and Work Behavior, R.M. Steers and L.W. Porter, eds. New York: McGraw-Hill, III-3I.

- Mowen, John C. (1990), Consumer Behavior. New York: Macmillan Publishing.

- Mudambi, Ram and Susan McDowell Mudambì (1995). "From Transaction Cost Economics to Relationship Marketing: A Model of Buyer-Supplier Relations," Intemational Business Review, 4 (4), 419-33.

- Murphy. Kevin R. and Charles O. Davidshofer (1988), Psychological Testing: Principles and Applications. Englewood Cliffs, NJ: Prentice Hall.

- Murphy, Brian, Keith Stevens, and Robert McLeod (1997), "A Stakeholderism Framework for Measuring Relationship Marketing," Joumal of Marketing Theory and Practice, 5 (2), 43-57.

- Narver, John C. and Stanley F. Slater (1990), "The Effect of a Market Orientation on Business Profitability," loumal of Marketing, 54 (4), 20-35.

- Nash, Edward (1993), Database Marketing. The Ultimate Marketing Tool. New York: McGraw-Hill.

- Naumann, Earl and Patrick Shannon (1992), "What is Customer-Driven Marketing?," Business Horizons, 35 (6), $44-52$.

- - (1995), Creating Customer Value. Cincinnati, OH: Thompson Executive Press.

- Nevin, John R. (1995), "Relationship Marketing and Distribution Channels: Exploring Fundamental Issues," Joumal of the A cademy of Marketing Science, 23 (4), 327-34.

- Newman, Joseph W. and Richard A. Werbel (1973), "Multivariate Analysis of Brand Loyalty for Major Houschold Appliances," Joumal of Marketing Reseanch, 10 (4), 404-9.

- Nielson, Charles C. (1998), "An Empirical Examination of the Role of "Closeness" in Industrial Buyer-Seller Relationships," European Joumal of Marketing, 32 (5/6), 441-63.

- Noordewier. Thomas G.. George John, and John R. Nevin (1990), "Performance Outcomes of Purchasing Arrangements in Industrial Buyer-Vendor Relationships," Joumal of Marketing. 54 (October), 80-93.

- Novak, Thomas P. and Bruce MacEvoy (1990), "On Comparing Alternative Segmentation Schemes: The List of Values (LOV) and Values and Life Styles (VALS)," Joumal of Consumer Research, 17 (June), 105-09.

- Nunnally, Jum C. (1967), Psychometric Theory. New York: McGraw-Hill.

- (1978), Psychometric Theory. New York: McGraw-Hill.

- _.- and 1.H. Bernstein (1994). Psychometric Theory. New York: McGraw-Hill.

O'Brien, Louise and Charles Jones (1995), "Do Rewards Really Create Loyalty?." Harvand Business Review. (May-June), 75-82.

- Odekerken-Schröder, Gaby and Kristof De Wulf (1999), "Relationship Marketing in a Consumer Context," working paper. University of Maastricht.

- Marcel van Birgelen. Jos Lemmink, Ko de Ruyter, and Martin Wetzels (2000), "Moments of Sorrow and Joy: An Empirical Assessment of the Complementary Value of Critical Incidents in Understanding Customer Service Evaluations," European Soumal of Marketing, forthcoming.

- O'Guinn. Thomas C. and Ronald Faber (1989), "Compulsive Buying: A Phenomenological Exploration." Journal of Consumer Research, 16 (September), 147-157.

- Oliva, Terence A., Richard L. Oliver, and lan C. MacMillan (1992), “A Catastrophe Model for Developing Service Satisfaction Strategies," Joumal of Marketing. 56 (3), 83-95. 
- Oliver, Richard L. (1980), "A Cognitive Model of the Antecedents and Consequences of Satisfaction Decisions, Joumal of Marketing Reseanch, 17 (4), 460-9.

- -... (1981), "Measurement and Evaluation of Satisfaction Processes in Retail Settings," Joumal of Retailing, 5? (3), 25-48.

- - (1993), "A Conceptual Model of Service Quality and Service Satisfaction: Compatible Goals, Differeat Concepts," in Advances in Services Marketing and Management: Research and Practice, 3, Teresa A. Swarts David E. Bowen and Stephen Brown, eds. Greenwich/London: JAI Press, 65-85.

- _- (1997), Satisfaction. A Behaviomal Perspective on the Consumer. New York: McGraw-Hill.

- .-. and John E. Swan (1989), "Consumer Perceptions of Interpersonal Equity and Satisfaction in Transactions. A Field Survey Approach." Joumal of Marketing, 53 (2), 21-35.

- Olsen Janeen E. and Kent L. Granzin (1992), "Gaining Retailers" Assistance in Fighting Counterfeiting. Conceptualization and Empirical Test of a Helping Model," Joumal of Retailing, 68 (1), 90-109.

- O'Reilly, Charles A. and Jennifer Chatman (1986), "Organizational Commitment and Psychological Attachment: The Effects of Compliance, Identification, and Internalization on Prosocial Behavior," Joumal of Applind Psychology. 71 (3), $492-99$.

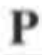

- Page, Narelle and Byron Sharp (1997), "Relationships in Consumer Markets? A Typology of Transaction Types," in Proceedings of the 26th EMA C Conference. Warwick: European Marketing Academy, 922-32.

- Palmer, Adrian (1995), "Relationship Marketing: a New Philosophy for Marketing or a New Function?" Proccedings of the Seventh Bi-Annual World Marketing Congress. Ken Grant and lan Walker, eds. Monash University: Melboume, 15/130-4.

- Pandya, Anil and Nikhilesh Dholakia (1992), "An Institutional Theory of Exchange in Marketing," Europran Joumal of Marketing, 26 (12), 19-41.

- Parasuraman, A. (1991), Marketing Research, second edition. Reading. Massachusetts et al.: Addison-Wesley Publishing Company.

- _.- (1997), "Reflections on Gaining Competitive Advantage Through Customer Value," Joumal of the Academy of Marketing Science, 25 (2), 154-61.

- .... Valarie A. Zeithaml, and Leonard L. Berry (1985), "A Conceptual Model of Service Quality and its Implications for Future Research," Joumal of Marketing, 49 (4), 41 -50.

- ........., and - (1988), "SERVQUAL: A Multiple-Item Scale for Measuring Consumer Perceptions of Service Quality," Joumal of Retailing, 64 (1), 12-37.

_ _........, and - (1991), "Refinement and Reassessment of the SERVQUAL Scale," Joumal of Retailing, 67 (4). 420-50.

- .... - ...., and .... (1993), "Research Note: More on Improving Service Quality Measurement," Joumal of Retailing, 69 (1), 104-7.

_ .......... and … (1994a), "Reassessment of Expectations as a Comparison Standard in Measuring Service Quality: Implications for Further Research," Joumal of Marketing, 58 (1), 111-24.

_ _ _-...... and -... (1994b), "Alternative Scales for Measuring Service Quality: A Comparative Assessment Based on Psychometric and Diagnostic Criteria." Joumal of Retailing, 70 (3), 201-30.

- Park, Jong-Won and Jiho Choi (1998), "Comparison Standards in Consumer Satisfaction Formation: Involvenent and Product Experience as Potential Moderators," Joumal of Consumer Satisfaction. Dissatisfaction, and Complaining Behavior, II, 28-38.

- Park, C. Whan and Banwari Mittal (1985), "A Theory of Involvement in Consumer Behavior: Problems and Issues," in Reseanch in Consumer Behavior, 1, Jagdish N. Sheth, ed., Greenwich. CT: Jai Press, 201-31.

- Park, Kathryn A. and Everett Waters (1988), "Traits and Relationships in Developmental Perspective", in Handbook of Personal Relationships, Steve W. Duck, ed. New York: John Wiley \& Sons Lid.

- Parker, Richard and G. Ray Funkhouser (1997), "The Consumer as an Active Member of the Channet: Implications for Relationship Marketing," Joumal of Marketing Theory and Practice, 5 (2), $72-9$.

- Peabody Dean and Lewis R. Goldberg (1989), "Some Determinants of Factor Structures From Personality-Trat Descriptors," Joumal of Personality and Social Psychology, 57 (3), 552-67.

- Pearson, Stewart (1994), "How to Achieve Return on Investment from Customer Loyalty - Part II." Joumal of Targeting, Measurement and Analysis for Marketing, 3 (2), $124-32$.

- Peelen, Ed. Harry Commandeur, and Erik Jan Hultink (1996), Multimedia in de Marketingstrategie. Bunnik: F\&G Publishing. 
- Pelon, Lou E, David Strutton and James R. Lumpkin (1997), Marketing Channels: A Relationship Management A pproach. Boston: Irwin, McGraw-Hill.

- Peppers, Don and Martha Rogers (1993), The One-to-One Future. Building Business Relationships one Customer ar Time. London: Piatkus.

- - and - (1995), "A New Marketing Paradigm: Share of Customer, not Market Share," Planning Review, 23 (2). 14-20.

- Perrien, Jean, Pierre Filiatrault and Line Ricard (1993), "The Implementation of Relationship Marketing in Commercial Banking," Industrial Marketing Management, 22, 141-8.

- - Sylvie Paradis, and Peter M. Banting (1995), "Dissolution of a Relationship: The Salesforce Perception," Industrial Marketing Management, 24 (4), 317-27.

- - and Line Ricard (1995). "The Meaning of a Marketing Relationship: A Pilot Study," Industrial Marketing Manayement, 24 (1), 37-43.

- Peter, J. Paul (1979), "Reliability: A Review of Psychometric Basics and Recent Marketing Practices," Joumal of Marketing Research, 16 (1), 6-17.

- Gilbert A. Churchill, and Tom J. Brown (1993), "Caution in the Use of Difference Scores in Consumer Rescarch." Joumal of Consumer Research, 19 (4), 655-62.

- - - and Jerry C. Olson (1996), Consumer Behavior and Marketing Strutegy. Chicago: Irwin.

- Peterson, Roben A. (1994), "A Meta-Analysis of Cronbach's Coefficient Alpha," Joumal of Consumer Research. 21 (2), 381-91.

- - (1995), "Relationship Marketing and the Consumer," Joumal of the Academy of Marketing Science, 23 (4), 278-81.

- Petrison, Lisa A., Robert C. Blattberg, and Paul Wang (1993), "Database Marketing: Past, Present, and Future," loumal of Direct Manketing. 7 (3), 27-43.

- Pierce, Gregory R., Irwin G. Sarason, Barbara R. Sarason, Jessica A. Solky-Butzel, and Lauren C. Nagle (1997), "Assessing the Quality of Personal Relationships," Joumal of Social and Personal Relationships, 14 (3), 339-56.

- Pine, B. Joseph, Don Peppers, and Martha Rogers (1995), "Do You Want to Keep Your Customers Forever?," Harvard Business Review, 73 (2), 103-14.

- Ping. Robert A. (1993), "The Effects of Satisfaction and Structural Constraints on Retailer Exiting. Voice, Loyalty, Opportunism, and Neglect," Joumal of Retailing, 69 (3). $320-52$.

- - (1994), "Does Satisfaction Moderate the Association between Alternative Attractiveness and Exit Intention in a Marketing Channel?." Joumal of the Academy of Marketing Science, 22 (4), 364-71.

- - (1995), "A Parsimonious Estimating Technique for Interaction and Quadratic Latent Variables," Journal of Marketing Research, 32 (August), 336-47.

- - (1997), "Voice in Business-to-Business Relationships: Cost-of-Exit and Demographic Antecedents", Journal of Retailing, 73 (2), 261-81.

- Pitts, Robert E. and Arch G. Woodside (1983). "Personal Value Influences on Consumer Product Class and Brand Preferences," The Joumal of Social Psychology, 119. 37-53.

- Popkowski Leszezye, Peter T.L., and Füsun F. Gönül (1996), "Multiple Ways of Measuring Brand Loyalty," Canadian Economics A ssociation, 29, $494-7$.

- -- and Harry J.P. Timmermans (1997), "Store -Switching Behavior," Marketing Letters, 8 (2), 193-204.

- Porter, L.W., R.M. Steers, R.T. Mowday, and P.V. Boulian (1974), "Organizational Commitment, Job Satisfaction, and Turnover among Psychiatric Technicians," Joumal of A pplied Psychology, 59, 603-9.

- Postma, Paul and Cor Molenaar (1988), Database marketing. Amsterdam/Brussels: De Management Bibliotheek.

- Prasad Mishra, Debi, Jan B. Heide, and Stanton G. Cort (1998), "Information Asymmetry and Levels of Agency Relationships," Joumal of Marketing Research, 35 (August), 277-95.

- Pressey, Andrew D. and Brian P. Mathews (1997), "Characteristics of Relationship Marketing and its Applicability to Consumer Transactions: Including Retailing." in Proceedings of the 26th EMAC Conference. Warwick: European Marketing Academy, 1043-57.

- Price, Retha A. (1991), "An Investigation of Path-Goal Leadership Theory in Marketing Channels," Joumal of Retailing, 67 (3), 339-6I.

$\mathbf{R}$

- Raj, S.P. (1982), "The Effects of Advertising on High and Low Loyalty Consumer Segments," Joumal of Consumer Research, 9 (1), 77-89. 
- Ramsey, Rosemary P. and Ravipreet S. Sohi (1997), "Listening to Your Customers: The Impact of Perceived Salesperson Listening Behavior on Relationship Outcomes," Joumal of the Academy of Marketing Science, 35 (2), 127-37.

- Rao, Tanniru R. (1969). "Consumers' Purchase Decision Process: Stochastic Models," Joumal of Marketing Research, 6 (3), 321-9.

- Rapp. Stan and T.L. Collins (1990), The Grat Marketing Tumaround: The Age of the Individual and How so Profit from it. Englewood Cliffs: Prentice-Hall.

- Ratchford, Brian T. (1987), "New Insights About the FCB Grid," Joumal of Advertising Reseanch, 27 (Augus. September), 24-38.

- Reichheld, Frederick F, (1993), "Loyalty-Based Management," Harvand Business Review, 71 (2), 64-73.

- - (1996), The Loyalty Effect. The Hidden Force behind Growth, Profits, and Lasting Value. Boston: Harvand Business School Press.

- - and W. Earl Sasser (1990), "Zero Defections: Quality Comes to Services," Hanvand Business Review, 68 (September-October), 105-11.

- Rempel, John K.. John G. Holmes, and Mark P. Zanna (1985), "Trust in Close Relationships," Joumal of Personality and Social Prychology, 49 (1), 95-112.

- Reynolds, Fred D., William R. Darden, and Warren S. Martin (1974/1975), "Developing an Image of the StoreLoyal Customer," Joumal of Retailing, 50 (4), 73-84.

- Robbins, George W. (1947), "Notions About the Origins of Trading," Joumal of Marketing. 11 (3), 228-36.

- Robicheaux, Robert A. and James E. Coleman (1994). "The Structure of Marketing Channel Relationships," Joumal of the A cademy of Marketing Science, 22 (1), 38-51.

- Rodgers, William C. and Kenneth C. Schneider (1993), "An Empirical Evaluation of the Kapferer-Laureat Consumer Involvement Profile Scale," Psychology \& Marketing. 10 (4), 333-45.

- Rokeach, Milton (1973), The Nanure of Human Values. New York: Free Press.

- Rosenberg, Larry J, and John A. Czepiel (1984), "A Marketing Approach for Customer Retention," The Joumd of Consumer Marketing, 45-51.

- - and L.W. Stern (1971), "Conflict Measurement in the Distribution Channel," Joumal of Markering Reseanch. 8 (November), 437-42.

- Ruekert, R.W. and G.A. Churchill (1984), "Reliability and Validity of Alternative Measures of Channel Member Satisfaction," Joumal of Marketing Research, 21 (May), 226-33.

- Rusbult, Caryl E. (1980), "Commitment and Satisfaction in Romantic Associations: A Test of the Investment Model," Joumal of Experimental Social Psychology, 16 (2), $172-86$.

- ... (1983), "A Longitudinal Test of the Investment Model: The Development (and Deterioration) of Satisfaction and Commitment in Heterosexual Involvement," Joumal of Personality and Social Psychology, 45 (1). 101-17.

- Rust, Roland T. and Anthony J. Zahorik (1993), "Customer Satisfaction, Customer Retention, and Market Share", Joumal of Retailing, 69 (2), 193-215.

- Rylander, David. David Strutton, and Lou E. Pelton (1997). "Toward a Synthesized Framework of Relational Commitment: Implications for Marketing Channel Theory and Practice," Joumal of Marketing Theory and Practice, 5 (2), 58-71.

Sadowski, Cyril, J. and Helen E. Cogburn (1997), "Need for Cognition in the Big-Five Factor Structure," The Joumal of Psychology, 131 (3), 307-12.

- Salancik, Gerald R. and Jeffrey Pfeffer (1978), "Uncertainty, Secrecy, and the Choice of Similar Others," Socid Psychology, 41 (3), 246-55.

- Samli, A. Coskun (1975), "Use of Segmentation Index to Measure Store Loyalty," Joumal of Retailing, 51 (1), 51 60.

- Saxe, Robert and Barton A. Weitz (1982), "The SOCO Scale: A Measure of the Customer Orientation of Salespeople," Joumal of Marketing Research, 19 (3), 343-51.

- Scheer, Lisa and Louis Stern (1992), "The Effect of Influence Type and Performance Outcomes on Artitude toward the influencer," Joumal of Marketing Research. 29 (1), 128-42.

- Schiffman, Leon G. and Leslie L Kanuk (1987), Consumer Behavior. Englewood Cliffs: Prentice-Hall.

- Schijns, Jos M.C. (1999). "Het Meten en Managen van Klant-Organisatie Relaties", doctoral dissertation. Maastricht University. 
- _- and Gaby J. Schroder (1996), "Segment Selection by Relationship Strength," Joumal of Direct Marketing, 10 (3). 69.79 .

- Schienker, Barry R., Bob Helm, and James T. Tedeschi (1973). "The Effects of Personality and Situational Variables on Behavioral Trust," Joumal of Personality and Social Psychology, 25 (3), 419-27.

- Scholl. Richard W. (1981), "Differentiating Organizational Commitment for Expectancy as a Motivating Force," Academy of Management Review, 6, 589-99.

- Schul, Patrick L., Taylor E. Little, and William M. Pride (1985), "Channel Climate: Its Impact on Channel Member' Satisfaction," Joumal of Retailing. 61 (2), 9-38.

- Schurr, Paul H. and Julie L. Ozanne (1985), "Influences on Exchange Processes: Buyers" Preconceptions of a Seller's Trustworthiness and Bargaining Toughness," Joumal of Consumer Research, 11 (March), 939-53.

- Schwartz, Shalom H. (1992), "Universals in the Content and Structure of Values: Theoretical Advances and Empirical Tests in 20 Countries," Advances in Experimental Social Psychology. 25, 1-65.

- - and Wolfgang Bilsky (1987). "Toward A Universal Psychological Structure of Human Vahues," Joumal of Penonality and Social Psychology, 53 (3). 550-62.

- _- and - (1990), "Toward a Theory of the Universal Content and Structure of Values: Extensions and CrossCultural Replications," Joumal of Personality and Social Psychology, 58 (5), 878-91.

- Selnes, Fred (1998), "Antecedents and Consequences of Trust and Satisfaction in Buyer-Seller Relationships," Earopean Joumal of Marketing. 32 (3/4), 305-22.

- Shani, David and Sujana Chalasani (1992), "Exploiting Niches Using Relationship Marketing," Joumal of Services Marketing, 6 (4), 43-52.

- Sharma, S., S. Durvasula and William R. Dillon (1989), "Some Results on the Behavior of Altemate Covariance Structure Estimation Procedures in the Presence of Non-Normal Data," Joumal of Markering Research, 26, 214. 21 .

- Sharma, Arun and Jagdish N. Sheth (1997), "Relationship Marketing: An Agenda for Inquiry," Industrial Marketing Management, 26, 87-9.

- Sharp, Byron and Anne Sharp (1997). "Loyalty Programs and their Impact on Repeat-Purchase Loyalty Patternsas, Intemational Joumal of Research in Marketing, 14 (5), 473-86.

- Sheth, Jagdish N. (1994), "The Domain of Relationship Marketing," briefing paper for the AMA Faculty Consortium on Relationship Marketing. Atlanta: Emory University Center for Relationship Marketing.

- - and Atul Parvatiyar (1995a), "The Evolution of Relationship Marketing," Intemational Business Review, 4 (4). $397-418$.

- - and - (1995b), "Relationship Marketing in Consumer Markets: Antecedents and Consequences," Joumal of the Academy of Marketing Science, 23 (4), 255-71.

- - and Arun Sharma (1997), "Supplier Relationships," Industrial Marketing Management, 26 (2), 91-100.

- Shim, Soyeon and Mary Ann Eastlick (1998), "The Hierarchical Influence of Personal Values on Mall Shopping Attitude and Behavior," Joumal of Retailing, 74 (1), 139-60.

- Siguaw, Judy A., Penny M. Simpson, and Thomas L. Baker (1998), "Effects of Supplier Market Orientation on Distributor Market Orientation and the Channel Relationship: The Distributor Perspective," Joumal of Marketing. 62 (July), 99-111.

- Simpson, Jeffry A., Steven W. Gangestad, and Margaret Lerma (1990), "Perception of Physical Attractiveness: Mechanisms Involved in the Maintenance of Romantic Relationships," Joumal of Personality and Social Psychology, 59 (6), 1192-201.

- Sirohi, Niren, Edward W. McLaughlin, and Dick R. Wittink (1998), "A Model of Consumer Perceptions and Store Loyalty Intentions for a Supermarket Retailer," Joumal of Retailing, 74 (2), 223-45.

- Skinner. Steven J., Jule B. Gassenheimer, and Scott W. Kelley (1992), "Cooperation in Supplier-Dealer Relations," Joumal of Retailing, 68 (2), 175-93.

- - - and Joseph P. Guiltinan (1985), "Perceptions of Channel Control," Joumal of Retailing. 61 (4), 65-88.

Slama, Mark E and Armen Tashchian (1985), "Selected Socioeconomic and Demographic Characteristics Associated with Purchasing Involvement," Joumal of Marketing. 49 (1), 72-82.

- Smith, J. Brock and Donald W. Barclay (1997). "The Effects of Organizational Differences and Trust on the Effectiveness of Selling Partner Relationships," Joumal of Marketing, 61 (1), 3-21.

- Solomon, Michael R. (1987). "The Wardrobe Consultant: Exploring the Role of a New Retailing Partner," Joumal of Retailing, 63(1), 110-28.

- Carol Surprenant, John A. Czepiel, and Evelyn G. Guttman (1985), "A Role Theory Perspective on Dyadic Interactions: The Service Encounter," Joumal of Marketing. 49 (1), 99-1II. 
- Spekman, Robert E. (1988), "Strategic Supplier Selection: Understanding Long-Term Buyer RelationshipxBusiness Horizons, (July-August), 75-81.

- Sprecher, Susan (1988), "Investment Model, Equity, and Social Support Determinants of Relationahip Commitment," Social Psychology Quarterly. 51 (4), 318-28.

- Spreng. Richard A. and Robert D. Mackoy (1996), "An Empirical Examination of a Model of Perceived Service Quality and Satisfaction," Joumal of Retailing. 72 (2), 201-14.

- Stanley, Scott M. and Howard J. Markman (1992), "Assessing Commitment in Personal Relationships," Joumal of Marriage and the Family, 54, 595-608.

- Steenkamp, Jan-Benedict E.M. and Hans C.M. van Trijp (1991), "The Use of LISREL in Validating Marketing Constructs," Intemational Joumal of Research Marketing, 8, 283-99.

- Stern, Louis W. and Torger Reve (1980), "Distribution Channels as Political Economies: A Framework for Comparative Analysis," Joumal of Marketing, 44 (Summer), 52-64.

- Stewart, David W. (1981), "The Application and Misapplication of Factor Analysis in Marketing Research," Joumal of Marketing Research, 18 (1), 51-62.

- Stone, Gregory P. (1954). "City Shoppers and Urban Identification: Observations on the Social Psychology of City Life," American Joumal of Sociology, 60, 36-45.

- Stone, Merlin. Neil Woodcock, and Muriel Wilson (1996), "Managing the Change from Marketing Planning to Customer Relationship Management," Long Range Planning. 29 (5), 675-83.

- Storbacka. Kaj. Tore Strandvik, and Christian Grönroos (1994), "Managing Customer Relationships for Profit The Dynamics of Relationship Quality." Intemational Joumal of Service Industry Management. 5 (5), 21-38.

- Strandvik, Tore and Veronica Liljander (1994), "Relationship Strength in Bank Services," in Research Conference Pmceedings. Relationship Marketing: Theory, Methods and Applications. Jagdish N. Sheth and Atul Parvatiyar, eds. Atlanta: Emory University.

- Stum. David L. and Alain Thiry (1991), "Building Customer Loyalty," Truining and Development Joumd, (April), 34-6.

- Stump, Rodney L. and Ven Sriram (1997), "Employing Information Technology in Purchasing: Buyer-Seller Relationships and Size of the Supplier Base," Industrial Marketing Management, 26, 127-36.

- Sullivan, Jeremiah and Richard B. Peterson (1982), "Factors Associated with Trust in Japanese-American Joint Ventures," Management Intemational Review, 22 (2), 30-40.

- Sudman, Seymour (1980), "Improving the Quality of Shopping Center Sampling," Joumal of Marketing Researh, $17(4), 423-31$.

- Surprenant, Carol F. and Michael R. Solomon (1987), "Predictability and Personalization in Service Encounter." Joumal of Marketing, 51 (2), 86-96.

- Swan, John E., Michael R. Bowers, and Lynne D. Richardson (1999), "Customer Trust in the Salesperson: An Integrative Review and Meta-Analysis of the Empirical Literature," Joumal of Business Research, 44, 75-92.

- Swinyard, William R. (1993), "The Effects of Mood, Involvement, and Quality of Store Experience on Shopping Intentions," Joumal of Consumer Research, 20 (2), 271-80.

- Tate, Russell S. (1961), "The Supermarket Battle for Store Loyalty," Joumal of Markering, 25 (October), 8-13.

- Tauber, Edward M. (1972). "Why Do People Shop?," Joumal of Marketing, 36 (October), $46-59$.

- Tax. Stephen S.. Stephen W. Brown, and Murali Chandrashekaran (1998), "Customer Evaluations of Service Complaint Experiences: Implications for Relationship Marketing," Joumal of Marketing, 62 (2), $60-76$.

- Taylor, Steven A. and Thomas L. Baker (1994), "An Assessment of the Relationship Between Service Quality and Customer Satisfaction in the Formation of Consumers' Purchase Intentions," Joumal of Retailing. 70 (2), $163-78$.

- Teas, R. Kenneth (1993), "Expectations, Performance Evaluation and Consumer's Perceptions of Quality," Joumal of Marketing, 57 (October), 18-34.

- Thibaut, John W. and Harold H. Kelley (1959), The Social Psychology of Groups. New York: John Wiley and Sons.

- Tigert, Douglas J.. Lawrence R. Ring, and Charles W. King (1976). "Fashion Involvement and Buying Behavior. A Methodological Study." in Advances in Consumer Research, 3, Beverly B. Anderson. ed. Provo, UT: The Association for Consumer Research, 46-52.

- Treacy, Michael and Fred Wiersema (1993), "Customer Intimacy and Other Value Disciplines," Harvand Business Review, (January/February), 84-93. 
Tucker, L and C. Lewis (1973), "A Reliability Coefficient for Maximum Likelihood Factor Analysis," Prychometrika, 38 (1). 1-10.

Turnbull, Peter W. and David T. Wilson (1989), "Developing and Protecting Profitable Customer Relationships," Industrial Marketing Management, 18, 233-8.

\section{$\mathbf{U}$}

Ulrich, Dave (1989), "Tie the Corporate Knot: Gaining Complete Customer Commitment," Sloan Management Review, (Summer), 19-27.

- Uncles, Marc and Gilles Laurent (1997), "Editorial," Intemational Joumal of Research in Marketing, 14 (5), 399. 404.

- Usunier, Jean-Claude (1993), Intemational Marketing - A Cultural A pproach. Englewood Cliffs, NJ: Prentice Hall International.

\section{V}

- Van der Walt, Nicolas, Don Scott, and Arch G. Woodside (1994), "CPA Service Providers: A Profile of Client Types and Their Assessment of Performance," Joumal of Business Research, 31 (2/3), 225-33.

- Van Kenhove, Patrick, Kristof De Wulf, and Walter van Watenschoot (1999), "The Impact of Task Definition on Store Attribute Saliences and Store Choice," Joumal of Retailing, forthcoming.

- Van Lange, Paul A.M., Christopher R. Agnew, Fieke Harinck, and Gemma E.M. Steemers (1997), "From Game Theory to Real Life: How Social Value Orientation Affects Willingness to Sacrifice in Ongoing Close Relationships," Joumal of Personality and Social Psychology, 73 (6), 1330-44.

- ...., Caryl E. Rusbult, Stephen M. Drigotas, Ximena B. Arriaga, Betty S. Witcher, and Chante Cox (1997). "Willingness to Sacrifice in Close Relationships," Joumal of Personality and Social Psychology, 72 (6), 1373-95.

- Varadarajan, P. Rajan and Margaret H. Cunningham (1995). "Strategic Alliances: A Synthesis of Conceptual Foundations," Joumal of the A cademy of Marketing Science, 23 (4), 282-96.

- Venetis, Karin A. (1997), Senvice Quality and Customer Loyalty in Professional Service Relationships, Ph.D. Dissertation, Maastricht University: Maastricht.

- Verhallen, Theo M.M. and Gert Jan de Nooij (1982), 'Retail Attribute Sensitivity and Shopping Patronage", Joumal of Economic Psychology, 2(1), 39-55.

- Villani. Kathryn E. and Yoram Wind (1975), "On the Usage of 'Modified' Personality Trait Measures in Consumer Research," Joumal of Consumer Reseanch. 2 (December), 223-8.

- Voss, Glenn B. and Zannie Giraud Voss (1997), "Implementing a Relationship Marketing Program: A Case Study and Managerial Implications," The Joumal of Services Management. 11 (4), 278-298.

\section{W}

- Webster. Frederick E. (1992), "The Changing Role of Marketing in the Corporation," Joumal of Marketing. 56 (4), 1-17.

- (1994a). "Defining the New Marketing Concept," Marketing Management, 2 (4), 23-31.

- - (1994b). "Executing the New Marketing Concept," Marketing Management, 3 (1), 9-16.

- Weiers, Ronald M. (1988), Marketing Reseanch. Englewood Cliffs, NJ: Prentice-Hall International.

- Weitz, Barton E. and Sandy D. Jap (1995), "Relationship Marketing and Distribution Channels," Joumal of the Academy of Marketing Science, 23 (4), 305-20.

- Westbrook, Robert A. and William C. Black (1985), "A Motivation-Based Shopper Typology," Joumal of Retailing, 61 (1), 78-103.

- Wetzels, Martin G.M. (1998), "Service Quality in Customer-Employec Relationships", doctoral dissertation, Maastricht University.

- Williams, L.J. and J.T. Hazer (1986) "Antecedents and Consequences of Satisfaction and Commitment in Turnover Model: A Reanalysis Using Latent Variable Structural Equation Methods". Journal of Applied Psychology, 71 (2), 219-31.

- Williamson. Oliver E. (1975), Markets and Hierarchies: A nalysis and Antitnst Implications. New York: Free Press.

- (1979). "Transaction Cost Economics: The Governance of Contractual Relationships," Joumal of Law and Economics, 22, 223-60.

- (1985), The Economic Institutions of Capitalism. New York: Free Press. 
- Wilson, David T. (1995), "An Integrated Model of Buyer-Seller Relationships," Joumal of the Acodemy of Marketing Science, 23 (4), 335-45.

- Wilson, Jan (1994), Marketing Interfaces - Exploring the Marketing and Business Relationship. London: Pitman Publishing.

- Wish, Myron, Morton Deutsch, and Susan J. Kaplan (1976), "Perceived Dimensions of Interpersonal Relations," Joumal of Penonality and Social Psychology, 33 (4), 409-20.

- Woodruff, Robert B., Emest R. Cadotte, and Roger L. Jenkins (1983), "Modeling Consumer Satisfactioe Processes Using Experience-Based Norms," Joumal of Marketing Research, 20 (3), 296-304.

- 1997), "Customer Value: The Next Source for Competitive Advantage," Joumal of the Academy of Marketing Science, 25 (2), 139-53.

- Wray, Barry, Adrian Palmer, and David Bejou (1994), "Using Neural Network Analysis to Evaluate Buyer-Seller Refationships," Eumopean Joumal of Marketing, 28 (10), 32-48.

Y

- Yau, Olivier H.M. (1988), "Chinese Cultural Values: Their Dimensions and Marketing Implications," European Joumal of Marketing, 22 (5), 44-57.

- Yim, Chi Kin (Bennett) and P.K. Kannan (1999), "Consumer Behavioral Loyalty: A Segmentation Model and Analysis," Joumal of Business Research, 44, 75-92.

- Yoo, Changjo, Jonghee Park, and Deborah J. Macinnis (1998), "Effects of Store Characteristics and In-Store Emotional Experiences on Store Attitude," Joumal of Business Research, 42 (3), 253-63.

- Young Louise C. and Sara Denize (1995), "A Concept of Commitment: Alternative Views of Relational Continuity in Business Service Relationships," Joumal of Business \& Industrial Marketing, 10 (5), 22-37.

- ..- and Ian F. Wilkinson (1989), "The Role of Trust and Cooperation in Marketing Channels: A Preliminary Study," European Joumal of Marketing, 23 (2), 109-22.

- Yu, Julie and Harris Cooper (1983), "A Quantitative Review of Research Design Effects on Response Rates to Questionnaires," Joumal of Marketing Research, 20 (1), 36-44.

- Zaichkowsky, Judith Lynne (1985), "Measuring the Involvement Construct," Joumal of Consumer Research. 12 (3), 341-52.

- Zeithaml, Valarie A. (1988), "Consumer Perceptions of Price, Quality, and Value: A Means-End Model and Synthesis of Evidence," Joumal of Marketing, 52 (3), 2-22.

- ..... Leonard L. Berry, and A. Parasuraman (1993), "The Nature and Determinants of Customer Expectations of Service," Joumal of the Academy of Marketing Science, 21 (1), 1-12.

- Zinkhan, George M. (1994), "Keeping Customers," Joumal of Marketing, 58 (2), 124-5. 


\section{Appendices}





\section{Appendix 1 Theories Underlying Relationship Marketing}

In this appendix, we first discuss three underlying relationship marketing theories that are economically inspired: (1) neoclassical microeconomic theory. (2) transaction cost theory, and (3) relational contracting theory. Second, we describe two more behaviorally inspired theories: (1) social exchange theory and (2) equity theory. Third, the integration of both economic and behavioral elements is touched upon in the discussion of (1) political economy theory and (2) resource dependence theory.

For each theory. we discuss its content and its strengths and limitations. A discussion of theories underlying relationship marketing is not intended to lead to an exhaustive and detailed picture of all possible influencing theories. We limited ourselves to a discussion of those theories that are most commonly referred to in relationship marketing literature.

\section{Economically Inspired Theories}

In this section, neoclassical microeconomic theory. transaction cost theory, and relational contracting theory are described on their content and strengths and limitations.

\section{Neoclassical Microeconomic Theory}

\section{Description}

Neoclassical microeconomic theory depends most heavily on analytical frameworks borrowed from economics. learning theory, statistics, mathematics, psychology, sociology, and cognitive and social psychology (Amdt 1983; Webster 1992).

At the root of managerial and academic marketing literature is the microeconomic paradigm with its emphasis on profit maximization in competitive markets. The mission of the microeconomic perspective is to explain relative prices. market equilibrium, and income distribution (Amdt 1983). Exchange parties are price taken and utility maximizers in price equilibrium markets, under the assumptions of well-defined and stable preference structures where individuals independently worry about creating value (Dabholkar, Johnston, and Cathey 1994; Pandya and Dholakia 1992; Sheth and Parvatiyar 1995a). Neoclassical microeconomic theory states that firms engage in market transactions in order to secure the resources they require for producing goods and services they sell in the competitive marketplace. In addition to the costs associated with the price paid, such market transactions involve other types of transaction costs: searching costs, negotiating and contracting costs, and costs of monitoring supplier performance (Webster 1992).

\section{Strensths and Limitations}

The marketing management tradition based upon the microeconomic maximization paradigm has made a strong point of distinguishing between the environment and controllable decision variables in the marketing mix (Arndt 1983). The microeconomic framework has been very relevant in the development of marketing theory and served a useful purpose in explaining value distribution among marketing actors (Sheth and Parvatiyar 1995a). 
However, several scholars have stated that it is doubtful that research problems faced in the 1990 s can be adequately dealt with on basis of a microeconomic approach centering on costs, functional differentiation, and market structures (Webster 1992). Pandya and Dholakia (1992) criticized the microeconomic framework for its limited applicability to transactional exchange situations. The microeconomic view is inadequate in the sense that it provides insufficient tools for analyzing exchange structures and processes within and between exchange parties (Arndt 1983). Researchers are increasingly hesitant to apply the microeconomic framework to explain marketing exchanges following its many assumptions that seldom occur in practice (Dabholkar, Johnston, and Cathey 1994). For example, Sheth and Parvatiyar (1995b) claim that, contrary to assumptions of microeconomic theory, consumers have a natural tendency to reduce choices. Also the assumption of rational behavior is often not realistic. Economists generally view markets as interpersonal vacuums in which buyers and sellers only know each other in their role dictated by the market (Frenzen and Davis 1990).

\section{Trunsaction Cost Theory}

Transaction cost and resource dependence theories are both related to the economic theory of the firm. This economic theory of the firm explains the continuity of a relationship in terms of the costs and benefits of staying in the relationship versus leaving it (Bendapudi and Berry 1997; Robicheaux and Coleman 1994). While the transactionoriented economic theory of the firm departs from the premise that relationships are built in order to reduce conflict and transaction costs, the resource-based economic theory of the firm states that a company, seen as a collection of productive resources, tries to upgrade these resources as part of an attempt to initiate, develop, and terminate reiationships (Krapfel, Safmond, and Spekman 1991; Williamson 1985). The transaction cost theory parallels the resource dependence theory in that they both consider non-market governance as an adequate response to environmental uncertainty and dependence (Heide 1994: Varadarajan and Cunningham 1995). The tension that exists between a party's needs for resources (the focus of resource dependence theory) and the belief that these needs will be fulfilled in a cost-efficient way by his exchange partner (the focus of transaction cost theory) unites both theories (Andaleeb 1996). Both theories focus on the best responses to various environmental conditions and are not concerned with proactively seeking to change these conditions (Varadarajan and Cunningham 1995). In this section, we discuss the transaction-oriented economic theory of the firm.

\section{Description}

Transaction cost theory uses arguments from micro- and institutional economics, contract law, and organizational theory (Arndt 1983; Heide and John 1992; Robicheaux and Coleman 1994). Its principles have been most often applied to sales organization decisions, market entry decisions, and the structuring of distribution channels and purchase relationships (Heide and John 1992).

In the original transaction cost theory. Coase (1937) classified transactions according to whether they occurred within a firm or across markets. Williamson (1975) further built upon his work by examining the transaction cost advantages of different forms of internally and externally organized transactions within the constraints of bounded rationality and opportunistic behavior (Amdt 1983). At the core of the paradigm are the axioms that certain exchange characteristics give rise to transaction difficulties and that different governance mechanisms vary in their cost-minimizing properties (Heide and John 1992). 
Williamson (1975) indicated that market transactions may become very costly due to human factors, such as bounded rationality and opportunism, and environmental factors, such as uncertainty and economically concentrated input or output markets. Transaction cost theory departs from the assumptions that individuals are limited in their cognitive capabilities and that they are inclined towards opportunistic and seif-interest seeking behavior. Consequently, in situations when information is unequally spread across exchange parties, opportunistic behavior is believed to prevail and exchange may be commercially hazardous (Andaleeb 1992; Stern and Reve 1980). Opportunism has been described by Williamson (1975, p. 6) as "self-interest seeking with guile" and it generally involves deceit as a central clement (Bowen and Jones 1986; Davis 1995: Gundlach, Achrol, and Mentzer 1995; Morgan and Hunt 1994). In order to reduce the risks of being exploited by each other, exchange partners can build in a safeguarding mechanism by making substantial transaction specific investments that are uniquely related to the exchange relationship and that cannot be retrieved in case it terminates (Andaleeb 1992; Ganesan 1994; Dahistrom; MeNeilly and Speh 1996; Wilson 1995). If both partners make such investments, they create incentives to maintain or obstacles to leave the relationship they are in by communicating their credibility of commitment to the relationship (Anderson and Weitz 1992: Dwyer, Schurr, and Oh 1987). Evidently, investments in transaction specific assets also create dependence relationships between exchange partners given the fact that they are difficult or costly to replace (Bowen and Jones 1986; L.ewin and Johnston 1997; Williamson 1985). Organizational economics literature has demonstrated that one-sided investments are open to exploitation as a result of the fact that the specific assets, which are related to these investments, cannot be safeguarded (Ganesan 1994).

Every market transaction involves transaction costs or frictional losses that lead to inefficiencies for the firms engaged in these exchange transactions (Mudambi and Mudambi 1995: Sheth and Parvatiyar 1995a). Such transaction costs include costs associated with information search, reaching a satisfactory agreement, relationship monitoring, adapting agreements to unanticipated contingencies, and contract enforcement (Bowen and Jones 1986; Ganesan 1994; Krapfel. Saimond, and Spekman 1991). Transaction costs can be subdivided into two general dimensions: performance ambiguity and goal incongruence (Bowen and Jones 1986). Because of bounded rationality and the existence of transaction costs, a comprehensive contract related to controlling all aspects of a relationship is not a viable option for partners in a relationship (Ganesan 1994; Sheth and Sharma 1997). Instead, parties have to rely on 'incomplete contracting' involving the development of long-term relationships that permits sequential, adaptive decision making (Ganesan 1994). Transaction costs are minimized by selecting a relationship governance mode that is 'optimal' given transaction properties such as asset specificity, uncertainty, and infrequency and that curbs small numbers bargaining and opportunism (Bowen and Jones 1986; Heide and John 1992; Mudambi and Mudambi 1995; Robicheaux and Coleman 1994: Sheth and Sharma 1997; Varadarajan and Cunningham 1995; Williamson 1985). The extremes in governance modes are arm's length spot-market governance (external governance mechanism) and vertical integration (internal governance mechanism) (Krapfel, Salmond, and Spekman 1991). In arm's length exchange situations, buyers pit sellers against each other in order to achieve lower costs. In vertically integrated exchange situations, buyers and sellers can reduce transaction costs by aligning their objectives and internal systems (Wilson 1995). Williamson (1985) argues that under conditions of asset specificity, opportunism, and uncertainty, transaction costs of arm's length market exchanges are far larger than those of more long-term relational exchanges (Grönroos 1990a: Juttner and Wehrli 1994; Pandya and Dholakia 1992). As a general rule, Bowen and Jones (1986) state that an increase in transaction costs is accompanied by a movement from external to internal govemance mechanisms. While Williamson (1975) initially considered only these two governance structures, he recognized intermediate forms of organization, such as relational contracting, in his later work (Williamson 1985). 


\section{Strengths and Limitations}

A main contribution of the transaction cost framework is its economically rooted assumption that a firm will internalize those activities which it is able to perform at a lower cost and that it will rely on market mechanisms for those activities in which other providers have an advantage (Dabholkar, Johnston, and Cathey 1994). Moreover, the framework helps to identify problems that can arise when idiosyncratic or transaction-specific investments are involved in an exchange relationship (Weitz and Jap 1995).

However, there exists a growing body of criticism towards transaction cost theory and its underlying assumptions. The enthusiasm for the transaction cost theory has almost been matched by the strength of its criticism (Heide and John 1992). Its major limitations that are generally referred to are outlined next.

(1) The unilateral focus of transaction cost theory on the potential costs that are associated with idiosyncratic investments, fails to recognize the potential value that is generated by these investments (Weitz and Jap 1995). Transaction cost theory focuses on one single criterion - cost efficiency - for shaping transactions. The role of other microeconomic criteria tends to be downplayed in most transaction cost analyses (Robicheaux and Coleman 1994). As a result, the term 'transaction costs' should be extended to include also positive returns that can result from exchanges (Houston and Gassenheimer 1987).

(2) Transaction cost analysis does not take into account the interdependencies created between partners in a relationship (Bendapudi and Berry 1997). Transaction cost theory proponents have generally been reluctant to acknowledge the potential contributions of power-dependence theory.

(3) Transaction cost theory is mainly preoccupied with the conditions that motivate exchange partners to structure relationships in a particular way without specifying the mechanisms that provide the ability to implement these desired structures (Heide and John 1992). Consequently, the transaction cost theory is of a more or less static nature. It focuses on a relationship structure at one moment in time and neglects the possible dynamic evolution of a governance structure and transactions.

(4) The role of people and their importance in the governance of exchanges is virtually ignored by transaction cost analysis (Weitz and Jap 1995).

(5) The fact that transaction cost theory assumes opportunistically inclined parties is overly simplistic and misleading Empirical research demonstrates that human behavior in relationships is not as Machiavellian as described in transaction cost theory (Morgan and Hunt 1994). Arguments drawn from sociology stress that exchange typically is embedded in social structures in which opportunism is the exception rather than the rule. As a result, transaction cost theory has failed to offer predictions about the implications of a deviance from opportunism (Dabholkar, Johnston, and Cathey 1994; Heide and John 1992). Many exchanges are based on a gradual development of trust that helps exchange partners to lower transaction costs by safeguarding against opportunism. The implications of the effect of trusting behavior on governance structures are generally ignored in transaction cost theory.

(6) Transaction cost theory has difficulties in explaining that idiosyncratic investments occur in relationships that are not vertically integrated (Weitz and Jap 1995). Though transaction specific investments play an important role in affecting relationships through creating dependence and locking in customers, they are not sufficient to explain long-term orientation in exchanges (Ganesan 1994). Transaction cost analysis makes no allowance for safeguarding transaction-specific assets other than vertical integration. This is an important omission becaus vertical integration is not always a feasible or relevant strategy (Dahlstrom, McNeilly, and Speh 1996; Robicheaux and Coleman 1994). Anderson and Weitz (1992) indicate that, although vertically integrated exchange parties can 
more effectively coordinate exchanges, quasi-integrated relationship forms based on mutual commitment can be less costly and more flexible.

\section{Relational Contracting Theory}

\section{Dexcription}

Relational contracting theory is primarily based upon contract law (Rylander, Strutton, and Pelton 1997). Contract law applies to the legal rights of exchange parties and guides the planning and conduct of exchange. While classical contract law views exchange as composed of single, independent, and static transactions, modem contract law tries to deal with the dynamic nature of intermediate and long-term exchanges. Modern contract law explicitly refers to exchange planning and contract formation. adjustments to existing contract relationships, and resolution of contractual conflict. Many researchers have questioned the contemporary relevance and theoretical inconsistencies of elassical contract law for explaining modern exchanges.

The relational contracting theory proposed by MacNeil (1980) provides a rich conceptual framework that is able to capture the dimensions and dynamics that underlie the nature of exchange relationships as well as the belief structures and activities that are necessary for successful exchange relationships (Nevin 1995). MacNeil (1980) distinguishes intermediate types of exchange between discrete transactions and complete internalization of exchanges (Gundlach and Murphy 1993; Pandya and Dholakia 1992). He refers to such intermediate forms of exchange as 'contractual ways of exchange' or 'relational transactions' where exchange parties are still independent but at the same time coupled by weak or strong contractual agreements (MacNeil 1978; Pandya and Dholakia 1992), Since a pure reliance on the law mechanism can be costly in terms of both resources and time and since unforescen circumstances can affect the exchange relationship, extra-legal governance methods are needed (Nevin 1995). In line with this, MacNeil (1980) defines the concept of contract very broadly in the sense that it means nothing more than a relationship between exchange parties who expect to sustain this relationship into the future (Robicheaux and Coleman 1994). To MacNeil (1980), contracts are about exchange because contracts capture the relations among parties and these relations project exchange into the future (Nevin 1995).

MacNeil's (1980) relational contracting framework describes types of contracts in terms of the norms they share (Krapfel, Salmond, and Spekman 1991). Norms are expectations about behavior that are at least partially shared by a group of decision makers (Dwyer, Schurr, and Oh 1987: Heide and John 1992: Houston and Gassenheimer 1987; Weitz and Jap 1995). They can differ in content and general orientation and may relate to particular kinds of behaviors. For example, while norms can be oriented towards a more discrete versus a more relational nature (general orientation), relational norms may be translated into several different behaviors such as flexibility, mutuality, consistency, solidarity, creation and use of power, and information exchange (Heide and John 1992; Krapfel, Salmond. and Spekman 1991; MacNeil 1980). A general propenty of relational norms is their prescription of behaviors that are aimed at maintaining a relationship and their rejection of behaviors that promote individual goal seeking (Heide and John 1992). During an exchange act, buyers and sellers often establish norms that did not exist prior to this exchange (Dwyer, Schurr, and Oh 1987).

Contracts can be based on either the traditional promise of contract law (promissory norms) or more relation-based promises (non-promissory norms) (Nevin 1995). MacNeil (1980) argues that formal contracts guided by promissory norms do not play a substantial role in most relationships. Rather, it is the set of understandings among exchange 
partners or the 'implicit contract' guided by non-promissory norms that substantially affects relationships (Anderson and Weitz 1992). Parties who engage in exchanges based upon implicit contracts are less in need of monitoring their exchange partners or building safeguards in the relationship (Andaleeb 1996).

\section{Sirrngths and Limitations}

Relational contracting theory deals with the criticisms that have been directed at transaction cost theory by including social dimensions of exchange and by making elear that hierarchical relationship govemance mechanisms are not the only mechanisms available. Consequently, the theory of relational contracting offers a valuable complement to Williamson's (1975) transaction cost approach (Robicheaux and Coleman 1994).

Relational exchange theory has been criticized for failing to preseribe optimal types of governance to deal with specific characteristics of the exchange. Until now, relational exchange theory has mainly been used for descriptive and conceptual purposes.

\section{Behavionally Inspired Theories}

In this section, social exchange theory and equity theory are described on their content and their strengths and limitations.

\section{Social Exchange Theory}

\section{Description}

People are believed to use cognitive schema to organize their perceptions of social interactions and relationships. There are many schools of researchers and vast literature examining the structure of such perceptions (lacobucci and Ostrom 1996). The ideas that are at the basis of social exchange theory are mainly derived from marital theory, bargaining theory, and power theory (Dwyer, Schurr, and Oh 1987). Moreover, the qualities of interpersonal relationships have been extensively investigated in disciplines such as psychology and social psychology.

One of the most popular theories of relationships is social exchange theory (Fischer and Bristor 1994). This theory explicitly compares the formation and continuity of a relationship with those of a marriage and places the interactions between people and organizations at the core of relationships (Dwyer, Schurr, and Oh 1987; Levitt 1983; Metcalf. Frear and Krishnan 1992; Perrien and Ricard 1995). Given the importance it attaches to interactions, social exchange theory has inspired the development of the interaction approach of the Industrial Marketing and Purchasing (IMP) group. The IMP group of researchers has examined the dynamics of interaction quite extensively. Their interaction approach focuses on exchange episodes that are embedded in a framework of a relationship in which the parties adapt to one another in order to produce mutually beneficial outcomes (Grönroos 1994a: Krapfel, Salmond, and Spekman 1991: Nielson 1998; Wilson 1995). It views marketing as an interactive process occurring in a social context where relationship management is central (Gronroos 1994a). The IMP Group considered the concept of interaction as a series of short-term social interactions that are affected by the long-term business process or atmosphere that binds exchange parties together. They concluded that a model characterized by cooperation was a better representation of the data they collected than a model characterized by conflict and opposition (Wilson 1995). The interaction approach suggested six 
different types of bonds: social, technological, knowledge, planning, legal, and economic bonds (Stortacka, Strandvik, and Grönroos 1994a).

While some scholars use love or marriage as a metaphor for the type of relationship that should exist between a buyer and a seller, others have actually drawn on marriage theories to conceptualize buyer-seller exchange processes (Fisher and Bristor 1994: Fournier 1998). Dwyer, Schurr, and Oh (1987, p. 14) argue that "research analyzing the interpersonal urraction and the interdependence relationships between husbands and wives provides an apt framework for describing the evolution of buyer-seller relations". When acting according to social norms, members usually expect reciprocal benefits in the form of personal affection, trust, gratitude, and sometimes economic returns (Morgan and Hunt 1994: Sheth and Parvatiyar 1995b). Social norms are generally defined as expectations regarding behavior (Gundlach. Achrol, and Mentzer 1995). Bagozzi (1995) views reciprocity as an essential feature of self-regulation and mutual coordination in exchange relationships. It is the social mechanism by which actions of one party evoke compensating xtions by the other party (Houston and Gassenheimer 1987).

Self-interest and relationship outcome evaluation are at the basis of maintaining and exploiting relationships (Oliver and Swan 1989: Smith and Barclay 1997). As is stated by Fischer and Bristor (1994, p. 329); "Social exchange theory sxplicitly predicts social relationships to be based on each partner's motivational investment and anticipated social pain". The general objective of parties in interpersonal relationships is to derive benefits from their relationship that vould not be achievable on their own. These benefits can include non-economic rewards and even altruistic rewards derived from increasing their partner's utility (Andaleeb 1992; Weitz and Jap 1995). Especially the interpersonal unction literature directed a lot of its attention at rewards flowing from perceived similarity or complementary resources such as money, information, or status (Dwyer, Schurr, and Oh 1987). Frenzen and Davis (1990) distinguish between two types of utilities related to a purchase: 'acquisition utility' derived from the product or service itself and 'exchange utility' derived from strong relationships between exchange partners.

Thibaut and Kelley (1959) distinguished between positive and negative motivations for engaging in and maintaining exchange relationships. This corresponds with the views of Bendapudi and Berry (1997), Ganesan (1994), and Morgan and Hunt (1994) who are in favor of considering both desires and constraints as relationship determining factors. Bendapudi and Berry (1997) and Stanley and Markman (1992) classify relationship marketing theories into dedicationbased and constraint-based ones according to the importance that these theories attribute to negative respectively positive motivations for enhancing relationships. Thibaut and Kelley (1959) posited two constructs as bases for evaluating relationship outcomes: (1) 'comparison level' or the quality of outcomes expected from experience and knowledge with similar relationships and (2) 'comparison level for alternatives' or the average quality of outcomes from the best alternative that is still above the level of acceptance. According to them, comparing outcomes by comparison leveis determines the attractiveness of a relationship and the degree of relationship satisfaction, while comparing outcomes by comparison levels for alternatives determines relationship dependence (Anderson and Narus 1984: Wilson 1995). As a consequence, power is explicitly integrated in the framework of Thibaut and Kelley (1959): the more dependent one party is, the more the other party can influence the quality of this party's outcomes.

The basic conceptual tool that is used by Kelley and Thibaut (1978) for evaluating relationship outcomes is this matrix. In this cutcome matrix, the behavior of one party is crossed with the resultant outcome of this behavior given the other party's behavior. Kelley and Thibaut (1978) make a distinction between the given and the effective matrix. While the given matrix is determined by environmental and personal factors that are external to the interdependence relationship. this matrix is re-conceptualized into an effective matrix through communication and transformation processes. One 
party can increase its satisfaction with the other party by making use of the transformations available to that parn (Oliver and Swan 1989).

\section{Strneths and Limitations}

While resource dependence theory can be regarded as a constraint-based relationship theory. social exchange theon can be considered as a dedication-based relationship theory (Bendapudi and Berry 1997: Stanley and Markman 1992), As already mentioned before, constraint-based relationship theories are mainly based on negative motivations for initiating and maintaining relationships, while dedication-based relationship theories are generally derived from positive motivations for enhancing relationships. Ganesan (1994) and Morgan and Hunt (1994) stress the importance of addressing both types of theories in order to fully understand the relationship formation and continuity process.

Dwyer, Schurr. and Oh (1987) criticize social exchange theory for not being able to explain the processes related to relationship dissolution.

\section{Equity Theory}

\section{Dexcription}

Equity theory is related to social exchange theory, relative deprivation theory, and distributive justice theory given their unifying basic premise that outcomes should be evaluated in a relative sense within some frame of reference (Geyskens 1998).

Equity theory focuses upon outcome evaluations that result from relationships characterized by economic productivity objectives (Adams 1965; Geyskens 1998). Since the theory is referred to as distributive justice in sociological literature, it departs from the norm of distributive justice in dyadic relationships, i.e. the desire on the part of exchange parties to have a fair and just distribution of profits (Huppertz, Arenson, and Evans 1978; Houston and Gassenheimer 1987; Oliver and Swan 1989). Equity theory postulates that parties in exchange relationships compare their ratios of exchange inputs to outcomes. Inequity is said to exist when the perceived inputs and/or outcomes in an exchange relationship are psychologically inconsistent with the perceived inputs and/or outcomes of the referent (Huppertz. Arenson, and Evans 1978).

Since parties sometimes need to evaluate each other before engaging in an exchange, role expectations play a crucial role in determining the equity level of a potential exchange relationship. Each party to the exchange has certain expectations about his own role as well as that of the other party. According to role theory, the fact that each exchange partner has learned a set of behaviors that is appropriate in an exchange context will increase the probability of goal attainment by each partner (Solomon et al. 1985: Wetzels 1998). Role stress can affect long-term relationships if role expectations are unclear (role ambiguity) or if actual behaviors deviate from expectations (role conflict) (Dabholkar. Johnston, and Kathey 1994).

Perceived inequities lead exchange parties to feel under- or over-rewarded, angry, or resentful, affect behavion in subsequent periods by encouraging these parties to change their inputs into the relationship, and result in suspicion and mistrust of the exchange partner (Ganesan 1994; Geyskens 1998; Gruen 1995). Huppertz. Arenson, and Evans (1978) stated that the closer the exchange relationship, the more likely it is that relationship participants will perceive inequity. If equity prevails, the ratio of one's outcomes to inputs is assumed to be constant across exchange partners. which 
results in the satisfaction of exchange partners with their outcomes (Adams 1965; Ganesan 1994; Lewin and Johnston 1997; Oliver and Swan 1989). Equitable outcomes stimulate confidence that parties do not take advantage of each other and that they are concerned about each other's welfare (Ganesan 1994). Parties in a relationship can compare their own ratio to (1) the one of their exchange partner, (2) those of others who interact with their exchange partner at the same level, and (3) the one of their best alternative exchange partner (Bagozzi 1986; Geyskens 1998).

Though both equity and disconfirmation are comparison processes, these processes are viewed as conceptually distinct and complementary. While one's outcomes and inputs are compared to those of the other party in equity processes, outcomes in general are compared to one's expectations for those outcomes in expectancy disconfirmation processes (Huppertz, Arenson, and Evans 1978; Oliver and Swan 1989). Moreover, equity theory is fundamentally different from consumer behavior's cognitive dissonance theory. While cognitive dissonance research primarily focused on the relationship between a person and a product, equity theory research is concerned with a group process and an equitable distribution of benefits (Huppertz, Arenson, and Evans 1978),

\section{Strengths end Limitations}

A major strength of equity theory is that it explicitly recognizes the inherent inequality between exchange partnen. In case roles are disparate, theories of distributive justice or what has come to be known as expectation states theory are useful paradigms for understanding exchange relationships. These theories require only that each party has expectations of the role of the other party and interpret justice in terms of how well this other party performs on his role dimensions. Equity theory is considered to be more useful in commercial exchange situations than social exchange theory with its assumption of equal partners to the exchange. Moreover, it appears to provide a useful framework for understanding consumer behavior (Huppertz, Arenson, and Evans 1978).

As a result of the fact that contradictory findings were generated with respect to the effects of over-rewarding parties in a relationship, equity theory declined in research popularity and application (Geyskens 1998: Mowday 1991). An important shortcoming of equity theory is the absence of a unifying framework that can explain both positive as well as negative effects of over-rewarding (Geyskens 1998).

\section{Economically/Behaviorally Inspired Theories}

In this section, political economy theory and resource dependence theory are described on their content and their strengths and limitations

\section{Political Economy Theory}

\section{Description}

The political economy paradigm integrates economic efficiency theories of organizations with behavioral power theories (Stern and Reve 1980). It basically is an institutional analysis based on political science, sociology, and organization theory (Amdt 1983: Pandya and Dholakia 1992). Central notions within the political economy framework are borrowed from social exchange theory, the behavioral theory of the firm, and transaction cost theory. Moreover. political economy theory is related to many of the sub-fields within marketing. For instance, the macro-marketing 
school addresses the environmental sphere in the paradigm. The consumerlecologist activist sub-field similarly focuse on the interplay of environmental conditions and corporate response (Amdt 1983).

The political economy framework has most often been used in order to conceptualize structure and process in channels of distribution (Krapfel, Salmond, and Spekman 1991; Ping 1993; Stem and Reve 1980). However, several authon claim that it offers solid potential for better understanding all types of relationships and alliances in marketing (Amdt 1983: Krapfel, Salmond, and Spekman 1991). As Amdt (1983, p. 51) states, "in consumer behavior analyses, the household may be viewed as a special case of small organizations leading to emphasis on goals, power bases, conflict management, and allocation rules".

While the previously discussed theories were either mainly of an economic or a behavioral nature, the political economy theory integrates both economic and behavioral aspects of relationship management. Stern and Reve (1980) were the first to propose political economy theory as a guiding framework for the study of distribution channels. A substantial stream of research followed that relied either explicitly or implicitly on that theory. Political economy theory views "a social system as comprising interacting sets of major economic and sociopolitical forces which affect collective behavior and performance" (Robicheaux and Coleman 1994). Political economy theory focuses on authority and control patterns, conflict and conflict management procedures, and external and intemal determinants of institutional exchange (Arndt 1983: Krapfel, Salmond, and Spekman 1991: Pandya and Dholakia 1992: Robicheaux and Coleman 1994). Political economy analysts evaluate exchanges between parties on basis of three dimensions: (1) polity-economy, (2) external-internal, and (3) substructure-superstructure (Arndt 1983).

An essential characteristic of political economy theory is its simultaneous and interdependent analysis of political and economic systems of production and consumption (Pandya and Dholakia 1992; Stern and Reve 1980). Economy refers to institutions that transform inputs into output and to the processes by which goods and services are allocated within and between institutions (ranging from market to vertical exchange processes). Polity refers to the power and control systems that legitimize, facilitate, monitor, and regulate exchange transactions (ranging from minimal to centralized power) (Amdt 1983; Pandya and Dholakia 1992; Robicheaux and Coleman 1994). The economy and polity can be considered as allocation systems allocating scarce economic resources and power or authority respectively (Stern and Reve 1980).

\section{Strensths and Limitations}

The main contribution of political economy theory results from its dyadic approach that integrates both economic and sociopolitical factors and that explicitly insists that economic and sociopolitical forces are not analyzed in isolation (Dabholkar, Johnston, and Cathey 1994: Stem and Reve 1980). Moreover, the value of the theory lies in its capacity of identifying socioeconomic interactions between exchange partners in terms of their internal structure and external environment (Krapfel, Salmond, and Spekman 1991). Political economy theory is considered to be a more appropriate paradigm than the microeconomic paradigm as it focuses on authority and control pattems, conflict and conflict management procedures, and external and internal determinants of institutional change (Amdt 1983). In contrast to the microeconomic paradigm and its emphasis on prices, political economy theory is better suited for understanding all types of relationships and alliances in marketing (Webster 1992). Amdt (1983) further states that the value of political economy theory results from both its generality and its integrative potential. It is a fairly general theory that can support theory construction in a wide range of marketing areas. It is an integrative one given the fact that it offers a unifying framework in which major economic and sociopolitical constructs can be used for comparing marketing 
relationships. The microeconomic and political economy paradigms are complementary rather than alternatives. The nicroeconomic framework, with its emphasis on controllable variables and problem solving, is appropriate in the sornative marketing management tradition. However, for purposes of building positive theories in marketing, the political economy worldview seems more relevant (Amdt 1983).

An often cited limitation of political economy theory is that the model is so comprehensive that it has proven difficult w apply empirically (Dabholkar, Johnston, and Cathey 1994). As a result of its complexity, political economy theory is often confronted with criticisms reflecting its methodological problems, vagueness, and incompleteness, It specifies many constructs and relationships that are difficult to capture through conventional research methods. At its present level. political economy is more vague and less precise than for instance the microeconomic paradigm. Finally, the paradigm still is incomplete as it may be criticized for putting too little emphasis on performance or goal attainment of scial units in terms of effectiveness and efficiency (Amdt 1983).

\section{Rrsource Dependence Theory}

\section{Description}

The resource-based theory of the firm was developed at the intersection of organizational behavior, economics, and itrategic management and moved beyond the traditional emphasis on the microeconomic paradigm (Webster 1992). The ideas formulated by resource-based theorists are based upon balance power theories, bilateral oligopoly and doopoly theories in economics, and relative deprivation theories of collective conflict (Stern and Reve 1980).

Many theorists regard dependence and power as central to explaining organizational and interpersonal behavior (Andaleeb 1996; Morgan and Hunt 1994). Nevertheless, the traditional discussion of exchange in marketing generally does not focus on differences in negotiation power and the consequently unequal and unsatisfactory nature of exchange transactions. Resource dependence theory explicitly addresses these issues by examining sources of power and dependence in exchange relationships (Pandya and Dholakia 1992). As aiready mentioned, the resource-based economic theory of the firm states that a company, seen as a collection of productive resources, tries to upgrade these resources as part of an attempt to initiate, develop, and terminate relationships (Krapfel, Salmond, and Spekman 1991: Williamson 1985). Several scholars state that, for a relationship to truly exist, interdependence between exchange purtners must exist (Fournier 1998). Emerson (1962) described dependence as the extent to which (1) each party's reward or motivation is reliant upon the reward or motivation received by the other party and (2) the reward or motivation exceeds what would be available outside the relationship.

A lack of self-sufficiency with respect to acquiring and developing resources leads to dependence and introduces uncertainty in a party's decision making environment (Varadarajan and Cunningham 1995). The dependence of a party is intrinsically tied to the power of the other party: when one party in a relationship controls resources that are wanted or needed by the other party, this other party becomes dependent upon the controlling party (Andaleeb 1996; Dwyer. Schurr, and Oh 1987; Ganesan 1994; Wilson 1995). As posited by psychological reactance theory, dependent exchange partners may wish to regain control and influence their power balance by acquiring and defending a secure and adequate supply of critical resources or by developing substitute sources which can reduce their dependence (Andaleeb 1992; Arndt 1983). 
The work of resource dependence theorists suggests that dependencies between exchange partners are a function of multiple factors. Exchange partners become more dependent upon each other as (1) outcomes from an exchange become more important (referred to as criticality), (2) the magnitude or proportion of trade with one partner increases (referred to as quantity), (3) the business is concentrated with fewer partners (referred to as replaceability), and (4) it becomes more difficult to locate potential alternative exchange partners (referred to as slack) (Andaleeb 1992; Krapfel, Salmond, and Spekman 1991). Exchange partners engage in relational behavior through increasing interdependence levels in order to mitigate short-term seif-interest (Emerson 1962). Power-dependence theory suggests that an exchange party's investment in specific assets may constrain its ability to acquire control and may transfer this control to the party receiving the investment (Heide and John 1992). Consequently, resource dependence theory directs our attention at the dangers of increased dependence in terms of increased strategic vulnerability. Improper screening of an exchange relationship can leave exchange partners worse off than if they had engaged in looser arm's length relationships (Krapfel, Salmond, and Spekman 1991).

Stern and Reve (1980) state that, while exchange partners will peacefully coexist and interact co-operatively as long as there remains a balance of power between them, conflict potential and the magnitude of dysfunctional conflict are highest in unbalanced power situations given the exploitation opportunities that result from this imbalance (Anderson and Weitz 1989; Dwyer, Schurr, and Oh 1987; Geyskens 1998). Consistent with bargaining and negotiation biterature. in case of a power imbalance, the high power party will attempt to exploit its advantage and the low power party will become dissatisfied with the relationship (Anderson and Narus 1984; Anderson and Weitz 1989; Ganesan 1994: Varadarajan and Cunningham 1995). Also bilateral deterrence theory suggests that, all else being equal, increasing interdependence asymmetry results in higher levels of aggression and conflict expressed by both parties in a relationship (Kumar, Scheer, and Steenkamp 1995).

\section{Sirnengths and Limitations}

Resource dependence theory is an appropriate framework for many interaction types (Dabholkar, Johnston, and Cathey 1994). It is an economic/behavioral approach centering on conflict and power assuming that goal conflict is inherent in relationships and that exchange partners act to increase their control of and decrease their dependence on other exchange partners (Dabholkar, Johnston, and Cathey 1994).

Resource dependence theory has difficulties explaining long-term exchange relationships resulting from co-ordinative behavior based on trust. Exchange partners can rely on co-operation, collaboration, and co-ordination instead of power. influence and control. Morgan and Hunt (1994, p. 22) express the same concern when they state that "the presence of relationship commitment and trust is central to successful relationship marketing. not power and its ability to 'condition others'". In a channel context. Young and Wilkinson (1989) argued that the primary focus of channel research on power and conflict has distorted our understanding of channel relationships focusing on sick rather than healthy relationships. According to Weitz and Jap (1995), the use of power as a coordinating mechanism is limited to asymmetric relationships - relationships in which one party is more powerful than another (Weitz and Jap 1995). Moreover, resource dependence theory cannot explain why and how exchange relationships are initiated and bow exchange outcomes are evaluated by exchange partners (Dabholkar. Johnston, and Cathey 1994). Proponents of transaction cost theory criticized resource dependence theory for its focus on descriptive issues and its failure to examine the efficiency implications of various structural arrangements (Heide and John 1992). Therefore, Heide and John (1992) suggest to integrate both by augmenting the normative insights from transaction cost analysis with the descriptive insights offered by power-dependence theory. 


\section{Appendix 2 Overview of Empirical Research on Attitudinal} Relationship Outcomes 
Tulle A2-1: Sungery of Rebliomblip Satisfaction Rocarch (perind 1985.1998,

\begin{tabular}{|c|c|c|c|c|c|c|}
\hline $\mathrm{Niv}$ & $\begin{array}{l}\text { Auchor, } \\
\text { bumnal, Year }\end{array}$ & Research Desigw & Consext & Conceptualization & Opentionatisunion & 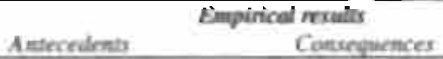 \\
\hline 1. & $\begin{array}{l}\text { Andalect. IR. } \\
1996\end{array}$ & $\begin{array}{l}\text { Laburatory experiment } \\
\text { of } 72 \text { U.S, managers in } \\
\text { role of distributor } \\
\text { reporting on } \\
\text { relationships with } \\
\text { supplier (liqueur) }\end{array}$ & Channel & $\begin{array}{l}\text { An overall positive affect } \\
\text { reflecting the focal } \\
\text { ongmization's overall } \\
\text { contentment regarding its } \\
\text { relationstup with another } \\
\text { purty (p. } 80 \text { ) }\end{array}$ & 3 isems, $\alpha=95$ & $\begin{array}{l}\text { Dependesce }(*) \\
\text { Trust }(*)\end{array}$ \\
\hline 2 & $\begin{array}{l}\text { Anderson and } \\
\text { Narus, M, } 1990\end{array}$ & $\begin{array}{l}\text { Field study of } 213 \text { U.S. } \\
\text { manufacturers reporting } \\
\text { on relationships with } \\
\text { distributors (cross- } \\
\text { section of industries) }\end{array}$ & Channe! & $\begin{array}{l}\text { A positive affective state } \\
\text { resulting from the } \\
\text { appraisal of all aspects of } \\
\text { a firm' s working } \\
\text { relationship with another } \\
\text { firm (p. 45). Based on } \\
\text { Anderson and Narus } \\
\text { (1984, p. 66) }\end{array}$ & 1 item & 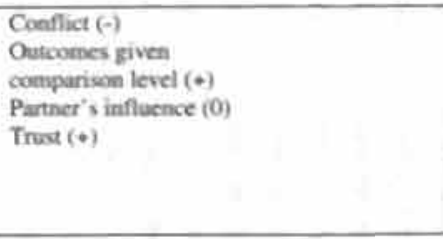 \\
\hline$=$ & $\begin{array}{l}\text { Baker, Simpson, } \\
\text { and Siguaw, } \\
\text { JAMS, } 1999\end{array}$ & $\begin{array}{l}\text { Field study of } 380 \\
\text { suppliers reporting on } \\
\text { relationships with } \\
\text { reselling firms (cross- } \\
\text { section of industries) }\end{array}$ & Channel & $\begin{array}{l}\text { The domain of all } \\
\text { characteristics of the } \\
\text { relationship between a } \\
\text { channel member and } \\
\text { another member in the } \\
\text { channel which the focal } \\
\text { organization finds } \\
\text { rewarding, profitable, } \\
\text { instrumental, and } \\
\text { satisfying (p. 52). Based } \\
\text { on Ruekert and Churchill } \\
\text { (1984,p. 227) }\end{array}$ & 3 items, $\alpha=.88$ & $\begin{array}{l}\text { Perteived market } \\
\text { ancentation }(+)\end{array}$ \\
\hline 4. & $\begin{array}{l}\text { Bolton, MS. } \\
1998\end{array}$ & $\begin{array}{l}\text { Field study of } 650 \\
\text { customers reporting on } \\
\text { relationship with their } \\
\text { service organization } \\
\text { (cellular telephone) }\end{array}$ & $B-1-C$ & $\begin{array}{l}\text { Prior cumulative } \\
\text { satisfaction with the } \\
\text { services received from the } \\
\text { company (p. 55) }\end{array}$ & 1 item & Duration $(+)$ \\
\hline
\end{tabular}




\begin{tabular}{|c|c|c|c|c|c|c|c|}
\hline \multirow[t]{2}{*}{ No. } & \multirow{2}{*}{$\begin{array}{l}\text { A uathor, } \\
\text { Nournal, Year }\end{array}$} & \multirow[t]{2}{*}{ Rexearch Drsign } & \multirow[t]{2}{*}{ Context } & \multirow[t]{2}{*}{ Conceptaalization } & \multirow[t]{2}{*}{ Opentionalization } & \multicolumn{2}{|c|}{ Lmpirical results } \\
\hline & & & & & & Artecedents & Consroquences \\
\hline 5. & $\begin{array}{l}\text { Brown, Johnson } \\
\text { and Koenig. } \\
\text { URM. I995 }\end{array}$ & $\begin{array}{l}\text { Field study of } 78 \text { U.S. } \\
\text { retailers reporting on } \\
\text { relationships with major } \\
\text { suppliers of a particular } \\
\text { product class (cross- } \\
\text { section of industries) }\end{array}$ & Channel & No definition reponed & 1 item & $\begin{array}{l}\text { Conflict ( } 0 \text { ) } \\
\text { Parner's control ( } 0 \text { ) } \\
\text { Partner's coecrive power } \\
\text { use (0) } \\
\text { Parner's assistance ( }(+) \\
\text { Partner's mediated power } \\
(-) \\
\text { Partner's non-mediated } \\
\text { power }(\epsilon)\end{array}$ & \\
\hline 6. & $\begin{array}{l}\text { Crosby. Evans } \\
\text { and Cowles, JM. } \\
1990\end{array}$ & $\begin{array}{l}\text { Field study of ISI U.S. } \\
\text { heads of households } \\
\text { reporting on } \\
\text { relationships with agents } \\
\text { (life insurance) }\end{array}$ & B-10-C & $\begin{array}{l}\text { An emotional state that } \\
\text { occurs in response to an } \\
\text { cvaluation of interaction } \\
\text { experiences (p. 70). Based } \\
\text { on Westbrook (1981) }\end{array}$ & 3 itema, $\alpha=99$ & $\begin{array}{l}\text { Partner's expertise ( }(+) \\
\text { Partner's relational selling } \\
\text { behaviors }(+) \\
\text { Partner's similarity }(*)\end{array}$ & $\begin{array}{l}\text { Amticipation of future } \\
\text { interaction }(*) \\
\text { Partner's vales } \\
\text { effectiveness }(0)\end{array}$ \\
\hline 7. & $\begin{array}{l}\text { Crosby and } \\
\text { Siephens, IMR. } \\
1987\end{array}$ & $\begin{array}{l}\text { Field study of } 1.362 \text { and } \\
447 \text { U.S. heads of } \\
\text { households reporting on } \\
\text { relationships with agents } \\
\text { (life insurance) }\end{array}$ & $B-10-C$ & No definition reponted & 1 item & $\begin{array}{l}\text { Satisfaction with contact: } \\
\text { person }(+) \\
\text { Satisfaction with core } \\
\text { service (*) } \\
\text { Satisfaction with } \\
\text { institution }(+)\end{array}$ & \\
\hline 8. & $\begin{array}{l}\text { Dwyer and Oh. } \\
\text { IMR, 1987. }\end{array}$ & $\begin{array}{l}\text { Field study of } 167 \text { U.S. } \\
\text { dealers reporting on } \\
\text { relationships with } \\
\text { principals (automobiles) }\end{array}$ & Channel & $\begin{array}{l}\text { Giobal cvaluation of } \\
\text { fulfillment in the relation } \\
\text { (p. 352) }\end{array}$ & 4 items, $\alpha=91$ & $\begin{array}{l}\text { Centralization (-) } \\
\text { Formalization }(t) \\
\text { Paricipation is decision } \\
\text { making }(t)\end{array}$ & \\
\hline 9 & $\begin{array}{l}\text { Frazier, Gill and } \\
\text { Kale, IM, } 1989\end{array}$ & $\begin{array}{l}\text { Field study of } 51 \text { Indian } \\
\text { dealers reporting on } \\
\text { relationships with } \\
\text { manufacturers (tungsten } \\
\text { carbide tool industry) }\end{array}$ & Channel & $\begin{array}{l}\text { A channel member's } \\
\text { overall approval of the } \\
\text { channel relationship ( } p \text {. } \\
57 \text { ). Based on Gaski and } \\
\text { Nevin (1985, p. 131) }\end{array}$ & 2 items, $\alpha=80$ & Conflica $(-)$ & \\
\hline 10. & $\begin{array}{l}\text { Fraxier and } \\
\text { Summen. JMR. } \\
1986\end{array}$ & $\begin{array}{l}\text { Ficld study of } \$ 35 \text { U.S. } \\
\text { franchised dealers } \\
\text { reporting on } \\
\text { relationships with } \\
\text { manutacturers } \\
\text { (automobiles) }\end{array}$ & Channel & No definition reponted & 1 isem & $\begin{array}{l}\text { Une of coercive strategies } \\
\text { (-) ino causal relationship } \\
\text { was lestod, only } \\
\text { comelation) }\end{array}$ & \\
\hline
\end{tabular}




\begin{tabular}{|c|c|c|c|c|c|c|}
\hline \multirow[t]{2}{*}{ No. } & \multirow{2}{*}{$\begin{array}{l}\text { A utheir, } \\
\text { loumal, } Y \in e r\end{array}$} & \multirow[t]{2}{*}{ Rrirarh Desigh } & \multirow[t]{2}{*}{ Context } & \multirow[t]{2}{*}{ Concepfualization } & \multirow[t]{2}{*}{ Openutianalization } & Empirical rrults \\
\hline & & & & & & Anteredents Consequences \\
\hline 14. & $\begin{array}{l}\text { Gaski and Nevin, } \\
\text { JMR. } 1985\end{array}$ & $\begin{array}{l}\text { Field study of } 238 \\
\text { dealers and } 43 \text { districı } \\
\text { managers reporting on } \\
\text { relationships with one: } \\
\text { another (heavy industrial } \\
\text { machinery) }\end{array}$ & Channel & $\begin{array}{l}\text { Overall approval of the } \\
\text { channel arrangement (p. } \\
\text { 13i) }\end{array}$ & 5 items, $\alpha=\overline{76}$ & $\begin{array}{l}\text { Partner's non-contingent } \\
\text { cocrave power sources } \\
\text { (0) } \\
\text { Partner's exercise of non- } \\
\text { contingent coencive power } \\
\text { sources }(-) \\
\text { Partner's exercise reward } \\
\text { power source }(4) \\
\text { Partner's reward power } \\
\text { source }(+)\end{array}$ \\
\hline 15. & $\begin{array}{l}\text { Gassenbeimer } \\
\text { and Ramsey, JR, } \\
1994\end{array}$ & $\begin{array}{l}\text { Field study of } 324 \text { U.S. } \\
\text { dealers reporting on } \\
\text { relationships with each } \\
\text { of top three suppliers } \\
\text { (office systems and } \\
\text { furniture) }\end{array}$ & Channel & $\begin{array}{l}\text { A positive affective state } \\
\text { resulting from the } \\
\text { appraisal of all aspects of } \\
\text { a firm's working } \\
\text { relationship with another } \\
\text { firm (p. 257). Based on } \\
\text { Anderson and Narus } \\
\text { (1984, p. 66) }\end{array}$ & 7 items, $\alpha=89 / .83 / .83$ & $\begin{array}{l}\text { Partner's coercive } \\
\text { influence attempts }(-/ 00) \\
\text { Partner's logistics support } \\
(0++/+) \\
\text { Partner's product support } \\
(+/+/ 0) \\
\text { Parner's rales sapport } \\
(+/+/+)\end{array}$ \\
\hline 16. & $\begin{array}{l}\text { Howell. JMR. } \\
1987\end{array}$ & $\begin{array}{l}\text { Field study of } 238 \\
\text { dealers and } 43 \text { districa } \\
\text { managers reporting on } \\
\text { relationships with one } \\
\text { another (beavy industrial } \\
\text { machinery) }\end{array}$ & Channel & No definition reported & 5 items, $\alpha$ not reported. & $\begin{array}{l}\text { Partner's coercive power } \\
(0) \\
\text { Partner's expent power (0), } \\
\text { Partner's legitimate power } \\
(0) \\
\text { Partner's referent power } \\
(0) \\
\text { Partner's ansistance }(0) \\
\text { Partner's power }(0)\end{array}$ \\
\hline 17. & $\begin{array}{l}\text { Johnson et al. } \\
\text { JM. } 1993 \text {. }\end{array}$ & $\begin{array}{l}\text { Field study of } 74 \\
\text { Japanese distributors } \\
\text { reporting on their } \\
\text { relationships with US } \\
\text { sappliers (coasumer } \\
\text { goods) }\end{array}$ & Chaninel & $\begin{array}{l}\text { Level of satisfaction with } \\
\text { the overall relationship } \\
\text { isub-dimension of } \\
\text { relationship quality) (p. 5) }\end{array}$ & $\begin{array}{l}\text { Number of items not } \\
\text { reponted, } \alpha \text { not reported }\end{array}$ & $\begin{array}{l}\text { Parther's use of } \\
\text { authonitative power }(+) \\
\text { Parner's use of nurturing } \\
\text { power }(+)\end{array}$ \\
\hline
\end{tabular}




\begin{tabular}{|c|c|c|c|c|c|c|c|}
\hline \multirow[t]{2}{*}{ Na. } & \multirow{2}{*}{$\begin{array}{l}\text { Author, } \\
\text { loumel, year }\end{array}$} & \multirow[t]{2}{*}{ Restach Design } & \multirow[t]{2}{*}{ Content } & \multirow[t]{2}{*}{ Conceptranlization } & \multirow[t]{2}{*}{ Opcranionalisention } & \multicolumn{2}{|c|}{ Empinical monlss } \\
\hline & & & & & & Antroedents & Conserpucncrs \\
\hline 18. & Kale, IMR., 1986 & $\begin{array}{l}\text { Field study of } 5 \text { I Indian } \\
\text { dealers reporting on } \\
\text { relationships with } \\
\text { manufacturers (tunguen } \\
\text { carbide tool) }\end{array}$ & Channel & $\begin{array}{l}\text { A channel member's } \\
\text { overall satisfaction in the } \\
\text { channel relationship ( } p \text {. } \\
390 \text { ) }\end{array}$ & $\begin{array}{l}\text { Number of items bot } \\
\text { repoined, } \alpha \text { sot reponted }\end{array}$ & Partuct's power (-) & \\
\hline 19. & $\begin{array}{l}\text { Keith, Jackson } \\
\text { and Crosby. JM. } \\
1990\end{array}$ & $\begin{array}{l}\text { Laboratory experiment } \\
\text { of } 232 \text { retailers (brokers) } \\
\text { reporting on } \\
\text { relationships with } \\
\text { manufacturers (food) }\end{array}$ & Channel & $\begin{array}{l}\text { Satisfaction with a singie } \\
\text { interaction (p. 32) }\end{array}$ & 6 ilems, $\alpha=.95$ & $\begin{array}{l}\text { Dependence }(\bullet) \\
\text { Reward er coetrive baves } \\
\text { of power }(-) \\
\text { Expert, information or } \\
\text { referent bases of power } \\
(\dagger)\end{array}$ & \\
\hline 20. & $\begin{array}{l}\text { Kumar. Stern and } \\
\text { Achrol. JMR. } \\
1992\end{array}$ & $\begin{array}{l}\text { Field study of two focal } \\
\text { suppliers reporting on } \\
\text { their relationships with } \\
98 \text { resellers (vehicle } \\
\text { leasing) and with } 63 \\
\text { resellers (installation and } \\
\text { maintenance centers) }\end{array}$ & Channel & $\begin{array}{l}\text { Supplier's overall } \\
\text { satisfaction with the } \\
\text { exchange relationship (p. } \\
\text { 243) }\end{array}$ & 2 items, $\alpha$ not repontod & 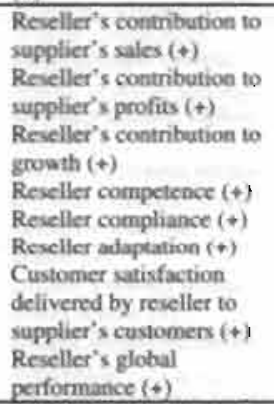 & \\
\hline 21. & $\begin{array}{l}\text { Lewis and } \\
\text { Lambert, JR, } \\
1991\end{array}$ & $\begin{array}{l}\text { Ficld study of } 107 \text { U.S. } \\
\text { (ranchisees reporting on } \\
\text { relationships with } \\
\text { franchiser (fast food) }\end{array}$ & Channel & $\begin{array}{l}\text { Satisfaction with role } \\
\text { performance is the level } \\
\text { of overall satisfaction } \\
\text { with the franchiser's } \\
\text { performance (p. 214) }\end{array}$ & I item & $\begin{array}{l}\text { Satisfaction with multiple } \\
\text { dimensions of role } \\
\text { performance ( } t)\end{array}$ & $\begin{array}{l}\text { Would enter relationship } \\
\text { again }(+)\end{array}$ \\
\hline
\end{tabular}




\begin{tabular}{|c|c|c|c|c|c|c|c|}
\hline$\overline{N o}$. & $\begin{array}{l}\text { Authri, } \\
\text { suimal, Year }\end{array}$ & Rneiorh Drign & Camert & Conceptualization & Operutionalization & Antrocedents & $\begin{array}{l}\text { renults } \\
\text { Consequences }\end{array}$ \\
\hline 22. & $\begin{array}{l}\text { Macintosh and } \\
\text { Lockshin, URM. } \\
1997\end{array}$ & $\begin{array}{l}\text { Field study of } 308 \\
\text { customers reporting on } \\
\text { their relationships with } \\
\text { stores (wine) }\end{array}$ & $\overline{B-T C}$ & $\begin{array}{l}\text { Customer's overall } \\
\text { evaluation of the store } \\
\text { experience ( } p .489 \text { ) }\end{array}$ & 3 items, $\alpha=95$ & 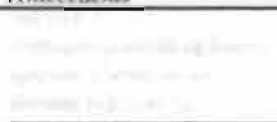 & $\begin{array}{l}\text { Store altutude }(*) \\
\text { Purchase intention }(*)\end{array}$ \\
\hline 23. & $\begin{array}{l}\text { Motur. Fisher and } \\
\text { Nevin, JM. } 1996\end{array}$ & $\begin{array}{l}\text { Field study of } 125 \text { US. } \\
\text { dealers reporting on } \\
\text { relationships with one } \\
\text { of their manufacturers } \\
\text { (personal computers and } \\
\text { related products) }\end{array}$ & Channel & $\begin{array}{l}\text { Evaluation of the } \\
\text { characteristics of the; } \\
\text { channel relationstrip (p. } \\
\text { 105) }\end{array}$ & 4 items, $\alpha=85$ & $\begin{array}{l}\text { Colliaborative } \\
\text { communication }(+) \\
\text { Conflict }(-) \\
\text { Dealer size }(0) \\
\text { Manufacturer control }(+) \\
\text { Reiationahip length }(0) \\
\text { Franchiseloompany } \\
\text { owned structure }(+)\end{array}$ & \\
\hline 24. & Ping. JR, 1993 & $\begin{array}{l}\text { Field study of } 222 \text { US. } \\
\text { retailers reporting on } \\
\text { relationships with } \\
\text { primary wholesalers } \\
\text { (hardware) }\end{array}$ & Channel & $\begin{array}{l}\text { The firm's global } \\
\text { evaluation of relationship } \\
\text { fulfillment (p. 329), Based } \\
\text { on Dwyer and Oh (1987. } \\
\text { p. 352) }\end{array}$ & 5 items, $\alpha=.94$ & & $\begin{array}{l}\text { Exil }(-) \\
\text { Loyalty }(0) \\
\text { Neglect }(-) \\
\text { Opportunism }(0) \\
\text { Voice }(+)\end{array}$ \\
\hline 25 & $\begin{array}{l}\text { Ping, JAMS, } \\
1994\end{array}$ & $\begin{array}{l}\text { Field study of } 288 \\
\text { retailers reporting on } \\
\text { relationships with } \\
\text { primary wholesales } \\
\text { (harfware) }\end{array}$ & Channel & $\begin{array}{l}\text { The firm's global } \\
\text { evaluation of relationship } \\
\text { fulfillment (p. 365). Based } \\
\text { on Dwyer and Oh (1987. } \\
\text { p. 352) }\end{array}$ & 5 items, $\alpha$ not reponted & $=$ & $\begin{array}{l}\text { Exit intention }(-) \\
\text { Attractiveness of } \\
\text { alternatives (-) }\end{array}$ \\
\hline 26 & Ping, IR, 1997 & $\begin{array}{l}\text { Field study of } 204 \\
\text { retailers reporting on } \\
\text { relationships with } \\
\text { primary wholesalers } \\
\text { (handware) }\end{array}$ & Charnel & $\begin{array}{l}\text { Belief that the relationship } \\
\text { is satisfactory (p, 270) }\end{array}$ & S items, $\alpha=94$ & & Voice (*) \\
\hline
\end{tabular}




\begin{tabular}{|c|c|c|c|c|c|c|c|}
\hline \multirow[t]{2}{*}{ No. } & \multirow{2}{*}{$\begin{array}{l}\text { Anthor, } \\
\text { boonal, Yees }\end{array}$} & \multirow[t]{2}{*}{ Reseanch Design } & \multirow[t]{2}{*}{ Comered } & \multirow[t]{2}{*}{ Canceptualization } & \multirow[t]{2}{*}{ Operutionalizatien } & \multicolumn{2}{|c|}{ Empirical ersultr } \\
\hline & & & & & & Antrondondx & Comunguernces \\
\hline 28. & $\begin{array}{l}\text { Scheer and Stem, } \\
\text { IMR, } 1992\end{array}$ & $\begin{array}{l}\text { Laboratory experiment } \\
\text { of } 208 \text { students in role of } \\
\text { marketing manager for a } \\
\text { distribution company } \\
\text { reporting on } \\
\text { relationships with } \\
\text { supplier (medical } \\
\text { diagnostic equipment) }\end{array}$ & Channel & $\begin{array}{l}\text { The overall approval of } \\
\text { and positive affect towand } \\
\text { another party }\end{array}$ & & $\begin{array}{l}\text { Favorable vs, unfavorable } \\
\text { outcomes ( }(\text { ) } \\
\text { Partner's contingemt } \\
\text { reward vs contingent } \\
\text { penalty ( }(+) \\
\text { Partiner's non-cantingent } \\
\text { reward vs, contingent } \\
\text { reward ( }(*) \\
\text { Partner's positive vx. } \\
\text { negative framing of power } \\
\text { use ( }(+)\end{array}$ & \\
\hline
\end{tabular}




\begin{tabular}{|c|c|c|c|c|c|c|}
\hline \multirow[t]{2}{*}{ Na. } & \multirow{2}{*}{$\begin{array}{l}\text { Awhor, } \\
\text { humal, Year }\end{array}$} & \multirow[t]{2}{*}{ Reserweh Ilexigh } & \multirow[t]{2}{*}{ Canert } & \multirow[t]{2}{*}{ Concrptualization } & \multirow[t]{2}{*}{ Oproutinamization } & \multirow{2}{*}{$\begin{array}{l}\text { Fimpirical results } \\
\text { Consequences }\end{array}$} \\
\hline & & & & & & \\
\hline 29 & $\begin{array}{l}\text { Schul, Little and } \\
\text { Pride, JR. } 1985\end{array}$ & $\begin{array}{l}\text { Field study of } 349 \text { U.S. } \\
\text { franchisees reporting on } \\
\text { relationships with } \\
\text { franchiser (real estate } \\
\text { brokerage services) }\end{array}$ & Channel & $\begin{array}{l}\text { A channel member's } \\
\text { affective atritudes and } \\
\text { feelings conceming the } \\
\text { domain of characteristics } \\
\text { describing the intemal } \\
\text { environment of the } \\
\text { channel onganization and } \\
\text { the relationships between } \\
\text { the channel member and } \\
\text { other institutions in the } \\
\text { channel arrangement }\end{array}$ & & $\begin{array}{l}\text { Autonomy (t) } \\
\text { Partner's consideration } \\
(+) \\
\text { Partner's initiating } \\
\text { structure ( } 4) \\
\text { Reward orientation }(+) \\
\end{array}$ \\
\hline 30. & $\begin{array}{l}\text { Siguaw, Simpson } \\
\text { and Baker, JM. } \\
1998\end{array}$ & $\begin{array}{l}\text { Field study of } 179 \\
\text { suppliers and distributors } \\
\text { reporting on } \\
\text { relationships with one } \\
\text { another (cross-section of } \\
\text { industries) }\end{array}$ & Channel & $\begin{array}{l}\text { Satisfaction with } \\
\text { performance (p. 103) }\end{array}$ & $\begin{array}{l}\text { I item } \\
\text { (averape score of } 7 \text { items) }\end{array}$ & $\begin{array}{l}\text { Distributor's market. } \\
\text { orientation ( }(\theta) \\
\text { Trust }(+) \\
\text { Cooperation }(-) \\
\text { Commitment }(+)\end{array}$ \\
\hline 31. & $\begin{array}{l}\text { Skinner, } \\
\text { Gassenheimer } \\
\text { and Kelley. JR. } \\
1992\end{array}$ & $\begin{array}{l}\text { Field study of } 226 \text { U.S. } \\
\text { dealers reporting on } \\
\text { relationships with } \\
\text { suppliers (farm and } \\
\text { power equipment) }\end{array}$ & Channel & $\begin{array}{l}\text { The overall evaluation of } \\
\text { the relationship between } \\
\text { two channel members (p. } \\
\text { 179). Based on Andernon } \\
\text { and Narus }(1990, p .45)\end{array}$ & 4 items, $\alpha=72$ & $\begin{array}{l}\text { Conflice (-) } \\
\text { Cooperation (*) }\end{array}$ \\
\hline 32. & $\begin{array}{l}\text { Skinner and } \\
\text { Guiltinan. JR. } \\
1985\end{array}$ & $\begin{array}{l}\text { Field study of } 103 \text { U.S. } \\
\text { dealers and } 4 \text { managers } \\
\text { from the manufacturing } \\
\text { organiration reporting } \\
\text { on relationships with one } \\
\text { another (farm supplies) }\end{array}$ & Channel & $\begin{array}{l}\text { Satisfaction with partner's } \\
\text { role performance }\end{array}$ & & Resource dependence $(+)$ \\
\hline
\end{tabular}




\begin{tabular}{|c|c|c|c|c|c|c|}
\hline No. & $\begin{array}{l}\text { Auther, } \\
\text { Journal, Year }\end{array}$ & Rrseurh Design & Cantex & Conceptanalization & $O_{\text {prrationaliontion }}$ & 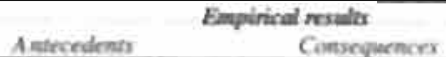 \\
\hline 33. & $\begin{array}{l}\text { Smith and } \\
\text { Barclay. JM. } \\
1997\end{array}$ & $\begin{array}{l}\text { Field study of } 103 \text { sales } \\
\text { representatives and their } \\
\text { selling partners reporting } \\
\text { on relationships with onc } \\
\text { another (computer } \\
\text { industry) }\end{array}$ & B-to-B & $\begin{array}{l}\text { Positive affective state } \\
\text { resulting from the } \\
\text { appraisal of all aspects of } \\
\text { a wodking relationship } \\
\text { relative to alternatives } \\
\text { experienced or observed } \\
\text { ip. 5). Based on Anderson } \\
\text { and Nanus (1984, p. 66) }\end{array}$ & $\begin{array}{l}6 \text { items, } \alpha=70 \text { (sponsor } \\
\text { model), } 60 \text { (purther } \\
\text { model) }\end{array}$ & $\begin{array}{l}\text { Sponsor model: } \\
\text { Perceived task } \\
\text { performance }(*) \\
\text { Relationship investment } \\
(0) \\
\text { Communication openness } \\
(+) \\
\text { Forbearance froen } \\
\text { opportunism }(0) \\
\text { Character and/or motives } \\
(+) \\
\text { Role Competence }(0) \\
\text { Judgment }(+)\end{array}$ \\
\hline * & & 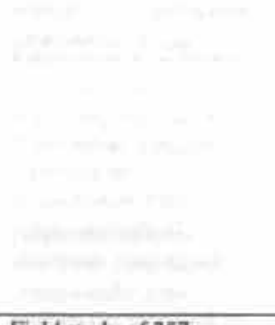 & & 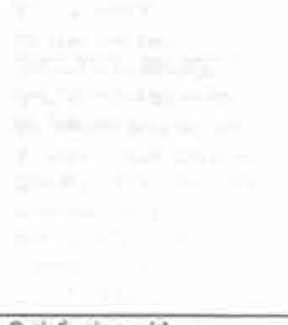 & 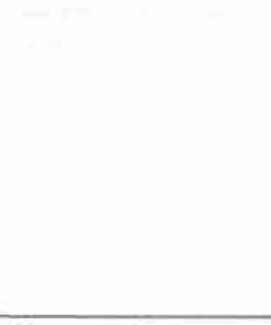 & $\begin{array}{l}\text { Parther model: } \\
\text { Perceived task } \\
\text { performance }(+) \\
\text { Relationship investment- } \\
\text { communication }(-) \\
\text { Forbearance from } \\
\text { goportunism }(+) \\
\text { Character and } \\
(+) \\
\text { Role motives } \\
\text { Judgment }(+)\end{array}$ \\
\hline 34 & $\begin{array}{l}\text { Tax. Brown and } \\
\text { Chandrashckaran } \\
\text { JM. } 1998\end{array}$ & $\begin{array}{l}\text { Field stridy of } 257 \\
\text { consumers reporting on } \\
\text { complaints aboul firms } \\
\text { (cross-section of } \\
\text { industries) }\end{array}$ & $B-t-C$ & $\begin{array}{l}\text { Satisfaction with } \\
\text { complaint handling (p. } \\
64)\end{array}$ & 4 items, $\alpha=96$ & $\begin{array}{l}\text { Distributive justice ( }+ \text { ) } \\
\text { Procedural justice }(+) \\
\text { Interactional justice }(+)\end{array}$ \\
\hline
\end{tabular}


Thale A2-2: Susminary of 7inst Rescarch (period 1985-1998)

\begin{tabular}{|c|c|c|c|c|c|c|c|}
\hline \multirow[t]{2}{*}{ Na. } & \multirow{2}{*}{$\begin{array}{l}\text { Author, } \\
\text { lowmal, } Y_{\text {ear }}\end{array}$} & \multirow[t]{2}{*}{ Resiar:h Design } & \multirow[t]{2}{*}{ Conteri } & \multirow[t]{2}{*}{ Corncephudization } & \multirow[t]{2}{*}{ Openutionalization } & \multicolumn{2}{|c|}{ Empirical resudts } \\
\hline & & & & & & Antecedonts & Consequences \\
\hline I. & $\begin{array}{l}\text { Andaleeb, URM. } \\
1995\end{array}$ & $\begin{array}{l}\text { Laboratory experiment } \\
\text { of } 120 \text { U.S. business } \\
\text { school sudents and } 72 \\
\text { U.S. masagers in role of } \\
\text { distributor reporting on } \\
\text { relationships with } \\
\text { supplier (liqueur) }\end{array}$ & Channel & $\begin{array}{l}\text { One party's belief thas } \\
\text { another party can be } \\
\text { relied upon to produce } \\
\text { positive outcomes or not } \\
\text { produce negative } \\
\text { outcomes for this party } \\
\text { from the investment in the } \\
\text { relationship (p. 159) }\end{array}$ & 4 items, $\alpha=96$ & & $\begin{array}{l}\text { Cooperation }(+) \\
\text { Controil }(-) \\
\text { Influence stance (threats) } \\
\text { of partner }(-)\end{array}$ \\
\hline 2. & $\begin{array}{l}\text { Andaleeb, JR, } \\
1996\end{array}$ & $\begin{array}{l}\text { Laboratory experiment } \\
\text { of } 72 \text { U.S. managers in } \\
\text { role of distributor } \\
\text { reporting on } \\
\text { relationships with } \\
\text { supplier (liqueur) }\end{array}$ & Channel & $\begin{array}{l}\text { Willingness of a party to } \\
\text { rely on the behaviors of } \\
\text { others, especially when } \\
\text { these behaviors have } \\
\text { outcome implications for } \\
\text { the party bestowing trust } \\
\text { (p. } 79 \text { ) }\end{array}$ & $\begin{array}{l}2 \text { new items, } \alpha=82 \text {. } \\
4 \text { existing items, } \alpha=95\end{array}$ & & $\begin{array}{l}\text { Commitment }(+) \\
\text { Relationship satisfaction } \\
(+)\end{array}$ \\
\hline 3 & $\begin{array}{l}\text { Anderson, } \\
\text { Lodish and } \\
\text { Weitz. MMR. } \\
1987\end{array}$ & $\begin{array}{l}\text { Field study of } 71 \text { U.S. } \\
\text { independent sales } \\
\text { agencies reporting on } \\
\text { relationships with a total } \\
\text { of } 492 \text { U.S. principals } \\
\text { (electronic components) }\end{array}$ & Channel & $\begin{array}{l}\text { Willingness to accept } \\
\text { short-term dislocations } \\
\text { because of confidence that } \\
\text { such dislocations will } \\
\text { balance out in the long } \\
\text { nun (p. 87). Bassed on } \\
\text { Ouchi (1980) }\end{array}$ & 2 items, $\alpha>84$ & & $\begin{array}{l}\text { Time allocated to } \\
\text { principal }(*)\end{array}$ \\
\hline 4 & $\begin{array}{l}\text { Anderson and } \\
\text { Weitr, MS, } 1989\end{array}$ & $\begin{array}{l}\text { Ficld study of } 95 \text { U.S. } \\
\text { independent sales agents } \\
\text { reporting on. } \\
\text { relationships with a total } \\
\text { of } 690 \text { U.S. principals } \\
\text { (electronic components) }\end{array}$ & Channel & $\begin{array}{l}\text { One party's belief that its } \\
\text { neods will be fulfillod in } \\
\text { the future by actions } \\
\text { undertuken by the other } \\
\text { party (p. } 312 \text { ) }\end{array}$ & 2 items, $\alpha=84$ & $\begin{array}{l}\text { Communication }(+) \\
\text { Cultural vimilarify }(0) \\
\text { Goal congruence }(+) \\
\text { Power imhalance }(-) \\
\text { Negative seputation }(-) \\
\text { Relationship age }(*) \\
\text { Support proviled }(+)\end{array}$ & $\begin{array}{l}\text { Communication ( }+ \text { ) } \\
\text { Perceived continuity of } \\
\text { relationship }(+)\end{array}$ \\
\hline
\end{tabular}




\begin{tabular}{|c|c|c|c|c|c|c|c|}
\hline \multirow[t]{2}{*}{ Nis. } & \multirow{2}{*}{$\begin{array}{l}\text { Aithor, } \\
\text { burmal, Year }\end{array}$} & \multirow[t]{2}{*}{ Research Design } & \multirow[t]{2}{*}{ Contex } & \multirow[t]{2}{*}{ Conceptrantization } & \multirow[t]{2}{*}{ Osvirionalizunion } & \multicolumn{2}{|c|}{ Empirical msults } \\
\hline & & & & & & Antenchilontr & Conserguences \\
\hline 5. & $\begin{array}{l}\text { Anderson and } \\
\text { Narus, JM. } 1990\end{array}$ & $\begin{array}{l}\text { Field study of } 249 \text { U.S, } \\
\text { distributor firms and } 213 \\
\text { U.S. manufacturer firms } \\
\text { reporting on } \\
\text { relationships with one } \\
\text { another (cross-section of } \\
\text { industries) }\end{array}$ & Channel & $\begin{array}{l}\text { Firm's belief that partnet } \\
\text { will perform actions that } \\
\text { will result in positive } \\
\text { outcomes for the firm, as } \\
\text { well as not take } \\
\text { unexpected actions that } \\
\text { would result in negative } \\
\text { outeomes for the firm (p. } \\
\text { 45). Based on Andersoa } \\
\text { and Narus (1986, p. 326) }\end{array}$ & $\begin{array}{l}\text { Distributor side, } 1 \text { item } \\
\text { Manufacturer side. } 3 \\
\text { ilems, } \alpha \text { nok reported. }\end{array}$ & $\begin{array}{l}\text { Communication }(*) \\
\text { Cooperation }(*)\end{array}$ & $\begin{array}{l}\text { Conflict }(-) \\
\text { Satisfaction }(*)\end{array}$ \\
\hline 6. & $\begin{array}{l}\text { Baker, Simpsion. } \\
\text { and Siguaw. } \\
\text { JAMS. } 1999\end{array}$ & $\begin{array}{l}\text { Field study of } 380 \\
\text { suppliers reporting on } \\
\text { relationships with } \\
\text { reselling firms (cross- } \\
\text { section of industries) }\end{array}$ & Channel & $\begin{array}{l}\text { Reliance on and } \\
\text { confidence in partners, } \\
\text { comprising credibility and } \\
\text { benevolence (p. } 51 \text { ). } \\
\text { Based on Moorman, } \\
\text { Zaltuman, and Deshpande } \\
\text { (1992, p. 315) }\end{array}$ & 12 items, $\alpha=.92$ & $\begin{array}{l}\text { Perseived market } \\
\text { oricntation ( }+)\end{array}$ & 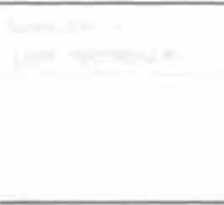 \\
\hline 7. & $\begin{array}{l}\text { Crosby, Evans } \\
\text { and Cowles, JM. } \\
1990 \text {. }\end{array}$ & $\begin{array}{l}\text { Field study of } 151 \text { heads } \\
\text { of U.S. households } \\
\text { reporting on } \\
\text { relationships with agents } \\
\text { (life insurance) }\end{array}$ & $B+1-C$ & $\begin{array}{l}\text { A confident belief that the } \\
\text { salesperson cun be relied } \\
\text { upon to behave in such a } \\
\text { manner that the long-term } \\
\text { interest of the customer } \\
\text { will be served (p. } 70 \text { ) }\end{array}$ & 9 items, $\alpha=89$ & $\begin{array}{l}\text { Expertise of partner }(*) \\
\text { Similarity }(0) \\
\text { Relational selfing } \\
\text { behavior by partner }(*)\end{array}$ & $\begin{array}{l}\text { Anticipation of future } \\
\text { interaction }(+) \\
\text { Sales effectiveness of } \\
\text { partner (0) }\end{array}$ \\
\hline 8. & $\begin{array}{l}\text { Dahistrom and } \\
\text { Nygaard. IR. } \\
\text { 1995. }\end{array}$ & $\begin{array}{l}\text { Field study of } 40 \text { Polish, } \\
29 \text { East-German and } 216 \\
\text { Norwegian dealers } \\
\text { reporting on } \\
\text { relationships with } \\
\text { franchisers (gasoline } \\
\text { stations) }\end{array}$ & Channel & $\begin{array}{l}\text { Willingness to rely on } \\
\text { parner in whom one has } \\
\text { confidence (p. 341). } \\
\text { Based on Moorman, } \\
\text { Zaltman and Desphande } \\
\text { (1992, p. 315) }\end{array}$ & $\begin{array}{l}\text { S items, } \alpha=, 80 \text { in Poland, } \\
62 \text { in East Germany and } \\
87 \text { in Norway }\end{array}$ & $\begin{array}{l}\text { Centralization }(0.0,0) \\
\text { Formalization }(0 .+.4)\end{array}$ & Performance $(+\ldots+)$. \\
\hline
\end{tabular}




\begin{tabular}{|c|c|c|c|c|c|c|c|}
\hline \multirow[t]{2}{*}{ Na. } & \multirow{2}{*}{$\begin{array}{l}\text { Auhor, } \\
\text { loumal, Year }\end{array}$} & \multirow[t]{2}{*}{ Rervarh Dexign } & \multirow[t]{2}{*}{ Conert } & \multirow[t]{2}{*}{ Conceptundization } & \multirow[t]{2}{*}{ Opentionalization } & \multicolumn{2}{|c|}{ Empirical mxultr } \\
\hline & & & & & & Antecodents & Consequences \\
\hline 9 . & $\begin{array}{l}\text { Doney and } \\
\text { Cannom. IM. } \\
1997\end{array}$ & $\begin{array}{l}\text { Field study of } 210 \\
\text { members of the U.S. } \\
\text { Association of } \\
\text { Punchasing Management } \\
\text { reporting on their } \\
\text { relationship with } \\
\text { supplier's salesperson } \\
\text { (cross-section of } \\
\text { industries) }\end{array}$ & $\mathrm{B}-1-\mathrm{B}$ & $\begin{array}{l}\text { Perceived credibility and } \\
\text { benevolence of a target of } \\
\text { trust (p. 36) }\end{array}$ & $\begin{array}{l}\text { Trust of supplier firm, 8 } \\
\text { items, } \alpha=94 \\
\text { Trust of salesperson, } 7 \\
\text { items, } \alpha=90\end{array}$ & $\begin{array}{l}\text { Supplier size ( }+) \\
\text { Supplier's willingness to } \\
\text { customize ( }+) \\
\text { Supplier's willingness to } \\
\text { share confidential } \\
\text { information (0) } \\
\text { Lengeth of the relationship } \\
(0) \\
\text { Trust of the supplier's } \\
\text { salesperson on trist of the } \\
\text { selling firm and vv. ( }+) \\
\text { Salesperson expertise ( }+) \\
\text { Powerful ( } 0) \\
\text { Likable }(+) \\
\text { Frequency of contact ( }+) \\
\text { Frequency of interaction } \\
\text { and length of time }(0)\end{array}$ & Purchase choice (0) \\
\hline 10 & $\begin{array}{l}\text { Dwyer and Oh. } \\
\text { JMR. } 1987\end{array}$ & $\begin{array}{l}\text { Field study of } 157 \text { U.S. } \\
\text { dealers reporting on } \\
\text { relationships with } \\
\text { manufacturers } \\
\text { (automobiles) }\end{array}$ & Channel. & $\begin{array}{l}\text { A firm's expectations that } \\
\text { partner dexires } \\
\text { coordination, will fulfill } \\
\text { its obligations, and will } \\
\text { pull tts weight in the } \\
\text { relationship (p. 349). } \\
\text { Based on Anderson and } \\
\text { Narus (1986, p. 326) }\end{array}$ & 4 items, $\alpha=79$ & $\begin{array}{l}\text { Centralization (-) } \\
\text { Formalization }(+) \\
\text { Participation in decision } \\
\text { making }(+)\end{array}$ & 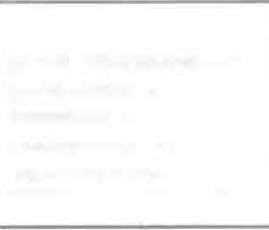 \\
\hline 11 & $\begin{array}{l}\text { Ganesan. IM. } \\
1994\end{array}$ & $\begin{array}{l}\text { Field study of } 120 \text { U.S } \\
\text { retail buyers and } 52 \text { U.S. } \\
\text { vendors supplying to } \\
\text { those retailers on } \\
\text { relationships with one } \\
\text { another (department } \\
\text { store chains) }\end{array}$ & Channel & $\begin{array}{l}\text { Willingness to rely on an } \\
\text { exchange partner in whom } \\
\text { one has confidence (p. 3). } \\
\text { Based on Moorman. } \\
\text { Zaltman and Desphande } \\
\text { (1992, p. 315) }\end{array}$ & $\begin{array}{l}\text { Vendor's credibility, } 7 \\
\text { liems, } \alpha=901 \\
\text { Retailer's credibility, } 4 \\
\text { items, } \alpha=80 \\
\text { Yendor's benevolence, } 5 \\
\text { items, } \alpha=88 \\
\text { Retailer's benevolence, } 3 \\
\text { items, } \alpha=76\end{array}$ & $\begin{array}{l}\text { Relationship age }(0) \\
\text { Speciflc investments by } \\
\text { partner }(+) \\
\text { Reputation of partner ( }(*) \\
\text { Satisfaction with previops } \\
\text { outcomes }(*)\end{array}$ & Long-termi orientation $(+)$ \\
\hline
\end{tabular}




\begin{tabular}{|c|c|c|c|c|c|c|c|}
\hline \multirow[t]{2}{*}{$\mathrm{Na}$} & \multirow{2}{*}{$\begin{array}{l}\text { Awhor; } \\
\text { Joumel', Yeus }\end{array}$} & \multirow[t]{2}{*}{ Research Dexigsi } & \multirow[t]{2}{*}{ Camerns } & \multirow[t]{2}{*}{ Canceptiontitiotion } & \multirow[t]{2}{*}{ Openationalizations } & \multicolumn{2}{|c|}{ Enpinical misults } \\
\hline & & & & & & Antecrelfens & Consepernces \\
\hline 12. & $\begin{array}{l}\text { Geysicens, } \\
\text { Steenkamp, } \\
\text { Scheet and } \\
\text { Kumar, IRRM, } \\
1996\end{array}$ & $\begin{array}{l}\text { Field study of } 417 \text { small } \\
\text { US. dealers and } 289 \\
\text { small Dutch dealers } \\
\text { reporting on } \\
\text { relationihips with } \\
\text { suppliens (automobiles) }\end{array}$ & Channei & $\begin{array}{l}\text { Belief that partner is } \\
\text { boness and benevolent ( } p \text {. } \\
\text { 307) }\end{array}$ & 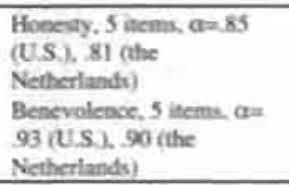 & & $\begin{array}{l}\text { Affective commitment } \\
(+,+) \\
\text { Cilculative commitment } \\
(-,-)\end{array}$ \\
\hline 13. & $\begin{array}{l}\text { Grayson and } \\
\text { Ambler. JMR. } \\
1999\end{array}$ & $\begin{array}{l}\text { Field study of } 200 \\
\text { marketing and/or } \\
\text { advertising managers } \\
\text { reporting on } \\
\text { relationships with } \\
\text { advertising agency } \\
\text { representatives (cross. } \\
\text { section of industries) }\end{array}$ & Industrial & No definition reported & 5 inems, $\alpha=72$ & 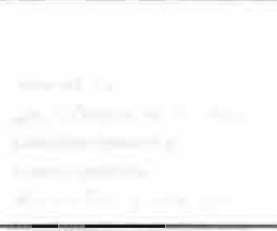 & $\begin{array}{l}\text { Advertixing use }(+) \\
\text { Comanitment }(+) \\
\text { Interaction }(+) \\
\text { Involvement }(+) \\
\text { Rising expectations }(+)\end{array}$ \\
\hline 14. & $\begin{array}{l}\text { Kamar. Scheer } \\
\text { and Steenkamp. } \\
\text { JMR, 1995a }\end{array}$ & $\begin{array}{l}\text { Field study of } 417 \text { small } \\
\text { U.S. dealers and } 289 \\
\text { small Dutch dealen } \\
\text { reporting on } \\
\text { relationships with } \\
\text { suppliers (automobiles) }\end{array}$ & Channei & $\begin{array}{l}\text { Belief that partner is } \\
\text { bonest and benevolent (p. } \\
\text { 58) }\end{array}$ & $\begin{array}{l}\text { Honetry and benevolence. } \\
10 \text { items, } \alpha \text { nos reported }\end{array}$ & $\begin{array}{l}\text { Age (0) } \\
\text { Distributive faimess }(+) \\
\text { Procedunal faimess }(+) \\
\text { Environunental } \\
\text { uncertainty }(-) \\
\text { Outcomes given } \\
\text { alfernatives }(+)\end{array}$ & \\
\hline 15. & $\begin{array}{l}\text { Kumar. Scheer } \\
\text { and Steenkamp. } \\
\text { IMR, 1995b }\end{array}$ & $\begin{array}{l}\text { Field study of } 417 \text { small } \\
\text { U.S. dealers reporting onı } \\
\text { relationsthips with } \\
\text { suppliers (automobiles) }\end{array}$ & Channel & $\begin{array}{l}\text { Belief that partner is } \\
\text { honest and benevolent (ip. } \\
351 \text { ? }\end{array}$ & $\begin{array}{l}\text { Honexty, } 5 \text { iems, } \alpha=.85 \\
\text { Benevolence, } 5 \text { itemx, } \alpha= \\
93\end{array}$ & $\begin{array}{l}\text { Total interdependence }(+) \\
\text { Interdependence } \\
\text { asymmetry }(-)\end{array}$ & \\
\hline 16. & $\begin{array}{l}\text { Macintosh and } \\
\text { Lockshin, URM, } \\
1997\end{array}$ & $\begin{array}{l}\text { Field study of } 308 \\
\text { customen reporting on } \\
\text { their relationships with } \\
\text { stores (wine) }\end{array}$ & $B-1-C$ & $\begin{array}{l}\text { A party's confidence in an } \\
\text { exchange partner's } \\
\text { relizbility and integrity (1). } \\
\text { 489). Based on Morgan } \\
\text { and Hunt (1994, p. 23) }\end{array}$ & $\begin{array}{l}\text { Trust in the salesperson, } 2 \text {. } \\
\text { items, } \alpha=80, \\
\text { Trusa in the store. } 3 \text { irems, } \\
\alpha=91\end{array}$ & & $\begin{array}{l}\text { Store attitude ( }+ \text { ) } \\
\text { Commitment to the } \\
\text { calesperson }(+)\end{array}$ \\
\hline
\end{tabular}




\begin{tabular}{|c|c|c|c|c|c|c|c|}
\hline \multirow[t]{2}{*}{ Nas } & \multirow{2}{*}{$\begin{array}{l}\text { Author, } \\
\text { Joumal, } Y_{\text {ear }}\end{array}$} & \multirow[t]{2}{*}{ Rescrozh Drsign } & \multirow[t]{2}{*}{ Condert } & \multirow[t]{2}{*}{ Conceptualizarion } & \multirow[t]{2}{*}{ Opentionalization } & \multicolumn{2}{|c|}{ Enpirical nesulses } \\
\hline & & & & & & Antencrelents & Comsequences \\
\hline 17. & $\begin{array}{l}\text { Moorman, } \\
\text { Zaltman and } \\
\text { Desphande. } \\
\text { JMR. 1992 }\end{array}$ & $\begin{array}{l}\text { Field study of } 779 \text { U.S. } \\
\text { marketing managers. } \\
\text { marketing researchers } \\
\text { and non-marketing } \\
\text { managers reporting on } \\
\text { their relationships with } \\
\text { various providers of } \\
\text { market research }\end{array}$ & $B-10-B$ & $\begin{array}{l}\text { Willingness to sely on an } \\
\text { exchange partner in whom } \\
\text { one has confidence (p. } \\
\text { 315) }\end{array}$ & 5 items, $\alpha=84$ & & $\begin{array}{l}\text { Quality of interactions ( }+ \text { ) } \\
\text { Researcher involvement } \\
(+) \\
\text { User commitment to the } \\
\text { reseanch relationship }(+) \\
\text { Utilization of market } \\
\text { reiearch }(0)\end{array}$ \\
\hline 18 & $\begin{array}{l}\text { Moorman. } \\
\text { Deshpandé and } \\
\text { Zaltman. IM. } \\
1993\end{array}$ & $\begin{array}{l}\text { Field study of } 779 \text { U.S. } \\
\text { marketing managers. } \\
\text { marketing researchers } \\
\text { and non-marketing } \\
\text { managers reporting on } \\
\text { their relationships with } \\
\text { various providers of } \\
\text { market research }\end{array}$ & $B-1-B$ & $\begin{array}{l}\text { Willingess to rely on an } \\
\text { exchange parner in whom } \\
\text { one has confidence ( } \mathrm{p} \text {. } \\
\text { 82). Based on Mooman. } \\
\text { Zaltman and Desphandé } \\
\text { (1992. p. 315) }\end{array}$ & 5 items, $\alpha=84$ & 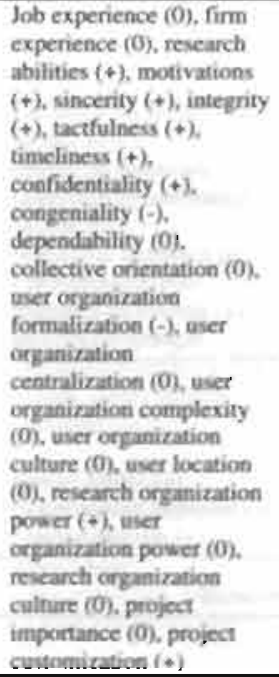 & 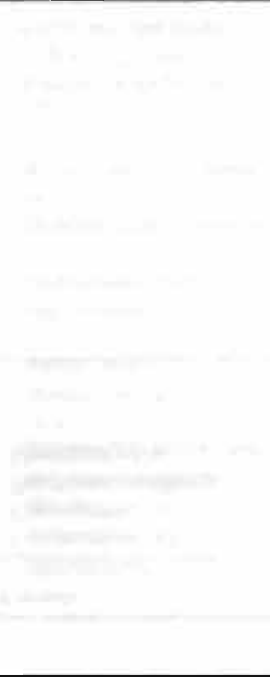 \\
\hline
\end{tabular}




\begin{tabular}{|c|c|c|c|c|c|c|c|}
\hline \multirow[t]{2}{*}{ No. } & \multirow{2}{*}{$\begin{array}{l}\text { A wehor, } \\
\text { bownd, Year }\end{array}$} & \multirow[t]{2}{*}{ Reseunch Design } & \multirow[t]{2}{*}{ Context } & \multirow[t]{2}{*}{ Conceptunitization } & \multirow[t]{2}{*}{ Openanionditition } & \multicolumn{2}{|c|}{ Empirical morulitix } \\
\hline & & & & & & Antecenlents & Comungurnces \\
\hline 19. & $\begin{array}{l}\text { Morgan and } \\
\text { Hunt. JM, } 1994\end{array}$ & $\begin{array}{l}\text { Field study of } 204 \text { U.S. } \\
\text { independent retailers } \\
\text { reporting on } \\
\text { relationships with } \\
\text { suppliers (automobile } \\
\text { tires) }\end{array}$ & Channel & $\begin{array}{l}\text { When one party has } \\
\text { confidence in an exchange } \\
\text { parmer's reliability and } \\
\text { integrity (p. 23) }\end{array}$ & Hooesty, 7 iterms, $\alpha=95$ & $\begin{array}{l}\text { Cemmunicatical ( }+ \text { ) } \\
\text { Opportanistic betarvior (-) } \\
\text { Shared values }(t)\end{array}$ & $\begin{array}{l}\text { Commitment }(+) \\
\text { Cooperation }(+) \\
\text { Functional conflict }(+) \\
\text { Uncertainty }(-)\end{array}$ \\
\hline 20 & $\begin{array}{l}\text { Scheer and Stem. } \\
\text { RMR, } 1992\end{array}$ & $\begin{array}{l}\text { Laboratory experiment } \\
\text { of } 233 \text { U.S. MBA } \\
\text { students in role of } \\
\text { marketing manager of } \\
\text { discributor company } \\
\text { reporting on } \\
\text { relationships with } \\
\text { upplier (medical } \\
\text { equipment) }\end{array}$ & Channel & $\begin{array}{l}\text { Belief that partner can be } \\
\text { relied on to fulfill its } \\
\text { future obligations and to } \\
\text { behave in a manner that } \\
\text { will serve the firm's needx } \\
\text { and long-term interests }\end{array}$ & Honesty. 4 itema, $\omega=86$ & $\begin{array}{l}\text { Reward vx. penalty } \\
\text { influence by partner }(+) \\
\text { Contingent vx, non- } \\
\text { contingent influence by } \\
\text { partner ( } 0 \text { ) } \\
\text { Positively va, nepatively } \\
\text { framed influence by } \\
\text { parteer }(+) \\
\text { Favorable outcomes }(+)\end{array}$ & \\
\hline 21. & $\begin{array}{l}\text { Schurr and } \\
\text { Oranne, JCR, } \\
1985\end{array}$ & $\begin{array}{l}\text { Laboratory experiment } \\
\text { of } 103 \mathrm{U}, \mathrm{S} \text {. industrial } \\
\text { buyers reporting on } \\
\text { relationships with } \\
\text { supplier (high-sech } \\
\text { plugs, socket, and cable) }\end{array}$ & Channel & $\begin{array}{l}\text { Belief that partner's word } \\
\text { or promise is reliable and } \\
\text { that partner will fulfill its } \\
\text { obligations in an } \\
\text { exchange relationship (p. } \\
940 \text { ) }\end{array}$ & $\begin{array}{l}\text { Honeury and benevolence. } \\
\text { experimental } \\
\text { manipulation }\end{array}$ & & $\begin{array}{l}\text { Distributive bargaining (-) } \\
\text { Integrative bargaining (0) } \\
\text { Mutual self-disclosure }(0) \\
\text { Level of agreemeni } \\
\text { reached }(\phi) \\
\text { Attinule toward partner } \\
(+) \\
\text { Attitude toward loyalty } \\
(+) \\
\text { Reject partner as too } \\
\text { tough }(-) \\
\text { Total concessions }(0)\end{array}$ \\
\hline
\end{tabular}




\begin{tabular}{|c|c|c|c|c|c|c|c|}
\hline \multirow[t]{2}{*}{ No. } & \multirow{2}{*}{$\begin{array}{l}\text { A suthor, } \\
\text { bournal, } Y_{\text {ear }}\end{array}$} & \multirow[t]{2}{*}{ Rescandi Desien } & \multirow[t]{2}{*}{ Conuen } & \multirow[t]{2}{*}{ Conceptualization } & \multirow[t]{2}{*}{ Operationnlization } & \multicolumn{2}{|c|}{ Empirical results } \\
\hline & & & & & & Antecedentr & Consequences \\
\hline 22. & $\begin{array}{l}\text { Siguaw, Simpson } \\
\text { and Baker. JM. } \\
1998\end{array}$ & $\begin{array}{l}\text { Field study of } 179 \\
\text { suppliers and distributors } \\
\text { reporting on } \\
\text { relationships with one } \\
\text { another (cross-section of } \\
\text { industries) }\end{array}$ & Channel & $\begin{array}{l}\text { Credibility is comprised } \\
\text { of the belief that a trading } \\
\text { partner is expert and } \\
\text { reliable in conducting } \\
\text { transactions effectively } \\
\text { Benevolence is based on } \\
\text { the beneficial intentions } \\
\text { and motives of one } \\
\text { partner for the other ip. } \\
\text { 101/102). Based on } \\
\text { Ganesan (1994, p. 3) }\end{array}$ & $\begin{array}{l}\text { Credibility, } 5 \text { items, } \\
\alpha=80 \\
\text { Benevolence, } 4 \text { items. } \\
\alpha=94\end{array}$ & $\begin{array}{l}\text { Supplier's market } \\
\text { orientation }(0) \\
\text { Distributor's market } \\
\text { oricntation }(+)\end{array}$ & $\begin{array}{l}\text { Cooperation }(+) \\
\text { Commitment }(0) \\
\text { Satisfaction with } \\
\text { performance }(+ \text { ? }\end{array}$ \\
\hline 23 & $\begin{array}{l}\text { Smith and } \\
\text { Barclay, JMt. } \\
1997\end{array}$ & $\begin{array}{l}\text { Field study of } 103 \text { sales } \\
\text { representatives and their } \\
\text { selling partners reporting } \\
\text { on relationships with one } \\
\text { another (compateir } \\
\text { industry) }\end{array}$ & B-t-B & $\begin{array}{l}\text { Perceived trustworthiness } \\
\text { is the extent to which } \\
\text { partners jointly expect } \\
\text { fiduciary responsibility in } \\
\text { the performance of their } \\
\text { individual roles and } \\
\text { believe that each will act } \\
\text { in the best interest of the } \\
\text { partnership (p. } 6)\end{array}$ & $\begin{array}{l}\text { Perceived trustwonthiness: } \\
\text { Character and/or motives. } \\
5 \text { items, } c 0=78 \\
\text { Role competence, } 4 \text { items, } \\
\omega=.86 \\
\text { Jodgement, } 3 \text { items, } \\
\alpha=80\end{array}$ & 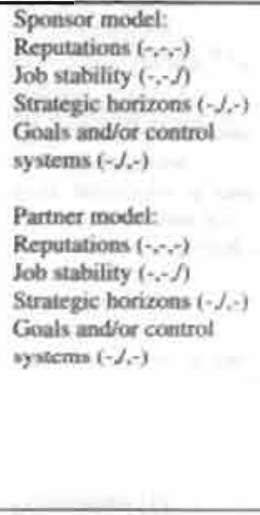 & $\begin{array}{l}\text { Sponsor model: } \\
\text { Mutual satisfaction } \\
(+, 0,+) \\
\text { Relationship investment } \\
(+,+, 0) \\
\text { Communication openness } \\
(+J /) \\
\text { Forbearance from } \\
\text { opportunism }(+J,+) \\
\text { Partner model: } \\
\text { Murtual satisfaction } \\
(+,+,+) \\
\text { Relationship investment } \\
\text { and communication } \\
(0,+, 0) \\
\text { Forbearance from } \\
\text { opportunism }(+J,+)\end{array}$ \\
\hline 24. & $\begin{array}{l}\text { Tax, Brown and } \\
\text { Chandrashekaran } \\
\text { M. } 1998\end{array}$ & $\begin{array}{l}\text { Field study of } 257 \\
\text { consumers reponting on } \\
\text { complaints abous firms } \\
\text { (cross-section of } \\
\text { industries) }\end{array}$ & $\mathrm{B}+\mathrm{C}$ & $\begin{array}{l}\text { When one partner has } \\
\text { confidence in an exchange } \\
\text { partnet's reliability and } \\
\text { integrity (p. 64) }\end{array}$ & 4 items, $\alpha=96$ & $\begin{array}{l}\text { Diwatisfaction with } \\
\text { complaint handling ( }- \text { ) }\end{array}$ & \\
\hline
\end{tabular}


The A2-3: Surrurbey of Commitment Research (peried 1985-1998)

\begin{tabular}{|c|c|c|c|c|c|c|c|}
\hline Nor. & $\begin{array}{l}\text { A whor, } \\
\text { kownd, } Y_{\mathrm{Ca}}\end{array}$ & Research Derign & Context & Conceptualization & Opornionalizerion & \multicolumn{2}{|c|}{ Empirical monals: } \\
\hline I. & $\begin{array}{l}\text { Andaleeb, JR. } \\
1996\end{array}$ & $\begin{array}{l}\text { Laboratory experiment } \\
\text { of } 72 \text { U.S. managers in } \\
\text { role of distributor } \\
\text { reporting on } \\
\text { relationships with } \\
\text { supplier (liqueur) }\end{array}$ & Chamnel & $\begin{array}{l}\text { Party's desire to maintain } \\
\text { a valued relationship ( } p \text {. } \\
81 \text { ) }\end{array}$ & 4 ilens, $c=92$ & $\begin{array}{l}\text { Trass }(\uparrow) \\
\text { Dependence (t) }\end{array}$ & \\
\hline 2. & $\begin{array}{l}\text { Anderson and } \\
\text { Weitz, JMR. } \\
1992\end{array}$ & $\begin{array}{l}\text { Field study of } 378 \text { U.S. } \\
\text { industrial distributors } \\
\text { and their manufacturers } \\
\text { reporting on } \\
\text { relationkhips with one } \\
\text { another (cross-section of } \\
\text { industries) }\end{array}$ & Channel & $\begin{array}{l}\text { A desire to develop a } \\
\text { stable relationship. a } \\
\text { willingness to make short- } \\
\text { term sacrifices to maintain } \\
\text { the relationship, and a } \\
\text { confidence in the stability } \\
\text { of the relationship (p. 19) }\end{array}$ & $\begin{array}{l}\text { Distributor's } \\
\text { cominitment, } 10 \text { ifeins, } \\
\alpha=83\end{array}$ & $\begin{array}{l}\text { Distr. perception of man. } \\
\text { commitment }(+) \\
\text { Distr. Adicsyactatic } \\
\text { investments }(+) \\
\text { Distr. exclusive dealing in } \\
\text { man. product class }(0) \\
\text { Distr. perception of level } \\
\text { of commanication ( }+ \text { ) } \\
\text { Distr. perception of man. } \\
\text { repatation (0) }\end{array}$ & 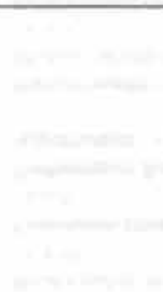 \\
\hline & & & & 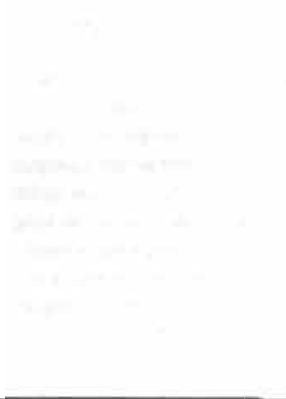 & $\begin{array}{l}\text { Manufacturer's } \\
\text { commitment, } 10 \text { items, } \\
\alpha=87\end{array}$ & $\begin{array}{l}\text { Man. petception of dixtr. } \\
\text { commitunent }(\omega) \\
\text { Man. idiosyncratic } \\
\text { iavestments }(+) \\
\text { Man. granting of } \\
\text { ternitorial exclusivity to } \\
\text { distr. }(+) \\
\text { Man, working with } \\
\text { minimum performance } \\
\text { standands }(0) \\
\text { Man. perception of level } \\
\text { of communication }(+) \\
\text { Man. peroeption of distr. } \\
\text { reputation }(0)\end{array}$ & -2 \\
\hline
\end{tabular}




\begin{tabular}{|c|c|c|c|c|c|c|c|}
\hline Na. & $\begin{array}{l}\text { Awhor, } \\
\text { foumal, Year }\end{array}$ & Hescurd, Desigh" & Context & Conceptamelicationt & Openusianalizetion & \multicolumn{2}{|c|}{$\begin{array}{l}\text { Bmphlricad results } \\
\text { Consequarnces }\end{array}$} \\
\hline 3. & $\begin{array}{l}\text { Baker. Simpson. } \\
\text { and Siguaw. } \\
\text { JAMS, } 1999\end{array}$ & $\begin{array}{l}\text { Field study of } 380 \\
\text { suppliers reporting on } \\
\text { relationships with } \\
\text { reselling firms (cross- } \\
\text { section of industries) }\end{array}$ & Chamnel & $\begin{array}{l}\text { A desire to develop a } \\
\text { sable relationstip, } 3 \\
\text { willingness to make short. } \\
\text { term sacrifices to maintain } \\
\text { the relationship, and the } \\
\text { confidence in the stability } \\
\text { of the relationship (p. } 51 \text { ). } \\
\text { Based on Anderson and } \\
\text { Weitz (1992, p. 19) }\end{array}$ & 5 items, $\alpha=65$ & $\begin{array}{l}\text { Perceived market } \\
\text { orientation ( } 4 \text { ) }\end{array}$ & \\
\hline 4 & $\begin{array}{l}\text { Brown, Lusch } \\
\text { and Nicholson, } \\
\text { IR. I995 }\end{array}$ & $\begin{array}{l}\text { Field study of } 302 \\
\text { dealers reporting on } \\
\text { relationships with. } \\
\text { xuppliers (farm. } \\
\text { equipenent) }\end{array}$ & Channel & $\begin{array}{l}\text { A's attitudinal } \\
\text { commmitment is a long- } \\
\text { lerm orientation to its } \\
\text { relationship with B and } \\
\text { may be predicated on } \\
\text { three independent } \\
\text { foundations: (a) } \\
\text { compliance of } \\
\text { instrumental involvemest } \\
\text { for specific extrinsic } \\
\text { rewands; (b) identification } \\
\text { or involvement based on a } \\
\text { desire for affiliation and } \\
\text { (c) internalization or } \\
\text { involvement predicated } \\
\text { on congruence between } \\
\text { individual and } \\
\text { organizational values (p. } \\
3655 \text {. Based on O' Reilly } \\
\text { and Chatuman (1986) }\end{array}$ & $\begin{array}{l}\text { Identification, } 2 \text { items, } \\
\alpha=, 71 \\
\text { Internalization, } 5 \text { items, } \\
\alpha=, 78 \\
\text { Compliance, } 3 \text { items, } \\
\alpha=67 \\
\text { Normative comimitment } \\
\text { (identification - } \\
\text { internalization), } 7 \text { items. } \\
\alpha=81 \\
\text { Instrumental commitment } \\
\text { (compliance), } 3 \text { items. } \\
\alpha=67\end{array}$ & $\begin{array}{l}\text { Normative commitment: } \\
\text { Mediated power }(-) \\
\text { Non mediated power ( } \rightarrow \text { ) } \\
\text { Instrumental commitment: } \\
\text { Mediatod power }(+) \\
\text { Non mediated power }(0)\end{array}$ & $\begin{array}{l}\text { Normative commitment: } \\
\text { Supplier's performance } \\
\text { (†) } \\
\text { Instrumental commitment } \\
\text { (-) } \\
\text { Instrumental commitment } \\
\text { Supplier's performance } \\
\text { (0) }\end{array}$ \\
\hline 5 & $\begin{array}{l}\text { Crosby, Evans } \\
\text { and Cowies, JM. } \\
\text { t990 }\end{array}$ & $\begin{array}{l}\text { Field study of } 15 \text { I beads } \\
\text { of U.S. households } \\
\text { reporting on } \\
\text { relationships with apents } \\
\text { (tife insurance: }\end{array}$ & $\mathrm{B}-1+\mathrm{C}$ & $\begin{array}{l}\text { Anticipation of future } \\
\text { internaction }(q, 70)\end{array}$ & 2 ilems, $\alpha=82$ & $\begin{array}{l}\text { Relationship Quality }(+) \\
\text { Sales Effoctiveness }(+)\end{array}$ & \\
\hline
\end{tabular}




\begin{tabular}{|c|c|c|c|c|c|c|c|}
\hline \multirow[t]{2}{*}{ Yo. } & \multirow{2}{*}{$\begin{array}{l}\text { A uthor, } \\
\text { Joumel, } Y_{\mathrm{ear}}\end{array}$} & \multirow[t]{2}{*}{ Research Dexign } & \multirow[t]{2}{*}{ Contra } & \multirow[t]{2}{*}{ Concrphadizarion } & \multirow[t]{2}{*}{ Opcrunienalication } & \multicolumn{2}{|c|}{ Empinical mraulss } \\
\hline & & & & & & A ntecridents & Covuegarmors \\
\hline 6. & $\begin{array}{l}\text { Doncy and } \\
\text { Caronon, JM. } \\
1997\end{array}$ & $\begin{array}{l}\text { Field study of } 210 \\
\text { members of the US. } \\
\text { Association of } \\
\text { Purchasing Management } \\
\text { reporting on their } \\
\text { relationship with } \\
\text { supplier's salesperson } \\
\text { (cross-section of } \\
\text { industries) }\end{array}$ & $\mathrm{B}-\mathrm{t}-\mathrm{B}$ & $\begin{array}{l}\text { Anticipated future } \\
\text { interaction with the } \\
\text { supplier (p. 4i) }\end{array}$ & 2 incms, $\alpha=95$ & $\begin{array}{l}\text { Trust of supplier firms ( }+ \text { ) } \\
\text { Delivery performance (0) } \\
\text { Relative pricelcost }(0) \\
\text { Product/service } \\
\text { performance }(0) \\
\text { Purchase experience with } \\
\text { supplier }(\bullet) \\
\text { Purchase choice }(*)\end{array}$ & \\
\hline 7. & $\begin{array}{l}\text { Ganesan. JM. } \\
1994\end{array}$ & $\begin{array}{l}\text { Field study of } 120 \text { U.S. } \\
\text { retail buyers and } 52 \text { U.S. } \\
\text { vendors supplying to } \\
\text { those retailers on } \\
\text { relationships with ons: } \\
\text { another (departmens } \\
\text { store chains) }\end{array}$ & Channel & $\begin{array}{l}\text { A retailer's long term } \\
\text { orientation is the } \\
\text { perception of } \\
\text { interdependence of } \\
\text { outcomes in which both a } \\
\text { vendor's outcomes and } \\
\text { joint outcomes are } \\
\text { expected to benefit the } \\
\text { retailer in the long rui } \\
\text { (p. } 2 / 3 \text { ). Based on Kelley } \\
\text { and Thibaut (1978) }\end{array}$ & $\begin{array}{l}\text { Vendor's long-term } \\
\text { ocientation, } 7 \text { items, } \\
c=82 \\
\text { Retailer's long-tern' } \\
\text { orientation, } 7 \text { items, } \\
\alpha=94\end{array}$ & $\begin{array}{l}\text { Credibility ( }+) \\
\text { Benevolence ( }(-) \\
\text { Retailer's dependence on } \\
\text { vendur }(*) \\
\text { Vendor's dependence on } \\
\text { retsiler }(0) \\
\text { Perception of vender's } \\
\text { dependence }(-) \\
\text { Perception of retailer's } \\
\text { dependence ( }+ \text { ) }\end{array}$ & 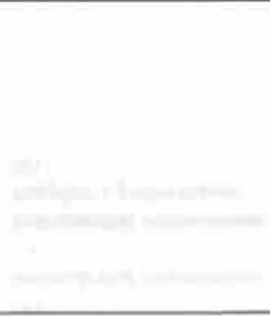 \\
\hline 8. & $\begin{array}{l}\text { Geyskens, } \\
\text { Sieenkamp, } \\
\text { Scheer and } \\
\text { Xumar, JJM. } \\
1996\end{array}$ & $\begin{array}{l}\text { Field study of } 417 \text { small } \\
\text { U.S. dealers and } 289 \\
\text { small Dutch dealers } \\
\text { reporting on } \\
\text { relationships with } \\
\text { suppliers (automobiles) }\end{array}$ & Channel & $\begin{array}{l}\text { Channel member's } \\
\text { intention to continue the } \\
\text { relationship (p. 304) }\end{array}$ & $\begin{array}{l}\text { Affective commitment, } 3 \\
\text { items, } \alpha=85 \text { (U.S.), } 81 \\
\text { (the Netherlands)! } \\
\text { Calculative commitment, } \\
3 \text { items, } \alpha=81 \text { (U.S.). } 80 \\
\text { (the Netherlands) }\end{array}$ & $\begin{array}{l}\text { Trust (t) } \\
\text { Interdependence }(+)\end{array}$ & \\
\hline 9. & $\begin{array}{l}\text { Gundlach. } \\
\text { Achrol and } \\
\text { Mentzer, IM. } \\
\text { 1995 }\end{array}$ & $\begin{array}{l}\text { Laboratory experiment } \\
\text { of } 130 \text { U.S. } \\
\text { manufacturets and } \\
\text { distributors reporting on } \\
\text { relationships with one } \\
\text { another (microcom- } \\
\text { puters) }\end{array}$ & Channe! & $\begin{array}{l}\text { Commitment is consisting } \\
\text { of three dimensions: } \\
\text { input, attitudinal and } \\
\text { temporal (p. } 83 \text { ) }\end{array}$ & $\begin{array}{l}\text { Input , } 5 \text { items, } \alpha=, 821,86 \\
\text { Autinatinal, } 4 \text { items, } \\
\alpha=, 84,92 \\
\text { Temporal, } 5 \text { inems. } \\
\alpha=861.86\end{array}$ & Relational norms $(+1+)$ & $\begin{array}{l}\text { Opportunistic behavior } \\
(+)\end{array}$ \\
\hline
\end{tabular}




\begin{tabular}{|c|c|c|c|c|c|c|}
\hline \multirow[t]{2}{*}{ No. } & \multirow{2}{*}{$\begin{array}{l}\text { A whor, } \\
\text { foumn, Year }\end{array}$} & \multirow[t]{2}{*}{ Researh Besign } & \multirow[t]{2}{*}{ Contery } & \multirow[t]{2}{*}{ Cancrptualization } & \multirow[t]{2}{*}{ Openationalization } & Empirical rexults \\
\hline & & & & & & Consequences \\
\hline 10. & $\begin{array}{l}\text { Hunt, Wood and } \\
\text { Chonko, IM. } \\
1989\end{array}$ & $\begin{array}{l}\text { Field study of } 499 \mathrm{US.S} \text {, } \\
\text { managen, } 417 \mathrm{US} \text {. } \\
\text { marketing nesearchers, } \\
\text { and } 330 \mathrm{U} . \mathrm{S} \text {. advertising } \\
\text { agency executives } \\
\text { reporting on corporate } \\
\text { ethical values and } \\
\text { organizational } \\
\text { commitmen: }\end{array}$ & $A-\{-B$ & $\begin{array}{l}\text { Organizational } \\
\text { commitment committed } \\
\text { individuals tend to } \\
\text { identify with the } \\
\text { objectives and goals of } \\
\text { their organizations and } \\
\text { want to remain with their } \\
\text { organizations (p. } 81 \text { ) }\end{array}$ & 4 itemx, $\alpha=87$ & $\begin{array}{l}\text { Age }(+) \\
\text { Income }(+) \\
\text { Education }(-) \\
\text { Feedback }(+) \\
\text { Identity }(0) \\
\text { Autonomy }(+) \\
\text { Variety }(+) \\
\text { Shared ethical values }(+ \text { ) }\end{array}$ \\
\hline !I, & $\begin{array}{l}\text { Kumar, Schees } \\
\text { and Sicenkamp. } \\
\text { JMR, 1995a }\end{array}$ & $\begin{array}{l}\text { Field study of } 417 \text { small } \\
\text { U.S. dealers and } 289 \\
\text { small Dutch dealers } \\
\text { seporting on } \\
\text { relationships with } \\
\text { suppliers (automobiles) }\end{array}$ & Channel & $\begin{array}{l}\text { Party's intention to } \\
\text { continue the relationship } \\
\text { (p. 58) }\end{array}$ & $\begin{array}{l}\text { Affective commitment. } 3 \\
\text { iterns, } \alpha \text { not reported }\end{array}$ & $\begin{array}{l}\text { Age }(0) \\
\text { Distributive faimess }(+) \\
\text { Procedural faimess }(+) \\
\text { Environmental } \\
\text { uocertainty }(-) \\
\text { Outcomes given } \\
\text { altematives }(+)\end{array}$ \\
\hline 12 & $\begin{array}{l}\text { Kumar, Scheet } \\
\text { and Steenkamp. } \\
\text { JMR, } 19956\end{array}$ & $\begin{array}{l}\text { Ficld study of } 417 \text { small } \\
\text { U.S, dealers reporting on } \\
\text { relationships with } \\
\text { suppliers (automobiles) }\end{array}$ & Channel & $\begin{array}{l}\text { Desire to continue a } \\
\text { relationship because of } \\
\text { positive affect toward the } \\
\text { partner (affective } \\
\text { commitment), perception } \\
\text { of its awn and its } \\
\text { partner's intent to remain } \\
\text { in the relationship } \\
\text { (expectation of } \\
\text { continuity), and intention } \\
\text { to become more deeply } \\
\text { involved in the } \\
\text { relationship through } \\
\text { investments of capital and } \\
\text { effort (willingness to } \\
\text { invess) (p. 351) }\end{array}$ & $\begin{array}{l}\text { Affective coenmitment. } 3 \\
\text { items, } \alpha \text { not reponed } \\
\text { Expectation of continuity. } \\
3 \text { items, } \alpha \text { not reponed } \\
\text { Willingness to invest. } 3 \\
\text { items, } \alpha \text { not reported }\end{array}$ & $\begin{array}{l}\text { Total intendependence ( }+) \\
\text { Interdependence } \\
\text { asymmetry }(-)\end{array}$ \\
\hline
\end{tabular}




\begin{tabular}{|c|c|c|c|c|c|c|c|}
\hline \multirow[t]{2}{*}{ No. } & \multirow{2}{*}{$\begin{array}{l}\text { Airthor: } \\
\text { burnal, Year }\end{array}$} & \multirow[t]{2}{*}{ Arseouch Draign } & \multirow[t]{2}{*}{ Comexd } & \multirow[t]{2}{*}{ Concrptualization } & \multirow[t]{2}{*}{ Opentiondicanion } & \multicolumn{2}{|c|}{ Eimpirined msults } \\
\hline & & & & & & A ntroceidents & Conseparmires \\
\hline 15. & $\begin{array}{l}\text { Moormin, } \\
\text { Zaltman and } \\
\text { Desphandé. } \\
\text { JMR, } 1992\end{array}$ & $\begin{array}{l}\text { Field study of } 779 \text { U.S. } \\
\text { marketing managers. } \\
\text { marketing researchers } \\
\text { and non-marketing } \\
\text { managers reporting on } \\
\text { their relationships with } \\
\text { various providers of } \\
\text { market research. }\end{array}$ & B-to-B & $\begin{array}{l}\text { Enduring desire to } \\
\text { maintain a valued } \\
\text { relationship (p.316) }\end{array}$ & 3 itemx, $c 0=, 78$ & $\begin{array}{l}\text { Trust }(\bullet) \\
\text { Perceived quality of } \\
\text { interactions }(+)\end{array}$ & \\
\hline
\end{tabular}




\begin{tabular}{|c|c|c|c|c|c|c|c|}
\hline \multirow[t]{2}{*}{$\mathrm{Na}$. } & \multirow{2}{*}{$\begin{array}{l}\text { Awhor, } \\
\text { Joumal, Year }\end{array}$} & \multirow[t]{2}{*}{ Resecorh Derign } & \multirow[t]{2}{*}{ Convext } & \multirow[t]{2}{*}{ Concephalizetion } & \multirow[t]{2}{*}{ Openationalization } & \multicolumn{2}{|c|}{ Empirical serults } \\
\hline & & & & & & Antecedents & Consequencer \\
\hline 16. & $\begin{array}{l}\text { Morgan and } \\
\text { Hunt, JM, } 1994\end{array}$ & $\begin{array}{l}\text { Field study of } 204 \text { U.S. } \\
\text { retailers reporting on } \\
\text { their relationship with } \\
\text { supplier (tires) }\end{array}$ & Channel & $\begin{array}{l}\text { An exchange partner } \\
\text { believing that an ongoing } \\
\text { relationship with another } \\
\text { is so important as to } \\
\text { warrant maximum efforts } \\
\text { at maintaining it: that is, } \\
\text { the comminted party } \\
\text { believes the relationship is } \\
\text { worth working on to } \\
\text { ensure that it endures } \\
\text { indefinitely }[\mathrm{p}, 23 \text { ) }\end{array}$ & 7 itemx, $\alpha=90$ & $\begin{array}{l}\text { Trust }(+) \\
\text { Relationship termination } \\
\text { costs }(\phi) \\
\text { Relationship benefits }(0) \\
\text { Shared values }(+)\end{array}$ & $\begin{array}{l}\text { Acquiescence }(+) \\
\text { Propensity to leave }(- \text { ) } \\
\text { Cooperation }(\uparrow)\end{array}$ \\
\hline 17. & $\begin{array}{l}\text { Olsen and } \\
\text { Granzin, JR. } \\
1992\end{array}$ & $\begin{array}{l}\text { Field study of } 92 \\
\text { retailers reporting on } \\
\text { their relationship with } \\
\text { manufacturers (auts } \\
\text { parts) }\end{array}$ & Channel & $\begin{array}{l}\text { Willingness to belp: a } \\
\text { general sense how much } \\
\text { the retailer perceiver the } \\
\text { situation to be } \\
\text { troublesome for the } \\
\text { manufacturet who thus } \\
\text { bas a definite need for } \\
\text { assistance (p. 94) }\end{array}$ & $\begin{array}{l}\text { Willingness to help, } 12 \\
\text { items, } \alpha=94\end{array}$ & $\begin{array}{l}\text { Retailer responsibility (+) } \\
\text { Manufachurer } \\
\text { responsibility }(0) \\
\text { Government } \\
\text { responsibility }(0)\end{array}$ & \\
\hline 18. & Ping. IR, 1997 & $\begin{array}{l}\text { Field study of } 204 \\
\text { retailen reporting on } \\
\text { relationships with } \\
\text { wholesalers (handware) }\end{array}$ & $B+1-B$ & $\begin{array}{l}\text { Structural commitment: } \\
\text { Alternative attractiveness: } \\
\text { satisfaction believed to be } \\
\text { arailable in the best } \\
\text { alternative relationship } \\
\text { Investment: magnitude of } \\
\text { the cost that went into } \\
\text { building and maintaining } \\
\text { the current relationship } \\
\text { Switching cost: cost and } \\
\text { loss required to terminate } \\
\text { the current relationship } \\
\text { and secure an alternative } \\
\text { relationship (p. } 270)\end{array}$ & $\begin{array}{l}\text { Structural commitment: } \\
\text { Altemative attractiveness, } \\
\text { if items, } \alpha=93 \\
\text { Investment, } 4 \text { nens, } \\
\alpha=92 \\
\text { Switching coits, } 4 \text { thems, } \\
\alpha=94\end{array}$ & s. & Vaice (t) \\
\hline
\end{tabular}




\section{Appendix 3 Pilot Study}

In general I am someone who...

completely

disagree

completely agree

\section{$\mathbf{v}$}

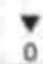

$\mathbf{v}$

3

... likes to have a special tie with an apparel store

.- wants to be a steady customer of the same apparel store

enjoys having a close tie with an apparel store

a d a d a a a a a

... likes to be a regular customer of an apparel store

a

is wiling "to go the extra mile" to purchase at the same apparel store

$\begin{array}{lllllll}a & a & a & a & a & a & a\end{array}$

... tends to buy in the same apparel store

The following is a list of things that some people look for or want out of life. Please study the list carefully and then rate each thing on how important it is in your daily life.

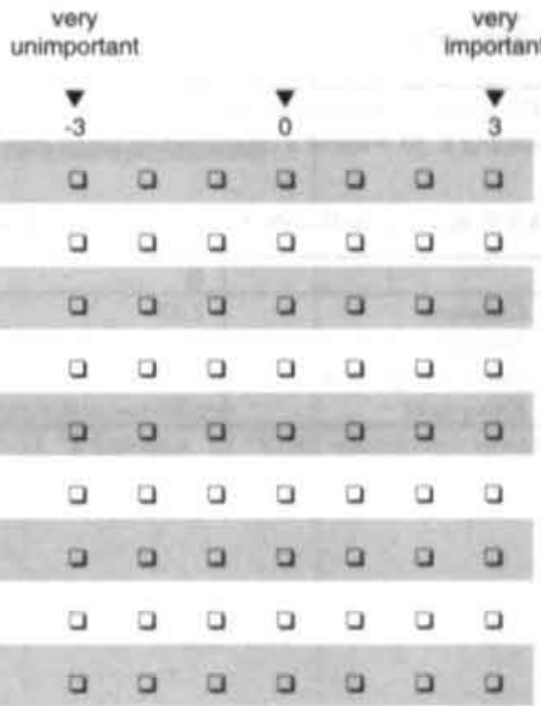

Thank you for your cooperation! 
Table A.3-1: Intemal Consistency of Constnucts

\begin{tabular}{|c|c|c|c|}
\hline Construct & LOV Items and comesponding iter & & $\bar{\alpha}$ \\
\hline Sociability & $\begin{array}{l}\text { 1. Sense of belonging } \\
\text { 3. Warm relationships with others } \\
\text { 7. Security }\end{array}$ & $\begin{array}{l}52 \\
52 \\
45\end{array}$ & .67 \\
\hline Social recognition & $\begin{array}{l}\text { 4. Self-fulfillment } \\
\text { 5. Being well respected } \\
\text { 8. Self-respect } \\
\text { 9. Sense of accomplishment }\end{array}$ & $\begin{array}{l}53 \\
50 \\
.61 \\
51 \\
\end{array}$ & .74 \\
\hline Enjoyment & $\begin{array}{l}\text { 2. Excitement } \\
\text { 6. Fun and enjoyment of life }\end{array}$ & $\begin{array}{l}.39 \\
39 \\
\end{array}$ & .55 \\
\hline
\end{tabular}

Table A3-2: Principal Components Results

\begin{tabular}{ll|c|c|c|}
\hline & & \multicolumn{4}{c}{ Component } \\
\cline { 3 - 5 } Construct & Item & \multicolumn{1}{c}{$\mathbf{1}$} & $\mathbf{3}$ \\
\hline Sociability & 1. & .000 & .000 & $\frac{870}{710}$ \\
& 3. & .170 & .470 & $\frac{710}{.614}$ \\
\hline Social recognition & 7. & .448 & -112 & .112 \\
& 4. & 578 & 539 & .000 \\
& 5. & .806 & .000 & .158 \\
& 8. & 681 & .282 & .260 \\
\hline Enjoyment & 9. & .597 & .349 & .118 \\
& 2. & .000 & .851 & .000 \\
& 6. & .334 & 652 & .000 \\
\hline
\end{tabular}

The underlined main loadings are $\geq .65$. The shaded areas represent items with a main loading $\geq .65$ without a cross-loading larger than .30 .

\section{A3-3: Regression Results LOV-Components Independent and Buyer Relationship Proneness Dependent}

\begin{tabular}{l|llll}
\hline & B & Std. Emor & Beta & Significance \\
\hline Constant & 1.45 & 1.01 & & .15 \\
Sociability & 39 & .12 & .26 & $.00^{* *}$ \\
Social recognition & .40 & .18 & .19 & $.03^{*}$ \\
Enjoyment & -.37 & .15 & -.19 & $.01^{*}$ \\
\hline
\end{tabular}

Model significance $.00, \mathrm{R}^{2}, 12$, Adjusted $\mathrm{R}^{2} .11$

$* p<, 05, * *<, 01$ 


\section{Appendix 4 Quantitative Item Testing}

We quantitatively tested an initial set of items in order to investigate whether these items correctly measured the following intended constructs: sociability, social recognition, shopping enjoyment. product category involvement, buyer relationship proneness, seller relationship orientation, relationship satisfaction, trust, relationship commitment, and behavioral loyalty. The samples used for testing items were spread across countries and product categories (the Netherlands $\mathrm{N}=92$, the Netherlands food $\mathrm{N}=104$, Belgium clothing $\mathrm{N}=90$, Belgium food $\mathrm{N}=85$ ). Principal components analysis was used for this purpose. In order to determine which constructs to group in the principal components analyses, we constructed the matrix described below. This matrix indicates that constructs differ on two dimensions: what is the construct about (one store versus the respondent or stores in general) and who does the construct concern (the respondent versus regular customers). Since we do not have any theoretical argument to assume that constructs in different quadrants measure the same concept as they relate to a different unit of analysis, we conducted separate principal components analyses including the constructs of each quadrant.

What is it about?

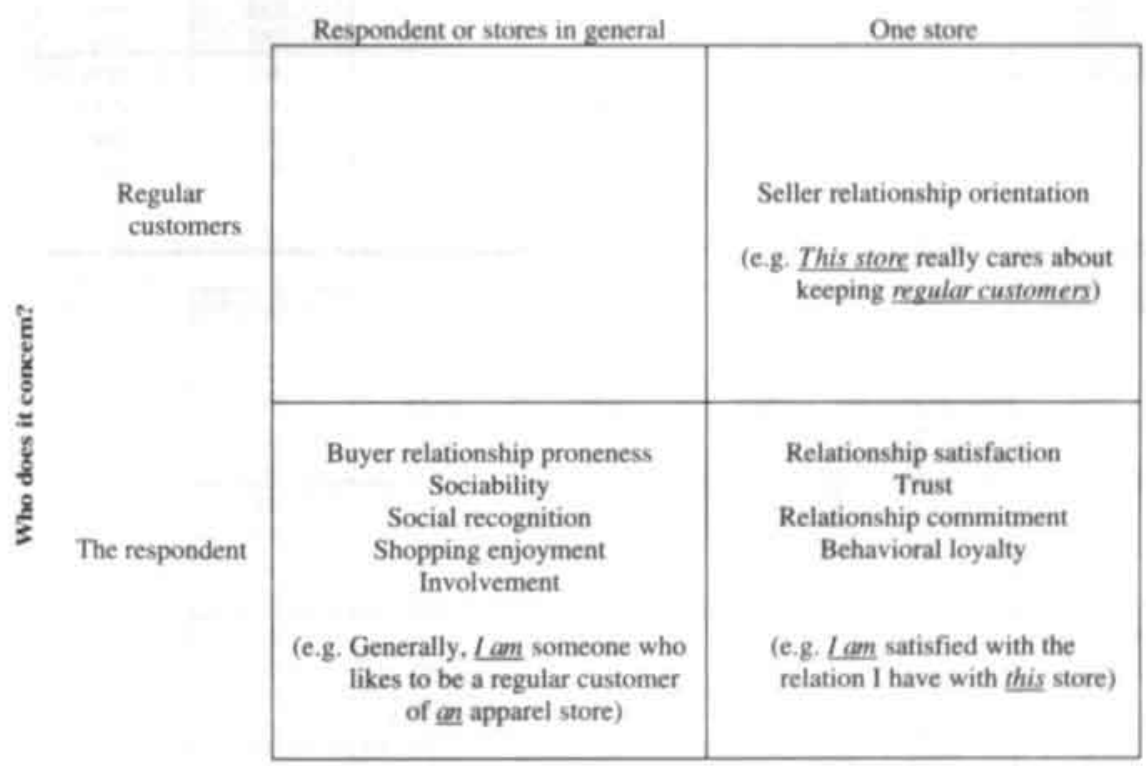

As the underlying structure of the data sets was known in advance based upon previous studies (De Wulf and Odekerken-Schröder 1998/1999), the number of components to be derived was predetermined. In tables A4-I to A4-4, underlined loadings exceed .65 and shaded loadings exceed .65 and cross-load equal to or less than .30 . 
Table A4-1: Principal Components Analysis with Oblique Rotation (the Netherlands Clothing)

\begin{tabular}{|c|c|c|c|c|c|c|}
\hline \multirow[b]{2}{*}{ Comtruet } & \multirow[b]{2}{*}{ Item } & \multicolumn{5}{|c|}{ Component } \\
\hline & & 1 & 2 & 3 & 4 & 5 \\
\hline \multirow[t]{6}{*}{ Sociability } & 1 & .115 & .119 & .099 & -.079 & 716 \\
\hline & 2 & .040 & -.133 & .156 & -.000 & 743 \\
\hline & 3 & -.019 & -120 & -108 & .287 & .712 \\
\hline & 4 & .017 & .049 & .152 & .031 & 742 \\
\hline & 5 & .152 & 198 & 006 & -.293 & 434 \\
\hline & 6 & .093 & .055 & .162 & -.242 & 513 \\
\hline \multirow[t]{6}{*}{ Social recognition } & 1 & .057 & .176 & 736 & -.084 & -.011 \\
\hline & 2 & .150 & .030 & 777 &, 073 & -.010 \\
\hline & 3 & -.161 & -.136 & 653 & .090 & .122 \\
\hline & 4 & .079 & -.177 & .733 & .166 & .009 \\
\hline & 5 & -.061 & .035 & 737 & .061 & .182 \\
\hline & 6 & .018 & .027 & 839 & -.068 & -.075 \\
\hline \multirow[t]{6}{*}{ Shopping enjoyment } & 1 & $\frac{x 35}{2}$ & .013 & .046 & .025 & .188 \\
\hline & 2 & 698 & .064 & .143 & .075 & -315 \\
\hline & 3 & 914 & .042 & .020 & .075 & .044 \\
\hline & 4 & 880 & -.097 & .011 & .055 & -.063 \\
\hline & 5 & 764 & .053 & -.067 & -.000 & .253 \\
\hline & 6 & 872 & -.019 & -.064 & .008 & .201 \\
\hline \multirow[t]{3}{*}{ Product category involvement } & 1 & .112 & .029 & .034 & 814 & -.040 \\
\hline & 2 & .070 & .174 & .121 & 804 & -.024 \\
\hline & 3 & .056 & 214 & .026 & 785 & 141 \\
\hline \multirow[t]{6}{*}{ Buyer relationship proneness } & 1 & .257 & 716 & .035 & 048 & -.050 \\
\hline & 2 & .070 & 890 & .084 & .013 &,- 169 \\
\hline & 3 & -.111 & 886 & -.053 & -.030 & .068 \\
\hline & 4 & .098 & 828 & -103 & .026 &, 033 \\
\hline & 5 & -.080 & 786 & -.080 & .175 & -.016 \\
\hline & 6 & -.317 & 483 & .049 & 145 & 112 \\
\hline Construct & Item & 1 & 2 & 3 & 4 & \\
\hline \multirow[t]{6}{*}{ Relationship satisfaction } & 1 & .019 & .230 & -.069 & 807 & \\
\hline & 2 & 668 & -.060 & -.095 & .307 & \\
\hline & 3 & .588 & .127 & .197 & .150 & \\
\hline & 4 & .355 & -.042 & -.448 & .132 & \\
\hline & 5 & .355 & .043 & -.344 & .219 & \\
\hline & 6 & 898 & .109 & .113 & -.088 & \\
\hline \multirow[t]{4}{*}{ Trust } & 1 & 877 & .025 & .005 & -.094 & \\
\hline & 2 & .786 & .006 & .113 & .206 & \\
\hline & 3 & 542 & -.262 & -.275 & .344 & \\
\hline & 4 & 777 & .065 & -.206 & -.300 & \\
\hline \multirow[t]{4}{*}{ Relationship commitment } & 1 & .026 & .558 &. .526 & -197 & \\
\hline & 2 & -.032 & -.144 & -861 & .071 & \\
\hline & 3 &,- 067 & .113 & 894 & -029 & \\
\hline & 4 & .037 & .112 & .735 & -.015 & \\
\hline \multirow[t]{3}{*}{ Behavioral loyalty } & 1 & -.067 & 825 & -.017 & .215 & \\
\hline & 2 & .093 & 896 & .047 & -.029 & \\
\hline & 3 & .111 & 846 & -.027 & .038 & \\
\hline Construct & Item & 1 & & & & \\
\hline \multirow[t]{6}{*}{ Seller relationship orientation } & 1 & $\frac{783}{789}$ & & & & \\
\hline & 2 & 787 & & & & \\
\hline & 3 & 780 & & & & \\
\hline & 4 & 819 & & & & \\
\hline & 5 & 884 & & & & \\
\hline & 6 & 793 & & & & \\
\hline
\end{tabular}


The Role of the Buyer in Affecting Buyer-Seller Relationships

Table A4-2: Principal Components Analysis with Oblique Rotation (the Netherlands Food)

\begin{tabular}{|c|c|c|c|c|c|c|}
\hline \multirow[b]{2}{*}{ Construct } & \multirow[b]{2}{*}{ Item } & \multicolumn{5}{|c|}{ Component } \\
\hline & & 1 & 2 & 3 & 4 & 5 \\
\hline \multirow[t]{6}{*}{ Sociability } & 1 & .198 & -.128 & -.005 & .008 & 663 \\
\hline & 2 & .071 & .119 & -.029 & .078 & .616 \\
\hline & 3 & .011 & -.013 & -010 & .225 & .611 \\
\hline & 4 & .193 &,- 090 & -.034 & -.048 & 275 \\
\hline & 5 & -134 & 122 &,- 063 & .002 & 717 \\
\hline & 6 & -.085 & .134 & -089 & -.055 & 753 \\
\hline \multirow[t]{6}{*}{ Social recognition } & 1 & .479 & -.024 & .066 & -162 & 319 \\
\hline & 2 & 677 & .040 & .069 & 138 & .421 \\
\hline & 3 & .528 & -.039 & -.299 & .050 & .003 \\
\hline & 4 & 827 & .130 & .100 & .017 & 137 \\
\hline & 5 & 698 & -.040 & -.177 & .018 & .234 \\
\hline & 6 & 813 & .068 & .009 & .167 & .128 \\
\hline \multirow[t]{6}{*}{ Shopping enjoyment } & 1 & .035 & .090 & -.835 & .121 & -.081 \\
\hline & 2 & 339 & .041 & .595 & .085 & -.040 \\
\hline & 3 & .021 & -.057 & .887 & -008 & .038 \\
\hline & 4 & -.082 & -.063 & .864 & .007 & .052 \\
\hline & 5 & -.051 & .045 & .821 & .079 & .123 \\
\hline & 6 & .040 & .108 & .861 & .007 & .071 \\
\hline \multirow[t]{3}{*}{ Product category involvement } & 1 & -.057 & .049 & .012 & 890 & .009 \\
\hline & 2 & .028 & -.052 & -.090 & 884 & .033 \\
\hline & 3 & .018 & .041 & .022 & 918 & .075 \\
\hline \multirow[t]{6}{*}{ Buyer relationship proneness } & 1 & -.023 & 752 & .045 & .030 & .001 \\
\hline & 2 & .090 & 849 & .012 & .076 & .016 \\
\hline & 3 & -.072 & 833 & -.068 & .069 & .032 \\
\hline & 4 & -.070 & 824 & -.071 & -.047 & .029 \\
\hline & 5 & -.049 & 863 & -.036 & -050 & -.029 \\
\hline & 6 & .249 & .632 & .161 & .063 & .066 \\
\hline Construct & Item & 1 & 2 & 3 & 4 & \\
\hline \multirow[t]{6}{*}{ Relationship satisfaction } & 1 & -.023 & .141 & .608 & .299 & \\
\hline & 2 & 802 & .074 & .054 & 308 & \\
\hline & 3 & 672 &,- 000 & .091 & .088 & \\
\hline & 4 & .056 & -.043 & 768 & .074 & \\
\hline & 5 & -.075 & -.085 & 898 & -.014 & \\
\hline & 6 & .077 & .053 & 852 & 179 & \\
\hline \multirow[t]{4}{*}{ Trust } & 1 & 695 & .078 & .107 & -.167 & \\
\hline & 2 & 752 & .035 & -.025 & .296 & \\
\hline & 3 & 854 & -.099 & .011 & .022 & \\
\hline & 4 & .534 & -.081 & .258 & -.276 & \\
\hline \multirow[t]{4}{*}{ Relationship commitment } & 1 & 512 & .500 & .096 & .095 & \\
\hline & 2 & .143 & -.031 & .555 & -.193 & \\
\hline & 3 & .251 & .200 & .220 & -.495 & \\
\hline & 4 & .039 & .018 & .076 & .883 & \\
\hline \multirow[t]{3}{*}{ Behavioral loyalty } & 1 & .033 & 929 & -.116 & .063 & \\
\hline & 2 & -.092 & 981 & .035 & -.034 & \\
\hline & 3 & -.036 & 958 & 109 & .087 & \\
\hline Construct & Item & 1 & & & & \\
\hline \multirow{6}{*}{ Seller relationship orientation } & 1 & 776 & & & & \\
\hline & 2 & 838 & & & & \\
\hline & 3 & 830 & & & & \\
\hline & 4 & 731 & & & & \\
\hline & 5 & 771 & & & & \\
\hline & 6 & 887 & & & & \\
\hline
\end{tabular}


Table A4-3: Principal Components Analysis with Oblique Rotation (Belgium Cothing)

\begin{tabular}{|c|c|c|c|c|c|c|}
\hline \multirow[b]{2}{*}{ Construct } & \multirow[b]{2}{*}{ Item } & \multicolumn{5}{|c|}{ Component } \\
\hline & & 1 & 2 & 3 & 4 & 5 \\
\hline \multirow[t]{6}{*}{ Sociability } & 1 & 742 & .021 & .044 & .077 & .082 \\
\hline & 2 & 540 & .209 & -.062 & 225 & -.021 \\
\hline & 3 & 656 & -.074 & .061 & -.242 & .280 \\
\hline & 4 & 837 & .077 & -.118 & -.084 & .010 \\
\hline & 5 & 669 & .088 & -.298 & -.026 & -.035 \\
\hline & 6 & 728 & .168 & -.113 & .000 & .120 \\
\hline \multirow[t]{6}{*}{ Social recognition } & 1 & 300 & -.092 & .068 & .625 & .150 \\
\hline & 2 & 511 & -.180 & 109 & .475 & .070 \\
\hline & 3 & .074 & .154 & -.095 & 738 & -.017 \\
\hline & 4 & .611 & -.171 & 002 & .423 & .071 \\
\hline & 5 & -193 & .160 & -.096 & 808 & .061 \\
\hline & 6 & 533 &,- 024 & -.022 & 415 & .111 \\
\hline \multirow[t]{6}{*}{ Shopping enjoyment } & 1 & -.026 & 836 & -.120 & -.104 & 121 \\
\hline & 2 & .194 & 669 & .250 &, 021 & .128 \\
\hline & 3 & .171 & 842 & -.057 & .014 & -036 \\
\hline & 4 & .086 & 882 & -.069 & -.019 & .085 \\
\hline & 5 & -.081 & 822 & -.052 & .128 & .113 \\
\hline & 6 & .044 & 864 & -.076 & .047 & -.025 \\
\hline \multirow[t]{3}{*}{ Product category involvement } & 1 & .026 & .036 & -.181 & .086 & 748 \\
\hline & 2 & -.083 & .096 &,- 018 & -.069 & 899 \\
\hline & 3 & 089 & .009 & -127 & .132 & 779 \\
\hline \multirow[t]{6}{*}{ Buyer relationship proneness } & 1 & -.170 & .061 & -.566 & 310 & .199 \\
\hline & 2 & .141 & .072 & -833 &,- 031 & .005 \\
\hline & 3 &,- 008 & 038 & .744 & -.113 & .182 \\
\hline & 4 & .033 & 022 & .788 & 268 & .020 \\
\hline & 5 & .064 & -.027 & .767 & .016 & 237 \\
\hline & 6 & .134 & -.084 & -.807 & -.109 & -.036 \\
\hline Construct & Item & 1 & 2 & 3 & 4 & \\
\hline \multirow[t]{6}{*}{ Relationship satisfaction } & 1 & .252 & .190 & .581 & -.102 & \\
\hline & 2 & .430 & -.018 & .595 & -161 & \\
\hline & 3 & .737 & -.066 & .225 & -.035 & \\
\hline & 4 & .003 & .000 & .713 & .230 & \\
\hline & 5 & .045 & -.056 & 750 & .124 & \\
\hline & 6 & -030 & .071 & 875 & .052 & \\
\hline \multirow[t]{4}{*}{ Trust } & 1 & 814 & .064 & -.063 & .067 & \\
\hline & 2 & 797 & .016 & .104 & .046 & \\
\hline & 3 & 864 & .033 & .050 & -.028 & \\
\hline & 4 & 686 & -.038 & 133 & .155 & \\
\hline \multirow[t]{4}{*}{ Relationship commitment } & 1 & .508 & .451 & -.054 & .204 & \\
\hline & 2 & .324 & -.049 & .171 & .566 & \\
\hline & 3 & .416 & .210 & -.027 & .515 & \\
\hline & 4 & -.070 & .022 & .119 & 849 & \\
\hline \multirow[t]{3}{*}{ Behavioral loyalty } & 1 & -.188 & 829 & .195 & -.053 & \\
\hline & 2 & .045 & 881 & -.076 & .083 & \\
\hline & 3 & .183 & 862 & .093 & .000 & \\
\hline Construct & Item & 1 & & & & \\
\hline \multirow[t]{6}{*}{ Seller relationship orientation } & 1 & 801 & & & & \\
\hline & 2 & 875 & & & & \\
\hline & 3 & 804 & & & & \\
\hline & 4 & 724 & & & & \\
\hline & 5 & 832 & & & & \\
\hline & 6 & 794 & & & & \\
\hline
\end{tabular}


Table A4-4: Principal Components Analysis with Oblique Rotation (Belgium Food)

\begin{tabular}{|c|c|c|c|c|c|c|}
\hline \multirow[b]{2}{*}{ Construct } & \multirow[b]{2}{*}{ Item } & \multicolumn{5}{|c|}{ Component } \\
\hline & & 1 & 2 & 3 & 4 & 5 \\
\hline \multirow[t]{6}{*}{ Sociability } & 1 & -.051 & .028 & .069 & .042 & .873 \\
\hline & 2 & -.030 & .371 & -177 & 285 & -.459 \\
\hline & 3 & .431 & .218 & .423 & .005 &,- 411 \\
\hline & 4 & .282 & .047 & .649 & -.016 & -.270 \\
\hline & 5 & -158 & 086 & .018 & .002 & -698 \\
\hline & 6 & .101 & 135 & 676 & .022 & .239 \\
\hline \multirow{6}{*}{ Social recognition } & 1 & .151 & 308 & -.071 & .093 & .576 \\
\hline & 2 & .235 & .605 & .399 & -176 & -.065 \\
\hline & 3 & .015 & 690 & -020 & .098 & -199 \\
\hline & 4 & 371 & 471 & .445 & -.303 & .005 \\
\hline & 5 & .017 & 377 & -038 & .010 & -.159 \\
\hline & 6 & .026 & 812 & .086 & 118 & 047 \\
\hline \multirow[t]{6}{*}{ Shopping enjoyment } & 1 & 843 & .021 & .030 & .009 & .006 \\
\hline & 2 & 590 & .089 & .137 & 149 & 085 \\
\hline & 3 & 844 & -.025 & .000 & .066 & -.073 \\
\hline & 4 & 804 & .026 & .048 & -.013 & -.079 \\
\hline & 5 & 773 & .061 & 5.106 & .115 & .192 \\
\hline & 6 & 862 & .077 & .177 & 022 & .042 \\
\hline \multirow[t]{3}{*}{ Product category involvement } & 1 & .156 & -.016 & 769 & .118 & .054 \\
\hline & 2 &,- 107 & -.029 & 900 & .114 & 193 \\
\hline & 3 & -.089 & .051 & 883 & 138 & 122 \\
\hline \multirow[t]{6}{*}{ Buyer relationship proneness } & 1 & -.159 & .149 & .100 & 690 & -.052 \\
\hline & 2 & .123 & 127 & .134 & 810 & 146 \\
\hline & 3 & .081 & .011 & .032 & 880 & .035 \\
\hline & 4 & .062 & .143 & .190 & 831 & 197 \\
\hline & 5 & .265 & -.201 & 137 & 698 & -.221 \\
\hline & 6 & .165 & .175 & -.157 & 705 & -.202 \\
\hline Construct & Item & 1 & 2 & 3 & 4 & \\
\hline \multirow[t]{6}{*}{ Relationship satisfaction } & 1 & .012 & .253 & 667 & .008 & \\
\hline & 2 & .390 & -008 & .644 & -180 & \\
\hline & 3 & 896 & -.128 & .130 & -.081 & \\
\hline & 4 & .188 & .010 & .584 & 162 & \\
\hline & 5 & -.000 & -.061 & 728 & .163 & \\
\hline & 6 & -.070 & .041 & 919 & .040 & \\
\hline \multirow[t]{4}{*}{ Trust } & 1 & 705 & .112 &,- 067 & 122 & \\
\hline & 2 & 706 & .081 & .104 & .165 & \\
\hline & 3 & 904 & .067 & .060 & -.139 & \\
\hline & 4 & .710 & -.022 & .016 & .241 & \\
\hline \multirow[t]{4}{*}{ Relationship commitment } & 1 & .279 & .608 & .010 & .244 & \\
\hline & 2 & .223 & .071 & 102 & 682 & \\
\hline & 3 & .291 & 398 & .028 & 532 & \\
\hline & 4 & -.061 & .065 & .151 & .825 & \\
\hline \multirow[t]{3}{*}{ Behavioral loyalty } & 1 & .097 & .797 & .163 & .046 & \\
\hline & 2 & -.040 & 920 & .018 & .064 & \\
\hline & 3 & .058 & 966 & .060 & -101 & \\
\hline Construct & Item & 1 & & & & \\
\hline \multirow[t]{6}{*}{ Seller relationship orientation } & 1 & 812 & & & & \\
\hline & 2 & 836 & & & & \\
\hline & 3 & 843 & & & & \\
\hline & 4 & 650 & & & & \\
\hline & 5 & 847 & & & & \\
\hline & 6 & 811 & & & & \\
\hline
\end{tabular}


Table A4-5: Principal Components Analysis with Oblique Rotation (Aggregated Sample)

\begin{tabular}{|c|c|c|c|c|c|c|}
\hline \multirow[b]{2}{*}{ Comstruct } & \multirow[b]{2}{*}{ Item } & \multicolumn{5}{|c|}{ Component } \\
\hline & & 1 & 2 & 3 & 4 & 5 \\
\hline \multirow[t]{6}{*}{ Sociability } & 1 & .110 & -.005 & .043 & -.095 & .746 \\
\hline & 2 & .167 & -.005 & -.025 & -.111 & -.595 \\
\hline & 3 & -.158 & -.040 & -.071 & .195 & -.697 \\
\hline & 4 & .025 & -.031 & -.065 & .069 & $=795$ \\
\hline & 5 & .038 & .112 & .018 & -.053 & -.598 \\
\hline & 6 & 052 & 050 & -.074 & .053 & -.645 \\
\hline \multirow[t]{6}{*}{ Social recognition } & I & .638 & .009 & .015 & -.088 & -.201 \\
\hline & 2 & 682 & -.050 & -.014 & .030 & -217 \\
\hline & 3 & 706 & 012 & -.061 & .008 & .034 \\
\hline & 4 & 700 & -.054 & .003 & .140 & -.131 \\
\hline & 5 & 810 & .034 & .055 & -.027 & 170 \\
\hline & 6 & 778 & .045 & .027 & .081 & $\begin{array}{r}-035 \\
\end{array}$ \\
\hline \multirow[t]{6}{*}{ Shopping enjoyment } & 1 & -.037 & .044 & -848 & .054 & -.010 \\
\hline & 2 & 148 & .012 & .670 & .066 & .064 \\
\hline & 3 & .006 & -.015 & .885 & .006 & -.054 \\
\hline & 4 & -043 & -086 & .873 & .041 & -.016 \\
\hline & 5 &,- 022 & .069 & $=813$ & -130 & -.043 \\
\hline & 6 & .012 & .036 & -881 & -.045 & -033 \\
\hline \multirow[t]{3}{*}{ Product category involvement } & 1 & .058 & .038 & .029 & 858 & .006 \\
\hline & 2 & .015 & -.005 & -.057 & 899 & .039 \\
\hline & 3 & 035 & .081 & 032 & 866 &,- 068 \\
\hline \multirow[t]{6}{*}{ Buyer relationship proneness } & 1 & .081 & 2u & -.065 & .006 & .076 \\
\hline & 2 & .033 & 855 & -.061 & .015 & .013 \\
\hline & 3 & -.105 & 866 & -.011 & -.009 & -.051 \\
\hline & 4 & .027 & 837 & -.071 & -.028 & .031 \\
\hline & 5 & -.038 & 826 & -.004 & .073 & -.037 \\
\hline & 6 & -.004 & 656 & .131 & .027 & -.063 \\
\hline Construct & Item & 1 & 2 & 3 & 4 & \\
\hline \multirow[t]{6}{*}{ Relationship satisfaction } & 1 & .252 & .190 & .581 & -.102 & \\
\hline & 2 & .430 & -.018 & 895 & -.161 & \\
\hline & 3 & .737 & -.066 & .225 & -.035 & \\
\hline & 4 & .003 & .000 & .713 & .230 & \\
\hline & 5 & .045 & -.056 & 750 & .124 & \\
\hline & 6 & -.030 & .071 & 875 & .052 & \\
\hline \multirow[t]{4}{*}{ Trust } & 1 & 814 & .064 & -.063 & .067 & \\
\hline & 2 & 797 & .016 & .104 & .046 & \\
\hline & 3 & 864 & .033 & .050 & -.028 & \\
\hline & 4 & 686 & -.038 & .133 & .155 & \\
\hline \multirow[t]{4}{*}{ Relationship commitment } & 1 & .508 & .451 & -.054 & .204 & \\
\hline & 2 & .324 &. .049 & .171 & .566 & \\
\hline & 3 & .416 & .210 & -.027 & 515 & \\
\hline & 4 & -.070 & .021 & .119 & 849 & \\
\hline \multirow[t]{3}{*}{ Behavioral loyalty } & I & -.188 & 829 & .195 & -.053 & \\
\hline & 2 & .045 & 881 & -.076 & .083 & \\
\hline & 3 & .183 & 862 & -.093 & .000 & \\
\hline Construct & Item & 1 & & & & \\
\hline \multirow[t]{6}{*}{ Seller relationship orientation } & 1 & 799 & & & & \\
\hline & 2 & 838 & & & & \\
\hline & 3 & 812 & & & & \\
\hline & 4 & 734 & & & & \\
\hline & 5 & 826 & & & & \\
\hline & 6 & 824 & & & & \\
\hline
\end{tabular}




\section{Appendix 5 Questionnaire}

Dear visitor,

This questionnaire from University of Central Florida deals with the efforts that apparel stores undertake towards their regular customers.

- It applies to the following types of stores:

- ready-to-wear apparel stores that sell regular clothing (no special event clothing)

- large department stores / clothing chains as well as smaller stores / boutiques

- no mail order stores (like fi. Land's End, L.L. Bean, etc.)

- Regular customers of a store are those who:

- regularly buy clothes in this store

- and not simply visit this store only to "look around"

With this survey, we like to find out your honest opinion. Thus there are no right or wrong answers. Don't worry about questions that seemingly look alike.

\section{Many thanks for your cooperation!}


Do you over bury clothes yoursell?

\section{$\square$ yes $\rightarrow$ please continue}

I no $\rightarrow$ sorry, thanks anyway

\section{a}

In which $\mathbf{5}$ stores do you usually bury your clothes?

Name of the store
2

What percentage of your tolat expenditures for clothing do you spend in each of these stores?

Percentage between $0 \%$ and $100 \%$ (total may be less than $100 \%$ )

To what extent do you consider yourselit a regular customer in each of these stores?

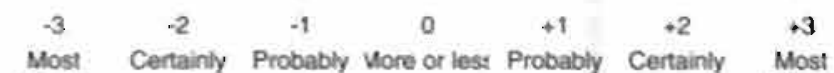

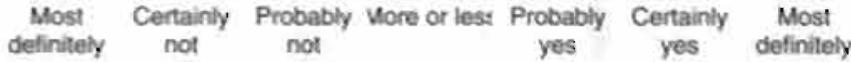

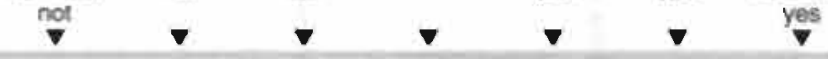

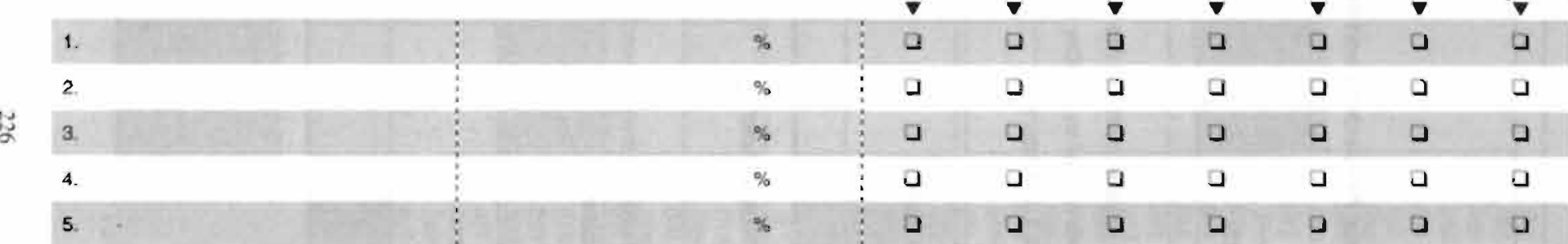

\section{(1)}

Name of the slore:

The questions below are about OME STORE. which is indicated alongside

\begin{tabular}{|c|c|c|c|c|c|c|c|c|}
\hline & $\frac{1}{\nabla}$ & $\frac{2}{7}$ & 4 & 5 & $\stackrel{6}{\nabla}$ & $\dot{7}$ & 8 & 10 \\
\hline \multirow[t]{2}{*}{$\begin{array}{l}\text { Or the } 10 \text { times that you select a store to buy clothes al. } \\
\text { how many times do you select this store? }\end{array}$} & $\square$ & $\square$ & a & $\perp$ & $\square$ & $J$ & 3 & $\mathrm{~J}$ \\
\hline & & $\begin{array}{c}\text { Much less } \\
\text { trequently }\end{array}$ & $\begin{array}{l}\text { Less } \\
\text { frequently } \\
\nabla\end{array}$ & $\begin{array}{l}\text { Somewhat } \\
\text { less } \\
\text { frequently } \\
\nabla\end{array}$ & $\begin{array}{c}\text { Just as } \\
\text { trequently } \\
\nabla\end{array}$ & $\begin{array}{c}\text { Somewhat } \\
\text { more } \\
\text { trequently } \\
\bar{\nabla}\end{array}$ & $\begin{array}{c}\text { More } \\
\text { Irequently } \\
\nabla\end{array}$ & $\begin{array}{l}\text { Much more } \\
\text { frequently }\end{array}$ \\
\hline $\begin{array}{l}\text { How often do you buy clothes In Ihis atore } \\
\text { compared to other stores where you buy clothes? }\end{array}$ & & $\square$ & 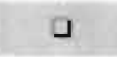 & $\square$ & 0 & $\square$ & 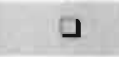 & $\square$ \\
\hline
\end{tabular}


Neme of the store:

To what extent do you agres, or dleagres, with the following statements?

This store ...

is

... makes an effort to increase regular customers' loyalty

makes various efforts to improve its tie with regular customers

.... really cares about keeping regular customers
Please provide your general opinion about the eflorts of this store towands regutar customers

\begin{tabular}{|c|c|c|c|c|c|c|}
\hline $\begin{array}{l}-3 \\
\text { Strongtr } \\
\text { disagree }\end{array}$ & $\begin{array}{c}-2 \\
\text { Deagres }\end{array}$ & $\begin{array}{c}-1 \\
\text { Somewhat } \\
\text { disagree }\end{array}$ & $\begin{array}{c}0 \\
\text { Nother agree. } \\
\text { nor disagree }\end{array}$ & $\begin{array}{l}+1 \\
\text { Somewhar } \\
\text { agrese }\end{array}$ & $\stackrel{+2}{+2}$ & $\begin{array}{l}+3 \\
\text { Strongly } \\
\text { agrowe }\end{array}$ \\
\hline$\nabla$ & $\nabla$ & $\nabla$ & $\boldsymbol{v}$ & $\nabla$ & $\nabla$ & $\nabla$ \\
\hline a & ב & 0 & 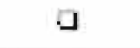 & 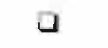 & 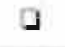 & $\square$ \\
\hline a & a & 0 & J & $\square$ & 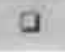 & 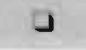 \\
\hline ב & 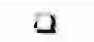 & U & $\square$ & $\Xi$ & 0 & a \\
\hline
\end{tabular}


Meme of the store:

To what extent do you agree, or disagree. with the following statements?

This store gives me a feeing of trusl

I am willing to "go the extra mile" to remain a customer of this store

As a regular customer. I have a high quality relationship with this store

This store gives me a trustworthy impression

I feel loyal lowards this store

I am happy with the efforts this store is making lowards a regular customer like me

I have trust in this store.

I am satisfied with the relationship I have with this store

Even it this store would be more difficult to reach, I would still keep buying there

The following statements are aboul your ankude fowards and exporivireo with this store.

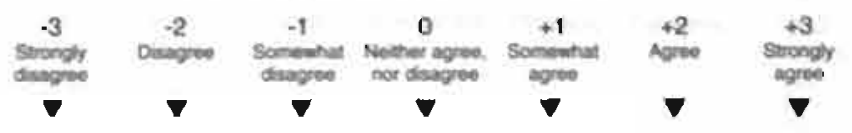

$\begin{array}{lllllll}\lrcorner & a & a & a & a & a & 0 \\ \lrcorner & 0 & a & 0 & a & a & 0\end{array}$

\begin{tabular}{|c|c|c|c|c|c|c|}
\hline$\square$ & $\square$ & $\square$ & $\boldsymbol{J}$ & $a$ & $\square$ & $\square$ \\
\hline
\end{tabular}

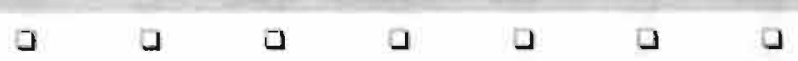

\begin{tabular}{|c|c|c|}
\hline a & a & \\
\hline
\end{tabular}

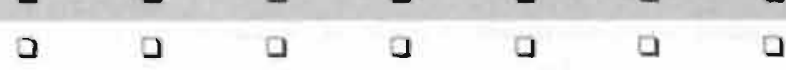

\begin{tabular}{|c|c|c|c|c|c|}
\hline a & $\mathrm{J}$ & D & 口 & $\square$ & $\square$ \\
\hline
\end{tabular}

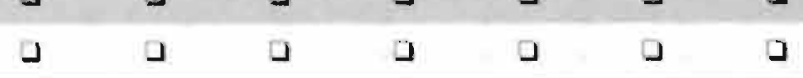

a

a

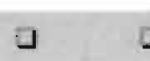

ఎ


To what extent do you egree, or dleagres, whin the following statements?

The previous statements were about one store. The next statements are about:

shopping for clothes (above the line).

- shopping in general and yoursell (below the line).

Generally, I am someone...

\begin{tabular}{|c|c|c|c|c|c|c|}
\hline $\begin{array}{c}-3 \\
\text { Strongy } \\
\text { disagree } \\
\overline{7}\end{array}$ & $\begin{array}{c}-2 \\
\text { Divagee } \\
\nabla\end{array}$ & $\begin{array}{c}-1 \\
\text { Somewhat } \\
\text { disagree } \\
\overline{7}\end{array}$ & $\begin{array}{c}0 \\
\text { Neither apree, } \\
\text { nor disagree } \\
\nabla\end{array}$ & $\begin{array}{c}+1 \\
\text { Somemhat } \\
\text { ngree } \\
\text { v }\end{array}$ & $\begin{array}{c}+2 \\
\text { Apreo } \\
\nabla\end{array}$ & $\begin{array}{l}+3 \\
\text { Strongly } \\
\text { apreo } \\
=\end{array}$ \\
\hline$\square$ & a & 1 & 口 & 0 & 0 & a \\
\hline$\square$ & 0 & $a$ & a & 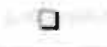 & $\square$ & a \\
\hline a & J & $\square$ & $\square$ & J & 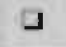 & a \\
\hline$\square$ & 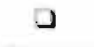 & $\square$ & $\square$ & J & 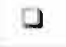 & $\square$ \\
\hline ב & J & 1 & $\Delta$ & J & a & J \\
\hline$\square$ & d. & $\square$ & 3 & a & $a$ & $\square$ \\
\hline
\end{tabular}

\begin{tabular}{|c|c|c|c|c|c|c|c|}
\hline who enjoys shopping & $\square$ & $\square$ & $\square$ & 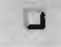 & a & \lrcorner & 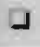 \\
\hline .... Who likes to be appreciated by others & $\sqcup$ & 3 & $\square$ & 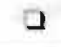 & D & 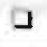 & a \\
\hline ... Who has no difficulty "mingling" in a group & $\square$ & 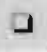 & 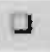 & 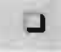 & $a$ & 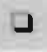 & コ \\
\hline .... Who likes to be respected by others & $\unlhd$ & 3 & 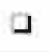 & $\square$ & a & 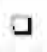 & $\square$ \\
\hline Who enjoys shopping to see whether there is anything new & $\square$ & 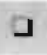 & 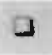 & 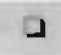 & 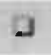 & 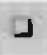 & J \\
\hline ... Who, given the chance, seeks contact with others & $\square$ & a & 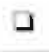 & 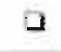 & J & $\square$ & $\boldsymbol{\Xi}$ \\
\hline who considers shopping as a pleasant way to spend his or her spare time & a & 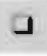 & a & $\square$ & $\exists$ & 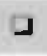 & J \\
\hline .... Who likes to be appreciated by acquaintancesi & 口 & a & $\square$ & $\Delta$ & a & 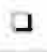 & a \\
\hline Who likes to seek contact with others & $\mathbf{I}$ & 9 & 3 & a & 9 & $\square$ & a \\
\hline
\end{tabular}


Please Indicate your age nonge:

$\square .25$ years
$\square .40$ years
$\square .71-55$ years
$\square>55$ years

Many thanks for your cooperatlon!

To be filled out by the interviewer only:

Gender of the respondent :armale

ig Male.

Loyalty of the respondent

$00-20 \%$

(a) $21-40 \%$

$-141-60 \%$

: $61-80 \%$

ias1-100\%

Name of the interviewer

垱

ia

告

:

Day of data collection

:]

浔

Number questionnaire 


\section{Appendix 6 Univariate Statistics}

Table A6-1: Univariate Statistics (The Netherdands Clothing)

\begin{tabular}{l|ccccc}
\hline Construct & Item & Minimum & Maximum & Mean & Std deviation \\
\hline Sociability & 1 & 1 & 7 & 6.30 & 95 \\
& 3 & 1 & 7 & 5.43 & 1.37 \\
& 4 & 1 & 7 & 5.73 & 1.22 \\
\hline Social recognition & 2 & 1 & 7 & 5.76 & 1.22 \\
& 4 & 1 & 7 & 6.08 & .97 \\
\hline Shopping enjoyment & 6 & 1 & 7 & 5.91 & 1.03 \\
& 1 & 1 & 7 & 5.37 & 1.87 \\
& 3 & 1 & 7 & 5.40 & 1.84 \\
\hline Product category involvement & 6 & 1 & 7 & 5.17 & 1.95 \\
\hline Buyer relationship proneness & 1 & 1 & 7 & 5.88 & 1.21 \\
& 2 & 1 & 7 & 5.93 & 1.12 \\
& 3 & 1 & 7 & 5.60 & 1.37 \\
\hline Seller relationship orientation & 2 & 1 & 7 & 4.46 & 1.88 \\
& 3 & 1 & 7 & 4.47 & 1.80 \\
& 5 & 1 & 7 & 4.43 & 1.88 \\
\hline Relationship satisfaction & 2 & 1 & 7 & 4.83 & 1.60 \\
& 5 & 1 & 7 & 4.87 & 1.61 \\
& 6 & 1 & 7 & 4.46 & 1.88 \\
\hline Trust & 4 & 1 & 7 & 4.74 & 1.66 \\
& 5 & 1 & 7 & 4.43 & 1.81 \\
& 6 & 1 & 7 & 5.42 & 1.33 \\
\hline Relationship commitment & 1 & 1 & 7 & 5.65 & 1.15 \\
& 2 & 1 & 7 & 5.79 & 1.01 \\
\hline Behavioral loyalty & 3 & 1 & 7 & 5.74 & 1.04 \\
\hline & 3 & 1 & 7 & 4.95 & 1.65 \\
& 4 & 1 & 7 & 4.88 & 1.63 \\
& 1 & -2.06 & 2.41 & .00 & 1.74 \\
\hline & 2 & -2.50 & 1.67 & .00 & 1.00 \\
& 3 & -3.54 & 1.22 & .00 & 1.00 \\
& & & & & 1.00 \\
\hline
\end{tabular}


Tahle A6-2: Univariate Statistics (The Netheriands Food)

\begin{tabular}{l|ccccc}
\hline Construct & Item & Minimum & Maximum & Mean & Std. deviation \\
\hline Sociability & 1 & 1 & 7 & 6.14 & .94 \\
& 3 & 1 & 7 & 5.26 & 1.46 \\
& 4 & 1 & 7 & 5.61 & 1.22 \\
\hline Social recognition & 2 & 1 & 7 & 5.61 & 1.39 \\
& 4 & 1 & 7 & 5.95 & 1.17 \\
\hline Shopping enjoyment & 6 & 1 & 7 & 5.81 & 1.22 \\
\hline Product category involvement & 1 & 1 & 7 & 5.28 & 1.83 \\
& 3 & 1 & 7 & 5.34 & 1.74 \\
& 6 & 1 & 7 & 5.07 & 1.81 \\
\hline Buyer relationship proneness & 1 & 1 & 7 & 5.87 & 1.14 \\
& 2 & 1 & 7 & 5.91 & 1.08 \\
& 3 & 1 & 7 & 5.77 & 1.23 \\
\hline Seller relationship orientation & 2 & 1 & 7 & 4.55 & 1.72 \\
& 3 & 1 & 7 & 4.56 & 1.76 \\
& 5 & 1 & 7 & 4.41 & 1.77 \\
\hline Relationship satisfaction & 2 & 1 & 7 & 5.14 & 1.52 \\
& 5 & 1 & 7 & 4.99 & 1.52 \\
& 6 & 1 & 7 & 4.93 & 1.48 \\
\hline Trust & 4 & 1 & 7 & 4.45 & 1.55 \\
& 5 & 1 & 7 & 4.36 & 1.65 \\
& 6 & 1 & 7 & 5.11 & 1.35 \\
\hline Relationship commitment & 1 & 1 & 7 & 5.37 & 1.26 \\
& 2 & 1 & 7 & 5.49 & 1.17 \\
\hline Behavioral loyalty & 3 & 1 & 7 & 5.51 & 1.08 \\
\hline & 2 & 1 & 7 & 4.60 & 1.64 \\
& 3 & 1 & 7 & 4.77 & 1.69 \\
& 4 & 1 & 7 & 3.51 & 1.99 \\
\hline & 1 & -2.19 & 1.47 & .00 & 1.00 \\
& 2 & -2.77 & 1.18 & .00 & 1.00 \\
& 3 & -2.98 & .89 & .00 & 1.00 \\
\hline
\end{tabular}


Table A6-3: Univariate Statistics (Belgium Cothing)

\begin{tabular}{|c|c|c|c|c|c|}
\hline Construct & litem & Mlinimum & Maximum & Mean & Std. deviation \\
\hline \multirow[t]{3}{*}{ Sociability } & 1 & 1 & 7 & 6.00 & 1.06 \\
\hline & 3 & i & 7 & 5.04 & 1.68 \\
\hline & 4 & 1 & 7 & 5.54 & 1.30 \\
\hline \multirow[t]{3}{*}{ Social recognition } & 2 & 1 & 7 & 6.07 & 99 \\
\hline & 4 & 1 & 7 & 6.21 & 87 \\
\hline & 6 & 2 & 7 & 6.17 & 91 \\
\hline \multirow[t]{3}{*}{ Shopping enjoyment } & 1 & 1 & 7 & 5.49 & 1.77 \\
\hline & 3 & 1 & 7 & 5.60 & 1.77 \\
\hline & 6 & 1 & 7 & 5.42 & 1.73 \\
\hline \multirow[t]{3}{*}{ Product category involvement } & 1 & 1 & 7 & 5.79 & 1.27 \\
\hline & 2 & $i$ & 7 & 5.75 & 1.24 \\
\hline & 3 & $i$ & 7 & 5.60 & 1.35 \\
\hline \multirow[t]{3}{*}{ Buyer relationship proneness } & 2 & 1 & 7 & 4.93 & 1.59 \\
\hline & 3 & i & 7 & 4.93 & 1.57 \\
\hline & 5 & i & 7 & 4.79 & 1.57 \\
\hline \multirow[t]{3}{*}{ Seller relationship orientation } & 2 & 1 & 7 & 4.50 & 1.71 \\
\hline & 5 & 1 & 7 & 4.41 & 1.67 \\
\hline & 6 & 1 & 7 & 4.44 & 1.62 \\
\hline Relationship satisfaction & 4 & I & 7 & 4.66 & 1.59 \\
\hline 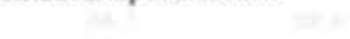 & 5 & 1 & 7 & 4.86 & 1.56 \\
\hline & 6 & 1 & 7 & 5.26 & 1.13 \\
\hline \multirow[t]{3}{*}{ Trust } & 1 & 1 & 7 & 5.48 & 1.04 \\
\hline & 2 & 1 & 7 & 5.54 & 1.01 \\
\hline & 3 & $i$ & 7 & 5.62 & 98 \\
\hline \multirow[t]{3}{*}{ Relationship commitment } & 2 & 1 & 7 & 4.92 & 1.53 \\
\hline & 3 & 1 & 7 & 5.03 & 1.42 \\
\hline & 4 & 1 & 7 & 4.48 & 1.82 \\
\hline \multirow[t]{3}{*}{ Behavioral loyalty } & 1 & -2.15 & 2.25 & .00 & 1.00 \\
\hline & 2 & -2.63 & 2.07 & .00 & 1.00 \\
\hline & 3 & -2.61 & 1.55 & .00 & 1.00 \\
\hline
\end{tabular}


Tahle A6-4: Univariate Statistics (Belgium Food)

\begin{tabular}{l|ccccc}
\hline Construct & Item & Minimum & Maximum & Mean & Std deviation \\
\hline Sociability & 1 & 2 & 7 & 5.97 & 1.17 \\
& 3 & 1 & 7 & 4.81 & 1.75 \\
& 4 & 1 & 7 & 5.40 & 1.50 \\
\hline Social recognition & 2 & 1 & 7 & 6.02 & 1.10 \\
& 4 & 2 & 7 & 6.18 & .94 \\
\hline Shopping enjoyment & 6 & 1 & 7 & 6.11 & 1.01 \\
& 1 & 1 & 7 & 5.14 & 1.96 \\
& 3 & 1 & 7 & 5.38 & 1.85 \\
\hline Product category involvement & 6 & 1 & 7 & 5.05 & 1.91 \\
& 1 & 2 & 7 & 5.87 & 1.12 \\
& 2 & 2 & 7 & 5.79 & 1.01 \\
\hline Buyer relationship proneness & 3 & 1 & 7 & 5.73 & 1.11 \\
\hline Seller reiationship orientation & 2 & 1 & 7 & 4.52 & 1.67 \\
& 3 & 1 & 7 & 4.69 & 1.62 \\
& 5 & 1 & 7 & 4.55 & 1.66 \\
\hline Relationship satisfaction & 2 & 1 & 7 & 4.84 & 1.60 \\
& 5 & 1 & 7 & 4.61 & 1.61 \\
& 6 & 1 & 7 & 4.71 & 1.55 \\
\hline Trust & 4 & 1 & 7 & 4.59 & 1.57 \\
& 5 & 1 & 7 & 4.80 & 1.46 \\
& 6 & 1 & 7 & 5.03 & 1.33 \\
\hline Relationship commitment & 1 & 1 & 7 & 5.32 & 1.29 \\
& 2 & 1 & 7 & 5.52 & 1.17 \\
\hline Behavioral loyalty & 3 & 1 & 7 & 5.49 & 1.09 \\
\hline & 2 & 1 & 7 & 4.49 & 1.74 \\
& 3 & 1 & 7 & 4.88 & 1.55 \\
& 4 & 1 & 7 & 3.53 & 1.92 \\
\hline & 1 & -2.15 & 2.04 & .00 & 1.00 \\
& 2 & -2.83 & 1.62 & .00 & 1.00 \\
& 3 & -2.94 & 1.21 & .00 & 1.00 \\
\hline
\end{tabular}


Tahle A6-5: Univariate Statisties (United States Clothing)

\begin{tabular}{l|ccccc}
\hline Construct & Item & Minimum & Maximum & Mean & Std. deviation \\
\hline Sociability & 1 & 1 & 7 & 5.74 & 1.23 \\
& 3 & 1 & 7 & 5.54 & 1.33 \\
& 4 & 1 & 7 & 5.62 & 1.34 \\
\hline Social recognition & 2 & 1 & 7 & 6.03 & 1.06 \\
& 4 & 2 & 7 & 6.22 & .95 \\
\hline Shopping enjoyment & 6 & 2 & 7 & 6.17 & 94 \\
& 1 & 1 & 7 & 5.26 & 1.80 \\
& 3 & 1 & 7 & 5.27 & 1.65 \\
\hline Product category involvement & 6 & 1 & 7 & 4.95 & 1.85 \\
& 1 & 2 & 7 & 5.65 & 1.24 \\
& 2 & 1 & 7 & 5.83 & 1.17 \\
\hline Buyer relationship proneness & 3 & 1 & 7 & 5.47 & 1.44 \\
\hline Seller relationship orientation & 2 & 1 & 7 & 5.11 & 1.57 \\
& 3 & 1 & 7 & 5.00 & 1.47 \\
& 5 & 1 & 7 & 4.95 & 1.59 \\
\hline Relationship satisfaction & 2 & 1 & 7 & 5.36 & 1.32 \\
& 5 & 1 & 7 & 5.22 & 1.30 \\
& 6 & 1 & 7 & 5.30 & 1.34 \\
\hline Trust & 4 & 1 & 7 & 4.75 & 1.56 \\
& 5 & 1 & 7 & 4.96 & 1.56 \\
& 6 & 1 & 7 & 5.43 & 1.26 \\
\hline Relationship commitment & 1 & 1 & 7 & 5.37 & 1.19 \\
& 2 & 1 & 7 & 5.37 & 1.21 \\
\hline Behavioral loyalty & 3 & 1 & 7 & 5.35 & 1.24 \\
\hline & 3 & 1 & 7 & 5.03 & 1.45 \\
& 4 & 1 & 7 & 5.15 & 1.46 \\
& 1 & -1.84 & 2.38 & .00 & 1.63 \\
\hline & 2 & -2.65 & 1.54 & .00 & 1.00 \\
& 3 & -3.37 & 1.24 & .00 & 1.00 \\
\hline
\end{tabular}


Table A6-6: Univariate Statisties (United States Food)

\begin{tabular}{|c|c|c|c|c|c|}
\hline Constnet & Item & Minimum & Meximum & Mean & Std deviation \\
\hline \multirow{3}{*}{ Sociability } & 1 & 1 & 7 & 5.57 & 1.32 \\
\hline & 3 & 1. & 7 & 5.32 & 1.23 \\
\hline & 4 & 1 & 7 & 5.45 & 1.21 \\
\hline \multirow[t]{3}{*}{ Social recognition } & 2 & 3 & 7 & 6.02 & 91 \\
\hline & 4 & 3 & 7 & 6.20 & 90 \\
\hline & 6 & 2 & 7 & 6.03 & .96 \\
\hline \multirow[t]{3}{*}{ Shopping enjoyment } & 1 & I & 7 & 4.88 & 1.71 \\
\hline & 3 & 1 & 7 & 4.97 & 1.69 \\
\hline & 6 & 1 & 7 & 4.45 & 1.87 \\
\hline \multirow{3}{*}{ Product category involvement } & I & 1 & 7 & 5.70 & 1.08 \\
\hline & 2 & 2 & 7 & 5.82 & 92 \\
\hline & 3 & 1 & 7 & 5.44 & 1.27 \\
\hline \multirow[t]{3}{*}{ Buyer relationship proneness } & 2 & 1 & 7 & 5.27 & 1.22 \\
\hline & 3 & 2 & 7 & 5.19 & 1.23 \\
\hline & 5 & 1 & 7 & 4.61 & 1.58 \\
\hline \multirow[t]{3}{*}{ Seller relationship orientation } & 2 & 1 & 7 & 5.28 & 1.25 \\
\hline & 5 & 1 & 7 & 5.06 & 1.27 \\
\hline & 6 & 1 & 7 & 5.16 & 1.32 \\
\hline \multirow[t]{3}{*}{ Relationship satisfaction } & 4 & 1 & 7 & 4.65 & 1.45 \\
\hline & 5 & 1 & 7 & 4.64 & 1.43 \\
\hline & 6 & 1 & 7 & 5.26 & 1.24 \\
\hline \multirow[t]{3}{*}{ Trust } & 1 & 1 & 7 & 5.46 & 1.12 \\
\hline & 2 & 1 & 7 & 5,41 & 1.15 \\
\hline & 3 & 1 & 7 & 5.39 & 1.25 \\
\hline \multirow[t]{3}{*}{ Relationship commitment } & 2 & 1 & 7 & 4.73 & 1.61 \\
\hline & 3 & 1 & 7 & 5.09 & 1.44 \\
\hline & 4 & 1 & 7 & 4.08 & 1.84 \\
\hline \multirow[t]{3}{*}{ Behavioral loyalty } & 1 & -2.46 & 1.09 & 0.00 & 1.00 \\
\hline & 2 & -3.14 & .99 & 0.00 & 1.00 \\
\hline & 3 & -3.34 & .76 & 0.00 & 1.00 \\
\hline
\end{tabular}




\section{Appendix 7 Measure Evaluation}

The results of the principal component analyses performed on all items are presented in tables A7-1 to A7-6. It can be concluded that items loaded on unique components, underlining the unidimensionality of all constructs.

The internal consistency is presented in tables A7-7 to A7-9, distinguishing between item-to-total correlations and Cronbach alpha values. All constructs revealed Cronbach alpha values exceeding .70, indicating acceptable reliability levels. 
Table A7-1: Principal Components Analysis with Oblique Rotation (the Netherfands Clothing)

\begin{tabular}{|c|c|c|c|c|c|c|}
\hline \multirow[b]{2}{*}{ Construct } & \multirow[b]{2}{*}{ Item } & \multicolumn{5}{|c|}{ Component } \\
\hline & & 1 & 2 & 3 & 4 & 5 \\
\hline \multirow[t]{3}{*}{ Sociability } & 1 & 436 & -.093 & .064 & 338 & .128 \\
\hline & 3 & -.040 & .026 & -.078 & 910 &,- 042 \\
\hline & 4 & .011 & .047 & .019 & 900 & .032 \\
\hline \multirow[t]{3}{*}{ Social recognition } & 2 & .002 & -.010 & -.115 & -.025 & 861 \\
\hline & 4 & .157 & .012 & .027 & -.062 & 860 \\
\hline & 5 & -125 & .026 & .043 & .061 & 930 \\
\hline \multirow[t]{3}{*}{ Shopping enjoyment } & 1 & -.008 & -.002 & -.944 & .006 & .032 \\
\hline & 3 & .092 & -.035 & .892 & .027 & .029 \\
\hline & 6 & -.031 & .027 & .957 & .009 & -.024 \\
\hline \multirow[t]{3}{*}{ Product category involvement } & 1 & 830 & .018 & -.064 & -.021 & .009 \\
\hline & 2 & 860 & .069 & .021 & -.037 & .019 \\
\hline & 3 & 833 & .060 & -.077 &,- 037 & -038 \\
\hline \multirow[t]{3}{*}{ Buyer relationship proneness } & 2 & .003 & 903 & -.024 & .006 & -.011 \\
\hline & 3 & .028 & 930 & 059 & -.003 & .002 \\
\hline & 5 & .019 & 871 & -.026 & .043 & .038 \\
\hline \multirow[b]{2}{*}{ Construct } & \multicolumn{5}{|c|}{ Component } & \\
\hline & Item & 1 & 2 & 3 & 4 & \\
\hline \multirow[t]{3}{*}{ Relationship satisfaction } & 4 & 841 & .050 & .115 & -.097 & \\
\hline & 5 & 847 & -.030 & -.038 & .119 & \\
\hline & 6 & .737 & -039 & .194 & -.059 & \\
\hline \multirow[t]{3}{*}{ Trust } & 1 & .263 & .059 & 563 & .138 & \\
\hline & 2 & -.040 & 017 & 945 & .023 & \\
\hline & 3 & .056 & .005 & 886 & .022 & \\
\hline \multirow[t]{3}{*}{ Relationship commitment } & 2 & .264 & .032 & 053 & .593 & \\
\hline & 3 & .523 & .144 & -.112 & .386 & \\
\hline & 4 & -.079 & .018 & .117 & .881 & \\
\hline \multirow[t]{3}{*}{ Behavioral loyalty } & 1 & .031 & .883 & .024 & -.170 & \\
\hline & 2 & -.066 & 785 & .071 & .119 & \\
\hline & 3 & .006 & 808 & -.061 & .072 & \\
\hline \multicolumn{7}{|c|}{ Component } \\
\hline Construct & Item & 1 & & & & \\
\hline \multirow[t]{3}{*}{ Seller relationship orientation } & 2 & 885 & & & & \\
\hline & 5 & 925 & & & & \\
\hline & 6 & 924 & & & & \\
\hline
\end{tabular}


Table A7-2: Principal Components Analysis with Oblique Rotation (the Nethertands Food)

\begin{tabular}{|c|c|c|c|c|c|c|}
\hline \multirow[b]{2}{*}{ Construct } & \multirow[b]{2}{*}{ Item } & \multicolumn{5}{|c|}{ Component } \\
\hline & & 1 & 2 & 3 & 4 & 5 \\
\hline \multirow[t]{3}{*}{ Sociability } & 1 & .018 & 372 & .155 & -046 & 563 \\
\hline & 3 & .035 & .151 & .143 & -.053 & 861 \\
\hline & 4 & .081 & -.043 & .047 & -.018 & 856 \\
\hline Social recognition & 2 & 898 & .001 & .047 & .092 & 103 \\
\hline 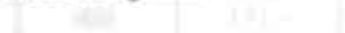 & 4 & 905 & .080 & .043 & .037 & .024 \\
\hline & 5 & 891 & -.061 & .002 & .037 & .121 \\
\hline Shopping enjoyment & 1 & .031 & .002 & -.015 & .936 & -.067 \\
\hline (x) & 3 & -.028 & .051 & .035 & .908 & .014 \\
\hline & 6 & .004 & -.059 & .016 & .918 & .072 \\
\hline \multirow[t]{3}{*}{ Product category involvement } & 1 & .087 & 861 & .034 & .003 & -.016 \\
\hline & 2 & .020 & 914 & .043 & -.008 & .000 \\
\hline & 3 & -.043 & 897 & .099 & -015 & .038 \\
\hline \multirow[t]{3}{*}{ Buyer relationship proneness } & 2 & .046 & .008 & 878 & .021 & .042 \\
\hline & 3 & -037 & .007 & 902 & .001 & .041 \\
\hline & 5 & .005 & .102 & 854 & .004 & -.022 \\
\hline
\end{tabular}

\section{Component}

\begin{tabular}{|c|c|c|c|c|c|}
\hline Construct & Item & 1 & 2 & 3 & 4 \\
\hline \multirow{3}{*}{ Relationship satisfaction } & 4 & .076 & .035 & 893 & -.123 \\
\hline & 5 & .161 & -.115 & 652 & .051 \\
\hline & 6 & 465 & .035 & $\overline{433}$ & -.103 \\
\hline \multirow[t]{3}{*}{ Trust } & 1 & 698 & .040 & .154 & .001 \\
\hline & 2 & 896 & .030 & -.057 & .052 \\
\hline & 3 & 878 & -.021 & -.030 & .086 \\
\hline \multirow[t]{3}{*}{ Relationship commitment } & 2 & -.062 & .038 & .543 & .473 \\
\hline & 3 & -.023 & .141 & .559 & .412 \\
\hline & 4 & .190 & .009 & -.064 & 856 \\
\hline \multirow[t]{3}{*}{ Behavioral loyalty } & 1 & .038 & 872 &,- 030 & -.011 \\
\hline & 2 & -.065 & 946 & .007 & .006 \\
\hline & 3 & .046 & 918 & -015 & -.017 \\
\hline
\end{tabular}

\section{Component}

\begin{tabular}{ll|c} 
Construct & Item & 1 \\
\hline Seller relationship orientation & 2 & $\frac{864}{901}$ \\
& 5 & $\frac{883}{}$ \\
\hline
\end{tabular}


Table A7-3: Principal Components Analysis with Oblique Rotation (Belgium Clothing)

\begin{tabular}{|c|c|c|c|c|c|c|}
\hline \multirow[b]{2}{*}{ Construct } & \multirow[b]{2}{*}{ Item } & \multicolumn{5}{|c|}{ Component } \\
\hline & & 1 & 2 & 3 & 4 & 5 \\
\hline \multirow[t]{3}{*}{ Sociability } & 1 & 525 & .028 & -.062 & .051 & .406 \\
\hline & 3 & -.079 & .027 & .075 & -.034 & 873 \\
\hline & 4 & .084 & -.029 & -.008 & -.064 & 852 \\
\hline \multirow[t]{3}{*}{ Social recognition } & 2 & 832 & .023 & .089 & .012 & -.134 \\
\hline & 4 & 795 & 002 & .102 & -.153 & .009 \\
\hline & 5 & 866 & -.001 & -.042 & .001 & .063 \\
\hline \multirow[t]{3}{*}{ Shopping enjoyment } & 1 & -.049 & -.008 & 915 & .009 & .076 \\
\hline & 3 & .174 & .010 & 727 & -.088 & -.108 \\
\hline & 6 & -.025 & .006 & 936 & .046 & .057 \\
\hline Product category involvement & 1 & .012 & -.025 & -.044 & .877 & .074 \\
\hline 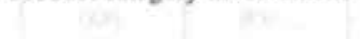 & 2 & -.003 & -.027 & .033 & .910 & -.051 \\
\hline & 3 & -.004 & .093 & .010 & .847 & .028 \\
\hline \multirow[t]{3}{*}{ Buyer relationship proneness } & 2 & -.054 & 910 & .100 & .043 & .033 \\
\hline & 3 & .019 & 866 & -.038 & -.033 & -.013 \\
\hline & 5 & .037 & 850 & -.064 &.,- 028 & -.025 \\
\hline \multicolumn{7}{|c|}{ Component } \\
\hline Construct & Item & 1 & 2 & 3 & 4 & \\
\hline \multirow[t]{3}{*}{ Relationship satisfaction } & 4 & -.100 & .016 & .203 & 799 & \\
\hline & 5 & .005 & .002 &,- 105 & 893 & \\
\hline & 6 & .201 & -.060 & -.066 & .698 & \\
\hline \multirow[t]{3}{*}{ Trust } & 1 & 806 & .013 & .060 & .068 & \\
\hline & 2 & 932 &,- 008 &,- 003 & -.047 & \\
\hline & 3 & 878 & .003 & .004 & .003 & \\
\hline \multirow[t]{3}{*}{ Relationship commitment } & 2 & 126 & .063 & 689 & .165 & \\
\hline & 3 & .225 & .201 & .298 & .346 & \\
\hline & 4 & .013 & -.019 & 874 & -.058 & \\
\hline \multirow[t]{3}{*}{ Behavioral loyalty } & 1 & .034 & 858 & -.191 & .020 & \\
\hline & 2 & -.054 & 828 & .151 & .012 & \\
\hline & 3 & .015 & 818 & .070 & -.059 & \\
\hline \multicolumn{7}{|l|}{ Construct } \\
\hline Construct & Item & 1 & & & & \\
\hline \multirow[t]{3}{*}{ Seller relationship orientation } & 2 & 858 & & & & \\
\hline & 5 & 911 & & & & \\
\hline & 6 & 896 & & & & \\
\hline
\end{tabular}


Table A7-5: Principal Components Analysis with Oblique Rotation (United States Clothing)

\begin{tabular}{|c|c|c|c|c|c|c|}
\hline \multirow[b]{2}{*}{ Construct } & \multirow[b]{2}{*}{ Item } & \multicolumn{5}{|c|}{ Component } \\
\hline & & 1 & 2 & 3 & 4 & 5 \\
\hline \multirow[t]{3}{*}{ Sociability } & 1 & -.037 & 776 & .198 & .113 & .078 \\
\hline & 3 & .090 & 914 & -.069 & -.105 & -.045 \\
\hline & 4 & -.008 & 856 & .040 & -.093 & .052 \\
\hline \multirow[t]{3}{*}{ Social recognition } & 2 & .028 & -.071 & 891 & -.050 & .062 \\
\hline & 4 & .059 & .068 & 885 & -.006 & -.127 \\
\hline & 5 & -.023 & .208 & 740 & -.060 & .034 \\
\hline \multirow[t]{3}{*}{ Shopping enjoyment } & 1 & .073 & -.115 & .143 & -.873 & .058 \\
\hline & 3 & .178 & 213 & -.102 & -.788 & -101 \\
\hline & 6 & -151 & .027 & .064 & -890 & .122 \\
\hline \multirow[t]{3}{*}{ Product category involvement } & 1 & 768 & .021 & .176 & -.004 & 108 \\
\hline & 2 & 892 & .034 &, 009 & -.074 & -.029 \\
\hline & 3 & 571 & .076 & -.054 & -.033 & 408 \\
\hline \multirow[t]{3}{*}{ Buyer relationship proneness } & 2 & 360 & -.074 & .086 & -.052 & .635 \\
\hline & 3 & .193 & -.020 & .000 & -.036 & 798 \\
\hline & 5 & +.116 & .115 & -.031 & -.077 & 918 \\
\hline & \multicolumn{6}{|c|}{ Component } \\
\hline Construet & Item & 1 & 2 & 3 & 4 & \\
\hline \multirow[t]{3}{*}{ Relationship satisfaction } & 4 & 926 & -.021 & .007 & .039 & \\
\hline & 5 & 941 & -.037 & -.042 & -.048 & \\
\hline & 6 & 795 & .057 & .049 & .014 & \\
\hline \multirow[t]{3}{*}{ Trust } & I & -.038 & .029 & 945 & -.002 & \\
\hline & 2 & .017 & .004 & 957 & .070 & \\
\hline & 3 & .030 & -.072 & 900 & -.068 & \\
\hline \multirow[t]{3}{*}{ Relationship commitment } & 2 & 157 & .215 & .276 & -.488 & \\
\hline & 3 & .546 & .075 & .129 & -.278 & \\
\hline & 4 & .191 & .051 & .069 &. .767 & \\
\hline \multirow[t]{3}{*}{ Behavioral loyalty } & 1 & .106 & 912 & .018 & .226 & \\
\hline & 2 & -.036 & 793 & .017 & -.229 & \\
\hline & 3 & -.059 & 875 & -031 & -.111 & \\
\hline \multicolumn{7}{|l|}{ Construct } \\
\hline Construct & Item & 1 & & & & \\
\hline \multirow[t]{3}{*}{ Seller relationship orientation } & 2 & 929 & & & & \\
\hline & 5 & 948 & & & & \\
\hline & 6 & 931 & & & & \\
\hline
\end{tabular}


Table A7-6: Principal Components Analysis with Oblique Rotation (United States Food)

\begin{tabular}{|c|c|c|c|c|c|c|}
\hline \multirow[b]{2}{*}{ Construct } & \multirow[b]{2}{*}{ Item } & \multicolumn{5}{|c|}{ Component } \\
\hline & & 1 & 2 & 3 & 4 & 5 \\
\hline \multirow[t]{3}{*}{ Sociability } & 1 & .022 & .028 & .040 & 805 & .060 \\
\hline & 3 & .063 & .042 & -.083 & 920 & -058 \\
\hline & 4 & .080 & .027 & .012 & 870 & 025 \\
\hline \multirow[t]{3}{*}{ Social recognition } & 2 & 859 & .074 & -071 & .060 & .035 \\
\hline & 4 & 893 & .008 & -.015 & .013 & 027 \\
\hline & 5 & 776 & .042 & -.050 & 190 & .013 \\
\hline \multirow[t]{3}{*}{ Shopping enjoyment } & 1 & .041 & -.031 & .870 & .025 & 121 \\
\hline & 3 & .085 & .009 & .887 & .017 & .049 \\
\hline & 6 & .002 & .007 & -.903 & .118 & .059 \\
\hline \multirow[t]{3}{*}{ Product category involvement } & I & .038 & -.061 & .093 & .042 & 218 \\
\hline & 2 & .082 & .058 & .011 & .064 & 813 \\
\hline & 3 & -.090 & 117 & 196 & .097 & 713 \\
\hline \multirow[t]{3}{*}{ Buyer relationship proneness } & 2 & .102 & 874 & .068 & .024 & .046 \\
\hline & 3 & .067 & 943 & .052 & .022 & .066 \\
\hline & 5 & -189 & 668 & .170 & .024 & .122 \\
\hline
\end{tabular}

\begin{tabular}{|c|c|c|c|c|c|}
\hline \multirow[b]{2}{*}{ Construet } & \multirow[b]{2}{*}{ Item } & \multicolumn{4}{|c|}{ Component } \\
\hline & & 1 & 2 & 3 & 4 \\
\hline \multirow[t]{3}{*}{ Relationship satisfaction } & 4 & .043 & .040 & .213 & .182 \\
\hline & 5 & -.017 & -.035 & .143 & 849 \\
\hline & 6 & .154 & .092 & .003 & 779 \\
\hline \multirow[t]{3}{*}{ Trust } & 1 & 920 & -.004 & -.019 & .013 \\
\hline & 2 & 939 & .003 & .021 & -.046 \\
\hline & 3 & 861 & -.018 & -.066 & .182 \\
\hline \multirow[t]{3}{*}{ Relationship commitment } & 2 & .008 & -.062 & 946 & -.027 \\
\hline & 3 & .620 & .114 & 335 &., 040 \\
\hline & 4 & .008 & -.002 & 858 & .056 \\
\hline \multirow[t]{3}{*}{ Behavioral loyalty } & 1 &,- 048 & 941 & -.065 & .096 \\
\hline & 2 & .053 & 919 & .100 &,- 100 \\
\hline & 3 & -.000 & 954 & .024 & .002 \\
\hline
\end{tabular}

\section{Component}

\begin{tabular}{ll|c} 
Construct & Item & 1 \\
\hline Seller relationship orientation & 2 & $\frac{916}{950}$ \\
& 5 & $\frac{9516}{916}$ \\
\hline
\end{tabular}


Table A7-7: Intemal Consistency of Constructs (the Netheriands)

\begin{tabular}{|c|c|c|c|c|c|}
\hline \multirow[b]{2}{*}{ Corstnuct } & \multirow[b]{2}{*}{$\begin{array}{l}\text { Item } \\
(*)\end{array}$} & \multicolumn{2}{|c|}{ Clothing } & \multicolumn{2}{|c|}{ Food } \\
\hline & & $\begin{array}{l}\text { Item-to-total } \\
\text { correlation }\end{array}$ & $\begin{array}{c}\text { Cronbach's } \\
\text { alpha }\end{array}$ & $\begin{array}{l}\text { Item-to-total } \\
\text { correlation }\end{array}$ & $\begin{array}{c}\text { Cronbach's } \\
\text { alpha }\end{array}$ \\
\hline Sociability & $\begin{array}{l}1 \\
3 \\
4\end{array}$ & $\begin{array}{l}.33 \\
.61 \\
.68 \\
\end{array}$ & .71 & $\begin{array}{l}.40 \\
.68 \\
.72 \\
\end{array}$ & .75 \\
\hline Social recognition & $\begin{array}{l}2 \\
4 \\
5\end{array}$ & $\begin{array}{l}.73 \\
.76 \\
.75\end{array}$ & 86 & $\begin{array}{l}.76 \\
.81 \\
.81 \\
\end{array}$ & .89 \\
\hline Shopping enjoyment & $\begin{array}{l}1 \\
3 \\
6\end{array}$ & $\begin{array}{l}.89 \\
.89 \\
.87 \\
\end{array}$ & .94 & $\begin{array}{l}.82 \\
.82 \\
.84\end{array}$ & .91 \\
\hline Product category involvement & $\begin{array}{l}1 \\
2 \\
3\end{array}$ & $\begin{array}{l}.70 \\
.74 \\
.70\end{array}$ & .84 & $\begin{array}{l}.79 \\
.84 \\
.81\end{array}$ & 91 \\
\hline Buyer relationship proneness & $\begin{array}{l}2 \\
3 \\
5\end{array}$ & $\begin{array}{l}.78 \\
.84 \\
.76 \\
\end{array}$ & .90 & $\begin{array}{l}.77 \\
.78 \\
.74 \\
\end{array}$ & .88 \\
\hline Seller relationship orientation & $\begin{array}{l}2 \\
5 \\
6\end{array}$ & $\begin{array}{l}.75 \\
.82 \\
.82 \\
\end{array}$ & 90 & $\begin{array}{l}.70 \\
.77 \\
.73 \\
\end{array}$ & 86 \\
\hline Relationship satisfaction & $\begin{array}{l}4 \\
5 \\
6\end{array}$ & $\begin{array}{l}.73 \\
.72 \\
.66\end{array}$ & .83 & $\begin{array}{l}.65 \\
.57 \\
.56 \\
\end{array}$ & .76 \\
\hline Trust & $\begin{array}{l}1 \\
2 \\
3\end{array}$ & $\begin{array}{l}.66 \\
.78 \\
.80 \\
\end{array}$ & .86 & $\begin{array}{l}.65 \\
.73 \\
.71 \\
\end{array}$ & .83 \\
\hline Relationship commitment & $\begin{array}{l}2 \\
3 \\
4\end{array}$ & $\begin{array}{l}.55 \\
.57 \\
.54 \\
\end{array}$ & .73 & $\begin{array}{l}.59 \\
.61 \\
.49 \\
\end{array}$ & .73 \\
\hline Behavioral loyalty & $\begin{array}{l}1 \\
2 \\
3\end{array}$ & $\begin{array}{l}.61 \\
.62 \\
.60\end{array}$ & .77 & $\begin{array}{l}.73 \\
.85 \\
.81\end{array}$ & .90 \\
\hline
\end{tabular}

(") These item numbers refer to the items included in table 6-3. 
Table A7-8: Internal Consistency of Constructs (Belgium)

\begin{tabular}{|c|c|c|c|c|c|}
\hline \multirow{2}{*}{ Construct } & \multirow[b]{2}{*}{$\begin{array}{l}\text { flem } \\
(*)\end{array}$} & \multicolumn{2}{|c|}{ Cothing } & \multicolumn{2}{|c|}{ Food } \\
\hline & & $\begin{array}{l}\text { ftem-to-total } \\
\text { correlation }\end{array}$ & $\begin{array}{c}\text { Cronbach's } \\
\text { alpha }\end{array}$ & $\begin{array}{l}\text { Item-to-total } \\
\text { correlation }\end{array}$ & $\begin{array}{l}\text { Cronbach's } \\
\text { alpha }\end{array}$ \\
\hline Sociability & $\begin{array}{l}1 \\
3 \\
4 \\
\end{array}$ & $\begin{array}{l}.41 \\
.56 \\
.66 \\
\end{array}$ & .71 & $\begin{array}{l}.47 \\
.64 \\
.75 \\
\end{array}$ & .77 \\
\hline Social recognition & $\begin{array}{l}2 \\
4 \\
5\end{array}$ & $\begin{array}{l}.64 \\
.76 \\
.71 \\
\end{array}$ & 84 & $\begin{array}{l}.77 \\
.77 \\
.80\end{array}$ & .88 \\
\hline Shopping enjoyment & $\begin{array}{l}1 \\
3 \\
6\end{array}$ & $\begin{array}{l}.75 \\
.61 \\
.80\end{array}$ & .85 & $\begin{array}{l}.77 \\
.75 \\
.82\end{array}$ & 89 \\
\hline Product category involvement & $\begin{array}{l} \\
2 \\
3 \\
\end{array}$ & $\begin{array}{l}.73 \\
.75 \\
.75 \\
\end{array}$ & 87 & $\begin{array}{r}.69 \\
.79 \\
.72 \\
\end{array}$ & .86 \\
\hline Buyer relationship proneness & $\begin{array}{l} \\
3 \\
5 \\
\end{array}$ & $\begin{array}{l}.76 \\
.72 \\
.69 \\
\end{array}$ & .85 & $\begin{array}{l}.70 \\
.80 \\
.75 \\
\end{array}$ & 87 \\
\hline Seller relationship orientation & $\begin{array}{l}2 \\
5 \\
6\end{array}$ & $\begin{array}{l}.70 \\
.79 \\
.76\end{array}$ & .87 & $\begin{array}{l}.79 \\
.80 \\
.76\end{array}$ & .89 \\
\hline Relationship satisfaction & $\begin{array}{l}4 \\
5 \\
6\end{array}$ & $\begin{array}{l}57 \\
.64 \\
.60\end{array}$ & .76 & $\begin{array}{l}67 \\
.67 \\
.69 \\
\end{array}$ & .82 \\
\hline Trust & $\begin{array}{l}1 \\
2 \\
3 \\
\end{array}$ & $\begin{array}{l}.73 \\
.77 \\
.73 \\
\end{array}$ & .87 & $\begin{array}{l}.67 \\
.72 \\
.77 \\
\end{array}$ & .85 \\
\hline Relationship commitment & $\begin{array}{l}2 \\
3 \\
4\end{array}$ & $\begin{array}{l}.62 \\
.49 \\
45\end{array}$ & .70 & $\begin{array}{l}.68 \\
.54 \\
.57 \\
\end{array}$ & .76 \\
\hline Behavioral loyalty & $\begin{array}{l}1 \\
2 \\
3\end{array}$ & $\begin{array}{r}.58 \\
.68 \\
.64 \\
\end{array}$ & .79 & $\begin{array}{l}.72 \\
.86 \\
.84 \\
\end{array}$ & 90 \\
\hline
\end{tabular}

(*) These item numbers refer to the items included in table 6-3. 
Table A7-9: Intemal Consistency of Constructs (United States)

\begin{tabular}{|c|c|c|c|c|c|}
\hline \multirow[b]{2}{*}{ Construct } & \multirow[b]{2}{*}{$\begin{array}{c}\text { Item } \\
(\bullet)\end{array}$} & \multicolumn{2}{|c|}{ Clothing } & \multicolumn{2}{|c|}{ Food } \\
\hline & & $\begin{array}{c}\text { Item-to-total } \\
\text { correlation }\end{array}$ & $\begin{array}{c}\text { Cronbach's } \\
\text { alpha }\end{array}$ & $\begin{array}{l}\text { Item-to-total } \\
\text { correlation }\end{array}$ & $\begin{array}{c}\text { Cronbach's } \\
\text { alpha }\end{array}$ \\
\hline Sociability & $\begin{array}{l}1 \\
3 \\
4 \\
\end{array}$ & $\begin{array}{l}68 \\
.85 \\
.83 \\
\end{array}$ & .89 & $\begin{array}{l}.62 \\
.78 \\
.80 \\
\end{array}$ & .85 \\
\hline Social recognition & $\begin{array}{l}2 \\
4 \\
5\end{array}$ & $\begin{array}{l}.74 \\
.79 \\
.76 \\
\end{array}$ & .88 & $\begin{array}{l}.71 \\
.76 \\
.75 \\
\end{array}$ & .86 \\
\hline Shopping enjoyment & $\begin{array}{l}1 \\
3 \\
6\end{array}$ & $\begin{array}{l}.83 \\
.75 \\
.80 \\
\end{array}$ & .90 & $\begin{array}{l}.79 \\
.77 \\
.85 \\
\end{array}$ & 90 \\
\hline Product category involvement & $\begin{array}{l}1 \\
2 \\
3\end{array}$ & $\begin{array}{r}.77 \\
.75 \\
.73 \\
\end{array}$ & .86 & $\begin{array}{l}.64 \\
.69 \\
.60 \\
\end{array}$ & .79 \\
\hline Buyer relationship proneness & $\begin{array}{l}2 \\
3 \\
5 \\
\end{array}$ & $\begin{array}{l}.80 \\
.85 \\
.72 \\
\end{array}$ & .89 & $\begin{array}{l}.69 \\
.71 \\
.57 \\
\end{array}$ & .80 \\
\hline Seller relationship orientation & $\begin{array}{l}2 \\
5 \\
6 \\
\end{array}$ & $\begin{array}{l}.84 \\
.88 \\
84\end{array}$ & .93 & $\begin{array}{l}81 \\
88 \\
.81 \\
\end{array}$ & .92 \\
\hline Relationship satisfaction & $\begin{array}{l}4 \\
5 \\
6\end{array}$ & $\begin{array}{l}.76 \\
.82 \\
.72 \\
\end{array}$ & .88 & $\begin{array}{l}.70 \\
.74 \\
.73 \\
\end{array}$ & .85 \\
\hline Trust & $\begin{array}{l}1 \\
2 \\
3\end{array}$ & $\begin{array}{l}.83 \\
.85 \\
.87 \\
\end{array}$ & 93 & $\begin{array}{l}.85 \\
.82 \\
.86 \\
\end{array}$ & 92 \\
\hline Relationship commitment & $\begin{array}{l}2 \\
3 \\
4 \\
\end{array}$ & $\begin{array}{l}.74 \\
.69 \\
.73 \\
\end{array}$ & .85 & $\begin{array}{l}.79 \\
.66 \\
.77 \\
\end{array}$ & .86 \\
\hline Behavioral loyalty & $\begin{array}{l}1 \\
2 \\
3\end{array}$ & $\begin{array}{l}.68 \\
.74 \\
.74\end{array}$ & .85 & $\begin{array}{l}.84 \\
.88 \\
.88\end{array}$ & .93 \\
\hline
\end{tabular}

(") These item numbers refer to the items included in table 6-3. 


\section{Appendix 8 Covariance Matrices}




\section{Table A\& 1: Covarience Mrotrix the Netherlands Cootting}

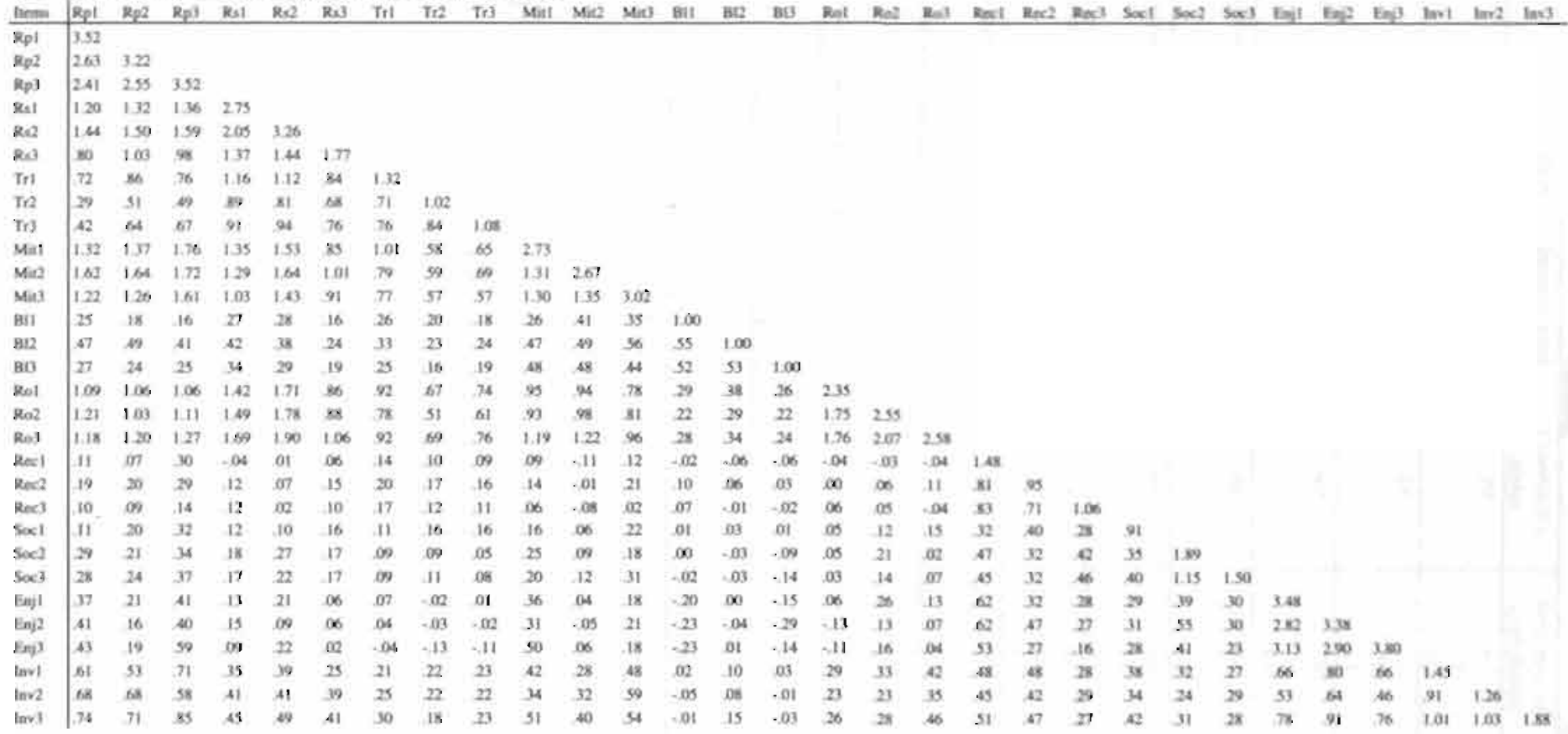

Rp 1-3: buyer relationship proneness, rs 1-3: relationship satisfaction, tr 1-3: trust, mit1-3: relationship commitment, bl1-3: behavioral loyalty, rol-3: seller relationship orientation, rec1-3: social recognition, soc1-3: sociability, enj1-3: shopping enjoyment, inv1-3: product category involvement. 
Table As-2: Covariance Matrix the Netherlands Frod

\begin{tabular}{|c|c|c|c|c|c|c|c|c|c|c|c|c|c|c|c|c|c|c|c|c|c|c|c|c|c|c|c|c|c|c|}
\hline theng & Rp! & $R_{R 2}$ & $\mathrm{Rp}$ & Rail & $R=2$ & 2,3 & $\mathrm{nt}$ & $m$ & Tr 3 & Miti & $\mathrm{M} i \mathrm{z}$ & Min & BAI & an: & 83 & Rol & Rot & Ras & Resl & $\operatorname{los} 2$ & $\operatorname{Res} 3$ & $5 \times 1$ & Soed & $5 \times 3$ & Enit & Eny? & (Eo) 3 & Invi & $\ln 22$ & $\operatorname{lan} x$ \\
\hline Rpi & 2.97 & & & & & & & & & & & & & & & & & & & & & & & & & & & & & \\
\hline $\mathrm{R}_{\mathrm{p} 2}$ & 2.25 & 3.10 & & & & & & & & & & & & & & & & & & & & & & & & & & & & \\
\hline $\mathrm{Mp3}$ & 2.07 & 217 & us & & & & & & & & & & & & & & & & & & & & & & & & & & & \\
\hline Ral & 80 & 91 & 105 & 2401 & & & & & & & & & & & & & & & & & & & & & & & & & & \\
\hline$R=2$ & 50 & 25 & 93 & 1.43 & 2.74 & & & & & & & & & & & & & & & & & & & & & & & & & \\
\hline Res & 16 & 18 & 42 & 1.15 & 95 & 152 & & & & & & & & & & & & & & & & & & & & & & & & \\
\hline $\mathbf{m} 1$ & 48 & 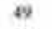 & 99 & 98 & S1 & 76 & 159 & & & & & & & & & & & & & & & & & & & & & & & \\
\hline $\mathrm{Tr} 2$ & 38 & 31 & 57 & 81 & s. & 76 & 90 & 1,35 & & & & & & & & & & & & & & & & & & & & & & \\
\hline $\mathrm{Fr} 3$ & 39 & 42 & 50 & $n$ & 73 & 81 & 99 & 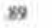 & 1.17 & & & & & & & & & & & & & & & & & & & & & \\
\hline Ma1 & 1.13 & 1.17 & 158 & 1.301 & $10 \mathrm{f}$ & $\pi$ & 91 & 67 & 70 & 269 & & & & & & & & & & & & & & & & & & & & \\
\hline Min2 & 1.24 & 1.14 & 134 & 1.38 & 1.21 & $\Rightarrow$ & 56 & 82 & .76 & 105 & 2.84 & & & & & & & & & & & & & & & & & & & \\
\hline Moo & 91 & 100 & 1.36 & 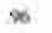 & 1.25 & 96 & 27 & s1 & $n$ & 1.38 & 1.49 & 3.96 & & & & & & & & & & & & & & & & & & \\
\hline BI & 15 & $\infty 6$ & 21 & 18 & 63 & 12 & 19 & 30 & 14 & 28 & 36 & 32 & 100 & & & & & & & & & & & & & & & & & \\
\hline Bu & 06 & -03 & II & is & 00 & 16 & 13 & 11 & as: & 24 & 39 & 38 & 33 & 100 & & & & & & & & & & & & & & & & \\
\hline $\mathrm{Ba}$ & 194 & .03 & .14 & 19 & os & $x$ & 21 & 21 & 15 & 24 & 4 & 38 & 64 & 53 & 100 & & & & & & & & & & & & & & & \\
\hline Rol & 50 & 4 & 49 & s4 & 1.01 & 84 & 70 & $n$ & $\pi$ & $\pi$ & 104 & 93 & is & 29 & 28 & 2.44 & & & & & & & & & & & & & & \\
\hline $\mathrm{Re} 2$ & 39 & 30 & 40 & 76 & 96 & 74 & 74 & $n$ & $x$ & 6? & 34 & 90 & 20 & 16 & 19 & 156 & 2.12 & & & & & & & & & & & & & \\
\hline Ros & $B$ & ss & $\mathrm{kz}$ & 100 & 1.07 & 76 & 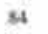 & 76 & 79 & $\$ 2$ & 94 & $x$ & 17 & 14 & 14 & 1.41 & 160 & 2.18 & & & & & & & & & & & & \\
\hline Res! & $5 s$ & 36 & 41 & di & A7 & 231 & $n$ & 33 & 20 & is & 3n. & 28 & os & 0 & as & 25 & 15 & 27 & 194 & & & & & & & & & & & \\
\hline Rex2 & 31 & 24 & 28 & 31 & As & 23 & 15 & 35 & 31 & 27 & 39 & 19 & $\infty$ & $\infty$ & BI & $n$ & 19 & 25 & 1.16 & 136 & & & & & & & & & & \\
\hline Itecl & 37 & 22 & 21 & 23 & 36 & 13 & s4 & 5 & 13 & 28 & 30 & II & . on & -14 & -08 & 60 & 03 & 16 & 12 & 1.12 & 1.50 & & & & & & & & & \\
\hline Soel & .15 & 20 & 10 & 30 & 24 & 23 & 25 & 32 & 34 & 201 & 30 & 36 & O4 & $\infty 2$ & $\boldsymbol{c a}$ & 28 & 24 & $n$ & y & 4 & 40 & บ & & & & & & & & \\
\hline Soce 2 & 61 & 6 & 4 & 53 & is & 27 & 21 & 39 & 20 & 47 & 55 & 58 & -108 & -04 & - or & 25 & 34 & 10 & $n$ & $\alpha$ & $n$ & 99 & 2.12 & & & & & & & \\
\hline Sect & 40 & 23 & 30 & 16 & 3 & 27 & 13 & 34 & 36 & 36 & A2 & 20 & $-\infty$ & -01 & -03 & $2 t$ & HI & 34 & 6I & 56 & 3 & 45 & 1.30 & 1.48 & & & & & & \\
\hline EnjI & 73 & ss & 60 & is & 46 & 49 & 30 & 33 & $\omega$ & 31 & a) & $\mathbf{5 0}$ & at & .13 & -03 & 53 & $\theta$ & ea & $M_{1}$ & 58 & 82 & 10 & 75 & $\infty$ & 34 & & & & & \\
\hline Itajl & $n$ & $\mathrm{Tr}$ & CS & 37 & es & $y$ & 17 & 22 & 31 & 39 & (7) & bs & $-\infty 9$ & -10 & $-0 s$ & 50 & 6 & $\pi$ & 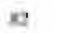 & $s$ & si & 41 & 30 & 64 & $2 A \mathrm{f}$ & $3 \mathrm{es}$ & & & & \\
\hline Eoj & ex & 4 & s4 & 40 & 4 & 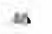 & 29 & 57 & 5 & st & 80 & $n$ & .11 & -13 & $-\infty$ & $s 2$ & 16 & is & $\infty$ & st & 3 & $\infty$ & $10 t$ & st & $2 \leqslant 2$ & 25 & $3: 2$ & & & \\
\hline $\ln 1$ & 58 & is & 51 & $x$ & 37 & $n$ & 27 & 10 & 30 & 33 & 37 & 23 & .04 & -13 & -98 & 11 & 3 & 37 & s) & 4 & 31 & $n$ & is & 34 & 36 & 35 & 30 & 13 & & \\
\hline $\ln 22$ & AD & 50 & 98 & is & $\Leftrightarrow$ & 28 & 35 & 31 & 34 & 30 & 4 & 33 & $-\infty$ & in & $-\infty$ & 14 & 28 & 37 & $\pi$ & 36 & 24 & 37 & $n$ & $\Rightarrow$ & 40 & 36 & 20 & 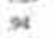 & 1.16 & \\
\hline bas 3 & $\$$ & 90 & $\pi$ & 37 & 20 & 23 & 31 & 34 & is & is & 29 & 28 & $-\infty 9$ & $-n_{i}$ & -38 & 17 & $\mathrm{n} 2$ & (3) & 88 & 30 & II & 32 & as & 17 & an & a & 28 & $1 \mathrm{~m}$ & 1.06 & 1.51 \\
\hline
\end{tabular}

Rp1-3: buyer relationship proneness, rs1-3: relationship satisfaction, tr 1-3: trust, mit 1-3: relationship commitment, b11-3: behavioral loyalty, ro 1-3: seller relationship orientation, recl-3: social recognition, socl-3: sociability, enj1-3: shopping enjoyment, inv 1-3: product category involvernent. 


\section{Table A8-3: Covariance Matrix Belgium Cothing}

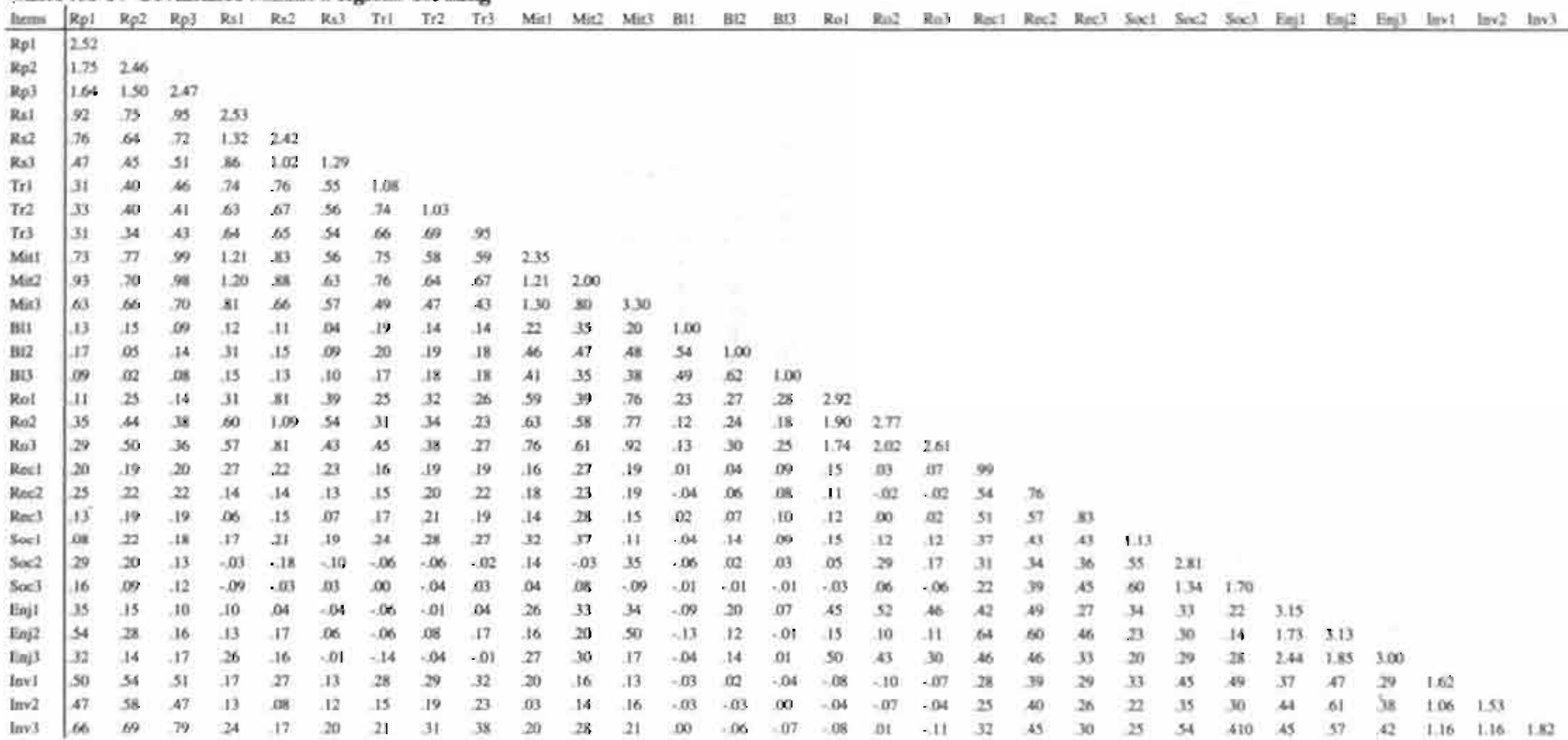

Rp I-3; buyer relationship proneness, rs 1-3: relationship satisfaction, tr 1-3: trust, mit 1-3: relationship commitment, bl1-3: behavioral loyalty, rol-3: seller relationship orientation, rec1-3: social recognition, soc 1-3: sociability, enjl-3: shopping enjoyment, inv 1-3: product category involvement. 
Trible A8-4: Covariance Matrix Belgium Food

\begin{tabular}{|c|c|c|c|c|c|c|c|c|c|c|c|c|c|c|c|c|c|c|c|c|c|c|c|c|c|c|c|c|c|c|}
\hline firms & $\mid \mathrm{Rp}_{\mathrm{p}}$ & $R_{p} p^{2}$ & $\mathrm{Rps}$ & Rel & $k=2$ & $R, 3$ & $\mathrm{Tri}$ & $\mathrm{T} 2 \mathrm{2}$ & $\mathrm{Tr}$ & Mlins & Minz & Min' & mil & faiz. & B13 & Ror & Ros. & Bist & Res 1 & $\ln x=$ & Res! & Sosel & $300:$ & soct & E) & $\operatorname{lng} 2$ & $\operatorname{Eag} 3$ & {$[\ln 1$} & Inar?" & $(\operatorname{me})$ \\
\hline $\mathrm{B} p \mathrm{I}$ & 2.1.80 & & & & & & & & & & & & & & & & & & & & & & & & & & & & & \\
\hline Rp2 & 1.87 & 262 & & & & & & & & & & & & & & & & & & & & & & & & & & & & \\
\hline Kal & 172 & 202 & 274 & & & & & & & & & & & & & & & & & & & & & & & & & & & \\
\hline Kat & M & 36 & 1.15 & $2 \mathrm{Wh}$ & & & & & & & & & & & & & & & & & & & & & & & & & & \\
\hline $\mathrm{Rat}$ & 24 & 73 & 79 & 1.36 & 2.14 & & & & & & & & & & & & & & & & & & & & & & & & & \\
\hline Ras & 61 & 33 & $\mathrm{~kg}$ & 1.28 & 1.19 & 17 & & & & & & & & & & & & & & & & & & & & & & & & \\
\hline Tril & 30 & 45 & 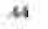 & 96 & 97 & 52 & 106 & & & & & & & & & & & & & & & & & & & & & & & \\
\hline$m$ & .48 & 63 & 31 & 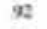 & $\infty$ & n2 & 90 & 1.36 & & & & & & & & & & & & & & & & & & & & & & \\
\hline ThI & 37 & 12 & 40 & 73 & $\mathrm{BS}$ & 86 & 91 & 92 & 1.19 & & & & & & & & & & & & & & & & & & & & & \\
\hline Met & 1.08 & 1.28 & 1.26 & 1,00 & 1.19 & 1.25 & (x) & 75 & 90 & 304 & & & & & & & & & & & & & & & & & & & & \\
\hline Min2 & S3 & 97 & 97 & 1.21 & 1.06 & 1.09 & 1.04 & $\$ 0$ & 1.00 & 150 & 2.59 & & & & & & & & & & & & & & & & & & & \\
\hline Mit3 & 1.14 & 105 & 100 & 112 & or & 76 & 53 & 31 & 34 & 1.97 & 122 & 369 & & & & & & & & & & & & & & & & & & \\
\hline 84 & 12 & -09 & ar & 28 & 12 & 11 & 23 & 23 & 21 & 20 & 4 & 12 & 1.00 & & & & & & & & & & & & & & & & & \\
\hline n12 & $\infty$ & of & 旬 & 30 & 42 & 28 & 30 & 28 & 27 & $\$ 0$ & 43 & $y$ & . & 100 & & & & & & & & & & & & & & & & \\
\hline Bas & 14 & as & 13 & As & 48 & $2 \pi$ & 15 & 38 & 32 & 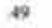 & 52 & 5H & 69 & 87 & 109 & & & & & & & & & & & & & & & \\
\hline Kai & 10 & 50 & 34 & as & 97 & 6s & $\approx 2$ & 60 & ss & 56 & 24 & क⿻ & 23 & $A 1$ & A1 & 235 & & & & & & & & & & & & & & \\
\hline Ro:2 & As & 49 & *6 & 90 & 1.04 & $\infty$ & $\mathrm{ss}$ & 35 & so & $n$ & . 1 & 58 & .24 & 41 & $A 2$ & 1.50 & 299 & & & & & & & & & & & & & \\
\hline Ras & as & 4 & 52 & 96 & 100 & $\pi$ & 53 & 5 & ss & 76 & Mo & 61 & .24 & 39 & 45 & 1.74 & 1.70 & 241 & & & & & & & & & & & & \\
\hline Keel & $-\infty$ & as & 20 & 11 & $B$ & 26 & 20 & 23 & 22 & .1s & 30 & 15 & 02 & oi & 08 & -02 & aब & $\infty 0$ & 1.26 & & & & & & & & & & & \\
\hline Reca & $\omega$ & 14 & 21 & at & 19 & 34 & 24 & 30 & 24 & 13 & 26 & " & 00 & 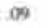 & 09 & an: & 10 & en & 72 & $w 0$ & & & & & & & & & & \\
\hline Reci. & -00 & .11 & Is & 13 & 19 & 사 & 22 & 28 & 23 & 13 & 21 & .09 & ol & 07 & os & 10 & 12 & $\infty$ & MI & 71 & 100 & & & & & & & & & \\
\hline $\operatorname{Sax} 1$ & 02 & 08 & 12 & 00 & 22 & 20 & 28 & 33 & 39 & 23 & 26 & is & an & 10 & 12 & 024 & . 22 & ess & 52 & 64 & 61 & $13 x$ & & & & & & & & \\
\hline $\sec 2$ & 10 & -12 & 07 & 87 & 23 & a7 & -01 & .04 & 15 & 09 & 11 & 31 & ot & as & as & 14. & is & 37 & 31 & 90 & 32 & 79 & 108 & & & & & & & \\
\hline Soxl & 13 & 94 & 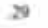 & 20 & 31 & 3 & -6 & 16 & 25 & 16 & 14 & $\omega$ & .90 & 10 & 00 & $\infty 0$ & . & 23 & $\Delta 0$ & 40 & 47 & 59 & 153 & 2.25 & & & & & & \\
\hline Eajt & 12 & .10 & 29 & $n$ & $\therefore 6$ & 39 & 24 & 21 & 27 & 30 & 25 & $\$ 2$ & - as & $\infty$ & as: & 03. & 14 & 10 & $=0$ & 53 & A & 30 & 1.01 & 些0 & Ies & & & & & \\
\hline $\operatorname{Eg} 2$ & 18 & 50 & 55 & 18 & 50 & 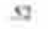 & 10 & 2n & 36 & $\$ s$ & 39 & 53 & an & 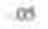 & 踝 & OSi & 18 & 22 & 64 & 58 & $\approx$ & $\omega$ & $\infty$ & 1.00 & 20 & 3,44 & & & & \\
\hline $\operatorname{Lin} 3$ & 22 & 23 & 01 & is & 37 & $\mathbf{x}$ & 23 & $n$ & 33 & 43 & 38 & $\infty$ & at & $\infty$ & 12 & $a s i_{1}$ & 13 & 11 & sh & 53 & $\pi$ & 70 & 12001 & $1 \leqslant 3$ & $2 \mathrm{s3}$ & 262 & 346 & & & \\
\hline $\ln 1$ & 12 & 46 & 50 & 33 & 36 & A? & 32 & to & 38 & 35 & is & $11 i$ & 13 & 11 & 12 & 28 & 15 & $x$ & $\Rightarrow$ & 38 & 23 & 39 & -13 & 18 & IA & 33 & 19 & 1.25 & & \\
\hline $\ln 22$ & 36 & 46 & $A A_{i}$ & 31 & 36 & 34 & 13 & 4 & $2 x$ & 23 & 23 & 12 & 97 & 10 & iso & 15 & 11 & 28 & ak & $\mathbf{s}$ & 27 & 29 & a & to & 36 & 30 & 30 & $7 x$ & 108 & \\
\hline $\ln 3$ & 100 & 47 & 81 & ss & 36 & 33 & 33 & 42 & 28 & 28 & 3 & 15 & 12 & 11 & a & 23 & 11 & 12 & 표 & $x$ & 36 & 30 & (0) & 17 & $n$ & 34 & 18 & $x$ & $m$ & 136 \\
\hline
\end{tabular}

Rp1-3: buyer relationship proneness, rs 1-3; relationship satisfaction, tr1-3: trust, mit1-3: relationship commitment, bl1-3; behayioral loyalty, rof-3: seller relationship orientation, rec)-3: social recognition. soc1-3: sociability, enj1-3: shopping enjoyment, inv 1-3: product calegory involvernent. 
Table A8-5: Covariance Matrix United States Cotlung

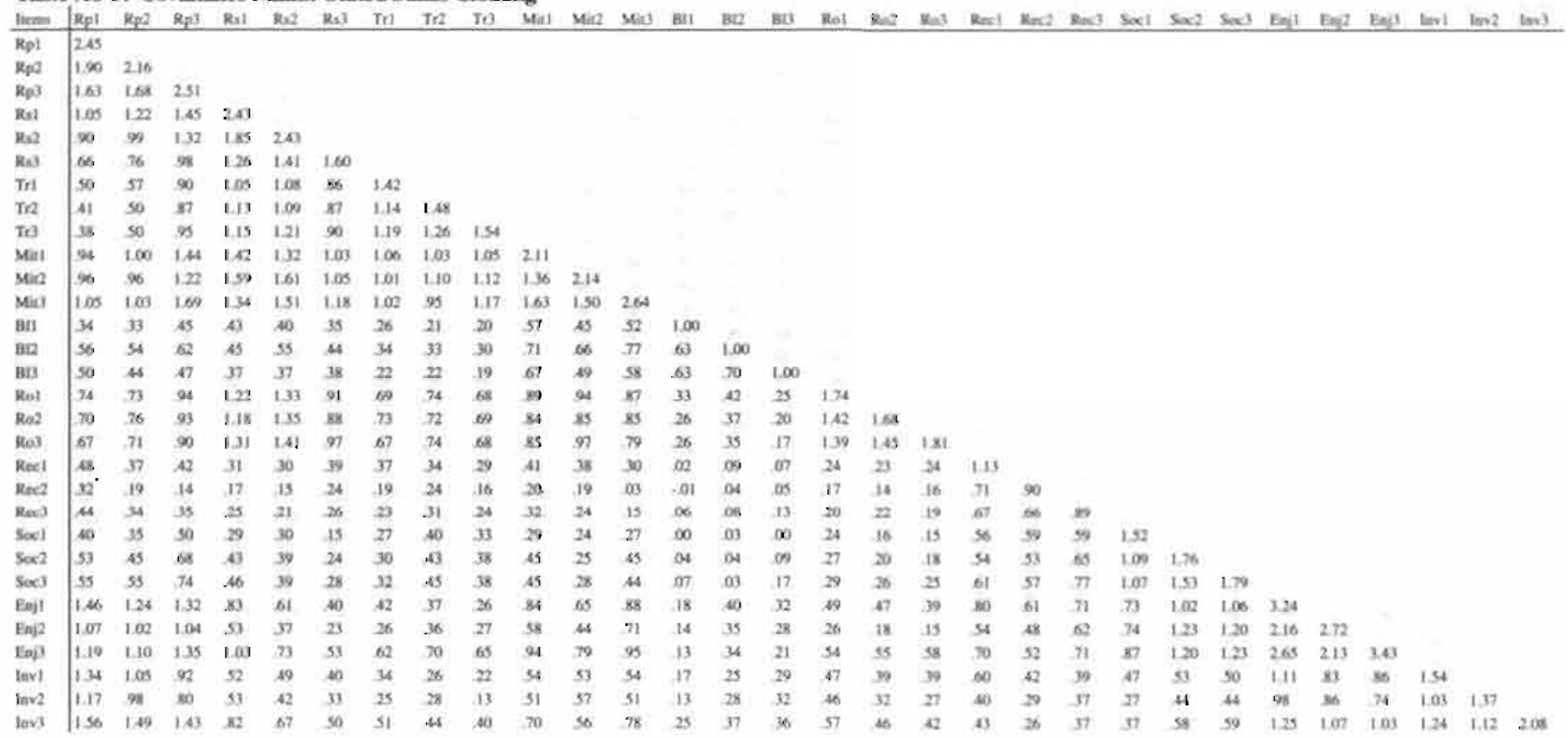

Rp1-3: buyer relationship proneness, rs 1-3: relationship satisfaction, tr1-3: trust, mit1-3: relationship commitment, bl1-3: behavioral loyalty, rol-3: seller relationship orientation, rec1-3: social recognition, soc1-3: sociability, enj1-3: shopping enjoyment, inv 1-3: product category involvement. 


\section{Table A8-6: Covarlame Merntx United States Food}

\begin{tabular}{|c|c|c|c|c|c|c|c|c|c|c|c|c|c|c|c|c|c|c|c|c|c|c|c|c|c|c|c|c|c|c|}
\hline larmen & $\mathrm{kpl}$ & $\mathrm{Bp} d$ & $\mathrm{kp} 3$ & Rel & $B=2$ & $R \times 3$ & ThI & $T 12$ & $\mathrm{Tr} 3$ & Min & Min2 & Mit3 & BII & $\mathrm{Bn}$ & as & Rol & $R_{02}$ & Ros 3 & $\operatorname{Res} 1$ & $\operatorname{loc}_{2}$ & $\operatorname{Rec} 3$ & $\operatorname{soc} 1$ & $5 \infty 2$ & $\operatorname{soc} 3$ & Eay 1 & Evj? & $\mathrm{Ea3}$ & $\ln 21$ & $\ln x 3$ & $\ln 3$ \\
\hline Kp1 & 1.49 & & & & & & & & & & & & & & & & & & & & & & & & & & & & & \\
\hline $\mathrm{K}_{\mathrm{p} 2} 2$ & 1.10 & 154 & & & & & & & & & & & & & & & & & & & & & & & & & & & & \\
\hline $\mathrm{kpl}$ & $\phi$ & 1.04 & 251 & & & & & & & & & & & & & & & & & & & & & & & & & & & \\
\hline Rat & 93 & 91 & 122 & $=10$ & & & & & & & & & & & & & & & & & & & & & & & & & & \\
\hline$k=2$ & $\infty$ & Get & 9 & 136 & 206 & & & & & & & & & & & & & & & & & & & & & & & & & \\
\hline $\mathrm{X}, \mathrm{S}$ & 50 & 35 & es & 114 & 123 & 153 & & & & & & & & & & & & & & & & & & & & & & & & \\
\hline $\mathrm{m}$ & 51 & 43 & is & 90 & 91 & su & 1.25 & & & & & & & & & & & & & & & & & & & & & & & \\
\hline$m$ & 50 & 42 & 34 & M & 89 & .88 & $\infty$ & 1.31 & & & & & & & & & & & & & & & & & & & & & & \\
\hline $\mathrm{ma}$ & is & 50 & 52 & 99 & 1.11 & $10 \mathrm{H}$ & 1.15 & 1.16 & 156 & & & & & & & & & & & & & & & & & & & & & \\
\hline Mil & $x_{2}$ & 76 & 1.67 & 171 & 1.40 & 113 & $s$ & 94 & 108 & 260 & & & & & & & & & & & & & & & & & & & & \\
\hline Miez & 78 & $n$ & 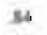 & 1.43 & 123 & 1.14 & 1.10 & 1.24 & 136 & 1.4 & 201 & & & & & & & & & & & & & & & & & & & \\
\hline Meis & 99 & 91 & 190 & 1.81 & 162 & is & 104 & 1.11 & 1.29 & 228 & 1.61 & 3.35 & & & & & & & & & & & & & & & & & & \\
\hline B4 & as & 12 & 10 & is & 29 & 30 & 4 & 37 & 38 & 30 & 52 & 46 & 100 & & & & & & & & & & & & & & & & & \\
\hline an & is & 21 & 17 & 50 & 12 & s) & 4) & 42 & 41 & 52 & 64 & 53 & $\mathbf{x 1}$ & 100 & & & & & & & & & & & & & & & & \\
\hline 841 & 11 & 13 & 10 & 41 & 26 & 30 & 34 & 36 & 30 & 37 & 60 & 40 & 50 & 56 & 100 & & & & & & & & & & & & & & & \\
\hline Ret & 69 & 46 & 61 & $\mathbf{N}$ & $\nabla x$ & $\infty 2$ & 65 & 4 & 67 & $\pi$ & .70 & 87 & If & 24 & 23 & 156 & & & & & & & & & & & & & & \\
\hline$k w 2$ & 45 & 45 & 63 & 97 & 100 & .64 & 67 & 50 & 68 & 82 & 桖 & 93 & is & 26 & 23 & 130 & 1.62 & & & & & & & & & & & & & \\
\hline $\mathrm{Rol}$ & 50 & 47 & 90 & L.85 & 100 & $\pi$ & 73 & 60 & 78 & 92 & 94 & 1.10 & 30 & 32 & 28 & 1.21 & 1.39 & 179 & & & & & & & & & & & & \\
\hline Reci & 28 & 22 & 13 & 17 & 17 & 24 & 26 & 31 & 31 & 11 & 29 & $\infty$ & is & 12 & 15 & 12 & 37 & 16 & 53 & & & & & & & & & & & \\
\hline$N_{0 \times 2}$ & 21 & 19 & .09 & 12 & 09 & 18 & 18 & 25 & 20 & 12 & 23 & 14 & 20 & 10 & is & ot & 09 & os & ss & 51 & & & & & & & & & & \\
\hline $\mathrm{kad}$ & 12 & 18 & 03 & $\mathbf{\infty}$ & $\infty 6$ & 12 & 17 & 17 & 25 & 102 & 17 & $-\alpha s$ & 13 & 04 & os & as & a & as & 57 & 62 & 93 & & & & & & & & & \\
\hline Sed 1 & so & IX & 16 & 10 & 14 & 15 & 20 & 10 & 3 & 10 & on & $\infty$ & of & $a$ & es & 91 & to & in & $w$ & a) & 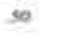 & 174 & & & & & & & & \\
\hline $\sec 2$ & 22 & 24 & 34 & 02 & 26 & ot & 19 & 92 & 19 & is & of & is & 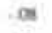 & 13 & 13 & 24 & 25 & 21 & 37 & 37 & 57 & 94 & 131 & & & & & & & \\
\hline seat & 27 & $2 x$ & 18 & o1 & 27 & ot & 25 & 17 & 28 & $0 s$ & $\infty$ & 11 & or & $-0 s$ & or & in & 17 & 16 & to & 49 & 67 & 97 & 122 & $|A|$ & & & & & & \\
\hline In: 1 & $\infty$ & $\$$ & 50 & $\mathrm{AK}$ & 56 & St & 27 & 31 & 32 & $\pi 2$ & 28 & 51 &.$\infty 6$ & $-\infty$ & $\omega 2$ & 10 & $x$ & 37 & $5 s$ & 30 & As & 52 & 60 & $s x$ & $2 n 2$ & & & & & \\
\hline Eng & 38 & ev & 7 & 37 & $\mathbf{\mu}$ & 4 & 23 & 10 & 35 & 53 & $x$ & $7 \mathrm{~K}$ & .14 & -12 & .32 & $\infty$ & 12 & is & 50 & A7 & $\omega 0$ & 20 & 57 & S4 & 199 & 2.85 & & & & \\
\hline fing & 59 & $\$ 2$ & $n$ & 47 & 53 & $w$ & 30 & 20 & $\pi 7$ & .50 & 15 & $x_{1}$ & 16 & -14 & in & 27 & 34 & 4 & 59 & 47 & (5) & 76 & $x$ & $\mathbf{M}$ & 251 & 200 & 1.48 & & & \\
\hline $\ln 1$ & 51 & 40 & 58 & 43 & 32 & $2 x$ & 35 & 23 & 28 & .47 & (1) & $3 x$ & 06 & .05 & at & 36 & 20 & 32 & 23 & 17 & 14 & 14 & 11 & $2 \pi$ & $\Delta 4$ & $n$ & $x$ & 1.16 & & \\
\hline $\tan 2$ & 53 & at & 51 & st & .19 & 22 & 22 & 34 & 24 & 35 & 36 & As & of & $\infty 6$ & $9 s$ & 23 & 3 & $2 v$ & 30 & 22 & 21 & 20 & 19 & 2 & 20 & 30 & 42 & 63 & ss & \\
\hline $\ln (\mathbf{s})$ & 103 & .61 & 91 & $M$ & 43 & 42 & 24 & 28 & 27 & $7 \mathrm{~s}$ & 3s & $N$ & $\infty$ & es & (3) & 33 & 31 & 36 & 21 & 10 & a & it & $m 2$ & 12 & $\mathbf{A 1}$ & 56 & Sa & $\pi$ & 57 & 151 \\
\hline
\end{tabular}

Rp 1-3: buyer relationship proneness, $\mathrm{n}$ 1-3; relationship satisfaction, trl-3: trust, mit 1-3; relationship commitment, bl1-3: behavional loyalty, ro 1-3: seller relationship orientation, rec1-3: social recognition, soc1-3: sociability, enj 1-3: shopping enjoyment, inv1-3: product category involvernent. 


\section{Samenvatting De rol van de koper in het beïnvloeden van relaties tussen kopers en verkopers}

Empirische studies in de detailhandel

\section{Inleiding tot de probleemstelling}

In hoofdstuk één gaven we aan dat relatiemarketing één van de belangrijkste onderzoeksdomeinen is in de huidige marketingliteratuur. Met name onderzoek naar relaties tussen kopers en verkopers ${ }^{\prime}$ in een consumentenomgeving en de rol van respectievelijk de koper en de verkoper in het versterken van deze relaties worden gezien als interessante onderzoeksthema's. Bestaand onderzoek vertoonde tekortkomingen op zowel conceptueel als empirisch vlak. Ten eerste ontbreken er in de literatuur over relatiemarketing precieze definities van diverse relationele constructen. Bovendien is de toepasbaarheid van deze constructen nog niet onderzocht in een consumentenomgeving. Ten tweede was empirisch onderzoek hoofdzakelijk gericht op distributiekanalen en industrièle relaties, waarbij consumentenrelaties grotendeels verwaarloosd werden. Verder besteedde voorgaand onderzoek voomamelijk aandacht aan de percepties van de verkoper met betrekking tot relaties tussen kopers en verkopers en werden de percepties van de koper verwaarloosd. Tot slot benadrukte voorgaand onderzoek relaties die gebaseerd zijn op beperkingen in tegenstelling tot relaties die gebaseerd zijn op toewijding. Onze studie beoogt een bijdrage te leveren tot de verdere ontwikkeling van deze onderbelichte onderzoeksgebieden.

Als een gevolg daarvan formuleerden wij de volgende onderzoeksvragen:

(1) Wat zijn de antecedenten van de relatiegeneigdheid van de koper?

(2) Wat zijn de effecten van de relatiegeneigdheid van de koper op relatie-uitkomsten?

(3) Wat is het effect van de relatiegeneigdheid van de koper op de relatie-orièntatie van de verkoper?

(4) Wat zijn de effecten van de relatie-oriëntatie van de verkoper op relatie-uitkomsten?

(5) Wat is de onderlinge relatie tussen de verschillende relatie-uitkomsten?

(6) In welke mate worden de effecten van

a) de relatiegeneigdheid van de koper gemodereerd door de relatie-oriëntatie van de verkoper?

b) de relatie-oriëntatie van de verkoper gemodereerd door de relatiegeneigdheid van de koper?

c) relatie-oriëntatie van de verkoper gemodereerd door de betrokkenheid bij de produktcategorie?

Onze studie werd uitgevoerd in twee markten gekenmerkt door een sterke concurrentie en transparantie; de kleding- en voedingdetailhandel. Om de externe validiteit van het onderzoek te bevorderen werden gegevens verzameld in Nederland. België en Amerika. Hoewel voorgaand onderzoek vooral de percepties van de verkoper benadrukte, is dit onderzoek gebaseerd op percepties van de koper met betrekking tot relaties tussen kopers en verkopers. Aangezien

Een koper verwijst in dit onderzoek naar een individuele consument. Een verkoper verwijst in dit onderzoek naar een winkel. 
koopgedrag in de detailhandel gedomineerd wordt door individuele besluitvorming richten wij onze aandacht op de individuele consument als analyse-eenheid.

\section{Relatiemarketing in een consumentenomgeving}

In hoofdstuk twee definieerden wij een relatie tussen koper en verkoper als "één of meerdere uitwisselingen tussen een koper en een verkoper die door de koper gepercipieerd worden als onderling gerelateerd met potentiële uitwisselingen in het verleden en de toekomst". Relatiemarketing is gedefinieerd als "de inspanningen van een verkoper die gericht zijn op het versterken van uitkomsten van een relatie tussen koper en verkoper". Deze definities dragen conceptueel bij tot de bestaande literatuur aangezien zij één uitwisseling beschouwen als het begin van een continuüm van relaties, aangezien zij geschikt zijn voor operationalisering en bovendien de hoofdelementen van bestaande definities van relatiemarketing bevatten. Omdat relatiemarketing niet effectief wordt geacht in iedere situatie, hebben wij diverse kenmerken beschreven die de effectiviteit van relatiemarketing kunnen beïnvloeden. In ons onderzoek zijn twee van deze kenmerken, de relatiegeneigdheid van de koper en de mate van betrokkenheid bij de productcategorie, opgenomen.

Om de toepasbaarheid van relatiemarketing in een consumentencontext te beoordelen, hebben wij zeven theorieën die ten grondslag liggen aan relatiemarketing in consumentenomgevingen geëvalueerd. Vervolgens hebben wij de voornaamste verschillen tussen consumenten- en industrièle marketing in kaart gebracht en hebben wij de relevantie van de onderliggende theorieën vergeleken in het kader van deze verschillen. Dit resulteerde in onze keuze voor 'social exchange theory' en 'equity theory'. De constructen van relatiegeneigdheid van de koper en relatie-oriëntatie van de verkoper komen overeen met de ideeèn uit beide theorieën. Omdat relatietevredenheid, vertrouwen en relatiecommitment bovendien worden gezien als voornaamste constructen in deze theorieën integreerden wij deze constructen in ons conceptueel model. Ten slotte hebben wij gedragsmatige trouw aan ons model toegevoegd om de gedragsmatige invloed van de relatiegeneigdheid van de koper en de relatie-oriëntatie van de verkoper te beoordelen.

\section{De nol van relatiegeneigdheid van de koper}

Hoofdstuk drie introduceerde een nieuw construct binnen relatiemarketing, de relatie-geneigdheid van de koper, en bracht potentiële antecedenten van dit construct in kaart. Het construct is uiterst relevant in huidige marketingsituaties vanwege de voordelen die er voor de verkoper kunnen ontstaan wanneer deze in staat is kopers te identificeren die geneigd zijn om relaties aan te gaan met deze verkoper. Ondanks dit belang zijn er weinig empirische pogingen ondernomen om te meten in welke mate kopers relatiegeneigd zijn en wat het effect is van relatiegeneigdheid op relatieuitkomsten.

Wij positioneerden het construct relatiegeneigdheid van de koper als een individueel kenmerk van deze koper en definieerden het als "de relatief stabiele en bewuste neiging van een koper om relaties aan te gaan met verkopers van een bepaalde productcategorie". Omdat informatie over factoren die de relatiegeneigdheid van de koper beïnvloeden waardevolle inzichten kan bieden voor 
communicatie- en segmentatiestrategieẽn, werden potentiěle antecedenten van de relatiegeneigdheid van de koper in kaart gebracht.

De relatiegeneigdheid van de koper wordt echter niet geacht in iedere situatie van invloed te zijn. Derhalve hebben wij onderzocht of er mogelijke modererende effecten zijn van de relatie-oriëntatie van de verkoper en de betrokkenheid van de koper bij de productcategorie op de invloed van relatiegeneigdheid van de koper op relatie-uitkomsten. De relatie-oriëntatie van de verkoper werd gedefinieerd als "de overkoepelende evaluatie door een koper van de mate waarin een verkoper actief inspanningen richt tot de koper die bedoeld zijn om bij te dragen tot de klantenwaarde die deze koper ervaart". Daarnaast werd de betrokkenheid van de koper met de producteategorie gedefinieerd als "het door de koper gepercipicerde belang van de productcategorie gebaseerd op zijn behoeften, waarden en interesses".

\section{Relatie-uitkomsten}

In hoofdstuk vier bespraken wij drie houdinggerelateerde relatie-uitkomsten: relatietevredenheid, vertrouwen en relatiecommitment. Bovendien introduceerden wij gedragsmatige trouw als een gedragsmatige relatie-uitkomst. Wij definieerden relatie-uitkomst als "de houding van een koper met betrekking tot, of zijn gedrag tijdens, zijn relatie met een verkoper". Op basis van een uitgebreid literatuuronderzoek concludeerden wij dat de drie houdinggerelateerde relatie-uitkomsten van verschillende aard zijn. Het is doorgaans aanvaard dat deze constructen een cruciale rol spelen in onderzoeken op het gebied van relatiemarketing.

Wij definieerden relatietevredenheid als "de affectieve toestand van een koper die voortkomt uit zijn overkoepelende waardering van zijn relatie met een verkoper". Vertrouwen werd gedefinieerd als "de zelfverzekerde overtuiging van een koper in de eerlijkheid van een verkoper ten opzichte van de koper". Relatiecommitment zien we als "de aanhoudende wens van de koper om zijn relatie met een verkoper voort te zetten, vergezeld van zijn bereidheid om inspanningen te leveren gericht op het handhaven van deze relatie". Deze definities zijn in overeenstemming met bestaande definities van deze constructen hoewel zij licht zijn aangepast om tegemoet te komen aan de specifieke kenmerken van de detailhandelsmarkten die in dit onderzoek onderzocht werden.

\section{Onderzoeksmethodologie en ontwikkeling van meetvragen}

In hoofdstuk zes onderbouwden wij onze keuze voor het gebruik van cross-sectioneel, nietexperimenteel onderzoek gebaseerd op persoonlijke ondervraging in winkelcentra. Wij bespraken bovendien het proces dat werd gebruikt om meetvragen te genereren en te testen. Voor het genereren van meetvragen voerden wij een literatuurstudie uit gevolgd door focusgroepgesprekken met consumenten. De daaruit resulterende meetvragen werden kwalitatief getest door consumenten. wat leidde tot aanzienlijke aanpassingen in formuleringen, volgorde en lay-out van de meetvragen. Vervolgens voerden wij een uitgebreide kwantitatieve test uit. Op basis van een principale componentenanalyse verfijnden wij de meetvragen verder om de meest geschikte meetschalen voor elk van de constructen af te leiden. Tenslotte lichtten wij de keuzes toe die ten grondslag lagen aan de ontwikkeling van de vragenlijst die wij gebruikten in de uiteindelijke gegevensverzameling. 


\section{Onderzoeksmodel, -hypothesen en -resultaten}

Nadat wij de constructen van ons conceptuele model definieerden in hoofdstukken drie en vier toonden wij de veronderstelde relaties tussen de constructen in hoofdstuk vijf. In hoofdstuk zeven bespraken wij de empirische resultaten die gerelateerd waren aan deze hypothesen.

Om te beslissen of het noodzakelijk was om verschillende modellen te schatten voor elk van de zes steekproeven, onderzochten wij de mogelijkheid om steekproeven samen te voegen over landen en/of productcategorieèn. De resultaten hiervan toonden aan dat het niet was toegestaan om de gegevens samen te voegen over landen en/of productcategorieèn. Als een gevolg hiervan werd het model geschat voor iedere steekproef afzonderlijk. Alle geschatte modellen vertoonden toereikende 'overall goodness of fit' indices en de meetschalen werden gekenmerkt door goede psychometrische eigenschappen.

De resultaten van ons onderzoek worden besproken aan de hand van de eerder besproken onderzoeksvragen.

(1) Wat zijn de antecedenten van de relatie-geneigdheid van de koper?

Ons onderzoek toont aan dat 'sociability' alleen in de Nederlandse voedingsmarkt tot relatiegeneigdheid van de koper leidt. Sociale herkenning vertoont in twee steekproeven een negatief verband met relatiegeneigdheid van de koper. Kopers die relatief meer plezier beleven aan winkelen bleken in diverse steekproeven ook een hogere relatiegeneigdheid te vertonen dan andere kopers. Dit in tegenstelling tot het negatieve verband dat we verwacht hadden. Tot slot bleek de betrokkenheid van de koper bij de productcategorie van doorslaggevend belang te zijn bij het totstandkomen van relatiegeneigdheid.

(2) Wat zijn de effecten van de relatiegeneigdheid van de koper op relatie-uitkomsten?

Een hogere relatiegeneigdheid van de koper leidt in iedere steekproef tot een hogere relatietevredenheid en een hogere relatiecommitment van de koper.

(3) Wat is het effect van de relatiegeneigdheid van de koper op de relatie-oriëntatie van de verkoper?

Een hogere relatiegeneigdheid van de koper leidt in iedere steekproef tot een hogere door de koper gepercipieerde relatie-oriëntatie van de verkoper.

(4) Wat zijn de effecten van de relatie-oriëntatie van de verkoper op relatie-uitkomsten?

Een hogere relatie-oriëntatie van een verkoper leidt in alle zes steekproeven tot een hogere tevredenheid van de koper over zijn relatie met de verkoper. Ook de relatiecommitment van de koper neemt toe als gevolg van de verhoogde relatie-oriëntatie van de verkoper, alhoewel dit in slechts drie van de zes steekproeven van toepassing was.

(5) Wat is de onderlinge relatie tussen de verschillende relatie-uitkomsten?

In elke steekproef bestaat er een positief verband tussen relatietevredenheid en vertrouwen, tussen vertrouwen en relatiecommitment en tussen relatiecommitment en gedragsmatige trouw. 
(6) In welke mate worden de effecten van

a) de relatiegeneigdheid van de koper gemodereend door de nelatie-onièntatie van de venkoper?

b) de relatie-onïntatie van de venkoper gemodereend door de relatiegeneigdheid van de koper?

c) relatie-oriëntatie van de verkoper gemodereend door de betrokkenheid bij de produktcategorie?

Bij een hogere relatie-geneigdheid van de koper was het verband tussen de relatie-orièntatie van de verkoper en de relatietevredenheid en -commitment in enkele steekproeven sterker dan bij een lagere relatiegeneigdheid van de koper. Verder bleek dat bij cen hogere relatie-oriëntatie van de verkoper het verband tussen de relatiegeneigdheid van de koper en de relatietevredenheid en commitment in enkele steekproeven sterker was dan bij een lagere relatie-oriëntatie van de verkoper. Tenslotte was het verband tussen relatie-oriëntatie van de verkoper en relatietevredenheid en -commitment sterker indien de koper een hogere betrokkenheid bij de productcategorie vertoonde.

\section{Onderzoeksbeperkingen}

Een aantal beperkingen geldt met betrekking tot de interpretatie van de resultaten van dit onderzoek. Ten eerste is dit onderzoek niet in staat om causale verbanden aan te tonen vanwege het crosssectionele en niet-experimentele karakter ervan. Een tweede beperking betreft de mogelijke weglating van belangrijke variabelen uit het onderzoeksmodel. Verder is er mogelijk sprake van 'common method bias' gezien alle constructen middels één vragenlijst gemeten zijn. Bovendien is de meting van gedragsmatige trouw gebaseerd op schattingen van de respondent en niet op gegevens die voortvloeien uit een gegevensbestand. Een vierde mogelijk beperking van ons onderzoek heeft betrekking op de niet normale verdeling van de gegevens. Deze zou namelijk een opwaartse tendens kunnen creëren bij het vaststellen van de significantie van coëfficiënten. De steekproeven zijn echter groot genoeg om dit probleem deels te compenseren. Een andere beperking heeft betrekking op de invloed die de interviewer heeft op het verzamelen van de gegevens. Een intensieve training en instructie van de interviewers, voorafgaand aan de verzameling van de gegevens, was echter gericht op het reduceren van deze mogelijke tekortkoming. Bovendien zorgde de gestructureerde vragenlijst met gedetailleerde instructies voor de respondent ervoor dat de invloed van de interviewer gering was, evenals het feit dat de interviewers niet op de hoogte waren van de onderzoekshypothesen. Tot slot zou ons onderzoek beïnvloed kunnen zijn door sociaal wenselijk gedrag van de respondenten, vanwege het persoonlijke karakter van de gegevensverzameling. Zowel interviewers en respondenten zijn erop gewezen dat er geen goede of foute antwoorden bestaan, om op deze manier sociaal wenselijk gedrag te beperken.

Een laatste mogelijke beperking heeft betrekking op het schatten van slechts eén structureel model in tegenstelling tot het schatten van diverse alternatieve modellen. Hoewel uit het schatten van een alternatief model bleek dat het conceptuele model robuust is, zou de gevonden statistische nauwkeurigheid mogelijk ook bereikt kunnen worden met andere modellen. Het geschatte model is echter gebaseerd op een zorgvuldige theoretische onderbouwing. 


\section{Suggesties voor verder onderzoek}

Ten eerste zou het interessant zijn om te onderzoeken of ons model verschillend is voor kleine buurtwinkels en grote winkelketens. Ten tweede kan verder onderzoek zich richten op potentielle additionele antecedenten van de relatie-geneigdheid van de koper, aangezien wij slechts een beperkt aantal mogelijke antecedenten in kaart hebben gebracht. Dit onderzoek zou inzicht kunnen verschaffen in het relatieve belang van de diverse antecedenten, wat zinvol is voor communicatieen segmentatiedoeleinden. Ten derde was de meting van gedragsmatige trouw niet gebaseerd op werkelijk koopgedrag. zoals we bij de beperkingen reeds hebben aangegeven. Gegevensbestanden die individuele aankoopinformatie bevatten, zijn een mogelijke bron voor deze informatie. Indien deze informatie naast de vragenlijsten gebruikt zou worden, is het waarschijnlijk dat ook de 'common method bias' zal afnemen. Een nadeel van deze methode is dat de externe validiteit af zal nemen, aangezien er minder winkels betrokken zullen worden in het onderzoek. Ten vierde zou experimenteel onderzoek een sterkere basis bieden voor causale verbanden en daarnaast zou experimenteel onderzoek de invloed van de interviewer en 'common method bias' helpen reduceren. Daarnaast zou het opnemen van culturele variabelen in relatiemarketing onderzoek in de consumentenmarkt inzicht kunnen bieden in de rol van cultuur bij het tot stand komen van de gevonden patronen. Tot slot, zou het interessant zijn om kritische incidenten te bestuderen, aangezien verwacht wordt dat trouwe kopers bereid zijn om incidenteel lagere niveaus van productof diensteninspanningen te accepteren zonder de relatie met de winkel te beëindigen.

\section{Theoretische implicaties}

Tot op heden wordt de relatiemarketing literatuur vooral gekenmerkt door algemene en onduidelijke definities van de concepten 'relatie' en 'relatie marketing'. Ons onderzoek heeft bijgedragen aan een herformulering van beide concepten door een expliciet beginpunt van een relatie vast te stellen, door een relatie te formuleren als perceptie van de koper. Dit is een mogelijke eerste stap in het verbeteren van de consistentie tussen onderzoekers op het gebied van relatiemarketing.

Een andere bijdrage van ons onderzoek betreft de introductie, definitie en operationalisering van twee nieuwe constructen 'relatiegeneigdheid van de koper' en 'relatie-oriëntatie van de verkoper'. Hoewel beide constructen niet eerder onderzocht zijn, bleken ze van cruciaal belang te zijn in het bepalen van tevredenheid met de relatie en relatiecommitment. Dit onderstreept dat niet alleen verkoper gerelateerde factoren onderzocht dienen te worden om relatie-uitkomsten te verklaren. maar ook koper gerelateerde factoren. Aangezien de relatiegeneigdheid van de koper van doorslaggevende betekenis bleek te zijn in zes steekproeven, is het mogelijk dat eerder onderzoek lijdt onder de weglating van dit construct. Wij zien de relatiegeneigdheid van de koper dan ook als een hoofdconstruct van relatiemarketing onderzoek in consumentenrelaties gebaseerd op toewijding.

In ons onderzoek hebben we persoonlijkheidskenmerken in verband gebracht met de relatiegeneigdheid van kopers en niet rechtstreeks met hun koopgedrag. We hebben in diverse steekproeven empirisch bewijs gevonden voor deze verbanden, hoewel deze niet altijd in de veronderstelde richting bleken te zijn. Deze initiële resultaten tonen aan dat 
persoonlijkheidskenmerken een rol spelen bij relatiemarketing in de consumentenmarkt, zoals recent verondersteld werd door Fournier (1998).

Ten vierde onderstrepen onze resultaten de algemene wetenschap dat tevredenheid met de relatie, vertrouwen en relatie-commitment hoofdconstructen zijn in relatiemarketing onderzoek. Zover wij weten, is dit echter de eerste studie in een consumentenomgeving die de drie constructen gezamenlijk in één onderzoek opneemt. Daarnaast tonen we aan dat er voldoende discriminant validiteit bestaat tussen de drie constructen.

Tot slot tonen onze resultaten aan dat relatie-commitment en gedragsmatige trouw significant maar slechts zwak gerelateerd zijn. Het lijkt er dan ook op dat een breed scala aan factoren gedragsmatige trouw bepaalt, hoewel in onderzoek de nadruk vaak ligt op commitment. Voorbeelden van zulke factoren zijn bijvoorbeeld bekendheid met de winkel, afstand tot de winkel, concurrerende winkels of het bestaan van een monopolie. Deze resultaten ondersteunen het idee van ware trouw door te benadrukken dat zowel houding als gedrag moeten worden opgenomen in het bepalen van trouw en niet te focussen op één van beide.

\section{Management implicaties}

De eerste belangrijke conclusie is dat de effectiviteit van relatiemarketing niet alleen bepaald wordt door inspanningen van de detaillist, maar voor een groot deel door de aard van de klanten. Onze resultaten tonen zelfs aan dat het gedrag van kopers relatief meer afhankelijk is van de relatiegeneigdheid van de koper dan van de relatie-oriëntatie van de verkoper. Derhalve zouden detaillisten zich niet voornamelijk moeten richten op het optimaliseren van hun eigen inspanningen voor klanten, maar zouden zich vooral ook moeten richten op het vinden van geschikte klanten. Detaillisten zouden gevoelig moeten zijn voor de relatiegeneigdheid van bepaalde productmarktcombinaties. Dit zou niet alleen het marktaandeel positief kunnen beïnvloeden maar ook het klantenaandeel aangezien relatiegeneigde klanten een grotere tendens vertonen om trouw te worden aan een bepaalde winkel.

Ten tweede toont het modererende effect van de relatiegeneigdheid van klanten dat relatie-oriëntatie van de verkoper leidt tot een hogere tevredenheid met de relatie en een hogere relatie-commitment als kopers relatiegeneigd zijn. Derhalve zou het voor detaillisten zinvol kunnen zijn om hun inspanningen af te stemmen op de relatiegeneigdheid van klanten. Een voorbeeld zou kunnen zijn dat klanten die niet relatiegeneigd zijn, minder belangstelling hebben voor een klantenkaart dan klanten die wel relatiegeneigd zijn. Het modererend effect van betrokkenheid bij de product categorie toont dat de invloed van de inspanningen van de detaillist afhankelijk is van de betrokkenheid van de klant bij de product categorie. Aangezien deze betrokkenheid kan verschillen tussen marktsegmenten, zou de effectiviteit van relatiemarketing strategieèn eveneens kunnen verschillen tussen marktsegmenten.

Verder zouden detaillisten zich bewust moeten zijn van het feit dat gedragsmatige trouw niet alleen afhankelijk is van relatie-commitment. Gedragsmatige trouw kan afhankelijk zijn van verkoper-, koper- en situatie-gerelateerde factoren. Hoewel onze resultaten aantonen dat verkoper- en koper- 
gerelateerde factoren een belangrijke rol spelen in het totstandkomen van gedragsmatige trouw, spelen situationele factoren ogenschijnlijk ook een cruciale rol.

Tot slot tonen onze empirische resultaten aan dat gedragsmatige trouw in de voedingsmarkten minder bepaald worden door commitment dan in de kledingmarkten. Dit zou een indicatie kunnen zijn voor het feit dat gewoonte en inertic een belangrijke rol spelen in voedingsmarkten die 'convenience goods' verkopen in tegenstelling tot kledingmarkten die 'shopping goods' verkopen. Het lijkt erop dat het creëren van ware trouw in een kledingomgeving eenvoudiger is dan het creëren van trouw in een voedingsomgeving. 


\section{Curriculum Vitae}

Gaby Odekerken-Schröder was born on March $25^{\text {th }}, 1971$ in Heerlen (the Netherlands). After completing secondary school at 'Sint Maartenscollege' in Maastricht (the Netherlands), she studied Business Economics at the Faculty of Economics and Business Administration at Maastricht University (the Netherlands). During her studies she specialized in Marketing and Marketing Research. In 1992, she joined the department of Marketing and Market Research as a Research Assistant. In 1993, she did an internship at the Headquarters of Shell in London (Great Britain). Subsequently, she joined a group of 20 Dutch students to conduct a marketing research in Indonesia. Her final thesis concerned an empirical research investigating relationship-strength in a consumer environment and in 1994 she obtained her Master's Degree. She immediately started her academic career as a Marketing Lecturer at Maastricht University. In January 1997, she initiated her doctoral dissertation. Her main research interests are related to the domain of relationship marketing. customer loyalty and consumer behavior. Her work has been published in the Joumal of Direct Marketing, in several conference proceedings, and has been accepted for publication in the European Joumal of Marketing. 
Identifying those consumers who are most prone to engage in relationships is considered to yield important benefits to retailers given the considerable investments needed for enhancing these relationships. Moreover, knowing the outcomes of relationship marketing strategies can provide retailers with powerful guidelines for fine-tuning their efforts aimed at enhancing consumer relationships. The author of this study measures the impact of both aspects on key relationship outcomes. The first aspect is operationalized as buyer relationship proneness, defined as a consumer's relatively stable tendency to engage in relationships with retailers. The second aspect is represented by seller relationship orientation, defined as a consumer's perception of a retailer's efforts actively made towards regular customers. Moreover, the study provides an answer to the question if and which individual differences incorporated in the study - sociability, social recognition, shopping enjoyment, and product category involvement - influence a consumer's level of buyer relationship proneness. The author administered more than 1,700 face-to-face questionnaires to consumers in the Netherlands, Belgium, and the US, covering a wide variety of clothing and food retailers including discount stores, mass merchandisers, traditional department stores, as well as prestige stores.

\section{$\mathrm{F}_{\text {rom 1989-1994, Gaby Odekerken-Schröder studied Business }}$}

Economics at the Faculty of Economics and Business Administration of Maastricht University (the Netherlands). During her studies, she specialized in Marketing and Marketing Research. In 1992, she joined the department of Marketing and Marketing Research as a Research Assistant. In 1993, she conducted a research at the Headquarters of Shell in London (Great Britain). Subsequently, she participated in a research team consisting of 20 Dutch students in order to conduct a multidisciplinary research in Indonesia. Her final thesis concerned an empirical research investigating relationship-strength in a consumer environment and, in 1994, she obtained her Master's Degree. She started her academic career as a Marketing Lecturer at Maastricht University. In January 1997, she initiated her doctoral dissertation. Her main research interests are related to the domain of relationship marketing, retail marketing, customer loyalty, and consumer behavior. Her work has been published in the Journal of Direct Marketing, in several conference proceedings, and has been accepted for publication in the European Journal of Marketing. 